\title{
Monatsschrift
}

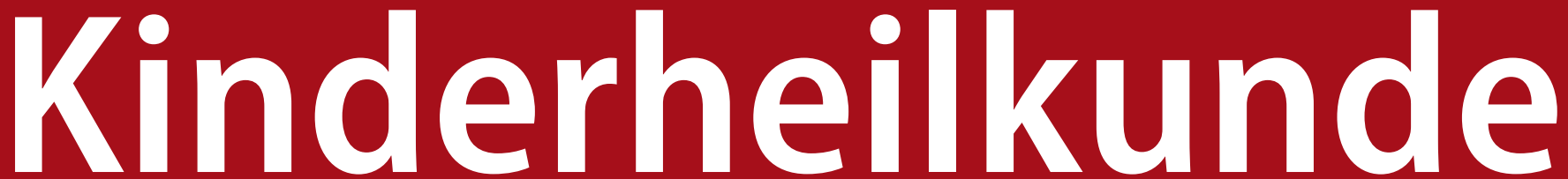

Organ der Deutschen Gesellschaft für Kinder- und Jugendmedizin

Organ der Österreichischen Gesellschaft für Kinder- und Jugendheilkunde

\section{Abstracts 2013}

109. Jahrestagung der DGKJ

Düsseldorf, 12. bis 15. September 2013

Indexed in Science Citation Index Expanded
Gemeinsam mit der

65. Jahrestagung der DGSPJ

51. Herbsttagung der DGKCH

35. Jahrestagung des BeKD

30. Jahrestagung der API

49. Arbeitstagung Pädiatrische Forschung

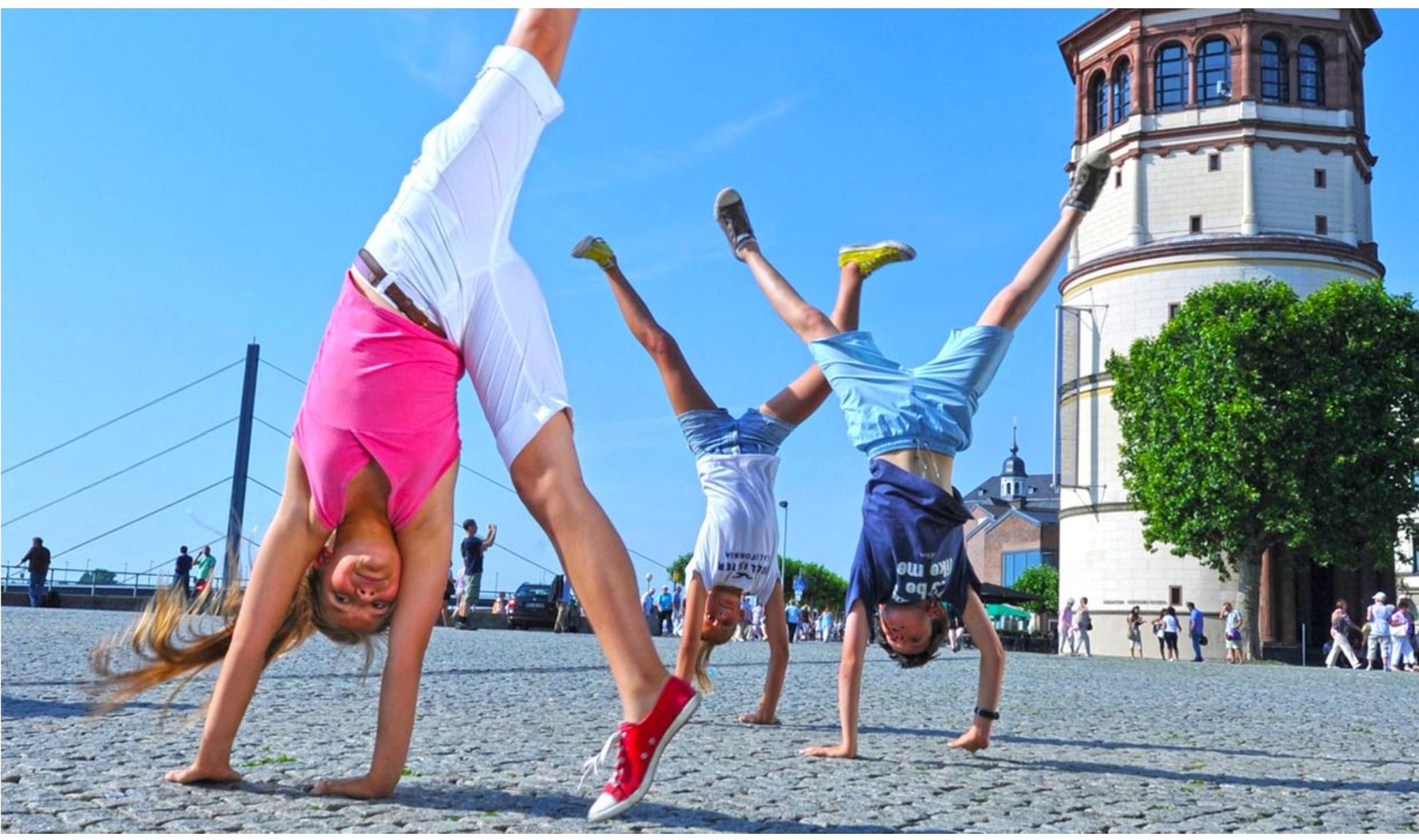

www.MonatsschriftKinderheilkunde.de www.springermedizin.de
Springer Medizin 
Monatsschr Kinderheilkd 2013 [Suppl 2] 161:94-267

DOI 0.1007/s00112-013-2984-6

○) Springer-Verlag Berlin Heidelberg 2013

\section{Abstracts der 109. Jahrestagung der Deutschen Gesellschaft für Kinder- und Jugendmedizin e.V. (DGKJ)}

Gemeinsam mit der

65. Jahrestagung der Deutschen Gesellschaft für Sozialpädiatrie und Jugendmedizin (DGSPJ)

51. Herbsttagung der Deutschen Gesellschaft für Kinderchirurgie (DGKCH)

35. Jahrestagung des Berufsverbandes Kinderkrankenpflege Deutschland (BeKD)

30. Jahrestagung der Arbeitsgemeinschaft Pädiatrische Immunologie (API)

49. Arbeitstagung Pädiatrische Forschung

12. bis 15. September 2013, Düsseldorf

Prof. Dr. med. Ertan Mayatepek, Kongresspräsident DGKJ

Dr. med. Ulrike Horacek, Kongresspräsidentin DGSPJ

Prof. Dr. med. Udo Rolle, Kongresspräsident DGKCH

Frauke Leupold, Tagungspräsidentin BeKD

Prof. Dr. med. Arndt Borkhardt, Kongresspräsident API

Prof. Dr. med. K.-M. Debatin, Tagungspräsident Forschungstagung 


\section{Abstracts der 109. Jahrestagung der Deutschen Gesellschaft für Kinder und Jugendmedizin e. V. (DGKJ)}

\section{Vorträge}

\section{Donnerstag, 12.09.2013 und Freitag, 13.09.2013}

\section{Pneumologie (1)}

\section{DGKJ-SY-PN1-3}

Lungenfunktionsmessungen einmal ganz anders

Hinrichs $B{ }^{1}$

${ }^{1}$ Helios Mariahilf Klinik Hamburg, Kinder- und Jugendmedizin, Hamburg

Lungenfunktion hat viel mit Physiologie und Physik zu tun: für die Atemwege mit Strömungsphysik, für die Lungenmechanik mit Druck/ Flussbeziehungen. Zum Verstehen typischer klinischer Muster von Lungenerkrankungen benötigen wir eine Vorstellung über die normale und die pathologische Atmungsmechanik (Beispiel: Erkennen intra- vs. extrathorakaler funktioneller Atemwegsstenosen). Durch die Verbindung von Physik und Physiologie wird Pathophysiologie lebendig und Lungenerkrankungen besser verständlich.

- Warum ist die Fluss-Volumen-Kurve dreiecksförmig? Zentral hierfür: der „EPP“ - der „,equal pressure point“, über dessen Determinanten gesprochen wird.

- Was ist Compliance in der Lungenfunktionsdiagnostik? Aufbauend auf Kenndaten der Lungenfunktion (Druck, Fluss, Widerstand) sollen anhand klinischer Beispiele Charakteristika restriktiver Lungenerkrankungen verstanden werden.

- Warum ist bei einer Hämosiderose die CO-Diffusionskapazität erhöht? Ausgehend von der normalen Anatomie können wir die alveolokapilläre Grenzfläche „sezieren“ und interstitielle Lungenerkrankungen verstehen.

Für Fragen und Antworten sollte genügend Raum bleiben.

\section{Hormonelle Komplikationen der Therapie chronischer Erkrankungen}

\section{DGKJ-SY-EN1-1}

Besonderheiten des Diabetes bei zystischer Fibrose (CFRD)

\section{Konrad K. ${ }^{1}$}

'Universitätsklinikum Essen, Kinderklinik, Pädiatrische Endokrinologie und Diabetologie, Essen

Fragestellung. Mit verbesserten Therapiemodalitäten und erhöhter Lebenserwartung von Patienten mit zystischer Fibrose (CF), steigt die Inzidenz des CF-assoziierten Diabetes (CFRD) deutlich an. Es handelt sich um die häufigste Komorbidität dieser Patientengruppe. Die angegebene Häufigkeit schwankt dabei in Abhängigkeit von Screeningmethoden und diagnostischen Kriterien. Das Früherkennen ist dringend notwendig, um einen zusätzlichen Gewichtsverlust, Proteinkatabolismus, eine Verschlechterung der Lungenfunktion und letztlich auch eine erhöhte Mortalität von Patienten mit CF-Diabetes zu verhindern. Die Ätiologie der Erkrankung ist komplex und resultiert aus einer Kombination von Insulinmangel und Insulinresistenz mit zusätzlichen Risikofaktoren. Basierend auf aktuellen Empfehlungen, ist die Insulintherapie die einzig empfohlene Therapie.

Material und Methode. Anhand aktueller Literatur, sowie nationaler und internationaler Empfehlungen werden die Besonderheiten des CFRD im Vergleich zu anderen Diabetesformen dargestellt und die Screening- und Therapieoptionen diskutiert.

Ergebnisse. Beim CFRD handelt es sich um eine eigene Entität mit klaren Unterschieden zu anderen Diabetesformen. Zusätzliche Risikofaktoren (chronische Inflammation, hochkalorische Zusatznahrung, Glukokortikoide u. a.) beeinflussen Screening und Therapie. Dies bedingt spezielle Anforderungen an die Diabetestherapie, notwendige Verlaufskontrollen und die Patientenschulung.

Diskussion oder Schlussfolgerung. Die Betreuung von Patienten mit CFRD sollte in einem CF- und Diabetes-erfahrenen, multidisziplinären Team durch einen CF-Diabetes-erfahrenen Diabetologen erfolgen.

\section{DGKJ-SY-EN1-4}

Schilddrüsenbeteiligung bei onkologischen Erkrankungen

Rohrer T. ${ }^{1}$

'Universität des Saarlandes, Klinik für Allg. Pädiatrie, Homburg

Einleitung. Die mittlere 5-Jahres-Überlebensrate für alle Krebserkrankungen im Kindesalter liegt bei über 80\%. Diese ist auf den Einsatz multimodaler Therapiestrategien zurückzuführen, die deutliche Toxizität verursacht. Störungen der Schilddrüsenfunktion gehören zu den endokrinologischen Spätfolgen.

Methoden. Bestrahlungen im Hals-, Kopf- und Brustbereich sowie Ganzkörperbestrahlungen und der Einsatz von 131I-MIBG können Störungen der Schilddrüsenfunktion auslösen. Während sich das Risiko für eine Hyperthyreose auf niedrigem Niveau verdoppelt, steht die Entwicklung einer Hypothyreose im Vordergrund. Fast 20\% aller an Kopf/ Hals bestrahlten Patienten werden im Verlauf hypothyreot, wobei die kumulative Strahlendosis für die Schilddrüse den wichtigsten Risikofaktor darstellt. Auch eine Chemotherapie kann zu einer Hypothyreose führen.

Ergebnisse. Das Risiko von Neubildungen der Schilddrüse ist nach Bestrahlung erhöht. Auch nach Chemotherapie, alleine oder in Kombination mit einer Radiotherapie der Schilddrüse, erhöht sich das Risiko für Schilddrüsenkarzinome. Die höchsten Raten von sekundären Malignomen der Schilddrüse sind bei einer Bestrahlung zwischen 10 und 20 Gy nach einem zeitlichen Intervall von 10 bis 30 Jahren beobachtet worden. 
Schlussfolgerung. Patienten sollten nach Strahlentherapie regelmäßig nachuntersucht werden. In den ersten Jahren muss die Entwicklung einer Schilddrüsenfehlfunktion geprüft werden. Fehlfunktionen werden nach Standardverfahren therapiert. Da die Inzidenz von Zweittumoren der Schilddrüse mit dem zeitlichen Abstand nach Bestrahlung zunimmt, sollte zudem eine langfristige sonographische Kontrolle der Schilddrüse in mindestens 2-jährigen Abständen durchgeführt werden. Werden dabei knotige Strukturen nachgewiesen, sollten diese weiter abgeklärt werden, um ein Schilddrüsenkarzinom auszuschließen.

\section{Pharmakotherapie (1) - Kindergerechte Arzneimittel, Pharmakokinetik, Applikationsformen}

\section{DGKJ-SY-P1-3 \\ Pharmakovigilanz und Nebenwirkungsmeldungen in der Kinder- heilkunde}

\section{Stammschulte T. \\ 'Arzneimittelkommission der deutschen Ärzteschaft, Pharmakovigilanz, Berlin}

Zum Zeitpunkt der Zulassung und Markteinführung liegen Daten zur Sicherheit eines Arzneimittels nur eingeschränkt vor: So sind zum Beispiel seltene und sehr seltene Nebenwirkungen, die bei weniger als 1 von 1000 Patienten auftreten, durch die Zulassungsstudien in der Regel nicht sicher festzustellen. Darüber hinaus fehlen aufgrund der Einschlusskriterien in den Zulassungsstudien häufig Informationen zu speziellen Patientengruppen wie Kindern, Schwangeren, älteren oder multimorbiden Patienten. Um das Sicherheitsprofil eines Arzneimittels zu vervollständigen, ist daher die kontinuierliche Überwachung nach der Markteinführung durch die Pharmakovigilanz erforderlich. Ein wichtiges Instrument in der Pharmakovigilanz sind die Spontanmeldungen von Nebenwirkungen durch Ärzte, Apotheker und Patienten. Durch sie können zu einem frühen Zeitpunkt wichtige Hinweise zu möglichen Arzneimittelrisiken gewonnen werden. Dies gilt nicht nur für neue Arzneimittel, sondern auch für bereits seit Jahren verfügbare Präparate, über deren Langzeitsicherheit oder sichere Anwendung in speziellen Gruppen wie Kindern und Jugendlichen oft nur begrenzt Daten vorliegen. Die Hinweise („Signale“) aus Spontanmeldungen müssen meist zunächst durch gezielte Untersuchungen, wie z. B. pharmakoepidemiologische Studien, geprüft werden. Konkrete Beispiele aus der Kinderheilkunde, wie die Narkolepsie im Zusammenhang mit Pandemrix ${ }^{\bullet}$, zeigen den Weg von spontan gemeldeten Einzelfällen bis zur Bestätigung oder Widerlegung von Sicherheitssignalen durch Studien. Jede einzelne Spontanmeldung trägt dazu bei, die Anwendung von Arzneimitteln sicherer zu machen, vor allem bei speziellen Patientengruppen wie Kindern, die in klinischen Studien häufig nicht berücksichtigt werden.

\section{DGKJ-SY-P1-4}

\section{Arzneimittelsicherheit in der Kinderheilkunde}

\section{Rascher W. ${ }^{?}$}

'Universitätsklinikum Erlangen, Kinder- und Jugendklinik, Erlangen

Einleitung. Die Arzneimitteltherapie spielt in Pädiatrie eine große Rolle und in den letzten Jahrzehnten ist das Therapiearsenal mit Pharmaka für Kinder und Jugendliche deutlich erweitert worden. Aber wirksame Medikamente können auch unerwünschte Wirkungen hervorrufen und der Medikationsprozess selbst, also der Weg von der Verordnung zur Verabreichung, ist nicht ohne Komplikationen. Bei Kindern sind Medikationsfehler häufiger als bei Erwachsenen mit negativen Folgen behaftet. Die medikamentöse Therapie ist somit ein Hochrisikoprozess und Kinder sind besonders gefährdet.
Methoden. Die Off-label-Anwendung beträgt in der ambulanten Versorgung 13,2\% (Bücheler et al. 2002) bzw. 15,7\% (Mühlbauer et al. 2009), und in der stationären Versorgung zwischen 60 und 90\%. Legt man nicht die Verordnungsdaten zu Grunde, sondern analysiert die Verabreichung durch die Eltern (7-Tages-Prävalenz der KiGGS-Studie, Neubert, Knopf et al. 2013) liegt die Off-label-Anwendung in der ambulanten Versorgung bei über $30 \%$.

Ergebnisse. Medikationsfehler sind bei Kindern wie bei Erwachsenen häufig ( $5,7 \%$ vs. $5,3 \%$ der verordneten Medikamente; Kaushal et al. 2001), aber das Potenzial für Ereignisse mit gefährlichen Folgen liegt bei Kindern dreimal höher (1,1\% vs. $0,35 \%)$. In einer eigenen Untersuchung an 372 Patienten (437 stationären Aufnahmen) lag die Anzahl der Medikationsfehlern mit potentieller Schädigung des Patienten bei fast 59,1\% (Toni et al. 2013).

Schlussfolgerung. In Zeiten eines höheren Patientenschutzes und der Meldemöglichkeit von unerwünschten Arzneimittelereignissen durch die Eltern, muss das Problembewusstsein für rationale Arzneimitteltherapie bei Kinder- und Jugendärzten verbessert werden. Auch müssen Fehler im Medikationsprozess vermindert werde, um die Arzneimitteltherapiesicherheit für Kinder und Jugendliche zu verbessern.

\section{Pädiatrische Epidemiologie und ESPED-Daten}

\section{DGKJ-SY-EP1-1 \\ Steigende Inzidenz verschiedener Diabetesformen im Kindesalter?}

Rosenbauer J.', in Kooperation mit ESPED, der DPV-Initiative

'Deutsches Diabetes-Zentrum, Leibniz-Institut an der Heinrich-Heine-Universität Düsseldorf, Institut für Biometrie und Epidemiologie, Düsseldorf

Fragestellung. Aktuelle Trendschätzung der Inzidenz von Typ-1$\left(\mathrm{T}_{1} \mathrm{DM}\right)$ und Typ-2-Diabetes (T2DM) bei Kindern und Jugendlichen in NRW im Zeitraum 2002-2012.

Material und Methoden. Neuerkrankungen an Typ-1- oder Typ-2-Diabetes wurden mit Hilfe von drei Datenquellen erfasst: dem aktiven Surveillance-System ESPED, jährlichen Praxisbefragungen und der bundesweiten DPV-Datenbank. Die Erfassungsvollständigkeit wurde mit der Capture-Recapture-Methode geschätzt. Inzidenzschätzungen [pro 100.000 Personenjahre, (95\%-KI)] wurden nach Korrektur für die Erfassungsvollständigkeit alters- und geschlechtsstandardisiert. Zeittrends wurden mit Poisson-Regressionen analysiert.

Ergebnisse. Im Zeitraum 2002-2012 wurden 8265 [321] Neuerkrankungen an T1DM [T2DM] (4459 Jungen) [(133 Jungen)] im Alter von o-19 [519] Jahren erfasst. Die Erfassungsvollständigkeit betrug 97,9\% [87,0\%]. Die Inzidenz des T1DM [T2DM] lag bei $20.36(20,90 ; 21,81)[1,15(1,04$; $1,27)]$. Die Inzidenz des TiDM [T2DM] war bei Jungen höher $(22,47$; $(21,82 ; 23,12)$ [niedriger $(0,97 ;(0,82 ; 1,11)]$ als bei Mädchen $(20,25 ;(19,61$; $20,92), \mathrm{p}<0,001[(1,34 ;(1,16 ; 1,52), \mathrm{p}<0,001])$. Die Neuerkrankungsrate des $\mathrm{T} 1 \mathrm{DM}\left[\mathrm{T}_{2} \mathrm{DM}\right]$ hing signifikant vom Alter $\mathrm{ab}(\mathrm{p}<\mathrm{o}, \mathrm{Oo1})$. Die Inzidenz des $\mathrm{T}_{1} \mathrm{DM}\left[\mathrm{T}_{2} \mathrm{DM}\right]$ stieg im Beobachtungszeitraum durchschnittlich um $1,9 \%((1,2 ; 2,6 \%), p<0,001)[2,3 \%((-1,0 ; 5,8 \%), p=0,180)]$ pro Jahr an. Diskussion. Der T2DM ist im Kindes- und Jugendalter selten im Vergleich zum TiDM. Jährlich erkranken in Deutschland etwa 3200-3400 bzw.130--160 Kinder und Jugendliche unter 20 Jahren an T1DM bzw. T2DM. Die Häufigkeit des T2DM wird möglicherweise aufgrund nicht diagnostizierter Fälle unterschätzt. Der Inzidenzanstieg von etwa $2 \%$ pro Jahr erwies sich für den $\mathrm{T}_{2} \mathrm{DM}$ im Gegensatz zum T1DM als nicht signifikant.

Gefördert vom BMBF-Kompetenznetz Diabetes mellitus (FKZ 01Glo802, 01Gl1109A, 01Glo859, 01Gl1106). 


\section{DGKJ-SY-EP1-3}

Der natürliche Krankheitsverlauf von Allergie und Asthma in Kindesalter und Adoleszenz - was hat uns die MAS-Kohortenstudie gelehrt?

\section{Wahn U. ${ }^{?}$}

${ }^{1}$ Charité - Universitätsmedizin Berlin, Klinik für Pädiatrie mit Schwerpunkt Pneumologie und Immunologie, Berlin

Einleitung. Im Jahr 1990 wurden in 5 deutschen Städten (Berlin, München, Freiburg, Mainz und Düsseldorf) 1314 Neugeborene für eine Nicht-Interventionsstudie rekrutiert, die bis zum 20. Lebensjahr verfolgt werden konnten. Ziel der Studie war die Beschreibung des natürlichen Krankheitsverlaufs, die Identifikation verlaufsbestimmender Determinanten (Genetik, Umwelt, Lebensstil etc.) und etwaiger Möglichkeiten für eine präventive Intervention.

Methoden. Die wichtigsten atopischen Manifestationen und ihre Beziehung zu allergischen Sensibilisierungen konnten evaluiert werden, wobei sich zeigte dass die atopische Dermatitis ihre höchste Periodenprävalenz in den ersten 2 Jahren hat und dann zur Remission neigt. Eine späte Manifestation, schwere Ausprägung und Assoziation mit multiplen Nahrungsmittelsensibilisierungen sind Risikofaktoren für eine Krankheitspersistenz.

Ergebnisse. Asthma manifestiert sich im Vorschulalter häufiger beim männlichen Geschlecht, erst mit der frühen Adoleszenz ist die Prävalenz bei Mädchen höher. Risikofaktoren für eine eingeschränkte Lungenfunktion und die Krankheitspersistenz bis ins Erwachsenenalter sind früh auftretende allerg. Sensibilisierungen gegen Katzen und Milben bei hoher Exposition in den ersten 2 Lebensjahren. Die allergische Rhinitis hat die höchste Inzidenz zwischen dem 3. und 12. Lebensjahr, wobei allergische Sensibilisierungen gegen Außenluftallergene der klinischen Manifestation vorausgehen. Eine manifeste Pollenallergie im Vorschulalter ist ein Risiko für eine spätere Asthmaentwicklung. Schlussfolgerung. Es erscheint gerechtfertigt und sinnvoll, die Wirksamkeit einer präventiven Immuntherapie bei Kleinkindern mit früher Sensibilisierung gegen Pollen oder Hausstaubmilben in randomisierten Studien zu untersuchen.

\section{DGKJ-SY-EP1-4}

H1N1 - war das Pandemie-Virus wirklich ohne Zähne?

Haas W. ${ }^{\prime}$, Fiebig L.'

'Robert Koch Institut, Abteilung für Infektionsepidemiologie, Fachgebiet für Respiratorisch übertragbare Erkrankungen, Berlin

Fragestellung. Ein neues Influenza-A(H1N1)-Virus breitete sich 2009 rasant global aus und verursachte die erste Pandemie des 21. Jahrhunderts. Da bis dahin wenig zum Ausmaß schwerer Erkrankungen bei Kindern bekannt war, untersuchten und verglichen wir Risikofaktoren Krankheitsverläufe und Erkrankungsschwere von Influenza bei Kindern während der Pandemie und der ersten postpandemischen Saison. Material und Methode. Wir führten eine bundesweite, prospektive Beobachtungsstudie zwischen August 2009 und Juli 2011 durch, an der alle 375 Kinderkliniken in Deutschland über das ESPED-Netzwerk beteiligt waren. In der Falldefinition wurden intensivstationpflichtige oder tödliche Fälle bei Kindern < 15 J. mit labordiagnostischem Nachweis einer Erkrankung durch die jeweils zirkulierenden Influenzaviren erfasst. Die statistische Auswertung umfasste multivariable Regressionsanalysen zur Berechnung des Chancenverhältnisses (Odds-Ratio = OR).

Ergebnisse. 156 Fälle mit bestätigter Infektion durch $\mathrm{A}\left(\mathrm{H}_{1} \mathrm{~N}_{1}\right)$ pdmog wurden identifiziert: 112 während der Pandemie 2009/10 und 44 in der postpandemischen Saison 2010/11. Bei 114/146 (78\%) Kindern war (mindestens) eine chronische Grundkrankheit bekannt, darunter am häufigsten neurologische Erkrankungen/Entwicklungsverzögerung. Die Letalität der intensivmedizinisch behandelten Kinder lag bei $17 \%$ (25/150) und unterschied sich nicht zwischen 2009/10 und 2010/11. Die
Diagnose einer Myokarditis war mit einem tödlichen Verlauf assoziiert (OR 30,9; 95\% KI 2,6-360,7; p=0,006).

Schlussfolgerung. Die Schwere der Erkrankungen durch Influenza $\mathrm{A}\left(\mathrm{H}_{1} \mathrm{~N}_{1}\right)$ pdmog unterschied sich nicht zwischen der Pandemie und der ersten postpandemischen Influenzasaison. Auch seltene Komplikationen, wie die virale Myokarditis traten auf und waren prädiktiv für einen tödlichen Verlauf.

\section{DGKJ-SY-EP1-5}

Entwicklung der Inzidenz invasiver Pneumokokkeninfektionen und der Serotypenverteilung bei Kindern $<16$ Jahren - drei Jahre Impfung mit dem 10- bzw. 13-valenten Impfstoff (2010-2012)

von Kries R. ${ }^{1}$, Weiß S. ', Falkenhorst G. ${ }^{2}$, Böhmer M. ${ }^{2}$, van der Linden M. ${ }^{3}$ ${ }^{1}$ Ludwig-Maximilians-Universität München, Institut für Soziale Pädiatrie und Jugendmedizin, München, ${ }^{2}$ Robert Koch Institut, Abteilung für Infektionsepidemiologie, Fachgebiet Impfprävention, Berlin, ${ }^{3}$ Universitätsklinikum RWTH Aachen, Institut für Medizinische Mikrobiologie, Aachen

Einleitung. In Deutschland führte die generelle Säuglingsimpfung mit dem 7-valenten Pneumokokkenkonjugat-Impfstoff (PCV7) 2007-2009 zu einer Abnahme der Inzidenz invasiver Pneumokokkenerkrankungen (IPD) bei Kindern < 16 Jahre. Die Gesamtbilanz wurde durch den Anstieg der nicht im Impfstoff enthalten Serotypen gedämpft. Um eine breitere Abdeckung der Serotypen zu erreichen, wird seit April bzw. Dezember 2009 ein 10- bzw. 13-valenter Impfstoff verwendet.

Ziel. Vergleich der Inzidenz und der Serotypenverteilung zwischen den Impfperioden mit $\mathrm{PCV}_{7}$ (2007-2009) und mit PCV10/13 (2010-2012).

Methoden. Nationale Surveillance von IPD auf Basis zweier unabhängiger Quellen: aktive Surveillance in pädiatrischen Kliniken in Deutschland und passive webbasierte Labor-Surveillance. Die Inzidenz wurde mit Capture-Recapture-Berechnungen geschätzt.

Ergebnisse. PCV7-Serotypen verschwanden fast ganz. Die Inzidenz der sechs zusätzlich im 13-valenten Impfstoff enthaltenen Serotypen nahm $\mathrm{ab}$, wenn auch in geringerem Umfang: $-53 \%(95 \% \mathrm{KI}:-50$ bis -57$)$ für Kinder $<16$ Jahre. Die Inzidenz derjenigen Serotypen, die nicht im 13-valenten Impfstoff enthalten sind, nahm zu, insbesondere bei Kindern < 2 Jahren: $+145 \%(+109$ bis +167$)$. Für Kinder $<2$ Jahre sowie für alle Kinder $<16$ Jahre konnte keine signifikante Veränderung festgestellt werden. Für Kinder zwischen 2 und 4 Jahren zeigte sich jedoch eine Abnahme der Meningitis-Fälle: $-68 \%$ ( -59 bis -75$)$. Weiterhin fand sich eine Abnahme von Nicht-Meningitis-Fällen bei Kindern im Schulalter ( $5-15$ Jahre): $-78 \%$ ( -65 bis -90$)$.

Schlussfolgerung. Die kommenden Jahre werden zeigen, ob der erwartete stärkere Erfolg der höhervalenten Impfstoffe noch eintritt oder durch das Auftreten von Serotypen, die nicht im Impfstoff enthalten sind, geschwächt wird.

\section{Kinderorthopädie}

\section{DGKJ-SY-0-1}

Der kindliche Plattfuß - eine Indikation für Einlagen?

Westhoff $B$ ? $^{\text {? }}$

'Universitätsklinikum Düsseldorf, Orthopädische Klinik, Düsseldorf

Der Knick-Senk-Fuß ist einer der häufigsten Gründe, der zur Vorstellung von Kindern beim Orthopäden führt. Pathoanatomisch handelt es sich um eine Außenrotationsfehlstellung des subtalaren Gelenkkomplexes. Häufig ist der Plattfuß assoziiert mit einer Verkürzung der Wadenmuskulatur. Zur Beurteilung der Notwendigkeit einer Therapie ist eine sorgfältige klinische Untersuchung erforderlich. Es muss unterschieden werden zwischen dem physiologischen, flexiblen und dem pathologischen, fixierten Knick-Senk-Fuß. Der flexible Knick-Senk-Fuß ist in der Regel harmlos - eine Therapie in der überwiegenden Mehr- 
zahl der Fälle nicht erforderlich; insbesondere konnte bislang ein positiver Effekt von Einlagen auf die Entwicklung des Längsgewölbes nicht wissenschaftlich belegt werden. Bei Vorliegen einer Verkürzung der Wadenmuskulatur soll diese physiotherapeutisch behandelt werden. Bei Beschwerden bzw. fixierten Plattfüßen ist eine Therapie indiziert, die entweder konservativ und/oder operativ erfolgen muss.

\section{DGKJ-SY-0-3}

Einwärtsgang, Malalignement-Syndrom - ein Grund zur Besorgnis?

\section{Thielemann F.D.M. ${ }^{\text {? }}$}

'Universitätsklinikum Carl Gustav Carus, Klinik für Orthopädie, Dresden

Der Einwärtsgang bei Kindern ist häufig Anlass ärztlicher Konsultationen. Die physiologische Schwäche der pelvitrochantären Muskulatur zum Zeitpunkt des Laufbeginns mit hoher Innendrehfähigkeit der Hüftgelenke, eine generalisierte Bandlaxität und die hohe femorale Antetorsion zu Beginn der kindlichen Entwicklung sind Ursachen dieses zeitlich begrenzt auftretenden Einwärtsgangs. Die muskuläre Adaptation an den aufrechten bipedalen Gang mit der Kräftigung der pelvitrochantären Muskulatur, die Abnahmeder Schenkelhalsantetorsion, die in zwei Detorsionsschüben stattfindet und die allgemein abnehmende Überbeweglichkeit von peripheren Gelenken führt bis zur Adoleszenz bei der Mehrzahl der Kinder zu einer Normalisierung des Gangbildes. Die Fußeingangsebene richtet sich, von einer neutralen bis leicht innen rotierten Ausrichtung im Neugeborenenalter, in eine $10^{\circ}-20^{\circ}$ Außenrotation aus. Der genetisch-familiären Disposition kommt in diesem Entwicklungsprogramm eine wesentliche Bedeutung zu. Der zeitliche Ablauf und die Befunde selbst sind von einer hohen Variabilität geprägt. Die einfühlsame Erklärung dieser altersabhängigen Änderungen trägt dazu bei Ängste bei den betroffenen Eltern abzubauen und eine Übertherapie zu vermeiden. Kontrolluntersuchungen dokumentieren den natürlichen Verlauf. Spezielle angeborene und erworbene Krankheitsbilder, wie beispielsweise die infantile Zerebralparese, schwere Formen der Hüftdysplasie, Klump- und Sichelfüße, ein Malalignement-Syndrom mit innen rotierter Knieebene und verstärkter Außentorsion der Unterschenkel oder Rotationsfehler nach Ober- oder Unterschenkelfrakturen u. v. m., die ebenfalls Ursache eines Einwärtsgangs sein können, sollten erkannt und frühzeitig einer spezialisierten Behandlung zugeführt werden.

\section{Migration}

\section{DGKJ-SY-MI-1}

Migrantenkinder und Jugendliche in Deutschland - aktuelle Zahlen, Daten, Fakten zur gesundheitlichen Situation

\section{Sievers $E^{\prime}$}

${ }^{1}$ Akademie für öffentliches Gesundheitswesen, Sozialpädiatrie, Kinder- und Jugendgesundheitsdienst, Düsseldorf

Fragestellung. In Deutschland haben über 30\% der Neugeborenen einen Migrationshintergrund, etwa $5 \%$ eine ausländische Staatsbürgerschaft. Über 60.000 ausländische Kinder wanderten 2011 nach Deutschland zu. Unterscheiden sich gesundheitliche Situation/Zugang zum Gesundheitswesen der Kinder in Deutschland mit und ohne Migrationshintergrund?

Aktuelle Situation. Für alle Familien mit Migrationshintergrund stellt sich die Frage, wie mit Mehrsprachigkeit in der Familie umgegangen werden soll und dementsprechend qualifizierter Beratungsbedarf. Der KIGGS, RKI 2008, verdeutlichte Unterschiede insbesondere zwischen Kindern mit beidseitigem Migrationshintergrund/selbst zugewanderten Kindern zu Vergleichsgruppen. Kindern ohne gesicherten Aufenthalts- bzw. Versicherungsstatus fehlt oft vor allem der volle Zugang zu Leistungen der Gesundheitsförderung/Prävention. Familien behinder- ter und von Behinderung bedrohter Kinder sowie Kindern chronisch kranker Eltern fehlen darüber hinaus oft Systemkenntnisse zur Nutzung von Sozialleistungen oder medizinischen Maßnahmen. Die Umsetzung einer systematischen interkulturellen Öffnung in der pädiatrischen Versorgung und Verankerung als Merkmal der Strukturqualität steht aus. Dementsprechend fehlt ein abgestuftes Konzept zum qualifizierten Dolmetschen und dessen Finanzierung. Die Elternselbsthilfe wird bisher zu selten von Familien mit Migrationshintergrund genutzt. Schlussfolgerung. Es besteht deutlicher Handlungsbedarf. Dieser ist besonders dringlich für die gesundheitliche Versorgung selbst zuwandernder Kinder, ausländischer Neugeborener sowie chronisch kranker Kinder. Die Realisierung eines effektiv gleichwertigen Zugangs zu Prävention und medizinischer Versorgung sollte als Frage der Versorgungsqualität für Kinder angesehen werden.

\section{DGKJ-SY-MI-3 \\ Sucht und Gewalt bei Migranten}

Bode H. ${ }^{1}$

'Universitätsklinikum Ulm, Kinder- und Jugendmedizin, SPZ und Kinderneurologie, Ulm

Etwa 15 Millionen Menschen haben in Deutschland einen Migrationshintergrund (MH). Etwa 30\% aller Kinder/Jugendlichen stammen aus Zuwandererfamilien. Migranten haben häufiger einen niedrigeren Sozialstatus, geringere Schulabschlüsse und ein höheres Armutsrisiko. Der Sozialstatus hat in vielen Fällen auf Sucht und Gewalt einen größeren Einfluss als der MH.

Jungen und Mädchen mit MH trinken weniger und rauchen seltener, Jungen mit MH nutzen elektronische Medien häufiger als die ohne $\mathrm{MH}$. Besonders Aussiedler waren in den letzten Jahren von Suchtproblemen betroffen (Alkohol, Drogen). Zur Mediensucht existieren keine migrantenspezifischen Daten.

Alkohol ist der maßgebliche Faktor bei häuslicher und öffentlicher Gewalt. Frauen türkischer Herkunft und aus der ehem. Sowjetunion erlebten als Kinder häufiger körperliche Auseinandersetzungen zwischen den Eltern als solche deutscher Herkunft. Der Ausländeranteil in der polizeilichen Kriminalstatistik und bei Gewaltdelikten Jugendlicher ist wegen methodischer Verzerrungen in der Erfassung nicht genau bekannt. Trotz Rückgang des Anteils der nichtdeutschen Jugendlichen und Erwachsenen an der Gewaltkriminalität sind diese weiterhin deutlich höher belastet als deutsche Jugendliche und Heranwachsende. Soziale Randlage, migrationsspezifische Benachteiligungsprozesse, öffentliche und institutionelle Diskriminierung, traditionelle gewaltlegitimierende Männlichkeitsnormen, familiäre Erziehung, Gewalterfahrung, Rollenmodelle in Medien und Cliquen sowie Drogenkonsum sind Risikofaktoren für eine erhöhte Kriminalitätsrate jugendlicher Migranten. Sprachkompetenz, Bildung, Abbau von Segregation und interkulturelle Akzeptanz wirken präventiv. Darüber hinaus existieren eine Vielzahl spezifischer Sucht- und Gewaltpräventionsprogramme. Datenfriedhof oder Informationsquelle? - Vom Nutzen der Abrechnungsdaten

\section{DGKJ-SY-OE-2 \\ Dokumentationsbelastung und -nutzen aus der Sicht eines Ärzt- lichen Direktors}

Riedel F.

'Altonaer Kinderkrankenhaus, Hamburg

Die Notwendigkeit der exakten Kodierung zum Zwecke der DRG-Einordnung hat zweifelsohne den positiven Effekt erbracht, dass der ärztliche Dienst die Diagnosen präzise formulieren und sich auch über alle relevanten Nebendiagnosen klar werden muss. Gleichzeitig besteht die Verpflichtung, sich über die indizierte Diagnostik Gedanken zu machen, um die Diagnose zu stützen oder zu korrigieren. 
In vielen Krankenhäusern obliegt die Diagnosekodierung, zumindest in der Verantwortung, dem ärztlichen Dienst. Hieraus resultiert ein negativer Effekt der Dokumentationsnotwendigkeit mit der Folge einer vermehrten patientenferne Arbeitsbelastung. Eine Versorgungsstudie der BÄK ergab 2008 ein angestiegenes und vom Arbeitgeber erwartetes Arbeitstempo sowie einen höheren Zeitdruck, ähnliche Daten ergaben sich aus einer kürzlich durchgeführten Umfrage an 3800 Ärzten durch das Picker-Institut. Ein Abbau von Arztstellen ist nicht eingetreten, hingegen wurden aber im Pflegebereich Stellen reduziert (Daten der IGES-Versorgungsforschung). Bei der Pflege sind von 2003 bis 2008 Arbeitsbelastung und Zeitdruck angestiegen, durch den wirtschaftlichen Druck ist auch das Selbstverständnis der Pflege verändert worden und die Qualität der Pflege wird aus pflegerischer Sicht als reduziert wahrgenommen. Die einzelnen Studien (BÄK, Picker, IGES, WAMP) werden detailliert dargestellt.

\section{DGKJ-SY-OE-4}

Nutzung von Routinedaten zur Steuerung einer Universitätskinderklinik

\section{Kowalzik Fi}

'Universitätsmedizin der Johannes Gutenberg-Universität Mainz, Zentrum für Kinder- und Jugendmedizin, Mainz

Fragestellung. Seit der Einführung des Abrechnungssystems der Diagnosis Related Groups (DRG) generiert jedes Krankenhaus eine erhebliche Menge, häufig ungenutzter, aber für die Abrechnung zwingend erforderlicher Daten. Während die Nutzbarkeit dieser Daten für die unmittelbare Steuerung einer Klinik begrenzt ist, können sie ggf. einen sinnvollen Beitrag bei der längerfristigen, strategischen Ausrichtung leisten.

Material und Methoden. Anhand ausgewählter DRGs soll aufgezeigt werden, wie eine solche Analyse des bestehenden Patientenkollektivs einer Universitätskinderklinik aussehen kann.

Ergebnisse. Ausgehend von einer oberflächlichen, rein numerischen Betrachtung der Fälle eines vorgegebenen Zeitraumes, mit den entsprechenden Limitationen und Risiken, bis hin zu einer detaillierten Analyse der einzelnen Fallgruppen, soll die Nutzbarkeit der Daten verdeutlicht werden. Die Betrachtung der Steuerungsmöglichkeiten erfolgt vor dem Hintergrund der jährlichen Veränderungen und der Besonderheiten des bestehenden DRG-Kataloges.

\section{DGKJ-SY-OE-5}

Beispiele sinnvoller Nutzung der Abrechnungsdaten bei den Krankenversicherungen

\section{Malzahn J.? \\ ${ }^{1}$ AOK-Bundesverband, Berlin}

Abrechnungsdaten haben zahlreiche bei den gesetzlichen Krankenkassen zahlreiche Nutzungskontexte. Zunächst erfolgt auf Basis dieser Daten die Vergütung der Krankenhäuser, d. h. es werden jährlich über 60 Mrd. Euro an die Krankenhäuser verteilt. Das SGB V verpflichtet die Kassen zur sparsamen Mittelverwendung der Versichertenbeiträge und daher kontrollieren die Kassen die Abrechnungsdaten genau. Im Ergebnis werden rund $2 \mathrm{Mrd}$. Euro erfolgreich regressiert.

Weiterhin sind die Abrechnungsdaten ein wichtiger Bestandteil der Verhandlungen zum Landesbasisfallwert sowie zu den Budgetverhandlungen. Beispielsweise werden aus den Abrechnungsdaten die Erlösausgleiche bestimmt. Zusammenfassend lässt sich sagen, dass diese Daten für das wirtschaftliche Überleben des Krankenhauses von elementarer Bedeutung sind.

Das AOK-System nutzt die Abrechnungsdaten intensiv für Zwecke der Qualitätssicherung. Dies hat den Vorteil, dass kein bürokratischer Erfassungsaufwand für die Krankenhäuser entsteht und viele Qualitätsindikatoren wie Wiederaufnahme, nach dem Krankenhausaufenthalt erworbene Komplikationen oder Tod sind gegenüber Manipulationen vollkommen resistent. Erste Ergebnisse für die Kinderheilkunde können für sehr kleine Frühgeborene gezeigt werden. Das AOK-System plant den weiteren Ausbau der Routinedaten basierten Qualitätssicherung.

\section{DGKJ-SY-OE-6}

Daten des morbiditätsorientierten Risikostrukturausgleichs (MorbiRSA) für die Versorgungsforschung: Beispiele, Erfahrungen und Perspektiven

Arndt $V^{1}$

'Bundesversicherungsamt Bonn, Risikostrukturausgleich, Geschäftsstelle des Wissenschaftlichen Beirats, Bonn

Mit der am 18. September 2012 in Kraft getretenen Datentransparenzverordnung (Verordnung zur Umsetzung der Vorschriften über die Datentransparenz im Gesundheitswesen „DaTraV“) wurde eine Grundlage für eine bessere Nutzung von Routinedaten der gesetzlichen Krankenversicherung geschaffen. Die Bereitstellung ausgewählter Leistungs- und Abrechnungsdaten auf Versichertenebene durch das DIMDI soll bundesweite Analysen des Versorgungsgeschehens im Rahmen der Versorgungsforschung und für Steuerungsaufgaben in der gesetzlichen Krankenversicherung ermöglichen und zur Weiterentwicklung des Versorgungssystems beitragen.

Der Vortrag gibt einen Überblick über den gesetzlichen Hintergrund inkl. vorgesehener Nutzerkreis, Zugangsmöglichkeiten und Datenumfang, diskutiert Fragen zur Qualität von Routinedaten, stellt anhand empirischer Ergebnisse erste Erfahrungen vor und erörtert mögliche Fragestellungen und Grenzen bei der Auswertung des Datenkörpers.

\section{Humangenetik}

\section{DGKJ-SY-HG-1}

Anwendung der Array-Diagnostik bei Entwicklungsstörungen

Moog U.'

'Universität Heidelberg, Institut für Humangenetik, Heidelberg

Die Array-Diagnostik (molekulare Karyotypisierung) hat gegenüber der klassischen, mikroskopischen Chromosomenuntersuchung den Vorteil einer deutlich höheren Auflösung (meist $100 \mathrm{~kb}$ vs. 5-10 Mb bei der klassischen Chromosomenanalyse). Sie hat sich zu einer unverzichtbaren Technologie bei der Abklärung von psychomotorischen Entwicklungsstörungen und geistiger Behinderung entwickelt. Chromosomenstörungen stellen derzeit die größte Gruppe (bis zu ca. 25\%) nachweisbarer Ursachen von Entwicklungsstörungen dar, in 10-14\% betrifft es hierbei submikroskopische Imbalancen (Mikrodeletionen oder -duplikationen), die dem Nachweis mit der klassischen Chromosomenanalyse entgehen. Andererseits können mit der mikroskopischen Analyse nachweisbare balancierte Chromosomenstörungen oder niedriggradige Mosaike mit Array-Verfahren nicht detektiert werden. In vielen Laboren wird die Array-Diagnostik inzwischen als Methode der 1. Wahl bei der Abklärung von Entwicklungsstörungen eingesetzt und findet erstrangig keine klassische Chromosomenuntersuchung mehr statt. Einsatz findet die Array-Diagnostik auch z. B. bei der Abklärung von Kleinwuchs und multiplen angeborenen Fehlbildungen. Nach dem Nachweis einer Imbalance im Array folgt eine Bestätigungsdiagnostik und Untersuchung der Eltern, z. B. mittels herkömmlicher Chromosomenuntersuchung und FISH-Analysen. In etwa $18 \%$ zeigen sich dann strukturelle Auffälligkeiten, die mit der Array-Diagnostik nicht dargestellt werden konnten.

Nach kurzer Vorstellung verschiedener Array-Verfahren (Array-CGH, SNP-Array) werden anhand von Fallbeispielen sowohl die diagnosti- 
schen Möglichkeiten als auch die Grenzen der Methode und die Fallstricke bei der Interpretation der Befunde illustriert.

\section{DGKJ-SY-HG-2}

\section{Fehler im Genom - neue und alte genetisch bedingte Syndrome}

\section{Gillessen-Kaesbach G.}

'Universitätsklinikum Schleswig-Holstein, Institut für Humangenetik, Lübeck

Einleitung. Ein Syndrom ist gekennzeichnet durch ein ätiologisch definiertes Muster multipler Anomalien. Die Diagnosestellung eines Syndroms stellt eine große Herausforderung für klinische Genetiker und Pädiater dar, insbesondere da viele Syndrome eine große phänotypische Variabilität aufweisen. Neben einer exakten Erhebung der $\mathrm{Fa}$ milienanamnese und der körperlichen Befunde ist die Beachtung von Leitsymptomen wie z. B. Adipositas, Makrosomie, Mikrozephalie, präoder postnataler Kleinwuchs, oder spezifischer Fehlbildungsmuster hilfreich bei der klinischen Diagnostik.

Methoden. In den letzten Jahren konnte durch die Anwendung von modernen molekularzytogenetischen Methoden (CGH-Array) eine ätiologische Klärung von zahlreichen Krankheitsbildern erfolgen. Neue Hochdurchsatzsequenzierverfahren wie das „Next Generation Sequencing" (NGS) haben unerwartet schnell Einzug in den diagnostischen Alltag genommen. Fast täglich werden au f diese Weise neue krankheitsverursachende Gene identifiziert. Diese Methoden ermöglichen aber nicht nur eine Klärung der Krankheitsursache, sondern helfen auch, das phänotypische Spektrum von syndromalen Krankheitsbildern zu charakterisieren und Krankheitsentitäten zu definieren.

Schlussfolgerung. Dieser enorme Fortschritt wird durch die Präsentation von klinischen und genetischen Aspekten von alten und neuen Syndromen, die eine Relevanz für die Kinderheilkunde haben, illustriert.

\section{DGKJ-SY-HG-3}

\section{Blickdiagnosen: vom Leitsymptom zum Syndrom}

\section{Spranger . $^{1}$}

${ }^{1}$ Praxis für Humangenetik, Bremen

Die Möglichkeit, viele neue Laboruntersuchungsmethoden in der humangenetischen Diagnostik anzuwenden, könnte den Eindruck entstehen lassen, dass differenzialdiagnostische Überlegungen bei einem Kind mit Fehlbildungs- und/oder Retardierungssyndrom nicht mehr so wichtig sind. Überspitzt formuliert, wird die Untersuchung des Bluts entweder mit „next-generation sequencing“ oder ,array CGH“, die Diagnose schon erbringen.

Aber, Denken hilft! Der Vortrag soll dazu ermuntern, trotz aller Technik noch den klinischen Blick zu nutzen und Verdachtsdiagnosen zu stellen, damit Laboruntersuchungen möglichst gezielt eingesetzt werden können.

Anhand von Fallbeispielen wird auf charakteristische äußere Merkmale aufmerksam gemacht, die eine solche gezielte Verdachtsdiagnose im Einzelfall ermöglichen.

\section{DGKJ-SY-HG-5}

Mismatch-Repair-Defizienz-Syndrom und genetische Prädisposition für kindliche Tumoren

\section{Wimmer K. ${ }^{\prime}$}

'Medizinische Universität Innsbruck, Division Humangenetik, Innsbruck, Österreich

Eine Reihe genetisch-bedingter Syndrome geht mit einem erhöhten Risiko für Malignome im Kindes- und Jugendalter einher. Bei diesen Syndromen, die durch nicht-neoplastische Leitsymptome gekennzeich- net sind, ist das Malignom Risiko in der Regel gering. Dem gegenüber stehen rezessiv vererbte (Kinder-)Krebs-Syndrome, die durch bi-allele Keimbahn-Mutationen in Genen verursacht werden, welche in verschiedene DNA-Reparatur-Prozesse involviert sind. Die Fanconi Anämie ist das bekannteste Syndrom dieser Gruppe. Noch immer kaum wahrgenommen wird das konstitutive Mismatchreparatur-DefizienzSyndrom (CMMR-D; OMIM 276300). Dieses Krebsdispositions-Syndrom zeigt Überlappung mit dem Turcot-Syndrom und resultiert aus einem konstitutiven DNA-Reparatur-Defekt. Fehler, die bei der Verdoppelung der DNA während der Zellteilung entstehen, können daher nicht korrigiert werden. CMMR-D ist durch ein vermutlich nahezu 100\%-iges Malignomrisiko gekennzeichnet. Das Spektrum der Krebserkrankungen ist sehr breit, umfasst aber hauptsächlich hämatologische und Gehirn-Tumoren, sowie kolorektale Karzinome. CMMR-DPatienten zeigen häufig Café-au-lait-Flecken, welche neben anderen nicht-neoplastischen Zeichen als diagnostisches Merkmal herangezogen werden können. Dennoch wird bei pädiatrischen Krebspatienten die Diagnose aufgrund des Fehlens eindeutiger Kennzeichen häufig nicht oder erst dann gestellt, wenn ein zweites Malignom beim Patienten oder einem Geschwisterkind auftritt. Eine frühzeitige Diagnose würde es erlauben Maßnahmen zu Früherkennung von Zweitmalignomen sowie angepasste Therapien einzusetzen. Darüber hinaus ist die korrekte Diagnose für die Beratung der Eltern essenziell. Sie sollten über das Wiederholungsrisiko bei Geschwisterkindern und ihr eigenes Krebsrisiko aufgeklärt werden.

\section{Das „,besondere" Symposium: Wertevermittlung bei Kindern und Jugendlichen im Zeitalter der neuen Medien und sozialen Netzwerke}

\section{DGKJ-SY-W-2 \\ Wie ticken Jugendliche? Lebenswelten von Jugendlichen (im Alter von 14-18 Jahren) in Deutschland}

\section{Calmbach M. ${ }^{1}$}

'SINUS-Institut, Berlin

Der soziokulturelle Wandel in unserer Gesellschaft verändert tiefgreifend die Struktur und Kultur des Alltags. In keiner Altersgruppe ist dieser Wandel so frühzeitig und deutlich spürbar wie bei Jugendlichen. Doch wie ist die „Jugend von heute“? Darüber gibt der Vortrag von Dr. Marc Calmbach über die aktuelle Sinus-Jugendstudie Auskunft. Der Beitrag schildert mit zahlreichen audiovisuellen Beispielen die Vielfalt jugendlicher Lebenswelten in Deutschland.

\section{DGKJ-SY-W-3}

Pluralität der Angebote: Jugendliche auf der Suche nach der eigenen Identität

\section{Gäfgen-Track K.'}

\section{'Landeskirchenamt Hannover, Hannover}

Festgefügte Rollenzuschreibungen und Lebensmuster haben sich heute weitgehend aufgelöst bzw. sind in einer sich permanent verändernden Gesellschaft immer weniger durchzuhalten. Propagiert wird der flexible Mensch, der im Laufe seines Lebens nicht nur verschiedene Berufe ergreift oder neue Arbeitsstellen annimmt, immer neue Produkte kauft, sondern auch immer wieder neue Beziehungen und unterschiedliche zivilgesellschaftliche Engagements eingeht. Der Mensch soll sich selbst „bilden“, neu erschaffen oder sein Selbst- und Fremdbild neu entwerfen sowie seine eigene Geschichte aktiv fortschreiben.

Dieses Konzept einer sich ständig weiterentwickeln Identität, ohne dass es verbindliche bzw. tradierte Rollen oder Lebensmuster als Orientierung gibt, fordert Jugendliche sehr heraus, gerade weil von ihnen ex- 
plizit erwartet wird, dass sie sich nicht auf eine bestimmte Rolle, in bestimmtes Lebenskonzept und auch einen Beruf festlegen lassen.

Zur Bildung einer Identität gehört aber notwendigerweise ein Konzept von Sinn, Wahrheit und Hoffnung, das offen für Neues ist, aber gleichzeitig auch Halt und Orientierung gibt und es so ermöglicht, mit den unterschiedlichen Erwartungen, aber auch den unterschiedlichen Situationen, die ein immer differenzierteres Handeln erfordern, umgehen zu können.

Es soll überlegt werden, welche Rolle Sinn, Wahrheit, Hoffnung, Werte und Normen sowie Beziehung für die Identitätsfindung von Jugendlichen spielen und inwiefern hier z. B. eine christliche Daseins- und Handlungsorientierung zur Identitätsbildung von Jugendlichen, die nicht notwendiger Weise religiös geprägt sein muss, beitragen kann.

\section{Kinder- und Jugendrheumatologie}

\section{DGKJ-SY-R-1 \\ Differenzialtherapie der juvenilen idiopathischen Arthritis mit Biologika}

Horneff G.

'Asklepios Klinik Sankt Augustin, Sankt Augustin

Bei der JIA sind Evidenzen aus kontrollierten klinischen Studien und die Zulassungssituation für differenzielle Therapieentscheidungen maßgeblich.

Für die Polyarthritis mit/ohne Rheumafaktoren stehen die meisten klinischen Biologikastudien zur Verfügung. Die TNF-Inhibitoren Etanercept und Adalimumab sind ab einem Alter von 2 Jahren als Second-line-Therapie nach Methotrexat zugelassen. Abatacept, ein T-Zell-Second-Signal-Inhibitor ist nur zugelassen nach Versagen von TNF-Inhibitoren bei Kindern ab 6 Jahren, wenngleich die Effektivität bei TNF-Versagern geringer war. Die Hemmung der IL-6-Signalkaskade mit Tocilizumab ist bei Polyarthritis ebenfalls ab 2 Jahren geprüft wirksam und zugelassen.

Für den Einsatz von Biologika bei der selteneren Psoriasisarthritis und Enthesitis-asssoziierte Arthritis ab 12 Jahre und erweiterten Oligoarthritis ab 2 Jahre steht derzeit speziell nur Etanercept zur Verfügung. Bei der systemischen Arthritis (Still-Syndrom) ist bislang nur Tocilizumab als Second-line-Therapie zugelassen. Die Applikation erfolgt derzeit noch als intravenöse Infusion alle 14 Tage, doch wird die Option einer s.c. Applikation nach Abschluss einer Pharmakokinetikstudie möglich.

Die aus pathophysiologischen Gründen sinnvolle Hemmung der Interleukin-1 Signalkaskade stehen Anakinra, ein Interleukin-1-Rezeptorantagonist, und Canakinumab, ein IL-1-Antikörper zur Verfügung, deren Zulassung erwartet wird. Zahlreiche Biologika sind bislang nur als Offlabel-Therapeutika einsetzbar. Die Verträglichkeit von Biologika wird nachhaltig in Therapieregistern untersucht und erscheint mit geringer Intoleranzrate günstig.

Der Einzug der Biologika hat nicht nur die Therapieoptionen erweitert, sondern zu neuen Therapiekonzepte geführt und Remission als Therapieziel erreichbar gemacht.

\section{DGKJ-SY-R-2}

\section{Bildgebung in der Kinderrheumatologie}

\section{Windschall D. ${ }^{\prime}$}

${ }^{1}$ Asklepios Klinik Weißenfels, Klinik für Kinder- und Jugendmedizin, WeiBenfels

Thematik. Bildgebende Verfahren ergänzen im Zusammenspiel mit dem klinischen Befund und der Labordiagnostik die Diagnosestellung einer rheumatischen Erkrankung im Kindesalter. In den vergangenen Jahren hat die hochauflösende Gelenksonographie einen zentralen Stellenwert in der Erstdiagnostik und Verlaufskontrolle einer JIA eingenommen. Für bestimmte Fragestellungen müssen weitere bildgebende Verfahren wie das MRT oder das Röntgen hinzugezogen werden. Bei Kollagenosen besitzt die Kapillarmikroskopie einen hohen Stellenwert. Eine neuere Bildgebungsmethode ist das fluoreszenzoptische Verfahren.

Methodik. Neben dem B-Mode-Verfahren wird beim Gelenkultraschall der Powerdoppler-Modus eingesetzt. Sonomorphologische Kriterien für eine Entzündung sind ein Erguss, die synoviale Hypertrophie,die Hypervaskularisation oder eine lokale Wachstumsbeschleunigung. Standards und Entzündungsscores für die pädiatrische Rheumatologie müssen noch evaluiert werden. Das MRT kommt vor allem in der Differenzialdiagnostik und im Bereich der Iliosakral-, Kiefer- und Wirbelsäulengelenke zum Einsatz. Mit dem Nachweis von Veränderungen der Kapillarmorphologie kann die Kapillarmikroskopie einen entscheidenden Hinweis für das Vorliegen einer Kollagenose liefern. Die Fluoreszenzoptik zeigte in ersten Studien bei Kindern mit JIA gute Ergebnisse. Schlussfolgerung. Bildgebende Verfahren sind in der kinderrheumatologischen Diagnostik unverzichtbar. Sie helfen bei der Diagnosestellung, bei der Verlaufskontrolle und Therapieentscheidung. Den höchsten Stellenwert in der Routinediagnostik nimmt inzwischen die Arthrosonographie ein. Sie ist aber nicht bei jeder Fragestellung ausreichend und muss durch andere bildgebende Verfahren ergänzt werden.

\section{Demenzkrankheiten bei Kindern und Jugendlichen - erkennen und damit umgehen}

\section{DGKJ-SY-LS-1 \\ Demenz im Kindesalter - eine Einführung}

Kohlschütter A. ${ }^{1}$

'Universitätsklinikum Hamburg-Eppendorf, Klinik für Kinder- und Jugendmedizin, Hamburg

In der Praxis des Kinder- und Jugendarztes ist eine echte Demenz, d. h. ein neu eingetretener Verlust geistiger Fähigkeiten, viel seltener als ein stationäres kognitives Defizit. Die rechtzeitige Erkennung von oft subtil beginnenden dementiellen Veränderungen hat jedoch große, manchmal dramatische Konsequenzen. Ursächlich handelt es sich dabei meist um genetische Erkrankungen, für die ein hoher Bedarf an Familienberatung und palliativer Therapie besteht. Die anwendbaren lindernden Maßnahmen können dabei sehr krankheitsspezifisch sein. In gewissen Fällen ist eine kausal gerichtete Therapie möglich, und es kann sogar eine dringliche Intervention angebracht sein, deren Verpassen in Katastrophen mündet.

Demenz kann lange das Leitsymptom einer Krankheit sein und erst später von weiteren Abbauerscheinungen wie Störungen der Motorik oder des Visus begleitet werden. Umgekehrt können dementielle Veränderungen im späteren Verlauf einer Krankheit auftreten, die anfänglich als reine Bewegungs- oder Sinnesstörung imponierte. Scheinbare Demenzen (wie auch scheinbare stationäre Oligophrenien), die bei Kindern mit neurologischen Störungen der sprachlichen Expression leicht irrtümlich angenommen werden, sind eine besondere Herausforderung für die Rehabilitation.

\section{DGKJ-SY-LS-3}

Demenz bei weiteren Krankheiten der grauen Substanz (Gangliosidosen, M. Niemann-Pick Typ C)

Beck M.', AG Lysosomale Speicherkrankheiten (Villa Metabolica) ${ }^{1}$ Universitätsmedizin Mainz, Zentrum für Kinder- und Jugendmedizin, Mainz

Lysosomale Speicherkrankheiten zeichnen sich aus durch eine beträchtliche klinische Variabilität. Neben infantilen Formen, die schon innerhalb der ersten Dekade zum Tode führen, sind juvenile und adulte 
Formen bekannt, die oft eine völlig andere Symptomatik wie zum Beispiel eine Psychose oder Demenz aufweisen. Der M. Niemann-Pick Typ C (NPC) ist eine Lipid-Speicherkrankheit, die auf einer Störung im intrazellulären Transport von Cholesterin beruht. Neben dem infantilen NPC-Typ werden juvenile und adulte Formen beobachtet, die sich im Manifestationsalter und in der Ausprägung der verschiedenen Symptome beträchtlich unterscheiden (Varianten des M. Niemann-Pick Typ C). Im Erwachsenenalter kann sich eine Demenz entwickeln, die oft mit einer Ataxie und Augenmotilitätsstörungen einhergeht.

Die GM1-Gangliosidose zeigt ebenfalls eine große klinische Variabilität. Während der infantile und juvenile Typ als Krankheitsbild klinisch verhältnismäßig klar umrissen werden können, ist ein einheitliches Symptomenmuster bei den adulten Formen, von denen lediglich Einzelbeobachtungen vorliegen, nicht abzuleiten. Neben neurologischen Symptomen wie Dysarthrie, Ataxie und Dystonie wurden auch leichte Skelettveränderungen beschrieben. Das Ausmaß der geistigen Retardierung reicht von einer leichten Intelligenzminderung bis zur schweren Demenz.

Es ist eine Vielzahl von jugendlichen und erwachsenen Patienten mit einer GM2-Gangliosidose beschrieben worden, die sehr unterschiedliche Symptomenmuster aufwiesen. Einige manifestieren sich als amyotrophe Lateralsklerose oder als spinale Muskelatrophie. Oft liegt gleichzeitig eine Demenz vor.

Zusammenfassend muss bei unklaren Demenz-Zuständen auch an eine lysosomale Speicherkrankheit gedacht werden.

\section{DGKJ-SY-LS-4 \\ Im Spiel bleiben - Umgang mit kindlicher Demenz aus Sicht des Kinder- und Jugendpsychiaters}

\section{Richterich A.}

'HELIOS St. Josefs-Hospital Bochum, Kinder- und Jugendpsychiatrie, -psychosomatik und -psychotherapie, Bochum

Wenn Kinder oder Jugendliche aufgrund einer körperlichen Krankheit, beispielsweise einer neuronalen Ceroid-Lipofuszinose (NCL), zunehmende Defizite in kognitiven, emotionalen und sozialen Fähigkeiten zeigen, stellt dies die Betroffenen und ihre Familien vor schwerwiegende Aufgaben. Aus Sicht der Kinder und Jugendlichen gibt es viele Fragen („was geschieht mit mir?", „wie lange werde ich leben?"), die nicht immer einfach mit Eltern, Geschwistern oder Lehrern zu besprechen sind. Familien und auch betreuende Ärztinnen und Ärzte stehen vor dringend zu beantwortenden Fragen und komplexen Problemen. Trotzdem ist es wichtig, die Perspektive der Patienten im Blick zu behalten. Nicht zuletzt haben auch Eltern und Geschwister Sorgen und Ängste, mit denen sie sich häufig alleingelassen fühlen. Wie viel soll und darf ich sagen? Gibt es denn überhaupt noch Hoffnung? Aus dem Bereich der Kinder- und Jugendpsychiatrie und Psychotherapie können Beiträge zur Betreuung und Behandlung von Betroffenen und deren Familien geleistet werden. Dies betrifft sowohl die Psychopharmakologie als auch die psychotherapeutische Begleitung. Wesentliche Prinzipien hierbei sind Berücksichtigung des Entwicklungsstandes des Kindes, Respekt vor den Entscheidungen der Eltern, Bereitschaft zu einem offenen Umgang mit schwierigen Themen, auch wenn es manchmal keine „richtigen“" Antworten gibt. In diesem Vortrag werden eigene Erfahrungen aus der Betreuung von Kindern mit neurodegenerativen Erkrankungen dargestellt. Weiterhin wird das Buch für Familienangehörige „Im Spiel bleiben“ der Ärztin Riet Niezen aus dem NCL-Zentrum Bartiméus in den Niederlanden vorgestellt, welches sie in Zusammenarbeit mit einer Psychologin und einem Seelsorger geschrieben hat und das nun in deutscher Übersetzung vorliegt.

\section{DGKJ-SY-LS-5}

Die NCL-Stiftung - ihre Strategie und Maßnahmen zur Bekämpfung der häufigsten Kinderdemenz (NCL)

Stehr F.

${ }^{1} \mathrm{NCL}-$ Stiftung, Hamburg

Einleitung. Seit 2002 setzt sich die gemeinnützige NCL-Stiftung für die Bekämpfung der Kinderdemenz Neuronale Ceroid Lipofuszinose (NCL) ein. Ziel ist es, die Rate an Fehldiagnosen zu minimieren und den Bekanntheitsgrad in Fachkreisen zu erhöhen, da es in der Regel 2 bis 4 Jahre dauert, bis die korrekte Diagnose gestellt wird. Hierzu werden gezielt Augen- und Kinderärzte über NCL informiert. Darüber hinaus werden auch Sehschulen berücksichtigt und die Lehre wird gestärkt. Zum Mix der Fortbildungsstrategien zählen z. B. Vorträge, die thematische Einbindung in bestehende Kongresse, die Stärkung der Differenzialdiagnostik mit Hilfe eines Poster-Projektes und Patientenvorstellungen. Begleitend werden verschiedene Marketing- und PR-Maßnahmen vorgenommen. Als nächstes sollen die Aktivitäten in einer „Fortbildungsakademie für Kinder- und Jugenddemenzen“ gebündelt werden.

Methoden. Um das wissenschaftliche Netzwerk auf- und auszubauen, werden von der Stiftung regelmäßig Wissenschaftler-Treffen organisiert und Forschungslabore persönlich besucht. Darüber hinaus findet ein aktiver Austausch mit anderen Non-Profit-Organisationen statt. Schlussfolgerung. Um die NCL-Forschung voranzubringen, werden von der NCL-Stiftung Doktorandenstipendien vergeben und alle 2 Jahre ein Forschungspreis ausgelobt, welcher der höchstdotierte in Europa in Bezug auf Seltene Krankheiten ist. Mit diesen Fördermaßnahmen sollen identifizierte Forschungslücken geschlossen werden.

\section{Pädiatrische Epidemiologie in Deutschland}

\section{DGKJ-SY-EP2-1 \\ Allergie und Adipositas - Nutzen, Besonderheiten und Sinn der Epidemiologie bei Kindern}

von Kries $R$.

'Ludwig-Maximilians-Universität München, Institut für Soziale Pädiatrie und Jugendmedizin, München

Einleitung. Epidemiologie beschäftigt sich mit dem Auftreten von Erkrankungen in Bevölkerungen. Im Zähler steht der Erkrankte, im Nenner die Zahl der potentiell Erkrankten (also die Summe aus Menschen mit der spezifischen Erkrankung und Gesunden, die diese Erkrankung nicht haben). Diesen Quotient nennt man die Prävalenz. Ändert sich die Prävalenz über die Zeit, ist es von Interesse zu wissen: wer, wo, wann? Hieraus können Hinweise auf potenzielle Risiken für Adipositas abgeleitet werden.

Methoden. Ideal für die Beurteilung des Spontanverlaufs sind Kohorten. Hierbei werden z. B. Kinder von der Geburt an nachbeobachtet. Wann beginnt die Adipositas - bleibt sie bestehen oder verschwindet sie wieder? Solche Daten zum Spontanverlauf sind u. a. für die Beratung wichtig.

Schlussfolgerung. In Kohorten können auch Risikofaktoren identifiziert werden. Wie solche Risikofaktoren für Adipositas identifiziert werden können und wann Kausalität angenommen werden kann, wird in dem Vortrag erläutert. 


\section{DGKJ-SY-EP2-2}

\section{KiGGS: epidemiologische Studie zur Gesundheit von Kindern und} Jugendlichen in Deutschland

\section{Schlaud M.', für die KiGGS Study Group \\ 'Robert-Koch-Institut, Abt. für Epidemiologie und Gesundheitsmonitoring, Berlin}

Einleitung. Epidemiologie beschreibt die Häufigkeit, Verteilung und Determinanten gesundheitsbezogener Merkmale in der Bevölkerung mit dem Ziel der Prävention. Bevölkerungsbezogene Daten zur Gesundheit von Kindern und Jugendlichen in Deutschland liefert die KiGGS-Studie.

Methoden. In der KiGGS-Basiserhebung wurden in einem komplexen Stichprobenverfahren zunächst 167 Orte ausgewählt und aus deren Meldeämtern Eltern von Kindern im Alter von 0-17 Jahren zufällig gezogen. Die Probanden wurden vom RKI zu Untersuchungen und Befragungen vor Ort eingeladen, die in den Jahren 2003 bis 2006 von 4 ärztlich geleiteten Teams in standardisierter Weise durchgeführt wurden. Insgesamt 17.641 Mädchen und Jungen (Teilnahmequote: 66,6\%) nahmen mit einem begleitenden Elternteil an der Studie teil, die erstmals flächendeckend erhobene und bundesweit repräsentative Daten zur körperlichen und geistigen Gesundheit, zur sozialen Lage, zum Gesundheitsverhalten und zur Inanspruchnahme von Versorgungsangeboten bei Kindern und Jugendlichen lieferte.

Ergebnisse. Die Querschnittstudie konnte als Kohortenstudie fortgesetzt werden. Die KiGGS-Welle 1 (2009-2012) besteht aus der standardisierten telefonischen Wiederbefragung der KiGGS-Basisprobanden (KiGGS-Kohorte) im Alter von 7-24 Jahren (Wiederteilnahmequote $72 \%, n=11.407$ ) und der Befragung einer neu gezogenen Bevölkerungsstichprobe im Alter von o-6 Jahren (Teilnahmequote $42 \%, n=4455$ ).

Schlussfolgerung. Die Daten erlauben neben aktuellen Prävalenzschätzungen zu wichtigen Gesundheitsindikatoren, stratifiziert nach soziodemographischen Merkmalen, auch analytisch-epidemiologische Kohortenauswertungen von Entwicklungsverläufen und Kausalanalysen. Ab 2014 soll die KiGGS-Welle 2 erneut Untersuchungs- und Befragungsdaten aus der KiGGS-Kohorte (10-27 Jahre) und aus einer neuen Querschnittstichprobe Jüngerer liefern.

\section{DGKJ-SY-EP2-3}

\section{Das Deutsche Kinderkrebsregister, Stärken und Grenzen}

Spix C. ${ }^{1}$, Kaatsch P. ${ }^{1}$

'Universitätsmedizin Mainz, IMBEI, Deutsches Kinderkrebsregister, Mainz

Das Deutsche Kinderkrebsregister wurde 1980 in West-Deutschland gegründet, im Jahre 1991 wurde es auf die neuen Länder erweitert. Es werden flächendeckend alle Krebserkrankungen bei in Deutschland lebenden Kindern unter 15, seit 2009 bis unter 18 Jahren erfasst. Seit 1987 ist die Erfassung mindestens 95\% vollzählig.

Das Deutsche Kinderkrebsregister wurde auf Initiative der Vorgängerorganisationen der Gesellschaft für pädiatrische Onkologie und Hämatologie $(\mathrm{GPOH})$ gegründet, mit der auch weiterhin eine enge $\mathrm{Zu}$ sammenarbeit besteht, Nach den Protokollen der GPOH werden mehr als 90\% aller Fälle in der Kinder- und Jugendonkologie in Deutschland behandelt.

Die besondere Stärke des Registers ist die Vollzähligkeit und dass Familien und ehemalige Patienten für wissenschaftliche Fragestellungen direkt angesprochen werden können.

Mit den Therapieverbesserungen stieg auch die Überlebenswahrscheinlichkeit, auf mittlerweile 80\% Langzeitüberleben, so dass sich im Lauf des letzten Jahrzehnts der Schwerpunkt der Registerarbeit und der am Register durchgeführten Forschung immer mehr auf die Langzeitnachbeobachtung und Spätfolgen verlagert hat. Von zentraler Bedeutung sind die Anstrengungen zur möglichst vollzähligen Erfassung von Folgeneoplasien.

\section{Literatur}

1. Spix C, Kaatsch P, Schüz J (2013) Umweltfaktoren bei Leukämieerkrankungen im Kindesalter. pädiat prax 80:233-54

2. Grabow D, Spix C, P Kaatsch (2012) Langzeitüberlebende nach Krebs im Kindesalter: eine populationsbezogene Kohorte am Deutschen Kinderkrebsregister. Ärzteblatt Rheinland-Pfalz 6

3. Kaatsch P, Reinisch I, Spix C, Berthold F, Janka-Schaub G, Mergenthaler A, Michaelis J, Blettner M (2009) Case-control study on the therapy of childhood cancer and the occurrence of second malignant neoplasms in Germany. Cancer causes \& control 20(6):965-80

\section{Pädiatrische Allergologie}

\section{DGKJ-SY-PA1-2}

\section{Bedeutung von Virusinfektionen für die Asthmaentwicklung}

\section{Ankermann $T^{1}$}

'Universitätsklinikum Schleswig-Holstein, Campus Kiel, Klinik für Allgemeine Pädiatrie, Kiel

Asthma bronchiale $(\mathrm{AB})$ ist durch entzündliche und fibroproliferative Prozesse, Veränderungen der Gefäßmuskulatur und neuronale Veränderungen gekennzeichnet. Da die meisten Patienten mit AB Atopiker sind, aber nur ein kleiner Teil der Atopiker ein $\mathrm{AB}$ entwickelt, spielen neben der Atopie offensichtlich Kofaktoren bei der AB-entstehung eine Rolle. Mit Beginn in den 1980er Jahren wurden frühe Virusinfektionen der Atemwege als ein Faktor für die Pathogenese von allergischen Erkrankungen und des $\mathrm{AB}$ und die Häufung von Virusinfektionen bei Atopikern beschrieben. In populationsgestützten Studien zeigten sich Virusinfektionen der unteren Atemwege als ein Faktor für die Entstehung eines $\mathrm{AB}$ und Atopie, wobei Infektionen mit RSV und Rhinoviren (RV) am besten untersucht sind. Auch In-vitro-Arbeiten zeigen synergistische Effekte von Atopie und Virusinfektionen für die Entstehung von Atemwegserkrankungen. Dies wurde insbesondere für RV gezeigt. Die Frage, ob Virusinfektionen der unteren Atemwege kausal für Atopie- und AB-entstehung oder Indikator sind, ist noch nicht vollständig verstanden. Tierexperimentelle Arbeiten und Arbeiten mit In-vitroTechniken belegen eine Interaktion zwischen antiviralen und atopiespezifischen Signal- und Effektorwegen. So gibt es Hinweise auf eine bei Atopikern differente Immunabwehr bei Virusinfektionen. Für einzelne Viren (RV) konnten eine direkte Induktion einer Fibroproliferation nachgewiesen werden. Diese Mechanismen führen zu Gewebeschäden und zu über die Virusinfektionen hinausgehende Veränderungen. Eine interessante Hypothese, die die kausale Rolle von Virusinfektionen bei der Entstehung von Atopie und $\mathrm{AB}$ unterstützt, ist die Induktion des hochaffinen IgE-Rezeptors auf dendritischen Zellen durch Virusinfektionen der Atemwege.

\section{DGKJ-SY-PA1-3}

\section{Therapeutische Optionen des „Infektasthmas"}

\section{Spindler T.}

'Fachkliniken, Wangen

Asthma? Infektasthma? Infektassoziiertes Asthma? - Ist diese Trennung sinnvoll? Zur Definition des „Asthma bronchiale“ gehört die Chronizität der Erkrankung, was eigentlich per se schon ein ausschließlich bei Infekten auftretendes Asthma ausschließen würde.

Die Differenzierung zwischen Asthma bonchiale als chronische entzündliche Atemwegserkrankung und rezidivierenden obstruktiven Bronchitiden, d. h. Begleitobstruktion bei Atemwegsinfekten insbesondere im Säuglings- und Kleinkindalter nicht immer einfach.

Die Möglichkeit einer objektiven Diagnosestellung „Asthma“ ist auf Grund fehlender Mitarbeit bei einer Lungenfunktion praktisch nicht vorhanden, obstruktive Symptome dagegen überaus häufig. Zur Diagnosestellung und den eventuellen Konsequenzen bezüglich einer Be- 
darfs- oder Dauerbehandlung ist der Arzt auf anamnestische und diagnostische Hilfskonstrukte angewiesen. Gerade in diesem Alter steht der behandelnde Kinder - und Jugendarzt aber nahezu täglich vor der Herausforderung einer Diagnosestellung der Frage möglicher therapeutischer Optionen.

Im Vortrag sollen mögliche Wege zu einer entsprechenden Entscheidungsfindung aufgezeigt und daraus resultierende Therapieempfehlungen diskutiert werden.

\section{DGKJ-SY-PA1-4}

\section{Berufsberatung für allergische Jugendliche}

Vogelberg C.

'Universitätsklinikum Carl Gustav Carus, Klinik und Poliklinik f. Kinder- u. Jugendmedizin, Bronchopneumologie/Allergologie, Dresden

Erkrankungen aus dem atopischen Formenkreis wie Asthma bronchiale, allergische Rhinitis oder atopische Dermatitis stehen an der Spitze chronischer Erkrankungen im Kindes- und Jugendalter. Jugendliche mit einer Erkrankung aus dem atopischen Formenkreis haben grundsätzlich ein erhöhtes Risiko für eine Verschlechterung der Erkrankung, wenn sie einen Risikoberuf wählen. Insbesondere in den ersten Monaten nach Aufnahme der Berufsausbildung ist das Risiko für eine Zunahme der Krankheitsausprägung erhöht, ein erheblicher Anteil an Ausbildungsabbrüchen und/oder -wechsel geht zu Lasten berufsbedingter allergischer Erkrankungen. Aus diesem Grunde ist eine sorgfältige und abwägende Beratung der betroffenen Personen im Vorfeld notwendig. Repräsentative Untersuchungen zeigen aber, dass sich Jugendliche bei der Berufswahl nicht von ihrer Erkrankung beeinflussen lassen und die Wahrnehmung von Beratungsangeboten gering ist. Daher liegt auch beim behandelnden Kinderarzt eine besonders hohe Verantwortung, das Thema Berufswahl mit dem betroffenen Jugendlichen und seinen Eltern zu besprechen. Dabei ist es wichtig, eine individuelle und an den jeweiligen Umständen des Jugendlichen angepasste Beratung zum richtigen Zeitpunkt vorzunehmen und keine pauschalen Empfehlungen auszusprechen. Aufgrund von Ergebnissen aus deutschen Kohortenstudien existiert inzwischen für jeden behandelnden Arzt die Möglichkeit neben der Zuhilfenahme von Beratungsbroschüren internetbasiert ein für den jeweiligen Patienten individualisiertes Risikoprofil für die Entwicklung einer atopischen Erkrankung nach Berufsbeginn zu erstellen.

\section{Neuropädiatrie (1) - Autoimmunerkrankungen mit ZNS-Manifestation}

\section{DGKJ-SY-NP1-1}

Neuromyelitis optica

\section{Huppke P. ${ }^{1}$}

${ }^{1}$ Georg-August-Universität, Pädiatrie II, Göttingen

Die Neuromyelitis optica (NMO) ist eine demyelinisierende Erkrankung des ZNS, die monophasisch oder rekurrierend auftreten kann. Die klinische Symptomatik ist geprägt von einer Neuritis nervi optici und langstreckigen Myelitiden. Diese können gleichzeitig aber auch Monate bis Jahre getrennt voneinander auftreten. Die Prognose der Erkrankung ist insbesondere bei den rekurrierenden Verläufen schlechter als bei der Multiplen Sklerose. Bei einem Teil der Patienten können Antikörper gegen den Wasserkanal Aquaporin 4 (NMO-IgG) im Serum gefunden werden. Insbesondere bei diesen Patienten ist die Prognose schlecht und daher eine frühe Therapie wichtig. Im Kindesalter finden sich in Deutschland überwiegend monophasische Verläufe mit guter Prognose. Trotzdem ist es sehr wichtig die wenigen Patienten mit Nachweis von Aquaporin 4 Antikörpern nicht zu übersehen und früh immunsuppressiv zu behandeln, da nur so die Prognose verbessert werden kann.

\section{DGKJ-SY-NP1-3}

Spektrum MOG-assoziierter entzündlicher ZNS-Erkrankungen

Rostásy K.

'Medizinische Universität Innsbruck, Department für Pädiatrie I,

Neuropädiatrie, Innsbruck, Österreich

Das Spektrum entzündlicher demyelinisierender ZNS-Erkrankungen umfasst Erkrankungen, die entweder akut und monophasisch verlaufen wie die akute disseminierte Enzephalomyelitis (ADEM) oder rezidivierend auftreten können wie die multiple Sklerose und Neuromyelitis optica (NMO). Mit großer Wahrscheinlichkeit spielen Autoantikörper wie im Falle der NMO (anti-APQ4-IgG) eine wichtige Rolle in der Diagnose und Pathogenese der unterschiedlichen Erkrankungen. Ein weiterer Autoantikörper, der vor allem bei Kindern mit ADEM, rezidivierenden Optikus-Neuritiden aber auch NMO-ähnlichen Verläufen gefunden wird ist gegen das Myelin-Oligodendrozyt-Protein (MOG) gerichtet, einem integralen Bestandteil der Myelinscheide. Die genaue Rolle der anti-MOG-IgG-Antikörper in der Pathogenese demyelinisierender Erkrankung ist noch nicht geklärt. Bekannt ist aber, dass sie unterschiedliche Epitope des MOG-Proteins erkennen und in der Zellkultur eine Komplementaktivierung auslösen können.

\section{DGKJ-SY-NP1-4}

Spektrum Autoantikörper-vermittelter Enzephalitiden im Kindesalter

Bien C.G.'

'Epilepsie-Zentrum Bethel, Krankenhaus Mara, Bielefeld

In den vergangenen Jahren hat sich eine neue neurologische Krankheitsgruppe etabliert: die autoimmunen Enzephalitiden. Die wissenschaftliche Erforschung dieser Erkrankungen und ihre zunehmend häufigere Entdeckung im klinischen Alltag ist eine Erfolgsgeschichte. Drei Gründe sind hierfür entscheidend: 1.) Es gibt spezifische Biomarker, nämlich die antineuralen Antikörper; sie erlauben - oft im Kontext typischer klinischer Bilder - eine verlässliche Diagnosestellung. 2.) Durch immuntherapeutische Behandlungen können die Patienten gebessert, teilweise sogar geheilt werden. 3.) Es gibt erste Befunde zur Pathophysiologie dieser Erkrankungen einschließlich erster Hinweise auf einen direkt pathogenen Effekt der Antikörper selbst.

Im Kindesalter sind es insbesondere anderweitig unerklärte Enzephalopathien, die durch Antikörper (hier vor allem gegen den NMDA-Rezeptor) diagnostisch eingeordnet und dann behandelt werden können. Aber auch neu aufgetretene Epilepsien, oft mit hoher Anfallsfrequenz, sowie subakut sich entwickelnde zerebelläre Ataxien legen den Verdacht auf eine autoimmune ZNS-Erkrankung nahe.

Eine besondere Herausforderung stellen Patienten dar, bei denen Verlauf, klinischer Befund sowie paraklinische Marker eine autoimmune Genese nahelegen, ohne dass spezifischen Autoantikörper nachgewiesen werden. Hier entwickeln sich gegenwärtig erste Anhaltspunkte für ein adäquates Management. Diese sollen im Vortrag ebenfalls erörtert werden.

\section{Moderne Bildgebung}

\section{DGKJ-SY-ND1-3}

Innovative Aspekte der präoperativen Bildgebung in der pädiatrischen Onkologie aus Sicht des Kinderchirurgen

Fuchs J. $^{1}$

'UniversitätsklinikumTübingen, Pediatric Surgery and Pediatric Urology, Tübingen

In den letzten Jahrzehnten konnte die stadienunabhängige Überlebensrate von kindlichen soliden Tumoren in beeindruckender Weise verbes- 
sert werden. Diese Ergebnisse basieren auf einheitlichen Behandlungsprotokollen in den verschiedenen Therapieoptimierungsstudien und einer guten interdisziplinären Kooperation verschiedenster medizinischer Fachdisziplinen.

Die chirurgische Behandlung von kindlichen soliden Tumoren stellt dabei einen sehr wichtigen und prognoserelevanten Mosaikstein dar. Ein essentieller Bestandteil zur Beurteilung der Resektabilität eines Tumors und zur Festlegung der dazu notwendigen chirurgischen Strategie ist die exakte präoperative Bildgebung dar.

Die Präsentation fokussiert auf ausgewählte Aspekte in der Bildgebung kindlicher Tumoren und neuer Erkenntnisse der 3-dimensionalen Rekonstruktion von Tumoren mit virtueller Tumorresektion am PC sowie der Wertigkeit der Bildgebung bei Metastasen. Außerdem werden neue bildgebende Verfahren wie das Ganskörper-MRT und die PET-MRT bei kindlichen soliden Tumoren vorgestellt.

\section{Diagnostik und Therapie bei Hypoglykämien}

\section{DGKJ-SY-SW1-4}

\section{Medikamentöse Therapie des kongenitalen Hyperinsulinismus}

Welters A. ${ }^{\prime}$, Marquard J.', Salgin B. ${ }^{1}$, Lerch C. ${ }^{2}$, Meissner T.'

${ }^{1}$ Universitätsklinikum Düsseldorf, Klinik für Allgemeine Pädiatrie, Neonatologie und Kinderkardiologie, Düsseldorf, ${ }^{2}$ Institut für Allgemeinmedizin, Cochrane Metabolic and Endocrine Disorders Group, Düsseldorf

Einleitung. Der kongenitale Hyperinsulinismus (KHI) ist eine der häufigsten Ursachen für persistierende Hypoglykämien im Säuglings- und Kindesalter. Die diffuse Form des KHI erfordert i. d. R. eine dauerhafte medikamentöse Therapie. Diazoxid ist das Einzige zur Langzeittherapie des KHI zugelassene Medikament. Weitere in der Anwendung befindliche Medikamente haben keine Zulassung. Angaben zu Dosierung und Nebenwirkungen (NW) dieser Medikamente sind unzureichend. Fragestellung. Ziel dieser Arbeit war die Zusammenstellung der medikamentösen Therapieoptionen bei KHI und die Erstellung strukturierter Angaben zu Dosierung, Therapiedauer und dem Auftreten von NW. Methode. Systematische Literaturrecherche in den Datenbanken Medline ( $\mathrm{ab}$ 1947) und Embase ( $\mathrm{ab}$ 1988) nach relevanten Artikeln über die medikamentöse Therapie des diffusen KHI und Auswertung relevanter Parameter.

Ergebnisse. Diazoxid ist das am häufigsten eingesetzte Medikament. Die Therapie beträgt durchschnittlich 4,9 Jahre, die mittleren Dosierung $13 \mathrm{mg} / \mathrm{kg} / \mathrm{d}$. NW umfassen Hypertrichose (47\%), Flüssigkeitsretention (29\%), dyspeptische Beschwerden (10\%), in Einzelfällen Herzversagen. Am zweithäufigsten werden die Somatostatin Analoga Octreotid bzw. Lanreotid angewendet. Die Therapiedauer beträgt durchschnittlich 3 bzw. 2,4 Jahre, die mittlere Dosierung $23 \mu \mathrm{g} / \mathrm{kg} / \mathrm{d}$ bzw. $57 \mu \mathrm{g} / \mathrm{kg} / \mathrm{d}$. Zu den NW zählen Tachyphylaxie (7\%), GI-Symptome (7\%), NEC (2\%) und Gallensteine (1\%). Seltener angewendet werden Kalziumkanalblocker und Glukagon, die sich durch ein geringes Nebenwirkungsprofil auszeichnen.

Schlussfolgerung. Diese Arbeit dient behandelnden Ärzten und betroffenen Familien als Grundlage für die Entscheidung und Überwachung einer medikamentösen Therapie bei KHI, insbesondere im Hinblick auf Dosierung sowie den zu erwartenden NW.

\section{Psychosomatik (1) - wir integrieren die \\ Psychosomatik in die Kinderklinik}

\section{DGKJ-SY-PS2-1}

\section{Psychosozialer Konsiliardienst und Psychosomatische Station -} essentielle Bausteine eines Kinderzentrums

\section{Lucas T.}

'Universitätsklinikum Schleswig-Holstein, Kinderzentrum, Campus Lübeck, Kinder- und Jugendpsychosomatik \& Psychotherapie/Kinder- und Jugendpsychiatrie, Lübeck

Ein psychosoziales Konsil beinhaltet im Kinderzentrum die fachliche Beratung eines Patienten und seiner Eltern, vor allem aber des Teams einer pädiatrischen oder kinderchirurgischen Station, bei psychosozial belasteten Patienten und bei Symptomen, denen seelischen Probleme zugrunde liegen könnten. Häufig geht es dabei um nicht organisch bedingte, funktionelle, körperliche Beschwerden mit psychosomatischer Entstehungsgeschichte, bis hin zu dissoziativen Anfällen oder Lähmungen, oder um die Verarbeitung, Akzeptanz und Compliance im Rahmen einer chronischen oder akuten körperlichen Krankheit. Regelmäßig resultieren Diagnosen behandlungsbedürftiger psychischer Störungen, deren Ätiologie vornehmlich (epi-)genetisch, oder aber psychoreaktiv bzw. posttraumatisch sein, aber auch (sub-)akute Suizidalität oder Fremdgefährdung mit Gefahr im Verzug aufzeigen kann.

In Zeiten rückläufiger klassisch-somatischer Kinderkrankheiten zugunsten der sog. „,neuen Morbidität", kommt einem effektiven Konsilund Liaisondienst, ergänzt durch eine psychosomatisch-psychotherapeutische Station, zunehmend hohe Bedeutung für eine hochwertige und umfassende Patientenversorgung im Kinderzentrum zu und verhindern diese essentiellen Bausteine zudem jahrelange, oft mit „ÄrzteHopping" gepaarte, leidvolle Umwege, sowie das Abwandern entsprechender Familien in "paramedizinische" bzw. "paratherapeutische" Bereiche mit fehlender Qualitätssicherung.

Am wirksamsten und effektivsten ist die Betreuung dann, wenn das Kinderzentrum ergänzend zur (Sozial-)Pädiatrie und Kinderchirurgie samt Spezialisierungen, eine eigene psychosomatisch-psychotherapeutische Station und Ambulanz mit entsprechender kinder- und jugendpsychiatrischer und kinderpsychotherapeutischer Expertise vorhält.

\section{DGKJ-SY-PS2-2}

Von der Notwendigkeit ganzheitlicher Betreuung chronisch kranker Kinder und Jugendlicher

Mönkemöller K.', Martens M. ${ }^{1}$, Mirza J.', Müksch B. ${ }^{1}$, Weiss M. ${ }^{1}$

'Kinderkrankenhaus der Stadt Köln gGmbH, Kinder- und Jugendmedizin, Köln

Eine chronische Erkrankung und ihre Behandlung stellen für die Patienten und ihre Familien eine große Herausforderung dar, die mit einschneidenden Veränderungen im Familienleben verbunden sind. Zunehmend wird deutlich, dass psychische und soziale Faktoren die Therapiedurchführung und somit den Behandlungserfolg mindestens ebenso beeinflussen wie somatische.

Entscheidend für eine erfolgreiche Behandlung ist es, seelische und soziale Faktoren jederzeit in die Therapie einzubeziehen. Das umfasst die Unterstützung gesundheitsfördernder Strategien und gleichzeitig die Kenntnis von Risikofaktoren. Das Behandlungsteam muss nicht nur aus mehreren Professionen wie Psychologen, Pädagogen, Lehrern, Sozialarbeitern oder Krankengymnasten bestehen. Erforderlich ist von Anfang an strukturiertes interdisziplinäres Arbeiten, um notwendige Therapieanpassungen zu erkennen und rechtzeitig Unterstützung anzubieten. Wesentlicher Bestandteil der Behandlungsmöglichkeiten ist das Angebot von Geh-Strukturen wie einer Nachsorgeschwester. 
Eine solche Herangehensweise ermöglicht ein niederschwelliges ganzheitliches Betreuungsangebot für die Patienten und ihre Familien und somit eine unabdingbare Optimierung der Therapie.

\section{DGKJ-SY-PS2-4}

\section{Kooperation mit der Kinder- und Jugendpsychiatrie}

\section{von Stauffenberg M. ${ }^{?}$ ${ }^{1}$ AGPPS, Frankfurt/Main}

Es ist wünschenswert und auch notwendig, dass jede Kinderklinik bzw. Pädiatrische Abteilung innerhalb einer Klinik für Erwachsene sich auf die Hilfe eines konsiliarisch tätigen Kollegen aus der Kinder- und Jugendpsychiatrie verlassen kann und guten Kontakt zur nächsten Kinder- und Jugendpsychiatrie pflegt.

1.) In der Kinderärztlichen Notfallambulanz werden häufig Kinder und Jugendliche vorgestellt, die in einer Kinderklinik in der Regel nicht ausreichend behandelt werden können: $u$. a. Patienten mit akuter Suizidalität, Suchterkrankungen, akuten Psychosen, selbstverletzendem oder dissozialem Verhalten.

2.) Zudem ergeben sich bei stationär behandelten Patienten häufig Fragen bzgl. einer psychischen Komorbidität, die psychologischer bzw. psychiatrischer Abklärung bedürfen: u. a. bei Kindern mit Regulationsstörungen, chronischen Erkrankungen, V. a. Misshandlung, nicht altersgerechten Ängsten und Schmerzen ohne organisch fassbares Korrelat.

3.) Auf einer psychosomatischen Station sollten im Laufe der Behandlung die zu Grunde liegenden unbewussten Konflikte erkannt und therapiert werden. Krisen innerhalb des Behandlungsprozesses können jederzeit auftreten und müssen adäquat behandelt werden können, u. U. mit Hilfe von Psychopharmaka. z. B. bei Spannungszuständen, motorischer Unruhe, Schlafstörungen, Depressionen, massiven Zwangsgedanken und Suizidalität.

4.) Ggf. muss eine stationäre Übernahme in die $\mathrm{K}+\mathrm{J}-\mathrm{Psychiatrie}$ von $\mathrm{Pa}$ tienten, die selbst oder fremdgefährdend sind, gewährleistet sein.

Psychosomatik ohne psychiatrische Kompetenz ist nicht denkbar.

\section{Kinderschutz in der Medizin}

\section{DGKJ-SY-KS-2 \\ Röntgenskelettscreening bei Verdacht auf Misshandlung und Ver- nachlässigung - Wann? Was? Wie?}

\section{Mentzel H.-J.', Stenzel M.? \\ 'Universitätsklinikum Jena, Sektion Pädiatrische Radiologie, Jena}

Die bildgebende Diagnostik besitzt neben Anamnese und klinischer Untersuchung einen hohen Stellenwert bei vermuteter körperlicher Misshandlung von Säuglingen und Kindern. Die Bildgebung dient dabei nicht nur dazu, therapeutisch relevante Verletzungsfolgen $\mathrm{zu}$ erkennen, sondern unter forensicher Fragestellung auch dem Ausschluss bzw. Nachweis von klinisch okkulten Verletzungsfolgen am Skelett. Bei zufälliger radiologischer Diagnostik von misshandlungstypischen Skelettveränderungen und bei der Nachweisdiagnostik vermuteter Kindesmisshandlung ist in Absprache mit den betreuenden Ärzten ein Röntgenskelettstatus indiziert. Nach dem ALARA-Prinzip sind die technischen Parameter der Aufnahmen der jeweiligen Körperabschnitte zu optimieren. Ein Babygramm ist obsolet. Bei zweifelhaften Befunden sind Zielaufnahmen bzw. Folgeaufnahmen nach 7 bis 14 Tagen zu indizieren. Neben der korrekten Aufnahmetechnik und leitliniengerechter Durchführung sind Kenntnisse über spezifische Verletzungsmuster Grundlage für eine exakte Befunderstellung. Die Befunderhebung und Beurteilung sollte möglichst nach dem 4-AugenPrinzip erfolgen.

\section{DGKJ-SY-KS-3 \\ Radiologische Frakturdatierung}

Born M. ${ }^{1}$

'Universitätsklinikum Bonn, Radiologische Klinik - FE Kinderradiologie, Bonn

Der Bestimmung des Alters einer Fraktur kann im Fall einer Kindesmisshandlung erhebliche forensische Bedeutung zukommen, insbesondere ist der Nachweis unterschiedlich alter Frakturen nahezu beweisend für eine nicht unfallbedingte Ursache einer Fraktur. Die Altersabschätzung einer Fraktur beruht auf den histologischen Reparaturvorgängen, die im zeitlichen Verlauf zu beobachten sind. Der Heilungsverlauf einer Fraktur kann in 5 histologische Stadien eingeteilt werden, die jedoch nicht alle ein radiologisch fassbares Korrelat haben. Radiologische Kriterien zur Altersabschätzung einer Fraktur sind u. a. die Schärfe der Frakturränder, die Weite des Frakturspaltes im zeitlichen Verlauf, das Auftreten periostaler Reaktionen, Kallusbildung und Remodellierung. Die wichtigsten Zeitpunkte des Auftretens verschiedener Kriterien werden in dem Vortrag vorgestellt. Der zeitliche Verlauf des Auftretens dieser Merkmale ist jedoch variabel und zudem von verschiedenen Parametern abhängig wie dem Grad der Ruhigstellung, dem Alter des Kindes, dem Ort der Fraktur, der Mineralisation u. a., so dass die Altersabschätzung einer Fraktur mit größeren Ungenauigkeiten behaftet bleibt.

\section{DGKJ-SY-KS-4}

Sexueller Missbrauch in Institutionen: Prävention und Intervention in Kinderkliniken

von Bismarck S.

'Klinik für Kinder- und Neugeborenenchirurgie, Vivantes Klinikum Neukölln, Berlin

Bei den Erhebungen des Runden Tisches bezüglich internen Missbrauchs in Institutionen sind Kinderkrankenhäuser kaum als Problemfeld bekannt geworden. Medienrelevante Einzelfälle haben für Schlagzeilen gesorgt. Verlässliches Zahlenmaterial über interne Missbrauchsfälle in Kinderkliniken ist nicht verfügbar. Dabei ist das Risikopotenzial erheblich. Trotz gesetzlicher Verpflichtung verfügen offensichtlich nur wenige Kinderkliniken über ein entsprechendes, tatsächlich gelebtes Schutz- oder Interventionskonzept. Bei der Erarbeitung von Schutzkonzepten kommt einer professionellen und altersgerechten Nähe-Distanz-Regulation eine entscheidende Rolle zu, zusätzlich ist ein strukturiertes Meldewesen für den Fall eines grenzverletzenden Verhaltens erforderlich. Umgangscodices helfen, erwartetes Verhalten des Personals verbindlich festzulegen. Forderungen nach einem generellen berührungsfreien Patientenumgang erscheinen ebenso wie ein generelles Vieraugenprinzip weder wünschenswert noch durchführbar. Für bestimmte medizinische Maßnahmen ist dagegen ein Vieraugenprinzip präventiv sinnvoll. Interdisziplinäre Fortbildungen müssen für das Thema sensibilisieren und eine Veränderung im Umgang mit dem Thema interner Missbrauch bewirken. Bei der Intervention kann häufig auf vorhandene Konzepte für „externen“ Missbrauch zurückgegriffen werden, diese müssen der lokalen Situation angepasst und um weitere Aspekte wie Meldewesen, Arbeitsrecht, Patientenrecht, Umgang mit Medien und Einschaltung der Strafverfolgungsbehörden ergänzt werden. Es besteht erheblicher Nachholbedarf sowohl in der Erkenntnis, dass sexueller Missbrauch auch in Kinderkliniken passieren kann als auch in der Erarbeitung von Konzepten, wie diesem präventiv oder interventionell begegnet werden soll. 


\section{Diabetes (1) und Endokrinologie}

DGKJ-SY-DB1-2

Ernähungstherapie beim Typ-1-und Typ-2-Diabetes: Gemeinsames und Unterschiede

Reinehr T.

${ }^{1}$ Vestische Kinder- und Jugendklinik, Universität Witten/Herdecke, Datteln

Früher lag der Schwerpunkt der Ernährungsberatung beim Typ-1-Diabetes bei der konventionellen Insulintherapie vorzugeben, wie viele Kohlenhydrate pro Mahlzeit gegessen werden müssen aufgrund des festgelegten Insulinregimes. Mit der Umstellung auf die intensivierte Insulin- und Insulinpumpentherapie sind solche festen Vorgaben nicht mehr erforderlich. Dies hat zur Lebensqualitätssteigerung beigetragen. Bei Typ-1-Diabetikern ist eine Zunahme der Adipositas zu verzeichnen. Eine Ernährungsberatung beim Typ-1-Diabetes ist daher von Anfang an auch eine gesunde Mischkost implementieren. Diese Kostform ist auch Therapie der Wahl beim Typ-2-Diabetes im Jugendalter. Damit hat sich die Ernährungsberatung des Typ-1- und Typ-2-Diabetes angenähert. Während der Typ-1-Diabetiker von Anfang an den Kohlenhydratanteil der Lebensmittel kennen muss, um das entsprechende prandiale Insulin ausrechnen zu können, ist eine solche Schulung beim Typ-2-Diabetes zu Beginn der Behandlung noch nicht erforderlich, sondern erst mit Beginn der Insulintherapie.

In der Praxis stellt die Ernährungsberatung bei Wunsch, das Übergewicht zu reduzieren, bei Typ-1-Diabetikern immer wieder eine Herausforderung dar. Eine Reduktion der Insulinzufuhr ist vom ersten Tag der Gewichtsreduktion erforderlich. Es empfiehlt sich dabei zunächst die prandiale Insulindosis zu vermindern. Im Alltag versuchen insbesondere weibliche Jugendliche durch Weglassen des Basalinsulins (Insulinpurging) ohne Ernährungsumstellung eine Übergewichtsreduktion zu erzielen. Durch die Flüssigkeitsausschwemmung nimmt auch das messbare Gewicht ab. In der Ernährungsberatung sollte daher frühzeitig auf die Gefahren des Insulinpurgings hingewiesen werden, wie die deutlich erhöhte Gefahr einer Ketoazidose und die schlechte Stoffwechseleinstellung.

\section{DGKJ-SY-DB1-4}

Diagnostik bei metabolischem Syndrom

\section{Salgin $B{ }^{1,2}$}

'Universitätsklinikum Düsseldorf, Klinik für Allgemeine Pädiatrie, Neonatologie und Kinderkardiologie, Düsseldorf, ${ }^{2}$ Universitätsklinikum Cambridge, Kinderklinik, Cambridge, UK

Das metabolische Syndrom soll Risikofaktoren für die Entwicklung von Herz-Kreislauf-Erkrankungen und Typ-2-Diabetes vereinigen. Die Definition des metabolischen Syndroms wurde jedoch wiederholt geändert, was eine genaue Bestimmung der Prävalenz und von langfristigen Folgen schwierig macht. Des Weiteren bestehen Bedenken bezüglich der diagnostischen Kriterien, so dass eine evidenzbasierte Diagnostik bei metabolischem Syndrom derzeit nicht gegeben ist und damit dessen Nutzen, insbesondere im Kindes- und Jugendalter, hinterfragt werden muss.

\section{Beiträge der infektionsepidemiologischen Forschung zu aktuellen Fragen in der pädiatrischen Infektiologie}

\section{DGKJ-SY-I5-1 \\ Antibiotikaverbrauch und Antibiotikaresistenzen an deutschen Kinderkliniken im europäischen Vergleich}

\section{Hufnagel M.', für die ARPEC-Projektgruppe}

'Universitätsklinikum Freiburg, Sektion Pädiatrische Infektiologie und Rheumatologie, Zentrum für Kinder- und Jugendmedizin, Freiburg

Einleitung. Antibiotikresistenzen nehmen weltweit zu und die Entwicklung neuer Antibiotika hält mit der Resistenzentwicklung nicht stand. Die Häufigkeit von Antibiotikaresistenzen ist mit dem Antibiotikaverbrauch assoziiert. Eine systematische Erhebung des Antibiotikaverbrauchs bei hospitalisierten Kindern fehlt.

Methodik. Das von der EU finanzierte ARPEC-Projekt (Antibiotic Resistance and Prescribing in European Children) hat eine Methode zur Erfassung des indikations- und körpergewichtsbezogenen Antibiotikaverbrauchs bei hospitalisierten Kindern entwickelt. In einer Punktprävalenzerhebung wurde der Verbrauch an einem Tag im November 2012 in 24 deutschen Kinderkliniken erhoben und mit dem Verbrauch in 156 Kinderkliniken in Europa verglichen. Zusätzlich wurden Resistenzen von 9 unterschiedlichen Bakteriämie-Isolaten aus dem Jahr 2011 erfasst. Ergebnisse. Die Antibiotikaprävalanz bei hospitalisierten Kindern in Deutschland entsprach mit 34\% dem europäischen Durchschnitt. Der Verbrauch zwischen den einzelnen Kliniken war hoch variabel. Im Südwesten Deutschlands ist der Verbrauch niedriger als im übrigen Bundesgebiet. Im Vergleich zu anderen europäischen Kinderkliniken werden in Deutschland Cephalosporine, v. a. Breitspektrum-Cephalosporine und Reserveantibiotika wie Glykopeptide und Carbapeneme vermehrt verwendet. Die wenigsten Kinder mit Atemwegsinfektionen erhalten leitliniengerecht Aminopenicilline oder Makrolide. Die Resistenzsituation bei Bakteriämie-Isolaten aus Deutschland ist ähnlich der anderer nordeuropäischer Länder und niedriger als in Südeuropa. Schlussfolgerung. Die Punktprävalenzerhebung zum Antibiotikaverbrauch bei hospitalisierten Kindern in Deutschland liefert Ansatzpunkte für eine Optimierung der Antibiotherapie.

\section{DGKJ-SY-I5-2}

Klinische und molekulare Epidemiologie von invasiven Gruppe-BStreptokokken(GBS)-Infektionen bei Neugeborenen und Säuglingen in Deutschland - Ergebnisse der Studie von ESPED und RKI 2008-2010

Lander F. ${ }^{1}$, Heinrich B. ${ }^{2}$, Hufnagel M. ${ }^{3}$, Berg A. ${ }^{3}$, Wicker E. ${ }^{4}$, von Kries R. ${ }^{5}$, Krause G. ${ }^{4,6}$, Berner R. ${ }^{1}$, im Namen der Studiengruppe der ESPED

'Universitätsklinikum Carl Gustav Carus, Klinik und Poliklinik für Kinderund Jugendmedizin, Dresden, ${ }^{2}$ Heinrich-Heine-Universität Düsseldorf, ESPED, Koordinierungszentrum für Klinische Studien (KKS), Düsseldorf, ${ }^{3}$ Universitätsklinikum Freiburg, Zentrum für Kinder- und Jugendmedizin, Freiburg, ${ }^{4}$ Robert-Koch-Institut, Berlin, ${ }^{5}$ Ludwig-Maximilians-Universität München, Institut für Soziale Pädiatrie und Jugendmedizin, München, ${ }^{6} \mathrm{Helmholtz-Zentrum}$ für Infektionsforschung, Abteilung Epidemiologie, Braunschweig

Fragestellung. In Zusammenarbeit mit der Erfassungseinheit für seltene pädiatrische Erkrankungen in Deutschland (ESPED) und dem Robert-Koch-Institut (RKI) wurden Inzidenz und Klinik neonataler GBSInfektionen untersucht und mit Ergebnissen einer Vorläuferstudie aus den Jahren 2001-2003 verglichen. Eingesandte invasive Bakterienisolate wurden analysiert, um Veränderungen der Resistenzsituation und der molekularen Epidemiologie aufzuzeigen.

Methode. Deutschlandweit wurden kulturell gesicherte invasive Erkrankungsfälle durch GBS bei Neugeborenen und Säuglingen $<3$ Mo- 
nate über das Meldesystem der ESPED in den Jahren 2008-2010 erfasst und mittels Fragebogen ausgewertet. In einer Zweiterfassung wurden in den Jahren 2009 und 2010 über das RKI mikrobiologische Labore in Deutschland abgefragt. Parallel wurden über den gesamten Untersuchungszeitraum invasive GBS-Isolate gesammelt.

Ergebnisse. Im Vergleich zur Vorläuferstudie zeigte sich die gemeldete durchschnittliche jährliche Rate von 174 auf 116 Fälle pro Jahr rückläufig. Dieser Rückgang war vor allem auf eine Verminderung der Early-Onset-Sepsis (EOS) zurückzuführen (aktuell 44\%; Vorläuferstudie $60 \%)$. Letalität $(3,2 \%)$ und Frühgeborenen-Anteil (32\%) unterschieden sich nicht wesentlich zur Voruntersuchung (4,3 bzw. 28\%). Es wurden 2008-2010 insgesamt 1085 invasive GBS-Isolate aller Altersgruppen eingesandt, davon 235 (22\%) von Neugeborenen und Säuglingen <3 Monate. Die Serotyp-Verteilung der neonatalen Isolate zeigte wenig Veränderung gegenüber 2001-2003 mit den häufigsten Typen III (66\%), Ia (17\%), V, Ib und II (zusammen 11\%). Resistenzen gegen Clindamycin (14\%) und Makrolide (22\%) waren doppelt so häufig nachweisbar.

Fazit. Die Häufigkeit invasiver GBS-Infektionen bei Kindern <3 Monate in Deutschland scheint um ein Drittel rückläufig.

\section{DGKJ-SY-I5-3}

Prospektive Surveillance schwerer viraler Atemwegsinfektionen (ARE) bei Kindern auf pädiatrischen Intensivstationen in Bayern

Streng A. ', Runge B. ', Hanke S. ', Prifert C. ${ }^{2}$, Weissbrich B. ${ }^{2}$, Liese J. ${ }^{1}$, Bavarian PICU Study Group on Influenza and Other Viral ARI

'Universitätsklinikum Würzburg, Kinderklinik und Poliklinik, Würzburg,

${ }^{2}$ Universität Würzburg, Institut für Virologie und Immunbiologie, Würzburg

Fragestellung. Ziel der Studie war, den jeweiligen Anteil der häufigsten viralen Erreger von schweren ARE in pädiatrischen Intensivstationen (PICUs) zu erfassen und Charakteristiken der jeweiligen viralen ARE zu bestimmen.

Methode. In 23 PICUs in Bayern wurden von Okt 2010 bis Sep 2012 respiratorische Proben von Kindern ( $>1$ Monat und $<17$ Jahren) mit ARE zentral auf 19 virale Erreger mit Multiplex-PCR getestet und deren klinische Daten erhoben.

Ergebnisse. Bei 224 (69\%) von 323 Kindern mit intensivpflichtiger ARE wurden Viren nachgewiesen (48 Mehrfachinfektionen): 85 RSV A/B (38\%); 72 Rhinoviren (RhV; 32\%); 28 Parainfluenza 1-4 (PIV; 12\%); 23 humane Bocaviren (hBoV;10\%); 21 Influenza A/B (IV; 9\%); 20 Coronaviren NL63/OC43/HKU1/229E (CoV; $9 \%)$; 9 humane Metapneumoviren (hMPV; 4\%); 9 Enteroviren (EV; 4\%); 7 Adenoviren (3\%); 4 Parechoviren (2\%). Bei viraler Monoinfektion (79\%) waren RSV- und RhV-Patienten am jüngsten (Median o,1 bzw. o,8 Jahre), IV- und CoV-Patienten am ältesten (Median jeweils 6 Jahre). Der Anteil an Kindern mit Vorerkrankung war bei RSV am geringsten (31\%), bei PIV, CoV und hBoV am höchsten $(\geq 75 \%)$. Bronchitis/Bronchiolitis war am häufigsten bei RSV (85\% aller RSV-Fälle), Pneumonie bei CoV, hBoV und hMPV (je 83\%), sekundäre bakterielle Pneumonie bei IV (37\%), Sepsis bei EV $(29 \%)$ und ARDS bei RhV (20\%). 30\%-40\% der ARE durch IV, CoV und hBoV waren lebensbedrohlich (mit 4 von 6 Virus-assoziierten Todesfällen); RSV- und RhV-Patienten erkrankten seltener lebensbedrohlich (Anteil jeweils <20\%). „Neue Viren“ (entdeckt ab Jahr 2000) wurden bei $28 \%$ aller viralen ARE und $67 \%$ der Todesfälle nachgewiesen.

Diskussion. RSV und RhV waren die häufigsten Erreger schwerer viraler ARE, aber selten lebensbedrohlich. IV- und CoV-Monoinfektionen verliefen in $10 \%$ bzw. $17 \%$ tödlich.

\section{Pneumologie (2)}

\section{DGKJ-SY-PN2-2}

Mukoviszidose: Welche neuen Therapien sollte der Kinderarzt kennen?

Schramm D.

'Universitätsklinikum Düsseldorf, Klinik für Allgemeine Pädiatrie, Neonatologie und Kinderkardiologie, Düsseldorf

Rund 8000 Patienten mit der Erbkrankheit Mukoviszidose leben zurzeit in Deutschland. Die jährliche Neuerkrankungsrate liegt bei ca. 200-40o Kindern. Der Erkrankung liegt ein Defekt des CFTR-Gens auf Chromosom 7 zugrunde. Dieses Gen kodiert für ein Protein mit der Funktion eines Chloridkanals in der Zellmembran. Defekte in diesem Gen führen zu vollständigem Fehlen, mindestens aber zu einer Funktionseinschränkung des Kanals, wobei insgesamt sechs verschiedene Mutationsklassen definiert sind. Mukoviszidose ist eine chronischprogrediente Erkrankung mit Multiorganmanifestation. Die Therapie dient dazu die Organfunktionen so lange wie möglich zu erhalten, einen oft dystrophen Ernährungszustand zu verbessern und rezidivierende Infekte zu behandeln. Eine besondere Rolle spielt hierbei die Besiedelung und Infektion mit Pseudomonas aeruginosa. Die Therapie der Mukoviszidose ist dauerhaft, muss sehr gewissenhaft durchgeführt und immer wieder überprüft werden. Die insgesamt sehr komplexe Therapie dient vor allem der Sekretolyse, welche medikamentös-inhalativ und atemphysiotherapeutisch erfolgt. Neben weiteren und immer neuen therapeutischen Aspekten zum Beispiel zur antibiotischen Therapie oder hochkalorischen Ernährung, existiert seit 2012 erstmals ein Medikament zur Genmodulation auf dem Markt, welches für eine Gruppe von Patienten mit der Mutation G551D zugelassen ist.

An den Therapeuten und Verordner sind besonders hohe Anforderungen hinsichtlich der Komplexität der Erkrankung gestellt. Insofern richtet sich dieser Vortrag an die verordnenden Kinder- und Hausärzte, um ihnen einen sinnvollen Überblick über Neuigkeiten in der Therapie zu liefern und ihnen eine relevante Auswahl neuer Medikamente sowie deren Indikation und Nebenwirkungen vorzustellen.

\section{Mykobakteriosen}

\section{DGKJ-SY-I2-2}

Probleme multiresistenter Tuberkulose - The problems of multiresistant tuberculosis (MDR-TB)

\section{Kampmann B.,2}

IImperial College London, Paediatrics, London, UK, ${ }^{2} \mathrm{MRC}$ Unit, The Gambia, Vaccinology, Banjul, Gambia

With rising prevalence in the European region, MDR TB represents a serious threat also to children in our clinical settings. Most children will be infected through a known adult case of MDR TB and contact tracing in the community is therefore key.

The same diagnostic challenges apply to MDR TB in children as for drug-sensitive TB, mainly to achieve bacteriological confirmation in the presence of pauci-bacillary disease.

My presentation will cover epidemiology in Europe, diagnostic tools and clinical and therapeutic challenges. I will explore the issues of prophylaxis in MDR-exposed and -infected children. Areas of need for further research will be identified. 
DGKJ-SY-I2-3

\section{Epidemiologie und Klinik der atypischen Mykobakteriose}

Haas W.', Drzymala S.', Hauer B. ', Reuss A.'

${ }^{1}$ Robert Koch Institut, Abteilung für Infektionsepidemiologie, Fachgebiet für Respiratorisch übertragbare Erkrankungen, Berlin

Fragestellung. 2003 bis 2005 führten wir gemeinsam mit der Erhebungseinheit seltener pädiatrischer Erkrankungen (ESPED) erstmals eine Erhebung bei immunkompetenten Kindern $<15$ Jahren in Deutschland durch und bestimmten eine durchschnittliche jährliche Inzidenz von Erkrankungen durch nichttuberkulöse Mykobakterien (NTM) von 1,3 pro 100.00o. In 2011 erfolgte eine Nachbefragung der Eltern zum langfristigen Therapieverlauf und Behandlungsergebnis. Zeitgleich starteten wir - erneut in Kooperation mit der ESPED - eine zweite Erhebung. Material und Methode. Telefonische Nachbefragung zwischen 5 und 8,5 Jahren nach der ersten Hospitalisierung wegen einer Erkrankung durch NTM. Eltern, die einer Kontaktaufnahme schriftlich zugestimmt hatten, wurden zunächst angeschrieben und nachfolgend wurden Interviews mittels eines standardisierten Fragebogens durchgeführt.

Ergebnisse. Die Rücklaufquote der Nachbefragung lag bei $89 \%(63 / 71$ kontaktierten Familien). 61 Kinder waren an einer Lymphadenitis durch NTM erkrankt. In etwa der Hälfte der Fälle erfolgte die initiale Therapie kombiniert chirurgisch und medikamentös. Bei Kindern mit einer kompletten Exzision der betroffenen Lymphknoten zeigte sich kein Unterschied in der Heilungsrate zwischen einer ausschließlich chirurgischen Therapie und einer zusätzlichen medikamentösen Behandlung (64\%, 95\% CI: $31-89 \%$ vs. $67 \%$, 95\% CI: $35-90 \%)$.

Schlussfolgerung. Den größten Anteil der Krankheitslast durch NTM bei immunkompetenten Kindern stellt die mykobakterielle Lymphadenitis dar. Entgegen der geltenden Empfehlungen erfolgt bei einem hohen Anteil dieser Patienten die initiale Therapie kombiniert chirurgisch und medikamentös, ohne dass (bei geringer Fallzahl) ein Vorteil dieses Ansatzes hinsichtlich des Therapieerfolges gezeigt werden kann.

\section{Updates/Refresher (2)}

\section{DGKJ-SY-RE2-1}

\section{Update: Stoffwechsel}

\section{Kölker S. ${ }^{\prime}$}

'Universitätsklinikum Heidelberg, Zentrum für Kinder- und Jugendmedizin, Klinik I, Sektion für Angeborene Stoffwechselerkrankungen, Heidelberg

Hintergrund. In den vergangenen Jahren wurde die molekulare Ursache einiger Stoffwechselerkrankungen aufgeklärt. Dies soll an ausgewählten Beispielen erörtert werden.

Methoden. Die molekulare Ursache der 2-Hydroxyglutarazidurien wurden entschlüsselt, krankheitsauslösende Gene für D-2-Hydroxyglutarazidurie Typ I (D2HGDH-Gen) und Typ II (IDH2), L-2-Hydroxyglutarazidurie Typ I (L2HGDH) und D-2-/L-2-Hydroxyglutarazidurie (SLC25A1) identifiziert. Hierdurch wurden neue Erkenntnisse zum Stoffwechsel und Transport von 2-Oxoglutarat gewonnen und neue Therapiemöglichkeit aufgezeigt. D-2-Hydroxyglutarsäure wurde zudem als Biomarker einiger neoplastischer Erkrankungen (somatische IDH1- oder IDH2-Mutationen) identifiziert. Desweiteren wurde D-2Hydroxyglutarsäure bei Patienten mit metaphysärer Chondromatose, multiplem Acyl-CoA-Dehydrogenase-Mangel und anderen Stoffwechselkrankheiten nachgewiesen.

Ergebnisse. Die heterogene Gruppe der nichtklassifizierten 3-Methylglutaconazidurie (Typ IV) konnte weiter aufgeschlüsselt werden und eine mitochondriale Dysfunktion ursächlich als gemeinsamer Nenner ermittelt werden. Vier Untergruppen - encephalomyopathisch, hepatocerebral, kardiomyopathisch und myopathisch - wurden klinisch definiert. Als zugrundeliegende Ursache wurden die bekanntermaßen eine mitochondriale Dysfunktion induzierenden Gene POLG1, SUCLA2,
TMEM7o und RYRı u. a. nachgewiesen. Als molekulare Ursache für das MEGDEL-Syndrom wurde SERAC1 identifiziert.

Schlussfolgerung. Das Vici-Syndrom ist eine Multisystemerkrankung mit Balkenagenesie, Katarakt, Kardiomyopathie, Immundefizienz und Hypopigmentierung. Als ursächlich wurden Mutationen im EPG5-Gen gefunden, das für ein Schlüsselprotein der Autophagozytose kodiert. Das Vici-Syndrom kann als Paradigma für die Multisystemerkrankungen mit defekter Autophagie angesehen werden.

\section{Pharmakotherapie (2) - Rationaler Einsatz von Antibiotika in der Pädiatrie}

\section{DGKJ-SY-P2-1}

Welche Antibiotika benötige ich in der pädiatrischen Praxis?

Schaaff F.'

${ }^{1}$ Gemeinschaftspraxis für Kinder- und Jugendmedizin, Eckental

Da eine Großzahl der Antibiotikaverordnungen in Deutschland in den ambulanten Bereich fällt, kommt dem niedergelassenen Kinderarzt eine große Chance zu, bewusst Antibiotika zu verordnen und unnötige Verordnungen zu vermeiden. Daher haben genaue Kenntnis und Diagnostik von infektiologischen Krankheitsbildern sowie der entsprechenden Therapieleitlinien eine hohe Bedeutung. Wird ein Antibiotikum verordnet, sollte für die jeweilige Indikation ein möglichst schmales Wirkspektrum gewählt werden.

Zudem spielen in der Kinderarztpraxis, neben Wirksamkeit und Kosten, Praktikabilität, Verträglichkeit und Compliance eine große Rolle, darunter auch die Wahl von Applikationsformen, -häufigkeit und Geschmack der Präparate.

Es ist sinnvoll, für die in der jeweiligen Praxis häufigen infektiologischen Krankheitsbilder Standardpräparate festzulegen, mit deren Dosierung, Wirkspektrum und Nebenwirkungen man vertraut ist. Im Bereich der Harnwegsinfektionen sollte man zusätzlich die lokale Resistenzlage der häufigen Erreger, v. a. von E. coli kennen, um geeignete Standardregime festlegen zu können.

Vorschläge für Standardregime für die häufigsten Infektionserkrankungen im pädiatrisch-ambulanten Bereich werden vorgestellt und diskutiert.

\section{DGKJ-SY-P2-4}

Infektionsprophylaxe mit Antibiotika

Beetz R. ${ }^{1}$

'Universitätsmedizin der Johannes Gutenberg-Universität, Pädiatrische Nephrologie, Mainz

Die Vorstellung, durch die Gabe antibakteriell wirksamer Substanzen das Infektionsrisiko für gefährdete Patienten zu senken, besteht seit den Anfängen der Antibiotika-Ära. Zu den etablierten Indikationsgebieten für kurzzeitige Ein- oder Mehrfachgaben gehören infektionsgefährdete operative Eingriffe, fraglich kontaminierte Wunden (z. B. Bissverletzungen) und die Umgebungsprophylaxe bei Erkrankungen durch hochpathogene Keime (z. B. Meningokokken). Kontrovers wurden noch bis vor kurzem die Indikationen zur Endokarditisprophylaxe diskutiert.

Für den länger dauernden präventiven Einsatz von Antibiotika besteht weitgehender Konsens bei Asplenie, Sichelzellanämie, erworbenen oder angeborenen schweren Immundefekten und tiefgreifender Immunsuppression. Eines der aktuell am stärksten umstrittenen Anwendungsgebiete stellt die Langzeitprophylaxe von Harnwegsinfektionen dar. Hier haben Zweifel an der Effektivität und die zunehmende Resistenzentwicklung uropathogener Keime zu einem kritischeren Umgang mit der antibakteriellen Prophylaxe beigetragen. Tatsächlich ist die derzeitige Strategie der Infektionsprophylaxe in einigen Anwendungsbereichen nicht evidenzbasiert. Randomisierte, placebokontrollierte Studien ver- 
bieten sich teilweise bereits aus ethischen Überlegungen und sind gerade in der Langzeitprophylaxe schwierig durchzuführen.

Ein Fortschritt im rationalen Einsatz von Antibiotika in der Infektionsprophylaxe ist unter den heutigen Bedingungen am ehesten durch die konsequente, risikoorientierte Eingrenzung auf klar definierte Indikationsgebiete und durch die Suche nach alternativen Präventions-Konzepten (z. B. Impfprophylaxe, verbesserte Hygienemaßnahmen etc.) erreichbar.

\section{Historisches Symposium (1)}

\section{DGKJ-SY-H1-1}

\section{Zur Geschichte der Phenylketonurie}

Osten P.

${ }^{1}$ Ruprecht-Karls-Universität Heidelberg, Institut für Geschichte und Ethik der Medizin, Heidelberg

Der genial einfache Ansatz, der autosomal rezessiv vererbten Stoffwechselstörung Phenylketonurie mit einer phenylalaninarmen Ernäh rungstherapie zu begegnen, gilt bis heute als Musterbeispiel für die Behandlung einer genetischen Erkrankung.

Der Vortrag rekapituliert die wissenschafts- und sozialhistorischen Eckdaten dieser Erfolgsgeschichte; von dem Einsatz des neuen Nachweissystems Papierchromatogramm, über die ersten Maßnahmen zur Früherkennung, bis hin zu den ethischen Debatten über die Einführung des Neugeborenenscreenings.

\section{DGKJ-SY-H1-2 \\ Ein Ärzteprozess in der Provinz - Blutskandal und Machtkampf an der Heidelberger Kinderklinik unter Philipp Bamberger, 1946-1966}

\section{Eckart W.U. ${ }^{1}$}

${ }^{1}$ Ruprecht-Karls-Universität Heidelberg, Institut für Geschichte und Ethik der Medizin, Heidelberg

Als die schwer durch ihre NS-Vergangenheit belastete Heidelberger Medizinische Fakultät bald nach der Wiedereröffnung der Universität im Januar 1946 Philipp Bamberger zu ihrem neuen Ordinarius für Pädiatrie berief, schienen die tiefbraunen Schlagschatten der NS-Diktatur endlich verlassen. Die Fakultät hielt Bamberger zurecht für einen „ausgezeichneten Klinikleiter“, für einen „sehr lebendigen Lehrer“, anerkannte ihn als "erfolgreichen wissenschaftlichen Arbeiter" besonders auf dem Gebiet der Infektionskrankheiten, als „voll ausgebildeten Chemiker", als „unermüdlichen und erfahrenen Arzt am Krankenbett" und hatte vernommen, dass er "gut vortragen“ könne und von „ausgezeichnetem Charakter" sei. Auch politisch sei er, soviel man wisse, „vollständig unbelastet“. Das Berufungsschreiben ist datiert vom 29. Januar 1946 und am 19. Februar 1946 traf auch das politische Gütesiegel des amerikanischen „Military Government“ mit der Einstufung in die Kategorie „employment discretionary“ (einstellbar bei Bedarf) in Heidelberg ein. Damit hätten eine ungestörte Karriere Bambergers in Heidelberg und der verzögerte Neubeginn der Heidelberger Kinderklinik nach einer bedrückenden nationalsozialistischen Phase unter Johann Duken hoffnungsvoll beginnen können. Indes, die Dinge sollten sich zunächst in eine ganz andere Richtung bewegen. Sie war bestimmt durch perniziöse, zeitbedingte Missstände an der Heidelberger Klinik und in der Heidelberger Presselandschaft, die der Frischberufene nur vielleicht hätte ahnen aber nicht wirklich hätte voraussehen können. Der Beitrag skizziert und reflektiert den Heidelberger TransfusionsSkandal mit syphilisinfiziertem Blut in den späten 1940er Jahren und den nachfolgenden „Heidelberger Ärzteprozess“.

\section{DGKJ-SY-H1-3 \\ Gezeichnete Kinder - Eugenische Diagnostik in der Kinderheil- kunde}

\section{Ritzmann : $^{1}$}

'Universität Zürich, Medizinhistorisches Institut und Museum, Zürich, Schweiz

Fragestellung. Bekanntlich prägte die Eugenik weite Bereiche der Medizin in der ersten Hälfte des 20. Jahrhundert. Die aktive Aufnahme eugenischer Denkinhalte in die Kinderheilkunde und konkrete Auswirkungen auf die pädiatrische Praxis sollen am Beispiel des Zürcher Kinderspitals schlaglichtartig beleuchtet werden.

Material und Methode. Ausgangsbasis bildet dabei die diagnostische Lehrbildersammlung, die der Formierung des spezifischen ärztlichen Blicks diente. Aufnahme in diese Sammlung fanden verschiedene diagnostische Zeichen, deren Relevanz für die kinderärztliche Ausbildung so hoch eingeschätzt wurde, dass einzelne Fotographien auch in Lehrbüchern abgedruckt wurden. Die Lehrbildersammlung selbst, pädiatrische Lehrbücher und Krankengeschichten aus dem Kinderspital Zürich werden quellenkritisch analysiert und kontextualisiert.

Ergebnisse. Wer degenerative Zeichen aufwies, galt als minderwertig. Die Einbindung in den eugenischen Diskurs wird in Lehrbuchtexten deutlich, während sich die soziale Relevanz dieser Diagnostik in einzelnen Krankengeschichten nachvollziehen lässt. Vor allem Kinder aus ärmeren Bevölkerungsschichten und Randgruppen galten als Träger degenerierter Erbmasse. Sie waren daher nicht einfache Patienten, sondern eine Bedrohung der völkischen Existenz.

Schlussfolgerung. Vor dem Hintergrund rassenhygienischer Degenerationsängste verhalf die Diagnostik degenerativer Zeichen der Kinderheilkunde, ihre Position als moderne medizinische Disziplin in der ersten Hälfte des 20. Jahrhunderts zu festigen. Die lange Persistenz dieser Lehrmeinung bis weit in die Kinderheilkunde der Nachkriegsära hinein weist aber auch darauf hin, wie hartnäckig sich einmal etablierte Denkstile halten können.

\section{DGKJ-SY-H1-4}

\section{Diagnose: Geschlecht? Lawson Wilkins und die Kinderendokrino-} logie am Johns Hopkins Hospital

\section{Eder S. ${ }^{1}$}

'Universität Zürich, Medizinhistorisches Institut und Museum, Zürich, Schweiz

Lawson Wilkins, Begründer und Direktor der Klinik für pädiatrische Endokrinologie am Johns Hopkins Spital (Baltimore, USA) von 1936 bis 1963, begann 1950 Kinder mit adrenogenitalem Syndrom mit Cortison zu behandeln. Wilkins hatte seit seinem ersten Patienten (1938) systematisch nach einer Behandlungsmethode für diese Kinder gesucht. Er war aber nicht nur daran interessiert, Symptome wie Salzverlust, Hirsutismus, verfrüht einsetzende Pubertätsentwicklung und „vermännlichte" Genitalien bei Mädchen zu behandeln. Für ihn bedeutete Gesundheit, dass seine Patienten ein „normales“ Leben führen konnten. Dazu gehörte, dass auch Kinder mit nicht eindeutigen Geschlechtsmerkmalen ein „richtiges“ Geschlecht haben mussten. Wilkins holte sich Unterstützung durch den Psychologen John Money, der im Zuge der Evaluierung der Cortisonbehandlung zum Schluss kam, das richtige Geschlecht müsse nicht biologisch determiniert sein. Kinder würden sich unabhängig von den Geschlechtsmerkmalen mit dem ihnen bei der Geburt zugeordneten Geschlecht identifizieren, und könnten daher eine Geschlechterrolle lernen, auch wenn diese nicht ihrem biologischen Geschlecht entsprach. Wilkins und sein Team suchten fortan nicht länger nach dem biologischen Geschlecht, sondern nach jenem Geschlecht, das es den Kindern ermöglichte, später ein „normales“ Leben als Mann oder Frau zu führen. In der Regel gehörte zur medizinischen Behandlung auch eine chirurgische Anpassung der Genitalien an das gewählte Geschlecht. Die damit verbundenen Eingriffe werden 
heute von Intersexuellen-Initiativen und Ethiker/innen zu Recht scharf kritisiert. Gleichzeitig wurde hier erstmals in der Geschichte der Medizin zwischen biologischem und sozialem Geschlecht („gender") unterschieden.

\section{Psychosomatik (2) - Wir gründen eine Psychosomatikstation}

\section{DGKJ-SY-PS1-2}

Therapeutisches Milieu als unverzichtbares Element einer psychosomatischen Station zum Zusammenspiel von Pädagogik und Psychotherapie

\section{Kunert $D .{ }^{1}$}

${ }^{1}$ Klinik für Kinder- und Jugendmedizin Klinikum Kassel, Pädiatrische Psychosomatik und Psychotherapie, Kassel

In dem Vortrag wird der Frage nachgegangen, welches Milieu und welche Rahmenbedingungen Kinder und Jugendliche mit psychosomatischen Erkrankungen brauchen, um so gesund zu werden, dass sie den Alltag in ihrem natürlichen Lebensumfeld wieder meistern können.

Der Stationsalltag (das therapeutische Milieu) wird in seiner Bedeutung für die psychosomatisch-psychotherapeutische Behandlung der oft schwerkranken Kinder und Jugendlichen dargestellt und mit seinen vielfältigen Fassetten ausgeleuchtet. Er stellt die tragende Säule der Behandlung dar. Dabei soll verdeutlicht werden, dass sich pädagogische, pflegerische und psychotherapeutische Überlegungen ständig überlagern und im Behandlungsteam kommuniziert werden müssen.

Möglichkeiten der Alltagsstrukturierung und der Gestaltung sinnvoller und verbindlicher Regeln werden exemplarisch dargestellt. Dabei sieht sich das gesamte Behandlungsteam und insbesondere die pflegerischen und pädagogischen Mitarbeiterinnen und Mitarbeiter vor Herausforderungen gestellt, die einer besonderen Grundhaltung bedürfen, damit zwischen Patienten und Mitarbeitern tragfähige und belastbare Beziehungen entstehen können, die den Kindern und Jugendlichen alternative Beziehungserfahrungen ermöglichen. Verlässliche und klare Kommunikationsstrukturen und ein hohes Maß an Professionalität sind notwendig, um den durch die Patienten verursachten hohen Problemdruck auszuhalten und in einen Halt gebenden Alltag zu überführen. Es wird die Notwendigkeit aufgezeigt, sich als Person auf die Kinder und Jugendlichen einzulassen, ebenso, wie ständig an der Teamentwicklung zu arbeiten, um Zusammenhalt und Bindung im Behandlungsteam zu festigen.

\section{DGKJ-SY-PS1-3}

\section{Struktur- und Prozessqualität einer Psychosomatikstation}

\section{Meister J.'}

${ }^{1}$ HELIOS Klinikum Aue, Klinik für Kinder- und Jugendmedizin, Aue

Die pädiatrische Psychosomatik hält in den letzten Jahren zunehmend Einzug in die stationäre Betreuung von Kindern und Jugendlichen in Kinderkrankenhäusern. Dabei sind durch den Operationen- und Prozedurenschlüssel (OPS) die zu erbringenden Leistungen vom Grundsatz und den zeitlichen Mindestanforderungen gut definiert. Darüber hinaus lagen aber in Deutschland keine allgemein gültigen Kriterien der Struktur- und Prozessqualität für pädiatrisch-psychosomatische Stationen vor. Vor diesem Hintergrund hat die Arbeitsgruppe Qualitätsmanagement der Arbeitsgemeinschaft Pädiatrische Psychosomatik (AGPPS) die Aufgabe übernommen, entsprechende Qualitätskriterien zu entwickeln, die hier vorgestellt werden.

Personelle Voraussetzungen:

- Ärztliche Leitung: Facharzt für Kinder- und Jugendmedizin

- Therapeutische Leitung: Psychotherapeut

- Kooperation mit einem Kinder- und Jugendpsychiater
- Multiprofessionelle Teamarbeit unter Einbeziehung verschiedener Berufsgruppen

Therapeutisches Setting: Was ist notwendig?

- Konzeptionspapier

- Biopsychosoziales Krankheitsverständnis

- Ein therapeutisches Milieu mit fester Tagesstruktur, gemeinsamer Alltagsgestaltung mit den Patienten durch kontinuierliche Präsenz des Pflege- und Erziehungspersonals. Dazu gehören auch Krankenhausunterricht, störungsspezifische Schulungen und regelmäßige Teambesprechungen

- Externe Supervision

- Vorgespräche vor Aufnahme auf die Station

- Individuelle Therapieplanung mit Formulierung eines Therapieziels Die Therapie besteht im Wesentlichen aus fünf Behandlungsbausteinen: Milieutherapie, Psychotherapie, somatische Behandlung, ergänzende Therapien (z. B. Physio-, Ergo-, Musiktherapie) und Schule für Kranke.

\section{Aus- und Weiterbildung in der Pädiatrie: von Unikliniken bis Praxen}

\section{DGKJ-SY-L-1}

Blended Learning in der pädiatrischen Weiterbildung: ein interprofessionelles Schulungsprojekt im Bereich der pädiatrischen Notfallversorgung

Huwendiek S. ${ }^{1}$, Klinke M. ${ }^{2}$, Lehmann R. ${ }^{2}$, Simon A. ${ }^{2}$, Hornberger M. ${ }^{2}$, Haag M. ${ }^{3}$, Tönshoff B. ${ }^{2}$, Hoffmann G.F. ${ }^{2}$, Meyburg J. ${ }^{2}$

'Institut für Medizinische Lehre, Assessment und Evaluation, Bern, Schweiz, 2Universitätsklinikum Heidelberg, Zentrum für Kinder und Jugendmedizin, Heidelberg, ${ }^{3}$ Zentrum für Virtuelle Patienten, Heidelberg

Fragestellung. Am Zentrum für Kinder- und Jugendmedizin Heidelberg wurde ein Blended-Learning-Programm, bestehend aus neu etablierten klinikinternen Notfallleitlinien, Virtuellen Patienten und praktischem Simulationstraining für Ärzte und Pflegekräfte durchgeführt, um beide Berufsgruppen besser auf pädiatrische Notfälle vorzubereiten. Bisher existieren wenige Daten zu „Blended Learning“ in der medizinischen Weiterbildung. Es wurde folgender Frage nachgegangen: Wie sollte ein solches Schulungsprogramm idealerweise gestaltet sein, um Ärzte und Pflegende optimal auf pädiatrische Notfälle vorzubereiten? Methode. Die Ausrichtung des Trainings wurde entsprechend einer Bedarfsanalyse festgelegt. Erfahrene Ärzte und Pflegende ( $n=14)$ wurden für die praktische Schulung als Trainer in Workshops ausgebildet. 56 Ärzte und 56 Pflegende durchliefen im Mai 2012 dieses Trainingsprogramm. Im Anschluss diskutierten die Teilnehmer und Trainer in 8 Fokusgruppen, welches die Stärken und Schwächen des Projekts sind und wie das Schulungskonzept idealerweise gestaltet sein sollte, um optimal auf pädiatrische Notfälle vorzubereiten. Die Fokusgruppen wurden nach internationalen Standards durchgeführt und ausgewertet.

Ergebnisse. Die Gestaltung des Projekts mit dreiteiligem Aufbau (Leitlinien, Virtuelle Patienten, Simulationstraining) wurde von allen Beteiligten als sehr lernwirksam und nahezu „ideal“ erfahren. Die Wichtigkeit weiterer Schulungen dieser Art wurde von beiden Berufsgruppen betont.

Schlussfolgerung. Blended Learning mit Notfallleitlinien, virtuellen Patienten und Simulationstraining wurde von allen Beteiligten als eine sehr sinnvolle Vorbereitung auf Kindernotfälle erachtet.

Dieses Projekt wurde unterstützt von der Klaus Tschira Stiftung gGmbH. 
DGKJ-SY-L-2

\section{Projekt „TouchPaed“ - Tablet(s) sind nicht nur zum Heilen von Krankheiten da}

Wulf D.', Bosse H.M.', Pillekamp F.'

'Universitätsklinikum Düsseldorf, Klinik für Allgemeine Pädiatrie, Neonatologie und Kinderkardiologie, Düsseldorf

Fragestellung. Verbessern Tablet-PCs den klinisch-praktischen Unterricht?

Material und Methode. Im Blockpraktikum Pädiatrie wurden leihweise iPads an Studenten verteilt. Mit Hilfe von uns erstellter elektronischer Lernhilfen (StudyGuide) auf den iPads können sich Studierende patientennah und bereits vor einem Patientenkontakt auf eine symptomzentrierte Anamnese und Untersuchung vorbereiten sowie diesen „Fall“ in unterschiedlichen Tiefen selbstbestimmt nachbereiten.

Ergebnisse. Eine Evaluation erfolgte durch Freitext. Es traten keine größeren technischen Probleme auf. Kein iPad wurde beschädigt oder ging verloren. Die Vorgaben der Landesdatenschutzgesetze konnten umgesetzt werden. Der Einsatz von iPads wurde von den Studenten mehrheitlich als gut und zeitgemäß bewertet. Die wichtigste Anregung war, das inhaltliche Angebot zu erhöhen (eBooks, Nachschlagewerke, StudyGuides). Weitere Kritikpunkte waren, dass die iPads zu groß und unhandlich sind („Es passt nicht in die Kitteltasche“) und dass kein flächendeckendes WLAN auf den Stationen vorhanden ist. Nur wenige Studenten hatten Angst, es zu verlieren oder zu beschädigen.

Schlussfolgerung. In unserem Projekt integrieren wir erfolgreich strukturierte, multimediale Lehrangebote als Blended Learning in den klinisch-praktischen Unterricht. Entscheidend für eine weitere Optimierung wird die Ausschöpfung einer größeren Auswahl von Inhalten sein.

\section{DGKJ-SY-L-5}

5 Jahre Pädiatrisches Praxiscurriculum Prävention (PÄPP): der Erfolg eines longitudinalen kinder- und jugendärztlichen Programms zur Begleitung eines Kindes durch Studierende

Cop I. ${ }^{1}$, Huwendiek S. ${ }^{2}$, Simon A. ${ }^{3}$, Fehr F. ${ }^{4}$

'Gemeinschaftspraxis für Kinder- und Jugendmedizin, Sandhausen, ${ }^{2}$ Universität Bern/Medizinische Fakultät, Assessment und Evaluation, Bern, Schweiz, ${ }^{3}$ Universitätsklinikum Heidelberg, Zentrum für Kinder- und Jugendmedizin, Heidelberg, ${ }^{4}$ Gemeinschaftspraxis für Kinder- und Jugendmedizin, Sinsheim

Ziel. Studierende (S) der Vorklinik vertiefen durch die Begleitung eines Kindes in seinem sozialen und medizinischen Umfeld in den ersten 2 Lebensjahren ihre Kenntnisse über Salutogenese und Ressourcen zur guten Entwicklung.

Methoden. Seit 5 Jahren werden jährlich 16 interessierte S gelost und je einer Familie zugeteilt, die von einer der am Programm teilnehmenden akademischen Lehrpraxen der Universität Heidelberg betreut wird und Interesse am Programm, ein intaktes soziales Umfeld und mindestens 1 gesundes Kind hat. Das Programm hat 3 Säulen:

Säule 1. Die S nehmen an 8 Tutorien in Kleingruppen teil, in denen die jeweilige Entwicklungsstufe der Kinder bezüglich motorische, psychosoziale und sprachliche Kompetenzen sowie jeweils ein allgemeines Thema besprochen wird. Sie reflektieren über ihre Treffen mit der Familie und ihre Begleitungen der Kinder zu den Vorsorgeuntersuchungen.

Säule 2. Jeder S begleitet sein Kind zu den Vorsorgeuntersuchungen beim Kinderarzt. Er wird angeleitet, aufmerksam die Entwicklung des Kindes zu beobachten, einzuschätzen und zu dokumentieren. Er erlebt die ärztliche Tätigkeit und übt die Gesprächsführung.

Säule 3. In 4 Hausbesuche nehmen die S wahr, welche Umgebung ein Kind für seine gute Entwicklung braucht.

Das Projekt wurde regelmäßig anhand von Fragebögen und direktem Feedback evaluiert. Aktuell wird eine umfassende Untersuchung an- hand von Fokusgruppen im Rahmen einer medizinischen Doktorarbeit durchgeführt.

Ergebnisse. In 5 Jahren haben 80 Studierende und Familien am Programm teilgenommen. Das Projekt wurde von den S, den Lehrärzten und den Familien sehr positiv aufgenommen. Der dreiteilige Aufbau wurde von den $S$ und beteiligten Lehrärzten als das Lernen unterstützend erfahren.

\section{Diagnostik und Behandlung von Hyperlipidämien}

\section{DGKJ-SY-A2-1 \\ Grundlagen und Einteilung der Hyperlipidämien}

Schwab K.O.'

'Universitätsklinikum Freiburg, Zentrum für Kinder- und Jugendmedizin, Freiburg

$\mathrm{Zu}$ den seltenen primären und somit genetisch bedingten Hypercholesterinämien führen Mutationen im LDL-Rezeptor- und Apolipoprotein B1oo-Gen oder konstitutiv-aktive Mutationen im PCSK9-Gen, die zu einem erhöhten Abbau der LDL-Rezeptoren an der Zelloberfläche und damit zu einer langsameren Katabolisierung der LDL-Partikel führen. Die polygenen Hypercholesterinämie-Formen sind dagegen erheblich häufiger anzutreffen, die Cholesterinspiegel sind aber in der Regel nicht ganz so hoch wie bei den primären Formen. Die Intima-media-Dicke korreliert bei diesen Patienten unter 18 Jahren nicht mit der Höhe der LDL-Cholesterinspiegel sondern dem Blutdruck. Daher könnte bei Patienten mit Hypercholesterinämie im Kindes- und Jugendalter der Blutdruck bei der frühen Atherosklerose-Entwicklung eine besondere Rolle spielen und sollte in der Therapie gut kontrolliert werden.

$\mathrm{Zu}$ den seltenen primären Hypertriglyceridämien führen Mutationen im Lipoproteinlipase-Gen oder im APOC2-Gen. Sehr viel häufiger dagegen kommt die polygenetische familiäre Hypertriglyzeridämie vor. Bei den gemischten Hyperlipidämien mit erhöhten Cholesterin- und Triglyceridwerten gibt es die häufige polygenetische, familiäre kombinierte Hyperlipidämie sowie die seltenere autosomal-rezessive Dysbetalipoproteinämie, die in 90\% eine Mutation im Gen des Apolipoproteins E und eines Kofaktors aufweist. Sekundäre Fettstoffwechselstörungen bei schlecht eingestelltem Diabetes, Hypothyreose, Niereninsuffizienz, Adipositas mit metabolischem Syndrom oder körperlicher Inaktivität bzw. Rauchen kommen häufig vor, eine Normalisierung der Lipide gelingt in der Regel durch die Behandlung der Grunderkrankung.

\section{DGKJ-SY-A2-2}

Leitliniengerechte Diagnostik und Behandlung von Hyperlipidämien aus Stoffwechselsicht

\section{Schlune A.}

'Universitätsklinikum Düsseldorf, Klinik für Allgemeine Pädiatrie, Neonatologie und Kinderkardiologie, Düsseldorf

Primär genetische Hyperlipidämien gehören zu den häufigsten angeborenen Stoffwechselerkrankungen überhaupt. Die am weitesten verbreitete Störung ist dabei die familiäre heterozygote Hypercholesterinämie, von der $0,2 \%$ aller Kinder in Deutschland betroffen sind. Die Hyperlipidämien spielen eine wichtige Rolle bei der Entstehung der Atherosklerose, welche bereits in der Kindheit beginnt und die wesentliche Ursache für die Koronare Herzkrankheit und damit die wichtigste Todesursache in den industrialisierten Ländern darstellt. Somit muss auch die Prävention kardiovaskulärer Erkrankungen bereits im Kindesalter beginnen.

Grundlage der Behandlung der Hyperlipidämien in der Pädiatrie ist die Ernährungsmodifikation. Diese kann schon im Kleinkindalter sicher durchgeführt werden, ist aber in ihrer Wirksamkeit begrenzt, so dass bei schwereren Formen zusätzlich eine medikamentöse Therapie 
in Frage kommt. Der Einsatz von Cholesterinsynthesehemmern ist dabei aufgrund der neueren Studien wesentlich liberalisiert worden. Mit Pravastatin, Rosuvastatin, Atorvastatin und Lovastatin sind mehrere Wirkstoffe aus dieser Gruppe zum Einsatz im Kindesalter in Deutschland zugelassen. Die Sicherheit und Wirksamkeit dieser Medikamente sind mittlerweile gut belegt, auch wenn Langzeitdaten weiterhin fehlen.

\section{Samstag, 14.09.2013}

\section{Interdisziplinäres Symposium Infantile Cerebralparese}

\author{
DGKJ-SY-CP-1a \\ Behandlungskonzepte mit Botulinumtoxin
}

Krauspe R. ${ }^{1}$, Weimann-Stahlschmidt K.', Westhoff B. ${ }^{1}$ 'Universitätsklinikum Düsseldorf, Orthopädische Klinik, Düsseldorf

Bei der ICP handelt es sich primär um eine zentrale Störung. Die sekundären Probleme resultieren aus den pathophysiologischen Charakteristika spastischer Muskulatur wie gesteigerter muskulärer Grundtonus, Übererregbarkeit der Dehnreflexe sowie muskuläre Schwäche. Es kommt zu typischen Muskeldysbalancen mit verkürzten Agonisten und verlängerten Antagonisten, progredienten, strukturellen Muskelverkürzungen bei insuffizientem Längenwachstum sowie zur Veränderung der biomechanischen Funktionen. Das Prinzip der Behandlung mit Botulinumtoxin besteht darin, den pathogenetischen Verlauf frühzeitig zu unterbrechen, nämlich durch eine temporäre Hemmung der neuromuskulären Erregungsübertragung im spastischen Muskel. Dabei stellt die Botulinumtoxin-Therapie lediglich einen Baustein im $\mathrm{Ge}$ samttherapiekonzept dar. Begleitende Physiotherapie und orthetische Maßnahmen sind stets erforderlich. Die Schwierigkeit besteht in der korrekten Auswahl der zu behandelnden Muskeln. Verschiedene Studien konnten eine Verbesserung des Gangbildes sowie eine Prävention von Muskelkontrakturen und schweren Knochendeformitäten nachweisen. Des Weiteren konnte gezeigt werden, dass die Operationshäufigkeit sowie der Umfang der operativen Maßnahmen reduziert werden konnte. Trotz der positiven Erfahrungen ist in Deutschland lediglich die Injektion des Musculus gastrocnemius bei Kindern mit infantiler Cerebralparese zugelassen, was aufgrund der positiven Datenlage insgesamt äußerst bedauerlich ist. Eine Ausweitung ist derzeit nur als „Offlabel“-Behandlung möglich, anders als in den meisten anderen europäischen Ländern.

\section{DGKJ-SY-CP-2a}

\section{Aktuelle operative Therapie bei CP}

\section{Westhoff B.', Weimann-Stahlschmidt K. ', Krauspe R. ${ }^{\text {? }}$ 'Universitätsklinikum Düsseldorf, Orthopädische Klinik, Düsseldorf}

Bei der infantilen Cerebralparese kommt es sekundär kommt aufgrund der spastischen Muskelaktivität im Verlauf zu zunächst flexiblen, später fixierten Muskelkontrakturen. Diese führen zu Bewegungseinschränkungen der Gelenke, Gelenk-Subluxationen und -Luxationen sowie knöchernen Deformitäten. Je nach Ausmaß und Lokalisation der cerebralen Schädigung bestehen unterschiedlich ausgeprägte funktionelle Einschränkungen.

Operative Korrekturen werden überwiegend im Bereich der unteren Extremität durchgeführt mit dem Ziel der Funktionsverbesserung. Für jeden Patienten muss individuell das Funktionsdefizit durch eingehende Untersuchungen (u. a. instrumentelle Ganganalyse) analysiert und das Behandlungsziel definiert werden. Bei gehfähigen Patienten kann durch Single-Event-Multi-Level-Surgery ein deutlicher Mobilitätszuwachs erzielt werden; sowohl Korrekturosteotomien als auch Weichteil- eingriffe mit Verlängerung und/oder Verkürzung von Muskeln werden durchgeführt.

Auch bei Schwerst-Betroffenen können chirurgische Maßnahmen indiziert sein zur Verbesserung der Sitz- und Pflegefähigkeit sowie zur Beschwerdelinderung - insbesondere bei Wirbelsäulendeformitäten und Dezentrierung der Hüfte. Zur Sicherstellung des Operationsziels ist häufig eine lange und intensive Rehabilitationsmaßnahme erforderlich. Mittels moderner Operationstechniken (minimal-invasive Verfahren, moderne Osteosyntheseverfahren) kann häufig auf längerfristige immobilisierende Verbände verzichtet und eine frühfunktionelle Therapie initiiert werden.

\section{DGKJ-SY-CP-3}

Leben mit CP - Orientierungspunkte für die Behandlungsplanung

\section{Hollmann $H^{?}$ \\ 'LVR-Klinik Bonn, Kinderneurologisches Zentrum, Bonn}

Cerebrale Bewegungsstörungen bedingen in unterschiedlichem Ausmaß eine nachhaltige Beeinflussung der Lebensgestaltung. Langfristig stehen für die betroffenen Patienten Aspekte der motorischen Alltagsbewältigung, Teilhabe und Lebensqualität im Vordergrund. Medizinische Maßnahmen und Therapie können große Lebensabschnitte bestimmen.

Je nach Ausprägung der Cerebralparese ist bereits die Diagnosestellung mit einem längeren Zeitfenster verbunden. Die Eltern müssen angemessen einbezogen werden, um Akzeptanz als Grundlage für eine gelingende Betreuung des Kindes aufbauen zu können. Physiotherapie in unterschiedlicher Ausprägung und mit Geräteunterstützung ist zunächst der führende Therapieansatz, unterstützt durch neuropädiatrisch-orthopädische Verlaufsuntersuchungen zur Adaptation anderer Maßnahmen und adäquater Versorgung mit Hilfsmitteln.

Die Integration in Kindergarten und Schule verlangt Entscheidungen auch unter dem Gesichtspunkt der Gestaltung von Inklusion. In der Adoleszenz ergeben sich vielfältige Fragestellungen nicht nur hinsichtlich Ausbildung und Berufsfindung, sondern auch durch körperliche und motivationale Veränderungen in Verbindung mit der Cerebralparese. Ungelöst sind viele Fragen der Transition bei Erreichen des jungen Erwachsenenalters. Neben Partnerschaft, Familie und Beruf ist dauerhaft auch die allgemeine gesundheitsfördernde motorische Aktivierung eine Herausforderung für Menschen, die mit Cerebralparese leben. Die interdisziplinäre Begleitung dieses Entwicklungsprozesses über fast 2 Jahrzehnte ist eine anspruchsvolle und befriedigende Aufgabe.

\section{DGKJ-SY-CP-4 \\ Seelische Gesundheit von Kindern und Jugendlichen mit CP/Spina bifida}

Bode H. ${ }^{1}$, Kohleis K. ${ }^{2}$, Storck M. ${ }^{2}$

'Universitätsklinikum Ulm, Kinder- und Jugendmedizin, SPZ und Kinderneurologie, Ulm, ${ }^{2} \mathrm{Ostfalia}$ Hochschule, Suderburg

Fragestellung. Ziele der Studie sind bei Kindern mit Cerebralparese (CP) und Spina bifida (SpB): 1) Einfluss von neurologischem/neuroradiologischem Befund und psychosozialen Risikofaktoren auf die seelische Gesundheit, 2) Einfluss der seelischen Gesundheit auf familiäre Belastung und Lebensqualität.

Methoden. 271 Kinder mit CP (Alter 4-16 Jahre) und 84 Kinder mit SpB wurden in eine multizentrische Querschnittsstudie eingeschlossen. Fragebögen (SDQ, FaBel, Kindl) wurden von den Eltern ausgefüllt und mit neurologischem Befund und dem motorischen Funktionsniveau korreliert (CP-Typ, GMFCS-, MACS-Level), bei CP-Kindern mit der Pathogenese der CP.

Ergebnisse. Der Gesamtproblemwert in SDQ war bei Kindern mit CP und $\mathrm{SpB}$ signifikant erhöht ( $29 \%$ bei $\mathrm{CP}, 18 \%$ bei $\mathrm{SpB}$ vs. $10 \%$ in der Normstichprobe). Probleme mit Gleichaltrigen $(23 \% \mathrm{CP} / 20 \% \mathrm{SpB})$, emo- 
tionale Probleme $(21 \% \mathrm{CP} / 20 \% \mathrm{SpB})$ und Hyperaktivität $(23 \% \mathrm{CP} / 7 \% \mathrm{SpB})$ waren im Vergleich zur Normstichprobe erhöht (7\%; 8\%; 10\%). Die Probleme korrelierten mit der elterlichen Belastung. Die gesundheitsbezogene Lebensqualität war bei den 8- bis 17-jährigen Kindern mit CP oder $\mathrm{SpB}$ geringer als bei gesunden Gleichaltrigen, nicht bei den 3- bis 7-jährigen. Neurologischer Status und neuroradiologische Befunde beeinflussten bei Kindern mit CP die seelische Gesundheit.

Schlussfolgerung. Die seelische Gesundheit ist bei Kindern mit CP oder SpB häufiger beeinträchtigt, ebenfalls die gesundheitsbezogene Lebensqualität bei älteren Kindern und Jugendlichen. Neurologischer Befund und Pathogenese beeinflussen bei Kindern und Jugendlichen mit CP die seelische Gesundheit. Daraus ergeben sich Konsequenzen für die interdisziplinäre Diagnostik und Therapie.

\section{Impfungen - Experten stellen sich der Diskussion}

\section{DGKJ-SY-IM1-1}

Influenza-Impfung im Kindes- und Jugendalter - neue Impfstoffe, aktuelle Konzepte

KnufM. ${ }^{?}$

'Dr. Horst Schmidt Klinik, Klinik für Kinder und Jugendliche, Wiesbaden

Die Influenza ist eine Viruskrankheit mit typischer Symptomatik: plötzlicher Beginn mit hohem Fieber, trockenem Reizhusten, Halsschmerzen sowie Muskel- und/oder Kopfschmerzen. Die Morbidität ist bei Kindern am höchsten wobei insbesondere Kleinkinder sehr wesentlich zur Ausbreitung der Influenza beitragen. Säuglinge und Kleinkinder erkranken häufig schwer und müssen hospitalisiert werden. Die WHO hat kürzlich die generelle Impfung gesunder Kinder im Alter von 6 bis 59 Monaten empfohlen, eine Maßnahme, die in einzelnen EU-Ländern bereits praktiziert wird. Da die konventionellen trivalenten Influenzaimpfstoffe (TIV) zur Grundimmunisierung nicht optimal sind, werden wirksamere Impfstoffe benötigt. Der seit 2011 die Altergruppe von 2-17 Jahren zugelassene attenuierte Lebendimpfstoff (LAIV) schützt Kinder effektiver vor Influenza als die konventionellen Vakzinen (TIV). Eine weitere Möglichkeit zur Steigerung der Effektivität ist die Kopplung von TIV an ein Adjuvans (z. B. MF59, Virosomen u. a.) Für Kinder ab 6 Monaten hat sich in klinischen Studien der MF-59 adjuvierte Impfstoff als wirksam erwiesen, ist jedoch für dieses Alter nicht zugelassen. Ein virosomaler Impfstoff steht für Kinder ab dem 6. Lebensmonat zur Verfügung. TIV scheinen im Kleinkindesalter wirksamer zu sein, wenn die Antigendosis erhöht wird. Es stellt sich die Frage einer allgemeinen Influenza-Impfempfehlung für Kinder, wobei zu diskutieren sein wird, auf welche Altersgruppe diese sich bezieht Wegen der Impfstoffvielfalt und sehr unterschiedlichen (Effektivitäts-) Profile wird eine „reine Impfempfehlung“ gegen Influenza wenig praktikabel sein, vielmehr gilt es altersgerechte Konzepte zu entwickeln.

\section{DGKJ-SY-IM1-2}

Die neue Impfung gegen Meningokokken B - Herausforderungen bei der Bewertung aus Public-Health-Sicht

\section{Hellenbrand W. \\ 'Robert Koch-Institut, Fachgebiet Impfprävention, Berlin}

Bexsero $^{\oplus}$, ein innovativer Meningokokken-Impfstoff basierend auf Oberflächenproteinen des Erregers, ist seit Januar 2013 in Europa zugelassen und wird demnächst auf dem deutschen Markt erwartet. Die STIKO prüft derzeit, für welche Bevölkerungsgruppen eine generelle Empfehlung zur Impfung mit diesem Impfstoff gegebenenfalls sinnvoll sein könnte. Dies geschieht unter Berücksichtigung von: A) epidemiologischen Aspekten der Meningokokken-B-Erkrankungen in Deutschland; B) Daten zur Immunogenität und Sicherheit von Bexsero ${ }^{\circ}$ C) Daten zur erwarteten Abdeckung der zirkulierenden Meningokokken-B-Stämme durch Bexsero ${ }^{\circledast}$ in Deutschland; D) Daten zu erwartenden Effekten auf das Trägertum von Meningokokken $B$, welche für eine mögliche Herdenimmunität relevant sind; E) Möglichkeiten, diese Impfung in den bestehenden Impfkalender zu integrieren bei möglichst hoher Akzeptanz; F) Modellierung der zu erwartenden epidemiologischen Effekte verschiedener Impfansätze als auch zu ihrer Kosten-Effektivität, und G) Erfahrungen aus der Routine-Impfung gegen Meningokokken der Serogruppe C. Die Herausforderungen dieser Bewertung werden beleuchtet. Sie ergeben sich aus der Neuartigkeit des Impfstoffes, der fehlenden Daten zur tatsächlichen klinischen Effektivität, welche von Daten zur jeweils unterschiedlichen Immunogenität der Einzelkomponenten des Impfstoffes abgeleitet werden muss, sowie der insgesamt begrenzten Anwendungserfahrungen im Rahmen der Zulassungsstudien.

\section{Updates/Refresher (3)}

\section{DGKJ-SY-RE3-3 \\ Update Hepatologie}

\section{Melter M $^{\top}$}

'Universitätsklinikum Regensburg, KUNO-Kliniken, Regensburg

Im Rahmen des Update Hepatologie werden aktuelle Themen der Hepatologie in Forschung und klinischer Anwendung mit Relevanz in der Pädiatrie behandelt. Gerade in letzter Zeit rückt die Leber als zentrales Organ in der Schnittstelle zwischen „eigen und fremd“ in den Fokus und nimmt dabei eine exklusive Rolle in der Balancierung zwischen Toleranz und Immunität ein.

In Hinblick auf das neonatale Leberversagen geraten intraunterine alloimmune Ursachen in den Vordergrund. Insbesondere bei der neonatalen Hämochromatose haben sich damit die pathophysiologischen Vorstellungen/Hypothesen und in der Folge auch die Diagnostik und Therapie diametral zum ursprünglichen Vorgehen verändert.

Ein weiteres Thema sind neue (pathophysiologische) Aspekte und Überlegungen im Rahmen von Leberschädigungen und -regeneration und ihre unterschiedliche Nuancen bei entzündlichen Prozessen, Fibrose oder Fettlebererkrankung. Im Rahmen der Differenzialdiagnosen von Fettlebererkrankungen sind möglicherweise Cholesterinester-Speichererkrankungen erheblich unterdiagnostiziert. Gerade in Anbetracht des Umstands, dass neue therapeutische Optionen, einschließlich möglicher Enzymersatz-Therapien, zur Verfügung stehen, macht eine frühe und präzise Diagnose notwendig.

Nicht zuletzt aufgrund des dramatischen Rückgangs an Verstorbenen-Organspenden nimmt die Leber-Lebendspende eine zunehmend große Bedeutung, v. a. auch bei pädiatrischen Patienten, ein. In diesem Zusammenhang würde der "sichere“ Einsatz ABo-inkompatibler Spenderorgane die therapeutischen Möglichkeiten erheblich erweitern. Neue Protokolle zur individuellen Reduktion der spezifischen Antikörper scheinen die Möglichkeiten des Einsatzes ABo-inkompatibler Spenderlebern sicher zu machen.

\section{Pharmakotherapie (3) - Schmerztherapie}

\section{DGKJ-SY-P3-1}

\section{Schmerzfreie Kindermedizin}

Weber A.-A. ${ }^{1}$

'Universitätsklinikum Düsseldorf, Klinik für Allgemeine Pädiatrie, Neonatologie und Kinderkardiologie, Düsseldorf

Bei richtiger Anwendung ist die analgetische Wirkung von EMLA (Eutektische Mischung von Lolalanästhetika - Lidocain/Prilocain) beim Anlegen von venösen Venenverweilkanülen („Braunülen“) bei Kindern wissenschaftlich unbestritten. Es ist ebenfalls bekannt, dass Venen- 
punktionen für Kinder und Säuglinge oft besonders schmerzhaft sind und wahrscheinlich das "Schmerzgedächtnis“ hinsichtlich einer erniedrigten Schmerzschwelle für zukünftige Schmerzerlebnisse negativ beeinflussen. Dennoch wird EMLA in Deutschland kaum eingesetzt (Perry \& Ebinger, 2012 sowie eigene unpublizierte Untersuchungen). Bemerkenswerterweise wird EMLA in anderen deutschsprachigen Ländern regelmäßig eingesetzt (z. B. „meistens/fast immer" in der Schweiz $100 \%$ vs. in Deutschland 33\%, Angaben für neuropädiatrische Einrichtungen). Die Gründe für diese länderspezifischen Unterschiede sind nicht bekannt. Eine klare Leitlinie der DGKJ bezüglich der pharmakologischen Reduktion von Schmerzen bei Impfungen, Blutentnahmen, Anlegen von venösen Venenverweilkanülen, Blasenpunktionen, Lumbalpunktionen etc. wäre sehr wünschenswert und würde den „Weg zur schmerzarmen Kinderklinik" auch in Deutschland ebnen.

\section{Literatur}

1. Perry D, Ebinger F (2012) Auf dem Weg zur schmerzarmen Kinderklinik. Monatsschr Kinderheilkd 160:251-259

\section{DGKJ-SY-P3-3}

Chronsiche Schmerzstörung mit muskuloskeletalen Schmerzen bei JIA - Krankheitsmodell und multimodale Therapie

\section{Frosch $M{ }^{1}$}

${ }^{1}$ Vestische Kinder- und Jugendklinik - Universität Witten/Herdecke, Kinderschmerzzentrum, Datteln

Muskuloskeletale Schmerzen sind auch im Kindes- und Jugendalter, insbesondere in der zweiten Lebensdekade, zunehmend häufig mit der Entwicklung einer chronischen Schmerzstörung verbunden. Die polyartikuläre JIA ist auch unter antientzündlicher Therapie oft gekennzeichnet durch einen remittierenden Verlauf der Entzündung, die wiederum mit multiplen artikulären Schmerzen einhergeht. Neben diesen biologischen Faktoren sind für die Chronizität und den Schweregrad der Schmerzstörung zusätzlich psychische und soziale Faktoren maßgeblich beteiligt. Vor allem die hohe Körperselbstaufmerksamkeit, die Angst vor starken Schmerzen, die Unsicherheit hinsichtlich des weiteren Krankheitsverlaufs und die familiäre Hilflosigkeit im Umgang mit der Schmerzsymptomatik sind aufrecht erhaltende Faktoren. Auch soziale Faktoren wie Schule, intrafamiliäre Beziehungen haben Einfluss auf den Verlauf der Erkrankung. In dieser Situation ist die Schmerzstörung deshalb unabhängig von der Entzündungsaktivität der JIA und somit durch eine überwiegend medikamentöse, antientzündliche oder analgetische Therapie nicht ausreichend zu beeinflussen.

Patienten mit chronisch muskuloskeletalen Schmerzen bei JIA, die keine Assoziation zur Krankheitsaktivität der JIA zeigen, sollten deshalb einer multimodalen Schmerztherapie zugeführt werden, bei der nichtmedikamentöse Behandlungsverfahren mit psychologischen, therapeutischen und pädagogischen Interventionen unter Einbeziehung der Familie im Vordergrund stehen. Dargestellt werden Grundsätze und Erfahrungen dieser Behandlung.

\section{Leitlinienvorstellung Kardiologie}

\section{DGKJ-SY-LK-4}

\section{Abklärung einer Zyanose}

Franke J.', Haas N.A. ${ }^{2}$

'Bezirkskrankenhaus Reutte/Tirol, Abteilung für Kinderheilkunde, Jugendmedizin und Neonatologie, Ehenbichl, Österreich, ${ }^{2} \mathrm{Herz}$ - und Diabeteszentrum NRW - Ruhr-Universität Bochum, Klinik für Kinderkardiologie und angeborene Herzfehler, Bochum

Die Zyanose ist das Leitsymptom der arteriellen Sauerstoffuntersättigung. Sie ist ein alarmierendes Zeichen eines sich anbahnenden und unter Umständen lebensgefährlichen Zustandes der sofort geklärt werden muss. Die Differenzialdiagnose umfasst neben Herzfehlern Erkrankungen des Herz-Kreislauf-Systems, Erkrankungen der Atemorgane, Erkrankungen des ZNS, Stoffwechselstörungen, hämatologische Störungen und Infektionen. Die kardiologische Diagnostik dient zum Nachweis oder Ausschluss kardiogener Ursachen oder Begleiterkrankungen. Die wichtigste Diagnostik ist die beweisende Pulsoxymetrie und die Echokardiographie. Die arterielle Blutgasanalyse ist der Goldstandard der das Ausmaß der Sauerstoffuntersättigung erfasst. Weitere diagnostische Möglichkeiten wie Hyperoxietest, weitere Laborparameter, EKG, Herzkatheteruntersuchung, Kernspintomographie und CT und Röntgen erweitern im Einzelfall die Diagnostik durch den Kinderkardiologen.

Die Therapie richtet sich nach der zu Grunde liegenden Erkrankung. Eine Früherkennung wird durch die fetale Echokardiographie ermöglicht; das Pulsoxymetriescreening des Neugeborenen am ersten Lebenstag ist eine kostengünstige und wichtige Untersuchung. Eine Prävention der Zyanose gibt es nicht.

\section{Neuropädiatrie (2) - Häufige neuropädiatrische Fragen}

\section{DGKJ-SY-NP2-1 \\ Diagnostisches Vorgehen bei Verdacht auf dissoziative Anfälle}

Opp J. ${ }^{1}$

'Evangelisches Krankenhaus Oberhausen, Sozialpädiatrisches Zentrum, Oberhausen

Einleitung. Es gibt viele Charakteristika, die den Verdacht auf nichtepileptische Anfälle/"non-epileptic seizures" (NES) lenken wie situationsabhängiger Beginn, fester Lidschluss, asynchrone Bewegungen, Kopfschütteln, geschlossener Mund, fehlende Zyanose, rasche Reorientierung, Wandel des Anfallsbildes im Verlauf. Jedoch hat man oft keine detaillierten Anfallsbeobachtungen und kein Symptom ist beweisend für NES. Ein unauffälliges EEG schließt NES nicht aus - umgekehrt beweisen epilepsietypische Potenziale im EEG nicht, dass Anfallsereignisse epileptisch sind.

Fragestellung. Gibt es zusätzliche Möglichkeiten die Diagnose von NES zu sichern?

Material und Methode. Forschungsgruppen aus Deutschland, England und Italien konnten zeigen, das eine linguistische Analyse von Anfallsschilderungen, also eine Analyse der Art, wie der Patient die Situation schildert, eine Unterscheidung von epileptischen und nicht epileptischen Ereignissen erlaubt: Patienten mit epileptischen Anfällen wollen den Anfall so präzise wie möglich beschreiben, wollen verstehen, wie es dazu kam, wollen den Anfallsbeginn rekonstruieren. Patienten mit NES liefern Situationsbeschreibungen, in denen sie eher passives Opfer sind, die Anderen handeln, Negationen sind häufig, es gibt kaum spontane Aktivitäten um dem Anfall entgegenzuwirken.

Diskussion. Anhand von Fallbeispielen wird belegt, dass sich viele der Erkenntnisse, die aus der linguistischen Forschungsarbeit gewonnen wurden, mit wenig Aufwand im Alltag nutzbar machen lassen. Wichtigstes Element der Methode ist eine Anamneseerhebung, die nicht in üblicher Weise auf Anfallssymptome fokussiert, sondern dem Patienten Raum gibt sein Erleben zu schildern.

\section{DGKJ-SY-NP2-2 \\ Diagnostik, Differenzialdiagnostik und Therapie lagebedingter Schädeldeformitäten}

Funke R. ${ }^{1}$

${ }^{1}$ Klinikum Kassel, Neuropädiatrie, Kassel

In den letzten 10 Jahren hat sich die Sprechstunde für Schädeldeformitäten in der Klinik für Neuropädiatrie am Klinikum Kassel fest etabliert. Pro Jahr werden etwa 180 Patienten untersucht und versorgt, der 
zahlenmäßige größte Anteil sind lagebedingte Schädeldeformitäten. Aber es werden auch prämature Nahtsynostosen, Hirnfehlbildungen, verschiedene klinisch-genetische Syndrome sowie weitere sekundär bedingte Schädeldeformitäten gefunden. Zur Diagnostik bei lagebedingten Auffälligkeiten werden regelhaft Handmessung und Vermessung mittels Scanner durchgeführt. In Zusammenarbeit mit der Orthopädietechnik in Hess. Lichtenau (OTZ) können ausgewählte Fälle auch mit Helmtherapie versorgt werden. Nach eigenen Vorarbeiten ist die Vorhersagemöglichkeit der physiologischen Verbesserung lagebedingter Schädeldeformitäten konzeptionell verbessert worden, so dass die Zahl der mit Helm versorgten Kinder deutlich rückläufig ist. In Zweifelsfällen stehen in der Neuropädiatrie weitere diagnostische Möglichkeiten zur Verfügung (Sonographie, Neurophysiologie, physiotherapeutische Diagnostik, Entwicklungsdiagnostik etc.), in Kooperation mit anderen Disziplinen im Klinikum (Neuroradiologie, Neurochirurgie, Pädiatrie) sind schließlich alle Möglichkeiten für Diagnostik und Therapie vorhanden.

Zur genaueren Auswertung wurde ein Beobachtungszeitraum von Mai 2010 bis April 2011 ausgewählt, in dem insgesamt 148 Kinder in unserer speziellen Sprechstunde untersucht wurden. Dabei überwiegen Jungs gegenüber Mädchen 3:1 und der rechtsbedingte Plagiozephalus gegenüber linksseitigem Plagiozephalus und vorwiegend brachyzephalen Schädeldeformitäten. Von den 148 erfassten Kindern haben 40 Kinder (27\%) eine Kopforthese bekommen. Dabei war die Versorgung mit individuellen Helmorthesen bezüglich der Korrektur der Kopfform in nahezu $100 \%$ erfolgreich. Behandlungsbeginn war im Schnitt bei 7,6 Monaten. Scanner- und Handmessung stimmen erstaunlich oft überein, die ermittelte Genauigkeit liegt bei ca 1,2 $\mathrm{mm}$. Nicht selten sind lagebedingte Schädeldeformitäten auch erste klinische Manifestation übergeordneter und meist neuropädiatrischer Krankheitsbilder. Nach unserer Meinung sollten daher spezielle Sprechstunden einem interdisziplinären Ansatz unter Leitung der Neuropädiatrie folgen.

\section{DGKJ-SY-NP2-3}

\section{Schiefe Köpfe und Helmtherapie}

Berg D. ', Grünberg P.

${ }^{1}$ Craniobene, Köln

Seit der Zeit der Neanderthaler wurde immer wieder erfolgreich versucht die Schädelform von Kindern durch äußere Kräfte vor allem aus ästhetischen und rituellen Gründen zu beeinflussen. Archäologische Funde belegen, dass die Bahnung des kindlichen Kopfwachstums zu einer dauerhaften Verformung des Schädels führt. Heute wird die Kopfform stark durch die Schlafposition von Säuglingen beeinflusst. Seit der Veröffentlichung der Empfehlungen zur Verhinderung des plötzlichen Kindstods (SIDS), nach der Säuglinge in Rücklage schlafen sollen, hat die Zahl von lagebedingten nichtsynostischen Schädelasymmetrien zugenommen. Bei höhergradigen, lagebedingten Schädeldeformationen ist die Versorgung mit einer individuell angefertigten Kopforthese eine sinnvolle Therapieoption ab dem 5 . Lebensmonat, sofern eine gezielte Lagerung und die physiotherapeutische Behandlung nicht zu einem befriedigendem Behandlungsergebnis führen. Mit modernen, nicht belastenden $3 \mathrm{D}$-Scanmethoden kann die Kopfform exakt vermessen werden und eine verlässliche Indikation für die Helmtherapie gestellt werden. Ein leichter Kunsstoffhelm verhindert, dass in Rücklage das Eigengewicht des Kopfes weiter auf die abgeflachte Stelle wirkt. Er bahnt das Kopfwachstum so, dass sich die Asymmetrie zurückbildet. Da der Erfolg der Helmtherapie direkt mit dem Wachstumspotential des Kopfes in den ersten Lebensmonaten korreliert, sollte die Therapie frühzeitig begonnen werden. Die Helmtherapie wird sehr gut toleriert, schwere Nebenwirkungen insbesondere eine negative Beeinflussung der psychomotorischen Entwicklung sind nicht bekannt. Problematisch sind das Fehlen qualitativ hochwertiger Studien zur Helmtherapie, die hohen Behandlungskosten und die mangelnde Bereitschaft der Krankassen die Kosten der Behandlung zu übernehmen.

\section{Jugendmedizin - Jugend und Migration}

\section{DGKJ-SY-JM-1}

Zur gesundheitlichen Lage von Kindern und Jugendlichen mit Migrationshintergrund - eine Analyse des Health Behaviour in Schoolaged Children - A WHO Cross National Survey 2010

Klocke A. ', Maier S.'

${ }^{1}$ Fachhochschule Frankfurt am Main, Forschungszentrum Demografischer Wandel (FZDW), Frankfurt

Fragestellung. Welche gesundheitlichen Unterschiede lassen sich zwischen Jugendlichen mit und ohne Migrationshintergrund feststellen? Material und Methode. Auf der Basis der Daten der internationalen Kinder- und Jugendstudie „Health Behaviour in School-aged Children A WHO Cross National Survey (HBSC)" wird der Gesundheitsstatus (Body-Mass-Index, subjektives Wohlbefinden u. a.) sowie das Gesundheitsverhalten (Ernährung, Sportverhalten, Zahnpflege etc.) jugendlicher Migranten analysiert. Der HBSC-Survey befragt in einer repräsentativen Erhebung alle vier Jahre Kinder und Jugendliche im Alter von 11, 13 und 15 Jahren an allgemeinbildenden Schulen (Deutschland: $n=5005$, Hessen: $n=3617$ ). Zunächst wird untersucht, wie stark die gesundheitliche Ungleichheit zwischen Jugendlichen mit und ohne Migrationshintergrund ausgeprägt ist und inwieweit sich ethnische Besonderheiten feststellen lassen. In Regressionsmodellen wird überprüft, ob die Unterschiede zwischen Jugendlichen mit und ohne Migrationshintergrund auch unter Kontrolle von Variablen wie Geschlecht und familiärer Wohlstand fortbestehen.

Ergebnisse. Jugendliche Migranten weisen einen durchschnittlich schlechteren Gesundheitsstatus auf als Jugendliche ohne Migrationshintergrund. Hinsichtlich des jugendlichen Gesundheitsverhaltens lässt sich ein differenziertes Ergebnis festhalten: Hier zeigen jugendliche Migranten z. B. einen niedrigeren Alkoholkonsum als ihre Altersgenossen ohne Migrationshintergrund.

Diskussion oder Schlussfolgerung. Die Ergebnisse der Analyse knüpfen gut an die Befunde der Diskussion über die gesundheitliche Lage von jugendlichen Migranten an [vgl. KIGGS-Studie (2003-2006)].

\section{DGKJ-SY-JM-2}

Sexualität und reproduktive Gesundheit - gibt es Unterschiede im Sexualverhalten?

Stier B.J.M. ${ }^{?}$

${ }^{1}$ Kinder- und Jugendarztpraxis, Butzbach

Internationale Kampagnen (z. B. der WHO) haben längst erkannt, dass das Verhütungsverhalten der Mädchen und Frauen sehr stark von der Einstellung des männlichen Partners geprägt ist. Seither stehen Jungen und Männer mehr im Fokus der internationalen Empfängnisverhütungsplanung. Rollenbilder/Rollenstereotype, soziale und sexuelle Normen, erlernte Verhaltensmuster, Moral- und Wertevorstellungen prägen dabei entscheidend männliches Sexualverhalten.

Jungen mit Migrationshintergrund zeichnen sich aus durch

- früheres Ejakularchealter,

- früherer Beginn sexueller Aktivität,

- geringere Akzeptanz von kontrazeptiven Maßnahmen,

- gehäuftes Vorkommen wechselnder Partnerschaften,

- eingeschränkte Informationsmöglichkeiten.

Hierdurch ergeben sich erhebliche - teilweise durch überkommene Rollenbilder geprägte - Risiken. Die Beratung zur Kontrazeption muss viel stärker auf Jungen mit Migrationshintergrund fokussieren. Traditionelle Geschlechterrollen sind zu hinterfragen. Mädchen sollten, wenn irgend möglich, ihren Freund zum Gespräch über Verhütung mitbringen und ihn so gleichberechtigt in die Verhütungsplanung einbinden. Eine erfolgreiche Sexualaufklärung muss vermehrt den Schwerpunkt legen auf... 
- das Verhütungsbewusstsein der Jungen,

- den genderspezifischen Aspekt der Sexualität,

- nichtegalitäre Beziehungskonstellationen,

- kulturelle Differenzen/traditionelle Geschlechterrollen,

- den Blick für soziale und sexuelle Fremdheit,

- prekäre Lebenssituationen,

- schulische Sexualerziehung,

- Ansprechen der Probleme bei der Verhütung mit beiden Geschlechtern und Förderung von Kommunikationskompetenzen,

- die "gleichberechtigte" Verantwortungsübertragung.

\section{DGKJ-SY-JM-3}

Probleme in der Behandlung von Jugendlichen mit Migrationshintergrund am Beispiel Adipositas

\section{Wiegand S. ${ }^{1}$}

${ }^{1}$ Charité - Universitätsmedizin Berlin, Kinderklinik; Pädiatrische Endokrinologie und Diabetologie, Berlin

Jugendliche mit Migrationshintergrund stellen in unterschiedlichen gesellschaftlichen Bereichen eine Herausforderung dar. So erreichen Sie signifikant häufiger keinen Schulabschluss im Vergleich zu Jugendlichen deutscher Herkunft. Bezogen auf die gesundheitliche Versorgung nehmen sie seltener Vorsorgeuntersuchungen wahr und suchen bei Symptomen später eine Behandlungseinrichtung auf. Dieses Phänomen ist auch bei adipösen Jugendlichen mit Migrationshintergrund zu beobachten. Dafür sind unterschiedliche Faktoren verantwortlich, die exemplarisch dargestellt werden: Eltern mit Migrationshintergrund finden ihre übergewichtigen bzw. adipösen Kleinkinder zu $78 \%$ bzw. $72 \%$ in der Selbsteinschätzung „gerade richtig“. Darüber hinaus sehen sie weniger Möglichkeiten den Gesundheitszustand ihres Kindes aktiv $\mathrm{zu}$ beeinflussen. Auch deshalb werden Krankheiten und ihr Verlauf als überwiegend schicksalhaft erlebt. Eine Überzeugung die bei Adipositas ein erhebliches Therapiehindernis darstellt. In den relevanten Lifestyle-Bereichen Ernährung und körperliche Aktivität sind ebenfalls Faktoren zu identifizieren, die eine nachhaltig erfolgreiche Gewichtsreduktion erschweren. So ist in vielen Familien aus dem muslimischen Kulturkreis das „Gebot der vollen Schränke“, also die Bevorratung mit z. B. Süßigkeiten und Softdrinks für unerwartete Gäste ein Ausdruck lebendiger Gastfreundschaft, kann aber adipöse Kinder/Jugendliche vor erhebliche Compliance-Probleme stellen. Die soziale Akzeptanz von sportlichen Aktivitäten ist in diesen Familien darüber hinaus für Mädchen und Jungen sehr unterschiedlich. Diese praxisrelevanten Beispiele unterstreichen die Bedeutung interkultureller Kompetenz in der Betreuung von (adipösen) Jugendlichen.

\section{Neonatologie (1)}

\section{DGKJ-SY-NE1-1}

Aktion Gute Heimfahrt - Sicherheit im Straßenverkehr für Frühgeborene. Eine Aktion der Abteilung Neonatologie an der Vestischen Kinder- und Jugendklinik Datteln

\section{Dieckerhoff C.}

'Vestische Kinder- und Jugendklinik, Universität Witten/ Herdecke, Abteilung Neonatologie und Pädiatrische Intensivmedizin, Datteln

Jeden Tag werden in Deutschland Frühgeborene nach Hause entlassen, die in herkömmlichen Rückhaltesystemen der Gruppe o+ nur mit zusätzlichen Hilfsmitteln zu sichern sind. Oft wird dieses Problem nicht erkannt, oder Eltern und Pflegepersonal sind überfordert und greifen zu inadäquaten Maßnahmen. Dieser Umstand führt dazu, dass Frühgeborene im Straßenverkehr sehr häufig nur unzureichend gesichert sind und während der Autofahrt in eine Position rutschen, die ihnen die Atmung erschwert.
Ausgehend von umfangreichen Studien zu diesem Thema ist es deshalb in den USA Pflicht, dass Neonatologien sogenannte "Car-seat fitter" beschäftigen, um Eltern fachkundig zu beraten. Gemeinsam mit europäischen Verkehrssicherheitsexperten und Herstellern von Babyschalen haben Mitarbeiter der Abteilung Neonatologie und pädiatrische Intensivmedizin der Vestischen Kinder- und Jugendklinik, Universität Witten/ Herdecke die Empfehlungen der amerikanischen Gesellschaft für Pädiatrie europäischen Sicherheitsstandards angepasst und Informationsmaterial für Eltern entwickelt und seit 2009 führen wir in unserer Abteilung Babyschalenanpassung durch.

Für dieses Engagement wurde die „Aktion Gute Heimfahrt“ in die Liste „Beispielhaftes Projekt Landesinitiative Gesundes Land NRW“ aufgenommen und im Jahr 2012 mit dem „Roten Ritter“" geehrt. Damit Eltern fachkundige Hilfe bekommen, haben wir 2012 mit Unterstützung der Hersteller und in Kooperation mit Verkehrssicherheitsexperten einen Flyer für Personal neonatologischer Abteilungen entwickelt, und planen ab dem Sommer 2013 Schulungen zur Verkehrssicherheit anzubieten.

Im Vortrag werden die Probleme bei der Nutzung unterschiedlicher Babyschalen dargestellt und die korrekte Anpassung sowie das Schulungskonzept erläutert und diskutiert.

\section{DGKJ-SY-NE1-2}

\section{Hyperbilirubinämie: Was gibt es Neues?}

\section{Schmid M. ${ }^{1}$}

'Universitätsklinikum Ulm, Klinik für Kinder- und Jugendmedizin, Ulm

Obwohl die Inzidenz des Kernikterus niedrig ist, kommen weiterhin Fälle dieser verhinderbaren Erkrankung vor. Die frühere Entlassung aus dem Krankenhaus, vor allem auch von relativ reifen Frühgeborenen, unzureichende Trinkmenge bei gestillten Kindern in den ersten Lebenstagen zusammen mit Lücken in der Nachverfolgung und eine Fehleinschätzung der Gefährlichkeit erhöhen das Risiko, eine Hyperbilirubinämie zu spät zu erkennen und zu behandeln.

Im Vortrag werden neuere Aspekte der Bestimmungsmethoden, des Screenings und der Risikostratifizierung, der Prävention, gestationsalterspezifische Behandlungsgrenzen und Besonderheiten bei Frühgeborenen diskutiert.

\section{DGKJ-SY-NE1-3}

\section{Probiotika - wem nützen sie und warum?}

Heep A. ${ }^{1}$

'University of Bristol, School of Clinical Sciences, Bristol, UK

Einleitung. Die Frage nach dem Einsatz von Probiotika in der Ernährung mit dem Ziel der Reduktion der Inzidenz nekrotisiernder Enterokolitis (NEC) bei Frühgeborenen stellt sich aktuell. Eine vorgeburtliche Steroidprophylaxe und die frühe Muttermilchernährung haben einen positiven Effekt auf die Häufigkeit der NEC bei Frühgeborenen. Methoden. Probiotika haben einen Effekt auf die postnatale Entwicklung der Darmbesiedlung (microbiome) und konkurrieren mit pathologenen Keimen bei verzögertem enteralem Nahrungsaufbau, Antibiotikagabe und unter Formula-Ernährung. Der protektive Effekt von Probiotika auf die Entwicklung einer NEC bei Frühgeborenen besteht vermutlich auch in der Maturation der unspezifischen Immunantwort. Ergebnisse. Experimentelle Arbeiten beschreiben einen immunmodulatorischen Effekt spezifischer Probiotika auf „pattern recognition receptor" (Toll-Like Rezeptor 2 und TLR4) Aktivität und Regulierung der lokalen Genexpression pro-inflammatorischer Zytokine. Auch wenn die vorliegenden klinischen Studien den Einsatz von Probiotika nahelegen, so sind dennoch Fragen zum Wirkungsmechanismus und Kombination mit Muttermilch, sowie zu Auswahl und Dosierung des Probiotikums, insbesondere in der Gruppe der Frühgeborenen $<1000 \mathrm{~g}$ Geburtsgewicht, nicht ausreichend geklärt. 
Schlussfolgerung. Um den bestmöglichen Effekt des Einsatzes von Probiotika in der Prävention der NEC insbesondere in der Hochrisikopopulation der Frühgeborenen $<1000 \mathrm{~g}$ zu erzielen, sollten daher weitere klinische und experimentelle Forschungsprotokolle verfolgt werden.

\section{Aktuelles aus der Kinder- und Jugendgynäkologie}

\author{
DGKJ-SY-G-1 \\ HPV-Impfung bei jungen Mädchen - warum? Aktueller Stand \\ Hampl M. ${ }^{1}$ \\ 'Universitätsklinikum Düsseldorf, Frauenklinik, Düsseldorf
}

Einleitung. Das humane Papillomvirus ist das häufigste durch Geschlechtsverkehr übertragene Virus. Etwa $70-80 \%$ der Bevölkerung macht in ihrem Leben die meist asymptomatische Infektion durch und heilt sie aus. Eine persistierende HPV-Infektion ist eine notwendige Voraussetzung für die Entstehung von Präneoplasien und Neoplasien. Durch die prophylaktischen HPV Impfstoffe können bei HPV-naiven Frauen Erkrankungen zu fast 100\% verhindert werden.

Für wen wird die HPV Impfung empfohlen? Die HPV-Impfung ist rein prophylaktisch und nicht therapeutisch und bietet deshalb den größten Nutzen für Frauen, die noch nicht mit dem Virus in Kontakt gekommen sind, also vor Aufnahme des ersten Geschlechtsverkehrs.

Beispiele für die Wirksamkeit der HPV Impfung. In Australien können Mädchen von 12-27 Jahren als Schulimpfung seit 2007 Gardasil kostenlos erhalten (Durchimpfungsraten ca. 75\%). Vier Jahre nach Einführung der Impfung zeigte sich ein Rückgang der Genitalwarzenerkrankungen um $90 \%$ bei geimpften Frauen und um $87 \%$ bei den ungeimpften Männern (Herdimmunität). Des Weiteren finden sich bei den geimpften jungen Frauen deutlich weniger hochgradige Zellveränderungen im Vergleich zu den Jahren vor Impfung.

Kann die Impfung nach Therapie ein Rezidiv verhindern? Eine Auswertung der Impfstoffstudien zeigt, dass die geimpften Frauen ein niedrigeres Rezidivrisiko nach erfolgter Therapie wegen CIN (5,3\% Rezidive) im Vergleich zu den Ungeimpften (8,7\% Rezidive) aufweisen. Dasselbe gilt für Frauen mit VIN und Warzen.

Sicherheitsprofil der HPV Impfung. Die Auswertung von Daten von 190.00o Frauen in USA, die geimpft wurden zeigt bis auf Ohnmacht und Hautreizung an der Einstichstelle kein gehäuftes Auftreten von Nebenwirkungen, so dass die Impfung als sehr sicher eingestuft wird.

\section{DGKJ-SY-G-2}

\section{Chlamydienscreening bei Adoleszenten - warum?}

\section{Oppelt P.G. ', Heusinger K.', Beckmann M.W.'}

'Universitätsklinikum Erlangen, Frauenklinik, Kinder- und Jugendgynäkologie, Erlangen

Eine Infektion mit Chlamydia trachomatis ist die häufigste sexuell übertragbare Infektion (STD) in Deutschland und war bis $2001 \mathrm{mel}$ depflichtig. Nach Schätzungen des Robert-Koch-Institutes (RKI) wird von einer Neuerkrankungsrate von 300.000 pro Jahr ausgegangen. Ca. 100.000 junge Frauen sind aufgrund einer abgelaufenen ChlamydienInfektion unfreiwillig steril. Dies ist umso erstaunlicher da eine frühzeitige Diagnose möglich und eine einfache und günstige Therapie vorhanden ist.

Vom gemeinsamen Bundesausschuss (G-BA) wurde das Chlamydienscreening 2007 als jährliche Kassenleistung für Frauen bis 25 Jahre eingeführt. Nach jetzt fast 6jähriger Laufzeit scheint das Ziel eines flächendeckenden Angebotes und somit eine gezielte Diagnostik auf Chlamydien nicht erfüllt zu sein. Bereits im Februar 2011 wurde in einer Stellungnahme der Deutsche Gesellschaft für Gynäkologie und Geburtshilfe (DGGG) über die Problematik des Chlamydienscreenings informiert. Zum eine wurde die Altersbegrenzung des Screenings in
Frage gestellt und empfohlen das Screening für Frauen bis 34 Jahre zu erhöhen, da der Großteil der Frauen in Deutschland jenseits der 25 Jahre Schwanger werden. Aufgrund des Übertragungsweges ist es sinnvoll auch Männer in das Screening ein zu schließen, wie im europäischen Umfeld.

Ein Problem der schlechten Akzeptanz bei Ärzten/Innen scheint die zeitaufwendige Beratung zum Chlamydienscreening ohne Abrechnungsziffer und somit ohne Vergütung zu sein.

Die Änderungsvorschläge bzw. Kritikpunkte der DGGG sind bisher nicht umgesetzt. Ein Screening ist aber nur erfolgreich und würde der Reduzierung der Chlamydieninfektionen dienen, wenn 80\% des Kollektivs getestet wird und wenn beiden Geschlechtern die Testung ermöglicht wird.

\section{DGKJ-SY-G-4}

\section{Fluor vaginalis bei kleinen und jugendlichen Mädchen - wann wird} es pathologisch?

Voss-Heine I. ${ }^{1}$

'Werl

Fluor vaginalis ist ein normaler oder vermehrter Sekretabgang aus der Scheide. Er kann hormonell physiologisch oder entzündlich pathologisch sein physiologischer Fluor kommt vor in Zeiten der Östrogenisierung, bei Kindern- und Jugendlichen in der Neugeborenen- und Säuglingsphase und wieder ab Präpubertät/Pubertät.

In der östrogenfreien kindlichen Ruhephase ist Fluor Zeichen einer Vaginitis. Diese kommt vor bei allgemeinen Infektionserkrankungen, bei unzureichender Hygiene oder durch Fremdkörper. Oft ist dabei auch die Vulva gereizt und gerötet. Endometritis und Adnexitis gibt es in dieser Zeit nicht. Die Vaginitis in der hormonellen Ruhephase ist meist unspezifisch, Erreger sind HNO-, Haut- und Darmkeime, die nach Verbesserung der Hygiene und kurzfristige Sitzbadanwendungen keiner spezifischen Therapie bedürfen.

Eine Keimbestimmung ist nur bei therapieresistentem Fluor sinnvoll. Das Sekret muss mit einem angefeuchteten dünnen Wattetupfer aus dem hinteren Scheidengewölbe ohne Berührung des äußeren Genitale und des Hymen gewonnen werden. Eine Vaginoskopie wird nötig bei therapieresistentem oder blutigem Fluor. Extrem schmerzhaft und mit einer ausgeprägten Vulvitis verbunden ist eine Infektion mit Streptokokken der Gruppe A, diese muss antibiotisch oral behandelt werden. Pilzinfektionen gibt es in dieser Zeit nicht.

Mit Beginn der Pubertät und der erneuten Östrogenisierung sind Vaginitiden bedingt durch spezifische Infektionen wie Candida albicans, Gardnerella vaginalis, Tichomonaden, Chlamydien und anderen, die einer spezifischen Therapie bedürfen. Durch die Ektropionierung der Cervixschleimhaut besteht für verschiedene Keime die Möglichkeit der aufsteigenden Infektion.

\section{Schlafstörungen im Kindesalter}

\section{DGKJ-SY-S-3}

Diagnostik und Therapie bei schlafbezogenen Atmungsstörungen

Wiater A. ${ }^{\prime}$

'Krankenhaus Porz am Rhein, Kinderklinik, Köln

Einleitung. Schlafbezogene Atmungsstörungen gehen einher mit Beeinträchtigungen des Schlafes und beeinflussen das Tagesverhalten der Kinder. Organische Veränderungen und Verhaltensprobleme sind die Folge. Das obstruktive Schlafapnoesyndrom ist mit einer Prävalenz von bis zu $4 \%$ im Kleinkindesalter die häufigste schlafbezogene Atmungsstörung. Symptomatik, Diagnostik und Therapiemöglichkeiten der schlafbezogenen Atmungsstörungen werden beschrieben. 
Methoden. Anhand von 3 Kasuistiken werden die Krankheitsbilder Säuglingsschlafapnoe, obstruktives Schlafapnoesyndrom und schlafbezogene Hypoventilation ausführlich dargestellt. Ätiologie und $\mathrm{Pa}$ thogenese werden ebenso besprochen wie alterstypische Leitsymptome, Risikofaktoren und Folgeerkrankungen. Konservative und operative Therapiemöglichkeiten werden erörtert.

Ergebnisse. Schlafbezogene Atmungsstörungen im Säuglings- und Kindesalter erfordern ein multidisziplinäres Vorgehen. Neben den Pädiatern sind die HNO-Ärzte, die Kieferorthopäden und gelegentlich auch die Mund-Kiefer-Gesichtschirurgen und Neurochirurgen gefordert. Den Pädiatern kommt dabei die Aufgabe zu, die betroffenen Kinder frühzeitig zu erkennen, das weitere Procedere zu koordinieren und die Kinder langfristig therapeutisch zu begleiten.

Schlussfolgerung. Schlafbezogene Atmungsstörungen gehen mit eindeutigen klinischen Symptomen einher, sind diagnostisch sicher zu erfassen und multidisziplinär frühzeitig therapierbar. Durch die frühzeitige Therapie sind organische Folgeerkrankungen und Einschränkungen der kognitiven Entwicklung sowie Verhaltensprobleme infolge von schlafbezogenen Atmungsstörungen zu verhindern.

\section{DGKJ-SY-S-5}

Medikamentöse Behandlung von Schlafstörungen im Kindes- und Jugendalter

Frölich J.'

'Zentralinstitut für Seelische Gesundheit, Klinik für Psychiatrie und Psychotherapie des Kindes- und Jugendalters, Mannheim

Persistierende Schlafprobleme im Kindes- und Jugendalter stellen oft lediglich das Symptom einer zugrunde liegenden psychiatrischen, neurologischen oder internistischen Erkrankung dar und erfordern deshalb im Vorfeld einen ausführlichen differenzialdiagnostischen Abklärungsprozess. Während in den meisten Fällen dieser Schlafstörung eine Beratung, zum Teil auch verhaltenstherapeutische Maßnahmen indiziert und auch ausreichend sind, spielen bei chronifizierten Störungsbildern vorübergehende medikamentöse Maßnahmen eine bedeutsame Rolle. Bislang fanden v. a. Antihistaminika, Benzodiazepine oder Neuroleptika und Antidepressiva Anwendung, die aber aufgrund von Langzeitnebenwirkungen, Abhängigkeitspotential und substanzieller negativer Auswirkungen auf die Tagesvigilanz und die Gedächtnisfunktionen sehr zurückhaltend oder zumindest nur kurzfristig eingesetzt werden können. Mit Melatonin als einem endogen produzierten, schlafanstoßenden Hormon könnte erstmals auch für das Kindesalter ein wirksamer und im Wesentlichen nebenwirkungsarmer pharmakologischer Behandlungsweg eröffnet werden. Die medikamentöse Behandlung von Schlafstörungen bei Kindern und Jugendlichen ist stets eingebettet in ein Gesamtkonzept der Beratung des Patienten oder der Eltern zur Schlafhygiene oder in eine verhaltenstherapeutische Behandlung.

\section{Neues zu den Impfungen}

\section{DGKJ-SY-IM2-1}

Rota-Virus-Impfung - Wirksamkeit, Verträglichkeit und gesellschaftlicher Nutzen

\section{Terhardt M. ${ }^{1}$}

${ }^{1}$ Kinder- und Jugendmedizinische Gemeinschaftspraxis, Ratingen

Einleitung. Sieben Jahre nach Zulassung der Rotavirus-Impfstoffe wird im August 2013 die neue STIKO-Empfehlung zur Rotavirus-Impfung veröffentlicht. Diese Empfehlung hat als erste die neue STIKO-Methodik nach GRADE durchlaufen und fußt auf guten Evidenz-Daten. Impfziel. Reduktion der RV-Hospitalisation bei Kindern < 5 Jahren. Wirksamkeit. Die Wirksamkeit wurde in gut angelegten randomisierten, kontrollierten Studien nachgewiesen, eine Metaanalyse der STIKO ergab eine Wirksamkeit gegen Hospitalisierung in den ersten beiden Jahren nach Impfung von bis zu 92\%. Um eine RV-assoziierte Hospitalisation zu verhindern, müssen 80 Kinder geimpft werden (NNV).

Verträglichkeit. Es ergab sich keine Impfstoff-spezifische erhöhte Reaktogenität bezüglich Fieber, Durchfall oder Erbrechen. Es gibt Hinweise für ein erhöhtes Invaginationsrisiko innerhalb von 1-7 Tagen nach der Impfung. Die vereinzelten Assoziationen zu Kawasaki-Syndrom nach Rotateq ${ }^{\circ}$ konnten nicht kausal dem Impfstoff zugeordnet werden. Die Kontamination der Impfstoffe mit PCV hatte keine human-pathogene Bedeutung.

Gesellschaftlicher Nutzen. Der gesellschaftliche Nutzen der Rota-VirusImpfung besteht vor allem in der deutlichen Senkung jeglicher RV-Morbidität. Am besten modellierbar ist dieser Nutzen bei der RV-assoziierten Hospitalisation, die bei einer 80\%igen Impfquote um 18.250 Fälle/ Jahr reduziert würde. Insgesamt rechnet man mit ca. 224.00o verhinderten RV-Erkrankungen pro Jahr, was neben der Verhinderung von Krankheit und deren Folgen auch die Verhinderung von Arbeitsausfall bei den Eltern zur Folge hat. Der gesundheitsökonomische Effekt besteht bei den derzeitigen Impfstoffpreisen nicht in einer Kosten-Einsparung. Es kostet die Gesellschaft ca. 2540 €, eine RV-assoziierte Hospitalisation zu vermeiden.

\section{Endokrinologische Diagnostik - der unerwartete Befund}

\section{DGKJ-SY-EN2-1}

Diagnostisches und therapeutisches Vorgehen bei TSH-Erhöhung zur Vermeidung einer Übertherapie von Kindern und Jugendlichen

\section{Mühlenberg R.L.K.'}

'Helios Klinikum Krefeld, Zentrum für Kinder- und Jugendmedizin, Krefeld

Gründe für eine Bestimmung des TSH sind oft unspezifisch und reichen von Konzentrationsstörungen, Verhaltensauffälligkeiten, Übergewicht, Kleinwuchs, sichtbarer Struma, familiären Schilddrüsenerkrankungen bis zur geforderten Messung bei der J1 Vorsorgeuntersuchung. Die aus den Labors übermittelten Referenzwerte sind Ergebnisse aus der Erwachsenenmedizin und weichen bei den oberen Grenzen deutlich von denen bei Kindern und Jugendlichen ab.

Tatsächlich erhöhte TSH-Werte mit normalem freien $\mathrm{T}_{4}\left(\mathrm{fT}_{4}\right)$ sollten nicht zur Diagnose einer latenten oder subklinischen Hypothyreose führen, sondern als Hyperthyreotropinämie bezeichnet werden. Es gibt keine pädiatrischen Studien, die belegen, dass die Behandlung dieser Konstellation zu einem Benefit für die Patienten führt. Vielmehr zeigt eine große Verlaufsstudie aus Israel, dass bei vielen Kindern die TSHErhöhung nur transient und Schwankungen unterworfen ist [1].

Bei übergewichtigen Patienten finden sich gleichfalls gehäuft höhere TSH- und sogar leicht erhöhte $\mathrm{T}_{3}$-Werte, die sich nach Gewichtsabnahme normalisieren und daher belegen, dass Übergewicht nicht Ursache, sondern Folge des TSH-Anstiegs ist [2].

Eine häufige Ursache für ein erhöhtes TSH ist die Hashimoto-Thyreoiditis, die in der Akutphase mit erhöhtem, meist aber mit normalem oder im Verlauf mit erniedrigtem freien Thyroxin sowie mit und ohne Struma einhergehen kann. Daher sollte ein erhöhtes TSH mit normalem fT4 nach 2-3 Monaten kontrolliert werden; erst bei Persistenz müssen sich die Bestimmung von TPO- und Tg-Antikörpern sowie eine SD-Sonographie anschließen. Eine Therapieindikation besteht nur bei Vorliegen einer Hypothyreose und/oder einer Struma.

\section{Literatur}

1. Lazar L et al (2009) J Clin Endocrinol Metab 94(5):1678-92

2. Reinehr T, Andler W (2002) Arch Dis Child 87(4):320-3 


\section{DGKJ-SY-EN2-3}

\section{Das leicht erhöhte 17-Hydroxyprogesteron im NG-Screening}

Kamrath C. ${ }^{1}$, Hartmann M.F.', Wudy S.A. ${ }^{1}$

'Justus-Liebig-Universität Gießen, Allgemeine Pädiatrie, Abteilung für Pädiatrische Endokrinologie und Diabetologie, Giessen

Ein Problem des Neugeborenenscreenings (NGS) auf das adrenogenitale Syndrom (AGS) vom Typ 21-Hydroxylasemangel (21OHD) besteht in der hohen Anzahl an falsch-positiven Befunden sowie des niedrigen positiven Vorhersagewertes. Am weitesten verbreitet ist die direkte Bestimmung des 17a-Hydroxyprogesterons (17OHP) mittels Fluoroimmunoassays (DELFIA). Probleme der Methode bestehen durch höhere 17OHP-Werte bei Frühgeborenen und kranken Neugeborenen sowie Kreuzreaktionen mit anderen Steroiden wie $17 \alpha-H y d r o-$ xypregnenolonsulfat. Einige Screeninglabore verwenden mittlerweile massenspektrometrische Verfahren („liquid chromatography-tandem mass spectrometry“, LC-MS/MS), wodurch zumindest das Problem der Kreuzreaktivität reduziert werden kann. Auch nur leicht erhöhte ${ }_{17} \mathrm{OHP}$ Werte im Screening schließen jedoch ein behandlungsbedürftiges klassisches AGS mit Salzverlust nicht aus. Somit sind Ärzte gerade auf neonatologischen Stationen in dem Dilemma, mit einer großen Anzahl an falsch-positiven Befunden konfrontiert zu sein. Die Gefahr besteht darin, dass bei auffälligem Screeningbefund das Bewusstsein für ein möglicherweise vorliegendes behandlungsbedürftiges Neugeborenes mit klassischem AGS und Salzverlust schwindet. Wichtig ist daher die sichere und möglichst definitive Bestätigungsdiagnose nach auffälligem Screeningbefund. Dazu sind massenspektrometrische Methoden am Besten geeignet. Ein spezifischerer Parameter als das $17 \mathrm{OHP}$ ist beim $21 \mathrm{OHD}$ das 21-Deoxycortisol. Die zusätzliche Bestimmung von 21-Deoxycortisol im Plasma mittels LC-MS/MS oder von dessen Harnmetabolit Pregnantriolon mittels GC-MS („gas chromatography-mass spectrometry“) führt zur Unterscheidung von Patienten mit $21 \mathrm{OHD}$ von Früh- oder gestressten Neugeborenen mit transitorisch erhöhten $17 \mathrm{OHP}-$ Werten.

\section{Extreme Adipositas bei Jugendlichen: eine diagnostische und therapeutische Herausforderung}

\section{DGKJ-SY-A1-2} Medikamentöse Therapie der Adipositas im Kindes- und Jugend-
alter

\section{Reinehr $T .^{?}$}

'Vestische Kinder- und Jugendklinik, Universität Witten/Herdecke, Datteln

Eine pharmakologische Therapie der Adipositas im Kindes- und Jugendalter wird insbesondere bei extrem adipösen Jugendlichen diskutiert, da eine hohe Prävalenz kardiovaskulärer Risikofaktoren vorliegt und meist eine weitere massive Gewichtszunahme zu verzeichnen ist, während Lebensstilinterventionen nur bei einer kleinen Minderheit einen ausreichenden Langzeiterfolg zeigen.

Zugelassen zur Gewichtsreduktion ist in Deutschland nur das Medikament Orlistat, wobei jedoch keine Kostenübernahme erfolgt. Der Effekt der Gewichtsreduktion ist nur sehr moderat. Neu zugelassen ist in USA für adipöse Erwachsene Lorcaserin, ein selektiver Serotonin-2-C-Rezeptoragonist sowie die Kombination aus Phentermine plus extendedrelease Topiramat. Eine weitere interessante Medikamentenklasse sind Glucagon-like-peptide-1(GLP-1)-Analoga. Diese werden in der Diabetes-Therapie eingesetzt und haben als Nebenwirkung eine moderate Gewichtsreduktion durch den appetithemmenden Effekt von GLP-1. Insgesamt kritisch muss bei jeder pharmakologischen Therapie die Notwendigkeit einer lebenslangen Medikation betrachtet werden. Eine medikamentöse Therapie kann daher nur zur Überbrückung von besonderen Schwierigkeiten der Adipositastherapie insbesondere in der Adoleszenz eingesetzt werden.
Eine medikamentöse Therapie der Komorbidität der Adipositas wie der arteriellen Hypertonie, Dyslipidämie und des Diabetes mellitus Typ 2, ist immer dann erforderlich, wenn keine Übergewichtsreduktion erzielt werden kann. Neuere Daten aus Deutschland zeigen, dass weniger als $1 \%$ der Kinder mit arteriellem Hypertonus und ohne Gewichtsreduktion und weniger als $1 \%$ der Kinder mit einer Dyslipidämie und ohne Gewichtsreduktion medikamentös behandelt werden.

\section{Jungengesundheit}

\section{DGKJ-SY-JG-1 \\ ... und wie geht's den Jungs? - Jungenmedizinische Krankheits- bilder}

Stier B.J.M. ${ }^{1}$

'Kinder- und Jugendarztpraxis, Butzbach

Nach dem großen Erfolg der Sitzung zum Thema Jungenmedizin auf der DGKJ-Tagung in Hamburg 2012 gibt es mit diesem Vortrag eine Fortsetzung über weitere relevante jungenmedizinische Krankheitsbilder. Kurz und übersichtlich werden für den Kinder- und Jugendarzt wichtige Krankheitsbilder präsentiert. Ziel ist es, die Kinder- und jugendärztliche Expertise zu erweitern und zu stärken, um damit eine zunehmend bessere medizinische Versorgung von Jungen zu fördern. Damit soll ein dringend benötigtes Netzwerk jungenmedizinischen Wissens aufgebaut werden. Dies ist die wichtigste Voraussetzung für das Entstehen von Beratungs- und Betreuungsangeboten für die Jungen im Sinne einer nachhaltigen Verbesserung von Jungen- und damit auch Männergesundheit.

Der Vortrag will das Interesse mit fundierten Erkenntnissen stärken und den Einstieg in dieses Gebiet fördern.

\section{DGKJ-SY-JG-2}

Macht die Schule Jungen gesund?

Neubauer G.

'SOWIT - Sozialwissenschaftliches Institut Tübingen, Tübingen

Zum Verhältnis von Schule und Jungengesundheit gibt es zwei konträre Positionen: „Schule schadet der Gesundheit, sie macht krank.“ - oder: „Schule fördert die Gesundheit, sie macht gesund.“ Für beides lassen sich Belege finden: Die physiologischen Folgen langjährigen Schulbesuchs sind teils erschreckend; auch psychologische Beeinträchtigungen (z. B. Schulangst als Zusammenspiel von Leistungsdruck und Versagensangst) sind nicht selten. Viele Jungen beschreiben Schule als „Hölle“, in der es an Anerkennung und persönlicher Bedeutung fehlt. Das System Schule stellt aber auch einen Raum für soziale Kontakte zur Verfügung, seine Struktur gibt Orientierung und Sicherheit - und nicht zuletzt Gelegenheit für Lernen und Bildung im Gesundheitskontext. Jungen werden derzeit neu als Zielgruppe von Prävention und Gesundheitsförderung entdeckt. Bislang jedoch sind jungenbezogene Gesundheitsaspekte in der Schule kaum "explizit" thematisiert. Es überrascht also nicht, dass es hier nur wenige Zugänge zur Jungengesundheit gibt. Was Jungen anstellen, damit sie nicht gesund bleiben, ist dagegen weitgehend bekannt. Dies korrespondiert mit der öffentlichen Aufmerksamkeit, die sich bevorzugt für die Problem-Spitzen des Jungeseins interessiert. Entsprechend orientieren sich die schulischen Präventionsprogramme vielfach an negativen Phänomenen wie Sucht, Gewalt oder problematischer Sexualität. Aber was macht und hält Jungen gesund? Jungengesundheit in der Schule bedeutet entschieden mehr als eine Beschränkung auf Schule als Ort für Prävention. Jenseits von Interventionen und Programmen, die direkt und ausschließlich auf die körperliche Gesundheit bzw. auf drastische Gesundheitsprobleme von Jungen abzielen, braucht es eine erweiterte Perspektive auf alle Gesundheitsthemen von Jungen in der Schule. 


\section{Pädiatrische Nephrologie (1) - Neue diagnostische Technologien in der Nephrologie}

\section{DGKJ-SY-NN-2 \\ Pulswellengeschwindigkeit zur nichtinvasiven Diagnostik der Gefäßelastizität niereninsuffizienter Kinder}

Nüsken K.-D.'

'Universitätsklinikum Köln, Klinik für Kinderheilkunde und Jugendmedizin, Köln

Kardiovaskuläre Komplikationen sind eine führende Ursache für die Mortalität von Kindern, Jugendlichen, jungen Erwachsenen und Erwachsenen mit chronischer Niereninsuffizienz. Eine kardiovaskuläre Morbidität, wie z. B. eine Hypertonie oder linksventrikuläre Hypertrophie, aber auch eine Arteriosklerose und Gefäßverkalkung, liegt häufig schon im Kindesalter und schon bei gering verminderter Nierenfunktion vor. Daher ist es zur Verbesserung der kurz- und langfristigen Prognose der Patienten entscheidend, das kardiovaskuläre Risiko frühzeitig zu erfassen und die Patienten optimal zu behandeln.

Die aortale Gefäßelastizität weist eine starke, unabhängige Korrelation mit dem kardiovaskulären Risiko auf. Die Messung der Pulswellengeschwindigkeit („pulse wave velocity“, PWV) ist eine einfache, nichtinvasive Methode, um eine Aussage über die Gefäßelastizität (und damit „Gefäßsteifigkeit") zu erhalten. Normwerte für Kinder und Jugendliche sind geschlechts- und alters- bzw. größenabhängig und wurden kürzlich erstellt. Daher ist die Messung der PWV auch in der pädiatrischen Nephrologie von großem Interesse und nimmt an Bedeutung zu.

\section{DGKJ-SY-NN-3}

Automatisierte Bestimmung des Knochenalters niereninsuffizienter Kinder

Imschinetzki D. ', Nüsken E.', Nüsken K.-D.', Peitz J.', Mentzel H.-J.', Körber F. ${ }^{3}$, Dötsch J.', GPN-Studiengruppe

${ }^{1}$ Kinder- und Jugendklinik, Köln, ${ }^{2}$ Kinderradiologie, Jena, ${ }^{3}$ Kinderradiologie, Köln

Retrospektive, multizentrische Studie (eingeschlossene Bilderzahl $\mathrm{n}=442$ ) zur Validierung von BoneXpert (Software zur automatisierten Bestimmung des Knochenalters) bei Kindern mit chronischer Niereninsuffizienz (primäres Studienziel) und zur Untersuchung der Auswirkungen einer chronischen Niereninsuffizienz auf den Bone Health Index (vgl. Thodberg et al. 2009).

Parallel zur Analyse mittels BoneXpert werden die Röntgenbilder von zwei unabhängigen Experten [Pädiatrischer Radiologe (U1), pädiatrischer Endokrinologe $\left.\left(\mathrm{U}_{2}\right)\right]$ und einer Medizinstudentin als Laiin $\left(\mathrm{U}_{4}\right)$ unter Leitung einer pädiatrischen Radiologin beurteilt, die das Knochenalter nach Greulich und Pyle bestimmen (Goldstandard).

Gescreent wurden 808 Patienten, davon lagen bei 359 Patienten 442 verwertbare Bilder vor. Mittels BoneXpert konnte bei 417 Bildern ein Knochenalter bestimmt werden, bei 25 Bildern konnte BoneXpert keinen Befund erheben (schlechte Qualität oder Knochenalter außerhalb des Grenzbereichs). Die Abweichung des automatisiert bestimmten Knochenalters zum Mittelwert aus Untersucher 1-3 lag bei $\pm 0,73$ Jahren (SD). Die Abweichung zu U1 betrug $\pm 0,84$ Jahre, zu U2 $\pm 0,90$ Jahre, zu $\mathrm{U}_{3} \pm 0,89$ Jahre. Zum Befund der Medizinstudentin betrug die Abweichung $\pm 0,82$ Jahre.

Der Bone Health Index liegt im Mittel bei -1,21 (SD 1,44) und korrelierte weder mit der GFR noch mit dem PTH-Wert, dem Kreatininwert oder dem Grad der Knochenalterretardierung. Auch bei chronischer Niereninsuffizienz ist BoneXpert geeignet das Knochenalter zu bestimmen. Niereninsuffiziente Patienten haben einen schlechteren Bone-Health-Index als gesunde Kinder.

\section{Nosokomiale Infektionen in der Pädiatrie}

\section{DGKJ-SY-I1-3}

Nosokomiale Infektionen in Kinderkliniken

Gehring S.'

'Universitätsmedizin der Johannes Gutenberg-Universität, Zentrum für Kinder- und Jugendmedizin, Mainz

Zielsetzung. Nosokomiale Infektionen in Kinderkliniken sind in den letzten Jahren durch eine Reihe von entsprechenden Berichten in die öffentliche Wahrnehmung geraten. Dabei wird fälschlicherweise das Problem der nosokomialen Übertragung gleichgesetzt mit Infektionen durch multiresistente Erreger. Im Rahmen dieser Präsentation soll einen Überblick über die tatsächliche Bandbreite nosokomialer Infektionen in Kinderkliniken geben und adäquate präventive Maßnahmen aufgezeigt werden, die den besonderen Bedingungen von Kinderkliniken gerecht werden.

Hintergrund. Nosokomiale Infektionen sind nur zu einem kleinen Prozentsatz Infektionen mit multiresistenten Erreger und in den meisten Fällen Infektionen mit virulenten Pathogenen, die bei Kindern mit hoher Morbidität zu entsprechenden Infektionen führen. Im Fokus der öffentlichen Berichterstattung sind Ausbruchssituationen mit gramnegativen Erregern auf neonatologischen Intensivstationen. Tatsächlich spielen ZVK-assoziierte Infektionen mit grampositiven Erregern sowie nosokomiale Virusinfektionen, die nicht nur Intensivstationen sondern auch allgemeinpädiatrische Abteilungen betreffen, im klinischen Alltag eine viel relevantere Rolle.

Prävention. Unverändert bleibt die wichtigste präventive Maßnahme die konsequente Umsetzung der Händehygiene. Darüber hinaus bedarf es gerade in Kinderkliniken einer hinreichenden Ausstattung mit Personal und einer ausreichender räumlichen Infrastruktur, die eine Trennung (potentiell) infektiöser von nichtinfektösen Patienten erlaubt. Die Vermeidung der häufigsten nosokomialen Infektion auf Intensivstation - der ZVK-assoziierten Sepsis - kann durch ein Bündel von Maßnahmen, die von der sterilen Anlage bis hin zur Pflege der Kathetereintrittsstelle, erreicht werden.

\section{Pharmakotherapie (4) - Antihypertensive Therapie}

\section{DGKJ-SY-P4-4}

\section{Prävention der Hypertonie}

\section{Dalla Pozza R.}

'Ludwig-Maximilians-Universität München, Abt. für Kinderkardiologie, München

Der Vortrag beleuchtet die Möglichkeiten, die Entwicklung einer arteriellen Hypertonie bei Kindern und Jugendlichen zu verhindern oder zu verzögern. Im Wesentlichen werden dabei zwei Aspekte berücksichtigt: Ernährung und Sport. Im Bereich der Ernährung sollen besondere Aspekte der mediterranen Diät, der Kochsalzaufnahme, aber auch der Kalzium- und Kalium-Supplementierung berücksichtigt werden. Mit einer Modifikation der Nahrungszusammensetzung können bereits Erfolge erzielt und der Blutdruck gesenkt werden. Sport hilft ebenso, den Blutdruck zu senken. Gerade bei prähypertensiven Kindern und Jugendlichen kann damit der Übergang zu einer manifesten arteriellen Hypertonie verzögert werden.

Die Prävention der Hypertonie ist als primäre Präventionsstrategie von großer Wichtigkeit. Da bekannterweise der systolische Blutdruck des Jugendlichen auch den des Erwachsenen bestimmt, kann durch eine Senkung prähypertensiver Werte langfristig eine Senkung kardiovaskulärer Morbidität und Mortalität bewirkt werden. 


\section{Diabetes (2)}

\section{DGKJ-SY-DB2-2}

Jugendliche mit Diabetes - Herausforderungen in der Betreuung

\section{Holl R.W.' DPV-Wiss-Initiative}

'Universität Ulm, Epidemiologie, ZIBMT, Ulm

In einer pädiatrischen Diabetesambulanz stellen Jugendliche mit 58\% die größte Gruppe dar. Zwar wird dem Typ-2-Diabetes in dieser Altersgruppe große Aufmerksamkeit gewidmet, der Typ 1 überwiegt jedoch weiterhin deutlich mit $>90 \%$. Diabetes bei Mukoviszidose und MODY-Diabetes sind weitere relevante Diabetesformen in dieser Altersgruppe. Der Typ-1-Diabetes bei Jugendlichen geht mit altersspezifischen Besonderheiten einher: Die metabolische Einstellung (HbAic) ist häufig unbefriedigend: Daten der deutsch-österreichischen DPVInitiative zeigen für das Behandlungsjahr 2012 bei 12- bis 16-Jährigen $(\mathrm{n}=9431)$ nur $38,1 \%$ mit einem guten HbA1c-Wert $<7,5 \%$. Dagegen lagen $39,6 \%$ der Patienten zwischen 7,5 und 9, und 22,3\% hatten HbA1c-Werte $>9 \%$, was nach Leitlinien als unbefriedigend eingestuft wird und mit einem hohen Risiko für mikrovaskuläre Folgeerkrankungen (diabetische Retinopathie, Nephropathie) einhergeht. Auch Risikofaktoren für makrovaskuläre Folgeerkrankungen wie Hypertonie, Dyslipidämie oder Zigarettenrauchen sind bei Jugendlichen häufig und erfordern Schulung oder medikamentöse Intervention. Insbesondere bei weiblichen Jugendlichen und bei intensivierter Insulintherapie tritt oft eine deutliche Gewichtszunahme auf, was die Patienten sehr belastet, aber auch die Langzeitprognose verschlechtert. Essstörungen und „Insulin Purging" werden oft übersehen, auch psychiatrische Begleiterkrankungen wie Depression oder Psychose müssen diagnostiziert und behandelt werden. Die Rate ketoazidotischer Entgleisungen ist bei Jugendlichen höher als bei jüngeren Schulkindern. Mit Ende der Pubertät stellt der erfolgreiche Übergang zur internistischen Diabetestherapie (Transition), eine weitere gemeinsame Herausforderung für Diabetesteam, Patient und Familie dar.

\section{DGKJ-SY-DB2-3}

\section{Diabetes-Schulungsprogramme - ein Update}

\section{Neu $A .^{\prime}$}

'Universitätsklinikum Tübingen, Klinik für Kinder- und Jugendmedizin, Tübingen

Für Kinder und Jugendliche mit Diabetes mellitus ist die Schulung im Umgang mit der Erkrankung essentieller Bestandteil der Therapie. Sowohl bei Diagnosestellung als auch im weiteren Verlauf müssen die Betroffenen selbst, deren Eltern sowie weitere Betreuungspersonen (Erzieherinnen, Lehrer) einbezogen werden. Dafür werden unterschiedliche Medien und Materialien eingesetzt, die in aller Regel altersspezifisch verwendet werden.

Für Kinder im Alter von 6 bis 12 Jahren liegt ein kinderspezifisches Programm vor. Heranwachsenden steht das Jugendschulungsprogramm in vier Readern zur Verfügung. Für Eltern gibt es neben Ratgebern in diabetologischen Fragen auch Standardwerke, die sich mit Erziehungsfragen und psychologischen Problemen beschäftigen. Für den Einsatz in Kindergärten und Schulen hat die Arbeitsgemeinschaft für Pädiatrische Diabetologie (AGPD) spezifische Broschüren sowie eine DVD mit je einem Film für Grundschulen, weiterführende Schulen und Lehrer herausgegeben. Die bevorzugte Vermittlung von Wissen im Umgang mit Diabetes für Gleichaltrige erfolgt im Rahmen eines Kindergartenoder Schulbesuches durch eine Diabetesberaterin. Solche Besuche sind vielerorts etabliert, wenngleich eine Finanzierung im Gesundheitssystem nicht vorgesehen ist, sondern im Allgemeinen über Spenden o. ä. erfolgen muss.

Alle Schulungen sollten strukturiert im Rahmen eines Curriculums von einem multiprofessionellen Team in altersentsprechender und in- dividuell angepasster Form angeboten werden. Nur so können sie die Voraussetzung schaffen für die Bewältigung der Erkrankung und einen erfolgreichen Umgang mit Diabetes im Alltag. Ziel aller Bemühungen ist es, neben einer metabolisch ausgeglichenen Stoffwechsellage eine normale körperliche und psychosoziale Entwicklung zu ermöglichen.

\section{Pädiatrische Dermatologie (1) - Aktuelles zu Hauterkrankungen bei Kindern}

\section{DGKJ-SY-PD1-1 \\ Genetik und Epidemiologie des atopischen Ekzems}

\section{Weidinger $S^{\prime}$}

'Universitätsklinikum Schleswig-Holstein, Klinik für Dermatologie und Allergologie, Kiel

Das atopische Ekzem (AE) ist eine typische komplexe und somit multifaktorielle Erkrankung, bei der eine Vielzahl erblicher Faktoren und Umwelteinflüsse in der Pathogenese zusammenwirken. Die PhänotypPenetranz ist dabei gering bei hoher Phänotyp-Variabilität, und es erfolgt eine starke Modifikation seitens der Umwelt. Die Identifikation relevanter Gene ist von großer Bedeutung für ein verbessertes Verständnis der pathophysiologischen Mechanismen und die Entwicklung neuer präventiver und therapeutischer Strategien.

In den letzten Jahren eröffneten der wachsende Erkenntnisstand der genetischen Variabilität des humanen Genoms und rasante methodische Innovationen in der Hochdurchsatzgenotypisierung neue Perspektiven für die Aufklärung der genetischen Ursachen komplexer Erkrankungen. Mit der Identifikation von DNA Varianten im Filaggrin-Gen (FLG), die kein intaktes Genprodukt zulassen, als starke organspezifische Prädispositionsfaktoren des AE wurde ein wichtiger Durchbruch in der Ekzemgenetik erzielt. Genomweite Assoziationsstudien konnten weitere Risikogene aufdecken, die sowohl die epitheliale Barriere als auch die Immunantwort beeinflussen. Zum Teil spielen diese Gene auch für andere chronisch-entzündliche Barriereerkrankungen eine Rolle. Die Translation der Erkenntnisse aus der genetischen Epidemiologie in die Klinik wird die Herausforderung der nächsten Jahre darstellen.

\section{DGKJ-SY-PD1-2}

\section{Hämangiome - eine Darstellung aktueller Therapiemethoden}

\section{Schneider M}

\section{'SLK Kliniken Heilbronn, Kinderklinik, Heilbronn}

Hintergrund. Seit dem Jahr 2008 gibt es zur Behandlung problematischer Hämangiome die Therapieoption einer systemischen Behandlung mit Propranolol. Dieser Meilenstein hat eine Revolution im bisherigen Behandlungskonzept bei Hämangiomen ausgelöst. Beinahe regelhaft zeigt sich ein beeindruckendes Ansprechen der Hämangiome auf die Propranololbehandlung. Die systemische Therapie hat sich als äußerst wirkungsvolle und nebenwirkungsarme Behandlungsoption erwiesen. Methoden. Neben der systemischen Propranololbehandlung hat weiterhin auch insbesondere die Kontakt-Kryotherapie bei $-32^{\circ} \mathrm{C}$ ihren Stellenwert. Diese hat sich gerade bei Hämangiomen, die zu einem frühen Zeitpunkt einer Behandlung zugeführt werden, als rasche und effektive Therapie bewährt. Weitere Behandlungsoptionen stellen die Lasertherapie sowie in Ausnahmefällen die operative Therapie von Hämangiomen dar.

Ergebnisse. Im weiteren Verlauf kam es zur Entwicklung topischer Propranolol-Rezepturen und deren Anwendung im Rahmen individueller Heilversuche bei entsprechender Indikationsstellung.

Schlussfolgerung. Über die verschiedenen Behandlungsindikationen und Therapieformen sowie die aktuellsten Erkenntnisse soll im heutigen Vortrag berichtet werden. 


\section{Historisches Symposium (2) - Arthur Schlossmann - Albert Eckstein - Erna Eckstein-Schlossmann: zur besonderen Bedeutung der Pädiatrie für die Geschichte der Hochschulmedizin in Düsseldorf}

\section{DGKJ-SY-H-1}

Zur differenziellen Säuglingssterblichkeit im ausgehenden 19. und frühen 20. Jahrhundert - mit dem besonderen Blick auf Düsseldorf

\section{Vögele J.}

${ }^{1}$ Heinrich Heine-Universität Düsseldorf, Institut für Geschichte der Medizin, Düsseldorf

In den letzten 150 Jahren hat sich in Westeuropa die durchschnittliche Lebenserwartung bei der Geburt mehr als verdoppelt. Betrug sie bei der Gründung des Deutschen Reiches bei Männern 36 Jahre und bei Frauen 39 Jahre, hat sie sich mittlerweile auf etwa 78 Jahre bei Männern und 83 Jahre bei Frauen erhöht. Einen entscheidenden Anteil an dieser Entwicklung hatte die erfolgreiche Bekämpfung der Säuglingssterblichkeit. Während im letzten Drittel des 19. Jh. mehr als 20\% eines Geburtsjahrganges nicht den ersten Geburtstag erlebten, liegt die Säuglingssterblichkeit in Deutschland derzeit bei 3,4\%. Eine entscheidende Trendwende setzte nach 1900 ein und fällt in eine Zeit, in der die dramatisch hohen Sterbefälle erstmals verstärkt gesellschaftlichen wahrgenommen wurden. Sinkende Geburtenraten gegen Ende des 19. Jhs weckten die Sorge, dass die Zukunft der Nation in wirtschaftlicher und militärischer Hinsicht nicht mehr gewährleistet sei. Im Zuge des Aufstiegs der akademischen Pädiatrie Anfang des 20. Jh. eroberte sich die Sozialpädiatrie beim Thema Säuglingssterblichkeit Aufmerksamkeit und wissenschaftliche Deutungsmacht. Als Schlüsselvariable für das Überleben bzw. das gesunde Heranwachsen des Säuglings identifizierte man die Ernährungsweise, konkret: die Fragen, ob bzw. wie lange der Säugling gestillt wurde. Das Stillverhalten der Mütter wurde Gegenstand groß angelegter Aufklärungskampagnen. Neben Berlin spielten A. Schlossmann und der Düsseldorfer Verein für Säuglingsfürsorge eine bedeutende Rolle. Der Beitrag untersucht, wie der Zusammenhang von Säuglingsfürsorge und Säuglingssterblichkeit während des Kaiserreichs konstruiert wurde und wie sich Stillempfehlungen im Kontext von Säuglingssterblichkeit, Stillquoten und gesellschaftspolitischen Veränderungen entwickelten.

\section{DGKJ-SY-H-2}

Die Pädiatrie in der Vor- und Frühgeschichte der Universitätsmedizin in Düsseldorf - Arthur Schlossmann und Albert Eckstein

\section{Labisch $A{ }^{\prime}$}

${ }^{1}$ Heinrich-Heine-Universität Düsseldorf, Institut für Geschichte der Medizin, Düsseldorf

Ende des 19./Anfang des 20. Jahrhunderts wurde offenkundig, dass in Deutschland die Zahl der Geburten abnehmen würde: mit Blick auf die Interessen von Industrie und Staat wurden Kinderzahl und Säuglingssterblichkeit zu Themen nationaler Bedeutung Die Pädiatrie konnte sich im Zuge der Differenzierung der medizinischen Spezialdisziplinen mehr und mehr als eigenes Fach etablieren.

In diesen allgemeinen politischen, wirtschaftlichen und wissenschaftlichen Bedingungen ist die Entwicklung der Hochschulmedizin einschließlich der Pädiatrie in Düsseldorf einzuordnen. Düsseldorf war Zentrum der wichtigsten Industrieregion Deutschlands, gleichzeitig eine zu nationaler Bedeutung aufstrebende Stadt. In diesem Zusammenhang entstanden die schließlich 1907 eröffneten „Allgemeinen Städtischen Krankenanstalten in Verbindung mit einer Akademie für Praktische Medizin“. Von dem berühmt-berüchtigten Ministerialdirektor Friedrich Althoff („System Althoff“) befördert, war einer der ersten Professoren, die nach Düsseldorf berufen wurde, der junge, aber schon national bekannte Pädiater Arthur Schlossmann aus Dresden. Mit Schlossmann kam ein Arzt nach Düsseldorf, der es nicht nur verstand, sein Fach imperial - mit Erfolg in Wissenschaft und Praxis - zu vertreten, sondern der weit darüber hinaus sowohl für die Entwicklung der Hochschulmedizin in Düsseldorf, für die Entwicklung der Stadt Düsseldorf, Preußens und ganz Deutschlands eine wichtige Rolle einnehmen sollte. Diese Rolle sollte von seinem Nachfolger Albert Eckstein fortgesetzt werden - allein: Das NS-Regime setzte seinem Wirken ein schmähliches Ende. Welche Bedeutung Albert Eckstein hätte erlangen können, wird an den Berichten seiner Frau Erna Schlossmann über ihr Exil in der Türkei deutlich.

\section{DGKJ-SY-H-3}

Die Düsseldorfer Pädiatrie in der Weimarer Zeit und im Nationalsozialismus

\section{Fangerau $\mathrm{H}^{1}{ }^{1}$}

'Universität Ulm, Institut für Geschichte, Theorie und Ethik der Medizin, Ulm

Die Düsseldorfer Pädiatrie wurde in ihren Anfängen nach 1907 maßgeblich von Arthur Schlossmann geprägt (vgl. Vortrag A.L.), der hier nicht nur eine auf wissenschaftlichen Kriterien beruhende Kinderheilkunde zu etablieren suchte, sondern darüber hinaus auch eine institutionelle Säuglingsfürsorge in die Klinik integrierte (vgl. Vortrag J.V.). Diese Verbindung von Forschung, Anwendung und öffentlicher Gesundheitspflege prägte die Düsseldorfer Pädiatrie auch in den Jahren der Weimarer Republik. Nicht zuletzt die 1926 von Schlossmann als Geschäftsführer maßgeblich mitgestaltete messeartige Ausstellung für Gesundheitspflege, soziale Fürsorge und Leibesübungen (GeSoLei) bildete auch ein nach außen getragenes Kennzeichen dieser Strategie. Schlossmanns 1932 ins Amt getretenen Nachfolger, seinem Schwiegersohn Albert Eckstein, blieb wenig Zeit, diese 25 Jahre währende Kontinuitätslinie fortzuführen, denn nach der Machtübertragung an die Nationalsozialisten wirkte der nationalsozialistische Terror auch in die Düsseldorfer Pädiatrie hinein. Eckstein wurde zermürbt und in die Emigration getrieben (vgl. Vortrag L.P.J.). Der inzwischen 71-jährige berühmte Pädiater Adalbert Czerny übernahm in der Folge bis 1935 die Vertretung des Lehrstuhls und der Klinikleitung kommissarisch, ehe Fritz Goebel berufen wurde, der nach dem Krieg noch eine wichtige Rolle als Rektor (1945-1947) in den Diskussionen um den Erhalt der Düsseldorfer Akademie spielen sollte.

Der Vortrag rekonstruiert die Effekte der personalen Strukturveränderungen, politischen Einwirkungen und wissenschaftlichen Entwicklungen der Kinderheilkunde auf die Düsseldorfer Pädiatrie und analysiert an diesem Beispiel das Zusammenwirken von Wissenschaft und Politik bei der Ausgestaltung einer medizinischen Fachdisziplin.

\section{DGKJ-SY-H-4}

Erna Eckstein-Schlossmann. Ein deutsches Schicksal

Johannsen L.P.'

'ehem. Krankenhaus Düren, Kinderklinik, Düren

Die Kinderärztin Erna Eckstein-Schlossmann (1895-1998) stammte aus einer assimilierten jüdischen Familie. Ihr Vater, Arthur Schlossmann, initiierte als bedeutender Kinderarzt des frühen 20. Jahrhunderts eine „soziale Pädiatrie“ ebenso wie den akademischen Lehrbetrieb in Düsseldorf. Auch ihre Mutter, Clara Schlossmann, geb. Bondi, war sozialpolitisch engagiert. Diese frühe Prägung bestimmte Erna Eckstein -Schlossmanns Lebensweg. Sie übernahm die Leitung eines MusterSäuglingsheimes in Düsseldorf. 1935 musste sie mit ihrem ebenfalls jüdischen Ehemann Albert Eckstein, Direktor der Düsseldorfer Kinderklinik, und den drei Söhnen Deutschland verlassen. Die Familie ging ins türkische Exil. Sie unterstützte ihren Mann bei groß angelegten Untersuchungen des Gesundheitszustandes türkischer Kinder. Ihre 
hilfreiche Anteilnahme und Unterstützung anderer Exilantenfamilien machten das Haus Eckstein in Ankara zu einer „Menschlichen Botschaft“. So erlebte Erna Eckstein-Schlossmann, wie sie oft sagte, ihre glücklichsten Jahre im Exil.

Im Jahr 1950, nur einige Monate nach der Rückkehr nach Deutschland, änderte der plötzliche Tod ihres Mannes, seit kurzem Direktor der Hamburger Kinderklinik, ihr Leben von Grund auf. Erneut zeigte sich nun Ihre kraftvolle Persönlichkeit in der Bereitschaft, organisatorische Verantwortung für den Aufbau der neuen Kinderklinik in Ankara zu übernehmen. Sie setzte sich für die Rechte von Besatzungskindern im Rheinland ein und organisierte eine Hygieneausstellung in Düsseldorf. Später zog Erna Eckstein-Schlossmann zu ihren Kindern nach England. 1988 wurde sie als Ehrensenatorin der Universität Düsseldorf gewürdigt und erhielt 1994 die Ehrenmitgliedschaft der DGKJ. 1998 starb Erna Eckstein-Schlossmann im Alter von 102 Jahren in Cambridge.

\section{Anästhesie und Intensivmedizin}

\section{DGKJ-SY-AI-1 \\ Langzeitsedierung auf der Intensivstation - beyond Fentanyl und Midazolam}

\section{Hünseler C.}

'Universitätsklinikum Köln, Klinik für Kinder- und Jugendmedizin, Neonatologie und pädiatrische Intensivmedizin, Köln

Sedierungsstrategien müssen optimiert werden um unerwünschte Medikamentenwirkungen, verlängerte Beatmungszeiten und die Aufenthaltsdauer auf der Intensivstation so kurz wie möglich zu gestalten. Kurzwirksame und gut steuerbare Medikamente wie Remifentanil bieten hier Vorteile, Sedativa mit geringerem Abhängigkeitspotenzial und evtl. geringeren Nebenwirkungen wie Dexmedetomidin finden zunehmend Einsatz. In verzweifelten Situationen sind inhalative Narkotika eine Möglichkeit eine kontinuierliche Sedierung zu gewährleisten. Deren Sicherheit bei langzeitiger Anwendung gerade im Kindesalter ist aber umstritten. Grundlage der Therapie müssen bei ausreichender Personalkapazität evaluierte Sedierungs- und Analgesie-Protokolle, eine engmaschige Therapieüberwachung und Anpassung, optimierte Beatmungsstrategien unter Ausnutzung nichtinvasiver Verfahren und Maßnahmen wie tägliche Sedierungspausen sein.

\section{DGKJ-SY-Al-2}

Neuromonitoring im Kindesalter - Ziele, Möglichkeiten und Grenzen

\section{Gernoth C.}

${ }^{1}$ Gesundheit Nordhessen Holding AG Klinikum Kassel, Klinik für Kinderanästhesie und Intensivmedizin, Kassel

Obwohl seit mehr als 15 Jahren mit dem BIS-Monitoring die potentielle Möglichkeit zum cerebralen Neuromonitoring besteht, finden sich in der Literatur bis heute kaum nennenswerte Untersuchungen zu dessen Bedeutung zur Vermeidung von intraoperativer Wachheit bei Kindern. Dies könnte zum einen an den zugrundeliegenden Messinstrumenten liegen, an der sehr unterschiedlichen Patientenpopulation und andererseits aber auch an der vielleicht schwierigen Beurteilung von Awareness für diese Patienten. Aber inwieweit ist denn eine Überwachung von Narkosetiefe überhaupt von klinischer Relevanz? Es mehren sich in den letzten Jahren die Hinweise auf potentiell neurotoxische Eigenschaften von Anästhetika, insbesondere bei Kindern in den ersten drei Lebensjahren. Aufgrund der vorliegenden vorwiegend tierexperimentellen Daten ist eine Korrelation mit der Expositionsdauer und -dosis nicht sicher auszuschließen. Somit erscheint eine Überwachung von Narkosebesser Hypnosetiefe nicht nur im Hinblick auf potentiell geringere kardiovaskuläre Nebenwirkungen erstrebenswert um eine inadäquat hohe
Anästhetikadosis zu vermeiden. Doch anhand vorliegender Daten zu Komplikationen in der Kinderanästhesie ist auch eine zu gering ausgeprägte Narkosetiefe vor allem im Hinblick auf Broncho-Laryngospasmen, aber auch anderweitige vagale Reizantworten wie Bradykardien mit Gefahren behaftet. Um auf die eingangs gestellte Frage zurückzukommen, bleibt zu diskutieren, inwieweit intraoperative Wachheit deletäre Folgen für die Kinder haben kann. Sind implizite oder explizite Gedächtniseindrücke während einer Operation mit entsprechenden Verhaltens-Lernauffälligkeitend der Kinder assoziiert? Die Rolle und potentielle Bedeutung von perioperativem Neuromonitoring soll in diesem Kontext diskutiert werden.

\section{DGKJ-SY-AI-4 \\ Die Bedeutung der neuronalen Apoptose}

Fischer T. ${ }^{\prime}$

${ }^{1}$ Klinikum Kassel, Klinik für Kinderanästhesie und Intensivmedizin, Kassel

Die Notwendigkeit der Anästhesie bei operativen Eingriffen im Neugeborenenalter und durch die Erfolge im Bereich der Neonatologie bei extremen Frühgeborenen wirft die Frage der Neurotoxizität („anesthesia induced cell death") für die in der Entwicklung befindlichen neuronalen Strukturen dieser Kinder auf. Jevtovic-Todorovic konnte in einer tierxeperimentellen Studie aufzeigen, dass einige Anästhetika, welche über NMDA- und GABA- Rezeptoren wirken, einen ungünstigen Einfluss auf die zerebrale Entwicklung bei prämaturen Ratten haben. Nachfolgende Studien konnten diesen Effekt bei der Gabe von Ketamin und Isofluran/Stickoxydul im Tierexperiment bestätigen, wobei unterschiedliche Anästhetika auf unterschiedliche Hirnareale in Abhängigkeit vom Entwicklungsalter einwirken (Gleich et al., 2013). Allen Studien gemeinsam ist die Verstärkung der neuronalen Apoptose in den betroffenen Hirnarealen (ca. 10\%) bei Früh- und Neugeborenen. Das Korrelat des Ausmaßes der neuronalen Apoptose mit der kognitiven Einschränkung ist in allen Studien nicht gegeben und so wird die Frage aufgeworfen, inwiefern die beobachtete verstärkte neuronale Apoptose als Prädiktor für eine spätere kognitive Einschränkung monokausal zu werten ist (Sanders et al., 2013). Obwohl die Forderung nach prospektiven Studien gerechtfertigt ist, so stellt sich schon jetzt die Frage, ob die heutige Durchführung der Anästhesie bei Früh- und Neugeborenen den Erfordernissen der adäquaten neurologischen Entwicklung dieser Kinder gerecht wird, oder ob wir alternative Anästhesieverfahren und Sedierungskonzepte für diese Altersgruppe einhergehend mit einem adäquaten Neuromonitoring einsetzen müssen.

\section{Tropenpädiatrie - Globale Kindergesundheit}

\section{DGKJ-SY-TP-2 \\ Kindergesundheit der Aborigines in Australien}

\section{Hansmann $A{ }^{\prime}$}

'Unversitätsklinikum Bonn, Pädiatrie, Bonn

Die Urbevölkerung Australiens, ca. 450.00o Aborigines und Torres Straight Insulaner, macht etwa 2,4\% der australischen Bevölkerung aus. Wie die Indianer und Inuit in Amerika und Kanada, ist die Mortalität und Morbidität der Aborigines in Australien erschreckend hoch im Vergleich zur übrigen Bevölkerung. Der Gesundheitszustand der Kinder hängt, wie in allen Ländern der Welt, in den Aborigines Communities von sozioökonomischen Faktoren ab, die häufig historisch bedingt sind: der niedrige Bildungsgrad der Eltern, das geringe Einkommen der Familien, die überfüllten und verwahrlosten Wohnungen, die oft abgeschieden gelegenen Wohnorte sind einige der wichtigsten Faktoren. Dazu wachsen die Kinder häufig mit mangelnder Ernährung, Diskriminierung, Drogenkonsum und Missbrauch auf. Die wichtigsten Erkrankungen der Kinder sind wie in vielen Entwicklungsländern 
Infektionen der unteren und oberen Atemwege, Diarrhö, Darmparasiten, Mangelernährung, Verletzungen, Hautinfektionen, Post-Streptokokken-Glomerulonephritis und rheumatisches Fieber. Der Staat und das Gesundheitssystem haben mit verschiedenen Mitteln auf die schlimmen Gesundheitsstatistiken reagiert: Förderung des Wohnungsbau, früherer Eintritt in der Kinder in betreute Kindergärten, Subventionierung von frischem Obst und Gemüse in den „community stores“, Ausbau und Selbstverwaltung der lokalen Gesundheitszentren und deren Ausrichtung auf die Aborigines, Verbot von Alkohol und Drogen in ganzen Landstrichen und finanzielle Unterstützung zur Erforschung der wichtigsten Erkrankungen sind nur einige Maßnahmen die implementiert wurden. Dennoch hat sich an der schlechten gesundheitlichen Situation der Aborigines kaum etwas verändert und bleibt eine große Herausforderung für die Zukunft Australiens.

\section{DGKJ-SY-TP-3}

Neugeborenengesundheit in Entwicklungsländern. Der Schlüssel zur Senkung der Kindersterblichkeit?

Meissner P.E. ${ }^{1}$

'Universitätsklinikum Ulm, Klinik für Kinder und Jugendmedizin, Ulm

Seit 1990 sank die globale Kindersterblichkeit unter 5 Jahre von 12,5 auf 8,8 Millionen pro Jahr. Jedoch ereignen sich weltweit fast unverändert $41 \%$ aller Todesfälle unter 5 Jahre im Neugeborenenalter. $98 \%$ der Neugeborenen sterben in Entwicklungsländern, über $75 \%$ in den ersten Lebenstagen. Häufigste Ursachen sind Frühgeburtlichkeit, perinatale Asphyxie und Infektionen. Hinzu kommen jährlich noch 2,6 Millionen Totgeburten, sowie eine erhebliche perinatale Morbidität. Viele Fälle wären durch einfache Maßnahmen, wie bessere Betreuung in der Schwangerschaft (Ernährung, Management von Präeklampsie, Malariaprophylaxe, Impfungen), sicherere Entbindung (Hygiene, Neugeborenenversorgung, Hypothermie), sowie Wissen über Gefahrenzeichen bei Neugeborenen und die Bedeutung des Stillens, vermeidbar. Inzwischen sinken in vielen Entwicklungsländern die Geburtenraten und Familienplanung und Schwangerschaftsvorsorge werden besser angenommen. Dennoch entbinden, insbesondere in ländlichen Gegenden Afrikas und Asiens, weiterhin über 50\% aller Frauen ohne medizinische Hilfe („skilled attendance at delivery“) durch Hebammen, Pflegekräfte oder Ärzte/-innen. Die perinatale Mortalität ist direkt assoziiert mit dem Bildungsniveau der Mütter, dem sozioökonomischen Status und dem Zugang zum Gesundheitssystem. Randomisierte Studien aus Asien zeigen, dass Wissensvermittlung über Frauengruppen, die Neugeborenenmortalität um 30\% und die der Mütter um $80 \%$ reduziert. Kostengünstige, evidenzbasierte Interventionen auf Krankenhaus- und Dorfgesundheitsebene werden in vielen Ländern wegen Mangel an Mitarbeitern im Gesundheitswesen noch unzureichend umgesetzt. Daher ist auch die Schulung von Community-Health-Workern, sowie Hausbesuche nach der Geburt, essentiell für die Senkung der Neugeborenensterblichkeit.

\section{DGKJ-SY-TP-4}

Vernachlässigte „Krankheiten“ - Verkehrsunfälle und chronische Osteomyelitis - Auswirkungen auf die Kindergesundheit im subsaharen Afrika

Kiefer A.', Ndayizeye D.', Shakima F.' ${ }^{1} \mathrm{CHUB}$, Butare, Ruanda

Auch bei der Kindergesundheit sind im subsaharen Afrika die Themen HIV, Malaria und TB vorherrschend. Doch die Kindergesundheit in Afrika wird noch von anderen Krankheitsfolgen langfristig beeinflusst. Zwei Studien aus Ruanda am CHUB zeigen die Relevanz von Verkehrsunfällen und chronischer Osteomyelitis. In eine retrospektive Querschnittsstudie wurden 118 Schulkinder im Alter von 3-12 Jahren, eingeschlossen, die nach einem Verkehrsunfall stationär behandelt wurden. Vom Verletzungsmuster war hauptsächlich die untere Extremität betroffen $(43,2 \%)$, gefolgt von Verletzungen der oberen Extremität und Schädel-Hirn-Verletzungen. Thorax- und Abdominaltraumen, sowie Verletzungen des Beckens waren weniger häufig. Es wurden bei dem Kollektiv insgesamt 47 Operationen durchgeführt. Interventionen waren Osteosynthesen (79\%), Trepanationen (13\%) und Laparatomien (4\%). Die Mortalitätsrate betrug 4,2\%. 42,3\% der Patienten wurden für 1-3 Wochen stationär behandelt, ein Drittel blieb länger als drei Wochen im Krankenhaus. In einer zweiten Studie wurden erste Zahlen zur Morbidität der chronischen Osteomyeltis in Ruanda bei 135 Kindern im Alter von 5-15 Jahren erhoben. Ziel war es Daten zu erhalten, um die Morbidität mit anderen afrikanischen Ländern vergleichen zu können. Zum Zeitpunkt der stationären Aufnahme bestanden bereits bei 55\% sezernierende Sinusoide, hauptsächlich betroffen war die untere Extremität, hier insbesondere die Tibia (49,6\%), Staph. aureus war der vorherrschende Keim. Therapie waren chirurgische Interventionen und Antibiose $(85,1 \%)$. Weitere Forschung und präventive Interventionen sind notwendig, um insbesondere die langfristigen Folgen der geschilderten Krankheitsursachen zu verringern und so die Kindergesundheit in Entwicklungsländern zu verbessern.

\section{Pädiatrie trifft Augenheilkunde}

\section{DGKJ-SY-A-1 \\ Strabologie für den Kinderarzt}

Guthoff T.

'Universitätsklinikum Düsseldorf, Augenklinik, Düsseldorf

Fünf Prozent aller Kinder schielen. Das ist nicht nur ein ästhetisches Problem, sondern ein Strabismus führt ohne frühzeitige Behandlung häufig zu einer Sehverschlechterung. Weiterhin gilt es, neurologische und andere zu Grunde liegende Krankheiten auszuschließen. Oft ist der Kinderarzt der für betroffene Familien der erste Ansprechpartner. In diesem Vortrag werden die wichtigsten Untersuchungsmethoden, häufigsten Schielformen und therapeutische Möglichkeiten vorgestellt.

\section{DGKJ-SY-A-2}

Ophthalmologische Differenzialdiagnostik beim Battered-ChildSyndrom

\section{Guthoff R.}

'Universitätsklinikum Düsseldorf, Augenklinik, Düsseldorf

Kindesmisshandlung mit Kopfverletzung ist die wesentliche Todesursache bei Kindern unter 6 Monaten. Gerade beim Shaken-baby-Syndrom ohne wesentliche äußere Verletzungen sind die retinalen neben intrakraniellen Blutungen von großer diagnostischer Bedeutung. Weitere Zeichen sind die traumatische Retinoschisis und Netzhautfalten. Bei Neugeborenen ist die retinale Blutung durch das Geburtstrauma die wichtigste Differenzialdiagnose. Andere Ursachen wie hämatologische Erkrankungen, arterielle Hypertonie, Infektion oder Frühgeborenenretinopathie müssen abgegrenzt werden.

\section{DGKJ-SY-A-3}

Retinopathia praematurorum

\section{Wagenfeld $L$.}

'Universitätsklinikum Hamburg-Eppendorf, Klinik und Poliklinik für Augenheilkunde, Hamburg

Die Frügeborenenretinopathie („retinopathy of prematurity“; ROP) ist eine Erkrankung mit gestörter retinaler Gefäßreifung. Auch heute stellt diese Erkrankung Augenärzte und Neonatologen vor große Herausforderungen. Hierbei geht es in erster Linie um die Verhinderung ihrer 
Entstehung, um das rechtzeitige und konsequente augenärztliche Frühgeborenen-Screening, aber auch um die effektive und richtige Behandlung wenn es zur Ausbildung einer ROP gekommen ist. Klassischer Weise werden die Stadien mit anliegender Netzhaut mittels koagulierender - und destruktiver - Behandlung versorgt. In erster Linie kommen hier Laserverfahren zum Einsatz, in bestimmten Fällen auch eine Vereisungstherapie. Die späteren Stadien, bei denen die Netzhaut abgelöst ist, werden durch eine Vitrektomie und/oder eindellende Verfahren behandelt. Seit einigen Jahren gibt es vermehrt Berichte und Erfahrungen mit dem Einsatz intravitreal applizierter anti-VEGF-Medikamente. Der Vortrag soll einen kurzen Überblick über das Krankheitsbild und die aktuellen Optionen der Behandlung geben.

\section{DGKJ-SY-A-4}

Aktuelle Aspekte zu Ursachen und Therapie der kindlichen Katarakt

Lorenz B. ${ }^{1}$

'Justus-Liebig-Universität Gießen, UKGM GmbH Standort Gießen, Klinik und Poliklinik für Augenheilkunde, Gießen

Die kongenitale Katarakt ist mit einer Prävalenz von o,63 bis 13,6 pro 10.000 Kindern eine relativ seltene Erkrankung. Die Ätiologie ist vielfältig und umfasst genetische und exogene Faktoren. Hereditäre Formen liegen bei ca. $25 \%$ beidseitiger Katarakte vor und erfordern aufgrund unterschiedlicher Erbgänge mit variabler Expressivität und reduzierter Penetranz eine sorgfältige Stammbaumanalyse und gegebenenfalls die Untersuchung weiterer Familienmitglieder. Eine molekulargenetische Routinediagnostik ist derzeit nur in Ausnahmefällen möglich. Bei metabolischen Formen kann eine Prävention möglich sein. Bei syndromalen Formen kann die kongenitale Katarakt das Initialmerkmal sein, was dann ein interdisziplinäres Vorgehen erfordert. Entscheidend für die visuelle Prognose ist wegen des Risikos der Deprivationsamblyopie die Frühdiagnose funktionell relevanter Formen. Der Brückner Test sollte daher einen festen Platz im Rahmen der gesetzlich vorgeschriebenen Vorsorgeuntersuchungen einnehmen. Die operative Therapie der kindlichen Katarakt erfordert ein individuell angepasstes Vorgehen in Abhängigkeit von der spezifischen Pathologie und vom Alter des Kindes. Zur optischen Rehabilitation werden in zunehmendem Maß auch primär Intraokularlinsen implantiert. Die Wahl des Linsentyps ist entscheidend für die Vermeidung von Komplikationen. Ein ungelöstes Problem bleibt die eingeschränkte Vorhersagbarkeit der Refraktionsentwicklung aufgrund des individuell unterschiedlichen Bulbuswachstums. Aufgrund der Seltenheit des Krankeitsbildes ist die Behandlung in einem Zentrum für kindliche Augenerkrankungen empfehlenswert. Augenärztliche Langzeitkontrollen sind zur Prävention und Therapie der Amblyopie und wegen des Risikos für ein Sekundärglaukom und einer Ablatio retinae notwendig.

\section{Immunologie (1) - Infektanfälligkeit}

\section{DGKJ-SY-PI1-1 \\ Das Epstein-Barr-Virus als Herausforderung für das Immunsystem}

\section{Borkhardt A.}

'Universitätsklinikum Düsseldorf, Klinik für Kinder-Onkologie-, Hämatologie und klinische Immunologie, Düsseldorf

Das Epstein-Barr-Virus (EBV) ist ubiquitär verbreitet, im Laufe des Lebens beträgt die Wahrscheinlichkeit einer Infektion ca. 90\%. Die Symptomatik reicht von inapparenten Infektionen bis zu schwersten, vital bedrohlichen Krankheitsverläufen. Die Erstinfektion verläuft als infektiöse Mononukleose in der Regel selbstlimitierend, wobei Exanthem, Vaskulitis, Hepato-Spleonomegalie, Nephritis oder Hepatitis oder - wenn auch deutlich selterner - ein Guillian-Barre-Syndrom oder eine Hämophagozytose mit konsekutiver Zytopenie u. U. schwere
Verlaufsformen kennzeichnen. Eine Besonderheit stellen alle Patienten mit iatrogener Immunsuppression (Z.n. Organtransplantation) dar, die im Laufe ihres Lebens ein von Transplantionsart, Immunsuppression und vorherigem EBV-Status unterschiedlich großes Risiko haben, eine Post-Transplantations-assoziierte Lymphoproliferation (engl. PTLD) zu entwickeln. Die PTLD stellt eine schwere, sich bis zum Vollbild eines malignen Lymphoms entwickelnde Komplikation nach Organtransplantation dar.

Daneben wurden in den letzten Jahren eine zunehmende Zahl von angeborenen, monogenen Erkrankungen, die mit einem selektiven Unvermögen einhergehen eine EBV Infektion immunologisch adäquat zu kontrollieren, beschrieben. Bisher sind 5 derartige Erkrankungen molekulargenetisch identifiziert, die $u$. U. eine rasche therapeutische Intervention - bis hin zur allogenen Knochenmarktransplantion - erfordern. Der Vortrag stellt das große interindividuelle Spektrum dar, mit der Kinder auf eine EBV Infektion oder eine EBV-Reaktivierung reagieren können und zeigt die diagnostischen und therapeutischen Möglichkeiten auf.

\section{DGKJ-SY-PI1-2}

\section{AWMF-Leitlinie (S2): Diagnostik von primären Immundefekten}

\section{Schulze I.}

${ }^{1}$ Centrum für chronische Immundefizienz, Zentrum für Kinderheilkunde und Jugendmedizin, Freiburg

Nach den heute vorliegenden Daten wird die Prävalenz von angeborenen Immundefekten auf 1:200o geschätzt. Damit liegt die Häufigkeit eines primären Immundefektes im Bereich der Mukoviszidose und hat klinische Relevanz für jeden Kinderarzt. In der neuesten Klassifikation der primären Immundefekte werden 179 verschiedene, meist molekulargenetisch definierte Erkrankungen aufgeführt, und es können stetig neue Defekte des Immunsystems charakterisiert werden. Leitsymptom der meisten primären Immundefekte ist eine ungewöhnliche Infektanfälligkeit. Des Weiteren zeigen viele Patienten aber auch Zeichen der Immundysregulation, wie z.B. Autoimmunzytopenien, Ekzeme, Lymphoproliferation oder Kolitis. Eine rechtzeitige Basisdiagnostik und Kontaktaufnahme mit einem pädiatrischen Immunologen können lebensrettend sein. Im Beitrag wird die interdisziplinär erarbeitete AWMF Leitlinie zur „Diagnostik von primären Immundefekten“ vorgestellt.

\section{DGKJ-SY-PI1-3}

\section{Bilder aus der klinischen Immunologie für den Kinderarzt}

\section{Seger R.A. ${ }^{\prime}$}

'Univ.Kinderklinik Zürich, Immunologie, Zürich, Schweiz

Primäre Immundefizienzen (PID) sind potentiell lebensbedrohend, kommen gesamthaft ebenso häufig vor wie die zystische Fibrose, werden aber immer noch verspätet erkannt. Da pathognomonische Zeichen meist fehlen und immunologisch gesunde Säuglinge und Kleinkinder per se infektanfällig sind, ist die Erkennung von wichtigen Muster und Warnzeichen Schlüssel zur Frühdiagnostik und -therapie von PIDs. Wichtige Hinweise leisten bei der Anamnese-Erhebung und klinischen Untersuchung das Alter bei Erstpräsentation, das Muster infizierender Erreger, charakteristische Symptome einer Immundysregulation (an den Eintrittspforten oder systemisch), syndromale Befunde, eine auffällige Familienanamnese und ein Differenzialblutbild.

Dieses klinische Filter ermöglicht den intialen Verdacht einer Primären Immundefizienz und allenfalls die provisorische Zuordnung zu einer von 6 Kategorien (T-Zelldefekte, Antikörpermängel, Defekte der Innate Immunity (inkl. Phagozyten- u. Komplement-Defekte), syndromale Immundefizienzen, Störungen der Immunregulation sowie Autoinflammation), jedoch noch keine spezifische Krankheitsdiagnose. 
Anhand charakteristischer Beispiele soll im Vortrag das kritische Gleichgewicht von Über- und Unterdiagnostik bei der klinischen Triage visuell illustriert werden.

\section{Literatur}

1. Bousfiha A et al (2013) A phenotypic approach for PID classification and diagnosis. Guidelines for clinicans at the bedside J Clin Immunol (Epub ahead of print)

\section{Pädiatrie trifft HNO}

\section{DGKJ-SY-HN-1}

\section{Frequenzspezifischer Geräuschtest mit Tierstimmen - Hörtest zum} Screening in Kinderarztpraxen

\section{Nolte A. ${ }^{\prime}$, Rohlfs A.-K. ${ }^{2}$, Coninx F. ${ }^{3}$}

'Universitätsklinikum Heidelberg, HNO-Klinik, Heidelberg, ${ }^{2}$ Universitätsklinikum Hamburg-Eppendorf, Klinik und Poliklinik für Hör-, Stimm- und Sprachheilkunde, Hamburg, ${ }^{3}$ Universität zu Köln, Institut für Audiopädagogik, Köln

Einleitung. Der frequenzspezifische adaptive Geräuschtest mit Tierstimmen (Frequencyspecific Animal Sound Test-4) nach Prof. Coninx ist ein PC-basierter Hörtest für Kinder. Es wurde ermittelt, ob sich die Hörschwelle des FAST4-Tests bei Kindern und Erwachsenen von der des Reintonaudiogramms (RTA) unterscheidet.

Methoden. Dem Probanden wurden ein Hund und eine Kuh für den tieffrequenten Bereich $(<2 \mathrm{kHz})$ und eine Katze und ein Vogel für den hochfrequenten Bereich $(>2 \mathrm{kHz}$ ), nach dem Zufallsprinzip auf jedem Ohr einzeln über Kopfhörer vorgespielt. Man erhielt einen Wert in dB HV (Hörverlust) für den tief- und hochfrequenten Bereich für das linke und rechte Ohr. Der Wert „o dB HV“ stellte die kalibrierte, normale Hörschwelle dar. Es haben 159 normal- und 113 schwerhörige Kinder zwischen 2,5 und 14,3 Jahren (Median: 5,2 Jahre) und 41 Erwachsene teilgenommen. Der FAST4-Test unterschied sich nicht vom RTA mit einem p-Wert >0,05 bei den normalhörigen 4,0- bis 7,0-Jährigen Kindern, den 40- bis 90-Jährigen Erwachsenen als auch den schwerhörigen Kindern und Erwachsenen. Alle anderen Altersklassen zeigten keinen Zusammenhang. Der FAST4-Test wurde bei 65 Kindern im Alter von 2,5 bis 4,0 Jahren frühzeitig abgebrochen.

Ergebnisse. Die Differenzen zwischen dem FAST4 und dem RTA sind darauf zurückzuführen, da es bei einseitigen Schwerhörigkeiten zum Überhören kam, Hochtonschwerhörigkeiten $>4 \mathrm{kHz}$ nicht messbar sind, im RTA eine Normalhörschwelle mit $10 \mathrm{~dB}$ HV angegeben wurde und bei den Kindern unter vier Jahren aufgrund schlechter Mitarbeit und mangelnder Konzentration falsch positive Hörschwellen gemessen wurden.

Schlussfolgerung. Zusammenfassend ist der $\mathrm{FAST}_{4}$-Test durch seine einfache, schnelle und effiziente Bestimmung der Hörschwelle bei Kindern über vier Jahren ideal für eine Kinderarztpraxis, da er kein geschultes Personal benötigt.

\section{DGKJ-SY-HN-3}

\section{Logopädische Diagnostik und Therapie bei kindlichen Hörstörun- gen}

\section{Schatton D. ', Frommelt M.', Klenzner T.}

'Universitätsklinikum Düsseldorf, HNO-Klinik, Hörzentrum, Düsseldorf

Zunehmend wird diskutiert, ob zu viel logopädische Therapie verordnet wird. Braucht ein schwerhöriges Kind, das mit Hörhilfen versorgt ist überhaupt eine zusätzliche Förderung? Trotz sich stetig weiter entwickelnder technischer Versorgung kann das natürliche Gehör nicht ersetzt werden. Defizite können nicht immer ohne therapeutische Hilfe kompensiert werden und so weisen Kinder mit Hörstörungen häufig Auffälligkeiten in der Sprachentwicklung auf. In Abhängigkeit vom
Schweregrad des Hörverlustes und der apparativen Versorgung finden sich z. B. Artikulationsstörungen, ein eingeschränkter Wortschatz, ein eingeschränktes Sprachverständnis oder grammatikalische Auffälligkeiten. Ist die Sprachentwicklung beeinträchtig, kann sich auch die kognitive und sozial-emotionale Entwicklung nicht normal vollziehen. Aus diesem Grund ist eine frühe interdisziplinäre Beobachtung wichtig, um das Kind bei Bedarf durch logopädische Behandlung unterstützen zu können. Bei der Betrachtung der Sprachentwicklung muss bei hochgradig schwerhörigen Kindern eine Unterscheidung zwischen dem Lebensalter und dem Höralter erfolgen. Letzteres wird ab dem Zeitpunkt der apparativen Versorgung gerechnet und gilt als Maß für die Beurteilung der Sprachentwicklung. Zur objektiven Beurteilung der sprachlichen Leistungen stehen verschiedene standardisierte logopädische Testverfahren zur Verfügung. Ab dem 2. Hörjahr ist bereits durch den Einsatz des SETK-2 (Sprachentwicklungstest für Zweijährige) eine Einschätzung der rezeptiven und produktiven Sprachfähigkeiten auf Wort- und Satzebene möglich. Zu diesem Zeitpunkt kann bereits bei Auffälligkeiten eine logopädische Therapie mit intensiver Elternanleitung sinnvoll sein.

\section{DGKJ-SY-HN-4 \\ FEES - Endoskopische Schluckuntersuchung bei Kindern}

\section{Schramm D. ${ }^{1}$}

'Universitätsklinikum Düsseldorf, Klinik für Allgemeine Pädiatrie, Neonatologie und Kinderkardiologie, Düsseldorf

Die fiberoptisch-endoskopische Untersuchung des Schluckens („fiberoptic endoscopic evaluation of swallowing") ist eine etablierte Methode zur Untersuchung des Schluckaktes bei Erwachsenen, zunehmend auch bei Kindern. Sie dient der Untersuchung anatomischer oder funktioneller Störungen, die schließlich zu Aspirationen mit chronisch-entzündlichen Veränderungen der unteren Atemwege führen können. Die Untersuchung ist wenig invasiv und kann in jedem Lebensalter durchgeführt werden. Neben der direkten Sicht auf die anatomischen Strukturen kann der Umgang mit unterschiedlichen Konsistenzen, sowie des eigenen Speichels überprüft werden. Bei Kindern, die über nasogastrale Sonden ernährt werden, kann die Möglichkeit der oralen Nahrungsaufnahme untersucht werden. Dies ist ebenfalls von Bedeutung für Kinder, die über eine Trachealkanüle atmen und deren Beatmungs- und Ernährungssituation überprüft oder verändert werden soll. Für die Untersuchung wird ein flexibles Endoskop über die Nase vorgeschoben und mit Blick auf Larynx und Zungengrund platziert. Anschließend werden angefärbte Speisen unterschiedlicher Konsistenz verabreicht und der Schluckakt bezüglich der Bewegungsabläufe, zeitlicher Komponenten und Erfolg des Schluckes überprüft. Verschiedene Auffälligkeiten, wie das Leaking, bei dem der Schluckvorgang nicht oder nur sehr verspätet eingeleitet wird, bis hin zu Penetration und Aspiration können nun endoskopisch gesehen werden. Die Untersuchung ermöglicht eine gezielte Empfehlung zur weiteren oralen Ernährung mit bspw. angepassten Nahrungskonsistenzen, die Einleitung einer gezielten Therapie durch zum Beispiel Veränderung der Position während der Nahrungsaufnahme, bis hin zur vollständigen Nahrungskarenz mit alternativen Ernährungsmöglichkeiten über z. B. PEG-Sonden.

\section{DGKJ-SY-HN-5 \\ Klinische und apparative Diagnostik bei Säuglingen und Kindern mit Schluckstörungen}

Hübl N. ${ }^{1}$

'Universitätsklinikum Düsseldorf, Klinik für Allgemeine Pädiatrie, Neonatologie und Kinderkardiologie, Düsseldorf

Einleitung. In der oralen Ernährung können bei Säuglingen und Kleinkindern verschiedene Auffälligkeiten auftreten. Beim Trinken und Essen kann es zu Problemen im oropharyngealen Nahrungstrans- 
port, zum konsistenzabhängigen Würgen, Husten sowie Verschlucken kommen. Treten Aspirationen auf, können die Säuglinge und Kinder wiederkehrende Bronchitiden, Pneumonien und Fieber entwickeln. Die Mahlzeiten sind häufig anstrengend, dauern lange und können die Familie als System sehr belasten.

Methoden. Die logopädische Diagnostik umfasst zunächst die klinische Beobachtung der Trink- und Essfunktion und deren Bewertung anhand standardisierter Testverfahren. Für das Trinkverhalten eignen sich bspw. die Neonatal Oral Motor Assessment Scale (NOMAS) sowie das Early Feeding Skill Assessment (EFS). Für die Bewertung des Essens von fester Kost das Schedule for Oral Motor Assessment (SOMA). Jedoch spielt auch die apparative Diagnostik der Schluckfunktion bspw. mithilfe der FEES („fiberoptic endoscopic evaluation of swallowing“) eine zunehmend wichtige Rolle in der Versorgung dieser Patienten. Die FEES wird in interdisziplinärer Zusammenarbeit zwischen Logopädie und Pneumonologie, HNO oder Phoniatrie durchgeführt. In Abhängigkeit der Ergebnisse der klinischen und apparativen Diagnostik beinhaltet die logopädische Therapie eine Adaption der Positionierung während des Trinkens und Essens sowie der Nahrungskonsistenzen. Auch eine Anleitung der Eltern in Füttertechniken kann erfolgen. In einigen Fällen ist eine Empfehlung für die Versorgung mit einer PEGSonde notwendig.

\section{Pädiatrische Nephrologie (2)}

\section{DGKJ-SY-N2-2}

Therapie des hämolytisch-urämischen Syndroms (HUS)

\section{Kemper M.J.}

'Universitätsklinikum Hamburg-Eppendorf, Klinik für Kinder- und Jugendmedizin, Pädiatrische Nephrologie, Hamburg

Einleitung. Das HUS ist gekennzeichnet durch eine hämolytische Anämie, Thrombocytopenie und einer Niereninsuffizienz. Ursache ist eine thrombotische Mikroangiopathie (TMA), die meist erworben ist, aber auch genetisch bedingt sein kann. Die häufigste Ursache ist eine Infektion mit enterohämorhagischen E.coli, (STEC-HUS), die zum enteropathischen HUS führt (D+HUS). Davon abzugrenzen sind sog. atypische HUS Formen (aHUS), die durch Mutationen in complementregulierenden Faktoren beding sind (z. B. Faktor-H-Mangel).

Methoden. Die Therapie des enteropathischen und des aHUS unterscheiden sich. Während das STEC-HUS meist einen selbstlimitierten Verlauf hat, kommt es beim aHUS häufig zu Rezidiven und zum progressiven Verlauf. Somit steht beim D+HUS zunächst die symptomatische Therapie (z. B. Transfusion, Dialyse) im Vordergrund, während beim aHUS neuerdings die ungebremste Aktivierung des Komplementsystems durch einen monoklonalen Antikörper (Eculizumab) blockiert werden kann. Dadurch können die Symptome behandelt und Rezidive vermieden werden; allerdings ist eine lebenslange Behandlung mit Eculizumab nötig. Alternativ kann bei diesen Patienten durch eine präemptive oder kombinierte Transplantation von Leber und Nieren eine Korrektur des metabolischen Defekts erreicht werden. Beim D+HUS ist bei komplizierten Verläufen, insbesondere bei extrarenalen Manifestationen (neurologische Beteiligung), die Behandlung mit Plasmaseparation etabliert, in Einzelfällen ist zuletzt auch Eculizumab eingesetzt worden. Schlussfolgerung. Zusammenfassend ist die primäre ätiologische Einordnung des HUS für die Therapie wegweisend. Das STEC-HUS ist die häufigste Variante und kann primär supportiv behandelt werden. Bei der Behandlung des seltenen aHUS hat die Behandlung mit Eculizumab die Prognose entscheiden verbessert.

\section{DGKJ-SY-N2-3}

\section{Therapie des steroidsensiblen nephrotischen Syndroms}

Oh J.

'UKE Hamburg, Päd. Nephrologie, Hamburg

Das steroidsensitive nephrotische Syndrom (auch „minimal change glomerulonephritis") wurde über lange Zeit als eine rein immunologische Erkrankung angesehen. Dies vor allem wegen des häufig sehr guten Ansprechens auf eine immunsuppressive Therapie. In den letzten 10 Jahren rückte durch intensive Grundlagenforschung der Podozyt immer mehr in den Mittelpunkt des Interesses. Der Podozyt bildet mit der glomerulären Basalmembran und den gefensterten Endothel-zellen die glomeruläre Filtrationsbarriere. Es hat sich gezeigt, dass einige Medikamente, die bisher primär wegen ihrer immun-modulatorischen Wirkung zum Einsatz kamen zum Teil einen direkten nicht-immunologischen Effekt auf die Funktion und Morphologie des Podozyten haben. In meinem Vortrag möchte ich auf die derzeitige medikamentöse Behandlung des steroidsensiblen Nephrotischen Syndroms eingehen und versuchen dies in Bezug zu setzen mit neuesten wissenschaftlichen Erkenntnissen aus der podozyten Forschung.

\section{DGKJ-SY-N2-4}

Therapie des steroidresistenten nephrotischen Syndroms

\section{Büscher A.K.', Hoyer P.F.', Weber S.' \\ 'Universitätsklinikum Essen, Klinik für Kinderheilkunde ${ }^{2}$, Pädiatrische Nephrologie, Essen}

Das nephrotische Syndrom (NS) beruht auf einer Dysfunktion des glomerulären Filters mit konsekutivem Verlust von Plasmaproteinen. 15-20\% der Patienten sprechen nicht auf die Standardtherapie mit Steroiden an, erweisen sich als steroidresistent (SRNS). Bei diesen Patienten werden zunehmend Mutationen in podozytären Genen als ursächlich identifiziert. Die Therapie des SRNS ist eine Herausforderung für pädiatrische Nephrologen, da 50\% der Patienten, bei denen keine Remission erzielt werden kann, innerhalb von 5 Jahren eine Progredienz zum terminalen Nierenversagen zeigen. Empfohlen wird zum einen die medikamentöse Blockade des Renin-Angiotensin-Systems, zum anderen eine intensivierte immunsuppressive Therapie. Diese wird oft auch bei hereditären Formen angewandt, da in Einzelfällen Remissionsinduktionen beschrieben sind. Die größte klinische Erfahrung besteht für Cyclosporin A (CSA), dessen Wirksamkeit belegt ist. CSA weist jedoch eine ausgeprägte Nephrotoxizität auf und erfordert eine Langzeittherapie, da nach Absetzen Rezidive beobachtet wurden. Alternativ kommen Immunsuppressiva mit anderem Nebenwirkungsprofil (Tacrolimus, Mycophenolat Mofetil) zum Einsatz. Kombinationstherapien mit Cyclophosphamid zeigten keinen Benefit gegenüber einer alleinigen Steroidgabe und sind mit zahlreichen Nebenwirkungen assoziiert. Rituximab zeigt beim SRNS eine deutlich geringere Effektivität als bei der Therapie des steroidabhängigen NS. Aufgrund der schweren Nebenwirkungen (Sepsis) ist die Anwendung von Rituximab beim SRNS individuell zu prüfen. Die Therapie des SRNS ist gekennzeichnet durch geringe Ansprechraten insbesondere bei den hereditären Formen. Randomisierte Studien sind erforderlich, um die Therapie des SRNS zu optimieren und das Outcome der Patienten zu verbessern. 


\section{Neue diagnostische Technologien - Exome sequencing will change your life (as a paediatrician)}

\section{DGKJ-SY-ND2-2}

\section{Exome sequencing; Lessons from 500 diagnostic exomes}

\section{Brunner H.G. ${ }^{1}$}

'Radbouduniversität MC, Human Genetics, Nijmegen, Niederlande

The introduction of powerful DNA sequencing has rapidly changed the study of inherited diseases. We have used next generation sequencing in $>500$ patients with intellectual disability, movement disorders, blindness, and deafness. A large fraction of patients with these conditions are diagnosed by interrogating all 22,000 human genes in one experiment. This will change the practice of pediatrics. Previously, molecular testing would be ordered only after an accurate clinical diagnosis had been obtained, supported by other tests, some of which might be invasive, expensive and cumbersome to the patient. We shall now order an „exome“ screen immediately, in order to obtain a molecular differential diagnosis. Further clinical investigation may then confirm or refute suspected diagnoses.

It is clear, that any success of applying exome sequencing should not be limited to medical genetics. An estimated 1 in 16 individuals has a rare disease, and many of these are genetic. Most patients with a rare disease visit multiple doctors over an extended period before they reach a specialist who recognizes their particular rare condition.

One may now envisage a scenario whereby patients with complex clinical presentation be included in a program for undiagnosed diseases where the first step would be exome sequencing. I propose that such a strategy would provide many accurate diagnoses, thereby reducing doctor's delay, unnecessary invasive, costly and burdensome procedures, and allowing a prognosis and care pathway to be charted.

Since rare disease are not rare collectively, exome sequencing will soon move to the front end of the diagnostic process for many pediatric conditions, amongst which are intellectual disability, neurodegenerative diseases, immune deficiencies and several others.

\section{Pädiatrische Dermatologie (2) - Kutane Infektionen bei Kindern}

\section{DGKJ-SY-PD2-3}

\section{Kutane Pilzinfektionen bei Kindern}

Mayser P. ${ }^{1}$

'Universitätsklinikum Giessen und Marburg, Klinik für Dermatologie, Venerologie und Allergologie, UKGM, Giessen

Die Inzidenz der Tinea capitis ist steigend, das Spektrum der Erreger ändert sich hingegen. Um bei Infektionen durch anthropophile Erreger (T. tonsurans, T. violaceum, T. soudanense) ein Wiederauftreten der Infektion zu verhindern, ist ein Screening auf asymptomatische Überträger und deren Behandlung zwingend erforderlich.

Bei Tinea capitis gelten folgende Prinzipien:

1. Erregernachweis vor Therapie,

2. Therapie immer systemisch + adjuvant topisch,

3. Ziel : negative Kultur,

4. Zoophiler Erreger: (Haus-)tiere? (symptomatisch, asymptomatisch), 5. Anthropophiler Erreger: nahe Kontaktpersonen,

6. Kind mit T. corporis $=$ nach $\mathrm{T}$. capitis suchen .

Zur systemischen Behandlung von Kindern besteht in Deutschland derzeit eine Zulassung lediglich für Griseofulvin. Fluconazol ist für Kinder über einem Jahr zugelassen, sofern eine therapeutische Alternative fehlt. Bei Trichophyton-Arten ist Terbinafin sehr wirksam, während bei M. canis eine Therapie mit Griseofulvin oder Itraconazol indiziert ist. Superfizielle Mykosen der Haut- und Schleimhaut können mit erheblichen entzündlichen Veränderungen einhergehen. Ausmaß und Art der Entzündung hängen $a b$ a) vom Erreger b) von der Immunantwort des Wirtes und c) vom Ort der Infektion bzw. der Eintrittspforte. Bei stark entzündlichen Mykosen oft durch zoophile Erreger ist eine topische Kombinationstherapie aus einem Antimykotikum und einem Glukokortikosteroid erwägenswert, da sie zu einer rascheren Reduktion der objektiven und auch subjektiven Beschwerdesymptomatik führt als die antimykotische Monotherapie. Der Einsatz des Antimykotikums Nystatin in der Kombinationstherapie setzt den Nachweis einer Hefepilzinfektion voraus, da die Substanz bei Dermatophyten-bedingten Infektionen nicht wirksam ist.

\section{Gastroenterologie}

\section{DGKJ-SY-GE-1}

Entzündliche Erkrankungen des Magen-Darm-Traktes (Differenzialdiagnosen vom Rotavirus zu den (ED): infektiöse Ursachen

Pilic D.', Schmidt-Choudhury A. ${ }^{1}$

'Ruhr Universität Bochum, Klink für Kinder- und Jugendmedizin der RuhrUniversität, Bochum

Die häufigste Ursache von akut auftretenden Durchfällen im Kindesund Jugendalter mit oder ohne begleitendes Erbrechen stellt die infektiöse Gastroenteritis dar. Die Hauptverursacher sind laut der Erhebung von meldepflichtigen Erkrankungen durch das Robert-Koch-Instituts vor allem virale Erreger wie Noro- und Rotaviren gefolgt von bakteriellen Erregern wie Campylobacter, Salmonellen und E.-coli-Stämme. Die Therapie besteht vor allem aus einer symptomatischen Behandlung einer bestehenden Dehydration in Form von Gabe einer oralen, hypoosmolaren Rehydrationslösung. Eine restriktive Diät im Anschluss an die vierstündige Rehydrationsphase wird nicht empfohlen. Gestillte Kinder sollten weiter angelegt werden. Eine Antibiotikatherapie ist in der Regel nicht indiziert. Der Einsatz von Antiemetika und Probiotika wird kontrovers diskutiert. Eine weiterführende Diagnostik ist in der Regel nicht erforderlich, sollte jedoch erfolgen, wenn folgende Warnsymptome auftreten: schwere oder protrahierte Verläufe, lokalisierter abdomineller Druckschmerz/ akutes Abdomen, schwere blutige Durchfälle, galliges Erbrechen, primäre oder erworbene Immunschwäche, V. a. HUS, Auslandsaufenthalten in Risikoländern. Bei positivem Erregernachweis sollte auch bedacht werden, dass gastroenterologische Erkrankungen sich auf dem Boden einer akuten Gastroenteritis manifestieren können. So z. B. funktionelle Bauchschmerzen, Invaginationen, passagere sekundäre Fruktosemalabsorption und Laktoseintoleranz aber auch chronisch entzündliche Darmerkrankungen. Bei bestehender chronisch entzündlicher Darmerkrankung kann eine protrahierte Verschlechterung ebenfalls durch infektiöse Erreger wie z. B. CMV oder Clostridien bedingt sein. Dies sollte bei der weiteren Diagnostik bedacht werden.

\section{DGKJ-SY-GE-2}

Chronisch-entzündliche Erkrankungen des Gastrointestinal-Traktes

Friedt $M .^{1}$

'Universitätsklinikum Düsseldorf, Klinik für Allgemeine Pädiatrie, Neonatologie und Kinderkardiologie, Pädiatrische Gastroenterologie, Düsseldorf

Chronisch entzündliche Darmerkrankungen (CED) sind idiopathische Erkrankungen des Gastrointestinaltraktes, die durch einen chronisch rezidivierenden Verlauf des Entzündungsprozesses gekennzeichnet sind. Hierbei sind der Morbus Crohn und die Colitis ulcerosa die häufigsten und bisher am besten definierten Formen der CED. Bereits im Jahre 1761 wurde von einem italienischen Arzt und Pathologen - G. B. Morgagni - das Krankheitsbild einer Ileitis terminalis beschrieben, das dem Bild eines M. Crohn entsprach. In den letzten beiden Jahrzehnten 
hat die Inzidenz um den Faktor 4-5 sowohl im Kindesalter, als auch im Erwachsenenalter zugenommen. Sie liegt zwischen 1,3 und 6 pädiatrischen Patienten pro 100.00o Einwohnern. Die klinische Manifestation der Erkrankung beginnt bei ca. $30 \%$ bereits im Kindes- und Jugendalter und ist somit keine Erkrankung des Erwachsenenalters. Neben den genetischen Faktoren spielen auch Umweltfaktoren (Rauchen) in der Genese eine wichtige Rolle. Die klinische Symptomatik reicht von Dysphagie und Entwicklungsverzögerung bis zur perianalen Entzündung und der fistelnden Manifestation. Die endoskopische Diagnostik mit entsprechender Histopathologie ist weiterhin für die Diagnosesicherung wesentlich. Die fäkalen Entzündungsparameter (fäkales Calprotectin) können in der Abklärung von abdominellen Beschwerden differenzialdiagnostisch weiterhelfen. In der Therapie haben sich neben der enteralen Ernährungstherapie und Steroiden zur Remissionsinduktion die Behandlung mit Immunsuppressiva (Azathioprin/Mehtotrexat) und Biologika (die anti-TNF-Antikörper Infliximab und Adalimumab) etabliert und führen in der Mehrzahl der behandelten Patienten zur klinischen Beschwerdefreiheit.

\section{Kinderkardiologie}

\section{DGKJ-SY-K-2}

Der plötzliche Herztod im Kindes- und Jugendalter - was steckt dahinter?

Donner B.C. ${ }^{1}$

'Universitätsklinikum Düsseldorf, Klinik für Allgemeine Pädiatrie, Neonatologie und Kinderkardiologie, Kinderkardiologie, Düsseldorf

Der plötzliche Herztod im Kindes- und Jugendalter ist mit 10\% aller Todesfälle zwar selten, aber für die betroffenen Familien von großer Tragik. Die häufigsten Ursachen sind angeborene Herzrhythmusstörungen und strukturelle Herzerkrankungen wie zum Beispiel Kardiomyopathien. Patienten haben eine erhöhte Vulnerabilität für Herzrhythmusstörungen aufgrund von Mutationen in Genen, die für Ionenkanäle, assoziierte Proteine oder Strukturproteine des Kardiomyozyten kodieren. Meist handelt es sich um Erkrankungen mit inkompletter Penetranz und variabler Expression. Daher ist oft eine arrhythmogene Synkope oder der plötzliche Herztod die erste klinische Manifestation. Für das Long-QT Syndrom 1, die arrhythmogene rechtsventrikuläre Dysplasie und die polymorphe katecholaminerge ventrikuläre Tachykardie sind typischerweise sportliche Aktivität oder emotionale Erregung Auslöser einer ventrikulären Tachykardie. Im Gegensatz dazu treten beim LongQT Syndrom 3 fatale Herzrhythmusstörungen eher bei niedrigen Herzfrequenzen in Ruhe auf.

Der Vortrag möchte auf die genetischen Grundlagen der häufigeren Ionenkanalerkrankungen, Kardiomyopathien und anderer angeborener Erkrankungen wie z. B. dem Marfan-Syndrom, die mit einem erhöhten Risiko für einen plötzlichen Herztod vergesellschaftet sind, eingehen Zuhörer sollen für diskrete anamnestische Hinweise, die auf das Vorliegen einer angeborenen Herzrhythmusstörung oder strukturellen Herzerkrankung hindeuten, sensibilisiert werden. Möglichkeiten und Grenzen des EKGs und der genetischen Diagnostik und die Bedeutung von Screening Programmen werden thematisiert. Ebenso werden medikamentöse Therapieansätze, die Indikationen für einen automatischen implantierbaren Kardioverter/Defibrillator und Empfehlungen für sportliche Aktivität angesprochen.

\section{DGKJ-SY-K-3}

\section{Moderne Herzinsuffizienztherapie}

Stiller B. ${ }^{1}$

${ }^{1}$ UHZ Freiburg Bad Krozingen, Freiburg

Die Herzinsuffizienz im Kindesalter kann Folge angeborener oder erworbener Herzerkrankungen sein. Sie tritt mit Volumen- oder Druckbelastung oder auch als Folge einer eingeschränkten Funktion des Myokards auf und kann in kardiogenem Schock und Tod enden. Diese Verläufe sind bei Kindern mit dilatativer Kardiomyopathie, fulminanter Myokarditis und vereinzelt nach Herzoperationen oder bei Kindern mit angeborenen Herzfehlern und chronischen Verläufen bekannt. In diesem Vortrag werden kurz die Ursachen und Pathomechanismen der kindlichen Herzinsuffizienz, dann ausführlich die (neuen) medikamentösen therapeutischen Optionen und zuletzt kurz die heutigen Möglichkeiten des mechanischen Kreislaufersatzes zusammengefasst.

\section{Kinder und Jugendliche auf der Flucht}

\section{DGKJ-SY-ÄO-2 \\ Transkulturelle Aspekte in der psychotherapeutischen Arbeit mit Familien, Kindern und Jugendlichen}

Schröder M. ${ }^{?}$

'LVR-Klinikum Düsseldorf, Psychosomatische Institutsambulanz, Düsseldorf

Im Vortrag werden Besonderheiten in der psychotherapeutischen Behandlung von Familien, Kindern und Jugendlichen mit Fluchthintergrund aufgezeigt und mögliche Lösungsansätze skizziert: Was ist zu beachten bei der Diagnostik von psychischen Störungen, was kann hilfreich sein im Umgang mit Sprachbarrieren und welche Aspekte sind in der Interaktion mit Familien von zentraler Bedeutung?

\section{DGKJ-SY-ÄO-4}

STAY! - Kinder- und Schwangerenbetreuung: Erfolge und Herausforderungen

Joel S. ${ }^{1}$

'Praxis, Düsseldorf

5 Jahre alt ist STAY! - Düsseldorfer Flüchtlingsinitiative - in diesem Jahr geworden. Menschen ohne Papiere erhalten seitdem von Mitgliedern des Vereins neben einer Sozial- und Rechtsberatung eine medizinische Versorgung, zu der sie ohne Krankenversicherungskarte keinen Zugang hätten.

Ein Netz von u. a. ÄrztInnen verschiedener Fachrichtungen, Hebammen, PhysiotherapeutInnen und PsychologInnen sorgt für die erforderliche Diagnostik und Therapie. Ein Schwerpunkt der Tätigkeit liegt in der kontinuierlichen Betreuung schwangerer Frauen ohne Papiere, von der Erstvorstellung in den Büroräumen der Organisation bis zur Entbindung im Krankenhaus. Selbstverständlich vermitteln wir - falls gewünscht - Kontakte zu niedergelassenen KinderärztInnen, um die Betreuung des Nachwuchses sicherzustellen.

Der Vortrag soll die Geschichte, Gegenwart und Hoffnungen des Projektes modellhaft präsentieren, verbunden mit der Idee, irgendwann in der Zukunft überflüssig zu werden, weil „Kein Mensch ist illegal“. 


\section{Immunologie (2) - Management von Infektanfälligkeit}

\section{DGKJ-SY-PI2-2}

Möglichkeiten und Grenzen unspezifischer Immunstimulation

\section{Wahn V. ${ }^{1}$}

${ }^{1}$ Klinik für Pädiatrie m. S. Pneumologie und Immunologie, Berlin

Hintergrund. Pflanzliche Immunstimulanzien, Pharmaka und Prä-/ Probiotika werden von verschiedenen Herstellern zur „Stärkung“ des Immunsystems angeboten. Diese „Stärkung“ soll zu einer reduzierten Häufigkeit sowie zu einem reduzierten Schweregrad von banalen Infektionen führen. Der Wunsch, diese Ziele zu erreichen, ist verständlich, zumal Krankheitstage bei Kindern das Familienleben erheblich durcheinander bringen können. Hier sollen ein paar Wirkprinzipien diskutiert werden:

Pflanzliche Immunstimulanzien:

- Echinacea

- Pelargonium

Mikrobielle Produkte:

- Bakterienlysate

- Ribosomen-Präparationen

Probiotika (Präbiotika, Synbiotika)

Ergebnisse. Einige Studien an Erwachsenen und Kindern werden dazu diskutiert. Sie zeigen, dass es Studien mit negativen und positiven Ergebnissen, gibt, wobei quantitativ die Effekte sicher weit hinter dem zurück bleiben, was Eltern davon erwarten. Die Risiken sind nach derzeitiger Datenlage allerdings gering. Von einer „Indikation“ kann also kaum die Rede sein, der Einsatz von Immunstimulanzien basiert eher auf einer im Einzelfall vertretbaren Ermessensentscheidung. Viel wichtiger scheint im Umgang mit infektanfälligen Kindern die Frage: Könnte das Kind an einem angeborenen Immundefekt leiden? Haben wir Anhaltspunkte für zu häufige, zu schwere, destruierende oder opportunistische Infektionen? Ist das der Fall, muss eine entsprechende Diagnostik gemacht werden, und Immunstimulantien haben da nichts zu suchen.

Fazit.

- Wenn Kinder keinen Immundefekt haben, sind sie immunologisch gesund. Muss man gesunde Kinder überhaupt behandeln?

- Bei echten Immundefekten müssen spezifische Therapien eingesetzt werden

- Der klinische Effekt aber ist gering und entspricht meist nicht der Erwartung

\section{Sonntag, 15.09.2013}

\section{Kinderernährung und Prävention: von der Forschung in die Anwendung}

\section{DGKJ-SY-KE-1}

Alkalisierende Ernährung in Kindheit und Adoleszenz - präventivmedizinisch ohne Belang?

\section{Krupp D. ', Remer T.'}

'University of Bonn, DONALD Study at the Research Institute of Child Nutrition, Dortmund

Der menschliche Säure-Basen-Haushalt wird durch die Ernährung maßgeblich beeinflusst. Während der Abbau sulfathaltiger Aminosäuren aus (tierischem) Protein sowie phosphatreiche Lebensmittel die Nettosäurebelastung des Körpers erhöhen, trägt eine erhöhte Zufuhr v. a. von Kalium und Magnesium, insbesondere aus Obst und Gemüse, zu einer messbar alkalisierenden Wirkung bei. Besteht eine erhöhte ernährungsbedingte Protonenbelastung über einen längeren Zeitraum, können Säure-Basen-abhängige Prozesse nachteilig beeinflusst werden. Während eine Alkalitherapie im Fall einer manifesten metabolischen Azidose anerkanntermaßen zur Behebung endokriner und metabolischer Störungen beiträgt, wird die potentielle präventivmedizinische Bedeutung einer nutritiven Vermeidung von sogenannten milden, subklinischen Azidosen kontrovers diskutiert. Da die auch durch Nahrungs-Protonenbelastung forcierbaren Hypercalci- und Hypocitraturien zu den häufigsten metabolischen Störungen bei Kindern und Jugendlichen mit Harnsteinen zählen, kann eine alkalisierende Ernährung, die sowohl zu einer erhöhten Citratexkretion als auch einer reduzierten Calciumexkretion beiträgt, dass Harnsteinrisiko im Kindesalter senken. Trotz insgesamt noch nicht zufrieden stellender Datenlage gibt es deutliche Hinweise darauf, dass eine reduzierte nutritive Säurebelastung im Wachstumsalter mit erhöhter Knochenstabilität, niedrigerem Blutdruck sowie einem reduzierten Risiko für die Entwicklung einer nichtalkoholischen Fettleber bzw. einer Insulinresistenz einhergeht. Einflüsse einer reduzierten Säurebelastung des Organismus auf die Nierenfunktion sowie verschiedene endokrine Systeme, unter anderem den Glucocorticoidstoffwechsel und die somatotrope Achse, liefern potentielle Erklärungsansätze für die beobachteten Zusammenhänge.

\section{DGKJ-SY-KE-2}

Alles auf Zucker? - Kohlenhydratqualität birgt noch mehr Präventionspotenzial

\section{Goletzke J.', Buyken A.E.'}

'IEL-Ernährungsepidemiologie, Rheinische Friedrich-Wilhelms-Universität Bonn, DONALD Studie am Forschungsinstitut für Kinderernährung, Dortmund

Es wird kontrovers diskutiert, ob eine hohe Zufuhr an Kohlenhydraten mit ungünstigen Effekten auf das Risiko für Übergewicht, Diabetes und weitere chronische Erkrankungen assoziiert ist. Bei Kindern und Jugendlichen ist laut der von der DGE veröffentlichten Kohlenhydrat-Leitlinie vor allem bei bereits übergewichtigen Kindern ein hoher Konsum an zuckergesüßten Getränken mit einem erhöhten Adipositasrisiko verbunden. Der Einfluss von zugesetztem Zucker insgesamt ist für Kinder und Jugendliche jedoch unklar. Neue Analysen für Erwachsenen zeigen, dass beobachtete Gewichtsabnahmen durch eine reduzierte Zuckeraufnahme allein aus einer Senkung der Energiezufuhr resultieren.

Neben zugesetztem Zucker gibt es noch weitere Aspekte der Kohlenhydratqualität, die ein Präventionspotenzial in der Ernährung von Kindern und Jugendlichen bergen: Hinweise für einen protektiven Effekt einer hohen Ballaststoff- und Vollkornzufuhr gab es bisher nur bei Risikogruppen wie übergewichtigen lateinamerikanischen Jugendlichen. Der oftmals für die günstige Wirkung von Ballaststoffen diskutierte Mechanismus einer verringerten Blutzuckerantwort wird durch den glykämischen Index sehr viel genauer abgebildet. Besonders für den immer größer werdenden Teil von Menschen mit einer gestörten Insulinresistenz sowie in Phasen einer physiologisch vorkommenden Insulinresistenz wie der Pubertät könnten wiederkehrende Blutzuckerspitzen ungünstig sein. So konnte anhand von Daten der DONALD-Studie erstmals gezeigt werden, dass ein gewohnheitsmäßig hoher GI in der Ernährung Jugendlicher mit erhöhten Risikomarkern für Typ-2-Diabetes im jungen Erwachsenenalter zusammenhängt. Kinderärzte sollten also auf eine Reduzierung des Soft-Drink-Konsums sowie auf die Blutzuckerwirksamkeit verschiedener Lebensmittel hinweisen. 


\section{DGKJ-SY-KE-3}

\section{Mittagessen in der Schule - macht es Kinder schlau oder müde?}

Müller K.', Libuda L. ', Kersting M. ${ }^{1}$

'Forschungsinstitut für Kinderernährung, Dortmund

Fragestellung. Mit dem Angebot eines Mittagessens in Ganztagsschulen geht vielfach die intuitive Erwartung einher, dass die kognitive Leistung der Schüler gesteigert würde. In der Cognition Intervention Study Dortmund (COGNIDO Studie) ${ }^{*}$ wurde untersucht, inwiefern bei Schulkindern zu Beginn des nachmittäglichen Unterrichts ausgewählte Parameter der kognitiven Leistungsfähigkeit durch das Auslassen der Mittagsmahlzeit beeinflusst werden.

Methodik. Schulklassen der 6. Jahrgangsstufe einer großen Gesamtschule in Gelsenkirchen wurden randomisiert in zwei Gruppen eingeteilt und im Cross-Over-Design jeweils zweimal getestet. Am ersten Testtag erhielt Gruppe 1 zu Mittag ein standardisiertes Essen ad libitum, Gruppe 2 nur Wasser. Am zweiten Testtag jeweils eine Woche später bekam Gruppe 2 das Mittagsessen angeboten und Gruppe 1 Wasser. An beiden Testtagen wurden unmittelbar nach der Mittagspause mittels des computergestützten Wiener-Test-Systems Parameter der Kognition wie die tonische Alertness, selektive Aufmerksamkeit und die Gedächtniskapazität erfasst. Der Effekt des Mittagessens wurde anhand des Grizzle Modells für Cross-Over-Studien mittels ANOVA ausgewertet.

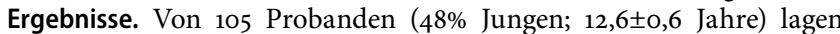
Daten für beide Testtage vor. Außer einer Nebenvariable der tonischen Alertness war kein Parameter der Kognition signifikant mit dem Verzehr der Mittagsmahlzeit assoziiert.

Diskussion. In der COGNIDO-Studie wurden bei Verzicht auf das Mittagsessen keine praxisrelevanten Effekte auf einfache Parameter der kognitiven Leistungsfähigkeit von Schulkindern festgestellt. Ob „höhere“ kognitive Prozesse (exekutive Funktionen) beeinflusst werden könnten, muss in weiteren experimentellen Studien getestet werden.

*Gefördert durch die Uniscientia Stiftung.

\section{DGKJ-SY-KE-4}

Alles Omega? - Was wissen und tun Mütter bei der Säuglingsernährung? Ergebnisse einer Bevölkerungsbefragung als Teilprojekt der PINGU-Studie*

\section{Libuda L.', Stimming M. ${ }^{1}$, Mesch C. ${ }^{1}$, Kersting M. ${ }^{1}$}

'Forschungsinstitut für Kinderernährung, Dortmund

Fragestellung. Die kognitive und visuelle Entwicklung von Säuglingen könnte durch die Versorgung mit mehrfach ungesättigten Omega-3Fettsäuren (n-3 PUFA) beeinflusst werden, die im Wesentlichen über Muttermilch, Rapsöl und Fisch erfolgt. Anhand einer Bevölkerungsbefragung wurde untersucht, wie gut Mütter in Deutschland über n-3 PUFA informiert sind und ob der Wissensstand der Mutter die Versorgung des Säuglings mit n-3 PUFA reichen Lebensmitteln beeinflusst. Methodik. Befragt wurden 985 Mütter aus einem Online-Panel der Kantar Health GmbH, die zum Zeitpunkt der Befragung im Dezember 2010 Kinder im Alter von 5 bis 36 Monaten hatten. Thematisiert wurden unter anderem Ernährungsverhalten, Einstellungen und Kenntnisse hinsichtlich n-3 PUFA. Um Repräsentativität zu gewährleisten wurden die Daten gewichtet.

Ergebnisse. Insgesamt 94,3\% der Mütter gaben an, von dem Begriff n-3 PUFA gehört zu haben. $27,6 \%$ haben alle Wissensfragen zu n-3 PUFA richtig beantwortet, 19,7\% wussten nichts über n-3 PUFA. Mütter mit fundiertem Wissen begannen häufiger zu stillen als Mütter ohne solche Kenntnisse ( $83,5 \%$ vs. $68,8 \%$ ), verwendeten in der Schwangerschaft häufiger Fischöl-Supplemente (33,8\% vs. 23,2\%) und häufiger Rapsöl für die Beikost (73,5\% vs. 26,2\%). Unabhängig vom Wissenstand setzten nur etwa ein Viertel der Mütter Fisch in der Beikost ein.

Diskussion. Das Wissen zur Bedeutung von n-3 PUFA bei Müttern in Deutschland ist verbesserungsbedürftig. Mütter mit fundiertem Wissen scheinen ihre Säuglinge besser mit n-3 PUFA reichen Lebensmitteln zu versorgen. $\mathrm{Ob}$ eine alleinige Wissensvermittlung als Public Health Ansatz zu einer verbesserten n-3-PUFA-Versorgung beiträgt, muss in Interventionsstudien untersucht werden.

\section{Primärversorgung und Schnittstellen: Zusammenarbeit zwischen Praxis und Klinik (1)}

\section{DGKJ-SY-PV1-1 \\ DAKJ-Versorgungsstudie: Womit werden Kinder und Jugendliche in den Praxen der pädiatrischen Grundversorgung vorgestellt?}

\section{Jäger-Roman E. ', Fegeler U. ${ }^{2}$, Martin R. ${ }^{3}$, Nentwich H.-J.'}

'Deutsche Akademie für Kinder und Jugendmedizin, Berlin, ${ }^{2}$ Berufsverband der Kinder- und Jugendärzte, Köln, ${ }^{3}$ Dresden International University, Dresden

Hintergrund. Die Deutsche Akademie für Kinder- und Jugendmedizin (DAKJ) hat 2010 eine Erhebung veranlasst, die u. a. klären sollte 1. welchen medizinischen Beratungsbedarf Familien mit Kindern und Jugendlichen haben, 2. welche akuten, chronischen, präventiven und sozialpädiatrischen Diagnosen diesen Vorstellungs-Anlässen durch ambulant tätige Allgemeinpädiater zugeordnet werden und 3. wie viel Zeit Ärzte dafür aufwenden.

Methoden. Dazu haben 29 niedergelassene Kinder- und Jugendärzte kontinuierlich und zusätzlich zu ihrer Praxisdokumentation 1 Jahr lang Vorstellungsanlässe, Diagnosen und Arzt-Patienten-Kontaktzeiten von 51.188 Patienten dokumentiert. 53,3\% aller Arzt-Patientenkontakte betrafen sog. Erst-Beratungsanlässe, 30,3\% Vorstellungen zu Präventionsmaßnahmen, 10,2 Wiedervorstellungen und 6.2\% andere Vorstellungen. Diagnosen zu den Beratungsanlässen betrafen zu 65\% Infektionserkrankungen, 13,1\% Hauterkrankungen, 8,7\% Störungen aus dem Bereich „Neue Morbidität“ und viele andere. Der Anteil der Patienten mit einer chronischen Grunderkrankung stieg kontinuierlich über die Altersgruppen, im Jugendalter betrug er $25 \%$.

Ergebnisse. Pädiater in der Grundversorgung brauchen mehr Zeit für Prävention und Beratungen aus dem Bereich der „Neuen Morbidität“ als für die Gesamtheit der Patienten mit akuten Erkrankungen.

Fazit. Das ambulante pädiatrische Versorgungsspektrum unterscheidet sich deutlich von dem stationärer Einrichtungen. Dies sollte in der pädiatrischen Weiterbildung sowohl inhaltlich als auch praktisch in Form der Weiterbildungsstätte Berücksichtigung finden.

\section{DGKJ-SY-PV1-3}

\section{Aufgabe, Auftrag und Auftraggeber in der Pädiatrie}

Nolte S.H.'

\section{${ }^{1}$ Gemeinschaftspraxis, Marburg}

Die Wahrnehmung des Kindswohls sollte erste Aufgabe der Pädiatrie sein und im Zentrum aller ärztlichen Entscheidungen stehen. Intraund interindividuelle Interessenkonflikte materieller, sozialer, intellektueller oder persönlichkeitsbedingter Natur können jedoch mit dem „Kindswohl“ kollidieren, zumal alle Versuche einer objektiven Definition eines Kindswohls im Sinne des „,best interest of the child“ bestreitbar sind.

Entscheidungen in der Pädiatrie werden weitgehend „paternalistisch“ gefällt, eine gemeinsame Entscheidungsfindung („shared decision making") im lebensgeschichtlichen Kontext ist angesichts einer Übermacht vermeintlicher medizinischer Notwendigkeiten im Rahmen von Forschung, Lehre, Krankenversorgung und zunehmend auch „Wertschöpfung" schwierig. Ein gesellschaftlicher Diskussionsprozess ist notwendig und durch die Patientenrechtsgesetzgebung geboten, der auch den Respekt vor der graduell möglichen Zustimmungsfähigkeit (,assent") der betroffenen Minderjährigen einbeziehen muss. 
Diese banal erscheinenden Fakten sind im Alltag schon bei einfachen medizinischen Maßnahmen wie Impfungen oder Blutabnahmen bedeutsam, erst recht aber bei schwierigen Entscheidungen bei chronisch kranken Kindern oder im Rahmen der Palliativbetreuung. Eine bessere Entscheidungsqualität durch Optimierung der Arzt-Patient-Angehörigen Kommunikation und eine ehrliche Kommunikation der Wahrscheinlichkeiten patientenrelevanter Ergebnisse sowie von Alternativen ist $u$. a. durch die neue Patientenrechtsgesetzgebung ( $\$ 630$ BGB vom 26.2.2013) gesetzlich gefordert.

Kenntnisse vom Konzept der „präferenzsensitiven Entscheidung“ sowie die Schulung eines integeren Urteilsvermögens zur Erkennung und Vermeidung von Interessenkonflikten gehören in die pädiatrische Ausund Weiterbildung.

\section{DGKJ-SY-PV1-4}

Strukturierte Weiterbildung in der allgemeinen ambulanten Pädiatrie: anvertraute professionelle Tätigkeiten

\section{Fehr F.', Buschmann J.' \\ 'Gemeinschaftspraxis für Kinderheilkunde und Jugendmedizin, Sinsheim}

Die Weiterbildung in der Pädiatrie wird von der Weiterbildungsordnung der jeweiligen Landesärztekammer bestimmt und an jeder Weiterbildungsstätte individuell operationalisiert. Bislang existiert kein gut begründeter und breit konsentierter Entwurf. Die Arbeitsgruppe Weiterbildung der Deutschen Gesellschaft für Allgemeine Ambulante Pädiatrie DGAAP hat eine Literaturrecherche zum Thema durchgeführt. Dabei haben sich Hinweise verdichtet, dass das Konzept der „entrustable professional activities“ des niederländischen Bildungswissenschaftlers Olle ten Cate in besonderem Maße den Bedürfnissen entsprechen. Unter einer „entrustable professional activity“ wird eine abgeschlossene wichtige Handlung verstanden, zum Beispiel: „Vorsorgeuntersuchung am bislang gesunden Kind“ oder „Impfung“. So kristallisieren sich etwa 50 Themen (Aktivitäten) für ein Fachgebiet heraus. Bei professionellen Aktivitäten werden dem Weiterzubildenden zunehmend mehr Aktivitäten ohne direkte Supervision zugetraut und anvertraut. Dabei entsteht mosaikartig ein Bild von Meisterschaft von immer mehr Schlüsselkompetenzen im relevanten praktischen Kontext. Nicht von der (Bildungs-) Zeit, sondern standardisiertes Ergebnis steuert die Zertifizierung.

Die DGAAP schlägt ein System von 12 Aktivitäten für die allgemeine ambulanten Pädiatrie vor, schlüsselt sie detailliert auf und entwickelt dadurch eine Landschaft des Lernens, die nicht nur alle bedeutsamen Bereiche abbildet, sondern auch deren Bedeutung erkennen lässt und Meilensteine zunehmenden Kompetenzerwerbs ausweist.

\section{Regenerative Therapien bei nichtonkologischen Erkrankungen in der Pädiatrie}

\section{DGKJ-SY-RT-5 \\ Einsatz von allogenem Nabelschnurblut bei der Behandlung häma- tologischer und nichthämatologischer Erkrankungen}

Kögler G.

'Universitätsklinikum Düsseldorf, Düsseldorf

Blutbildende Stammzellen „allogener“ Nabelschnurblutspenden aus Nabelschnurblut (CB)-Banken werden seit 1993 erfolgreich zur Behandlung von mehr als 70 hämatologischen Indikationen (Akute Leukämien, Immundefekte, Stoffwechselerkrankungen, Hämoglobinopathien, genetische Defekten,) eingesetzt. Seit der ersten Nabelschnurbluttransplantation wurde allogenes (unverwandtes und verwandtes CB) in über 30.000 Fällen verwendet. CB ist im Vergleich zu Knochenmark/Peripheren Stammzellen schneller, im Notfall innerhalb von zwei Werktagen verfügbar. Aufgrund der immunologischen Unreife des Nabelschnurblutes kann es auch mit gutem Erfolg transplantiert werden, wenn es nicht komplett mit dem Empfänger in den HLA-Gewebe-Merkmalen übereinstimmt, ohne dass eine schwere akute GvHD induziert wird. Entscheidend für den zunehmenden Erfolg der unverwandten allogenen Stammzelltransplantation und deren Einsatz bei erwachsenen Patienten war einerseits die Fokussierung der Stammzellbanken auf zellreiche Produkte sowie seit 2005 die Etablierung der Nabelschnurblut-Doppeltransplantation (zeitgleiche Transplantation zweier passender Transplantate für einen Patienten. Die Düsseldorfer Jose Carreras Stammzellbank hat bereit 1040 Transplantate (Mai 2013) weltweit für Patienten zur Verfügung gestellt und mehr 23.00o Spenden kryokonserviert. Zusätzlich enthält Nabelschnurblut neben den hämatopoietischen auch kleine Mengen nichthämatopoietischer Stammzellen, unter anderem Endothelzellen, mesenchymale Stromazellen (MSC) und unrestringierte Stammzellen (USSC), die möglicherweise eine Rolle bei der Behandlung von degenerativen und oder primär immunologischen Erkrankungen spielen können. Kritisch diskutiert wird der Einsatz bei Frühkindlichen Hirnschäden, Diabetes Typ 1und Herzklappenrekonstruktion.

\section{Infektionen unter Immunsuppression}

\section{DGKJ-SY-I3-1}

Therapie der HIV-Infektion im Kindesalter

Niehues $T^{?}$

'HELIOS Klinikum Krefeld, Krefeld

Durch die Grundlagenforschung wurde es möglich, den Replikationszyklus von HIV zu verstehen und potentielle Angriffspunkte der HI-Viren für Medikamente zu identifizieren. Es stehen 5 Substanzklassen zur Verfügung: nukleosidale reverse Transkriptase-Inhibitoren (NRTI), nicht-nukleosidale reverse Transkriptase-Inhibitoren (NNRTI), Protease-Inhibitoren (PI), Entry-Inhibitoren und Integrase-Inhibitoren. Voraussetzung für die erfolgreiche Therapie sind die Kenntnis der Pharmakokinetik der eingesetzten Medikamente und die Adhärenz, die besonders im Jugendlichenalter Probleme bereiten kann. Gerade im Neugeborenen-, Säuglings- und Kleinkindalter fehlen Pharmakokinetikdaten. Multizentrische, internationale Studien - z. B. die PENTA (Pediatric European Network Trial in AIDS)-Gruppe - sorgen dafür, dass diese Probleme bei Kindern und Jugendliche in gut geplanten und regelrecht durchgeführten klinischen Studien systematisch angegangen werden. Schließlich stehen von der HIV-Infektion betroffene Familien in der ständigen Gefahr auf Grund der hohen Stigmatisierung sozial isoliert zu werden. Daher ist eine enge psychosoziale Betreuung erforderlich, leider sind hier die notwendigen Ressourcen sehr limitiert.

Seitdem antiretrovirale Medikamente in 2-, 3- oder 4-fach Kombination verabreicht werden (sog. hochaktive antiretrovirale Therapie HAART), ist die tödliche Bedrohung aus der HIV-Infektion herausgenommen worden. Kinder und Jugendliche können mit wenigen Ausnahmen ein weitgehend normales Leben führen, vorausgesetzt sie erhalten eine umfassende, insbesondere auch psychosoziale Betreuung.

\section{DGKJ-SY-I3-3 \\ Pilzinfektionen bei immunsupprimierten Kindern und Jugend- lichen}

\section{Lehrnbecher T.}

'University of Frankfurt, Pediatric Hematology and Oncology, Frankfurt

Invasive Pilzinfektionen (IFI) sind eine wichtige Ursache von Morbidität und Mortalität immunsupprimierter Kinder und Jugendlicher. Patienten mit akuter myeloischer Leukämie oder nach allogener Stammzelltransplantation haben ein hohes Risiko für eine IFI mit einer Inzidenz von $>\mathbf{2 0} \%$. Entsprechend kürzlich erschienener Empfehlungen kann für diese Patienten eine systemische antimykotische Prophylaxe 
empfohlen werden, wobei verschiedene Substanzen aus unterschiedlichen Substanzklassen entsprechend Applikationsart (oral/intravenös) und Nebenwirkungsprofil individuelle Vor- und Nachteile bieten. Die klinischen Zeichen einer IFI sind meist uncharakteristisch, und die frühzeitige Diagnose einer IFI ist äußerst schwierig. Während der Galactomannan (GM)-Test bei Kindern die gleiche Wertigkeit wie bei Erwachsenen aufweist, gibt es kaum pädiatrische Daten zum $\beta$-D-Glucan. Computertomographische Befunde scheinen sich zwischen Kindern und Erwachsenen zu unterscheiden; so fehlen gerade bei jüngeren Kindern die bei Erwachsenen typischen radiologischen Zeichen einer invasiven pulmonalen Aspergillose wie Halo- oder Luftsichelzeichen, wohingegen sich uncharakteristische Befunde wie Konsolidierungen finden. Während bei Kindern die empirische antimykotische Therapie gut etabliert ist (Beginn einer antimykotischen Therapie bei granulozytopenen Kindern mit Antibiotika-refraktärem Fieber), gibt es kaum pädiatrische Daten zur präemptiven antimykotischen Therapie, bei der zur Indikation zusätzlich ein positiver GM-Test und/oder Lungeninfiltrate gefordert werden. Zur Therapie nachgewiesener IFIs kommen verschiedene Medikamente in Betracht, wobei für einige dieser Substanzen weder eine pädiatrische Zulassung noch eine pädiatrische Dosisempfehlung besteht.

\section{Primärversorgung und Schnittstellen: Zusammenarbeit zwischen Praxis und Klinik (2)}

\section{DGKJ-SY-PV2-1}

\section{Professioneller Umfang mit Gewalt in Familien}

\section{Kratzsch W. ${ }^{1}$}

'Stiftung Deutsches Forum Kinderzukunft, Düsseldorf

Fragestellung. Familiäre Gewalt, synonym mit dem Begriff „Häusliche Gewalt“, ist ein bislang in der Pädiatrie und Sozialpädiatrie (Lehrbücher, Kongresse) wenig beachtetes Thema, obwohl diese Gewaltform häufig in der Praxis vorkommt und auf die kindliche Entwicklung und die Familie erhebliche psychische und neurobiologische Auswirkungen haben kann. Die Bedeutung des Themas für die Kinderheilkunde soll in dem Referat dargestellt werden.

Material und Methode. Der Begriff häusliche Gewalt/familiäre Gewalt wird definiert, der Zusammenhang zur Kindesmisshandlung und Partnergewalt dargestellt und das Vorgehen bei familiärer Gewalt erläutert. Ergebnisse. Aktuelle Forschungsergebnisse zur Phänomenologie, Häufigkeit, Ursachen und Auswirkungen sowie erprobte Präventionsprogramme werden dargestellt. An einem Praxisbeispiel wird an der Schnittstelle von Praxis und Klinik gezeigt, 1. welche Stolpersteine bestehen, wenn Gewalt an Kindern und ihren Müttern erfolgt und beide gemeinsam ambulant und stationär behandelt werden müssen, 2. wie diese überwunden werden können und 3. welche rechtlichen Bestimmungen zum Verfahren bei häuslicher Gewalt bestehen.

Diskussion und Schlussfolgerung. Häusliche Gewalt ist ein Querschnittsthema der Pädiatrie, Sozialpädiatrie, Frauenheilkunde, Chirurgie, Rechtsmedizin und Familienmedizin. Es sollte zukünftig in der Lehre, Fortbildung und im klinischen Alltag stärkere Beachtung finden. Abschließend werden Wege in der Praxis (Schnittstelle Klinik und ambulante Versorgung) beschrieben, wie im Falle von familiärer Gewalt/ häuslicher Gewalt akut, aber auch präventiv vorgegangen werden kann.

\section{DGKJ-SY-PV2-2}

Jugendliche mit erhöhtem Risiko für Süchte identifizieren. Sucht sucht und Sucht siecht...

\section{Büsching U. ${ }^{1}$}

'Praxis, Bielefeld

Wenn die reale Welt (zu viele) Wünsche offen lässt, werden Angebote, die die negativen Seiten des realen Lebens kompensieren, hoch attraktiv und dominieren schließlich das Leben. So erhalten stoffgebundene und nicht stoffgebundene Süchte eine hohe Bedeutung, verschaffen für einen Augenblick Zufriedenheit, Glück und lenken von den Problemen der realen Welt ab. Die Flucht in die Süchte ist bequemer, schneller, erfolgversprechender als die eigene aktive Verbesserung der Lebensverhältnisse.

Wenn denn diese Jugendlichen überhaupt bereit sind, zu einem Gespräch mit einem Jugendarzt zu kommen, dann fragen wir nach den Bewältigungsanforderungen, wie die Jugendlichen damit umgehen welche Strategien sie haben. Wir fragen nach den Gewohnheiten der Eltern, die, trotz allem, - negative - Vorbilder sind und wir fragen nach den Dingen, die Spaß machen und wie viel Zeit Jugendliche damit zubringen.

Stoffgebundene Süchte sind illegal und oft teuer. Nichtstoffgebundene Süchte sind legal, schnell erreichbar, kosten wenig. War der Medienkonsum zunächst eine positive Erfahrung, so wird der Konsum gesteigert, wenn man im realen Leben immer mehr negative Erlebnisse hat. Deshalb wurde der Medienmissbrauch in den letzten Jahren zu einem ständig ernsteren Problem unsere Jugend. Auch weil zur Bewältigung vieler Entwicklungsaufgaben Jugendlicher Medien geradezu die perfekten Helfer sind. Die Suche nach Informationen, Lösungen aber auch Gleichgesinnten wird durch Medien enorm erleichtert.

Also hat der Gebrauch von Medien auch seine Vorteile. Wie vermitteln wir die Nachteile, wie intervenieren wir bei übermäßigem Gebrauch? Was ist denn übermäßig oder gar Sucht?

\section{DGKJ-SY-PV2-3}

\section{Größe - Gewicht - BMI: Welche Perzentilen sollen wir verwenden?}

Hermanussen $M$. $^{\prime}$

${ }^{1}$ Christian-Albrechts-Universität zu Kiel, Kiel

Fragestellung. In den vergangenen 150 Jahren hat sich das kindliche Entwicklungstempo in Europa um etwa 15\% beschleunigt; Erwachsene sind im Mittel etwa $15 \mathrm{~cm}$ größer; und in vielen Ländern besteht seit Mitte der 1980er Jahre ein signifikanter Anstieg des BMI. Diese Trends sind extrem inhomogen, auch innerhalb desselben Landes: in der Schweiz stieg die mittlere Körperhöhe seit 1891 in manchen Distrikten um $19 \mathrm{~cm}$, in anderen nur um $11 \mathrm{~cm}$. In Deutschland sistiert der Trend in Entwicklungstempo und Körperhöhe, nicht aber der BMI-Trend. Personen mit Migrationshintergrund neigen zu beschleunigter Entwicklung und Adipositas. Nach welchen Kriterien soll man sich für eine bestimmte Längen-, Gewichts- und BMI-Referenztabelle entscheiden.

Material. Heute in Deutschland verwendete Referenztabellen stammen überwiegend aus Zürich (1989), Dortmund (1980/1992), Berlin (1997) oder aus bundesweiten Studien (2011). Es gibt Referenzen für Deutschtürken (2007).

Ergebnisse. Referenztabellen unterscheiden sich. Im Mittel waren 18-jährige Männer in Zürich 177,1 cm, in Dortmund 180,4 cm, in Berlin $179,9 \mathrm{~cm}$, bundesweit 179, o cm groß; erwachsene Deutschtürken messen $175,1 \mathrm{~cm}$. Der mittlere BMI dieser Männer betrug in Zürich 20,2 kg/m2, in Dortmund $20,1 \mathrm{~kg} / \mathrm{m} 2$, in Berlin $20,8 \mathrm{~kg} / \mathrm{m} 2$, bundesweit $21,6 \mathrm{~kg} / \mathrm{m} 2$ und bei Deutschtürken $23,1 \mathrm{~kg} / \mathrm{m} 2$.

Schlussfolgerung. Die Prävalenz von Klein-/Großwuchs und Unter-/ Übergewicht wird stark durch die Entscheidung für eine bestimmte Referenz beeinflusst. Zum Beispiel unter Zugrundelegung der heutigen Berliner Referenzen wird knapp die Hälfte der türkischen Adoleszenten als übergewichtig angesehen. Bemühungen, moderne Software für die 
Aktualisierung und vor allem für die Regionalisierung von Längen-, Gewichts- und BMI-Perzentilen einzuführen, haben derzeit nur Pilotcharakter.

\section{DGKJ-SY-PV2-4 \\ Hodenhochstand: aktueller Stand der Therapie in Deutschland und Umsetzung der AMWF-S2-Leitlinie 2009-2012}

Hrivatakis G. ${ }^{1}$, Astfalk W. ${ }^{2}$, Hartwig A. ${ }^{3}$, Kugler T. ${ }^{4}$, Heim T. ${ }^{1}$, Clausner A. ${ }^{5}$, Frunder A. ${ }^{5}$, Weber H. ${ }^{6}$, Loff S. ${ }^{6}$, Fuchs J. ${ }^{7}$, Ellerkamp V. ${ }^{7}$

${ }^{1}$ Kinderchirurgische Gemeinschaftspraxis, Stuttgart, ${ }^{2}$ Chirurgische Gemeinschaftspraxis, Reutlingen, ${ }^{3}$ Kinderchirurgische Praxis, Stuttgart, ${ }^{4}$ Kinderchirurgische Praxis, Ulm, ${ }^{5}$ Loretto Klinik, Kinderchirurgie, Tübingen, ${ }^{6}$ Olgahospital Stuttgart, Kinderchirurgie, Stuttgart, ${ }^{7} U n i k l i n i k$ Tübingen, Kinderchirurgie und Kinderurologie, Tübingen

Fragestellung. Die existierende, 2011 abgelaufene S2-Leitlinie zur Therapie des Hodenhochstands sieht eine definitive operative Verlagerung der Hoden vor Abschluss des ersten Lebensjahres vor. Eine präoperative Hormontherapie mit LH-RH-Analoga in Kombination mit HCG ist aufgrund der aktuellen Literaturdatenlage innerhalb des ersten Lebensjahres empfohlen. In der vorliegenden Arbeit wurde die Umsetzung der Leitlinie evaluiert.

Methoden. In Zusammenarbeit mit zwei kinderchirurgischen Kliniken und fünf kinderchirurgischen Praxen wurden über den Zeitraum von 2009 bis 2012 sämtliche Fälle von Hodenhochstand retrospektiv ausgewertet. Die Patienten wurden in drei Gruppen eingeteilt: Gruppe I, OP<12 Lebensmonate (LM); Gruppe II, OP 12.-24. LM; Gruppe III, $>24$. LM. Weiterhin wurden die betroffene Seite und die Durchführung einer Hormontherapie evaluiert.

Ergebnisse. Insgesamt wurden 1746 Kinder mit einem primären Hodenhochstand erfasst. Die rechte Seite war in 737 Fällen $(42,4 \%)$ betroffen, die linke Seite in 616 Fällen $(35,2 \%)$ und in 392 Fällen $(22,6 \%)$ bestand ein beidseitiger Hodenhochstand. 293 Kinder $(16,7 \%)$ konnten der Gruppe I zugeteilt werden, 432 Kinder $(24,74 \%)$ der Gruppe II und 1021 Kinder $(58,48 \%)$ der Gruppe III. Eine präoperative Hormontherapie erfolgte bei 116 Patienten der Gruppe I $(6,6 \%)$ und bei 301 Patienten $(17,2 \%)$ der Gruppen II und III.

Diskussion. Ein alarmierend hoher Prozentsatz an Kindern wird erst nach Erreichen des ersten Lebensjahres oder sogar wesentlich später einer chirurgischen Therapie zugeführt. Der Empfehlung der Leitlinie zur Durchführung einer Hormontherapie wird kaum nachgekommen. Neben der ausstehenden Aktualisierung der Leitlinie ist dringend eine konsequentere Anwendung der LL in den pädiatrischen Praxen erforderlich.

\section{Adipositas bei Mädchen als interdisziplinäre Herausforderung}

\section{DGKJ-SY-A3-1 \\ PCOS und andere metabolische und endokrinologische Besonder- heiten adipöser Mädchen}

\section{Wiegand $S{ }^{1}$}

${ }^{1}$ Charité - Universitätsmedizin Berlin, Kinderklinik; Pädiatrische Endokrinologie und Diabetologie, Berlin

Adipöse Mädchen stellen diagnostisch und therapeutisch eine $\mathrm{He}$ rausforderung dar. Sie sind in besonderem Maß von Stigmatisierung betroffen. Als Folge besteht einerseits ein hoher Leidensdruck, andererseits sind diese Jugendlichen aufgrund der hohen Prävalenz an psychosozialer Komorbidität (sozialer Rückzug, Depressivität) schwierig $\mathrm{zu}$ behandeln. Insbesondere in Programmen mit Lifestyle-Intervention benötigen sie oft eine intensive Phase der Aktivierung und Motivationsförderung. Dazu können metabolische Besonderheiten wie z. B. ein polyzystisches Ovarsyndrom (PCOS) mit Zyklusstörungen, Insulinresistenz, Dyslipidämie und/oder Hirsutismus kommen. Die Diagnostik des PCOS erfordert bei (adipösen) Mädchen altersangepasste Kriterien, da das jeweilige Pubertätsstadium und der zeitliche Abstand von der Menarche berücksichtigt werden muss (physiologische Zyklusunregelmäßigkeit bis 2 Jahre nach Menarche). Da die Prävalenz des PCOS nicht nur mit dem Grad der Adipositas assoziiert ist, sondern meist zusätzlich eine familiäre oder ethnische Prädisposition besteht, sind die therapeutischen Ansätze multimodal. Basistherapie ist immer eine konservative Behandlung der Adipositas. Ergänzt wird diese durch entweder eine medikamentöse Therapie zu Verbesserung der Insulin-Resistenz (Metformin)- insbesondere bei Vorliegen eines metabolischen Syndroms, oder/und durch eine antiandrogene Therapie (z. B. orale Antikonzeptiva mit antiandrogener Gestagenkomponente) bei klinisch relevantem Hirsutismus und funktioneller Hyperandrogenämie. Auch aufgrund der starken psychischen Belastung dieser jugendlichen Patientinnen erfordert die Behandlung immer ein multiprofessionelles Team.

\section{DGKJ-SY-A3-2 \\ Verhütung bei Adipositas}

Oppelt P.G.', Heusinger K.', Schulze C.'

'Universitätsfrauenklinik Erlangen, Kinder- und Jugendgynäkologie, Erlangen

Die Beratung jugendlicher Mädchen über Verhütung sollte neben der Darstellung möglicher Verhütungsmethoden auch die Information über Abläufe im weiblichen Zyklus beinhalten. Damit Mädchen auch verstehen können wie die jeweiligen Verhütungsmethoden wirken. Verhütungsmethoden, die für Adoleszentinnen in Frage kommen, sollten sehr sicher, einfach in der Anwendung und wenig Einfluss auf die körperliche Gesundheit haben. Nach wie vor werden bei Erstverordnung vor allem orale Kontrazeptiva gewählt, da sie neben dem guten Verhütungsschutz und der meist guten Verträglichkeit auch positive Nebeneffekte auf häufige Beschwerden der Adoleszentinnen wie Dysmenorrhö, unreine Haut und Zyklusinstabilität haben.

Wenn zusätzlich Vorerkrankungen vorliegen muss bei der Auswahl der Verhütungsmethode diesen zusätzlich Rechnung getragen werden - wie z. B. bei Vorliegen einer Adipositas. Häufig finden wir bei adipösen Mädchen eine Hyperandrogenämie sowie eine Insulinresistenz. So sollten hier Verhütungsmethoden gewählt werden die einen positiven Effekt auf eine Hyperandrogenämie haben. Leider gibt es keine guten Studien die die Einflüsse einzelner Verhütungsmethoden bei Adoleszentinnen mit Übergewicht oder Adipositas vergleichen.

Insgesamt können bei adipösen Mädchen orale Kontrazeptiva zum Einsatz kommen und zwar mit antiandrogener Wirkung, außer es liegt bereits eine Hypertonie vor. In diesem Fall oder bei ausgeprägter Adipositas sollte über eine intrauterine Kontrazeption nachgedacht werden und ggf. Metformin zur Behandlung der Insulinresistenz, aber auch der Hyperandrogenämie in Erwägung gezogen werden.

\section{DGKJ-SY-A3-4}

\section{Adipöse Mädchen mit Migrationshintergrund - Anforderungen an} eine erfolgreiche Therapie

Rücker P.

${ }^{1}$ Charité - Universitätsmedizin Berlin, SPZ interdisziplinär - AdipositasSprechstunde, Berlin

Fragestellung. Repräsentative Untersuchungen wie der Kinder- und Jugendsurvey (Kurth und Schaffrath Rosario, 2007) zeigen, dass der Migrationshintergrund eine entscheidende Rolle für das Adipositasrisiko spielt. Besonders Mädchen mit Migrationshintergrund sind eine Herausforderung für Therapeutenteams. Im SPZ der Charité - Universitätsmedizin Berlin wurde untersucht, inwieweit sich deutsche und 
türkische Familien in der Adipositas-Betreuung unterscheiden. Auch geschlechtsspezifische Unterschiede wurden herausgearbeitet.

Material und Methoden. Ausgewertet wurden Daten von 612 Patient/ innen, die zwischen Januar 2003 und Oktober 2008 erstmalig in der Sprechstunde vorgestellt wurden. Die Daten der Kohorte wurden im Hinblick auf Unterschiede bezüglich des Migrationshintergrunds mit SPSS berechnet, weiterhin wurden qualitative Interviews mit Jugendlichen geführt und ausgewertet.

Ergebnisse. Kinder und Jugendliche mit türkischem Migrationshintergrund sind signifikant häufiger extrem adipös (BMI-SDS $>2,5$ ). Wird sowohl nach Migrationshintergrund, als auch nach Geschlecht differenziert, zeigen sich signifikante Unterschiede: während bei den deutschen Jungen 46,1\% adipös und 53,9\% extrem adipös sind, leiden 34,3\% der türkischen Jungen an Adipositas und $65,7 \%$ an extremer Adipositas $(\mathrm{p}=0,05)$. Noch deutlicher ist der Unterschied bei den Mädchen $(\mathrm{p}=0,01): 42,1 \%$ der deutschen Mädchen sind adipös und 57,9\% extrem adipös. Im Gegensatz dazu sind 28,6\% der türkischen Mädchen adipös und $71,4 \%$ extrem adipös.

Schlussfolgerungen. Unsere Ergebnisse zeigen, dass besonders Familien mit türkischem Migrationshintergrund und niedriger Elternbildung ein besonderes Betreuungskonzept benötigen. Insbesondere Mädchen benötigen einen geschützten Rahmen in der Therapie.

\section{Updates/Refresher (4)}

\section{DGKJ-SY-RE4-1 \\ Update: Pädiatrische Infektiologie}

Berner R.

'Universitätsklinikum Dresden, Klinik und Poliklinik für Kinder- und Jugendmedizin, Dresden

Aktuelle Studie aus der Pädiatrischen Infektiologie werden vorgestellt.

\section{DGKJ-SY-RE4-3}

\section{Was gibt es Neues in der Neuropädiatrie?}

Schara U.

'Universitätsklinikum Essen, Neuropädiatrie, Entwicklungsneurologie und Sozialpädiatrie, Essen

Die Neuropädiatrie ist ein wachsender Schwerpunkt, häufig überlappend mit anderen Subdisziplinen in der Pädiatrie. Viele der dort behandelten Erkrankungen sind selten mit Prävalenzen <1:200o. Dies macht es schwierig, evidenzbasiert Krankheitsbilder gut zu charakterisieren, Langzeitverläufe einheitlich retro- und/oder prospektiv zu beschreiben, neue Phänotypen zu identifizieren oder Therapieoptionen zu entwickeln. Hierzu sind oft nationale oder internationale Netzwerke nötig, idealer Weise erfolgt die Dokumentation in Patientenregistern. Die Diagnostik neuropädiatrischer Krankheitsbilder wird stetig komplexer. In naher Zukunft werden „,next generation sequencing“-Methoden vielleicht einige diagnostische Maßnahmen ersetzen und/oder neue Diagnosen ermöglichen. Gleichsam werden aber auch neue Fragen, insbesondere zur Befundinterpretation, zu beantworten sein. Die Auftraggeber müssen diese neuen Techniken einschließlich ihrer Stärken und Grenzen kennen, um sie sinnvoll nutzen zu können. Zunehmende Einsichten in pathophysiologische und molekulare Mechanismen neuropädiatrischer Krankheitsbilder ermöglichen neue symptomatische, seltener kausale, Therapieoptionen. Diese können zu einer längeren Lebenserwartung der Betroffenen und in der Regel auch zu einer verbesserten Lebensqualität für die ganze Familie führen. Patienten mit schon früh manifesten Erkrankungen erreichen heute durchaus das Erwachsenenalter und benötigen dann eine adäquate, oft multidisziplinäre, Versorgung, die in der Erwachsenenmedizin derzeit aber noch nicht so vorgehalten werden kann. Inklusion und Transition sind wesentliche
Ziele pädiatrischer Fachgesellschaften, aber eine flächendeckende Lösung ist auch hier noch nicht gegeben. Neues aus diesen Problemfeldern soll an Beispielen dargestellt werden.

\section{Vitamin-D-Therapie in der Kinderheilkunde}

\section{DGKJ-SY-EN3-1 \\ Wie kommt das Vitamin D ins Kind?}

\section{Moss A. ', Schnabel D. ${ }^{2}$, Koletzko B. ${ }^{3}$, Wabitsch M. ${ }^{1}$}

'Universitätsklinik für Kinder- und Jugendmedizin Ulm, Sektion Pädiatrische Endokrinologie und Diabetologie, Ulm, ${ }^{2}$ Charité - Universitätsmedizin Berlin, Interdisziplinäres SPZ der Kinderklinik, Berlin, ${ }^{3}$ Universitätsklinikum München, Dr. von Haunersches Kinderspital, Abteilung Stoffwechsel und Ernährung, München

Hintergrund. Aktuelle nationale und internationale Publikationen beschreiben eine suboptimale Vitamin-D-Aufnahme bzw. einen unzureichenden Vitamin D-Status in allen Altersstufen. Ziel der Stellungnahme der Ernährungskommission der Deutschen Gesellschaft für Kinder- und Jugendmedizin (DGKJ) in Zusammenarbeit mit der Arbeitsgemeinschaft Pädiatrische Endokrinologie (APE, heutige DGKED e. V.) war es, die vorhandene Evidenz zu den Referenzbereichen von Vitamin-D-Aufnahme und zur Vitamin-D-Versorgung sowie zum tatsächlichen Verzehr zusammenzustellen und Empfehlungen für das Säuglings-, Kindes- und Jugendalter zu geben.

Methoden. Die Literaturrecherche wurde in PubMed mittels definierter Suchbegriffe durchgeführt. Des Weiteren erfolgten eine Handsuche sowie die Einbeziehung relevanter Stellungnahmen, Konsensuspapiere, Reviews und Empfehlungen.

Ergebnisse. Das Kindes- und Jugendalter sind wichtige Phasen zum Aufbau der maximalen Knochenmasse. In Deutschland ist die übliche Sonnenbestrahlung von Oktober bis März im Hinblick auf die VitaminD-Bildung in der Haut unzureichend. Kinder und Jugendliche nehmen im Durchschnitt deutlich weniger Vitamin D auf, als den Referenzwerten entsprechen würde. Sinnvolle Maßnahmen zur Erreichung eines verbesserten Vitamin-D-Status sind: geschützte Sonnenlichtexposition (je nach Hauttyp), intensive Bewegung im Freien (mind. 1 h täglich) und Erhöhung der Vitamin-D-Zufuhr durch Supplemente. Besonderes Augenmerk, mit jährlichen Bestimmungen des Vitamin-D-Status, ist auf Risikogruppen zu legen.

Schlussfolgerung. Eine systematische Überwachung der Vitamin-DVersorgung im Kindes- und Jugendalter und eine Kosten-Nutzen-Analyse der empfohlenen bzw. durchgeführten Maßnahmen zur Verbesserung der Vitamin-D-Versorgung sollten erfolgen.

\section{DGKJ-SY-EN3-3}

\section{Vitamin-D-Stoffwechselstörungen}

\section{Schnabel D. ${ }^{1}$}

'Charité - Universitätsmedizin Berlin, Pädiatrische Endokrinologie \& Diabetologie, Otto-Heubner-Centrum für Kinder- und Jugendmedizin/SPZ, Berlin

Der Vitamin-D-Rezeptor wird in fast 40 Geweben exprimiert und gewährleistet dort nach Bindung des Vitamin D die Funktionsfähigkeit des entsprechenden Organs bzw. spezieller Organfunktionen. Im Kindes- und Jugendalter sind die Vitamin D-Metabolite vorwiegend zur altersgerechten Knochenmineralisation besonders in Phasen schnellen Wachstums (Säuglingsalter, Pubertät), aber auch zur Anlage eines Kalzium-Speichers im Skelettsystem erforderlich. Erworbene bzw. hereditäre Störungen im Vitamin-D-Metabolismus führen zu einem Kalzium-Mangel. In Abhängigkeit von der Schwere der Hypokalzämie kann sich dieser klinisch als progrediente Extremitätenfehlstellung, als Tetanie und/oder als epileptischer Krampfanfall manifestieren. 
Laborchemisch finden sich bei einem alimentären Vitamin-D-Mangel oder bei einer gestörten Vitamin-D-Synthese immer eine deutlich erhöhte Alkalische Phosphatase (AP), sowie ein massiv stimuliertes Parathormon (PTH). Die Analyse der Vitamin D-Metabolite (25-OHD, $\left.1,25(\mathrm{OH})_{2} \mathrm{D}\right)$ erlaubt dann die genauere Differenzierung der VitaminD-Stoffwechselstörung. Differenzialdiagnostisch kommen ursächlich für eine kalzipenische Rachitis der alimentäre Vitamin-D-Mangel, sowie die hereditären Störungen des $\mathrm{CYP}_{2} \mathrm{R}_{1}-\mathrm{Gens}$ (fehlende Bildung von 25-OHD), des CYP27B1-Gens [fehlende Bildung von 1,25 $(\mathrm{OH})_{2} \mathrm{D}$ ] und der Vitamin-D-Rezeptordefekt in Betracht.

\section{DGKJ-SY-EN3-5}

\section{Extra-ossäre Wirkungen des Vitamin D}

\section{Grasemann C.'}

'UK-Essen, University of Duisburg-Essen, Pediatric Endocrinology, Essen

Einleitung. Mit einer Einnahme von Vitamin D werden neben den bekannten Wirkungen auf den Knochen- und Kalziumstoffwechsel auch positive Effekte bei nicht ossären Erkrankungen verbunden. Dabei wird eine Wirkung von Vitamin D sowohl in der Prävention von Krebserkrankungen als auch in der Stärkung des Immunsystems angenommen. Weiterhin werden positive Effekte bei Bluthochdruck, Depression, Schizophrenie und Diabetes mellitus beschrieben. Diese Annahmen stützen sich zu großen Teilen auf Untersuchungen auf zellulärer Ebene und auf epidemiologische Beobachtungen, aber auch auf einige prospektive, randomisierte Studien bei Menschen.

Methoden und Ergebnisse. Die meisten Daten liegen zu einer präventiven Wirkung von Vitamin D in der Entwicklung einer malignen Erkrankung vor: In der „Nurses Health Study“ fand sich eine Assoziation von höheren 25-OH Vitamin-D-Spiegeln mit einem geringerem Risiko an Krebs zu erkranken. Diese Assoziation besteht bis zu einem Wert von $30 \mathrm{nmol} / \mathrm{L}$. In einer prospektiven, randomisierten Studie zur Osteoporoseprävention wurde ein signifikanter, protektiver Effekt einer Kalzium und Vitamin-D-Substitution in der Entwicklung einer malignen Erkrankung nachgewiesen (Lappe et al. 2007). Auch in der Entwicklung und dem Verlauf eines Diabetes mellitus scheint Vitamin D eine positive Wirkung zu haben, möglicherweise aufgrund einer Stimulation der Insulinsekretion durch 1,25 $(\mathrm{OH})_{2}$ Vitamin D. Gesicherte Wirkungen von Vitamin D auf das Immunsystem sind bisher nur in zellulären Experimenten nachgewiesen worden.

Schlussfolgerung. Zusammenfassend kann davon ausgegangen werden dass Vitamin D neben den Wirkungen auf den Knochenstoffwechsel auch extraossäre Wirkungen entfaltet auch wenn bisher nur wenige gesicherte Studienergebnisse dazu vorliegen. Inwieweit die bisher nachgewiesenen extraossären Wirkungen von Vitamin D auch auf Kinder und Jugendliche übertragbar sind ist noch nicht ausreichend untersucht.

\section{Zecken-übertragende Erkrankungen}

\section{DGKJ-SY-14-3}

\section{Pathogenese und Therapie der Lyme-Borreliose}

\section{Dressler F.}

'Kinderklinik der Medizinischen Hochschule, Pädiatrische Pneumologie, Hannover

Einleitung. Bei der Lyme-Borreliose werden Borrelia burgdorferi durch den Zeckenspeichel zunächst in die Haut übertragen. Von dort können sich die Erreger unter Bindung an Integrine über das Blut im Körper verteilen. Es gibt einen gewissen Organtropismus der verschiedenen B. burgdorferi-Spezies mit B.afzelii bevorzugt in der Haut, B. garinii häufiger im Nervensystem und bestimmten Genospecies häufiger bei Lyme-Arthritis. Borrelien führen zu einer Vielzahl von Wirtsreaktionen. In der Pathogenese der Lyme-Arthritis werden 4 Haupttheorien favorisiert: 1. persistierende Infektion, 2. Persistenz spirochätaler Antigene, 3. Autoimmunreaktion bei molekulrem Mimikry, 4. Aktivierung von Bystander-Zellen des innaten und des spezifischen Immunsystems. Methoden. Neue Studien zeigen, dass ein Toll-like-Rezeptor-1-Polymorphismus mit gesteigerten Th1-inflammatorischen Reaktionen bei Lyme-Arthritis assoziiert ist, Endothelial cell-growth factor ein humanes Autoantigen bei der Lyme-Arthritis ist und dass das Borrelien Neutrophil-Activating Protein A eine Vielzahl von B- und T-Zellreaktionen hervorruft.

Ergebnisse. Zur Vermeidung einer Borreliose helfen präventive Maßnahmen gegen Zeckenstiche wie adäquate Kleidung, Insektizide und prompte Zeckenentfernung. Eine prophylaktische Antibiotikatherapie nach Zeckenstichen wird nicht empfohlen.

Schlussfolgerung. Die Studien zur antibiotischen Therapie der LymeBorreliose werden vorgestellt. Neu ist eine Studie zur Äquivalenz von Amoxicillin und Clarithromycin in der Therapie des Erythema migrans im Kindesalter. In diesem Vortrag werden aktuelle Kenntnisse zur Pathogenese und Therapie der Lyme-Borreliose vermittelt.

\section{DGKJ-Workshops}

\section{Workshop: Neugeborenen-Notarzt}

\section{DGKJ-FS-NN-10 \\ Neugeborenen-Notarzt-Techniken}

\section{Selzer $G .^{1}$}

'Evang. Krankenhaus Hamm, Klinik für Kinder- und Jugendmedizin, Klinik für Neonatologie \& päd. Intensivmedizin, Hamm

Bei der Erstversorgung von Neugeborenen im Kreißsaal bedarf es in $10 \%$ aller Fälle einer Unterstützung meist der Atmung, in 1\% werden erweiterte Maßnahmen nötig. In dem Vortrag werden aufgeführt:

- Hilfestellung zum Erkennen dieser Situation,

- Tipps und Tricks zur Maskenbeatmung und Intubation,

- Möglichkeiten in dieser Notfallsituation einen Gefäßzugang zu etablieren.

Auch die folgenden Soft Skills werden kurz beleuchtet:

- Aufgabenmanagement,

- Teamwork,

- Fähigkeit zur Beurteilung der Situation.

Der Schwerpunkt liegt auf praktischen Tipps für diese Notfallsituationen.

\section{Workshop: Notfalltherapie bei Stoffwechselstörungen}

\section{DGKJ-FS-SW-1}

Grundlagen der Notfalltherapie bei Eiweißstoffwechselstörungen: medizinische Aspekte der Notfalltherapie

\section{Thimm E.}

'Universitätsklinikum Düsseldorf, Klinik für Allgemeine Pädiatrie, Neonatologie und Kinderkardiologie, Düsseldorf

Einleitung. Angeborene Stoffwechselerkrankungen sind individuell selten, die kumulative Inzidenz liegt jedoch bei ca. 1:2.0oo. Daher sollte jeder Pädiater mit den klinischen Symptomen sowie den Grundlagen der Diagnostik und Notfalltherapie angeborener Stoffwechselstörungen vertraut sein. Thema des Vortrags sind die Harnstoffzyklusstörungen, Organoazidopathien sowie die Ahornsirupkrankheit (MSUD) als Beispiele für Störungen des Eiweißstoffwechsels. Allen diesen Krankheitsbildern gemeinsam ist, dass es durch eine angeborene Enzymdefizienz in verschiedenen Abbauwegen des Eiweißstoffwechsels zu einem 
Anstau toxischer Metabolite kommt, dies resultiert im klinischen Bild einer akuten und chronischen endogenen Intoxikation.

Methoden. Grundprinzip der Behandlung ist eine bilanzierte alimentäre Eiweißzufuhr sowie die Reduktion der endogenen Proteinbelastung durch Vermeidung einer Katabolie. Zusätzlich sind krankheitsspezifische Möglichkeiten der Detoxifikation vorhanden: Bei Harnstoffzyklusstörungen werden Substrate zur Ausscheidung von Stickstoff über alternative Stoffwechselwege (Natriumbenzoat, Natirumphenylbutyrat, Arginin) verabreicht, bei Organoazidopathien erfolgte eine Behandlung mit Carnitin zur Bildung von renal eliminierbaren Acylcarnitinen.

Ergebnisse. Patienten mit den o. g. Störungen des Aminosäurestoffwechsels neigen während kataboler Stoffwechselphasen (interkurrente Erkrankungen, Nahrungsverweigerung) durch den Abbau von körpereigenem Protein zu krisenhaften Stoffwechselentgleisungen. Typische klinische Symptome sind Erbrechen, Bewusstseinsstörungen bis zum Koma sowie Krampfanfälle.

Schlussfolgerung. In der Stoffwechselkrise muss die übliche Dauerbehandlung sowie krankheitsspezifische medikamentöse Maßnahmen intensiviert werden, um Folgeschäden zu minimieren.

\section{Workshop: Pädiatrisch praktische Psychosomatik}

\section{DGKJ-FS-PP-3}

\section{Psychogene Atemstörungen abgrenzen und behandeln}

Meister J.'

${ }^{1}$ HELIOS Klinikum Aue, Klinik für Kinder- und Jugendmedizin, Aue

Der Zusammenhang von Symptomen im Bereich der Atemwege und der psychischen Befindlichkeit ist lange bekannt und führt im Sinne des bio-psycho-sozialen Krankheitsmodells zur Beeinflussung aller Erkrankungen der Atemwege. Als Beispiele seien die psychischen Auslöser von Asthmaexazerbationen und die chronisch-maladaptive Krankheitsbewältigung bei Kindern mit Mukoviszidose genannt. Darüber hinaus zeigen sich im klinischen Alltag Atemstörungen ohne Organpathologie: Dazu gehören unphysiologische Atemmuster (z. B. paradoxe Atmung), dysfunktionelle respiratorische Symptome (häufig als psychogene Atemstörungen bezeichnet) und funktionelle Atemstörungen (z.B. Vocal Cord Dysfunction). Zu den häufigsten dysfunktionellen respiratorischen Symptomen zählen die Hyperventilation, der habituelle Husten, der Räusper-Tic und die Seufzer-Dyspnoe. Gerade der habituelle Husten wird im praktischen Alltag häufig erst spät in die differenzialdiagnostischen Überlegungen einbezogen. Die Folgen sind wiederholte, für das Kind nicht ganz risikofreie Untersuchungen (Röntgen-Diagnostik, Bronchoskopien) und unbegründete Therapien (Antitussiva, Steroide). Vor allem aber besteht die Möglichkeit, durch die voreilige Wertung („Du hast doch nichts“) die eigentliche Not des Kindes oder der Umgebung nicht ernst zu nehmen und zu einer dysfunktionalen Anpassung an die Symptomatik beizutragen. Bei Vorhandensein bestimmter zusätzlicher Bedingungsgefüge kann dann der habituelle Husten in eine somatoforme Störung übergehen Vor diesem Hintergrund wird eine Übersicht über den derzeitigen Kenntnisstand von Symptomatik und Therapie der dysfunktionellen respiratorischen Symptome im Allgemeinen und des habituellen Hustens im Besonderen gegeben.

\section{Poster}

Freitag, 13.09.2013

\section{Pharmakotherapie}

DGKJ-PO-M-1

Grünverfärbung des Urins als Symptom einer Flupirtin-Intoxikation

Erdlenbruch B. ${ }^{\prime}$, Neurath H. ${ }^{2}$, Desel H.D. ${ }^{2}$

'Johannes Wesling Klinikum Minden, Kinderklinik, Minden, ${ }^{2}$ Universitätsmedizin Göttingen, Zentrum Pharmakologie und Toxikologie, Göttingen

Einleitung. Bei unklaren Bewusstseinsverlusten wird häufig nur nach illegalen Drogen gesucht. Ohne umfassende toxikologische Analytik bleiben jedoch zahlreiche zentral wirksame Substanzen unentdeckt. Flupirtin gehört zu den zentral wirkenden Nicht-Opioid-Analgetika mit analgetischen und muskelrelaxierenden Eigenschaften. Wir berichten über zwei schwere Intoxikationen, die aufgrund einer Grünverfärbung des Urins etwa $24 \mathrm{~h}$ nach Medikamenteneinnahme und nachfolgender toxikologischer Analyse diagnostiziert werden konnten.

Fall 1. Ein 14-jähriges Mädchen wurde morgens tief stuporös mit $\mathrm{Zu}$ ckungen von Armen und Beinen aufgefunden. Nach Intubation und Transport in die Klinik mit NAW erfolgte eine cCT und eine MRT ohne pathologische Befunde. Anschließend Extubation. Labor und Drogenscreening im Urin unauffällig. Nach etwa $24 \mathrm{~h}$ Absetzen von auffällig grünem Urin. Daraufhin toxikologische Analyse aus dem initial asservierten Urin. Nachweis von Flupirtin und dessen Metaboliten. Nach Konfrontation mit dem Analysenergebnis gab die Patientin die Einnahme weiterhin nicht zu, die Mutter fand aber eine leere Medikamentenpackung in der Wohnung.

Fall 2. Aufnahme eines tief sedierten 14-jährigen Mädchens mit ausgeprägter Zittrigkeit, das am Weserufer mit einer leeren Medikamentenschachtel Katadolon (Flupirtin) und einer Wodkaflasche aufgefunden wurde. Anamnestisch Einnahme von 5,4 g Flupirtin in suizidaler Absicht. Grünverfärbung des Urins am Tag nach der Aufnahme und Nachweis von Flupirtin in der toxikologischen Analytik aus dem initialen Urin.

Schlussfolgerung. Bei Grünverfärbung des Urins sollte an die Einnahme von Flupirtin gedacht werden. Bei Intoxikationsverdacht sollte neben einem Drogenscreening auch eine toxikologische Analyse des Urins erfolgen, um relevante zentral wirksame Substanzen nicht zu übersehen. 


\section{DGKJ-PO-M-2}

Brauchen wir neue Antiepileptika für Kinder? Erste Ergebnisse über Lacosamid im Kindesalter im Rahmen einer retrospektiven Analyse

Fiedler B.J.', Herkenrath P. ${ }^{2}$, Hethey S. ${ }^{3}$, Mundt D. ${ }^{4}$, Kovacevic-Preradovic T. ${ }^{5}$, Sassen R. ${ }^{6}$, Schubert-Bast S. ${ }^{7}$, van Baalen A. ${ }^{8}$, Vieker S. ${ }^{9}$, Zellner A. ${ }^{10}$, Kurlemann $G$.'

'Universitätsklinikum Münster, Klinik für Kinder- und Jugendmedizin, Bereich Neuropädiatrie, Münster, ${ }^{2}$ Universitäsklinikum Köln, Klinik und Poliklinik für Kinder- und Jugendmedizin, Köln, ${ }^{3}$ Kinder-und Jugendkrankenhaus Auf der Bult, Hannover, ${ }^{4}$ St. Marien-Hospital Düren, Sozialpädiatrisches Zentrum, Düren, ${ }^{5}$ Kleinwachau, Sächsisches Epilepsiezentrum, Radeberg, ${ }^{6}$ Universitätsklinikum Bonn, Klinik für Epileptologie, Bonn, ${ }^{7}$ Universitätsklinikum Heidelberg, Zentrum für Kinder- und Jugendmedizin, Neuropädiatrie, Heidelberg, ${ }^{8}$ Universitätsklinikum Schleswig-Holstein, Klinik für Neuropädiatrie, Kiel, ${ }^{9} \mathrm{Gemeinschaftskrankenhaus} \mathrm{Herdecke,} \mathrm{Kinder-} \mathrm{und}$ Jugendmedizin, Neuropädiatrie, Herdecke, ${ }^{10}$ Klinikum Traunstein, Sozialpädiatrisches Zentrum, Traunstein

Fragestellung. Effektivität und Verträglichkeit von Lacosamid (LCM) bei Kindern mit Epilepsie <16 Jahre.

Methodik. Retrospektive Analyse bei 110 Kindern unter LCM-Therapie aus 10 Epilepsieambulanzen in Deutschland.

Ergebnis. 61 männlich, Alter bei LCM-Beginn: 3 Monate bis 15,3 Jahre, 49 weiblich, Alter bei LCM-Beginn: 3 Monate bis 15,9 Jahre. Epilepsien symptomatisch fokal ( $\mathrm{n}=56) ; \mathrm{LGS}(\mathrm{n}=13) ; \mathrm{GM}(\mathrm{n}=8)$; CSWS $(\mathrm{n}=6)$; metabolisch $(n=5)$; genetisch $(n=9)$; Doose-Syndrom $(n=1)$; BECTS $(n=1)$; Absenceepilepsie $(n=1)$; fokal motorisch $(n=1)$; nicht klassifizierbar $(n=10)$. Alle Kinder waren mit $>3$ AED erfolglos vorbehandelt. LCM-Startdosis: 0,5 mg -8 mg/kg KG (Mittelwert 3,25). Aufdosierung: Erhöhung um die Startdosis im Wochenabstand (2-30 Tage). LCM-Enddosis: 4-20 mg/ kg KG (Mittelwert: 9,6). Nebenwirkungen: 73 zeigten keinerlei NW bei den übrigen 37 Kindern war die Haupt-NW Müdigkeit $(n=9)$. Komedikation: unterschiedlich. Na-Kanalwirksame Komedikation: $\mathrm{n}=78$ Zehn Kinder erhielten LCM in Monotherapie, bei 25 Kindern konnte die Komedikation reduziert, bei 36 mindestens 1 AED abgesetzt werden Therapieeffekt: Anfallsfreiheit bei 26 (24,3\%); 75\% Anfallsreduktion bei 14 (13,0\%), 50\% Anfallsreduktion bei 21 Kindern (19,6\%); bei 32 Kindern kein Effekt (29,9\%). Gruppe anfallsfreier Kinder $(n=26)$ : v. a. symptomatisch fokale Epilepsien $(\mathrm{n}=11) .6$ hatten einen LCM-Serumspiegel von 2,3-18,8 $\mu \mathrm{g} / \mathrm{ml}$ (Mittelwert: 10,3). Komedikation: prim. Monotherapie $(\mathrm{n}=3) ; 10$ Kinder erhielten 1 zusätzliches Na-Kanalwirksames AED.

Diskussion. Kinder $<16$ Jahre vertragen LCM sehr gut, sowohl in Monoals in Kombinationstherapie. 24,3\% des Kollektivs wurden anfallsfrei. In Kombination mit einem anderen $\mathrm{Na}$-Kanalwirksamen AED scheint sich die therapeutische Wirkung zu verstärken ohne Nebenwirkungen zu erhöhen.

\section{DGKJ-PO-M-3}

\section{Akzeptanz von Placebo-Minitabletten bei kleinen Kindern}

Klingmann V.', Spomer N. ', Lerch C. ${ }^{2}$, Stoltenberg I. ${ }^{3}$, Bosse H.M. ', Breitkreutz J. ${ }^{3}$, Meissner T. ${ }^{1}$

${ }^{1}$ Universitätsklinikum Düsseldorf, Klinik für Allgemeine Pädiatrie, Neonatologie und Kinderkardiologie, Düsseldorf, ${ }^{2}$ Cochrane Metabolic and Endocrine Disorders Group, Düsseldorf, ${ }^{3}$ Heinrich-Heine- Universität Düsseldorf, Institut für Pharmazeutische Technologie und Biopharmazie, Düsseldorf

Fragestellung. Bisher sind wenige Daten zu Akzeptanz und Schluckbarkeit von Minitabletten(MT) bei Kindern verfügbar. Die WHO empfiehlt die Verabreichung solider Partikel, die EMA zweifelt an deren Eignung. Studienziel: verlässliche Daten zur Akzeptanz von MT bei Kindern $<6$ Jahren zu generieren.

Material und Methoden. Randomisiertes Cross-over-Design mit $2 \mathrm{~mm}$ MT (beschichtet/unbeschichtet) im Vergleich zu $3 \mathrm{ml}$ Glukosesirup. 306 Kinder von 0,5-5 J. wurden nach schriftlichem Einverständnis der Eltern eingeschlossen. Geeignete Patienten wurden randomisiert untersucht. Dabei wurde den Kindern entweder eine der beiden MT oder $3 \mathrm{ml}$ Sirup verabreicht. Das Schluckverhalten wurde genau untersucht und dokumentiert. Danach wurde der Vorgang mit den beiden anderen Darreichungsformen wiederholt. Auswertungskriterien MT: geschluckt, gekaut, ausgespuckt, verschluckt, Verweigerung der Einnahme. Auswertungskriterien Sirup: komplett geschluckt, kleines Rinnsal floss aus Mund, ausgespuckt, verschluckt, Verweigerung der Einnahme.

Ergebnisse. In allen Altersgruppen war die Akzeptanz (geschluckt oder gekaut) der unbeschichteten MT höher oder gleich dem Sirup (95\% KI). Die Schluckbarkeit der MT zeigte Unterschiede in den einzelnen Altersgruppen: gerade sehr kleine Kinder waren vollständig in der Lage, die MT ohne Kauen zu schlucken. Überraschenderweise haben die kleinsten Kinder die MT besser akzeptiert als den Sirup, was in Widerspruch zur aktuellen Meinung der EMA steht. Einige Kinder zwischen 2 und 4 Jahren kauten die MT, was aber die Zuverlässigkeit der Einnahme nicht beeinträchtigte.

Schlussfolgerung. Minitabletten sind eine vielversprechende, sichere Alternative zu Sirup und sollten daher von der EMA auch für kleine Kinder ab 6 Monaten empfohlen werden.

\section{DGKJ-PO-M-4}

\section{Lebensqualität von Kindern mit primären Immundefekten}

Baumann U.', Hensel M. ${ }^{2}$, Gold R. ${ }^{3}$, Fasshauer M. ${ }^{4}$, Pittrow D. ${ }^{5}$, Huscher D. ${ }^{6}$, Stangel M. ${ }^{7}$, Reiser M. ${ }^{8}$, Kirch W. ${ }^{5}$, Borte M. ${ }^{4}$, SIGNS Studiengruppe

'Medizinische Hochschule, Klinik für Pädiatrische Pneumologie, Allergologie und Neonatologie, Hannover, ${ }^{2}$ Mannheimer Onkologie Praxis, Mannheim, ${ }^{3}$ St. Josef-Hospital, Klinikum der Ruhr-Universität, Klinik für Neurologie, Bochum, ${ }^{4}$ Immundefektzentrum Leipzig (IDCL), Jeffrey Modell Diagnostic and Research Center for Primary Immunodeficiencies, Leipzig, ${ }^{5}$ Technische Universität Dresden, Institut für Klinische Pharmakologie, Dresden, ${ }^{6}$ Epidemiologie, Deutsches Rheumaforschungszentrum, Berlin, ${ }^{7}$ Medizinische Hochschule, Klinik für Neurologie, Hannover, ${ }^{8}$ Praxis für Hämatologie und Internistische Onkologie (PIOH), Köln

Daten zur Lebensqualität (LQ) von Kindern mit primärem Immundefekt (PID), die eine Substitutionstherapie mit Immunglobulinen erhalten, sind für die Beurteilung des Therapieerfolgs von großem Interesse. „Assessment of Immunoglobulins in a long-term non-interventional study“" (SIGNS, NCT NCTo1287689) ist eine prospektive Beobachtungsstudie. Die Lebensqualität bei Kindern wurde mit Child Health Questionnaire Parental Form (CHQ-PF 50, 5-18 Jahre), DISABKIDS (4-7 bzw. 8-16 Jahre), und KIDSCREEN (8-16 Jahre) erfasst.

Von den 58 Kindern mit PID in der Datenbank (67\% männlich, mittleres Alter 10,2 $\pm 4,4$ Jahre) hatten 27 ein variables Immundefektsyndrom (CVID), 10 eine X-chromosomal vererbte Agammaglobulinämie (XLA), und 9 eine selektive IG Subklassendefizienz. Auf der o-10o Skala des CHQ-PF-50 $(n=49)$ lagen körperliche Funktionsfähigkeit bei $82 \pm 25$ Punkten, Rolle/soziale Limitation bei $85 \pm 24$, Schmerz bei $27 \pm 25$, allgemeine Gesundheitswahrnehmung bei $44 \pm 17$, allgemeine Gesundheit bei 62 \pm 22 , allgemeines Verhalten bei $70 \pm 20$, familiäre Aktivitäten bei $76 \pm 21$, und familiärer Zusammenhalt bei $77 \pm 18$. In DISABKIDS lag der allgemeine Gesundheitsscore bei den 4- bis 7-jährigen Kindern $(n=5)$ bei $79 \pm 16$ Punkten bzw. bei den 8 - bis 16-jährigen Kindern $(n=23)$ bei $77 \pm 13$ Punkten. Sowohl im DISABKIDS als auch im KIDSCREEN bewerteten Kinder bzw. Heranwachsende ihre LQ besser als ihre Eltern (Ausnahmen waren die Dimensionen "Familie und Freizeit" und "Schule und Lernen").

Schlussfolgerung. Die LQ von Kindern mit PID ist eingeschränkt. Wie bei anderen chronischen Erkrankungen erleben die Eltern die Einschränkung ihrer Kinder gravierender als diese selbst. Dies könnte an den unterschiedlichen Bewertungen liegen, oder auch an erfolgreichen Coping-Strategien der Kinder. 


\section{DGKJ-PO-M-5}

Wie häufig sind arzneimitteltherapiebezogene Probleme in der Pädiatrie? - Eine prospektive Kohortenstudie bei stationär behandelten Kindern und Jugendlichen

\section{Toni I.', Botzenhardt S. ', Wimmer S. ', Trollmann R. ', Rascher W. ', Neubert A. 'Universitätsklinikum Erlangen, Kinder- und Jugendklinik, Erlangen}

Fragestellung. Arzneimitteltherapiebezogene Probleme (ATBP) sind häufig und ein nicht zu unterschätzendes Risiko für die Patientensicherheit. Besonders vulnerabel sind hierbei Kinder und Jugendliche. Ziel der vorliegenden Studie war, ATBP bei stationär behandelten pädiatrischen Patienten systematisch zu untersuchen.

Material und Methode. In der Kinder- und Jugendklinik Erlangen wurden alle Patienten im Alter von o bis $<18$ Jahren, die zwischen Juli und Oktober 2012 auf die Studienstation aufgenommen wurden, erfasst und bezüglich ATBP [Medikationsfehler (MF) und unerwünschte Arzneimittelwirkungen (UAW)] untersucht. Die Identifizierung der Probleme erfolgte durch ein pharmakoepidemiologisches Team anhand von intensivem Chart-Review und regelmäßiger Befragung der Pflegekräfte. Ergebnisse. Insgesamt wurden 427 Aufnahmen ( $n=372$ Patienten) beobachtet und 100 Aufnahmen in einer Zwischenanalyse ausgewertet. In $83,0 \%$ fand eine medikamentöse Therapie statt, wobei 250 ATBP $(n=206$ MF, $n=44$ UAW) auftraten. Bei 8o,7\% (n=67) der Aufnahmen mit Arzneimitteln fand sich mind. 1 ATBP; bei $71,1 \%(n=59)$ traten Probleme be der Verschreibung und Dokumentation auf, bei $26,5 \%(n=22)$ war die Dosisauswahl und bei $18,1 \%(n=15)$ die Arzneimittelanwendung problembehaftet.

Schlussfolgerung. Diese Untersuchung zeigt, dass die Arzneimitteltherapie bei Kindern und Jugendlichen äußerst fehleranfällig ist. Eine Vielzahl der ATBP findet sich im Bereich Verordnung und Dokumentation. Diese haben im Stationsalltag jedoch selten klinische Konsequenzen, stellen aber dennoch potentielle Gefahren dar. Ein Ansatz zur Vermeidung dieser Probleme wäre der Einsatz von elektronischen Verordnungssystemen, die bereits in der Erwachsenenmedizin nachgewiesenermaßen zur Patientensicherheit beitragen.

\section{DGKJ-PO-M-6}

Unterdosierung als Hauptgrund für Off-label-Anwendung von Arzneimitteln bei Kindern und Jugendlichen in Deutschland: Ergebnisse einer populationsbasierten Studie

\section{Neubert A. ', Sarganas G. ${ }^{2}$, Zhuang W. ${ }^{3}$, Rascher W. ${ }^{1}$, Knopf H. ${ }^{3}$}

'Universitätsklinikum Erlangen, Kinder- und Jugendklinik, Erlangen, ${ }^{2} \mathrm{Cha}-$ rité - Universitätsmedizin Berlin, Institut für klinische Pharmakologie und Toxikologie, Berlin, ${ }^{3}$ Robert-Koch-Institut, Abteilung für Epidemiologie und Gesundheitsmonitoring, Berlin

Hintergrund. Off-label-Anwendung ist ein verbreitetes Problem in der Arzneimitteltherapie von Kindern und Jugendlichen. Bevölkerungsbasierte Daten in Deutschland fehlen jedoch. Ziel dieser Studie war es, den Off-label-Gebrauch von Arzneimitteln bei Kindern und Jugendlichen in der ambulanten Versorgung zu untersuchen und deren Prävalenz zu identifizieren.

Methoden. Die vorliegende Auswertung basiert auf Daten der Studie zur Gesundheit von Kindern und Jugendlichen in Deutschland (KiGGS), die zwischen 2003 und 2006 durch das Robert-Koch-Institut erhoben wurden. Die Datenerhebung erfolgte durch computergestützte Befragung sowie körperliche Untersuchungen durch Ärzte. Eingeschlossen wurden zufällig ausgewählte Kinder und Jugendliche im Alter zwischen o und 18 Jahre. Der Zulassungsstatus der angewendeten Arzneimittel wurde anhand von Fachinformationen ermittelt.

Ergebnisse. Von 17.450 Studienteilnehmern hatten 8899 in den letzten 7 Tagen vor der Befragung mindestens 1 Arzneimittel eingenommen. Von insgesamt 14.588 erfassten Arzneimitteln wurden 26,1\% off-label angewendet. Unterdosierung stellte hierbei die häufigste Off-labelKategorie $(57,9 \%)$ dar, gefolgt von Überdosierung (15,3\%), Indikation
$(14,2 \%)$ und Alter (12,5\%). Die Prävalenz des Off-label-Gebrauchs betrug $8,9 \%$ (95\% CI 8,4-9,4\%) in der Gesamtpopulation.

Schlussfolgerung. Off-label-Gebrauch von Arzneimitteln stellt ein erhebliches Risiko in der pädiatrischen Population dar und spiegelt den mangelnden Kenntnisstand in der pädiatrischen Pharmakotherapie wider. Auch darf, durch das Fehlen von therapeutischem Nutzen bei gleichzeitigem Risiko für Nebenwirkungen, eine Unterdosierung von Arzneimitteln im Bereich der Off-label-Anwendung nicht unterschätzt werden.

\section{DGKJ-PO-M-7}

Unerwünschte Arzneimittelwirkungen bei stationär behandelten Kindern - was hat sich zwischen 1999 und 2008 geändert?

Oehme A.-K.', Rashed A.N. ${ }^{2}$, Hefele B. ${ }^{1}$, Rascher W. ${ }^{1}$, Neubert A. ${ }^{1}$

'Universitätsklinikum Erlangen, Kinder- und Jugendklinik, Erlangen, 2University College London, School of Pharmacy, Centre for Paediatric Pharmacy Research, London, UK

Hintergrund. Das Auftreten und Erkennen von unerwünschten Arzneimittelwirkungen (UAW) spielt für die Verbesserung der Arzneimitteltherapiesicherheit bei Kindern eine besondere Rolle. Ziel dieser Untersuchung war es Veränderungen der Häufigkeit von UAW und deren Ursachen bei stationär behandelten Kindern zu identifizieren.

Methoden. Ausgangspunkt dieser Untersuchung sind zwei prospektive kohortenbasierte Beobachtungsstudien aus den Jahren 1999 und 2008 an der Kinder- und Jugendklinik des Universitätsklinikums Erlangen. Es wurden während der Studienzeiträume alle auf eine allgemeinpädiatrische Station aufgenommenen Kinder im Alter zwischen o und 18 Jahren eingeschlossen. UAW wurden mittels intensivierter Durchsicht der Patientenakten identifiziert und durch ein klinisches Expertenteam bewertet.

Ergebnisse. Insgesamt wurden 520 Patienten (574 Aufnahmen) eingeschlossen und 2053 Medikamente verabreicht (Median 2, SD $\pm 3,4$ ). 19,0\% der Kinder wurden nicht medikamentös behandelt. Die mittlere Liegedauer auf der Station war 4 Tage $(\mathrm{SD} \pm 10,4)$ bei einer signifikant längeren Aufenthaltsdauer im Jahr 1999. Die Gesamt-UAW-Inzidenz lag bei 13,1\% (95\% CI 9,8-16,3) mit einem signifikanten Unterschied zwischen beiden Studien (1999: 21,9\%, 95\% CI 14,7-29,0; 2008: 9,2\%, 95\% CI 5,9-12,5; $\mathrm{p}<0,001)$. Antibiotika und systemische Kortikosteroide verursachten in beiden Kohorten die meisten UAW.

Schlussfolgerungen. Zwischen 1999 und 2008 sank die Inzidenz der UAW auf der Studienstation signifikant. Eine Verbesserung der Behandlungsstrategien und die erhöhte Aufmerksamkeit der behandelnden Ärzte für UAW sind die wahrscheinlichsten Begründungen für diese positive Entwicklung. Jedoch sind Untersuchungen zu UAW in der Kinder- und Jugendmedizin, speziell im ambulanten Sektor, weiter notwendig.

\section{DGKJ-PO-M-8}

\section{Sind nicht interventionelle Arzneimittelstudien im Kindesalter} heute sinnvoll?

\section{Bufe A. ${ }^{1,2}$, Sandner B. ${ }^{2,3}$}

${ }^{1}$ Ruhr-Universität Bochum, Experimentelle Pneumologie, Bochum, ${ }^{2}$ Netzwerk für Klinische Studien in der Ambulanten Pädiatrie, NETSTAP e.V. Forschungsinstitut Borstel, ${ }^{3} Z$ Zentrum für Ambulante Medizin, Pädiatrische Pneumologie und Allergologie, Aschaffenburg

Der Weg zu einer besseren Medikamentenversorgung für Kinder und Jugendliche ist seit Jahrzehnten mit zahlreichen Stolpersteinen gepflastert. Dies liegt unter anderem daran, dass selbst von manchen Kinderärzten dem Thema Arzneimittelforschung mit gemischten Gefühlen begegnet wird: Neben dem Wunsch nach den bestmöglichen Medikamenten für Kinder und Jugendliche existieren gleichzeitig allenthalben Vorbehalte, diese Klientel in Arzneimittelstudien einzuschließen. 
Dabei hat der Gesetzgeber gerade während der letzten zehn Jahre erhebliche Anstrengungen unternommen, dem Schutz des Individuums allerhöchste Priorität einzuräumen mit dem Ziel, eine sichere klinische Pharmakotherapie im Kindesalter zu gewährleisten. Denn das Problem der Off-Label-Medikation schlägt selbst in der ambulanten (niedergelassenen) Pädiatrie mit einem geschätzten Prozentsatz von $40 \% \mathrm{zu} \mathrm{Bu}-$ che, in bestimmten Spezialbereichen erreicht er einen Anteil von über $80 \%$. Dieser Beitrag gibt zunächst detaillierte Einblicke in die pädiatrische Arzneimittelforschung, unter anderem mit dem Schwerpunkt der Deutschen Arzneimittelgesetzgebung (AMG) inklusive Einbeziehung der aktuellen 16. AMG-Novelle. Ferner werden wesentliche Inhalte der Guten Klinischen Praxis (GCP) referiert und an Beispielen belegt, dass eine sinnvolle, praxisgerechte Arzneimittelforschung im Kindesalter auch heute möglich ist. Ein zweiter Teil beschreibt schließlich den wichtigen Stellenwert von nicht interventionellen Arzneimittelstudien und warum sog Anwendungsbeobachtungen (AWB) sogar von Fachleuten als überflüssig empfunden werden, jedoch besondere Bedeutung erfahren unter dem Gesichtspunkt einer sicheren Pharmakotherapie im Kindesalter. Entsprechende praxisrelevante Aspekte einschließlich alltäglicher Fallstricke werden herausgearbeitet.

\section{Dermatologie und Urologie/Nephrologie}

\section{DGKJ-PO-D-1 \\ Hämangioendotheliome (HE) - eine eigene Entität der vaskulären Tumoren neben den infantilen Hämangiomen $(\mathrm{IH})$}

\section{Poetke M.', Urban P. ${ }^{1}$, Müller U. ${ }^{1}$, Philipp C.M. ${ }^{1}$, Berlien H.-P. ${ }^{1}$ 'Elisabeth Klinik Berlin, Lasermedizin, Berlin}

Einleitung. Kongenitale vaskuläre Tumoren haben ein sehr breites Spektrum an Erscheinungsformen. Der häufigste und bekannteste ist das GLUT-1-positive infantile Hämangiom (IH). Von den IH müssen die GLUT-1 negativen kongenitalen Hämangioendotheliome (HE) unterschieden werden. Hierbei handelt es sich um einen bei Geburt oder im ersten Lebensjahr auftretenden vaskulären Tumor, der sich als rötlichlivide, derb indurierte Weichteilschwellung, häufig im Bereich der Extremitäten, etwas seltener am Stamm, bereits von der Farbgebung und palpatorisch in typischer Weise von dem IH unterscheidet.

Methoden. Wir haben über einen Zeitraum von 15 Jahren retrospektiv die dokumentierten Daten von insgesamt 126 Patienten mit Hämangioendotheliomen anhand der Klinik, Thermographie, der farbkodierten Duplexsonographie, des histologischen Befundes, Gerinnungsparametern und des Verlaufs ausgewertet.

Ergebnisse. Anhand dieser Kriterien konnten wir 4 unterschiedliche Verlaufsformen unterscheiden, das NICH (Non involuting HE), das RICH (Rapid involuting HE), das Tufted Angioma und das kaposiforme HE. Von den insgesamt 126 Patienten mit einem HE wurden 13 mit einem NICH, drei Patienten mit einem Tufted Angioma und 8 Patienten mit einem kaposiformen HE behandelt. Bei den 102 Patienten mit einem RICH war keine Behandlung notwendig. Bei 10 Patienten mit einem HE traten schwere Gerinnungsstörungen auf mit KasabachMerritt-Syndrom

Schlussfolgerung. Hämangioendotheliome stellen eine eigene Entität der vaskulären Tumoren dar und müssen von den IH unterschieden werden. Dies ist immunhistochemisch aufgrund der unterschiedlichen Expression von GLUT-1 möglich. Die Therapieindikation beim HE ist abhängig vom Typ und der Verlaufsform, bei dem kaposiformen HE aufgrund des assoziiert auftretenden Kasabach-Merritts-Syndroms unumgänglich.

\section{DGKJ-PO-D-2}

\section{Kann die regelmäßige Gabe von IVIG den Verlauf beim Comel-} Netherton-Syndrom positiv beeinflussen?

\section{Scheffler N.', Brinkmeier T. ${ }^{1}$, Thuresson M. ${ }^{1}$, Fölster-Holst R. ${ }^{2}$, Yildiz I. ${ }^{1}$}

${ }^{1}$ Friedrich-Ebert-Krankenhaus, Klinik für Kinder- und Jugendmedizin, Neumünster, ${ }^{2}$ Universitätsklinikum Schleswig-Holstein, Klinik für Dermatologie, Venerologie und Allergologie, Kiel

\section{Material und Methode. Fallbericht.}

Ergebnisse. Familienanamnese: 5. Kind konsanguiner Eltern. 2 gesunde Töchter. 2 Söhne im Alter von 2 Jahren und 2,5 Monaten im Rahmen einer Sepsis bei Comel-Netherton-Syndrom verstorben. Ein Spätabort, männlich, vom Aspekt ebenfalls mit Comel-Netherton-Syndrom. Eigenanamnese: Geburt per Sectio nach 38+4 SSW. Unauffälliger Schwangerschaftsverlauf. Dystroph. GG $2185 \mathrm{~g}, \mathrm{~L} 45 \mathrm{~cm}, \mathrm{KU} 33 \mathrm{~cm}$. Verzögerte postnatale Anpassung. Ausgeprägte Beugehaltung der Extremitäten; dünne, pergamentartige Haut; Alopezie; auffallend kurze, verklebte Wimpern. Hautbiopsie: LEKTI/SPINK5-Protein stark erniedrigt; Beta-Def.-AK pos.; TG3-AK erniedrigt; Elafin-AK pos. Mikroskopie Augenbrauenhaare: Bambushaar. ImmundefektDiagnostik. V. a. funktionellen Defekt der Granulozyten, verminderte IFN- $\gamma$-Produktion. Verlauf: Der Junge entwickelte bald eine ichtyosiforme Erythrodermie, chronische Diarrhoen, rezidivierende (Haut-)Infektionen und Septikämien, Femoralvenenthrombosen bds., mehrfach hypertone Dehydratationen und eine Wachstumsverzögerung. Die Therapie erfolgte mit extensiv-hydrolysierter und AS-Nahrung, intensivmedizinischer Behandlung mit mehrfacher Antibiotika-Therapie, Infusionstherapie, Immunglobulin-Gaben, spezieller Hautpflege, Pimecrolimus und topischen Kortikosteroiden.Aktuell ist er knapp 3 Jahre alt und zeigt ein stark wechselndes Hautbild. Nach regelmäßigen Immunglobulingaben tritt jeweils eine deutliche Besserung ein. Es besteht eine mehr körperliche als geistige globale Entwicklungsverzögerung.

Schlussfolgerung. Comel-Netherton-Syndrom ist eine seltene (1:200.000 Geburten), autosomal rezessive Genodermatose mit Immundefekt. Unser Patient scheint von den Immunglobulingaben zu profitieren, da sich das Hautbild bessert und die Infektanfälligkeit abnimmt.

\section{DGKJ-PO-D-3 Condylomata acuminata bei Kindern - Diagnostik und Laserbe- handlung}

Poetke M.', Müller U.', Urban P.', Philipp C.M.', Berlien H.-P.'

'Elisabeth Klinik Berlin, Lasermedizin, Berlin

Einleitung. Humane Papillomaviren (HPV) sind die häufigste Ursache für sexuell übertragbare Erkrankungen weltweit. Bei Kindern können sie Zeichen eines sexuellen Missbrauchs sein. Eine Infektion ist aber auch ohne sexuellen Kontakt als Tröpfchen- und Schmierinfektion möglich. Für die Therapie stehen zahlreiche Behandlungsmöglichkeiten zur Verfügung, wobei sich keine Methode definitiv durchsetzen konnte, aufgrund des Rezidivrisikos.

Methoden. Zwischen 2001 und 2011 haben wir insgesamt 22 Kinder mit anogenitalen Condylomen mit dem $\mathrm{CO}_{2}$-Laser behandelt. Achtzehn der Kinder hatten anale Condylome, ein Mädchen hatte vulväre Befunde und bei 3 Mädchen haben sich die Befunde vulvär und anal ausgedehnt. Bei allen Kindern wurden im Rahmen des Eingriffs Biopsien zur Diagnosesicherung und zur HPV Bestimmung mittels PCR entnommen. Bei 20 der betroffenen Kinder lag ein positiver HPV Nachweis vor, bei denen HPV $6(n=18)$ festgestellt wurde. In nur 2 Fällen wurden High-risk-HPV nachgewiesen. In 2 Fällen war kein HPV Nachweis möglich. Wir führten 34 Eingriffe in Narkose durch. Bei 13 Kindern war eine Behandlung ausreichend, 6 Kinder benötigten 2 Behandlungen und in 3 Fällen waren 3 Therapiesitzungen notwendig.

Ergebnisse und Schlussfolgerung. HPV Infektionen bei Kindern beruhen häufig auf einer Schmierinfektion, aber auch ein sexueller Übertragungsweg sollte immer ausgeschlossen werden. Biopsien zum Aus- 
schluss von Dysplasien als auch eine HPV Typisierung mittels PCR sind fester Bestandteil der Diagnostik. Die CO2-Laserbehandlung ist eine sichere als auch effektive Behandlung zur Entfernung anogenitaler Warzen bei Kindern. Nebenwirkungen wie Schwellung oder Schmerzen sind relativ gering, die Wundversorgung wird gut toleriert. Das Rezidivrisiko ist mehr oder weniger vergleichbar zu anderen Therapien.

\section{DGKJ-PO-D-4 \\ Kokardenpurpura Seidlmayer - eine Sonderform des Erythema exsudativum multiforme}

Wieczorek H.', Bienemann K.', Michna D.'

'Elisabeth-Krankenhaus Essen, Allgemeine Pädiatrie, Essen

Hintergrund. Das Erythema exsudativum multiforme (EEM) präsentiert sich durch das plötzliche Auftreten von rundlichen erythematösen Maculae. Nach einigen Tagen bildet sich die typische trizonale Kokarden-Form aus: eine zentrale dunkle Macula ist umgeben von einer helleren, blassrötlichen ödematösen Zone und außen von einem dunkleren lividen Ring. Bei der Minor-Form ist nur die Haut, bei der Major-Form ist auch noch mindestens eine Schleimhautregion, meist die Mundschleimhaut mitbetroffen. Eine Sonderform stellt die Kokardenpurpura Seidlmayer dar, die hauptsächlich bei jungen Kleinkindern vorkommt. Für diese Form sind kokardenförmige Hautblutungen typisch. Das EEM ist bei Kindern meist parainfektiöser Genese. Herpessimplex-Virus gefolgt von Mycoplasma pneumoniae sind die häufigsten nachgewiesenen Erreger. In vielen Fällen bleibt der Auslöser jedoch unbekannt.

Kasuisitik. Wir berichten über einen 6-jährigen Jungen mit einem hämorrhagischen kokardenförmigen Exanthem, das 5 Tage vor der Vorstellung in unserer Klinik im Bereich der Anogenitalregion begonnen und sich von dort innerhalb weniger Tage auf den Körperstamm ausgebreitet hatte. Zusätzlich bestand ein Schleimhautbefall der Mundschleimhaut und der Glans penis mit einem hämorrhagischen Enanthem. Unter lokaler Prednison-Therapie und antiseptischer Mundpflege bildete sich das Exanthem innerhalb weiterer 5 Tage zurück. Ein Erregernachweis gelang nicht.

Fazit. Die Kokardenpurpura Seidlmayer ist ein klinisch sehr beeindruckendes Krankheitsbild mit ausgeprägten hämorrhagischen kokardenförmigen Hauteinblutungen. Ihr Verlauf ist meist gutartig und eine rein symptomatische Therapie ausreichend.

\section{DGKJ-PO-D-5}

Reifes Neugeborenes mit epidermalen eruptierenden Blasen: Ichthyosis congenita (Netherton-Syndrom)

\section{Schum C. ${ }^{1}$, Weber K. ${ }^{1}$, Fiedler A. ${ }^{1}$ \\ 'Klinikum St. Marien Amberg, Amberg}

Einleitung. Ichthyosen sind eine Gruppe von seltenen, generalisierten, erblichen Verhornungsstörungen. Das Comèl-Netherton-Syndrom ist eine seltene autosomal-rezessiv vererbte Verhornungsstörung mit einer Ichthyose und bestimmten Haaranomalien.

Methoden. Wir berichten über den Fall eines reifen männlichen Neugeborenen, bei dem unmittelbar nach Geburt epidermale, eruptierende nicht blutige Blasen auffielen.

Ergebnisse. Bei positiver Familienanamnese erfolgte die Durchführung einer genetischen Untersuchung, welche den Nachweis einer Mutation im KRT-10-Gen und somit die molekulargenetische Bestätigung einer epidermolytischen Hyperkeratose erbrachte. Durch unsere lokale symptomatische Therapie konnten wir eine deutliche Verbesserung des Hautbildes erreichen.

\section{DGKJ-PO-D-6}

Wirksamkeit und Sicherheit der Therapie mit Fumarsäureestern (Fumaderm ${ }^{\circledast}$ initial/Fumaderm ${ }^{\circledast}$ ) bei Kindern und Jugendlichen im Alter von 10-17 Jahren (KIFUderm-Studie)

\section{Hamm H. ${ }^{1}$, Wilsmann-Theis $D .{ }^{2}$, Reich $K{ }^{3}$, im Namen der KIFUderm Stu-} diengruppe

'Universitätsklinikum Würzburg, Klinik und Poliklinik für Dermatologie, Würzburg, ${ }^{2}$ Rheinische-Friedrich-Wilhelms Universität Bonn, Klinik und Poliklinik für Dermatologie, Bonn, ${ }^{3}$ Dermatologikum, Hamburg

Einleitung. Nach dem atopischen Ekzem ist die Psoriasis die zweithäufigste chronisch-entzündliche Hauterkrankung bei Kindern und Jugendlichen. Sie geht mit einem erhöhten Risiko für Komorbiditäten und daraus resultierenden Langzeitfolgen einher. Die Lebensqualität ist oft deutlich eingeschränkt. Fumarsäureester sind seit 19 Jahren zur oralen Systemtherapie erwachsener Patienten mit mittelschwerer und schwerer Plaque-Psoriasis zugelassen. Zunehmend werden aber auch betroffene Kinder und Jugendliche unter 18 Jahren im Off-Label-Use mit Fumaderm ${ }^{\circ}$ behandelt. In einer klinischen Studie wird nun die Wirksamkeit und Sicherheit von Fumaderm ${ }^{\circ}$ bei Kindern und Jugendlichen im Alter von 10-17 Jahren mit Bedarf für eine Systemtherapie überprüft (KIFUderm-Studie).

Methoden. In dieser 2:1 randomisierten, doppelblinden, Placebo-kontrollierten, multizentrischen Phase-IIIb-Studie werden die Patienten über einen Zeitraum von 6o Wochen in 2 Studienarmen (Fumaderm ${ }^{\circ}$ Fumaderm-Gruppe und Placebo-Fumaderm-Gruppe) beobachtet. Auch die Placebopatienten erhalten nach 20 Wochen Fumaderm. Die Maximaldosis von Fumaderm ${ }^{\circledR}$ beträgt in beiden Gruppen 3, ggf. 4 Tabletten pro Tag. Primärer Endpunkt der Studie ist die Überlegenheit der Fumaderm ${ }^{\circ}$ - gegenüber der Placebo-Gruppe nach 20 Wochen Therapie hinsichtlich des PASI 75 (75\%ige Verbesserung des Psoriasis Area and Severity Index) und/oder des PGA (Physician's Global Assessment) o oder 1. Die klinische Prüfung soll über 30 Monate vom Einschluss des ersten bis zum Ausschluss des letzten Patienten laufen. Insgesamt sollen 133 Patienten randomisiert werden.

Schlussfolgerung. Die KIFUderm-Studie soll zeigen, dass Fumarsäureester eine wirksame und sichere Therapieoption für Patienten im Alter von 10-17 Jahren mit mittelschwerer bis schwerer Psoriasis vulgaris sind. Finanziert von Biogen Idec.

\section{DGKJ-PO-U-1 \\ Heterogene Phänotypen einer Cystinurie basierend auf digenischer Vererbung mit Mutationen in SLC3A1 und SLC7A9}

Kummer S. ', Venghaus A. ${ }^{2}$, Schlune A. ', Leube B. ${ }^{3}$, Eggermann T. ${ }^{2}$, Mayatepek E. ', Spiekerkoetter $U{ }^{4}$

'Universitätsklinikum Düsseldorf, Klinik für Allgemeine Pädiatrie, Neonatologie und Kinderkardiologie, Düsseldorf, ${ }^{2}$ Universitätsklinikum RWTH Aachen, Institut für Humangenetik, Aachen, ${ }^{3}$ Universitätsklinikum Düsseldorf, Institut für Humangenetik, Düsseldorf, ${ }^{4}$ Universitätsklinikum Freiburg, Klinik für Allgemeine Kinder- und Jugendmedizin, Freiburg

Die Cystinurie ist eine vererbte Störung des renal-tubulären Cystintransporters mit dem Risiko einer Urolithiasis. Die phänotypische Klassifikation erfolgt in Typ I (unauffällige Heterozygote), Typ non-I (erhöhte dibasische Aminosäuren im Urin von Heterozygoten) oder gemischte Formen. Eine genotypische Klassifikation basiert auf Mutationen in $\mathrm{SLC}_{3} \mathrm{~A}_{1}$ (Typ A) oder SCL7A9 (Typ B).

Sechs Familienangehörige präsentieren sich mit einem komplexen phänotypischen Profil basierend auf einer digenischen Vererbung. Beim Indexpatienten wurde eine bekannte homozygote Mutation (p.T189M) im SLC $3 \mathrm{Al}_{1}-\mathrm{Gen}$ und eine weitere homozygote Variante (c.225T/T) im SLC7A9-Gen gefunden. Bioinformatik und Literaturrecherche legten eine Pathogenität der $\mathrm{SLC}_{3} \mathrm{~A}_{1}$ Mutation nahe, während für die neue c.225T/T-Variante in SLC7A9 keine Pathogenität anzunehmen war. 
Dagegen zeigte sich die p.T189M-Mutation auch homozygot in nicht betroffenen Individuen, während die c.225T/T-Variante mit dem Phänotyp segregierte. Anschließende RNA-Untersuchungen zeigten ein aberrantes Splicing infolge der SLC7A9-Mutation, welche die phänotypische Relevanz erklären. Somit zeigt sich letztere phänotypisch bestimmend, während die beschriebene $\mathrm{SLC}_{3} \mathrm{~A}_{1}$ Mutation hier aggravierend, allein jedoch auch homozygot nicht pathogen ist.

Dies verdeutlicht die Notwendigkeit einer exakten biochemischen Charakterisierung aller Familienangehörigen eines Indexfalles mit Cystinurie, während die genetischen Befunde nicht immer eine eindeutige Identifikation der Individuen mit einem therapierelevanten Phänotyp ermöglichen. Dabei ist aufgrund synergistischer Effekte die Analyse beider Cystinurie-Gene sinnvoll, die in unklaren Fällen auch die Möglichkeit eines aberranten Splicings als pathogenen Mechanismus berücksichtigen sollte.

\section{DGKJ-PO-U-2}

Hyperkalziämie als Leitsymptom einer Pneumocystis-jiroveciiPneumonie 20 Jahre nach Nierentransplantation: eine Kasuistik

\section{Schreiver C.', von Osten H.', Staude H. ', Warncke G.', Wigger M.' \\ 'Universitäts-Kinder- und Jugendklinik, Rostock}

Kasuistik. Die 36-Jährige Patientin leidet unter einem 18p-Syndrom. Bei chronischer Niereninsuffizienz erfolgte 1993 die Nierentransplantation. Es besteht unter Immunsuppression mit Cyclosporin A, Mycophenolat-Mofetil und Methylprednisolon eine chronische Transplantatdysfunktion (GFR $20 \mathrm{ml} / \mathrm{min} / 1,73 \mathrm{~m} 2$ ). Zur Behandlung eines sekundären Hyperparathyreoidismus wurde Cholecalciferol und Calcitriol substituiert. Aktuell bestand seit 4 Wochen eine Leistungsminderung und Malaise, zurückzuführen auf eine Hyperkalziämie von 3,95 mmol/l.

Verlauf. Laborchemisch zeigten sich ein leicht erhöhtes 1,25-DHCC $(134 \mathrm{pg} / \mathrm{ml})$ und ein erniedrigtes Parathormon $(9,6 \mathrm{pg} / \mathrm{ml})$ bei regelrechtem Phosphat, alkalische Phosphatase, LDH und 25-OHD. Unter forcierter Diurese (bis zu 6 l/d) und Absetzen der Vitamin-D-Substitution war keine wesentliche Besserung der Hyperkalziämie zu erzielen. Zum Ausschluss einer paraneoplastischen Hyperkalziämie erfolgte bei unauffälligem rPTH-Peptid ein PET-CT, welche interstitielle Zeichnungsvermehrungen aufwies. In der bronchioalveolären Lavage wurde Pneumocystis jirovecii nachgewiesen. Unter Therapie mit Calcitonin und hochdosiertem Cotrimoxazol kam es zu einer Normalisierung des Kalziums. Gleichzeitig wurde eine akute CMV-Infektion, welche eventuell die Pneumocystis-Pneumonie getriggert hat, mit Valganciclovir behandelt.

Diskussion. Eine Pneumocystis-jirovecii-Infektion als Ursache einer Hyperkalziämie ist selten und auch Jahre nach Nierentransplantation differenzialdiagnostisch zu bedenken. Der Pathomechanismus beruht wahrscheinlich auf einer granulomatösen Entzündungsreaktion, bei der aktivierte Gewebsmakrophagen 1,25-DHCC bilden.

\section{DGKJ-PO-U-3}

COL4A-Mutationen mitunter aus dem Formenkreis des M. Alport 2 Fallvorstellungen

Gohla A.M. ${ }^{1}$, Steidle G. ${ }^{2}$, Winter T. ${ }^{3}$, Krömer U. ${ }^{2}$, Hohenfellner K. ${ }^{2}$ ${ }^{1}$ Ludwig-Maximilian-Universität München, Traunstein, ${ }^{2}$ Klinikum, Traunstein, ${ }^{3}$ Klinikum Wels-Grieskirchen $\mathrm{GmbH}$, Traunstein

Einleitung. Hämaturie - ein klinischen Symptom mit vielfachen Ursachen, differenzialdiagnostisch kann auch der Verdacht auf einen M. Alport bestehen. Wir stellen im Folgenden zwei Patienten mit sehr unterschiedlichem Krankheitsverlauf und Mutationen im COL4AGen.

Männlicher Patient. 10 Jahre 3 Wochen, seit dem 2. LJ bekannte Mikrohämaturie (als benigne abgeklärt). Aktuell: Akanthozyten, große Proteinurie (10,2 g/gKrea), Hypalbuminurie (3,5 g/dl), Hörstörung, pos. Familienanamnese für unklare dialysepflichtige Erkrankung bei männlichen Mitgliedern der Familie.

Weibliche Patientin. 5 Jahre 10 Monate, Schwangerschaftsverlauf/Spotangeburt unauffällig, unklare Psychomotorische Retardierung mit auffälligen cerebralen Veränderungen, rez. Krampfleiden. Mikrohämaturie, eumorphe Erythrozytenform, rez.HWI fraglicher Schlaganfall des Vaters.

Ergebnis. Beide Patienten: Mutationene im COL4A- Gen. Männlicher Patient: M. Alport (COL4A5-Gen Mutation, hemizygot c.3791G>A,p. G1264D, bisher nicht beschrieben). Th: Wegen großer Proteinurie Beginn einer Therapie mit ACE-Hemmer, Meldung im Alport-Register zum eventuellen Einschluss in weitere Studien. Weibliche Patientin: COL4A1-Mutation (heterozygot, c.2263G $>A$, p.G755R) die zu Instabilität der Gefäße führen kann, psychomotorische Retardierung vermutlich aufgrund intrauteriner Blutungen sehr seltene Erkrankung. Nephrologische Beteiligung bekannt, meist nicht mit Dialysepflicht. Proc: Beobachtung.

Schlussfolgerung. Verschiedene Mutationen im COL4A-Gen können zu unterschiedlichen klinischen Symptomen führen. Leitsymptom Hämaturie kann mit unterschiedlichen Erythrozytenformem auftreten. Neben bekanntem Verlauf des Alport sollten Patienten mit pers. Hämaturie und weiteren Symptomen (u. a. Blutungen unklarer Genese) auch auf Mutationen im COL4A-Gen abgeklärt werden.

\section{DGKJ-PO-U-4 Hyponatriämisches hypertensives Syndrom}

Bühler A. ', Grohmann J. ${ }^{2}$, Müller J. ${ }^{3}$, Häffner K. ${ }^{1}$, Pohl M. ${ }^{1}$

'Universitätsklinikum Freiburg, Zentrum für Kinder- und Jugendmedizin, Freiburg, ${ }^{2}$ Universitätsklinikum Freiburg, Universitäts- Herzzentrum, Freiburg, ${ }^{3}$ St. Elisabethen Krankenhaus, Zentrum für Kinder- und Jugendmedizin, Lörrach

Hintergrund. Eine Hyponatriämie beim Kleinkind kann durch verschiedene Erkrankungen hervorgerufen werden und geht in der Regel mit normalen bzw. niedrigen Blutdrücken einher. Die Assoziation mit einer Hypertonie und einer Hypokaliämie ist selten.

Fallbericht. Ein 30 Monate alter Patient präsentierte sich mit zunehmender Polydipsie, fehlender Belastbarkeit und einer Gedeihstörung in den letzten 6 Monaten. Im Rahmen eines leichten Infektes kam es zu einer AZ-Verschlechterung. Laborchemisch bestand eine Hyponatriämie von $114 \mathrm{mmol} / \mathrm{l}$, eine Hypokaliämie von 2,8 mmol/l und eine Proteinurie von $4 \mathrm{~g}$ Eiweiß/g Creatinin. Nach Natrium- und Flüssigkeitssubstitution wurde ein Hypertonus von max. 205/144 mmHg manifest. Sonographisch ließ sich eine Nierenarterienstenose rechts retrocaval, ca. $2 \mathrm{~cm}$ nach Abgang der Nierenarterie, eine milde Hyperechogenität beider Nieren und eine kleinere Niere rechts im Vergleich zur linken Niere darstellen. In der Echokardiographie zeigte sich eine linksventrikuläre Hypertrophie. Initial erhielt unser Patient Captopril 1 mg 3-mal tgl. Daraufhin besserte sich sein Allgemeinzustand und die Proteinurie war auf $1 \mathrm{~g}$ Eiweiß/g Creatinin rückläufig. Sechs Tage nach Beginn der antihypertensiven Therapie wurde die Nierenarterienstenose mittels Ballon dilatiert. Anschließend war die rechte Niere deutlich besser perfundiert und die antihypertensive Therapie wurde reduziert. Nach 4 Wochen zeigte unser Patient einen Gewichtsverlauf von der 1. auf die 9. Perzentile.

Schlussfolgerung. Dieser Fall beschreibt eine seltene, aber typische Präsentation einer kritischen Nierenarterienstenose im Kleinkindalter. Eine schnelle Diagnosestellung ist wichtig, da ein Ausgleich der Hyponatriämie ohne die ursächliche Behandlung der Hypertonie eine bedrohliche Blutdruckkrise hervorrufen kann. 


\section{Endokrinologie/Diabetologie/Adipositas}

\section{DGKJ-PO-E-1 \\ Bronchiale und systemische Entzündung bei adipösen Jugend- lichen mit und ohne Rauchbelastung}

\author{
Kirwil M.', Rosewich M., Eickmeier O., Schubert R., Zielen S. \\ 'Goethe-Universität, Pädiatrische Pneumologie, Allergologie, Frankfurt
}

Fragestellung. Immer mehr Jugendliche leiden heutzutage an den Vorstufen des metabolischen Syndroms. Wir untersuchten, welchen Einfluss die Adipositas auf die systemische und bronchiale Entzündung hat und inwieweit diese Entzündung durch das Rauchen aggraviert wird. Methoden. Hierzu wurden jeweils die Lungenfunktion sowie ein Methacholintest von 20 Jugendlichen der Kontrollgruppe (Altersdurchschnitt 17,3, BMI 21,3), 20 adipösen Nichtrauchern (Altersdurchschnitt 16,0, BMI 36,4) und 19 adipösen Rauchern (Altersdurchschnitt 17,4 BMI 37,1) verglichen. Bei allen Patienten wurde eine Blutuntersuchung durchgeführt und ein induziertes Sputum entnommen.

Ergebnisse. Die Gruppen zeigten keine signifikanten Veränderungen in der Lungenfunktionsprüfung und der bronchialen Hyperreagibilität. Wir fanden signifikante Unterschiede bezüglich der systemischen Entzündungsmarker. Das „low grade“ CRP, IL-6 und IL-8 waren im Serum bei den adipösen Jugendlichen signifikant erhöht vs. Kontrollgruppe. Gleichzeitig war im Vollblut nach 24 Stunden Stimulation mit LPS die relative Freisetzung von IL-6, IP-10 und TNF- $a$, bei der Kontrollgruppe signifikant höher als bei den Adipösen, so dass eine intrinsische Stimulation der neutrophilen Entzündung bei den adipösen Jugendlichen wie beim metabolischen Syndrom anzunehmen ist. Dieser Gruppenunterschied war allerdings nach 24 Stunden Stimulation mit LPS für IL-8 nicht nachweisbar. Im Sputum waren die Gesamtzellzahl und die Neutrophilen bei den adipösen Rauchern signifikant erhöht.

Schlussfolgerung. Bereits bei adipösen Jugendlichen ist eine systemische sowie bronchiale Entzündung mit frühen Zeichen des metabolischen Syndroms mit einer „low grade“-Entzündung nachweisbar. Rauchen führt wie erwartet zu einer stärkeren bronchialen Entzündung.

\section{DGKJ-PO-E-2}

Polyglanduläres Autoimmunsyndrom Typ II mit Adrenalitis, Thyreoiditis und Ovariitis bei einem jugendlichen Mädchen

Döing C. ', Kummer S. ', Müller W. ${ }^{2}$, Mayatepek E. ', Meißner T.' 'Universitätsklinikum Düsseldorf, Zentrum für Allgemeine Pädiatrie, Neonatologie und Kinderkardiologie, Düsseldorf, ${ }^{2}$ Krankenhaus Neuwerk, Mönchengladbach

Hintergrund. Das polyglanduläre Autoimmunsyndrom Typ II (PAS-II, Schmidt-Syndrom) ist charakterisiert durch das Auftreten einer Autoimmunadrenalitis in Kombination mit einer Hashimoto-Thyreoidits und/oder einem Diabetes mellitus Typ I. Häufig treten zusätzlich auch ein primärer Hypogonadismus, eine Myasthenia gravis oder eine Zöliakie auf. Das PAS-II betrifft meist Frauen und tritt in der Regel erst im Erwachsenenalter auf.

Patient. Ein 16 Jahre altes Mädchen präsentierte sich mit zunehmender Müdigkeit, Emesis, Diarrhoe und Hyperpigmentierungen. In der Labordiagnostik zeigte sich ein primärer Hypocortisolismus, eine primäre Hypothyreose sowie ein primärer Hypogonadismus mit sekundärer Amenorrhoe für 9 Monate. Unauffällige Familienanamnese.

Resultat. Adrenale Autoantikörper konnten im Sinne eines Morbus Addison gegen die Steroid-c21-Hydroxylase nachgewiesen werden. Sowohl sonographisch als auch durch positive TPO-Antikörper zeigte sich eine Hashimoto-Thyreoidits. Die Therapie wurde zunächst mit Hydrocortison $(15 \mathrm{mg} / \mathrm{m} 2)$ sowie L-Thyroxin $(1 \mu \mathrm{g} / \mathrm{kg} / \mathrm{d})$ begonnen. Innerhalb von vier Monaten konnte die Hydrocortisondosis auf $6 \mathrm{mg} / \mathrm{m} 2$ reduziert werden. Die Acanthosis verschwand innerhalb von vier Monaten Aufgrund der persistierenden Amennorhoe führten wir einen GnRH-
Stimulationstest durch, welcher ein erhöhtes LH und FSH im Sinne einer primären Ovarialinsuffizienz zeigte. Ovarielle Autoantikörper (p450c17-Hydroxylase und p45oscc-Hydroxylase) konnten nachgewiesen werden. Die Therapie wurde mit Dienogest und Ethinylestradiol begonnen. Die Mens ist darunter nun regelmäßig.

Schlussfolgerung. Bei Patienten mit Morbus Addison und sekundärer Amenorrhoe sollte die Autoimmunovariitis als Teil eines polyglandulären Autoimmunsyndroms Typ II mit in Betracht gezogen werden.

\section{DGKJ-PO-E-3}

\section{Morbus Basedow im Kleinkindalter}

\section{Schneider D.', Salzgeber K. ${ }^{2}$}

${ }^{1}$ Kinderarztpraxis Dres. A. Fauser \& L. Károlyi, Lauingen, ${ }^{2}$ Endokrinologikum, Kinder- und Jugendendokrinologie, Ulm

Einleitung. Der Morbus Basedow kann sich in jedem Alter manifestieren, wobei der Häufigkeitsgipfel in der Pubertät liegt. Ätiologisch bedeutsam sind neben einer HLA-Assoziation virale Infekte und andere exogene Faktoren. Infolge der autonom unkontrollierten Schilddrüsenhormonproduktion zeigen sich erhöhte Werte für freies Trijodthyronin (fT3) und freies Tetrajodthyronin ( $\mathrm{fT}_{4}$ ) sowie Antikörper gegen TSH-Rezeptor (TRAK) und thyreoidale Peroxidase (TPO-AK). Klinisch imponieren obligat eine Struma und eine Tachykardie sowie im Kindesalter selten ein Exophthalmus. Die Initialtherapie erfolgt mit Thyreostatika, bei kardiovaskulärer Symptomatik temporär mit einem $\beta$-Blocker.

Kasuistik. Wir berichten über ein 3 9/12 Jahre altes Mädchen, das sich mit einer größenprogredienten Struma und einem beidseitigen Exophthalmus in der kinderärztlichen Praxis vorstellte. Neben einer zögerlichen Gewichtszunahme war in den letzten 9 Monaten eine gesteigerte Wachstumsgeschwindigkeit aufgefallen. Im Labor ließen sich eine hyperthyreote Stoffwechsellage sowie erhöhte Werte für TRAK und TPO-AK nachweisen. Sonographisch zeigte sich eine stark vergrößerte Schilddrüse mit inhomogener Echogenität. Unter thyreostatischer Therapie mit Carbimazol waren $\mathrm{fT}_{3}$ und $\mathrm{fT}_{4}$ nach 2 Wochen bereits deutlich rückläufig.

Fazit. Bei psychomotorischer Unruhe, Gewichtsverlust und Leistungsabfall sollte im pädiatrischen Praxisalltag an eine Hyperthyreose gedacht werden. Der Zeitraum von der klinischen Manifestation bis zur Diagnosestellung beträgt durchschnittlich 3 bis 4 Monate, im Kleinkindalter häufig länger. Differenzialdiagnostisch kommen primär der Morbus Basedow (TRAK $\uparrow$ ) oder die passagere Hyperthyreose bei Hashimoto-Thyreoiditis (TRAK $\downarrow$ ) in Frage. Neben den Laborwerten ist die Sonographie diagnostisch wegweisend.

\section{DGKJ-PO-E-4}

Saizen ${ }^{\oplus}$-online: Longitudinale Beobachtungsstudie zur Evaluation der Wirksamkeit und Sicherheit von rekombinantem Wachstumshormon

\section{Hartmann K.', Ramseger . $^{2}$}

${ }^{1}$ Medizinisches Kinder- und Jugendzentrum für Endokrinologie \& Diabetologie, Frankfurt, ${ }^{2}$ Merck Serono GmbH, Darmstadt

Fragestellungen. Saizen ${ }^{\circledast}$ ist ein rekombinantes humanes Wachstumshormonpräparat (r-hGH) das in vielen Ländern weltweit für die pädiatrische GH-Supplementationstherapie zugelassen ist. Im Rahmen der Studie sollen Daten zur Wirksamkeit, Sicherheit und Therapieadhärenz von Saizen ${ }^{\circ}$ bei dessen Langzeitanwendung im pädiatrischen Alltag gesammelt werden.

Population und Methoden. Dies ist eine multizentrische, longitudinale, prospektive, nichtinterventionelle Studie bei pädiatrischen Patienten mit Wachstumshormonmangel (GHD), vorgeburtlichen Wachstumsverzögerungen (Small for Gestational Age, SGA), Ullrich-Turner Syndrom (UTS) und chronischer Niereninsuffizienz (CRI), die mit Saizen 
behandelt werden. Der geplante Beobachtungszeitraum pro Patient beträgt 15 Jahre (Studienende 2031). Daten zu Demographie, Körpergrößenentwicklung, Laborparameter und unerwünschte Ereignisse werden erfasst. Adhärenzdaten werden vom Patienten selbst mittels easypod $^{\text {tw }}$ aufgezeichnet. Der easypod ${ }^{\text {tx }}$ ist der einzige Autoinjektor mit versteckter Nadel und Hautsensor für die GH-Applikation, der zudem die applizierte Dosis und Injektionszeit (Uhrzeit und Datum) dokumentiert und speichert.

Ergebnisse. Die Zwischenauswertung zur Wachstumsrate, IGF-1 und Verträglichkeit bei 1401 Patienten, die seit Studienbeginn 2007 behandelt wurden, belegt die Wirksamkeit und zeigt ein gutes Sicherheitsprofil von Saizen ${ }^{\circ}$.

Schlussfolgerungen. Die Langzeitbehandlung mit r-hGH Saizen verbessert die Wachstumsrate bei pädiatrischen Patienten mit GHD, SGA, UTS und CRI und wird gut vertragen. Der Behandlungserfolg ist deutlicher, je früher mit der r-hGH Supplementation begonnen wird.

\section{DGKJ-PO-E-5}

Die Herzfrequenzvariabilitätsanalyse zur kardiovaskuläre Risikostratifizierung bei Kindern mit Minderwuchs oder pathologischer Gewichtsentwicklung

Dippacher S.', Willaschek C.', Meint S. ', Buchhorn R.'

${ }^{1}$ Caritas Krankenhaus Bad Mergentheim, Klinik für Kinder- und Jugendmedizin, Bad Mergentheim

Einleitung. Die Herzfrequenzvariabilitäts(HRV)-Analyse hat sich in der kardiovaskulären Risikostratifizierung bei Erwachsenen bewährt. Aufgrund hoher Variabilität der Normwerte ist dieser Nutzen im Kindesalter noch unklar. In unserer Analyse werden der Einfluss des BodyMass-Index (BMI) und der Körpergröße auf die kindliche HRV untersucht.

Methode. HRV-Analyse von 24-h-Langzeit-EKGs von 174 Kindern im Alter von 9-16 Jahren: Gesunde normal $(n=63)$ und untergewichtige $(n=16)$ Kinder, Anorexia nervosa $(n=17)$, Übergewicht $(n=26)$, Minderwuchs vor $(n=17)$ und unter $(n=19)$ Wachstumshormontherapie. Vergleich mit 16 gleichaltrigen Kindern nach Operation eines schweren angeborenen Herzfehlers.

Ergebnis. Im Gesamtkollektiv besteht eine streng lineare Beziehung zwischen mittlerer nächtlicher Herzfrequenz (nHF) und der Gesamtvariabilität $\mathrm{SDNN}\left(\mathrm{R}_{2}=0,8\right)$. Diese beiden Parameter diskriminieren die normale HRV von gesunden dünnen (SDNN:157 \pm 27 ms, nHF: 70 $\pm 6 /$ min) und normalgewichtigen Kindern (SDNN:181 \pm 46 ms, nHF: $67 \pm 8 /$ min) von Kindern mit Anorexia nervosa (SDNN:256 $\pm 68 \mathrm{~ms}$, nHF: $50 \pm 9 / \mathrm{min}$ ) sowie Übergewicht (SDNN: $147 \pm 30 \mathrm{~ms}, \mathrm{nHF}: 74 \pm 7 / \mathrm{min}$ ) und Minderwuchs (SDNN:143 \pm 24 ms, nHF: $74 \pm 8 / \mathrm{min}$ ). Dagegen sind die Parameter nach Operation eines Herzfehlers nicht pathologisch verändert (SDNN:164 $\pm 59 \mathrm{~ms}, \mathrm{nHF}: 68 \pm 15 / \mathrm{min})$.

Schlussfolgerung. Die globale HRV korreliert vor allem mit der nächtlichen Herzfrequenz und ist bei Kindern mit Minderwuchs und Übergewicht erniedrigt und bei Anorexia nervosa erhöht. Das daraus abgeleitete kardiovaskuläre Risiko ist vor allem bei Übergewicht und Minderwuchs auch unter Wachstumshormontherapie (SDNN:143 $\pm 27 \mathrm{~ms}, \mathrm{nHF}: 75 \pm 10 / \mathrm{min}$ ) gleichsam erhöht. Die normalen HRV-Werte untergewichtiger Kinder zeigen, das nicht der BMI, sondern eher die kalorische Versorgung die globale HRV determiniert.

\section{DGKJ-PO-E-6}

\section{Kann eine Videosprechstunde die Compliance von Kindern bei} einer Therapie mit Wachstumshormon verbessern?

\section{Dörr H.G. ${ }^{1}$, Wilbert C. ${ }^{2}$, Angerer D. ${ }^{3}$}

${ }^{1}$ Kinder- und Jugendklinik, Pädiatrische Endokrinologie, Erlangen, ${ }^{2}$ Ipsen Pharma GmbH, Ettlingen, ${ }^{3}$ Innomedis AG, Köln

Hintergrund. Für eine erfolgreiche Behandlung mit Wachstumshormon $(\mathrm{hGH})$ ist eine gute Compliance unabdingbar.

Fragestellung. Kann eine Videosprechstunde zu einer gesteigerten $\mathrm{Zu}$ friedenheit von Patienten und Ärzten sowie zu einer besseren Therapietreue führen?

Patienten und Methode. An dem Pilotprojekt nahmen fünf kleinwüchsige Kinder $(4 \mathrm{w}, 1 \mathrm{~m})$ im Alter zwischen 6 und 10 Jahren teil, bei denen im Rahmen der zugelassenen Indikationen eine Therapie mit hGH $\left(\right.$ Nutropin ${ }^{\circ}$ ) begonnen wurde. Die Teilnehmer erhielten eine hochauflösende Kamera und die notwendige Software auf einem USB-Stick. Die Installation und Überprüfung des Systems erfolgte zuhause (DA). Die Videosprechstunden waren auf montags und mittwochs zwischen 17 und 18 Uhr festgelegt. Der Anruf musste durch die Patienten erfolgen. Neben den Fragen der Patienten bzw. Eltern wurden auch Fragen anhand eines Standardfragebogens gestellt. Die Gespräche wurden protokolliert.

Ergebnisse. Die Eltern/Patienten waren mit der Videosprechstunde sehr zufrieden. Die Teilnehmer berichteten, dass sie besser mit dem Arzt reden konnten und Probleme z. B. mit dem Injektionsgerät einfacher lösbar waren. Dank der hochauflösenden Kamera ließen sich Bedenken wegen möglicher Irritationen an den Einstichstellen aus der Ferne besprechen. In dem Zeitraum der Studie wurden nach Angaben der Eltern/Patienten keine hGH-Injektionen ausgelassen.

Schlussfolgerung. Die Videosprechstunde ersetzt keine regelmäßigen Kontrollen in der Klinik oder Praxis. Die Ergebnisse des Pilotprojekts lassen hoffen, dass mit der Videosprechstunde langfristig ein wichtiger Beitrag für die Arzt-Patienten-Beziehung und die Qualität der Compliance der Patienten geleistet werden kann.

\section{DGKJ-PO-E-7}

\section{Neonataler Diabetes}

\section{Quader J.', Schroers E.M.', Strier U. ${ }^{2}$}

'Lukaskrankenhaus Neuss, Kinder- und Jugendmedizin, Neuss, 'ElisabethKrankenhaus Rheydt, Kinder- und Jugendmedizin, Mönchengladbach

Einleitung. Der neonatale Diabetes hat eine Inzidenz von 1:500.000 Geburten. Dabei sind Säuglinge in den ersten Monaten betroffen. Die Diagnose kann dann gestellt werden, wenn diese Patienten eine über Wochen bestehende insulinpflichtige Hyperglykämie aufweisen. Ursächlich kommen diverse genetische Mutationen in Frage, welche Proteine betreffen, die für die Funktion der Beta-Zellen des Pankreas erforderlich sind. Diese können sowohl zu einer transienten, als auch zu einer permanenten Hyperglykämie führen. Im Rahmen des transienten neonatalen Diabetes ist meist das Chromosom 6 als uniparentalen Disomie oder unausgeglichenen Duplikation des paternalen Chromosom 6 ursächlich. Beim permanenten neonatalen Diabetes liegt meist eine Mutation des ATP-sensitiven Kaliumkanals vor, welcher die Ausschüttung des Insulins reguliert. Mutationen im KCNJ11 Gen stellen die häufigste Ursache eines permanenten neonatalen Diabetes dar. Therapeutisch kommen neben Insulin auch orale Sulfonylharnstoffe zum Einsatz. Andere Mutationen können zum Verlust der Beta-Zellen oder zu einer Hypoplasie/Agenesie des Pankreas führen.

Methoden und Ergebnisse. Wir berichten über einen fünf Monate alten männlichen Säugling, welcher sich mit Ketoazidose (ph 6,9; BE -30) und Hyperglykämie (BZ $450 \mathrm{mg} / \mathrm{dl})$ präsentierte. Familiär lag eine Belastung für neonatalen und frühkindlichen Diabetes vor. In den ersten 12 Stunden kam es trotz Insulintherapie zu einer Verschlechterung. Erst im weiteren Verlauf Besserung und Umstellung auf einen oralen Sulfo- 
nylharnstoff. Unter dieser Therapie konnte die Insulintherapie beendet werden. Es konnte eine heterozygote Mutation im KCNJ11-Gen nachgewiesen werden.

Schlussfolgerung. Beim neonatalen Diabetes spielen genetische Ursachen eine wichtige Rolle bei der Abklärung der ursächlichen Störung, welche zur Hyperglykämie führt.

\section{DGKJ-PO-E-8}

Neonataler Diabetes bei heterozygoter KCNJ11-Mutation Val59Met: frühe Glibenclamidtherapie führt zu normaler, psychomotorischer Entwicklung (im Alter von 16 Monaten)

Berlemann B. ${ }^{1}$, Bürüccüoglu T.', Seiffert P. ${ }^{1}$, Gong M. ${ }^{2}$, Simaite D. ${ }^{2}$, Raile K. ${ }^{2}$ ${ }^{1} \mathrm{HELIOS}$ St. Johannes-Klinik Duisburg, Pädiatrie, Duisburg, ${ }^{2}$ Charité - Universitätsmedizin Berlin, ECRC, Berlin

Fragestellung. Kann eine frühe Glibenclamidtherapie bei KCNJ11-Mutation bei persistierendem neonatalem Diabetes das neurologische Outcome verbessern?

Methoden. Gensequenzierung (ABCC8 und KCNJ11), HbA1c-Bestimmung, Bayley-Scale. Zwei Monate alter Säugling mit in der BGA erhöhter Serumglukose ( $325 \mathrm{mg} / \mathrm{dl}$ ) als Zufallsbefund bei Luftwegsinfekt. Unauffällige Patienten- und Familienanamnese. Zunächst Einstellung auf CSII-Pumpentherapie und kontinuierliches Glukosemonitoring. Antikörper und Ketone negativ. MODY negativ. C-Peptid niedrig. Unmittelbare umfassende molekulargenetische Diagnostik.

Ergebnisse. Nachweis einer heterozygoten KCNJ11-Mutation (Val59Met) als aktivierende Mutation, die den ATP-abhängigen Kaliumkanal Kir6.2/SUR kodieren (häufigste Ursache von transientem oder persistierendem neonatalem Diabetes). Häufiges Auftreten schwerer neurologischer Begleitsymptome (DEND-Syndrom) beschrieben. Unmittelbare Umstellung auf Glibenclamid zur Konformationsänderung des Kanals und Wiederherstellung der physiologischen Funktion (initialen Dosis o,2 mg/kgKG/die). Nun nahezu normoglykäme Einstellung innerhalb von Tagen. Dosis nach 12 Monaten 0,06 mg/kgKG. Beurteilungen mittels Bayley-Scale zu Beginn der Therapie und aktuell zeigen keinerlei neurologische Auffälligkeiten. HbAıc im Alter von 16 Monaten $5,8 \%$.

Schlussfolgerung. Dieser Fall und erste entwicklungsneurologische Analysen von KCNJ11-DEND-Fällen zeigen, dass neurologische Symptome komplett oder partiell durch eine möglichst frühe Therapie mit Glibenclamid verbessert werden können. Wir empfehlen bei Fällen mit der Diagnose „Neonataler Diabetes“ eine rasche, molekulargenetische Untersuchung bzgl. KCNJ11/ABCC8 Mutationen und eine unverzügliche Therapieumstellung auf Glibenclamid, falls DEND-assoziierte Mutationen (z. B. KCNJ11 Val59Met) vorliegen.

\section{DGKJ-PO-E-9}

Psychische Gesundheit von Jugendlichen mit frühmanifestem Typ1-Diabetes

Stahl-Pehe A. ', Lange K. ${ }^{2}$, Castillo K. ${ }^{1}$, Bächle C. ${ }^{1}$, Meissner T. ${ }^{3}$, Holl R.W. ${ }^{4}$, Giani G.', Rosenbauer J.', in Kooperation mit ESPED, der DPV-Initiative und gefördert vom Kompetenznetz Diabetes mellitus (Fördernummer ${ }^{01} \mathrm{G}{ }^{1802}$, ${ }^{01} \mathrm{Gl}{ }^{1109} \mathrm{~A}$ )

'Deutsches Diabetes-Zentrum (DDZ), Institut für Biometrie und Epidemiologie, Düsseldorf, ${ }^{2}$ Medizinische Hochschule Hannover, Medizinische Psychologie, Hannover, ${ }^{3}$ Universitätsklinikum Düsseldorf, Klinik für Allgemeine Pädiatrie, Neonatologie und Kinderkardiologie, Düsseldorf, ${ }^{4}$ Universität Ulm, Institut für Epidemiologie und medizinische Biometrie, Ulm

Fragestellung. Unterscheiden sich Jugendliche mit früher Manifestation und langjährigem Typ-1-Diabetes hinsichtlich der psychischen $\mathrm{Ge}$ sundheit von der Allgemeinbevölkerung?

Material und Methoden. 11- bis 17-jährige mit Typ-1-Diabetes (Manifestation im Alter von unter 5 Jahren im Zeitraum 1993-1999) und ihre Eltern nahmen an einer deutschlandweiten Befragung teil. Die repräsentative Vergleichsgruppe bestand aus 6813 Gleichaltrigen aus der KiGGS-Basiserhebung. Als Screeninginstrument für psychische Gesundheit wurde der Strengths and Difficulties Questionnaire (SDQ) eingesetzt. Odds Ratios (OR) für psychische Auffälligkeiten wurden mittels logistischer Regression geschätzt und für Alter und Geschlecht adjustiert.

Ergebnisse. An der Studie nahmen 629 Patienten teil (im Durchschnitt Alter 15,3 Jahre, Diabetesdauer 12,5 Jahre). Basierend auf dem Elternurteil unterschied sich der Anteil „auffällig“ klassifizierter Jugendlicher zwischen den beiden Gruppen weder insgesamt noch in den SDQ-Skalen Verhaltensprobleme, emotionale Probleme, Probleme mit Gleichaltrigen und prosoziales Verhalten. Eine auffällige Hyperaktivität wurde von den Eltern der Patienten seltener beschrieben [3,5\% vs. $6,5 \%$, $\mathrm{OR}=0,57(0,37-0,89), \mathrm{p}=0,014]$. Basierend auf dem Selbsturteil bestand zwischen den beiden Gruppen kein Unterschied hinsichtlich Verhaltensproblemen, emotionaler Probleme und Problemen mit Gleichaltrigen. Patienten hatten häufiger einen auffälligen Gesamtproblemwert $[4,4 \%$ vs. $2,9 \%, O R=1,62(1,08-2,48), p=0,024]$ sowie ein auffälliges prosoziales Verhalten [4,9\% vs. $2,9 \%, \mathrm{OR}=1,62(1,09-2,42), \mathrm{p}=0,017]$.

Schlussfolgerungen. Jugendliche mit Typ-1-Diabetes, nicht jedoch ihre Eltern, berichten etwas häufiger psychische Auffälligkeiten. Dies sollte bei der Diabetesbetreuung berücksichtigt werden.

\section{DGKJ-PO-E-10}

\section{Motivationsförderung in der Diabetesschulung für Jugendliche}

Stachow R.', Scheewe S. ', Burmester $H .{ }^{1}$

'Fachklinik Sylt für Kinder und Jugendliche, Westerland

Einleitung. Auf Basis der motivierenden Gesprächsführung (Miller \& Rollnik) wurde ein Gruppenschulungsprogramm entwickelt, um Krankheitsakzeptanz und Motivation zum Krankheitsmanagement (KM) für Jugendliche mit Diabetes mellitus Typ 1 (DM) zu fördern.

Methode. Programm mit 7 Modulen a 45 min. Themen: Reflexion über Lebensziele und Bedeutung des Diabetes. Aufarbeitung von Emotionen im Rollenspiel und Darstellung einer verbesserten Krankheitsakzeptanz. Fiktive Kommunikation mit dem eigenen Diabetes. Herausarbeiten möglicher Verhaltensänderungen im KM. Evaluierung u. Auflösung von Ambivalenzen zu den Verhaltensänderungen. Vertrag mit sich selbst für das zukünftige KM. Die Schulungsmodule wurden hinsichtlich Wichtigkeit, Lerneffekt und Befindlichkeit evaluiert, sowie Motivations- und Verhaltensänderungen statistisch (Wilcoxon-T.) am Ende der Schulung analysiert.

Ergebnisse. 25 Jugendliche partizipierten an insgesamt 4 Schulungen im Rahmen einer Rehabilitation (Alter 15,8 J, Anteil Jungen 55\%, DM-Dauer: $7,8 \mathrm{~J}) .27 \%$ der Patienten gaben initial wenig Motivation an. Bewertung der Module durch Schulnoten, im Mittel: Wichtigkeit: 1,9; Lerneffekt: 2,4; Emotionaler Effekt 2,2; Gesamtzufriedenheit: 1,65; etwas Neues gelernt zu haben: 1,97; mit den Schulenden: 1,38. Die emotionale Befindlichkeit verbesserte sich signifikant $(\mathrm{p}=0,035)$ und der HbAic $(\mathrm{p}=0,005)$. Steigerung der Motivation zum KM in der Selbstbewertung $(\mathrm{p}=0,001)$ und Fremdbewertung durch Therapeuten $(\mathrm{p}=0,003)$. Weiter gaben die Jugendlichen an, nun „eigenständiger leben zu können“ und „krankheitsbedingte Gefühle besser im Griff zu haben“.

Schlussfolgerung. Module zur Motivationsförderung lassen sich gut in Patientenschulungen integrieren, zeigen eine hohe Akzeptanz und mindestens eine kurzfristige Motivationssteigerung. 
DGKJ-PO-E-11

\section{Molekulare Charakterisierung 6 neuer TSHR-Mutationen}

Stock L. ', Pohlenz J. ', Hermanns P.'

'Zentrum für Kinder- und Jugendmedizin, Molekulare Endokrinologie, Mainz

Einleitung. Mutationen des TSH-Rezeptor(TSHR)-Gens können Ursache für verschiedene Schilddrüsenfunktionsstörungen sein. Sind sie aktivierend, resultiert eine Hyperthyreose, bei inaktivierenden $\mathrm{Mu}$ tationen kommt es zu einer Hypothyreose. In den letzten drei Jahren wurden in unserem Labor sechs Kinder mit Schilddrüsenfunktionsstörungen identifiziert, die Träger einer jeweils bisher nicht beschriebenen TSHR Mutation sind.

Fragestellung. Die neuen TSHR-Mutationen wurden molekulargenetisch charakterisiert.

Material und Methoden. Das TSHR-Gen wurde von genomischer DNA amplifiziert und direkt sequenziert. Die Sequenz der identifizierten Mutationen wurde in Expressionsvektoren einkloniert und HEK293 Zellen transfiziert. Zur Messung der Aktivität der jeweiligen Mutation wurde ein Dual Luciferase Assay verwendet. Dieser ermöglichte einen Rückschluss auf die Aktivität des TSH Rezeptors unter Einfluss von Thyreotropin.

Ergebnisse. Passend zur klinischen Beobachtung hatten die Patienten mit einer Hyperthyreose eine gesteigerte Expression von cAMP, was auf eine aktivierende Eigenschaft der Mutationen hindeutet. Die beiden anderen Mutationen waren im Vergleich zum Wildtyp inaktivierend.

Fazit. Unsere Untersuchungen bestätigen in vitro, dass die identifizierten TSHR Mutationen krankheitsverursachend sind.

\section{Infektiologie (1)}

\section{DGKJ-PO-J1-1}

\section{Benigne akute Myositis des Kindesalters: sechs Kasuistiken}

\section{Kalligerou E.', Damerow T. ${ }^{1}$ \\ ${ }^{1}$ Kinder- und Jugendklinik Gelsenkirchen, Allgemeine Pädiatrie, Gelsen- kirchen}

In der Kinder- und Jugendklinik Gelsenkirchen wurden im März/April 2013 fünf Kinder mit Symptomen einer ausgeprägten Myalgie der unteren Extremitäten, sowie passagerer Gangstörung, kurz nach oder während eines viralen Infekts aufgenommen. Vier der fünf Patienten wurden uns in einem Zeitraum von 10 Tagen vorgestellt. Eine weitere Patientin haben wir Ende Oktober 2012 mit den gleichen Symptomen betreut, so dass wir insgesamt 6 Fälle einer eher seltenen Krankheit in einer Saison zu betreuen hatten. 4 von 6 der Patienten waren Jungen, der Altersmedian betrug 9,6 Jahre. Laborchemisch zeigte sich bei jedem Patienten eine deutliche CK-Erhöhung, mit einem Median von 3232 U/l, sowie einer GOT-Erhöhung (Median betrug $140 \mathrm{O} / \mathrm{l}$ ), einer Leukopenie (Median von $3173 / \mu \mathrm{L}$ ) und bei 3 von 6 Patienten auch einer Thrombozytopenie. Das Symptom Myalgie dauerte durchschnittlich 2,5 Tage (Spannweite 1-4 Tage) und war bei allen unseren Patienten komplett rückläufig, so dass wir die Kinder nach wenigen Tagen symptomatischer Therapie mit Analgesie bzw. Antipyrese, Flüssigkeitszufuhr und Bettruhe in gutem Allgemeinzustand und beschwerdefrei nach Hause entlassen konnten. Bei einem Patienten erhielten wir nach der Entlassung das Ergebnis einer PCR von einem Nasen-Rachen-Abstrich, welcher eine Influenza-B-Infektion nachwies. Bei einem zweiten Kind konnte serologisch eine frische Echo- und Coxsackievirusinfektion nachgewiesen werden.

\section{DGKJ-PO-J1-2 Infektiöse Myositis}

Mathes K.', Wenzler J.O.D.M. ', Full H.O.D.M. ', Ruef P.K.P.D.M. ${ }^{1}$

'SLK Klinik, Pädiatrie, Heilbronn

Hintergrund. Die Myositis ist eine entzündliche Muskelerkrankung, die akut oder chronisch verlaufen kann. Als Ursache kann eine Infektiöse Myositis durch einen bekannten Erreger oder ein DermatomyositisPolymyositis-Komplex durch einen unbekannten Erreger, vermutlich autoimmun zugrunde liegen. Die Postinfektiöse Myositis ist eine gutartige Erkrankung, die häufig im Schulalter auftritt. In der Literatur sind nur wenige Daten zu dieser Erkrankung bekannt.

Patienten. Fünf Patienten in den letzten 2 Monaten, davon alle männlich mit einem Durchschnittsalter von 9,1 J ( 5,4-13 J). Alle Patienten konnten nicht mehr gehen, klagten über Waden- bzw. Knieschmerzen und litten 2-6 Tage vor dem Auftreten der Symptome an Infekten (viraler Infekt: 1, fieberhafter Infekt: 4). Bei Aufnahme litt einer an Fieber, 5 an einem auffälligen Gangbild, 4 an einem Druckschmerz in der Wade. Laborchemisch zeigte sich bei allen Patienten ein Leuko- und Thrombozytopenie sowie eine CK-Erhöhung von 1908 -4095 U/1, deren Urin war jeweils unauffällig. Vier der Patienten wurden mit Analgetika behandelt und allen wurde anfangs Bettruhe verordnet. Alle 5 Patienten waren nach 2-4 Tagen beschwerdefrei, die CK war rückläufig und es kam zu keinerlei Komplikationen. Bei einem der 5 Patienten trat nach 6 Wochen dieselbe Symptomatik erneut auf.

Ergebnisse. Kein Erregernachweis. Ein einmalig durchgeführter Influenzaschnelltest fiel negativ aus.

Schlussfolgerung. Sowohl die Klinik als auch die Laborauffälligkeiten sind typisch. Eine Bestimmung der Creatininkinase ist wegweisend. Der Verlauf ist in der Regel benigne. Nur selten sind komplizierten Verläufen mit Myoglobinurie beschrieben. Es findet sich eine Assoziation mit viralen Infekten in den Wintermonaten, die Pathogenese jedoch bleibt unklar.

\section{DGKJ-PO-J1-3 \\ Pneumokokken-assoziierte Pleuraempyeme in Deutschland - Ergebnisse der ESPED Studie 2010-2012}

Keller S.', Hagemann C.', Segerer F.', Schoen C. ${ }^{2}$, van der Linden M.P.G. ${ }^{3}$, Streng A. ${ }^{\prime}$, Rose M.A. ${ }^{4}$, Liese J.G. ${ }^{1}$

'Universitätsklinik Würzburg, Kinderklinik und Poliklinik, Würzburg, ${ }^{2}$ Universität Würzburg, Institut für Hygiene und Mikrobiologie, Würzburg, ${ }^{3}$ Universitätsklinikum RWTH Aachen, Nationales Referenzzentrum für Streptokokken Abteilung Medizinische Mikrobiologie, Aachen, ${ }^{4}$ J.W. Goethe Universität, Zentrum der Kinder- und Jugendmedizin, Frankfurt

Einleitung. Ein Inzidenzanstieg parapneumonischer Pleuraergüsse und Empyeme (PPE) bei Kindern und Jugendlichen wurde auch nach Einführung der Pneumokokken-Impfung beobachtet.

Methode. Surveillancestudie in allen 472 deutschen Kinderkliniken mittels der „Erhebungseinheit für seltene pädiatrische Erkrankungen (ESPED)“. Eingeschlossen sind Kinder $<18$ Jahren mit PPE, die $\geq 1$ Woche persistieren oder per Drainage behandelt werden. Bakterielle Erregerdiagnostik aus Pleurapunktat:

- 16s-rDNA-PCR,

- Pneumokokken-Serotypisierung.

Ergebnisse. Von 10/2010 bis o6/2012 wurden 400 PPE Fälle ausgewertet. Bei 116 (33\%) von 356 Kindern mit durchgeführter Erregerdiagnostik aus Blut oder Pleurapunktat wurde mindestens ein Erreger nachgewiesen. Bei 60 von 116 Kindern mit positivem Erregernachweis wurde S. pneumoniae nachgewiesen (P-PPE). Intensivpflichtig waren $72 \% \mathrm{der}$ P-PPE-Kinder und $22 \%$ hatten chronische Vorerkrankungen. Mögliche bleibende Krankheitsfolgen wurden bei $22 \%$ berichtet. Todesfälle traten nicht auf. Identifizierte Pneumokokken-Serotypen (P-ST) von 29 untersuchten Proben waren: P-ST 1 (10-mal), 3 (5-mal), 7F (4-mal) und 19A (3-mal); 7 Proben konnten nicht serotypisiert werden. Von den 22 
Kindern mit identifiziertem P-ST waren 13 (59\%) mindestens einmal mit $\mathrm{PCV}_{7}$ geimpft, 6 (27\%) waren ungeimpft und bei 3 (14\%) Kindern war der Impfstatus unbekannt. Impfdurchbrüche nach regelgerechter PCV13-Impfung bei 2 Kindern:

- P-ST 19A: 10-monatiges Kind; Brutonsche Agammaglobulinämie, - P-ST 3: 15-monatiges Kind; keine Vorerkrankungen bekannt.

Diskussion. Pneumokokken waren der häufigste Erreger von PPE. Die nachgewiesenen P-ST 1,3, 7F und 19A werden nicht durch PCV7, jedoch alle durch $\mathrm{PCV}_{13}$ erfasst. Weitere Surveillance ist notwendig, um den Einfluss der PCV13-Impfung auf PPE zu verfolgen.

\section{DGKJ-PO-J1-4}

Spezifische Detektion von Immunantworten gegen atypische Mycobakterien bei Kindern mit Lymphadenopathie unklarer Ätiologie

Chung D.-U.', Kohns M.', Seyfarth J.', Seibt A.', Mayatepek E.', Weber A.-A.', Bosse H.M.', Schramm D.', Jacobsen M.'

'Universitätsklinikum Düsseldorf, Klinik für Allgemeine Pädiatrie, Neonatologie und Kinderkardiologie, Düsseldorf

Einleitung. Die klinische Diagnose nicht-tuberkulöser mycobakterieller (NTM)-Infektionen bei Kindern mit Lymphadenopathie (LA) basiert derzeit auf dem kulturellen Erregernachweis. Immunologische Nachweismethoden für NTM-Infektionen sind nicht verfügbar. Frühere Studien zeigten, dass ein Vergleich der T-Zellantworten gegen M. avium (Sensitin)- und M. tuberculosis (Tuberculin)- Proteine zwischen Kindern mit Tuberkulose und NTM-Infektion unterscheiden kann. Ziel dieser Studie war die Etablierung einer immunologischen Methode zur Detektion von NTM-Infektionen in Kindern mit LA unklarer Ätiologie, sowie der Vergleich der Prävalenz mit Kontrollgruppen.

Methoden. Insgesamt wurden 28 Kinder mit LA rekrutiert. Bei 18 Kindern war die Ursache unbekannt, 2 Kinder hatten einen positiven Befund für NTM und 8 Kinder hatten eine bestätigte nicht-mycobakterielle Erkrankung. Vollblut und aufgereinigte Immunzellen wurden in vitro mit Sensitin bzw. Tuberculin restimuliert. Im Anschluss wurden verschiedene T-Zellzytokine durchflusszytometrisch sowie mittels ELISA bestimmt.

Ergebnisse. IFN $\gamma$ und das IFN $\gamma$-induzierte Protein(IP)-10 wiesen die höchste Spezifität für NTM-Infektionen auf. Beide Faktoren konnten im Überstand der Vollblutstimulation mittels ELISA detektiert werden. Insgesamt legten die Analysen bei 6 der 18 untersuchten Kinder mit LA unklarer Ätiolgie eine NTM-Infektion nahe, während keines der Kinder der Kontrollgruppe positiv getestet wurde. 2 der 6 Verdachtsfälle wurden anschließend auf mycobakterielle Erreger untersucht und beide hatten positive kulturelle Befunde für M. avium.

Schlussfolgerung. Diese Ergebnisse zeigten, dass die Bestimmung von IFN $\gamma$ bzw. IP-10 zur Diagnose von NTM-Infektionen prinzipiell geeignet ist und lassen einen hohen Anteil (>30\%) von NTM bei Kindern mit LA unklarer Ätiologie vermuten.

\section{DGKJ-PO-J1-5}

Differenzielle miRNA-Expression im Blut von Kindern mit aktiver Tuberkulose

Ueberberg B. ${ }^{1}$, Kohns M. ${ }^{1}$, Schattling S. ${ }^{2}$, Heesch K. ${ }^{2}$, Marx F.M. ${ }^{3}$, Mayatepek E.', Jacobsen M. ${ }^{1}$

'Universitätsklinikum Düsseldorf, Klinik für Allgemeine Pädiatrie, Neonatologie und Kinderkardiologie, Düsseldorf, ${ }^{2}$ Bernhard-Nocht-Institut für Tropenmedizin, Hamburg, ${ }^{3}$ Charité - Universitätsmedizin Berlin, Klinik für Pädiatrische Pulmonologie und Immunologie, Berlin

Einleitung. MicroRNAs (miRNAs) spielen eine bedeutende Rolle bei der Regulation des Immunsystems und damit assoziierten pathologischen Veränderungen (u. a. Immunzellentartung, Autoimmunität). Nur wenig ist über die Bedeutung von miRNAs bei chronischen Infektionskrankheiten wie der Tuberkulose (TB) bekannt.
Methoden. Aufgrund eigener Untersuchungen an T-Zellen von erwachsenen Patienten mit TB haben wir sieben Kandidaten miRNAs identifiziert, deren Expression in der vorliegenden Studie im Blut von 22 Kindern mit TB und 14 gesunden Kindern mit latenter M.-tuberculosisInfektion (LTBI) untersucht wurde. Des Weiteren wurde die Expression von Zielproteinen differentiell exprimierter miRNAs bestimmt.

Ergebnisse. Die Analyse der Kandidaten miRNAs mittels quantitativer PCR zeigte signifikant reduzierte Expression von miR-26a $(\mathrm{p}<0,01)$, miR-29a ( $\mathrm{p}<0,01)$, miR-142-3p ( $\mathrm{p}<0,05), \mathrm{miR}^{-155}(\mathrm{p}<0,05)$ und miR-223 $(\mathrm{p}<0,05)$ im Blut von Kindern mit TB im Vergleich zu Kindern mit LTBI. Ein Anstieg der miR-223 nach erfolgreicher Therapie war bei Kindern mit TB zu beobachten. Erste Untersuchungen zur Modulation der miR-29a Expression (transiente Inhibition der Expression mittels AntagoMiRs) zeigten keinen Effekt auf die T-Zellproduktion des beschriebenen Zielgens IFN $\gamma$.

Schlussfolgerung. Die in unserer Studie gezeigten Unterschiede im miRNA-Expressionsprofil zwischen Kindern mit TB und LTBI - sowie im Verlauf der Behandlung - deuten auf eine Rolle der miRNAs in der Pathogenese der TB hin. In laufenden Untersuchungen wird die Funktion der identifizierten differentiell exprimierten miRNAs für die T-Zellantwort näher charakterisiert.

\section{DGKJ-PO-J1-6}

Ein epidemiologischer und klinischer Vergleich der saisonalen H1N1-Influenza 2012/2013 und der H1N1-Pandemie 2009/2010 an der Universitätskinderklinik Bonn

\section{Schröder L.', Eis-Hübinger A.M.' , Born M. ${ }^{3}$, Franke I.'}

${ }^{1} K$ linik und Poliklinik für Allgemeine Pädiatrie, Zentrum für Kinderheilkunde, Universitätsklinikum, Bonn, ${ }^{2}$ Institut für Virologie, Universitätsklinikum, Bonn, ${ }^{3}$ Radiologische Klinik, FE Kinderradiologie, Universitätsklinikum, Bonn

Patienten und Methodik. Daten von insgesamt $\mathrm{n}=8 \mathrm{o}$ stationär behandelten Kindern mit nachgewiesener HiN1-Influenza wurden retrospektiv über einen Zeitraum von Juli 2009 bis Januar 2010 bzw. November 2012 bis April 2013 untersucht. Einschluss: PCR Nachweis auf Influenza A $\left(\mathrm{H}_{1} \mathrm{~N}_{1}\right)$ und stationäre Aufnahme. Am Kollektiv untersucht wurden die Krankenhausverweildauer, das Auftreten von Pneumonie (radiologisch gesichert) und extrapulmonalen Manifestationen, Entzündungsparameter (CRP, Leukozyten, Neutrophile, Lymphozyten), Vitalparameter, Sauerstoffbedarf, Inhalationstherapie, antivirale/antibiotische Therapie, Intensivpflichtigkeit und Todesrate.

Ergebnisse. In der Saison 09/10 wurden $61(\mathrm{w}=29)$ Patienten stationär behandelt, bei $19(\mathrm{w}=11)$ Patienten in der zurückliegenden Saison 12/13. Das Alter (SD) lag bei 9,4 bzw. 8,3 Jahre (o9/10 vs. 12/13). Die mittlere Verweildauer lag bei 5,1 d bzw. 11,1 d. Bei 14 Patienten (23\%) bzw. 6 (31\%) wurde radiologisch eine Pneumonie gesichert. O2-Bedarf bestand bei 7 (11\%) bzw. 9 (47\%), eine antivirale Therapie erfolgte bei 33 (54\%) bzw. 11 Patienten (57\%). Antibiotisch therapiert wurden 44 (72\%) bzw. $14 \mathrm{~Pa}$ tienten (74\%). Der Zeitraum der stationären Behandlungen erstreckte sich über 7 Monate bzw. 3 Monate.

Schlussfolgerungen. Die Pandemie 09/10 begann deutlich früher im Jahr als die saisonale 12/13. Während der Pandemie 09/10 war die Rate an Hospitalisierungen um 68\% höher als in der vergangenen Saison, die Verweildauer war jedoch 12/13 deutlich länger. Die Inzidenz an Pneumonien ist 12/13 signifikant höher, was sich auch in der deutlich erhöhten Rate an O2-Bedarf widerspiegelt. Weit weniger Kinder wurden im Rahmen der saisonalen Influenza krankenhauspflichtig, jedoch war der klinische Verlauf schwerer, als in der zurückliegenden PandemieSaison. 


\section{DGKJ-P0-J1-7}

Diffuse unilaterale subakute Neuroretinitis (DUSN) durch einen Hakenwurm - molekularbiologische Typisierung einer möglicherweise in Europa erworbenen Infestation durch Ancylostoma ceylanicum

Heideking M. ', Hufnagel M. ${ }^{1}$, Poppert S. ${ }^{2}$, Henneke P. ${ }^{1,3}$, Kern W. ${ }^{4}$, Agostini H. ${ }^{5}$ 'Universität Freiburg, Zentrum für Kinder- und Jugendmedizin, Freiburg, ${ }^{2}$ Bernhard-Nocht-Institut für Tropenmedizin, Hamburg, ${ }^{3}$ Universität Freiburg, Centrum für chronische Immundefizienz, Freiburg, ${ }^{4}$ Universität Freiburg, Department Infektiologie, Medizinische Universitätsklinik, Freiburg, ${ }^{5}$ Universität Freiburg, Universitäts-Augenklinik, Freiburg

Einleitung. DUSN ist eine durch Nematoden verursachte entzündliche Erkrankung der Aderhaut oder Retina. Die Erregeridentifikation gelingt nur in den wenigsten Fällen. Ancylostoma ceylanicum ist ein in Südostasien, Australien und Südamerika verbreiteter zoonotischer Hakenwurm.

Fallbericht. Ein 10-jähriger, aus Kolumbien stammender Adoptivjunge wurde aufgrund eines akuten Schattensehens am rechten Auge vorgestellt. Die augenärztliche Untersuchung ergab eine retinale Vaskulitis mit seröser Amotio retinae. Intraoperativ konnte ein 1-2 cm langer, weißlicher, gut beweglicher, subretinal gelegener Wurm dargestellt werden, der nur zerstückelt extrahiert werden konnte. Die weitere Diagnostik erbrachte negative Serologien für T. canis, F. hepatica, Strongyloides spp., Trichinella spp. und Zystizerkose. Die mikroskopische Untersuchung von Blut auf Filarien bzw. von Stuhl auf Wurmeier fiel negativ aus. In der operativ gewonnenen Spülflüssigkeit gelang molekulargenetisch der Nachweis von A. ceylanicum. Neben einer operativen Therapie erfolgte eine antihelminthische Therapie mit Albendazol. Dennoch ließ sich ein Visusverlust nach einer proliferativen Vitreoretinopathie nicht vermeiden.

Schlussfolgerung. Im vorliegenden Fall gelang der molekularbiologische Nachweis eines Hakenwurms als Auslöser einer DUSN. Bei einer Sequenzhomologie von $94 \%$ handelt es sich mit größter Wahrscheinlichkeit um A. ceylanicum. Bei negativer Reiseanamnese in den letzten 6 Jahren und wiederholtem Kontakt zu fremden Hunden hat die Übertragung möglicherweise in Mitteleuropa stattgefunden. Ungewöhnlich wäre die Alternative, dass der Hakenwurm in Kolumbien erworben wurde und vor Auftreten der DUSN jahrelang auf Wanderschaft in unserem Patienten gewesen ist.

\section{DGKJ-PO-J1-8}

\section{Varizellenimpfung in Bayern - Auswirkung der STIKO-Empfehlung zur MMRV-Impfung}

\section{Streng A. ', Hagemann C. ', Hanke S. ', Liese J.G.}

'Universitätsklinikum Würzburg, Kinderklinik und Poliklinik, Würzburg

Hintergrund. Seit 2009 besteht die Empfehlung der STIKO, alle Kinder mit 2 Dosen gegen Varizellen zu impfen. Aufgrund der leicht erhöhten Häufigkeit von Fieberkrämpfen bei Erstimpfung mit Kombinationsimpfstoffen für Masern-Mumps-Röteln-Varizellen (MMRV1) empfahl die STIKO im September 2011, für die erste Impfung monovalenten Varizellenimpfstoff ( $\left.\mathrm{V}_{1}\right)$ und MMR-Impfstoff (MMR1) separat zu verabreichen. Wir untersuchten die Auswirkung dieser Empfehlung. Methode. Vergleich von Varizellen- und MMR-Impfungen sowie Varizellenfällen im Jahr vor und im Jahr nach der Empfehlung 2011 anhand monatlicher Surveillance-Daten aus Kinderarztpraxen in München (Mü; Okt 2010 bis Jun 2011 vs. Okt 2011 bis Jun 2012) und Würzburg (Wü; Okt 2010 bis Sep 2011 vs. Okt 2011 bis Sep 2012).

Ergebnisse. In Mü wurden 1405 Monatsbögen ausgewertet, in Wü 326 Bögen. In Mü gingen nach der Empfehlung 2011 die Varizellenerstimpfungen insgesamt (V1 oder MMRV1) um 12\% ( $<<0,005)$ zurück, von durchschnittlich 10,1 auf 8,9 Impfungen pro Praxismonat. In Wü war der Rückgang 4\% (von durchschnittlich 9,9 auf 9,5 Impfungen pro Praxismonat; nicht signifikant). Die MMR-Erstimpfungen insgesamt (MMRı oder MMRV1) änderten sich in beiden Regionen nicht signi- fikant. Die durchschnittliche Anzahl der Varizellenfälle pro Praxismonat sank in Mü von 1,8 auf 1,3 (p<0,oo1), in Wü von 1,o auf o,7 ( $\mathrm{p}=0,004)$. Diskussion. Der weitgehende Verzicht auf MMRV1 nach der STIKOEmpfehlung 2011 wurde durch monovalente V1 nicht vollständig kompensiert; dies führte zu einem regional unterschiedlichen Rückgang der Varizellenerstimpfungen insgesamt. Der weitere Rückgang der Varizellenfälle beruht vermutlich auf Herdenschutzeffekten bei bereits hohen Impfquoten. Längerfristig ist zu erwarten, dass der Anteil der Kinder ohne vollen Impfschutz ansteigt.

\section{DGKJ-PO-J1-9}

Entwicklung der Varizellen-Impfquoten in München 2006 bis 2011 - Ergebnisse aus dem Bayerischen Varizellen-Surveillance-Projekt (BaVariPro)

\section{Hagemann C.' , Streng A.', Seeger K.', Grote V. ', Liese J.G.'}

'Universitätsklinikum Würzburg, Kinderklinik und Poliklinik, Würzburg, 2Universitätsklinikum München, Dr. von Haunersches Kinderspital, München

Hintergrund. Deutschland führte 2004 die generelle Varizellenimpfung für Kinder im Alter von 11-14 Monaten ein, seit 2009 mit einer 2. Dosis. Fragestellung. Entwicklung der Varizellen-Impfquoten im Raum München seit 2006 und Ermittlung von Einflussfaktoren auf die Impfentscheidung der Eltern.

Methode. Jährliche Ziehung einer Zufallsstichprobe $(\mathrm{n}=600)$ von Kindern im Alter 18-36 Monate in München 2006-2011; schriftliche Befragung der Eltern zu Impfstatus des Kindes, soziodemographischen Faktoren und Einstellung zur Impfung; bi- und multivariate Regressionsanalysen für jedes Erhebungsjahr.

Ergebnisse. Die Rücksenderaten lagen bei 50-62\%; 2021 Fragebögen wurden ausgewertet. Die Impfquote für die 1. Dosis stieg von $38 \%$ (2006) zunächst auf 51-53\% (2007-2009), dann auf 66-68\% (2010-2011). Die Impfquote für die 2. Dosis lag vor der Empfehlung bei 10-19\%, und stieg 2009 auf 29\%, 2010 auf 53\% und 2011 auf 59\%. Der Anteil der Ärzte, die eine Varizellenimpfung empfahlen, stieg von 48\% (2006) auf $57-61 \%$ (2007-2009), und lag bei $66-72 \%$ in $2010-2011$. Die Empfehlung der Impfung durch den Kinderarzt war der größte unabhängige Einflussfaktor für die Impfentscheidung der Eltern ( $\mathrm{p}<0,001$ für alle Untersuchungsjahre; adjustierte OR von bis zu 30,1, KI 14,9-60,6). Andere Faktoren hatten nur in einzelnen Jahren einen signifikanten Einfluss. Der Kombinationsimpfstoff MMR-V wurde vor 2009 kaum eingesetzt, danach stark präferiert (29\% der Varizellen-Geimpften in $2008,88 \%$ in 2010).

Diskussion. Die Impfquoten für die 1. Varizellendosis stagnierten 20072009 bei knapp über 50\%; mit der Empfehlung der 2. Dosis und dem damit zunehmenden Einsatz von MMR-V stieg die Rate 2010-2011 auf 66-68\%. Die Empfehlung des Kinderarztes hatte den größten Einfluss auf die Impfentscheidung der Eltern.

\section{DGKJ-PO-J1-10}

\section{Down-Syndrom - Immuniologie, Infektiologie, Immunisierung}

\section{Simon A. ${ }^{1}$ Schiller M. ${ }^{2}$, Rohrer T. ${ }^{2}$}

'Universitätsklinikum des Saarlandes, Pädiatrische Onkologie und Hämatologie, Homburg, ${ }^{2}$ Universitätsklinikum des Saarlandes, Allgemeine Pädiatrie, Neonatologie, Endokrinologie, Homburg

Children with Down syndrome (DS; trisomy 21) face an increased risk of severe respiratory infections (acute otitis media, bronchitis, bronchiolitis, and pneumonia) due to a hitherto incompletely understood immunodeficiency. This immunodeficiency in patients with DS impairs the innate, the specific cellular and humoral response to viral and bacterial pathogens.

Prematurely born infants with DS are at an increased risk to develop bronchopulmonary dysplasia and chronic lung disease of prematurity. 
Respiratory infections are the main reason for rehospitalization in the first two years of life (54\%).

The risk of death from sepsis and the risk of permanent lung injury after mechanical ventilation are increased in children with DS. A significant proportion of all children with DS have congenital heart disease; cardiac surgical interventions are necessary in many of these patients. Infection of the lower airways may result in persistent pulmonary hypertension. Our current knowledge about antibody response to vaccinations in children with DS is still very limited. Impaired avidity maturation has been observed in children with DS after tetanus toxoid booster. After immunization with the 23-valent pneumococcal polysaccharide vaccine (Pneumovax ${ }^{*}$ ) children with DS ( $\mathrm{n}=17$; age 6-13 years) mounted an immune response but the corresponding titers were significantly lower than in healthy controls. In a more recent study, no consistent pattern of immune response has been found in children with DS after Pneumovax ${ }^{\oplus}$ administration. The only study investigating the immune response of children with DS to a modern conjugate vaccine revealed a decreased humoral response after conjugated meningococcal serogroup $\mathrm{C}$ vaccination.

\section{Hämatologie und Onkologie (1)}

\section{DGKJ-PO-01-1 \\ Knochengesundheit und endokrinologische Funktion nach Be- handlung einer akuten lymphatischen Leukämie (ALL) im Kindes- alter}

Schündeln M.M.', Bauer J.J.', Goretzki S.C.', Eggert A.', Hauffa B.P. ', Grasemann C. $^{2}$

'Universität Duisburg-Essen, Pädiatrische Hämatologie und Onkologie, Essen, ${ }^{2}$ Universität Duisburg-Essen, Pädiatrische Endokrinologie und Diabetologie, Essen

Fragestellung. Die ALL ist die häufigste onkologische Erkrankung im Kindesalter. Sie hat eine Heilungsrate von über $80 \%$. Im Rahmen der Grunderkrankung und infolge von Therapietoxizität kommt es dabei häufig zu endokrinologischen Ausfällen, auch mit Beeinträchtigung der Knochengesundheit. Diese Studie untersucht die Knochengesundheit bei 90 Überlebenden einer ALL im Kindesalter.

Methoden. Erfassung klinischer und biochemische Parameter von Wachstum, Pubertät, Knochenstoffwechsel, Vitamin-D-Status und Knochendichte. Auswertung eines Fragebogens zur körperlichen Aktivität und Ernährung.

Ergebnisse. Mittelwerte für das Kollektiv (39 weibliche und 51 männliche Patienten). Chronologisches Alter: $11,47(3,8-20,9)$ Jahre (J), Diagnosealter: 6,9 $(0,8-16,9)$ J, Größe: SDS -0,04 $(-3,69-2,72)$, BMI: SDS 0,48 (-4,12-2,74), Tanner: SDS 0,22 $(-3,2-3,5)$. Alterskorrigierter $z-W e r t$ in DXA Messung: $-0,55(-3,3-2,1 ; n=30)$. Eine Vitamin-D-Defizienz fand sich bei $68 \%$, ein sekundärer Hyperparathyreoidismus bei $17 \%$, Knochenschmerzen bei 15\% und eine Osteopenie bei 15\% der Patienten. Frakturen nach Chemotherapie traten bei $11 \%$ auf. Es fanden sich keine signifikanten geschlechtsspezifischen Unterschiede aber ein Trend zu verzögertem Knochenalter bei Jungen. Es zeigte sich keine Korrelation zwischen der Knochendichte (Z-Wert) und Parametern des Knochenstoffwechsels, der Steroid- oder Methotrexatdosis.

Schlussfolgerung. Die Knochengesundheit nach ALL kann gestört sein. Die Identifikation einzelner Risikofaktoren hierfür ist schwierig. Man muss von einer multifaktoriellen Genese ausgehen. Ein Vitamin-D und Kalziummangel ist häufig und bedarf des Monitorings und der Behandlung.

\section{DGKJ-PO-01-2}

\section{Vier Jahre alter Junge mit BCR/ABL-positiver CML und eineiigem} gesundem $B C R / A B L-n e g a t i v e m$ Zwillingsbruder

Springer J. ', Imschweiler T.', Niehues T.

${ }^{1}$ Helios Klinikum Krefeld, Zentrum für Kinder- und Jugendmedizin, Krefeld

Einleitung. CML ist eine maligne Erkrankung in 95\% der Fälle verursacht durch die Fusion der Gene ABL und BCR. Diese ist bedingt durch die reziproke Translokation der Chromosomen 9 und 22, $\mathrm{t}(9 ; 22)$ (q34;q11) und führt zu einer Dysregulation der ABL-Tyrosinkinase. Imatinib (Glivec) hemmt die gesteigerte ABL-Tyrosinkinaseaktivität und führt zur Reduktion der BCR-ABL-Transkripte und ist somit Therapie der ersten Wahl vor der kurativen Knochenmarkstransplantation. Präsentiert wird ein eineiiges Zwillingsgeschwisterpaar, bei dem ein Bruder an einer BCR/ABL-positiven CML in chronischer Phase erkrankt und erfolgreich mit Imatinib behandelt wird.

Kasuistik. Vier Jahre alter Junge, ehem. Zwillings-FG mit massiver Splenomegalie, exzessiver Leukozytose $(322.000 / \mu l)$, Anämie und Thrombozytopenie. Durchflusszytometrisch CML, molekulargenetisch Nachweis des BCR/ABL-Rearrangements. Therapie mit Glivec $200 \mathrm{mg} / \mathrm{d}(=300 \mathrm{mg} / \mathrm{m} 2 \mathrm{KOF})$ gemäß CML-paed-II-Studie. Darunter Normalisierung der Milzgröße, des Blutbildes, und Reduktion der BCR-ABL-Transkripte um eine log-Stufe innerhalb von zwei Monaten. Der eineiige Zwillingsbruder ist gesund ohne Nachweis eines BCR/ ABL-Rearrangements.

Schlussfolgerung. Ziel der CML-Therapie ist eine weitgehende Reduktion des pathologischen Zellklons. Mit dem Tyrosinkinaseinhibitor Imatinib konnte hier eine klinische und hämatologische Remission, sowie eine Reduktion der BCR-ABL-Transkripte um eine log-Stufe erreicht werden. Der gesunde, BCR/ABL-negative eineiige Zwillingsbruder scheint aufgrund der HLA-Identität ein geeigneter Spender für eine evtl. Knochenmarkstransplantation zu sein. Die Frage nach einem erhöhten Risiko für den gesunden Bruder ebenfalls an einer CML zu erkranken muss durch regelmäßige Kontrollen geklärt werden.

\section{DGKJ-PO-01-3}

Das Internationale Krebsgenomkonsortium (ICGC) für maligne Lymphome (MMML-Seq)

Höll J.', Hezaveh K. ${ }^{1}$, Bernhart S. ${ }^{2}$, Hoffmann S. ${ }^{2}$, Langenberger D. ${ }^{2}$, Stadler

P. ${ }^{2}$, Binder V. ${ }^{1}$, Lenze D. ${ }^{3}$, Siebert R. $^{4}$, Hummel M. ${ }^{3}$, Borkhardt A. ${ }^{1}$, ICGC MMML-Seq

'Universitätsklinikum Düsseldorf, Klinik für Kinder-Onkologie,- Hämatologie und klinische Immunologie, Düsseldorf, ${ }^{2}$ Transcriptome Bioinformatics, LIFE Research Center for Civilization Diseases, Leipzig, ${ }^{3}$ Charité - Universitätsmedizin Berlin, Institut für Pathologie, Berlin, ${ }^{4}$ Institut für Humangenetik, Kiel

Lymphome gehören zu den häufigsten Krebserkrankungen im Kindes- und Erwachsenenalter. Das ICGC Verbundprojekt MMML-Seq („Molekulare Mechanismen der malignen Lymphome durch Sequenzierung") hat zum Ziel, tumorspezifische Genveränderungen in Keimzentrums-B-Zell-Lymphomen zu identifizieren. Vorgestellt werden sowohl die Struktur des Gesamtkonsortiums als auch die ersten Ergebnisse der miRNA-Analysen.

miRNAs sind einzelsträngige RNA-Moleküle mit einer Größe von 2023 Nukleotiden, die die Translation sowie die Stabilität von mRNAs von Zielgenen reduzieren und dadurch eine Reihe wichtiger Kontrollfunktionen in der Zelle und in dem komplexen Netzwerk der Genregulation und Genexpression ausüben.

Über einen Zeitraum von fünf Jahren werden deutschlandweit insgesamt 200 Patientenproben sowie Kontrollproben gesammelt und analysiert. Aus den Proben werden die miRNAs extrahiert, mit Hilfe eines Illumina-Protokolls kloniert und anschließend sequenziert.

Der Fokus der Analysen der ersten 6o Patientenproben liegt v. a. auf Mutationsanalysen sowie auf der Entdeckung neuer, bisher noch nicht 
beschriebener miRNAs. Bisher konnten zwei neue miRNAs identifiziert werden, die auch in weitergehenden Experimenten (Northern Blotting) bestätigt werden konnten. Darüber hinaus werden die Expressionsprofile der zwischen den Lymphomsubtypen differentiell exprimierten miRNAs erstellt. Hierbei zeigt sich z. B., dass sowohl miRNA-150, miRNA-211 als auch miRNA-1244/1-3 unterschiedliche Expressionslevel aufweisen.

Zusammengefasst werden im Rahmen des ICGC Verbundprojektes MMML-Seq über einen Zeitraum von fünf Jahren insgesamt 200 Keimzentrums-B-Zell-Lymphome umfassend genetisch charakterisiert. Initiale miRNA-Analysen haben bereits vielversprechende Ansätze für funktionelle Validierungen ergeben.

\section{DGKJ-PO-01-4}

\section{Erythema nodosum und myelodysplastisches Syndrom}

\author{
Goldhahn K.', Lieftüchter V. \\ 'DRK Kliniken Berlin Westend, Kinderklinik, Berlin
}

Hintergrund. Wir berichten über einen 6 Jahre alten Patienten mit Erythema nodosum und anhaltendem periodischem Fieber, dem ein myelodysplastisches Syndrom zu Grunde lag.

Einleitung. Erythema nodosum ist bei Erwachsenen als seltenes Symptom für eine maligne Erkrankung beschrieben. Kinder mit myelodysplastischem Syndrom zeigen vorrangig Müdigkeit/Abgeschlagenheit, Blässe sowie eine (Pan-)zytopenie als Symptomkonstellation.

Falldarstellung. Der Junge zeigte zu Beginn des stationären Aufenthaltes eine schmerzhafte knötchenförmige Hauterscheinung mit Rötung und Überwärmung an den Unterschenkeln, welche wir als Erythema nodosum werteten. Diagnostisch konnten keine Hinweise für Infektionen, eine chronisch entzündliche Darmerkrankung, SLE oder ein rheumatologisches Geschehen als Ursache gefunden werden. Eine empirische antibiotische Therapie führte zu keinerlei Symptombesserung. Bei anhaltendem Erythema nodosum, steigenden Entzündungsparametern und periodischem Fieber sowie zunehmender Abgeschlagenheit und Blässe führten wir eine Knochenmarkspunktion durch. Daraufhin stellten wir die Diagnose eines myelodysplastischen Syndroms.

Schlussfolgerung. Vorliegender Fall beschreibt den seltenen Zusammenhang zwischen einem Erythema nodosum und einer malignen Erkrankung im Kindesalter. Wir konnten zeigen, dass eine konsequente Diagnostik inklusive Knochenmarkspunktion (vor Steroidtherapie) bei ausbleibender Klärung der Krankheitsursache indiziert ist.

\section{DGKJ-PO-01-5 \\ Chondrogener Borderline-Tumor des proximalen Femurs beim 4-Jährigen}

Brauer N.D. ', Imschweiler T.', Niehues T.'

'Helios Klinikum Krefeld, Zentrum für Kinder- und Jugendmedizin, Päd. Hämatologie und Onkologie, Krefeld

Einleitung. Dantonello et al beschrieb 2008 ein Kollektiv von 15 pädiatrischen Fällen mit mesenchymalen Chondrosarkomen. Eine sichere Zuordnung ist nicht immer möglich und die Wahl der Therapieintensität umstritten.

Fallbericht. Ein 4 8/12 Jahre alter Junge entwickelte linksseitige Hüftschmerzen und Fieber. Nach 2 Wochen erfolgte die Aufnahme wegen zunehmender Bewegungseinschränkung. Sonographisch stellte sich ein geringer Hüftgelenkserguss mit periossärer Weichteilvermehrung dar. Radiologisch zeigte sich ein Osteolyseherd des Schenkelhalses links. Labor BKS 15/50, Normwerte für CRP, Blutbild, LDH, alkalische Phosphatase. In der Blutkultur Nachweis von Streptokokkus salivatius und Staphylokokkus epidermidis. Bei Verdachtsdiagnose Osteomyelitis begannen wir eine Therapie mit Clindamycin und Vancomycin. Darunter zeigten sich Klinik und Labor regredient. Die radiologische Kontrolle nach 2 Wochen dokumentierte eine Größenzunahme des Osteo- lyseherdes, woraufhin die Knochenbiopsie erfolgte. Histologisch wurde ein proliferationsaktiver chondroider Tumor, am ehesten Enchondrom, beschrieben. Die Referenzgutachter äußerten den Verdacht auf ein mesenchymalen Chondrosarkoms. Das Staging ergab keinen Hinweis auf weitere Tumormanifestationen. Im Alter von 6 2/12 Jahren Lokalrezidiv, 3 Monate später weiterer Progress. Die Eltern entschieden sich gegen eine erneute Biopsie. Mit 7 2/12 Jahren deutliches Humpeln und radiologisch weiteres intraossäres Tumorwachstums ohne Malignitätskriterien. Es erfolgte eine erneute Tumorkürretage mit Palacosplombage. 9 Monate postoperativ kein Hinweis für Rest- oder Rezidivtumors. Schlussfolgerung. Chondroide Borderline-Tumore können sich wie eine Osteomyelitis präsentieren. Ungewöhnlich ist das junge Alter unseres Patienten. Wir stellen das weitere Procedere in diesem Fall zur Diskussion.

\section{DGKJ-P0-01-6 \\ Sensitivierung für Zytostatika-vermittelte Apoptose-Induktion durch "smac mimetics" beim Neuroblastom}

Najem S. ', Hundsdörfer P. ${ }^{2}$, Reinshagen K. ', Eschenburg G. ${ }^{1}$

'Universitätsklinikum Hamburg-Eppendorf, Klinik und Poliklinik für Kinderchirurgie, Hamburg, ${ }^{2}$ Charité - Universitätsmedizin Berlin, Klinik für Pädiatrie m. S. Onkologie und Hämatologie, Berlin

Fragestellung. Beim Neuroblastom (NB) konnte eine Überexpression von XIAP, dem potentesten Mitglied der IAPs (,inhibitor of apoptosis"), nachgewiesen werden. Eine Inhibition der IAPs durch „smac mimetics" (SM) sensitiviert NB-zellen erheblich gegenüber Chemotherapie, dies jedoch stark abhängig vom verwendeten Zytostatikum. Es ist deshalb von großem Interesse eine systematische Analyse der Wirkung von SM in Kombination mit verschiedenen Zytostatikagruppen durchzuführen. Dies soll zu einem besseren Verständnis der Resistenz von NB-Zellen gegenüber Chemotherapie und zur Entwicklung neuer, wirksamer Therapiepläne in der Behandlung des NB beitragen.

Methodik. NB-Zelllinien dienten als experimentelles Modell für eine In-vitro-Behandlung des NB. Zytostatika aus den Substanzklassen der Antrazykline, Platin-Derivate, Topoisomerase-Inhibitoren und VincaAlkaloide, die auch in der Standardtherapie des NB eingesetzt werden, wurden in Kombination mit SM ausgetestet und ihre Wirkung auf die Proliferation und die Apoptose-Induktion untersucht.

Ergebnisse. Vinca-Alkaloide zeigten generell eine starke synergistische Wirkung in Kombination mit SM. Mit dieser Wirkstoffgruppe ist die signifikanteste Verstärkung der Proliferationshemmung und der Apoptosinduktion in der Kombinationstherapie nachweisbar. Topoisomerase-Inhibitoren zeigten dagegen nur einen schwach synergistischen Effekt mit SM.

Diskussion. Der Wirkmechanismus der Zytostatika hat offensichtlich einen großen Einfluss auf das Auftreten eines Synergismus in Kombination mit SM. Genauere Untersuchungen zu den molekularen Regulationsmechanismen, den aktivierten Signalwegen und der so induzierten Apoptose sind notwendig um einen möglichen zielgerichteten Einsatz von SM in der Chemotherapie des NB in der Zukunft zu ermöglichen.

\section{DGKJ-PO-01-7}

Metastasiertes Neurothekeom infraorbital, rezidivierender Verlauf - wie aggressiv behandeln?

Holtrup M. ${ }^{1}$, Brauer N. ', Imschweiler T.', Hemmerlein B. ${ }^{2}$, Niehues T. ${ }^{1}$ ${ }^{1}$ Helios Kliniken Krefeld, Zentrum für Kinder- und Jugendmedizin, Krefeld, ${ }^{2}$ Helios Kliniken Krefeld, Institut für Pathologie, Krefeld

Einleitung. Neurothekeome sind eine heterogene Gruppe gutartiger Tumore der peripheren Nerven. Weltweit sind circa 300 Fälle beschrieben, besonders junge Erwachsene sind häufig betroffen. Die Resektion ist Therapie der Wahl. Wir beschreiben hier erstmalig eine Metastasierung. 
Fallbericht. Im Alter von 9 9/12 Jahre wurde ein Mädchen mit infraorbitalen Tumor rechts bei einem niedergelassenen Dermatologen vorstellig. Es erfolgte eine Tumorresektion, der histologische Befund war vereinbar mit einem Histiozytom der Haut. Innerhalb von wenigen Wochen rasches Lokalrezidiv im Narbenbereich als $3-5 \mathrm{~cm}$ durchmessender, kugeliger, angiomatöser, rötlicher Tumor. Dort Verdacht auf ein Xanthogranulom DD zelluläres Neurothekeom. Im Verlauf weitere Tumorresektionen mit dem histologischen Nachweis eines Neurothekeoms. Im Alter von 10 8/12 Jahren cervicale Lymphadenopathie mit rascher Größenprogredienz. Aufgrund des ungewöhnlichen Verlaufs des infraorbitalen Tumors und der zunehmenden Lymphadenopathie erfolgte eine Lymphknotenexstirpation. Verdacht auf eine Non- Langerhans- Zell- Histiozytose mit nachweisbaren Malignitätskriterien im Sinne eines malignen Histiozytoms. 7 Monate später erneutes Lymphknotenrezidiv. Wir entschieden uns auf Grund der histologischen Ähnlichkeit zu einer Non-Langerhans-Zell- Histiozytose zur Einleitung einer Chemotherapie nach dem LCH IV Protokoll. Die Chemotherapie wurde für 4 Monate durchgeführt. Nebenwirkungen waren cytarabininduziertes Fieber und Obstipation. Hämatopoetische Nebenwirkungen und Infektionen traten nicht auf. Im Alter von 13 Jahren befindet sich die Patientin in anhaltender Remission.

Schlussfolgerung. Neurothekeome können metastasieren. In unserem Fall führte eine niedrig dosierte Chemotherapie mit akzeptablem Nebenwirkungsprofil zur erfolgreichen Tumorkontrolle.

\section{DGKJ-PO-01-8 \\ BET-Bromodomain-Inhibition als therapeutische Option für Medulloblastome}

Henssen A. ', Thor T.', Eggert A. ', Schulte J.'

'Kinderklinik III, Zentrum für Kinder- und Jugendmedizin Universitätsklinikum Essen, ${ }^{1}$ Arbeitsgruppe Pädiatrisch-Onkologische Forschung, Labor für Pädiatrische Hämatologie und Onkologie, Essen

Fragestellung. Medulloblastome sind die häufigsten bösartigen Hirntumoren im Kindesalter. Patienten, deren Tumoren eine Überexpression von MYC aufweisen, haben eine sehr schlechte Prognose. Jüngste Studien mit dem BET-Protein-Inhibitor JQ1 zeigten, dass MYC von BETProteinen reguliert wird. Aufgrund der pathogenetisch wichtigen Rolle von MYC im Medulloblastom, vermuten wir, dass JQ1 einen therapeutischen Nutzen haben könnte.

Material und Methode. Zunächst untersuchten wir die Expression der BET-Proteine immunhistochemisch in 86 Medulloblastomen. Wir ermittelten dann die funktionelle Bedeutung von JQ1. Medulloblastomzellen wurden mit JQ1 behandelt und GI50-Werte mittels MTT-Assay bestimmt sowie bezüglich Zellproliferation, Apoptose und Seneszenz untersucht. Die Effekte der JQ1 Behandlung auf die Expression verschiedener Gene wurde mittels Western Blot und qPCR untersucht. Wir erstellten zudem mRNA Arrays behandelter und unbehandelter Medulloblastom Zellen. Abschließend behandelten wir murine Xenografts mit JQ1.

Ergebnisse. Medulloblastome exprimieren BET-Proteine. Die Behandlung mit JQ1 reduzierte das Zellwachstum und die proliferative Kapazität sowohl in vitro als auch in vivo. JQ1 führte zu einer transkriptionellen Deregulation von MYC sowie von Genen, die im Zellzyklus und im p53 Signalweg eine Rolle spielen. Interessanter Weise reagierten p53 mutierte Zellen weniger sensibel auf JQ1.

Diskussion oder Schlussfolgerung. Die Hemmung von BET-Proteinen zeigte sowohl in vitro als auch in vivo einen antitumoralen Effekt im Medulloblastom. Diese Wirkung lies sich sowohl auf eine Deregulation von MYC als auch der p53 und Zellzyklus Signalwege zurückführen. Zusammenfassend vermuten wir, dass BET-Proteine ein vielversprechendes therapeutisches Ziel bei Medulloblastomen sind.

\section{DGKJ-P0-01-9 \\ Neurogene arterielle Hypertonie nach Resektion eines pilozyti- schen Astrozytoms}

\section{Krings A.E.', Clusmann H. ${ }^{2}$, Lassay L.', Wagner N.'}

'Universitätsklinikum RWTH Aachen, Klinik für Kinder- und Jugendmedizin, Aachen, ${ }^{2}$ Universitätsklinikum RWTH Aachen, Klinik für Neurochirurgie, Aachen

Kasuistik. Eine 10-jährige Patientin entwickelte in der Aufwachphase nach Resektion eines infratentoriellen pilozytischen Astrozytoms eine arterielle Hypertonie mit Blutdruckwerten um 180/9o mmHg. Die Einstellung der Hypertonie mit wiederholt auftretenden Blutdruckspitzen war schwierig und konnte mit Urapidil und Nifedipin erreicht werden. Etwa 30 Tage postoperativ normalisierten sich die Blutdruckwerte.

Diagnostik. Laborchemisch zeigten sich Normwerte für Renin, Aldosteron und ADH. Im 24-h-Sammelurin fand sich eine Erhöhung von Noradrenalin auf $1139 \mathrm{nmol}$, von Adrenalin auf 70 nmol und von Cortisol auf $1537 \mathrm{nmol} / \mathrm{d}$. In der Kontrolle vier Wochen postoperativ zeigte sich ein Abfall von Noradrenalin auf $353 \mathrm{nmol}$, von Adrenalin auf $26 \mathrm{nmol}$ und von Cortisol auf $124 \mathrm{nmol} / \mathrm{d}$.

Schlussfolgerung. Die Erhöhung der Katecholamine im Urin stützt die Diagnose einer sympathikogenen Hypertonie. Ursächlich könnte eine Affektion des Nucleus tractus solitarius (NTS) in der dorsalen Medulla oblongata sein. Der NTS erhält Afferenzen von Baro- und Chemorezeptoren, Amygdala und Hypothalamus und sendet Efferenzen zur ventrolateralen und rostralen ventrolateralen Medulla oblongata, zur Columna intermediolateralis, zum dorsalen Ncl. vagus und zum Ncl. ambiguus. Ein direktes mechanisches Trauma, ein indirektes Trauma mit inflammatorischer Reaktion und eine Hypoperfusion des NTS können zu einer verminderten Inhibition sympathischer Efferenzen führen. Auch für die Entstehung der essentiellen Hypertonie werden inflammatorische Prozesse in der Region des NTS auf dem Boden einer genetischen Prädisposition als eine wesentliche Ursache diskutiert.

\section{DGKJ-PO-01-10}

\section{Vorinostat in der onkologischen Therapie - Fallbeispiel}

Pekrun A.W. ${ }^{1}$, Titgemeyer C. ${ }^{1}$, Burhenne J. ${ }^{2}$, Schenk J.P. ${ }^{3}$, Milde T. ${ }^{4}$, Witt $0 .{ }^{5}$ ${ }^{1}$ Klinikum Bremen-Mitte, Prof. Hess-Kinderklinik, Bremen, ${ }^{2}$ UniversitätsKlinikum, Klinische Pharmakologie, Heidelberg, ${ }^{3}$ Universitäts-Klinikum, Pädiatrische Radiologie, Heidelberg, ${ }^{4}$ Universitäts-Klinikum, Pädiatrische Onkologie, Heidelberg, ${ }^{5}$ Deutsches Krebsforschungszentrum/UniversitätsKlinikum, Pädiatrische Onkologie, Heidelberg

Einleitung. Histondeacetylase-Hemmstoffe stehen für ein neues antitumoröses Therapieprinzip. Als Wirkmechanismus wird eine Beeinflussung der Genexpression angenommen, unter anderem kommt es zur Differenzierung von zuvor undifferenzierten malignen Zellen.

Fallbericht. Ein jetzt 7-jähriger Patient wurde als Säugling wegen einer disseminierten Neuroblastom-Erkrankung intensiv mit Zytostatika behandelt. Im 5. Jahr erfolgte eine Hemithyreoidektomie aufgrund eines SETTLE-Tumors („spindle cell tumor with thymus like differentiation") als Zweitmalignom. Angesichts progredienter Lungenmetastasierung wurden Antracycline appliziert. Bei weiterem Progress der Lungenherde wurde eine Therapie mit täglicher oraler Vorinostat-Applikation im Rahmen einer Phase-I/II-Studie begonnen. Innerhalb von einem halben Jahr waren die Lungenherde deutlich rückläufig im Sinne einer "partial response". Die Therapie wird gut vertragen, es entwickelten sich lediglich geringe ekzematöse Hautveränderungen und eine leichte Thrombozytopenie. Die pharmakokinetischen Untersuchungen zeigten eine Vorinostat-Konzentration im Blut oberhalb des bisher zumeist bei erwachsenen Patienten beschriebenen Bereichs.

Schlussfolgerung. Die Therapie mit Vorinostat ist eine neue Option zur Behandlung maligner Tumorerkrankungen und ist in kontrollierten Studien zu prüfen. 
DGKJ-PO-01-11

Schwere Methotrexat-Nebenwirkung nach intrathekaler Applikation unter Lachgassedierung. Case-Report und Literaturrecherche

\section{Trah J.M. ', Löbel U. ${ }^{2}$, Escherich G. ${ }^{1}$}

'UKE Hamburg, Pädiatrische Hämatologie und Onkologie, Hamburg, ${ }^{2}$ UKE Hamburg, Klinik und Poliklinik für Neuroradiologische Diagnostik und Intervention, Hamburg

Einleitung. Methotrexat ist ein in der Behandlung der ALL-Therapie etabliertes Medikament. Nach hochdosiertem MTX als auch nach intrathekalen MTX-Gaben sind akute und spät auftretende neurologische Nebenwirkungen beschrieben. Zur Sedierung bei kurzen Eingriffen wird Distickstoffmonoxid (Lachgas), verwendet. Sein Wirkmechanismus ist nicht vollständig geklärt, neurologiche Nebenwirkungen sind vorrangig nach langandauerdem Missbrauch beschrieben.

Methoden. Wir berichten über ein 7-jährigen Mädchens ohne Vorerkrankungen. Die Therapie gemäß CoALL 08-09 Protokoll wurde nach Diagnose einer ALL eingeleitet. Die zweite und dritte intrathekale Methotrexatapplikation der Induktion fand unter Lachgasanästhesie statt. Drei Tage nach der dritten therapeutischen Lumbalpunktion wurde das Mädchen mit Dysarthrie, Wesensveränderung und beginnender Tetraspastik aufgenommen. Eine infektiöse Ursache konnte ausgeschlossen werden. Im durchgeführten MRT wurden Veränderungen entsprechend einer vaskulären Schädigung gefunden. In den folgenden Tagen kam es zur Progredienz der Symptome mit Somnolenz, athetotischem Bewegungsmustern und Strecksynergismen, sowie fehlender Pupillenreaktion. Unter fortgesetzter modifizierter Chemotherapie kam es nach 2 Wochen zum Sistieren der Progredienz, über die folgenden 6 Monate zur langsamen Besserung, und nach weiteren 6 Monaten zur vollständigen Normalisierung der neurologischen Symptome.

Schlussfolgerung. Es wird hier von einer ungewöhnlich schweren, reversiblen Nebenwirkung nach ausschließlich intrathekaler MTX Gabe ausgegangen, welche möglicherweise durch Lachgas verstärkt wurde und so bisher nicht beschrieben worden ist. Eine Medikamenteninteraktion von Lachgas und Methotrexate erscheint möglich, da beide Medikamente im Folsäurestoffwechsel interagieren und ein additiver Effekt denkbar wäre.

\section{Kardiologie}

\section{DGKJ-PO-K-1}

Wissenstransfer in der frühen Geschichte der Pädiatrischen Kardiologie: Gerald Graham (London)

\author{
Meyer-Lenz J.', Mir T. ${ }^{2}$, Müller G. ${ }^{2}$, Weil J. ${ }^{2}$ \\ 'Universität Hamburg, Europäische Geschichte, Hamburg, ${ }^{2}$ Universitäres \\ Herzzentrum Hamburg, Kinderkardiologie, Hamburg
}

Fragestellung. Die Deutsche Gesellschaft für Pädiatrische Kardiologie (DGPK) hat 2008 ein Interview-Projekt zur Geschichte ihres Faches aufgelegt. Befragt wurde u. a. auch der Physiologe und Kinderkardiologe Gerald Graham (London). Welche Erkenntnisse lassen sich aus dem Interview für die Fachgeschichte ableiten?

Material und Methode. Das standardisierte Interview vom 9.10.2009 wurde nach den Vorgaben der Oral History transkribiert, der medizinhistorische Kontext recherchiert. Das Fallbeispiel zeigt u. a. ungewöhnliche Wege des Wissenstransfers von den USA über das UK nach Europa seit den 1950ern auf.

Ergebnisse. Biografische Daten: Gerald Graham, geboren 1918, wuchs in einem jüdischen liberalen Elternhaus in Berlin auf. Im Oktober 1940 emigrierte er in die USA. Nach seinem MD 1950/51 an der Western Reserve University in Cleveland - seine Lehrer waren Louis Katz und Carl Wiggers, wegweisende Forscher auf dem Gebiet der Physiologie und Kardiologie - begann er als Physiologe und Kinderkardiologe seine akademische medizinische Laufbahn an der Medical School Chicago.
Von 1954 bis 1983/84 war er am Great Ormond Street Hospital for Sick Children (GOSH) in London tätig. Er war seit 1979 Mitherausgeber der Zeitschrift „Pediatric Cardiology“.

Schlussfolgerung. Das hohes Expertenwissen Gerald Grahams trug dazu bei, dass das GOSH eine Spitzenstellung in der europäischen Kinderkardiologie einnahm. Darüber hinaus erfüllte es eine zentrale Aufgabe im internationalen Wissenstransfer. Zahlreiche Fellows aus Europa, darunter viele deutsche Nachwuchskardiologen, durchliefen eine Ausbildung in der Abteilung von Gerald Graham.

Diskussion. 1. Welche Aspekte trugen zur Veränderung der Rolle des GOSH als zentraler Entwicklungs-"Maschinerie" des Faches in Europa, besonders für die Bundesrepublik bei?

\section{DGKJ-PO-K-2}

Verschluss des Vorhofseptumdefektes vom Sekundumtyp als minimal-invasive Prozedur ohne Röntgendurchleuchtung

Rentzsch A.', Pfeifer J.', Schwarz P.', Abdul-Khaliq H.'

'Universitätsklinikum d. Saarlandes, Klinik für Pädiatrische Kardiologie, Homburg

Einleitung. Der Vorhofseptumdefekt vom Sekundumtyp (ASD) ist der zweithäufigste Herzfehler und sollte bei einer Volumenbelastung der rechten Herzhälfte rechtzeitig verschlossen werden. Die meisten Defekte werden zurzeit interventionell durch unterschiedliche Verschlusssysteme verschlossen. Wir berichten über den interventionellen Verschluss solcher Defekte nur unter transösophagealer Echokardiographie (TOE) ohne Röntgendurchleuchtung.

Methodik und Ergebnisse. Von Aug. 2006 bis Jan. 2013 wurden insgesamt 94 ASDs interventionell angegangen. Davon konnten 90 (96\%) erfolgreich verschlossen werden. 58 Verschlüsse $(65 \%)$ wurden nur unter TOE ohne Röntgendurchleuchtung durchgeführt. Bei allen Patienten wurde vor der Prozedur eine TOE zur Darstellung der Anatomie und zum Ausschluss anderer Anomalien durchgeführt. Bei 32 Patienten musste wegen nicht eindeutiger transösophagealer Bildgebung oder assoziierter Fehlbildungen eine Durchleuchtung durchgeführt werden. Unmittelbar und im Langzeitverlauf zeigte sich kein Unterschied hinsichtlich des Ausgangs des Verschlusses in beiden Gruppen. Sechs Patienten wiesen klinische Zeichen einer cerebralen Ischämie in der Vorgeschichte auf. Die Gründe für die vier nicht erfolgreichen Prozeduren waren ein zu großer Defekt, ein zu weiches Septum, eine Dislokation mit anschließender Bergung und ein postinterventioneller AV-Block mit der Notwendigkeit der Explantation.

Schlussfolgerung. Der ASD kann heute katheter-interventionell unter alleiniger TOE sicher und erfolgreich verschlossen werden. Sowohl die Anatomie des Defektes als auch die Platzierung des Devices ist damit ausreichend und in der Mehrzahl der Fälle adäquat visualisierbar. Eine Oxymetrie oder Druckmessung im Pulmonalkreislauf ist nicht immer zwingend erforderlich.

\section{DGKJ-PO-K-3}

Analyse der endothelialen Dysfunktion im Bereich der Lungenarterien und der peripheren Systemarterien bei Kindern mit Lungenhochdruck

Werz A. ', Kock I. ', Latus H. ', Kreuder J.', Schranz D. ', Apitz C. ${ }^{1}$

'Justus-Liebig-Universität Gießen, Kinderherzzentrum, Gießen

Fragestellung. Pathogenetisch liegt dem Lungenhochdruck eine Störung der pulmonal-arteriellen (PA) Endothelfunktion zugrunde. Unklar ist bisher, ob auch das Endothel des system-arteriellen (SA) Gefäßbettes betroffen ist. Ziel unserer Untersuchung war daher, bei Kindern mit Lungenhochdruck die PA- und SA-Endothelfunktion zu untersuchen.

Material und Methoden. Als Maß für die PA-Endothelfunktion wurde die endothelabhängige PA-Relaxation, bzw. pulmonale Flussreserve 
(PFR) als Reaktion auf eine lokale Acetylcholin-Infusion mithilfe von intravaskulären Doppler-Fluss-Messungen ermittelt. Die SA-Endothelfunktion wurde durch die scherkraftbedingte Gefäßreaktion auf eine reaktive Hyperämie mithilfe der peripher-arteriellen Fingertonometrie gemessen.

Ergebnisse. Insgesamt 13 Kinder und Jugendliche [Durchschnittsalter $16,7( \pm 5,6)$ Jahre] mit Lungenhochdruck und eine Kontrollgruppe mit 13 alters- und geschlechtsgematchten Kindern wurden in die Studie eingeschlossen. Der digitale reaktive Hyperämie-Index (RHI) der PAHPatienten lag bei 1,54 $( \pm 0,69)$ und bei der Kontrollgruppe 1,67 $( \pm 0,66$; $\mathrm{p}=0,64)$. Die mittlere Flussgeschwindigkeit in der Segment-PA betrug $18,5( \pm 5,5) \mathrm{cm} / \mathrm{s}$ und stieg unter Acetylcholin-Infusion auf $27,4( \pm 12,3)$ $\mathrm{cm} / \mathrm{s}$ an $(\mathrm{p}=0,003)$. Die hieraus errechnete PFR lag bei $1,48( \pm 0,4)$. Es ließ sich keine Korrelation zwischen PFR und RHI nachweisen ( $\mathrm{r}=0,14$; $\mathrm{p}=0,67)$.

Schlussfolgerungen. Unsere Ergebnisse zeigen, dass die periphere SAEndothelfunktion bei Kindern mit Lungenhochdruck im Vergleich zu einer altersentsprechenden Kontrollgruppe nicht signifikant beeinträchtigt erscheint. Zwischen SA- und PA-Endothelfunktion fand sich keine signifikante Abhängigkeit, was darauf hindeutet, dass für deren Pathogenese und Progression unterschiedliche Mechanismen verantwortlich sind.

\section{DGKJ-PO-K-4 \\ Linksseitige kardiothorakale sympathische Denervation als alter- native Therapieoption bei Kindern mit Long-QT-Syndrom}

\section{Lobstein S.', Lorenz N.', Paul T.' , Ruschewski W. ${ }^{2}$, Kabus M.', Heubner G. \\ 'Städtisches Krankenhaus Dresden- Neustadt, Klinik für Kinder- und Jugendmedizin, Dresden, ${ }^{2}$ Kinderherzklinik, Göttingen}

Hintergrund. Das Long-QT-Syndrom umfasst eine Gruppe von genetisch bedingten Ionenkanalerkrankungen der Herzmuskelmembran, die zu Störungen von Depolarisations- und Repolarisationsvorgängen führen, mit dem charakteristischen Bild einer QTc-Zeit-Verlängerung im EKG einhergehen und Herzrhythmusstörungen wie ventrikuläre Tachykardien bis zum plötzlichen Herztod hervorrufen können. Therapeutisch stehen die Vermeidung bekannter Auslösefaktoren sowie eine Betablockergabe an erster Stelle. Bei therapierefraktären Fällen kommt die Implantation eines internen Cardioverter-Defibrillators (ICD) und die linksseitige kardiothorakale sympathische Denervation (LCSD bzw. Stellektomie) in Betracht.

Fallberichte. Patient 1: 6-jähriger Junge. Im Säuglingsalter QTc-Verlängerung bei Systolikum-Abklärung. Nachweis einer heterozygoten Mutation im KCNQ1-Gen (LQT 1). FA: Mutter: positiv. Hochdosierte Metoprolol-Therapie. Belastungsabhängige Synkope mit 4 Jahren. Stellektomie mit postoperativerm Horner-Syndrom 2010, seitdem keine Synkopen. Patient 2: 5-jähriger Junge. Im Neugeborenenalter QTcZeit-Verlängerung bis o,6 s sowie Bradykardie. Nachweis einer heterozygoten Mutation im KCNQ1-Gen (LQT 1). FA negativ. Hochdosierte Therapie mit Propranolol. Keine aufgezeichneten ventrikulären Arrhythmien. Mit 4 Jahren 3 Synkopen. Stellektomie mit postoperativerm Horner-Syndrom 2011. Seitdem keine kardialen Auffälligkeiten.

Diskussion. Bisher im Kindesalter selten durchgeführt, stellt die LCSD mittels eines transaxillären Zugangsweges und minimalem Komplikationspotential bei persistierend symptomatischen Patienten unter Betablockertherapie eine effektive Behandlungsalternative dar.

\section{DGKJ-PO-K-5 \\ Coilembolisation bei schwerer neonataler Herzinsuffizienz durch Leberhämangioendotheliome}

Kehl H.G. ', Stege D. ', Rellensmann G. ${ }^{2}$, Verfürth A. ${ }^{1}$, Rieger-Fackeldey E. ${ }^{2}$, Köhler M. ${ }^{3}$

'Universitätsklinikum Münster, Klinik für Kinderheilkunde - Pädiatrische Kardiologie, Münster, ${ }^{2}$ Universitätsklinikum Münster, Klinik für Kinderheilkunde - Allgemeinpädiatrie, Münster, ${ }^{3}$ Universitätsklinikum Münster, Institut für klinische Radiologie, Münster

Einleitung. Leberhämangioendotheliome können bereits bei Neugeborenen ein lebensbedrohlichen Shuntvolumen durch sekundäre Herzinsuffizienz und/oder Kasabach-Merritt-Syndrom und/oder sekundärer Hypothyreose führen, unabhängig von verschiedenen Therapieverfahren wie medikamentöser Behandlung inklusive $\beta$-Blockern oder Laserverfahren.

Fallserie. Drei Neugeborene (Gewicht: 2,5 kg, 2,7 kg und 3,2 kg) waren bereits pränatal durch gefäßreiche Lebertumoren aufgefallen (Durchmesser 4-6 cm). Alle Kinder zeigten eine schwere Herzinsuffizienz entsprechend NYHA Grad 3-4, eine Thrombopenie und pathologische Werte der globalen Gerinnungstests. Im Echo fand sich bei allen Kindern ein Cardiac Index über $11 \mathrm{l} / \mathrm{min} / \mathrm{m} 2$. Wegen der Schwere der Befunde wurde am 4., 6. und 29. Lebenstag die Indikation zu einem individuellen Heilversuch mit Katheterokklusion gestellt. Bei zwei Kindern konnten über einen venösen Zugang via Ductus arteriosus antegrad, beim dritten Kind über arteriellen Zugang retrograd, die größten Gefäßäste der Leberhämangioendotheliome aus dem Truncus coeliacus und der AMS sondiert werden. Es wurden 21, 24 bzw. 29 Coils implantiert. Obwohl nur eine inkomplette Okklusion der Tumorgefäße gelang, sistierte die Herzinsuffizienz jeweils rasch, Katheter-assoziierte Probleme traten nicht auf, auch keine Lebernekrosen. Im Follow-up über 3, 25 bzw. 109 Monaten traten keine neuen Probleme auf, im Doppler fand sich über lange Zeit noch ein Restshunt.

Schlussfolgerung. Leberhämangioendotheliome mit schwerer neonataler Herzinsuffizienz können durch Katheterintervention mit Coilokklusion erfolgreich behandelt werden.

\section{DGKJ-PO-K-6}

Auswirkungen der restriktiven Anwendung der infektiösen Endokarditis(IE)-Prophylaxe in den internationalen Leitlinien nach 2007 auf Inzidenz, Morbidität und Mortalität der IE

\section{Eyermann R. $^{1}$}

'Dr. Richard Eyermann, Kinder- und Jugendmedizin, Kinderkardiologie, Sportmedizin, München

Hintergrund. IE ist eine Erkrankung mit hoher Morbidität und Mortalität. EbM ist das Konzept von Effektivität und Effizienz der IEProphylaxe nur Annahme (IIb/C). 2007 hatten US- und europäische Fachgesellschaften die Empfehlung auf Patienten mit höchsten Risikokonstellationen begrenzt (IIa/B). 3/2008 hatte NICE die IE-Prophylaxe ganz gestrichen. Die LL-Änderung wurde bei Ärzten kontrovers aufgenommen. Wie sind die epidemiologischen Auswirkungen?

Methodik. EbM Literaturrecherche.

Ergebnis. Epidemiologische Daten v. a. aus UK: Streichung der IEProphylaxe führte nicht zu höherer Morbidität und Mortalität (v. a. Erwachsenendaten). Dies zeigen IE-Daten für Erwachsene auch für Deutschland (Register ALKK). Bei AHF belegen Daten 1999-2012 zu Inzidenz, Prädiktoren und Mortalität der IE bei kontemporärer EMAHKohorte am tertiären EMAH-Zentrum Royal Brompton Hospital eine um 5,4-fache Reduktion der Therapiehäufigkeit an IE, bei 4,6\% Mortalitätsrate, bei dieser Hochrisikoklientel. Endokarditische Abzesse sind Hauptprädiktor IE-bedingter Mortalität (HR 10,99).

Schlussfolgerung. Die Inzidenz der IE scheint trotz restriktiver Anwendung der IE-Prophylaxe auch im Hochrisikoklientel (Erwachsene, EMAH) abnehmend zu sein. IE-assoziierte Mortalität bleibt hoch, 
hat im Vergleich zu früheren Studien nicht abgenommen. IE ist weiter ernstes Krankheitsbild. Kinderdaten fehlen, es bleibt beim Höchstrisiko-Procedere, d. h. Indikation zur IE-Prophylaxe bei dentalen und HNO-Eingriffen mit Verletzung von Mukosa, Gingiva, apikalem Zahnapparat bzw. bei AT, TE und Bronchoskopie mit Biopsie (s. Task Force ESC, ESCMID, ISC (new version 2009). EbM bleibt das Konzept von Effektivität und Effizienz der IE-Prophylaxe weiter nur Annahme. Bedeutsam ist konsequente Zahnsanierung und Umgebungsprophylaxe sowie optimale Mundhygiene.

\section{DGKJ-PO-K-7}

Neue Therapieform: Ferngesteuertes Hochfrequenzstromablationssystem (Amigo Remote Catheter System; Catheter Robotics/ Boston Scientific) bei atrialen Tachykardien nach palliativer Korrektur eines angeborenen Herzfehlers zur Strahlendosisreduktion

\author{
Will J.C.', Opgen-Rhein B. ', Haverkämper G.' , Herrmann S.', Weiss K.', \\ Berger $F$. \\ 'Charité - Universitätsmedizin Berlin, Kinderkardiologie, Berlin
}

Problemstellung. Bei der Ablation komplexer Herzrhythmusstörungen kommt es häufig trotz der Verwendung dreidimensionaler Mappingsysteme zu deutlicher Röntgenstrahlenexposition.

Fallbericht. Wir berichten über die weltweit erstmalige Anwendung einer ferngesteuerten, patienten-fernen Ablationstechnik bei einer $\mathrm{Pa}$ tientin mit angeborenem Herzfehler. Bei einer 31-jährigen Patientin mit Z. n. Senning-Operation bei dTGA kam es zu rezidivierenden, multiplen atrialen Tachykardien, die antiarrhythmische Medikation und Kardioversion erforderten. Bei der jetzigen Untersuchung konnten wir mit Hilfe eines dreidimensionalen Mappingsystems (NavX, SJM) 2 verschiedene atriale Tachykardien im systemvenösen und im pulmonalvenösen (retrograd) Vorhof erfolgreich abladieren. Durch die Benutzung des Amigo Remote Catheter System (Catheter Robotics) war eine weitmöglichste Verminderung der Strahlenexposition für den Untersucher möglich.

Fazit. Durch die Anwendung ferngesteuerter Kathetersysteme ist bei komplexen Eingriffen eine Verminderung der Strahlenexposition für den Untersucher möglich. Dieses ist vor allem relevant in Zentren mit hohen Fallzahlen zur Verminderung der individuellen kumulativen Röntgendosis.

\section{DGKJ-PO-K-8}

Überlebter plötzlicher Herztod bei einem 16-jährigen gesunden Adoleszenten - Torsade de Point Tachykardie mit Defibrillatorpflichtigkeit und Zeichen der frühen Repolarisation im Ruhe EKG

\section{Aring C. ${ }^{1}$, Etti N. ${ }^{1}$, von Beckerath N. ${ }^{2}$, Horn B. ${ }^{2}$, Schley P. ${ }^{3}$, Eckardt L. ${ }^{4}$ \\ ${ }^{1} \mathrm{AKH}$ Viersen $\mathrm{gGmbH}$, Klinik für Kinder- und Jugendmedizin, Viersen, ${ }^{2} \mathrm{AKH}$ Viersen $\mathrm{gGmbH}$, Klinik für Kardiologie und Angiologie, Viersen, ${ }^{3}$ Kardio- logische Gemeinschaftspraxis, Viersen, ${ }^{4}$ Universitätskliniken, Abteilung für Rhythmologie, Münster}

Fallbericht. Ein 16-jähriger gesunder Junge, deutsche Mutter, schwarzafrikanischer Vater, klagt nach einem Thoraxstoß beim Fußball plötzlich über Brustschmerzen und kollabiert wenig später. Bei Pulslosigkeit beginnen Lehrer mit effektiver Herzlungenwiederbelebung. Neun Minuten nach dem Kollaps wird von Rettungskräften ein AED angelegt, ein schockbarer Rhythmus liegt vor, mit 200 Joule einmalig defibrilliert, sofort tastbarer Puls. Der Junge wird spontan atmend, aber komatös (GCS 3 ) in die Klinik gebracht. Drei Tage nachlassendes Koma und mildes Durchgangssyndrom bei allzeit stabiler Kreislauffunktion und Herzrhythmus ohne Auffälligkeiten, nach 10 Tagen wieder geistig normal und körperlich beinahe normal belastbar mit retrograder Amnesie, das Ereignis betreffend. Kein plötzlicher Herztod oder kardiale Erkrankungen in der Anamnese. Der Junge ist Leistungssportler. Er konsumierte täglich Erfrischungsgetränke mit viel Coffein, so auch vor dem Fußballturnier.

Ergebnisse. Das EKG des AED zeigte eine Torsade de points Tachykardie, nach dem Schock einen normalen Sinusrhythmus. Eine kardiale Ischämie und Strukturanomalie konnten ausgeschlossen werden. Koronarangiographie und Ajmalintest lehnen die Eltern ab. Das RuheEKG weist eine frühe Repolarisation mit J um o,1 mV sowie eine erhöhte und aszendierende ST-Strecke auf, was sich unter Belastung zum Teil zurückbildet, keine Hinweise auf Brughada- oder Long-oder ShortQT-Syndrom, keine wegweisenden Laborbefunde. Nach 3 Monaten mit einer Monitor LifeVest ${ }^{\circledR}$ sekundärprophylaktische ICD-Implantation. Schlussfolgerung. Folgende Fragen werden diskutiert: Frühe Repolarisation tatsächlich benignes EKG-Phänomen? Diagnostische Optionen, gutartige oder maligne Verläufe vorherzusagen? Hohe Dosis Coffein als Trigger? Torsade nur Folge eines Thoraxtraumas?

\section{DGKJ-PO-K-9}

Passagerer linksposteriorer Hemiblock bei Risperidon-Intoxikation

Mayer S.', Paulsen J.', Thiel M. ${ }^{\text {? }}$

'Sana-Klinikum Remscheid GmbH, Klinik für Kinder und Jugendliche, Remscheid

Einleitung. EKG-Veränderungen gehören zu den bekannten Nebenwirkungen von Risperidon, konkrete Fälle bei Kindern sind in der Literatur aber selten beschrieben. Wir konnten einen passageren linksposterioren Hemiblock im Verlauf dokumentieren.

Fallvorstellung. Ein 12-jähriger Junge mit bekanntem Asperger-Syndrom und ADHS wurde morgens schwer erweckbar von seinen Eltern aufgefunden. In der Nacht (zwischen 1 und 7 Stunden zuvor) hatte er eigenmächtig 7,5 mg Risperidon eingenommen. Bei Aufnahme weiter schläfrig, sonst klinisch stabil. Im EKG zeigte sich ein linksposteriorer Hemiblock. Die zeitgleich ermittelte Plasmakonzentration von Risperidon und dem aktiven Metaboliten Paliperidon betrug $95 \mu \mathrm{g} / \mathrm{l}$ (therapeutischer Bereich bis $60 \mu \mathrm{g} / \mathrm{l})$. Im weiteren Verlauf rasches Aufklaren des Patienten. Bei einer EKG-Kontrolle 7 Stunden später wieder unauffälliges EKG mit Steiltyp. Ein routinemäßig 3 Monate zuvor durchgeführtes EKG zeigte ebenso wie eine 4 Wochen später durchgeführte Verlaufskontrolle ebenfalls ein unauffälliges EKG mit Steiltyp.

Schlussfolgerung. Hier konnte ein enger zeitlicher Zusammenhang zwischen einer Risperidon-Überdosierung und intrakardialen Erregungsleitungsstörungen dokumentiert werden. Dies unterstreicht die Bedeutung von regelmäßigen EKG-Kontrollen bei der Therapie von Kindern und Jugendlichen mit antipsychotischen Medikamenten.

\section{DGKJ-PO-K-10}

Genetik in der Kardiologie - Herzrhythmusstörungen, Kardiomyopathien, angeborene Herzfehler, Systemerkrankungen

\section{Eyermann $R^{\prime}$}

'Dr. Richard Eyermann, Kinder- und Jugendmedizin, Kinderkardiologie, Sportmedizin, München

Angetrieben durch die Genomforschung haben sich in den letzten Jahren viele neue diagnostisch relevante Gene und Untersuchungsverfahren in der Patientenversorgung etabliert. Bedeutsam sind bei den arrhythmogenen Erkrankungen v. a. die genetische Stufendiagnostik des - klinisch und genetisch heterogenen Long-QT-Syndroms (KCNQ1/ LQTS Typ 1, KCNH2/LQTS Typ 2, SCN5A/LQTS Typ 3, KCNE1/ LQTS Typ 5, KCNE2/LQTS Typ 6),

- autosomal-dominant vererbten Brugada-Syndroms (BrS Typ 1, BrS Typ 2, BrS Typ 3).

Bei den Kardiomyopathien ist die genetische Stufendiagnostik der jeweils autosomal-dominant vererbten

- hypertrophen Kardiomyopathie (HCM), 
- arrhythmogenen rechtsventrikulären Dysplasie/Kardiomyopathie (ARVD) und

- catecholaminergen polymorphen ventrikulären Tachykardie (CPVT) klinisch wichtig.

In der genetischen Diagnostik der angeborenen Herzfehler/Systemerkrankungen etabliert sich molekulargenetisch die Suche nach Genen bei

- Noonan-Syndrom (PTPN11-, KRAS-, SOS1-Gen),

- CHARGE-Syndrom (CHD7-Gen),

- Williams-Beuren-Syndrom (Mikodeletion 7q11.23),

- Mikrodeletion 22q11.2 (z. B. DiGeorge- oder Shprintzen-Syndrom),

- Marfan-Syndrom (FBN1-Gen),

- Marfan-Syndrom Typ II und Loeys-Dietz-Syndrom (TGFBR1- u. 2-Gen).

Wichtig für die klinische Diagnose sind die revidierten Ghent-Kriterien für Marfan-Syndrom und verwandte Erkrankungen.

$\mathrm{Zu}$ den wichtigsten neuen Verfahren zählen neben der MLPA die NGS, wodurch die simultane Analyse zahlreicher Gene für ein Indikationsgebiet bei mehreren Patienten in einem Ansatz möglich wird. Mittels NGS ist es z.B. möglich, bei schwieriger klinischer Differenzialdiagnose kardiologische Fragestellungen (z. B. plötzlicher Herztod ohne pathologisch-anatomisch erkennbare Ursache) in der molekulargenetischen Diagnostik die parallele Analyse von insgesamt mindestens 40 Genen durchzuführen.

\section{DGKJ-PO-K-11}

Kammerflimmern als Erstmanifestation eines Wolff-ParkinsonWhite-Syndroms (WPW-Syndrom) auf der Grundlage eines Divertikels der V. cordis magna

\section{Bahrke S.', Schneider H. ', Paul T. \\ 'Universitätsklinikum, Abteilung für Pädiatrische Kardiologie und Intensiv- medizin, Göttingen}

Hintergrund. Das WPW-Syndrom ist die häufigste Ursache einer supraventrikulären Tachykardie bei Kindern und Jugendlichen. Eine Erstdiagnose nach Kammerflimmern ist extrem selten.

Fallbericht. Ein bisher asymptomatischer 10-jähriger Junge kollabierte auf dem Schulhof und wurde laienreanimiert. Die Rettungskräfte diagnostizierten Kammerflimmern und defibrillierten erfolgreich. Im EKG zeigte sich eine ausgeprägte Präexzitation. In der elektrophysiologischen Untersuchung betrug die antegrade Refraktärperiode der akzessorischen Leitungsbahn maximal $200 \mathrm{~ms}$. Das endokardiale Mapping zeigte eine posteroseptale Lokalisation der Leitungsbahn. Angiographisch bestand ein großes Divertikel der Vena cordis magna. Durch die Hochfrequenzstromapplikation im Hals des Divertikels kam es zur prompten Leitungsunterbrechung der Leitungsbahn mit Verlust der Präexzitation.

Schlussfolgerung. Das WPW-Syndrom ist bereits im Kindesalter mit lebensbedrohlichen Herzrhythmusstörungen assoziiert. Bei Vorliegen einer posteroseptalen Leitungsbahn ist eine Venographie zur Diagnose eines Divertikels der Vena cordis magna hilfreich. Die Hochfrequenzstromablation ist kurativ.

\section{DGKJ-PO-K-12}

\section{Schwere passagere Kardiomyopathie bei PPHN}

Thiel C.', Gottschalk U.', Müller G.', Blohm M.', Weil J.'

'Universitäres Herzzentrum, UKE, Kinderkardiologie, Hamburg, 'UKE, Klinik für Geburtshilfe, Kinder- und Jugendmedizin, Hamburg

Fallbericht. Wir berichten über ein reifes Neugeborenes, welches im Alter von 48 Stunden klinische Zeichen einer schweren persistierenden pulmonalen Hypertonie des Neugeborenen zeigte. Die Geburt war nach 38 SSW erfolgt, die initale Anpassung erfolgte problemlos. Es gab keine Hinweise auf eine Infektion, Unterkühlung oder ähnliches.
Das Kind wurde uns aus der Geburtsklinik in schlechtem Allgemeinzustand mit beginnendem Kreislaufversagen verlegt. Echokardiographisch fand sich bereits unmittelbar nach der Verlegung eine schwere globale Funktionseinschränkung des linken Ventrikels (FS 12\%) bei anatomisch unauffälligem Herz. Insbesondere ließen sich beide Koronarien normal darstellen. Im rechten Ventrikel fand sich über eine Trikuspidalinsuffizienz gemessen Systemdruck. Wir begannen sofort mit einer umfangreichen Kreislauftherapie mit Adrenalin, Noradrenalin und Milrinon. Des Weiteren erfolgte eine Beatmung mit NO-Zufuhr. Laborchemisch bestand eine globale Minderperfusion, das Laktat stieg bis auf $24 \mathrm{mmol} / \mathrm{l}$ an. Unter der Therapie besserte sich die klinische Situation langsam, eine Extubation war nach 12 Tagen möglich. Die Funktion des linken Ventrikels war weiterhin global eingeschränkt, besserte sich aber in den Folgemonaten unter einer oralen Herzinsuffizienztherapie. Auf eine Herzkatheteruntersuchung wurde angesichts des Verlaufs verzichtet. Nach Ablauf von 3 Monaten hatte sich die linksventrikuläre systolische Funktion normalisiert (FS 37\%). Die Therapie besteht zurzeit nur noch aus einem ACE-Hemmer. Wir deuteten den gesamten Verlauf als Folge einer schweren Myokardhypoxie bei PPHN.

\section{Verschiedenes (1)}

\section{DGKJ-PO-V1-1}

Sind sich die deutschsprachigen Kinderorthopäden in der Diagnostik und Therapie der Säuglingshüfte einig?

\section{Seidl T.', Placzek R. ${ }^{2}$, Funk J. ${ }^{3}$}

'Franziskus Hospital, Klinik für Orthopädie, Unfallchirurgie und Wirbelsäulenchirurgie, Bielefeld, ${ }^{2}$ Universitätsklinikum Bonn, Klinik und Poliklinik für Orthopädie und Unfallchirurgie, Bonn, ${ }^{3}$ Charité - Universitätsmedizin Berlin, Sektion Kinder- und Neuroorthopädie, Berlin

Hintergrund. Die Hüftsonographie ist seit 1996 Bestandteil der „KinderRichtlinie“. Ziel der Arbeit ist herauszufinden, ob sich die deutschsprachigen Kinderorthopäden hinsichtlich Diagnostik und Therapie der Säuglingshüfte einig sind.

Methodik. Ein Fragebogen wurde an alle Mitglieder der Vereinigung für Kinderorthopädie verschickt. Erfragt wurden Angaben zu Ausbildung und Tätigkeitsbereich und zum diagnostischen Vorgehen. Darüber hinaus wurde ein Therapievorschlag für 4 Fallbeispiele inkl. Anamnese, Klinik und Sonogramm erbeten (Fall 1: 3 Tage alt, weiblich, Typ D; Fall 2: 2 Tage alt, weiblich, Typ IV; Fall 3: 4 Wochen alt, weiblich, Typ IIa; Fall 4: 4 Monate alt, weiblich, Typ IIIa).

Ergebnis. 78/179 Mitglieder antworteten. 75,6\% sind FÄ mit Zusatzbezeichnung Kinderorthopädie, 68\% arbeiten im Krankenhaus. Die Sonographie erfolgt bei $61,5 \%$ v. a. durch Orthopäden/Unfallchirurgen, einmal durch MTA. Die von Graf empfohlene Ausstattung besitzen 21,8\%. 23/50 gaben an, dass postnatal ein generelles Screening erfolgt. Beim Typ D empfehlen 15,4\% abwarten und kontrollieren ggf. Breitwickeln, 56,4\% eine Nachreifungsorthese und 26,9\% eine Reposition und Retention. Beim Typ IV empfehlen 3,8\% eine Nachreifungsorthese, $88,5 \%$ eine Reposition und Retention. Beim Typ IIa empfehlen 67,9\% abwarten und kontrollieren ggf. Breitwickeln, 25,6\% eine Nachreifungsorthese, ein Kollege eine Pavlik-Bandage. Beim Typ IIIa empfehlen 14,1\% eine Nachreifungsorthese, 8o,8\% eine Reposition und Retention.

Schlussfolgerung. Trotz klarer Empfehlungen zur Diagnostik und Therapie der Säuglingshüfte herrscht unter den Kinderorthopäden Uneinigkeit. Unsicherheiten bestehen v. a. bei der Beurteilung von physiologisch unreifen und dezentrierenden Gelenken und bergen die Gefahr der Übertherapie bzw. die der verzögerten Therapie. 
DGKJ-PO-V1-2

Epidemiologie invasiver Pneumokokkenerkrankungen bei Kindern in Deutschland von 1997-2013: Effekte nach Einführung der Pneumokokken-Konjugatimpfung

van der Linden M. ', Imöhl M.'

${ }^{1}$ Universitätsklinikum RWTH Aachen, Dept. of Medical Microbiology, German National Reference Center for Streptococci, Aachen

Fragestellung. Streptococcus pneumoniae gehört in Deutschland bei Kindern und älteren Erwachsenen zu den häufigsten Erregern von Pneumonie, Sepsis und Meningitis. Im Juli 2006 wurde eine generelle Pneumokokken-Impfempfehlung ausgesprochen. Nach dieser Empfehlung wurden ein 7-valenter Konjugatimpfstoff ( $\mathrm{PCV}_{7}$, bis Dez. 2009), ein 10-valenter Konjugatimpfstoff (PCV10, ab Apr. 2009) und ein 13-valenter Konjugatimpfstoff (PCV13, ab Dez. 2009) eingesetzt. In dieser Studie zeigen wir die Effekte der verschiedenen Konjugatimpfstoffe auf die Serotypverteilung bei invasiven Pneumokokkenerkrankungen (IPE) bei Kindern in Deutschland.

Material und Methoden. Auch wenn die IPE in Deutschland nicht meldepflichtig sind, sammelt das Nationale Referenzzentrum für Streptokokken in Zusammenarbeit mit dem RKI seit 1997 PneumokokkenIsolate von IPE bei Kindern. Die Serotypisierung erfolgt durch die Neufeldsche Quellungsreaktion.

Ergebnisse. Sieben Jahre nach Einführung der Konjugatimpfung wurden nahezu keine Krankheitsfälle mehr mit PCV7-Serotypen bei Kindern unter 16 Jahren gemeldet. Die Fallmeldungen von nicht-PCV7-Serotypen stiegen allerdings an (vor allem die Serotypen $19 \mathrm{~A}, 7 \mathrm{~F}$ und 1). Drei Jahre nach Einführung von PCV1o und PCV13 zeigt sich bei Kindern unter 2 Jahren ein starker Rückgang der 1-, 3-, 6A-, 7F- und 19AFälle. Die 19A-Fälle gingen von Juli 2009 bis März $2010(n=15)$ auf Juli 2012 bis März $2013(n=6)$ um 60\%, die Serotyp 3 Fälle um 57\% zurück. Diskussion. Sieben Jahre nach der generellen Impfempfehlung für Pneumokokken-Konjugatimpfstoffe bei Kindern sind die in $\mathrm{PCV}_{7}$ enthaltene Serotypen bei IPE bei Kindern $<16$ Jahren nahezu verschwunden. Die höher valente Impfung zeigt eine deutliche Wirkung bei Kindern unter 2 Jahren, bei denen 1-, 3-, 6A-, , $F$ - und 19A-Fälle seltener geworden sind.

\section{DGKJ-PO-V1-3}

Mikrobiologische Analyse der Mittelohrflüssigkeit (MOF) und nasopharyngealen Trägerisolate (NTI) bei Kindern mit akuter Otitis media (AOM) in Deutschland, 4. Studienjahr

Imöhl M. ', Laurenz M. ${ }^{2}$, Liebetrau K. ${ }^{3}$, Busse A. ${ }^{4}$, van der Linden M. ${ }^{1}$ 'Universitätsklinikum RWTH Aachen, Dept. of Medical Microbiology, German National Reference Center for Streptococci, Aachen, ${ }^{2}$ Pfizer Pharma GmbH, Berlin, ${ }^{3}$ Proinnovera GmbH, Münster, ${ }^{4}$ Kinder- und Jugendarztpraxis, Tegernsee

Fragestellung. Im Dezember 2009 wurde der 13-valente Pneumokokken-Konjugatimpfstoff ( $\left.\mathrm{PCV}_{13}\right)$ in Deutschland zugelassen. Eine generelle Pneumokokken Impfempfehlung wurde im Juli 2006 ausgesprochen. Wir berichten hier über die von Kindern mit AOM mit Erguss infolge einer Trommelfellruptur isolierten Krankheitserreger im Studienzeitraum Oktober 2011 bis Oktober 2012.

Material und Methoden. Bei Kindern mit AOM und spontanem Erguss wurden Abstriche von Mittelohrflüssigkeit und Nasopharynx gewonnen, unabhängig vom Pneumokokken-Impfstatus. Eine Serotypisierung von Streptococcus pneumoniae erfolgte durch die Neufeldsche Quellungsreaktion.

Ergebnisse. In den ersten 3 Studienjahren konnten 443, 310 und 210 Patienten eingeschlossen werden. Wegen der rückläufigen Zahl der Meldungen wurde im 4. Studienjahr die Rekrutierungsbasis von 50 auf 75 Zentren erhöht, so dass von 439 Patienten MOF gewonnen werden konnte [NTI: 416 (96,5\%)]. Bei 163 MOF Isolaten konnten Pathogene nachgewiesen werden: S. pneumoniae (30/18,5\%), S. pyogenes
(79/48,5\%), S. aureus (34/20,1\%), H. influenzae $(27 / 16,6 \%)$ und M. catarrhalis (1/o,6\%). Trägerraten waren: S. pneumoniae $49,8 \%$, M. catarrhalis $35,8 \%$, H. influenzae $41,3 \%$, S. pyogenes $21,3 \%$ und $\mathrm{S}$. aureus $7,2 \%$. Die häufigsten Serotypen in MOF und NTI waren 3, 19A und 11A. Die Durchimpfungsrate lag bei $91,7 \%$.

Diskussion und Schlussfolgerung. Im 4. Studienjahr wurden erheblich mehr S. pyogenes isoliert, sowohl aus MOF als auch bei NTI. Die Prävalenz von S. pneumonia bei MOF nahm im 4. Studienjahr nicht weiter ab. Die Serotypen 3 und 19A wurden am häufigsten gefunden. Der Anstieg des Serotyps 11A sollte weiter beobachtet werden.

\section{DGKJ-PO-V1-4}

Erhebung des Pneumokokken-Impfstatus bei Kindern unter 2 Jahren mit invasiver Pneumokokkenerkrankung nach Einführung der Pneumokokken-Konjugatimpfung

van der Linden M. ${ }^{1}$, Bertram M.', Otten J.', Imöhl M. ${ }^{1}$

'Universitätsklinikum RWTH Aachen, Dept. of Medical Microbiology, Ger-

man National Reference Center for Streptococci, Aachen

Fragestellung. Im Juli 2006 wurde in Deutschland eine generelle Pneumokokken Impfempfehlung ausgesprochen. Wir berichten hier über den Pneumokokken-Impfstatus von Kindern <2 Jahren mit invasiven Pneumokokkenerkrankungen (IPE) in den Jahren 2006-2007 bis 20122013.

Material und Methoden. IPE sind in Deutschland nicht meldepflichtig, dennoch sammelt das Nationale Referenzzentrum für Streptokokken seit 1997 Pneumokokken-Isolate von IPE bei Kindern. Alle Einsendungen wurden auf Angaben zum Impfstatus überprüft. Fehlende Angaben wurden telefonisch beim Einsendelabor oder schriftlich beim behandelnden Arzt erfragt.

Ergebnisse. Von 713 Einsendungen konnte bei bisher 320 der Impfstatus eruiert werden. 206 Kinder (64,4\%) waren geimpft; PCV7: n=35 (10,9\%), PCV10: $n=9$ (2,8\%), PCV13: $n=57$ (17,8\%), PCV7/13: $n=10$ (3,1\%), PCV10/13: $\mathrm{n}=2(0,6 \%)$, Impfstoff unbekannt $\mathrm{n}=93$ (29,0\%). In der Pneumokokkensaison 2011-2012 waren von 28 Kindern mit IPE durch einen im Impfstoff erhaltenen Serotypen $\left(1,3,4,5,6 \mathrm{~A}, 6 \mathrm{~B}, 7 \mathrm{~F}, 9 \mathrm{~V}, 14,18 \mathrm{C}, 19 \mathrm{~A},{ }_{19} \mathrm{~F}, 23 \mathrm{~F}\right)$ $17(60,7 \%)$ Kinder ungeimpft. Von diesen waren 11 Kinder 2-4 Monaten alt. In 3 weiteren Fällen lag eine unvollständige Impfung vor [kein Booster; PCV10 (14), PCV13 $(3,19 \mathrm{~A})]$. In sechs Fällen trat eine IPE mit einem im Impfstoff erhaltenen Serotyp bei Kindern die empfehlungsgerecht geimpft waren auf: PCV10 (6A, 19F), PCV13 [3, 19A (3x)]. Bei zwei Fällen blieb der Impfstatus ungeklärt.

Diskussion. Die ersten Ergebnisse dieser Studie zeigen, dass unter den noch auftretenden IPE-Fällen mit Impfstoff-Serotypen die meisten Kinder ungeimpft sind. In vielen Fällen wurde zu spät mit der Impfung begonnen oder die Boosterdosis nicht gegeben. Sechs Fälle stellten Impfversager dar und werden weiter auf mögliche Grunderkrankungen untersucht.

\section{DGKJ-PO-V1-5}

Eine prospektive Datenbank für pädiatrische Patienten mit chronischen Schmerzsyndromen - Ergebnisse 8 Wochen nach stationärer multimodaler Schmerztherapie

\section{Jäger $N^{1,2}$}

'Deutsches Zentrum für Kinder und Jugendrheumatologie, Garmisch Partenkirchen, ${ }^{2}$ Ludwig-Maximilian-Universität München, Institut für medizinische Psychologie, München

Hintergrund. Wirksamkeit einer stat. multimodalen Schmerztherapie auf Schulerfolg und Lebensqualität bei Kindern und Jugendlichen mit chronischen Schmerzen

Methoden. Von 12/o7 bis 11/10 konsekutive Aufnahme von Patienten in eine prospektive Datenbank. Einschlusskriterien: bestätigte Diagnose eines generalisierten oder regionalen Schmerzverstärkungssyndroms 
nach den Kriterien von Yunus und Masi bzw. Harden. Patienten und ihre Eltern erhielten einen Fragebogen mit den Schwerpunkten: Demographische, sozioökonomische Daten, Schmerz („numeric rating scale“), Lebensqualität (multidimensionaler Schmerzfragebogen für Kinder MPI-K nach Hermann) und funkt. Einschränkung (C-HAQ). Die Patienten wurden dann für 3-4 Wochen mit einer stationären multimodalen Schmerztherapie behandelt. Nach 8 Wochen ausfüllen desselben Fragebogens. Die Daten sowie medizinische Daten wurden in eine auf MS Access basierende Datenbank eingetragen und mit deskriptiver Statistik und non-parametrischen Testmethoden (Wilcoxon signed rank test) analysiert.

Ergebnisse. Von 514 eingeschlossenen Patienten wurden 240 nach 8 Wochen erneut befragt ( $47 \%$ ). $45 \%$ zeigten ein prim. generalisiertes, $41 \%$ ein sek. Schmerzsyndrom im Rahmen einer rheumat. Erkrankung und $14 \%$ ein lok.. Nach 8 Wochen zeigte sich ein Rückgang der Schmerzintensität im Median [5/10 auf 4/10 ( $\mathrm{p}<0,001)$ ], im MIP-K eine signifikante Verbesserung in den Bereichen Schule, Freizeit, Familie und Pflichten ( $\mathrm{p}<\mathrm{0}, 001)$, gleichbleibende funktionelle Einschränkung (vor Beh. med. C-HAQ 0,375, nach Beh. 0,375; $\mathrm{p}=0,507) .40 \%$ der Patienten nahmen regelmäßig Schmerzmedikamente.

Schlussfolgerungen. Die multimodale stat. Schmerztherapie führt nach 8 Wochen zu signifikanter Besserung von Schmerzintensität und Lebensqualität. Eine Verbesserung von funktionellen Einschränkungen ist nicht nachweisbar.

\section{DGKJ-PO-V1-6}

\section{Forschung für seltene Erkrankungen}

Franke-Rupp K. ', Parente Matschke B. ${ }^{1}$, Klein C. ${ }^{1}$

'Ludwig-Maximilians-Universität München, Dr. von Haunersches Kinderspital, München

Abstract im Namen der folgenden 12 Forschungsverbünde: AID-Net - Netzwerk für Autoinflammatorische Syndrome bei Kindern und Jugendlichen

CARPuD II - Zelluläre Verfahren für seltene Lungenerkrankungen

FACE - Netzwerk ausgewählter craniofacialer Entwicklungsstörungen GALENUS - Genetische Modifikation des CFTR-Gens bei zystischer Fibrose GERAMY - Netzwerk für Leichtketten (AL-) Amyloidose

HOPE2 - Netzwerk für Erbliche Netzhauterkrankungen

Imprinting - Netzwerk für Imprinting-Erkrankungen

IonNeurONet - Netzwerk für Neurologische und Ophthalmologische lonenkanalerkrankungen

mitonet - Netzwerk für mitochondriale Erkrankungen

MND-Net - Netzwerk für Motoneuronerkrankungen

PID-Net - Netzwerk für Primäre Immundefekte

TranSaRNet - Translationales Sarkom-Forschungsnetzwerk

Viele chronisch kranke Kinder und Jugendliche, die an tertiären medizinischen Zentren betreut werden, leiden an "seltenen Erkrankungen“. Diese „Waisen der Medizin“ stehen in vielfältiger Hinsicht im Schatten, nicht zuletzt weil die Krankheitsursachen immer noch im Dunkeln liegen. Das Bundesministerium für Bildung und Forschung fördert seit 2003 interdisziplinäre Forschungsverbünde und leistet damit einen wichtigen Beitrag für ein besseres Verständnis der Ursachen sowie für die Entwicklung neuer Therapieverfahren. Die Geschäftsstelle der gegenwärtig 12 Forschungsverbünde für seltene Erkrankungen am Dr. von Haunerschen Kinderspital übernimmt eine Servicefunktion für die interne und externe Vernetzung. Wir präsentieren hier die Forschungsthemen der Forschungsverbünde, die etablierten Plattformtechnologien wie Biobanken und Next-Generation-Sequenziermöglichkeiten, unsere Aktivitäten zum Thema Patientenregister sowie die Vernetzung mit internationalen Initiativen für seltene Erkrankungen.

\section{DGKJ-P0-V1-7 \\ PTEN-assoziierte Lipomatosen}

Händel N. ${ }^{1}$, Kässner F.', Garten A. ', Schmid G. ', Landgraf K. ', Tannert A. ${ }^{2}$, Wabitsch M. ${ }^{3}$, Kiess W. ${ }^{1}$, Körner A. ${ }^{1}$

'Universitätsklinikum Leipzig, Department für Frauen- und Kindermedizin, Klinik und Poliklinik für Kinder und Jugendliche, Leipzig, ${ }^{2}$ Universität Leipzig, Rudolf-Boehm-Institut für Pharmakologie und Toxikologie, Leipzig, ${ }^{3}$ Universitätsklinikum Ulm, Kinder- und Jugendmedizin, Pädiatrische Endokrinologie und Diabetologie, Ulm

Fragestellung. Bei Patienten mit Gendefekten im PTEN/PI 3 K/AKT-Signalweg, dem PTEN Hamartom-Tumorsyndrom (PHTS), kann es zur Entwicklung von extremen, konservativ schwer behandelbaren Veränderungen des Fettgewebes (Lipomatosen) kommen. Internistische, orthopädische und ästhetische Komplikationen sind dann die Folge, welche die Patienten vielfach zu operativen Korrekturen zwingen. Wir untersuchen die molekularen Mechanismen der Lipomatose.

Methoden. Aus reseziertem Lipomgewebe eines Patienten mit PHTS wurde eine Zellkultur gewonnen und hinsichtlich der Genexpression von Adipozytenmarkern während der Differenzierung, der Signaltransduktion im $\mathrm{PI}_{3} \mathrm{~K} / \mathrm{AKT}$-Signalweg und Induktion von Lipolyse sowie Glukoseaufnahme untersucht. Als Kontrolle dienten SGBS Präadipozyten.

Ergebnisse. Die Lipomzellen hatten eine 25-stündige Verdopplungszeit, eine verlängerte Lebensdauer von 91 Generationen und eine 50\%ige Differenzierungskapazität bis zur 29. Generation. Die Analyse des $\mathrm{PI}_{3} \mathrm{~K} /$ AKT-Signalweges zeigte eine verstärkte Aktivierung: die basale $\mathrm{PI}_{3} \mathrm{~K}$ Aktivität und AKT-Phosphorylierung waren signifikant erhöht. Im Gegensatz dazu gab es keinen signifikanten Unterschied in der Expression der Differenzierungsmarker PPAR-gamma, FASN, Adiponektin und $\mathrm{aP}_{2}$ im Vergleich zu SGBS Kontrollzellen. Funktionelle Analysen zeigten keine signifikanten Unterschiede hinsichtlich der Glukoseaufnahme und Lipolyseinduktion.

Fazit. Bei einem Patienten mit PTEN-assoziierter Lipomatose finden sich Lipomzellen mit hyperaktivierten Signalmolekülen im $\mathrm{PI}_{3} \mathrm{~K} / \mathrm{AKT}$ Signalweg. Diese Schlüsselmoleküle könnten als Angriffspunkte für die Entwicklung medikamentöser Behandlungsstrategien von Bedeutung sein. Betreuen Sie Patienten mit multiplen Lipomen, Lipomrezidiven oder schweren Lipomatosen?

\section{DGKJ-PO-V1-8}

\section{Immundysregulation und FOXP3+ regulatorische T-Zellen in Patien-} ten mit PTEN-Gendefekt

Händel N. ${ }^{1}$, Chen H. ${ }^{2}$, Hühn M. ${ }^{2}$, Ngeow J. ${ }^{3}$, Eng C. ${ }^{3}$, Kionke J. ${ }^{4}$, Aretz S. ${ }^{4}$, Powrie F. ${ }^{2}$, Uhlig H.H. ${ }^{2}$, stellvertretend für die PTEN Immunity Group 'Universitätsklinikum Leipzig, Department für Frauen- und Kindermedizin, Klinik und Poliklinik für Kinder und Jugendliche, Leipzig, ${ }^{2}$ University of Oxford, Translational Gastroenterology Unit, Oxford, UK, ${ }^{3} \mathrm{Cleveland}$ Clinic, Genomic Medicine Institute, Lerner Research Institute, Cleveland, USA, ${ }^{4}$ Universitätsklinikum Bonn, Institut für Humangenetik, Bonn

Einleitung. Die Phosphatase PTEN kontrolliert den $\mathrm{PI}_{3} \mathrm{~K} / \mathrm{AKT} / \mathrm{mTOR}-$ Signalweg. Patienten mit Keimbahnmutationen in PTEN entwickeln nicht nur ein Tumorsyndrom, sondern auch Autoimmunität und Immundysregulation im Darm. Die reduzierte Aktivität von PTEN beeinflusst insbesondere B-Zellen im Keimzentrum via mTOR und antiapoptotische Signale. Mausmodelle belegen die essentielle Rolle eines streng kontrollierten $\mathrm{PI}_{3} \mathrm{~K} / \mathrm{AKT}$ Signalweges für $\mathrm{FOXP}_{3}+$ regulatorische T-Zellen.

Methoden. Wir haben untersucht, ob ein Mangel an PTEN bei PTENMutationsträgern die Aktivität von regulatorischen T-Zellen inhibiert und dies $\mathrm{zu}$ intestinaler und extraintestinaler Immunpathologie beiträgt. Wir untersuchten Immunphänotyp und -dysregulation sowie periphere und intestinale Lymphozytenpopulationen, insbesondere 
$\mathrm{FOXP}_{3}+$ regulatorische T-Zellen, von 74 Patienten mit pathogener PTEN-Mutation durch FACS, Mikroskopie und Induktionsassays. Ergebnisse. Gastrointestinale, lymphatische Hyperplasien, Tonsillenund Thymushyperplasie, Autoimmunthyreoiditis, -anämie und Kolitis wurden bei Patienten mit PTEN-Mutation beobachtet. Lymphatische Hyperplasien sind mit einer Lymphopenie im Blut assoziiert. Im Unterschied zu B-Zellen wurden in T-Zell-Subpopulationen keine Unterschiede zwischen Patienten und Kontrollpersonen nachgewiesen. Trotz PTEN-Mutation waren FOXP $3+$ T-Zellen nicht vermindert. Die PTENInhibition in vitro zeigte eine nur marginal verringerte Induktion von FOXP $_{3}+\mathrm{T}-$ Zellen. Wir identifizierten PHLPP als kompensatorische Phosphatase. PTEN, PHLPP und NHERFı bilden ein Proteinnetzwerk im Bereich der immunologischen Synapse, welches die unkontrollierte AKT-Signalübertragung in $\mathrm{FOXP}_{3}+$ regulatorischen T-Zellen verhindert und den heterozygoten Verlust von PTEN in T-Lymphozyten kompensiert.

\section{DGKJ-PO-V1-9}

\section{Analyse des Diagnosewegs bei Kindern mit Retinoblastom zur Verbesserung der Früherkennung}

\section{Wilm J.', Beneda R. ${ }^{2}$, Bornfeld N. ${ }^{1,3}$, Lohmann D. ${ }^{1,4}$, Temming P. ${ }^{1,5}$ ${ }^{1}$ Klinische Forschergruppe ophthalmologische Onkologie und Genetik, Institut für Humangenetik, Universitätsklinikum, Essen, ${ }^{2}$ Institut für Medi- zinische Informatik, Biometrie und Epidemiologie, Universitätsklinikum, Essen, ${ }^{3}$ Klinik für Erkrankungen des hinteren Augenabschnittes, Klinik für Augenheilkunde, Universitätsklinikum, Essen, ${ }^{4}$ Institut für Humangenetik, Universitätsklinikum, Essen, ${ }^{5}$ Klinik für Pädiatrische Hämatologie und Onkologie, Universitätsklinikum, Essen}

Fragestellung. Das Retinoblastom (RB) ist ein seltener, maligner Augentumor im Kindesalter. Bei frühzeitiger Diagnose haben Patienten eine Überlebensrate von $>95 \%$. Die Erstsymptome werden häufig nicht als bedrohlich erkannt und die Diagnose verzögert. Daher wurde in der vorliegenden Studie das Diagnosealter, die Erstsymptome, das Diagnoseintervall und der Diagnoseweg bei RB-Patienten in Deutschland analysiert.

Methoden. Von 1166 Patienten mit RB-Behandlung zwischen 1992-2011 in Essen erfüllten 665 Patienten die Einschlusskriterien (Erstdiagnose RB in Essen, deutsche Krankenversicherung) für die retrospektive Datenerhebung. Zwei Kohorten (K1 und K2) für die Zeiträume 1992$2001(n=303)$ und 2002-2011 $(n=362)$ wurden verglichen. 60\% der Patienten waren unilateral, $40 \%$ bilateral betroffen.

Ergebnisse. Die beiden häufigsten Symptome waren Leukokorie $(n=296$, $44,5 \%)$ und Strabismus $(\mathrm{n}=196,29,5 \%)$. Diese Symptome wurden bei $77,7 \%(n=517)$ von den Eltern und $2 \%(n=13)$ bei den regulären U-Untersuchungen der Kinder auffällig; davon 5 bei $U_{4}, 3$ bei $U_{5}, 4$ bei $U 6$ und 1 bei U9. Das mediane Diagnoseintervall betrug 42 (Spannweite: o-613) Tage in K1 und 49 (1-1218) Tage in K2. Die Tumorstadienverteilung in beiden Kohorten war vergleichbar. Sechs $(0,9 \%)$ Patienten sind verstorben. Insgesamt mussten bei 10 (1,5\%) Kindern beide Augen und bei 533 $(80,2 \%)$ ein Auge enukleiert werden. Bei 122 (18,3\%) blieben beide Auge erhalten.

Schlussfolgerung. Die Erhebung zeigt die sehr gute Überlebensrate bei RB-Erkrankungen in Deutschland. Allerdings hat sich das Diagnoseintervall in den letzten 20 Jahren für das RB nicht signifikant verändert. Eine gezieltere Erhebung der Anamnese und Symptome bei der U-Untersuchung könnte zur verbesserten Früherkennung des RBs beitragen und damit Langzeitschäden reduzieren.

\section{DGKJ-PO-V1-10}

Förderbedarfe von Kindern bei Eintritt in die Kindertageseinrichtung - "Kita-Start-Untersuchung"

Doil H. ${ }^{1}$, Frevert S. ${ }^{2}$, Kloß S. ${ }^{3}$

'Bielefelder Institut für frühkindliche Entwicklung e.V., Bielefeld, ${ }^{2}$ Bielefelder Institut für frühkindliche Entwicklung e.V., Gütersloh, ${ }^{3}$ Kreis Gütersloh, Gesundheit, Kinder- und Jugendgesundheitsdienst, Gütersloh

Fragestellung. Ausgangspunkt des Projektes war die Einschätzung von Erzieherinnen, dass Kinder mit sprachlichen, kognitiven oder sozialemotionalen Entwicklungsauffälligkeiten, z. T. nicht oder erst spät die notwendige Förderung erhalten. Manche dieser Kinder würden erst bei der Schuleingangsuntersuchung erkannt. Dies ist bedenklich, da dies in der Regel Risikokinder für anhaltende Entwicklungsstörungen sind. Ziel der Untersuchung war es daher, Kinder mit Entwicklungsauffälligkeiten möglichst früh, und zwar beim Eintritt in eine Tageseinrichtung mit drei bis vier Jahren, durch ein Entwicklungsscreening zu erkennen. Material und Methode. Das Screening besteht aus einem medizinischem (Hören, Sehen, Motorik) und einem entwicklungspsychologischen (Kognition, Sprache, Sozial-emotionale Entwicklung) Modul. Es wurden 250 3- und 4-jährige Kinder untersucht. Bei auffälligem Hör- und Sehbefund wurden die Kinder zum Facharzt überwiesen. Auffällige Screeningergebnisse im Bereich Sprache und/oder Kognition wurden in Rahmen einer Validierungsphase nachuntersucht.

Ergebnisse. Bei etwa $20 \%$ der Kinder ergab sich ein Therapie/-Förderbedarf im sprachlichen und/oder kognitiven Bereich. Die Vorhersagegüte des eingesetzten Screenings im Rahmen des Projektes war sehr gut. Die Nachuntersuchung der identifizierten Risikokinder mit standardisierten Testverfahren liefert klare und spezifische Hinweise zum Förderbedarf.

Diskussion und Schlussfolgerungen. Um kumulativen Entwicklungsstörungen vorzubeugen sollten Kinder mit individuellem Förderbedarf möglichst frühzeitig erkannt werden. Der Einsatz des Screening als ergänzende Maßnahme zur U7a wäre vorstellbar.

\section{DGKJ-PO-V1-11}

\section{Paediatric needs - Sind wir auf dem richtigen Weg?}

\section{Wimmer S.', Rascher W.', Neubert A.'}

'Universitätsklinikum Erlangen, Kinder- und Jugendklinik, Erlangen

Fragestellung. Im Rahmen der EU-Kinderarzneimittelverordnung wurden pädiatrische Entwicklungspläne (PIP) bei Zulassungsanträgen obligatorisch; die Paediatric Working Party der EMA erarbeitete eine Aufstellung über Arzneimittel, bei denen ein Bedarf für weitere Forschung bzw. kindgerechte Formulierungen besteht („List of paediatric needs"). Zusätzlich wurde über das 7 . EU-Forschungsrahmenprogramm ( $\left.\mathrm{FP}_{7}\right)$ pädiatrische Forschung finanziell gefördert. Nach 5 Jahren Kinderarzneimittelverordnung war es das Ziel zu untersuchen, in welchem Umfang die „List of paediatric needs“ tatsächlich Gegenstand der pädiatrischen Forschung ist.

Methode. Die Webseiten der EMA und des Forschungs- und Entwicklungsinformationsdienstes (CORDIS) der Europäischen Kommission (EC) wurden systematisch nach PIP und pädiatrischen Projekten im Rahmen des $\mathrm{FP}_{7}$ durchsucht und mit der „List of paediatric needs“ verglichen.

Ergebnisse. Die Liste umfasst 325 Wirkstoffe aus 15 Therapiegebieten. Im Februar 2013 waren insgesamt 873 Entscheidungen über PIP auf der EMA-Webseite gelistet, wovon sich $45(5,2 \%)$ PIP mit der „List of paediatric needs“ deckten (13,9\% der Liste). Nur 11 (24,5\%) dieser PIP entfielen auf Off-Patent-Wirkstoffe. Bis 2012 förderte die EC 62 Forschungsprojekte mit direktem Bezug zu pädiatrischen Gesundheitsthemen mit 238,5 Mio. EUR. Von diesen Projekten waren 18 (86,4 Mio. EUR) tatsächliche Arzneimittelstudien an Kindern.

Diskussion. Die Anzahl pädiatrischer Entwicklungen steigt stetig. Der Hauptanteil der PIP bezieht sich jedoch auf neue Wirkstoffe, sodass 
etablierte Stoffe weiterhin zu wenig erforscht werden und sich ihre OffLabel-Anwendung fortsetzt. Weitere Bemühungen einschließlich der Bereitstellung von Geldern für die Kinderarzneimittelforschung sind notwendig.

\section{Neuropädiatrie (1)}

\section{DGKJ-PO-N1-1}

ADHS - Kritische Auseinandersetzung mit der Empfehlung zu einer kardialen Abklärung vor einer Stimulanzientherapie

\section{Eyermann $R^{?}$ \\ 'Dr. Richard Eyermann, Kinder- und Jugendmedizin, Kinderkardiologie, Sportmedizin, München}

Einleitung. Lange besteht in Fachkreisen eine Kontroverse zur kardiologischen Risikobeurteilung vor Stimulanzientherapie wie Methylphenidat (MPH) oder Atomoxetin bei ADHS

Methoden. Literaturrecherche EbM.

Ergebnisse. Kasuistiken von SCD bei jungen Patienten mit ADHS haben präexistente nicht diagnostizierte Herzerkrankungen detektiert. Guidelines zu einheitlicher Praxis wurden von der AHA 2008 veröffentlicht: Von den in praxi verfügbaren Stimulanzien führt keine zu erwiesenen EKG-Veränderungen, nur zu leichten kreislaufaktiven Veränderungen wie minimal HF-Beschleunigung u. RR-Anstieg. In vitro und in vivo zeigte $\mathrm{MPH}-30 \mathrm{mg} / \mathrm{kg}$ keine EKG-Veränderungen, v. a. keine QT-Verlängerung. Guidelines der AHA empfehlen aber ein EKG vor Therapiebeginn. Begründung: Wissen des Arztes um präexistente Herzerkrankung, Stimulanzien tragen Warnung bei Herzpatienten (Anwendung mit Vorsicht oder nicht). Es geht nicht um Nebenwirkungsscreening sondern um Detektion allfälliger Kardiopathie vor Therapiebeginn mit pharmakologischen Substanzen. Kosten-NutzenEffekt solcher Strategie nach aktuellen Daten nicht gegeben. Weiter war aktuell bei $>1400$ ADHS-Kindern im Screening das EKG in $8 \%$ abnorm, bei 5 von den 119 komplett kardiologisch untersuchten Kindern 1 kleiner ASD, 2 bicuspide Aortenklappen u. 2 Präexcitationen, therapeutische Konsequenzen keine. Auch die AAP hat 2008 Stellung genommen, sich klar gegen AHA-Empfehlungen gestellt: kein Screening-EKG vor Therapiebeginn mit Stimulanzien, da SCD-Rate unter Stimulanzien nicht höher als in pädiatrischer Normalpopulation.

Schlussfolgerung. Von Konsens weit entfernt kann man der Expertenargumentation AHA oder AAP folgen. In der BRD wird pragmatisch in Anlehnung an die AAP, die klare Empfehlung, vom Screening-EKG vor Therapiebeginn mit Stimulanzien abzusehen, favorisiert (AG ADHS Kinder- und Jugendärzte).

\section{DGKJ-PO-N1-2}

\section{Ketogene Diät im Kindesalter}

\section{Elpers C. ', Fiedler B. ', Linden T.', Omran H. ', Kurlemann G. ${ }^{1}$}

'Universitätsklinikum Münster, Klinik für Kinder- und Jugendmedizin, Allg. Pädiatrie, Münster

Einleitung. Einige Epilepsiesyndrome des Kindesalters zeigen eine ausgeprägte Pharmakoresistenz. Hier bietet die ketogene Diät (KD) eine Behandlungsalternative. Ebenfalls ist die KD bei ausgewählten Stoffwechselerkrankungen die Therapie der ersten Wahl. Wir präsentieren die Ergebnisse einer retrospektiven Studie zur KD hinsichtlich Effektivität, Sicherheit und Nebenwirkungsprofil.

Methoden. Retrospektive Analyse von 16 Patienten im Alter von 1 bis 19 Jahren [7 w,9 m ] mit pharmakoresistenter Epilepsie $(\mathrm{n}=13)$ oder Stoffwechselerkrankung $(\mathrm{n}=3)$ und Einleitung einer KD zwischen 2006-2011. Die KD wurde bei allen Patienten erst nach einer Behandlung von mindestens drei vollständig ausdosierten Antikonvulsiva be- gonnen. 9/16 Patienten erhielten vorher acht oder mehr antikonvulsive Medikamente.

Ergebnisse. Die KD wurde insgesamt gut vertragen, Nebenwirkungen traten nur bei insgesamt 4/16 Patienten auf. Eine lebensbedrohliche Stoffwechselentgleisung wurde bei keinem der Patienten beobachtet. Unter KD konnten bei 11/16 Patienten positive Effekte beobachtet werden, bei einem Patienten wurde durch die KD zumindest eine Stabilisierung der Anfallssituation erreicht. Ein Patient zeigte keine Anfallsbereitschaft mehr, jedoch ergab sich nur bei 4/16 Patienten eine Verbesserung des EEG-Befundes. Im Langzeitverlauf zeigte sich meist nach initialer Besserung der Anfallssituation eine erneute Zunahme der Anfallsfrequenz. Dieses Phänomen war in unserem Studienkollektiv der häufigste Grund für die Beendigung der KD (8/16).

Schlussfolgerung. Basierend auf den Ergebnissen unserer Studie ist die KD eine sichere und nebenwirkungsarme Behandlungsoption bei pharmakoresistenter Epilepsie im Kindesalter. Prospektive, möglichst randomisierte Studien sind notwendig um die Effektivität der KD gegenüber neuen Antikonvulsiva abschätzen zu können.

\section{DGKJ-PO-N1-3}

Psychogene nicht epileptische Anfälle oder doch tuberöse Sklerose? PNEA oder TS? Ein ungewöhnlicher Fall

\section{Gerling C. ${ }^{\prime}$, Rosenbaum $T^{2}{ }^{2}$, Mangold A. ${ }^{3}$, Krüger S. ${ }^{4}$, Finetti $C .{ }^{1}$}

'Elisabeth-Krankenhaus Essen, Kinderneurologisches Zentrum, Essen, ${ }^{2}$ Klinikum Duisburg, Klinik für Kinder- und Jugendmedizin, Duisburg, ${ }^{3}$ Klinikum Duisburg, Klinik für Radiologie und Neuroradiologie, Duisburg, ${ }^{4}$ Gemeinschaftspraxis für Humangenetik, Dresden

Einleitung. Die tuberöse Sklerose (TS) ist eine autosomal-dominant vererbte neurokutane Erkrankung. Epileptische Anfälle als Erstsymptom kommen meist in den ersten Lebensmonaten in Form von infantilen Spasmen vor. Postpubertär sind fokale Anfälle als Erstsymptom eine Seltenheit und die richtige Diagnose wird manchmal erst auf Umwegen gestellt.

Fallbeschreibung. Wir berichten über eine 15-jährige Jugendliche mit fokalen Anfällen. Nach pathologischem Wach-EEG bei sonst unauffälliger Diagnostik (Schlaf-EEG, cMRT, LP) wurde eine antikonvulsive Therapie mit Levetiracetam begonnen. Anfallsfreiheit konnte nicht erreicht werden, so dass bei einer chronischen familiären Belastungssituation psychogene nicht epileptische Anfälle (PNEA) differenzialdiagnostisch in Betracht gezogen wurden. Für eine Zweitmeinung erfolgte die Vorstellung in unserer Klinik.

Ergebnisse. Nach Absetzen von Levetiracetam kam es zu erneuten fokalen Anfällen. Das EEG zeigte einen Herdbefund und fokale epilepsietypische Aktivität. Das erneut durchgeführte cMRT erbrachte einen überraschenden Befund mit Nachweis subependymaler Knötchen. Unter Woodlicht konnten multiple Whitespots detektiert werden. Die Verdachtsdiagnose einer TS wurde durch den Mutationsnachweis im TSC1-Gen bestätigt. Eine erneute Familienanamnese ergab den Verdacht einer TS des Vaters.

Schlussfolgerung. Neu aufgetretene fokale Anfälle postpubertär sind immer hochverdächtig auf ein symptomatisches Geschehen. Manchmal findet man eine überraschende Ursache erst nach einem kritischen Blick auf die zuvor gestellte Diagnose. 
DGKJ-PO-N1-4

\section{Methodische Besonderheiten und Indikationsspektrum von evo-} zierten Potenzialen in der Pädiatrie

\section{Maier 0.', Peterli J.'}

'Zentrum für Kinderneurologie, Entwicklung und Rehabilitation (KERZentrum) Ostschweizer Kinderspital St. Gallen, Neuropädiatrie, St. Gallen, Schweiz

Fragestellung. Evozierte Potenziale sind auch in der Pädiatrie eine wichtige neurophysiologische Untersuchungsmethode. Methodische Besonderheiten und das Indikationsspektrum in der Pädiatrie werden aufgezeigt.

Methodik. Anhand von klinischen Beispielen werden methodische Besonderheiten und klinische Indikationen evozierter Potenziale bei Kindern und Jugendlichen beschrieben.

Ergebnis. Akustisch evozierte Potenziale (AEP) sind eine sinnvolle Methode zur Beurteilung des Gehörs im Rahmen des Hörscreenings sowie zur Beurteilung der Hirnstammfunktion. Visuell evozierte Potenziale (VEP) werden durchgeführt zur Beurteilung visueller Funktionen und zur Diagnostik bei demyelinisierenden Erkrankungen. Somatosensibel evozierte Potenziale (SEP) sind hilfreich in der Beurteilung der Funktion peripherer Nerven und somatosensibler Bahnen und haben einen Stellenwert in der Prognoseabschätzung bei Koma und Asphyxie. Altersabhängige Normwerte und Reifungsprozesse sind dabei zu beachten.

Schlussfolgerung. Bei der Durchführung Evozierter Potenziale im Kindes- und Jugendalter sind methodische Unterschiede im Vergleich zur Anwendung bei Erwachsenen zu beachten. Das pädiatrische Indikationsspektrum unterscheidet sich verglichen mit dem Indikationsspektrum bei Erwachsenen. Altersabhängige Normwerte sind zu beachten.

\section{DGKJ-PO-N1-5}

"Microcephalic osteodysplastic primordial dwarfism type II" (MOPD II) mit multiplen vaskulären Komplikationen fehldiagnostiziert als Dubowitz-Syndrom

\section{Sigler M. ', Dieks J.', Baumer A. ${ }^{2}$, Wilichowski E. ${ }^{3}$, Paul T.', Rauch A. ${ }^{2}$ \\ ${ }^{1}$ Universitätsklinikum, Göttingen, ${ }^{2}$ Universität Zürich, Medizinische Genetik, Zürich, Schweiz, ${ }^{3}$ Universitätsklinikum Göttingen, Neuropädiatrie, Göttingen}

Hintergrund. Bei dem genetisch bisher nicht determinierten DubowitzSyndrom (Kleinwuchs, Mikrozephalie, auffällige Facies, Ekzeme) sind vaskuläre Komplikationen nicht beschrieben. Cerebrale Aneurysmen sowie weitere vaskuläre Auffälligkeiten sind dagegen bei MOPD II (dysproportionierter Kleinwuchs, Mikrozephalie, auffällige Facies) eine häufige Komplikation. MOPD II beruht auf einer Mutation im Pericentrin(PCNT)-Gen (21q22).

Verlauf. Ein erheblich kleinwüchsiger 22-jähriger Patient (Körperlänge $112 \mathrm{~cm}$ ) wurde unter dem Bild einer akuten Subarachnoidalblutung auf unsere Kinder-Intensivstation aufgenommen, als deren Ursache eine rupturiertes Aneurysma der distalen A. carotis interna identifiziert werden konnte. Der bis dahin mit der Diagnose Dubowitz-Syndrom betreute Patient hatte im Alter von 17 Jahren aufgrund einer erheblichen Koronarangiopathie mehrere aortokoronare Venenbypässe in einer anderen Klinik erhalten. Eine zerebrale Bildgebung war bisher nicht durchgeführt worden. Wir veranlassten eine gezielte genetische Abklärung, die eine compound Heterozygotie für zwei beschriebene Mutationen im PCNT-Gen und damit die Diagnose MOPD II erbrachte. Nach Stabilisierung erfolgte die Verlegung in die Frührehabilitation, wo der Patient jedoch im Rahmen einer erneuten Aneurysmablutung verstarb. Schlussfolgerung. Bei erheblich kleinwüchsigen Patienten - vor allem mit vaskulären Komplikationen - sollte an MOPD II gedacht werden und eine genetische Abklärung erfolgen. Bei Nachweis einer Mutation im PCNT-Gen ist eine sorgfältige Erhebung des vaskulären Status mit zerebraler Schnittbildgebung sowie kardiologischer Abklärung zur Er- kennung von Gefäßauffälligkeiten indiziert, um ggf. eine frühzeitige prophylaktische Therapie einleiten zu können.

\section{DGKJ-PO-N1-6}

Mutationen im Laminin-ү3-Gen (LAMC3) führen zu okzipitaler Polymikrogyrie und Pachygyrie mit BNS-Anfällen, Leukenzephalopathie und Hyper-CK-ämie

\section{Kreth J.H.', Rahner N. ${ }^{2}$, Mayatepek E. ${ }^{1}$, Karenfort M. ${ }^{\text {' }}$}

'Universitätsklinikum Düsseldorf, Klinik für Allgemeine Pädiatrie, Neonatologie und Kinderkardiologie, Düsseldorf, ${ }^{2}$ Universitätsklinikum Düsseldorf, Institut für Humangenetik und Anthropologie, Düsseldorf

Einleitung. Strukturelle kortikale Malformationen entstehen durch Störungen in der Proliferation neuronaler Progenitorzellen, in der neuronalen Migration oder in der Schichtung des Kortex. Die häufigsten Gyrierungsstörungen sind die Lissenzephalie, Pachygyrie, Polymikrogyrie und neuronale Heterotypie. Das Verständnis über die komplexen molekularen Zusammenhänge der Hirnentwicklung und deren Fehlbildungen durch genetische Defekte ist in den letzten Jahren rasant gestiegen. Fallvorstellung. Wir präsentieren einen Jungen, der im Alter von 9 Monaten klinisch mit abortiven infantilen Spasmen auffiel. Im EEG zeigten sich beidseits wechselseitig betonte temporo-okzipitale sharpwaves. In der MRT des Neurokraniums zeigte sich eine auf parieto-okzipital beschränkte Gyrierungsstörung mit gleichzeitiger Pachygyrie an der Hirnoberfläche und einer Polymikrogyrie. Zusätzlich zeigten sich leukenzephalopathische Veränderungen periventrikulär und in der parieto-okzipitalen Region. Laborchemisch fand sich eine milde Hyper-CK-ämie. Es konnten zwei bisher noch nicht beschriebene und mit höchster Wahrscheinlichkeit pathogene Mutationen im Gen für Laminin- $\gamma 3$ gefunden werden. Laminin- $\gamma 3$ ist bedeutsam für die Entwicklung der korrekten Kortexarchitektur.

Schlussfolgerung. Wir beschreiben hier den weltweit vierten Fall in der Literatur mit einer Genveränderung in Laminin- $\gamma_{3}$, welche interessanterweise gleichzeitig eine Pachygyrie und eine Polymikrogyrie verursacht und auf die Okzipitalregion beschränkt ist. Der Zusammenhang und die Bedeutung der Leukenzephalopathie und der milden HyperCK-ämie bleiben zu klären.

\section{DGKJ-PO-N1-7}

\section{A stop mutation in WDR81 causes microcephaly with variable} penetrance

Cirak S. ', Petersen B. ${ }^{2}$, Chang Y. ${ }^{3}$, ElSharaw A. ${ }^{2}$, Alexandre.$^{4}$, Schoner $K^{5}$, Pagenstecher A. ${ }^{6}$, Volk A. ${ }^{7}$, Nurnberg P. ${ }^{8}$, Wilson $S .{ }^{9}$, Albrecht $B .{ }^{10}$, Huttner W. ${ }^{3}$, Morris-Rosendahl D. ${ }^{11}$, Uyanik G. ${ }^{12}$, Franke A. ${ }^{13}$, Voit T. ${ }^{14}$

${ }^{1}$ Childrens National Medical Centre, Research Centre for Genetic Medicine, Washington, USA, ${ }^{2}$ Institute of Clinical Molecular Biology, Christian-Albrechts-University, Kiel, ${ }^{3}$ Max Planck Institute of Molecular Cell Biology and Genetics, Dresden, ${ }^{4} \mathrm{UCL}$ Institute of Child Health, London, UK, ${ }^{5}$ Department of Pathology, University of Marburg, Marburg, ${ }^{6}$ University of Marburg, Department of Neuropathology, Marburg, ${ }^{7}$ Uniklinik Ulm, Institut für Humangenetik, Ulm, ${ }^{8}$ University of Cologne, Cologne Center for Genomics, Köln, ${ }^{9}$ University College London, London, UK, ${ }^{10}$ Humangenetik Uniklinik, Essen, "Imperial College London, London, UK, ${ }^{12}$ Zentrum für Medizinische Genetik, Wien, Österreich, ${ }^{13}$ Institute of Clinical Molecular Biology, Christian-Albrechts-University Kiel, Kiel, ${ }^{14}$ University Pierre et Marie Curie Paris VI, UM ${ }^{76}$, INSERM U ${ }^{974}$, CNRS UMR ${ }^{7215}$, Groupe Hospitalier Pitié-Salpêtrière, Institut de Myologie, Paris, Frankreich

Severe congenital primary microcephaly is a clinically and genetically heterogeneous disorder. Currently, 1o disease causing genes have been described. These genes alter three main pathways leading to microcephaly: centrosome function, DNA repair and cell cycle regulation. Using whole exome sequencing, we identified WDR81 as novel gene 
causing primary microcephaly. A co-segregating truncating mutation c. 5335 C >T, p.R $1779^{*}$ towards the C-terminus of WDR81 was identified in 5 affected siblings of a large consanguineous Turkish family. The same stop mutation in WDR81 was identified in another Turkish case with microcephaly. We observed marked variability of the phenotype. All four females had extreme microcephaly with enlarged extra-axial spaces and ponto-cerebellar hypoplasia (MICaxPCH). One male had a simplified gyral pattern and cerebellar hypoplasia and another male fetus with hydrops fetalis had not yet developed late microcephaly (at 21 weeks of gestation). A missense mutation in WDR81 was described recently by (Gulsuner et al., 2011) to cause cerebellar hypoplasia only. We created a zebrafish morpholino knock-out model of WDR81 which resembled the observed human microcephaly phenotype. Moreover, we observed in the zebrafish morpholino enlarged ventricles which are in analogy to the enlarged ventricles in the patients. WDR81 was highly expressed in the neocortex of human and mouse embryos. WDR81 was localised to the nucleus in the developing mouse brain shown by antibody staining and western-blot after subcellular fractionation. In summary, WDR81 mutations can cause microcephaly with variable penetrance. Remarkably, WDR81 as nucleoplasmic protein seems to be the first protein not directly associated with the centrosome that causes microcephaly.

\section{DGKJ-PO-N1-8 \\ Deciphering novel genes and expanding the clinical spectrum of muscular dystrophies with alpha-dystroglycan hypoglycosylation}

Cirak S. ${ }^{1}$, Foley R. ${ }^{2}$, Stevens E. ${ }^{2}$, Carss K. ${ }^{3}$, Willer T. ${ }^{4}$, Torelli S. ${ }^{2}$, Hurles M. ${ }^{3}$, Moore S.A. ${ }^{4}$, Sewry C.A. ${ }^{2}$, Campbell K.P. ${ }^{4}$, Voit T. ${ }^{5}$, Lin Y.-Y. ${ }^{3}$, Korinthenberg R. ${ }^{6}$, Stemple D.L. ${ }^{3}$, Muntoni F. ${ }^{2}$, UK ${ }^{10} \mathrm{~K}$ Consortium

${ }^{1}$ Childrens National Medical Centre, Research Centre for Genetic Medicine, Washington, USA, ${ }^{2}$ UCL Institute of Child Health, London, UK, ${ }^{3}$ Wellcome Trust Sanger Institute, Wellcome Trust Genome Campus, Hinxton, UK, ${ }^{4}$ Howard Hughes Medical Institute, University of lowa Roy J and Lucille A Carver College of Medicine, lowa, USA, ${ }^{5}$ University Pierre et Marie Curie Paris VI, UM ${ }^{76}$, INSERM U ${ }^{974}$, CNRS UMR ${ }^{7215}$, Groupe Hospitalier Pitié-Salpêtrière, Institut de Myologie, Paris, Frankreich, ${ }^{6}$ Division of Neuropaediatrics and Muscular Disorders, Department of Paediatrics and Adolescent Medicine, University Hospital, Freiburg

The dystroglycanopathies are a clinically and genetically diverse group of recessively inherited conditions ranging from the most severe Walker-Warburg syndrome (WWS), to mild forms of adult onset limb girdle muscular dystrophy (LGMD). Their hallmark is a reduction in the functional O-glycosylation of $\alpha$-dystroglycan. We have discovered 3 novel genes by whole exome sequencing. The first gene, beta-1,3-Nacetylgalactosaminyltransferase 2 ( $\left.\mathrm{B}_{3} \mathrm{GALNT}_{2}\right)$, transfers $\mathrm{N}$-acetyl galactosamine in a beta1,3 linkage to $\mathrm{N}$-acetyl glucosamine. Seven patients presenting with WWS or muscle-eye-brain disease (MEB) were identified with mostly recessive loss-of-function mutations in B3GALNT2. The second gene, GDP-mannose pyrophosphorylase B (GMPPB), catalyzes the formation of GDP-mannose from GTP and mannose-1phosphate with GDP-mannose being an important donor of mannose, required for O-mannosylation. Eight patients presenting with a clinical spectrum of MEB to LGMD were identified to have recessive mutations in GMPPB. Zebrafish morpholino knock-downs of b3galnt2 and gmppb resemble the human CMD phenotypes with hypoglycosylation of a-dystroglycan, structural myofibre defects, and eye abnormalities. The third gene, isoprenoid synthase domain containing (ISPD), was identified in 9 cases ranging from congenital muscular dystrophy (CMD) to LGMD phenotypes. While the function of ISPD in mammals is not yet known, mutations in this gene clearly lead to a reduction of $\alpha$ dystroglycan functional glycosylation. Remarkably, we identified a novel dystroglycanopathy phenotype in two cases harbouring mutations in ISPD characterized by mild LGMD, oculomotor apraxia, myopia and cerebellar hypoplasia, defining a novel and unique phenotype which we classified as "LGMD with cerebellar involvement" (LGMD-CRB).

\section{DGKJ-PO-N1-9 \\ Fallbeispiele zu Vitamin-B-Stoffwechselstörungen und ihrer neuro- logischen Präsentation}

Fiedler B.J.', Bimböse P.', Omran H.', Kurlemann G.'

'Universitätsklinik Münster, Klinik für Kinder- und Jugendmedizin, Münster

Einleitung. Die Vitamin-B-Gruppe setzt sich aus 8 Vitaminen zusammen. Sie agieren als Koenzyme in verschiedenen neurometabolischen Prozessen. Wir berichten über 3 Mangelzustände.

Vitamin-B1-Mangel. Weiblich, 17 Jahre. Deutliche Gewichtsabnahme über 3 Monate. Somnolenz und internukleäre Ophthalmoplegie als führende klinische Symptome und die MR-tomographisch typischen,symmetrischen Signalanhebung (FLAIR, T2) v. a. bithalamisch führten zur Diagnose einer Wernicke-Enzephalopathie. Therapie: Rasche i.v.-Substitution von Vitamin B1 (Thiamin). Bei verzögertem Therapiebeginn Letalität bis zu 20\%. CAVE: Eine Glukosezufuhr im Mangelzustand ohne Gabe von Thiamin beschleunigt den Krankheitsverlauf und verschlechtert die Prognose.

Vitamin-B6-Mangel. Männlich, 6. LT. Statenhafte epileptische Anfälle. 1. Gabe von Vitamin B6 (Pyridoxin) ohne Erfolg. Bei Therapieresistenz erneut Pyridoxin i.v. im Status (7. LW), sofortige Anfallsdurchbrechung. Unter oraler Gabe von Pyridoxin ist der Patient anfallsfrei und zeigt eine normale Entwicklung. Nachweis einer Mutation im ALDH7A1-Gen, somit Diagnose einer Pyridoxin-abhängigen Epilepsie. Die Prognose ist variabel, selbst ein früher intrauteriner Therapiebeginn garantiert keine normale psychomotorische Entwicklung. Selten kommt es zur Erstmanifestation jenseits des 1. Lj., Fälle bis zum 3. Lj. wurden beschrieben.

Vitamin-B12-Mangel. Männlich, 14,5 Monate. Zufallsbefund bei Pneumonie: Gedeihstörung, psychomotorische Retardierung, Muskelhypotonie. Biochemische Marker: megaloblastäre Anämie, erhöhte Methylmalonsäure i. U. Ursache: vegane Ernährung der noch voll stillenden Mutter. Unter Substitutionstherapie entwickelte der Patient mehrere fokale epileptische Staten sowie nichtepileptische Myoklonien. Dauertherapie mit Phenobarbital und Oxcarbazepin. Im Verlauf Sprachentwicklungsverzögerung.

\section{DGKJ-PO-N1-10}

\section{Gangstörungen bei Kindern - drei Beispiele}

Hildebrandt M. ', Kahleyss S. ', Wolz M. ${ }^{2}$, Pfeilstetter J. ${ }^{1}$, Knoetzsch A. ', Heine A.', Tittel J.', Pargac K.-N. ${ }^{1}$

'Elblandklinikum Meißen, Kinderklinik, Meißen, ${ }^{2}$ Elblandklinikum Meißen, Neurologie, Meißen

Einleitung. Gangstörungen können Symptome zahlreicher orthopädischer, neurologischer oder psychischer Erkrankungen sein. Oft bereitet besonders die Abgrenzung einer psychogenen Gangstörung von denen organischer Genese besondere Schwierigkeiten. Zielstellung: Der Beitrag soll beispielhaft drei Fälle von jugendlichen Patienten mit markanter Gangstörung als führendem Symptom darstellen.

Methode. Anhand von Fallbeispielen werden seltene neurologische Formen (Miller-Fisher-Syndrom, Segawa-Sandrom) und psychogene Ursachen einer Gangstörung beschrieben.

Diskussion. Die exakte klinisch-neurologische Untersuchung ist die Grundlage der Diagnostik. Häufig ist dennoch bei einer psychogenen Störung umfangreiche Diagnostik zum Ausschluss organischer Erkrankungen notwendig. Andererseits lassen sich auch bestimmte neurologische Erkrankungen, wie z. B. das Segawa-Syndrom nicht in der gängigen neurologischen Zusatzdiagnostik fassen und werden oft fälschlicherweise als psychogene Erkrankung verkannt. Entscheidend ist die genaue Charakterisierung der Gangstörung (Lähmung, Ataxie, 
Dystonie, zentral oder peripher) und die Beurteilung zusätzlicher Symptome. Insbesondere psychogene Gangstörungen lassen sich schwer klassifizieren.

Schlussfolgerung. Die richtige Diagnose einer Gangstörung ist schwierig. Die Beispiele sollen Anregung sein, im klinischen Alltag auch seltenere neurologische Erkrankungen in die differenzialdiagnostischen Überlegungen mit einzubeziehen.

\section{DGKJ-PO-N1-11}

Eine sehr seltene Ursache der Gangstörung bei einem 5-jährigen Mädchen: subakute postvirale Myelitis

Twal R. ${ }^{1}$, Dopp J. ${ }^{1}$, Yildiz I. ${ }^{1}$

${ }^{1}$ Klinik für Kinder- und Jugendmedizin, Friedrich-Ebert-Krankenhaus, Neumünster

Fragestellung. Gangstörung eines 5 9/12 Jahre alten Mädchens.Was ist die Ursache?

Material und Methode. Fallbericht.

Ergebnisse. Sieben Tage vor Aufnahme bei U9 Unsicherheit beim Einbeinstand und 6-Fach-Impfung links gluteal. Abends Schwäche im rechten Bein. Im Verlauf Entwicklung einer Gangstörung beider Beine und Kribbelparästhesien am Rumpf. Bei Aufnahme MER bds. auslösbar. Aktive und passive Bewegung der Beine schmerzhaft. Muskelkraft erhalten. Laseque positiv. Übrige Untersuchung unauffällig. Temp: $37,3^{\circ} \mathrm{C}$. Initale Hüftsonographie und Blut- sowie Liquorbefunde bis auf leicht erhöhte intrathekale IgG-Synthese unauffällig. Am 3. stationären Tag Progredienz der Symptomatik mit einer Parese der Beine. Im MRTSchädel und -Rückenmark eine langstreckige Auftreibung des Myelons zwischen $\mathrm{HWK}_{2} / \mathrm{BWK}_{10}$, pathologisches Kontrastmittelenhancement. DD:Myelitis oder ausgedehnter Tumor mit Begleitödem. Die zweite Lumbalpunktion zeigte eine Pleozytose und Eiweißerhöhung. Im Liquor IL-2 Expression auf den T-Zellen als Hinweis auf eine reaktive Genese. Beginn einer Kombinationstherapie mit Prednisolon, Aciclovir, Ceftriaxon und Erythromycin. Am 14. stationären Tag Entlassung mit geringer Restsymptomatik. MRT-Verlaufskontrolle nach 12 Tagen: Myelon normalkalibrig, Bild einer rückläufigen Myelitis. Im Liquor PCR auf Mykoplasmen, Enteroviren, HSV, EBV, VZV, CMV und Kultur bzw. Borrelien-AK sowie oligoklonale Banden negativ. ANA und Antiphospholipid-AK negativ. CMV-IgG AK im Serum und CMV-DNA PCR im Urin positiv.

Diskussion. Myelitis ist mit einer Inzidenz von 1,34-4,6:1 Mio. Einwohner eine seltene Erkrankung. Fälle unter 5 Jahren stellen eine Rarität dar. Die Ätiologie ist vielschichtig. Die Kinder erkranken vorwiegend an viralen bzw. postviralen und seltener an postvakzinalen Myelitiden.

\section{DGKJ-PO-N1-12}

Anti-NMDA-Rezeptor-Enzephalitis in Folge einer Herpes-simplexEnzephalitis als wichtige Differenzialdiagnose einer sekundären klinischen Verschlechterung

\section{Kehl T. ', Lischetzki G. ${ }^{2}$, Denecke J.'}

${ }^{1}$ Universitätsklinikum Hamburg-Eppendorf, Klinik für Kinder- und Jugendmedizin, Hamburg, ${ }^{2}$ Altonaer Kinderkrankenhaus, Pädiatrie, Hamburg

Fallbericht. Ein 9-jähriger Junge mit einer Herpes simplex-Enzephalitis wurde 21 Tage mit Aciclovir therapiert. In der anschließenden Rehabilitation entwickelte der Patient Verhaltensauffälligkeiten und eine schwere dystone Bewegungsstörung. Ein Rezidiv der Herpes-simplex-Infektion wurde zunächst postuliert und therapiert. Im Liquor und Serum fanden sich in der weiteren Abklärung jedoch hohe AntiNMDA-Rezeptor-Antikörpertiter. Neben erneutem Aciclovir erfolgte eine immunmodulative Therapie mit iv-Immunglobulinen und $\mathrm{Me}$ thylprednisolon, ohne Besserung, anschließend Plasmapheresen und Immunadsorption. Da es nur zu einer mäßigen Besserung der Befunde kam, erfolgte eine immunsuppressive Therapie mit Rituximab (375 mg/
m2/Woche über 4 Wochen). Darunter zeigte sich eine stetige Besserung der neurologischen Befunde.

Diskussion. Die Anti-NMDA-Rezeptor-Enzepahlitis beschreibt ein Krankheitsbild mit großer klinischer Variabilität und psychiatrischen sowie komplexen neurologischen Auffälligkeiten. Initial als paraneoplastische Erkrankung eingeordnet wurden seit der Erstbeschreibung zahlreiche Erkrankungen ohne begleitende Malignome berichtet; dies wurde vor allem bei Kindern beobachtet. Im Vergleich zeigen Kinder mit Anti-NMDA-Rezeptor-Enzephalitis initial häufiger neurologische Symptome oft in Form von Bewegungsstörungen, Erwachsene vermehrt psychiatrische Auffälligkeiten.

Ergebnisse. Die Erkrankung ist mit Immunmodulation bzw. -suppression therapierbar. Bei etwa Dreiviertel der Patienten ist darunter eine Remission der Befunde möglich.

Schlussfolgerung. Eine Anti-NMDA-Rezeptor-Enzephalitis muss nach sekundärer Verschlechterung in Folge einer Enzephalitis als Differenzialdiagnose bedacht werden und impliziert eine vollständig andere Therapie als ein Rezidiv.

\section{DGKJ-PO-N1-13}

\section{Isolierte Ataxie als Erstsymptom eines thorakalen Neuroblastoms}

Spönemann N. ', Lutz S. ', Reschke M. ${ }^{2}$, Finetti C. ${ }^{3}$, Schweiger B. ${ }^{4}$, Schulte J. ${ }^{2}$, Schara U.', Della Marina A.

'Universitätsklikum Essen, Neuropädiatrie, Essen, ${ }^{2}$ Universitätsklinikum Essen, Pädiatrische Onkologie, Essen, ${ }^{3}$ Elisabeth Krankenhaus Essen, Sozial Pädiatrisches Zentrum, Essen, ${ }^{4}$ Universitätsklinikum Essen, Pädiatrische

Radiologie, Essen

Einleitung. Das Opsoklonus-Myoklonus-Syndrom (OMS) ist eine neurologische Erkrankung mit folgenden Symptomen: Opsoklonien, Myoklonien und Ataxie. Etwa 2-3\% der Kinder mit Neuroblastom zeigen OMS als paraneoplastisches Syndrom. Es gibt Einzelfallbeschreibungen von Patienten, bei denen nur eine Ataxie im Vordergrund der Symptomatik steht.

Fallbericht. Ein 4 8/12 Jahre alter Junge wurde zur weiteren Abklärung einer akuten, progredienten Gleichgewichtsstörung vorgestellt. Er zeigte eine deutliche Gangataxie, Dysarthrie und eine okuläre Apraxie. Ein cMRT und die Abklärung bezüglich einer metabolischen/postinfektiösen Ataxie erbrachte keine Diagnoseklärung. Im Rahmen der weiteren Diagnostik stellte sich im Thorax-Röntgen eine intrathorakale Raumforderung dar; ein spinales MRT führte zum Verdacht eines Neuroblastoms links paravertebral (Höhe $\mathrm{HWK}_{7}-\mathrm{BWK}_{2}$ ), welches histopathologisch bestätigt werden konnte. Die Staging-Untersuchungen ergaben keinen Hinweis auf Metastasen (nMyc-Amplifikation negativ, keine Deletion/Imbalance an Chromosom 1p36). Die Diagnose eines OMS mit führendem Symptom einer Ataxie wurde gestellt. Es erfolgte eine R2-Resektion des Neuroblastoms und aufgrund der Ataxie eine Therapie mit 12 Dexamethasonstößen. Bei einem Tumor mit dem INSSStadium 1 wird eine Beobachtung gemäß NB-2004-Protokoll durchgeführt. In der Beobachtungszeit von einem Jahr konnte eine deutliche Besserung der neurologischen Symptome erreicht werden.

Schlussfolgerung. Bei der Abklärung einer isolierten Ataxie sollte differenzialdiagnostisch auch an das Vorliegen eines OMS im Rahmen eines Neuroblastoms gedacht werden und eine entsprechende Diagnostik mit bildgebenden Verfahren eingeleitet werden. Eine frühzeitige Therapie der Bewegungsstörung kann das Auftreten von kognitiven und neurologischen Langzeitdefiziten reduzieren. 


\section{DGKJ-PO-N1-14}

Retrospektive Analyse der kognitiven Entwicklung von 71 Patienten mit idiopathisch fokaler Epilepsie (Rolando-Epilepsie)

Weigt-Usinger K.', Neumann H.', Selzer L.M.', Helmke F.', Köhler C.', Thiels C.' , Lücke T. ${ }^{\text {? }}$

'Klinik für Kinder- und Jugendmedizin der Ruhr Universität Bochum, Neuropädiatrie, Bochum

Einleitung. Die Rolando-Epilepsie (RE) des Kindesalters ist gekennzeichnet durch Altersgebundenheit, fehlende Vorerkrankungen, unauffällige cerebrale Bildgebung, charakteristische EEG-Veränderungen und benignen Verlauf. Daten zu assoziierten kognitiven Störungen und deren Beeinflussbarkeit durch Antiepileptika (AED) sind rar.

Methoden. Monozentrische retrospektive Analyse klinischer und neuropsychologischer Daten von 71 Patienten mit RE (7/2000-6/2011) Erfasst wurden die allgemeine kognitive Entwicklung, assoziierte Teilleistungsstörungen und durchgeführte Therapien. Die psychometrischen Testverfahren (TV) erfolgten durch denselben Untersucher: KABC, SON 21/2-5; SON 5 1/2-7; CFT1; CFT2OR; HAWIK III; HAWIK IV. Ergebnisse. Gruppe 1 mit Anfällen $(n=37)$ : TV vor Beginn AED $n=21$; unter Therapie $n=31$, nach Beendigung $n=6$; Gruppe 2 ohne Anfälle $(n=34)$ : TV vor Beginn AED $n=19$, unter Therapie $n=23$; nach Beendigung $\mathrm{n}=10$, ohne Medikation $\mathrm{n}=5$; Gruppe 1 zeigt durchschnittliche intellektuelle Leistungen vor Beginn AED; Gruppe 2 liegt diesbezüglich im Mittel unterhalb von Gruppe 1. Statistisch signifikante Unterschiede im K-ABC in der Standardskala intellektueller Fähigkeiten SIF $(\mathrm{p}=0,036)$ und nonverbalen Teilskala NV $(\mathrm{p}=0,048)$. Unter $>6$-monatiger AED Therapie zeigt sich in Gruppe 1 eine positive kognitive Entwicklung in sämtlichen Teilbereichen, in Gruppe 2 positive kognitive Weiterentwicklung insbesondere in KABC-SIF $(\mathrm{p}=0,005)$, Standardskala ganzheitliches Denken SGD ( $\mathrm{p}=\mathrm{o}, \mathrm{oo1})$.

Schlussfolgerung. Der positive Trend der Entwicklung bestätigt sich nach Beendigung AED in beiden Teilgruppen. Probleme in der kognitiven Entwicklung zeigen sich v. a. bei klinisch anfallsfreien RE-Patienten, mit Besserung unter Therapie.

\section{Stoffwechselkrankheiten}

\section{DGKJ-PO-S-1}

Funktionalitäts- und Konformationsuntersuchungen mit 18 heterolog exprimierten Medium-Chain-Acyl-CoA-Dehydrogenase (MCAD)-Varianten

\section{Koster K.-L.', Sturm M.', Herebian D. ', Spiekerkötter U. ${ }^{2}$}

'Universitätsklinikum Düsseldorf, Klinik für Allgemeine Pädiatrie, Neonatologie und Kinderkardiologie, Düsseldorf, ${ }^{2}$ Universitätsklinikum Freiburg, Zentrum für Kinder- und Jugendmedizin, Freiburg

Einleitung. Der MCAD-Mangel ist die häufigste mitochondriale Fettsäurenoxidationsstörung. Seit Aufnahme dieser autosomal-rezessiv vererbbaren Erkrankung in das Neugeborenenscreening sind neue Mutationen mit unklarer klinischer Relevanz identifiziert worden. Eine Funktionsanalyse der Mutationen ist dringend notwendig, um den Schweregrad der einzelnen Mutationen einschätzen zu können. Da Mutationen bei Patienten überwiegend in compound heterozygoter Form vorliegen, ist bei einer Messung der Residualaktivität in Lymphozyten keine gezielte Bestimmung der Funktionalität einzelner Mutationen möglich.

Methoden. Es wurden 18 MCAD-Varianten durch site-directed mutagenesis erzeugt und heterolog in E. coli allein oder parallel mit den Chaperonen GroES und GroEL überexprimiert. Zur funktionellen Analyse der Mutanten wurde die Octanoyl-CoA Oxidation unter beiden Bedingungen gemessen.

Ergebnisse. Drei Mutanten (c.127G $>$ A, c.92G $>$ A, c.199T $>C$ ) wiesen eine signifikant höhere $(\mathrm{p}<0,05)$ Residualaktivität $(47 \%, 44 \%$ und $22 \%)$ auf als die anderen 15 getesteten Mutanten $(<10 \%)$. Bei Co-Überexpression mit GroES und GroEL steigerte sich die Residualaktivität der meisten untersuchten Mutanten erheblich, während c.92 G >A, c.127G $>A$ und der Wildtyp unbeeinflusst blieben.

Schlussfolgerung. In dieser Studie konnten drei MCAD-Varianten als mild identifiziert werden. Die Mutanten c.127G $>$ A und c.92G $>$ A zeigten mit $>40 \%$ doppelt so hohe Residualaktivitäten wie die milde prävalente Mutation c.199T>C, deren Träger keine klinischen Symptome zeigen. Da die Anwesenheit von Chaperonen bei den Mutationen c.92 $\mathrm{G}>\mathrm{A}$ und c.127G $>$ A ähnlich wie im Wildtyp zu keiner signifikanten Steigerung der Residualaktivität führte, ist anzunehmen, dass trotz Mutation eine korrekte Faltung erfolgt. Die klinische Relevanz dieser beiden Mutationen muss daher als gering eingestuft werden.

\section{DGKJ-PO-S-2}

Labor-Screening-Verfahren bei nichtklassischer, attenuierter GM1Gangliosidose

\section{Arash-Kaps L.', Seegräber M.', Karabul N.', Stumpfe K.', Smitka M.', Beck} M.', Mengel E.'

'ZKJM der JoGu Mainz, Villa Metabolica, Mainz, ${ }^{2}$ Universitätsklinik Carl Gustav Carus, Neuropädiatrie, Dresden

Hintergrund. GM1-Gangliosidose ist eine autosomal-rezessive lysosomale Speichererkrankung, die durch einen Defizit des Enzyms betaGalactosidase bedingt und durch Mutationen im GLB1-Gen verursacht wird. Leitbefund ist eine progrediente dyston-spastische Bewegungsstörung.

Methoden und Ergebnisse. Es wurden retrospektiv die Laborparameter MPS-Ausscheidung, Oligosaccharid-Ausscheidung und Chitotriosidase von insgesamt 13 Patienten ausgewertet. Alle Patienten wiesen einen deutlichen Mangel des Enzyms beta-Galactosidase auf. 6/11 Patienten zeigten eine signifikant erhöhte Aktivität der Chitotriosidase. Die Oligosaccharid-Ausscheidung im Urin war bei 5/10 Patienten nicht eindeutig pathologisch. Die MPS-Ausscheidung wurde nur bei 3 Patienten gemessen und war normal.

Schlussfolgerung. Chitotriosidase und Oligosaccharid-Ausscheidung können in der Diagnostik der Erkrankung wegweisend sein. Ein physiologisches Ausscheidungsmuster von Oligosacchariden schließt eine GM1-Gangliosidose jedoch nicht aus. Auch die Chitotriosidase ist nicht immer pathologisch. Daher ist es von bedeutender Relevanz bei der Abklärung von dyston-spastischen Bewegungsstörungen, die beta-Galactosidase als spezifischsten Parameter der GM1-Gangliosidose immer mit zu bestimmen.

\section{DGKJ-PO-S-3}

\section{Fehldiagnosen in einer Familie mit Morbus Fabry}

Karabul N. ${ }^{\prime}$, Kalkum G. ${ }^{2}$, Herzog A. ${ }^{3}$, Arash L. ${ }^{2}$, Klepper J. ${ }^{4}$, Mengel E. ${ }^{2}$

${ }^{1}$ Universitätsmedizin Mainz, Kinderklinik Villa Metabolica, Mainz, ${ }^{2}$ Villa Metabolica - Zentrum für Kinder- und Jugendmedizin der Universitätsmedizin, Mainz, ${ }^{3}$ Klinik für Kinder- und Jugendmedizin, Kinderklinik, Aschaffenburg, ${ }^{4}$ Klinik für Allgemeine Pädiatrie, Neonatologie und Kinderkardiologie, Kinderklinik, Aschaffenburg

Einleitung. Patienten mit Morbus Fabry weisen aufgrund einer Mutation auf dem X-Chromosom eine erniedrige bzw. Unzureichende Aktivität des Enzyms $\alpha$-Galactosidase A auf, so dass im Lysosom vor allem das Stoffwechselprodukt Globotriaosylceramid (auch Gb3 genannt) nicht mehr ausreichend abgebaut werden kann. Der Morbus Fabry ist eine Multisystemerkrankung.

Fallberichte. Fall 1: Der 12-jähriger Junge ist seit 2 Jahren als seronegative Rheumatoide Arthritis diagnostiziert. Anamnestisch sei er immer der kleinste und schmalste Junge gewesen. Klinisch am linken Ohr 2 Angiokeratome und 5 einzelne im Schienbeinbereich. Seit dem 6. Lebensjahr rezidivierende Akroparästhesien insbesondere bei Infekten und 
sportlicher Belastung. Fall 2: Mütterliche Tante seit über 10 Jahren als multiple Sklerose diagnostiziert und behandelt. Großmutter mütterlich hatte einen Schlaganfall und Beinvenenverschluss. Sie wurde bei unauffälligen Gerinnungsparametern als idiopathische Gerinnungsstörung diagnostiziert. Aufgrund der Gelenkbeschwerden ohne Laborauffälligkeiten wurde zusätzlich die Diagnose Fibromyalgie gestellt. Mutter hat seit Jahren Fatigue-Symptome und ihre Symptome wurden unter Burnout subsumiert.

Schlussfolgerung. Auch bei häufigen Symptomen sollten seltene Erkrankungen bedacht werden.

\section{DGKJ-PO-S-4}

\section{Langzeit-Erfahrungen mit Miglustat in der Therapie von Patienten} mit M. Niemann-Pick C

\section{Amraoui Y. ${ }^{1}$, Runz $H_{.}{ }^{2}$, Beck M. ${ }^{1}$, Mengel E.}

'Zentrum für Kinder- und Jugendmedizin der Universitätsmedizin Mainz, Villa Metabolica, Mainz, ${ }^{2}$ Institut für Humangenetik, Universitätsklinikum, Heidelberg

Einleitung. M. Niemann-Pick C (NPC) ist eine autosomal-rezessiv vererbte neuroviszerale Lipidspeichererkrankung. Die Klinik umfasst neurologische, psychiatrische und viszerale Symptome. 2009 wurde das Medikament Miglustat zur Behandlung der progressiven neurologischen Symptome des NPC zugelassen.

Methoden. Wir untersuchten bei NPC-Patienten, bei denen zwischen 2004 und 2010 eine Therapie mit Miglustat initiiert wurde, die Wirkung von Miglustat auf die neurologischen Symptome. Als Verlaufsparameter wurde der NPC Disability Score, ein Maß für die Schwere der Erkrankung, verwendet. 21 Patienten wurden in die Studie eingeschlossen, davon 15 Kinder und Jugendliche und 6 Erwachsene. Drei Patienten waren der früh-infantilen, 6 der spät-infantilen, 10 der juvenilen und 2 der adulten Verlaufsform zuzuordnen. Die Behandlungsdauer betrug im Durchschnitt 4,2 Jahre (2-8 Jahre). 2-Jahres-Daten vor und unter Therapie liegen von allen 21 Patienten vor. Hier zeigte sich ohne Therapie eine durchschnittliche jährliche Zunahme im NPC Disability Score von 2,6 Punkten, unter Therapie von nur 0,7 Punkten.

Ergebnisse. Betrachtet man die Untergruppen ergaben sich folgende Ergebnisse: früh-infantile Gruppe ohne Therapie durchschnittlicher jährlicher Scoreanstieg von 3,7 vs. 2,7 Punkte unter Therapie; spät-infantile Gruppe 0,8 vs. 0,7 Punkte; juvenile Gruppe 0,9 vs. 0,1 Punkte; adulte Gruppe o vs. 0,25 Punkte. Zwei Patienten zeigten während einer Therapiedauer von 4 Jahren sogar eine Abnahme im NPC Disability Score von durchschnittlich 0,25 Punkten jährlich.

Schlussfolgerung. Unsere Studie ergab, dass Miglustat die neurologischen Symptome bei NPC-Patienten stabilisieren und die Krankheitsprogression verlangsamen kann. Die beste Therapieantwort sahen wir bei Patienten mit der juvenilen Verlaufsform.

\section{DGKJ-PO-S-5}

\section{Verspätetes Gehen als prognostisch ungünstiges Zeichen bei atte-} nuierten Verlaufsformen des Morbus Pompe

Gökce S. ${ }^{1}$, Karabul N. ${ }^{1}$, Mengel K.E.'

'Zentrum für Kinder- und Jugendmedizin der Universitätsmedizin Mainz, Villa Metabolica, Mainz

Einleitung. Klinische Symptome des M. Pompe bestehen bei der klassischen infantilen Form aus einer Kombination von hypertropher Kardiomyopathie und generalisierter Muskelschwäche („floppy infant“). Bei attenuierten Formen dominiert vor allem die fortschreitende Skelettmuskelschwäche. Die Erstmanifestation und das Voranschreiten der Erkrankung sind außerordentlich variabel.

Patienten und Methoden. Wir untersuchten retrospektiv die Prävalenz vom verspäteten Erreichen der motorischen Meilensteine, insbesondere das Gehen, innerhalb der ersten 18 Lebensmonaten in unserer Kohorte von $58 \mathrm{M}$. Pompe Patienten mit attenuierten Formen. Zu dem korrelierten wir dieses Merkmal mit den Mutationsergebnissen in der Kohorte. Ergebnisse. Wir stellten bei 9/58 Patienten verzögertes Erlernen des Gehens fest. Bei 5/9 war der Verlust der motorischen Funktion fortschreitend entsprechend einer frühkindlichen Manifestation. Bei 4/9 Patienten war die Muskelschwäche zunächst nicht progressiv. Sie erreichten alle motorischen Meilensteine und konnten diese unter der Enzymersatztherapie halten. Im Vergleich der beiden Gruppen A „Verspätetes Gehen“ vs. B „Nicht-Verspätetes Gehen“, fällt auf, dass alle Patienten der Gruppe B die Mutation c.-32-13T >G tragen, in der Gruppe A nur 5/9. Schlussfolgerung. Bei verzögertem Gehen sollte M. Pompe in die Differentialdiagnostik einbezogen werden. Nach ausführlicher klinischer Untersuchung sollte das Augenmerk auf Zeichen einer Rumpfschwäche mit posturaler Haltungsschwäche, ausladendes Abdomen als Zeichen der Bauchwandschwäche, monoton-nasale und leise Stimme im Kleinkindesalter, oder orofaziale Schwäche (Facies myopathica) im Kleinkindesalter gerichtet werden. Bei erhöhtem CK, Transaminasen, LDH ggf. Myoglobin-Werte wäre die Enzymmessung Methode der Wahl. Zudem erscheint das verzögerte Erreichen der Meilensteine der frühkindlichen Bewegungsentwicklung mit einer progressiven Verlaufsform einherzugehen. Es besteht eine moderate Phänotyp-Genotyp Korrelation.

\section{DGKJ-PO-S-6}

Expressionsanalyse pathogener Glutaryl-Coenzym-A-Dehydrogenase-Mutanten

\section{Lohmöller B.', Lamp J.', Mühlhausen C.', Braulke T.}

'Universitätsklinikum Hamburg-Eppendorf, Kinderklinik-Arbeitsbereich Molekularbiologie, Hamburg

Einleitung. Das mitochondriale Matrixprotein Glutaryl-CoA-Dehydrogenase (GCDH) ist am Abbauweg der Aminosäuren Lysin und Trytophan beteiligt und katalysiert die oxidative Decarboxylierung von Glutaryl-CoA zu Crotonyl-CoA. Mutationen in der GCDH führen zur neurodegenerativen Stoffwechselkrankheit Glutarazidurie Typ 1 (GA1). Derzeit sind mehr als 150 verschiedene krankheitsverursachende Mutationen in unterschiedlichen Regionen des GCDH-Gens beschrieben worden. Eine Korrelation zwischen Genotyp und biochemischen, sowie klinischen Phänotyp der Krankheit konnte bisher nicht hergestellt werden. Methoden. In unserer Studie fokussieren wir uns auf 18 pathogene GCDH Mutationen, die auf der Proteinoberfläche lokalisiert sind und keinen direkten Einfluss auf das katalytische Zentrum aufweisen. Ziel ist es, mittels biochemischer Untersuchungen die Expression, Stabilität und intrazelluläre Lokalisation zu untersuchen und Aufschluss über die pathogenen Wirkungen der mutanten GCDH zu erlangen. WesternBlot-Analysen und Experimente mit metabolischer Markierung und anschließender GCDH-Immunpräzipitation zeigten, dass einige der untersuchten Mutanten (p.R94L, p.G101R, p.Y113H, p.G117R, p.S119L, p.G244C und p. $\mathrm{R}_{355} \mathrm{H}$ ) signifikant reduzierte Expressionsspiegel in $\mathrm{He}-$ La-Zellen im Vergleich zur Wildtyp-GCDH aufweisen, die auf eine erhöhte Instabilität und schnellen Abbau der Mutanten zurückzuführen sind. Doppelimmunfluoreszenzanalysen zeigten für alle Mutanten eine mitochondriale Lokalisation, was auf einen intramitochondrialen Abbau instabiler GCDH-Mutanten hindeutet. Die verminderte Bindung von stabilen Mutanten (z. B. p.C115Y oder p.P278S) an identifizierte GCDH-Interaktionspartner weisen auf die Bedeutung dieser Interaktionen für die Pathogenese von GA1 hin. 


\section{DGKJ-PO-S-7}

\section{Die kardiale Beteiligung der Mukopolysaccharidose II und Einfluss der Enzymersatztherapie}

\section{Sulistyo Winarto J.', Beck M.' , Kampmann C.}

'Zentrum für Kinder- und Jugendmedizin der Universitätsmedizin, Mainz, ${ }^{2}$ Villa Metabolica - Zentrum für Kinder- und Jugendmedizin der Universitätsmedizin, Mainz

Einleitung. MPS II ist eine seltene X-chromosomal vererbte lysosomale Speichererkrankung mit Multisystembeteiligung. Zugrunde liegt ein Mangel oder Fehlen des lysosomalen Enzyms Iduronat-2-Sulfatase, welches am Abbau von Mukopolysacchariden beteiligt ist. Die kardiale Beteiligung nimmt wegen der frühen Morbidität und Mortalität der Patienten eine wichtige Rolle ein.

Methoden. Von den 61 in Mainz untersuchten Hunter Patienten weisen $85 \%$ eine kardiovaskuläre Beteiligung auf. Die häufigste Manifestation mit bis zu $67 \%$ der Patienten ist eine Klappeninsuffizienz mit Überrepräsentation der linksventrikulären Klappen. Eine milde - moderate Kardiomyopathie zeigen $57 \%$ des Kollektivs. Nur $26 \%$ der Patienten haben eine normale Ventrikelkonfiguration, fast die Hälfte zeigt Merkmale einer konzentrischen Hypertrophie. Im Gegensatz dazu haben $97 \%$ der Patienten eine gut erhaltene systolische Funktion, nur ein Patient zeigt Merkmale einer schweren Kardiomyopathie. Bis zur Einführung der Enzymersatztherapie waren alle Behandlungen rein symptomatisch.

Ergebnisse. Seit 2007 ist das Enzym Elaprase ${ }^{\circledR}$, der Firma Shire auf dem Markt und ermöglicht eine kausale Therapie. Über fünf Jahre wurden 35 Patienten unter Enzymersatztherapie kardiologisch Betreut. Die ERT scheint die Progression einer Klappeninsuffizienz aufzuhalten. Bei über $80 \%$ der Patienten bleibt diese stabil. Auch ein Rückgang der Kardiomyopathie lässt sich beobachten. Von anfangs $63 \%$ zeigen nach 3 Jahren ERT nur noch $41 \%$ der Patienten eine vergrößerte linksventrikuläre Muskelmasse.

Schlussfolgerung. Von dem Mainzer Hunter Patienten-Kollektiv weisen $85 \%$ eine kardiale Beteiligung auf und es konnte gezeigt werden, dass wöchentliche Enzymgaben einen positiven Einfluss auf die kardiale Beteiligung haben

\section{DGKJ-PO-S-8}

\section{Neu diagnostizierte Harnstoffzyklusdefekte bei Patienten unter 16 Jahren}

Nettesheim S. , Häberle J. ${ }^{2}$, Karall D. ${ }^{3}$, Santer R. ${ }^{4}$, Heinrich B. ${ }^{5}$, von Kries.$^{6}{ }^{6}$, Hoffmann G.F.', Kölker S.'

'Zentrum für Kinder- und Jugendmedizin, Universitätsklinikum Heidelberg, Heidelberg, ${ }^{2}$ Kinderspital Zürich, Zürich, Schweiz, ${ }^{3}$ Universitätsklinik für Pädiatrie I, Innsbruck, Österreich, ${ }^{4}$ Klinik und Poliklinik für Kinder- und Jugendmedizin, Universitätsklinikum Hamburg Eppendorf, Hamburg, ${ }^{5}$ ESPED-Zentrale, KKS Universitätsklinikum Düsseldorf, Düsseldorf, ${ }^{6}$ Ludwig-Maximilian-Universität München, Institut für Soziale Pädiatrie und Jugendmedizin, München

Fragestellung. Zuverlässige Angaben zur Inzidenz von angeborenen Harnstoffzyklusdefekten liegen für den deutschsprachigen Raum bislang nicht vor. Die wichtigsten Ziele der Erhebung sind die Ermittlung der Inzidenz und Erfassung der klinischen Erstmanifestation bei Patienten mit Harnstoffzyklusdefekten in Deutschland, Österreich und der Schweiz.

Material und Methoden. Eingeschlossen werden Patienten unter 16 Jahren, bei denen die Diagnose einer Harnstoffzyklusstörung neu gestellt worden ist. Die Abfragen erfolgen monatlich (Kinderkliniken) bzw. vierteljährlich (Stoffwechsellaboratorien). Studienrelevante Daten werden per Fragebogen erhoben.

Vorläufige Ergebnisse. Studienbeginn war der 01.07.2012 (in der Schweiz der 01.01.2012). Die Studiendauer beträgt zwei Jahre. Bislang wurden in Deutschland 9 Fälle, in der Schweiz 2 Fälle und in Österreich 3 Fälle gemeldet. Basierend auf epidemiologischen Daten aus den USA und Japan (kumulative Inzidenz 1:80oo Neugeborene) wurde in den drei teilnehmenden Ländern pro Halbjahr mit durchschnittlich 43 neu diagnostizierten Patienten gerechnet.

Schlussfolgerung. Die bisherigen Meldezahlen für neu diagnostizierte Patienten mit Harnstoffzyklusdefekten liegen aktuell weit hinter dem Erwartungswert zurück. Neben einer tatsächlich niedrigen Inzidenz in den teilnehmenden Ländern kommen mehrere andere Gründe (u. a. geringe Studienbeteiligung) in Betracht.

\section{DGKJ-PO-S-9}

Gewichtsabnahme von $>10 \%$, Trinkschwäche und Lethargie beim Neugeborenen - ein Stoffwechseldefekt?

Trepels-Kottek S. ${ }^{1}$, Heimann K.', Schoberer M. ${ }^{,}$, Hütten M. ', Meissner T. ${ }^{2}$, Orlikowsky T.', Wagner N. ${ }^{3}$

'Universitätsklinikum RWTH Aachen, Klinik für Kinder- und Jugendmedizin, Sektion Neonatologie, Pädiatrische Intensivmedizin, Aachen, ${ }^{2}$ Universitätsklinikum Düsseldorf, Klinik für Allgemeine Pädiatrie, Neonatologie und Kinderkardiologie, Düsseldorf, ${ }^{3}$ Universitätsklinikum RWTH Aachen, Klinik für Kinder- und Jugendmedizin, Aachen

Kasuistik. Aufnahme eines eutrophen, 6 Tage alten Neugeborenen nicht konsanguiner Eltern (unauffällige Schwangerschaft) zwei Tage nach Entlassung wegen Trinkschwäche, Schläfrigkeit, fahlen Hautkolorits und Hypothermie $\left(34,4^{\circ} \mathrm{C}\right.$ rektal). Klinisch Dehydratation, Tachypnoe mit grauem Hautkolorit und Vigilanzminderung. Zusätzlich $15 \% \mathrm{Ge}-$ wichtsverlust gegenüber Entlassgewicht. BGA: pH 6,8, BE - 27 mmol/l, BZ $17 \mathrm{mg} / \mathrm{dl}$. Serologische Infektparameter negativ, Echokardiographie unauffällig. Initialtherapie: Volumensubstitution via ZVK inklusive parenteraler Ernährung, Natriumbicarbonat. $\mathrm{NH}_{3}$ im Serum $339 \mu \mathrm{mol} / \mathrm{l}$. Daraufhin Ende der Eiweißzufuhr, isolierte Glucoseinfusion und Natriumbenzoat i.v. Hierunter Normalisierung von $\mathrm{NH}_{3}$ und BGA. Stoffwechselscreening: 3-OH- Methylglutaryl-CoA-Lyase-Mangel. Bestätigung durch Bestimmung Acylcarnitine im Plasma und organischer Säuren im Urin (typisches Metabolitenprofil). Beim 3-Hydroxy3-Methyl-Gutaryl(HMG)-CoA-Lyase-Mangel gehemmte Bildung des Ketonkörpers Acetoacetat aus 3-Hydroxy-3-Methylglutaryl-CoA. Diese Reaktion ist der letzte Schritt des Abbaus der ketogenen Aminosäure Leucin. Typische Symptome: schwere Hypoglykämie, hypoketotische metabolische Azidose, Hyperammonämie, Erbrechen und Lethargie. Erhöhte Letalität durch akute Reye-Syndrom-artige Krise. Bei unserem Patienten nach Stabilisierung Umstellung auf Muttermilchernährung ohne Eiweißrestriktion. Die Langzeittherapie besteht in fettarmer (ca. $25 \%$ des täglichen Kalorienbedarfs) und eiweißreduzierter Diät. Zusätzlich kann Carnitin verabreicht werden.

Schlussfolgerung. Trinkschwäche und Gewichtsabnahme über 10\% des Geburtsgewichtes sollten immer zeitnah neonatologisch abgeklärt werden. Stoffwechselstörungen sind auch bei erfolgtem Stoffwechselscreening eine wichtige Differenzialdiagnose.

\section{DGKJ-PO-S-10}

Neugeborenen-Screening bei lysosomalen Speicherkrankheiten was nun?

\section{Karabul N. ${ }^{1}$, Beck M. ${ }^{2}$, Mengel E. ${ }^{3}$}

'Zentrum für Kinder und Jugendmedizin, Kinderklinik Villa Metabolica, Mainz, ${ }^{2}$ Universitätsmedizin Mainz, Kinderklinik Villa Metabolica, Mainz, 'Zentrum für Kinder- und Jugendmedizin, Universitätsmedizin Mainz, Kinderklinik Villa Metabolica, Mainz

Patienten mit lysosomalen Speicherkrankheiten (LSD) präsentieren sich mit diversen, nichtspezifische Symptomen. Es ist sehr schwierig, diese Fälle zu identifizieren und klinisch zu diagnostizieren. Oft liegt eine lange Verzögerung zwischen dem Beginn der Symptome und eine bestätigte Diagnose. Zum Beispiel beträgt die durchschnittliche Ver- 
zögerung von mehr als 13 Jahren für Männer und Frauen mit Morbus Fabry.

Das Screening von Familienangehörigen von Patienten mit Morbus Fabry oder anderen LSD (Pompe, Gaucher, Mukopolysaccharidosen) ist ein wichtiges Mittel für die Früherkennung von erkrankten Personen. Generelles Neugeboren-Screening wird unter den Experten kontrovers diskutiert, da die aktuelle Literatur häufiger attenuierte Fälle zeigt als erwartet (1:80o). Eine Literaturübersicht wird gezeigt und unsere Erfahrungen aus einem Zentrum werden berichtet. Screening von sog. Atrisk-Gruppen für Morbus Fabry schließen Patienten mit idiopathischer fortschreitende Erkrankung der Nieren, mit ungeklärter hypertropher Kardiomyopathie und junge Patienten mit ungeklärten Schlaganfall ein; auch hier wurden unterschiedliche Fallzahlen für Morbus Fabry gefunden. Die Möglichkeit, LSDs in Neugeborenen-Screening-Programme wurde ebenfalls untersucht, bleibt aber umstritten und wurde generell erstmals nicht angenommen.

\section{DGKJ-PO-S-11}

„Binationale Inzidenztestung des Morbus Hunter in einer Risikopopulation - Update 2013"

Güth C. ', Gödeke J.', Lampe C. ${ }^{2}$, Lagler F. ${ }^{3}$, Lukacs.$^{4}{ }^{4}$, Luxenburger E. ', Beck

$M{ }^{2}$, von Schweinitz D.'

'Ludwig-Maximilians-Universität München, Kinderchirurgische Klinik, Dr. von Haunersches Kinderspital, München, ${ }^{2}$ Johannes Gutenberg Universität Mainz, Villa Metabolica, Zentrum für Kinder- und Jugendmedizin, Mainz, ${ }^{3}$ Paracelsus Med. Privatuniversität Salzburg, Institut für angeborene Stoffwechselerkrankungen, Salzburg, Österreich, ${ }^{4}$ Universitätsklinikum Hamburg-Eppendorf, Stoffwechsellabor, Klinik für Kinder- und Jugendmedizin, Hamburg

Fragestellung. Beim M. Hunter (MPS II) kommt es durch einen Mange des Enzymes Iduronat-2-Sulfatase zu spezifischen Krankheitserscheinungen. U. a. zeigen alle Kinder eine Nabelhernie, ca. 60\% entwickeln schon früh eine Leistenhernie. Die Erkrankung wird wegen der sehr heterogenen Verlaufsform häufig nicht vor dem 4. Lj. diagnostiziert. Dies ist bedauerlich, da die Patienten signifikant von einem frühestmöglichen Therapiebeginn (u. a. Enzymersatztherapie) profitieren. Frühe Screeninguntersuchungen sind möglich, aufgrund der Seltenheit der Erkrankung aber für alle Neugeborenen zu teuer. Insgesamt werden die Patienten aktuell schlechter diagnostiziert und behandelt als es nach heutigem Kenntnisstand möglich wäre.

Material und Methoden. Seit Anfang 2012 wird in Deutschland und Österreich eine Screeninguntersuchung zum M. Hunter in einer Risikopopulation (männl. Geschlecht $<18 \mathrm{Lj}$., Diagnose Nabelhernie, OP an einer Leistenhernie) durchgeführt. Testzentren sind aktuell 112 kinderchirurgisch tätige Kliniken und Praxen. Die genetisch-enzymatische Diagnostik erfolgt über eine perioperative Blutentnahme auf eine Trockenblutkarte. Mittels eines Fragebogens werden zusätzlich Daten orientierend an der Morphologie des M. Hunter erhoben. Die Wertigkeit der Testung soll durch Vergleich mit allen im gleichen Zeitraum neu diagnostizierten Kindern mit M. Hunter bestimmt werden.

Ergebnisse und Diskussion. Bisher wurden 124 Kinder untersucht; das Durchschnittsalter betrug 8 Monate (Range o Monate bis 16 Jahre). Bislang ist kein Kind positiv für MPS II getestet worden. Bei einem positiven Screeningbefund sollte über ein Routinescreening innerhalb dieser Risikopopulation diskutiert werden. Gleichzeitig ist die Ausdehnung der Studie auf internationale Ebene geplant.

\section{DGKJ-PO-S-12}

\section{Infantile Hypophosphatasie - zwei Fallberichte mit schwerer Ver-} laufsform

Hempel C. ${ }^{1}$, Hofmann C. ${ }^{2}$, Liese J. ${ }^{2}$, Girschick H. ${ }^{3}$, Erdlenbruch B. ${ }^{1}$

'Johannes-Wesling-Klinikum Minden, Klinik für Kinder- und Jugendmedizin, Minden, ${ }^{2}$ Universitäts-Kinderklinik, Pädiatrische Infektiologie und Immunologie, Würzburg, ${ }^{3}$ Vivantes Klinikum im Friedrichshain, Kinderklinik, Berlin

Einleitung. Die Hypophosphatasie (HPP) ist eine sehr seltene, in der Regel autosomal rezessiv vererbte Erkrankung mit sehr variablem Verlauf. Das betroffene ALPL-Gen kodiert für die gewebeunspezifische alkalische Phosphatase TNAP. Innerhalb weniger Wochen wurden in unserer Klinik 2 Kinder mit unterschiedlich schweren Verlaufsformen einer infantilen HPP behandelt.

Kasuistik 1. Neugeborenes 39+2 SSW. Seit der 29. SSW auffällig verkürzte Röhrenknochen, Oligohydramnion, Caput membranaceum, Thoraxhypoplasie, Rippenfrakturen. Karyogramm normal, Ausschluss Osteogenesis imperfecta. Postnatal respiratorische Globalinsuffizienz mit kompliziertem Beatmungsverlauf. Diagnosestellung anhand der Röntgenbilder, Klinik und Laborbefunde. Exitus letalis am dritten Lebenstag. Kasuistik 2. 1 4/12 Jahre altes Mädchen mit schwerer Pneumonie. Seit einem Monat bekannte HPP unter Therapie mit Asfotase alfa (Enzymersatztherapie Phase-II-Studie). Klinisch schwerste Dystrophie, Nephrokalzinose, muskuläre Hypotonie mit Schluckstörung. Aufnahmegewicht $5330 \mathrm{~g}\left(<\mathrm{P}_{3}\right)$, Dyspnoe, O2-Bedarf, Intubation und komplizierter Beatmungsverlauf bis hin zur Relaxierung und $\mathrm{FiO}_{2}$ von 1,o. Keine CRP-Erhöhung, aber Nachweis von Acinetobacter baumanii in der BAL. Verlegung nach Würzburg. Rückübernahme nach 2 Monaten. Hochkalorische Ernährung via PEG. Gute Stabilisierung und Entwicklungsfortschritte. Nachreifung des Knochenskeletts unter Asfotase alfa, Entlassung 4 Monate nach Aufnahme, nun unter Masken-Heimbeatmung.

Schlussfolgerung. Die Hypophosphatasie manifestiert sich klinisch in sehr unterschiedlichen Schweregraden. Lungenhypoplasie, muskuläre Hypotonie und Thoraxstabilität limitieren den klinischen Verlauf. Die Wirksamkeit einer Enzymersatztherapie wird derzeit evaluiert.

\section{DGKJ-PO-S-13}

\section{Der 13C-Glycin-Atemtest in der Diagnostik der non-ketotischen} Hyperglycinämie

\section{Weiss D. ${ }^{1,2}$, Wutzke K.-D. ${ }^{2}$, Denecke J. ${ }^{1,2}$}

'Universitätsklinikum Hamburg Eppendorf, Klinik für Kinder- und Jugendmedizin, Hamburg, ${ }^{2}$ Universitäts-Kinder- und Jugendklinik, Rostock

Fragestellung. Die Diagnose der non-ketotischen Hyperglycinämie $(\mathrm{NKH})$ wird bei entsprechenden klinischen Auffälligkeiten überwiegend durch eine pathologische Glycin-Liquor/Plasma-Ratio gestellt, transiente Hyperglycinämien sind beschrieben, die die Diagnosestellung erschweren. Die Diagnosesicherung erfolgt molekulargenetisch, wobei 3 beteiligte Gene bekannt sind. In der Literatur wird der ${ }_{13} \mathrm{C}$-Glycin-Atemtestes als weitere diagnostische Möglichkeit beschrieben.

Material und Methode. Der ${ }_{13} \mathrm{C}$-Glycin-Atemtestes wird vorgestellt. Eigene Messungen eines Säuglings mit NKH vor und unter Therapie mit Dextrometorphan, Natrium-Benzoat und Folinsäure werden demonstriert.

Ergebnisse. Die Durchführung des Testes erwies sich auch bei Säuglingen als problemlos und praktikabel. Unsere Patientin zeigte eine deutliche Reduktion der C13-Exhalation und damit des 13C-Glycin-Abbaus im Vergleich zu gesunden Probanden und praktisch identisch mit anderen Patienten, die in der Literatur vorbeschrieben sind.

Diskussion oder Schlussfolgerung. Bisherige Daten zeigen eine Reduktion der C13-Exhalation bei allen untersuchten Patienten im Vergleich zu gesunden Kontrollprobanden mit nur geringer Streubreite der Befunde. Außerdem sind aufgrund der breiten Anwendung anderer 
Atemteste z. B. in der Diagnostik von Helicobacter-pylori-Infektionen, ${ }_{13} \mathrm{CO}_{2}$-Analyzer in vielen Kliniken verfügbar. Der ${ }_{3} \mathrm{C}$-Glycin-Atemtest eignet sich somit als einfach zugängliches und nichtinvasives Instrument zur Diagnostik der non-ketotischen Hyperglycinämie.

\section{DGKJ-PO-S-14}

\section{Schwere Leberfunktionsstörung bei einem 13-Jährigen}

Opitz D. ', Seitz K.-H. ${ }^{2}$, Veigel A. ', Kühr J.'

${ }^{1}$ Städtisches Klinikum, Kinderklinik, Karlsruhe, ${ }^{2}$ Städtisches Klinikum, Innere Medizin, Karlsruhe

Fragestellung. Schwere akute Leberfunktionsstörungen stellen oft eine diagnostische und therapeutische Herausforderung dar. Die Berücksichtigung seltenerer Ursachen spielt gelegentlich für die richtige Therapie eine entscheidende Rolle.

Material und Methoden. Ein 13 Jahre alter Patient wird wegen zweiwöchiger Anamnese mit Adynamie, Ikterus und Ödemen stationär aufgenommen. Erste Laborwerte sprechen für eine schwere leberabhängige Synthesestörung und eine milde Cholestase.

Ergebnisse. Ein erniedrigtes Coeruloplasmin und eine erhöhte Kupferausscheidung im Urin waren für die Diagnose wegweisend. Eine zwischenzeitlich durchgeführte Duplexsonographie erbrachte den Befund eines knotigen Umbauprozesses der Leber, histologisch liegt ein zirrhotischer Umbau des Leberparenchyms vor. Bei deutlich erhöhter Kupfereinlagerung im Biopsat konnte die Diagnose eines Morbus Wilson letztendlich gestellt werden, welcher in der Folge auch humangenetisch bestätigt wird. Unter Therapie mit Penicillamin und Zinkacetat normalisiert sich die Lebersyntheseleistung des Patienten.

Schlussfolgerung. Differenzialdiagnostisch kamen im konkreten Fall als Ursache des akuten Leberversagens eine fulminante Hepatitis, eine Intoxikation, ein Autoimmungeschehen, eine chronische cholestatische Erkrankung, eine primäre Stoffwechselerkrankung oder ein Morbus Wilson in Betracht. Das Ausmaß des Leberschadens, verursacht durch einen Morbus Wilson, reicht bekanntermaßen von einer asymptomatischen Transaminasenerhöhung bis zum fulminanten Leberversagen, wobei letzteres zwar selten, jedoch wie im obigen Fall möglich ist.

\section{Neonatologie/Pädiatrische Intensivmedizin (1)}

\section{DGKJ-PO-I1-1}

\section{Lues connata mit Makrophagenaktivierungssyndrom}

Müller-Bühl K. ', Emeis M. ', Jackowski-Dohrmann S.', Clausen J.', Rossi R. ${ }^{1}$

'Vivantes Klinikum Neukölln, Kinder- und Jugendmedizin - Perinatalzentrum, Berlin

Fallbericht. Bei einem 8 Wochen alten männlichen Säugling erfolgte die stationäre Einweisung mit Temperaturerhöhung bis $38,5^{\circ} \mathrm{C}$ seit $2 \mathrm{Wo}-$ chen, Trinkverweigerung, Exanthem, blass-ikterischem Hautkolorit und gespanntem Abdomen. Bei bedrohlich krankem Kind mit septischer Symptomatik und hohen Entzündungsparametern sowie Anämie, Thrombozytopenie und Gerinnungsstörung erfolgt eine breite i.v.-antibiotische Therapie und die Transfusion von FFP, TK und EK. Bei klinisch und sonographisch ausgeprägter Hepatosplenomegalie waren alle Diagnosekriterien eines Makrophagen-Aktivierungssyndroms erfüllt. Als ursächlich konnte eine frische Luesinfektion nachgewiesen werden, daher erfolgte die Umstellung der antibiotischen Therapie auf Penicillin. Da es hierunter nur langsam zum Rückgang von Organvergrößerung und Hepatopathie kam, wurden zusätzlich Steroide mit konsekutiv deutlicher Befundbesserung eingesetzt.

Schlussfolgerung. In Kenntnis der wieder zunehmenden Luesinfektion muss bei sepsisähnlichen Krankheitsverläufen mit Exanthem und Organomegalie immer auch eine Lues differenzialdiagnostisch in Betracht gezogen werden.

\section{DGKJ-PO-I1-2}

\section{Folgen einer Zytomegalievirusinfektion in der Schwangerschaft:} ein wenig bekanntes Risiko!

Brockow I.', Wirth M.', Nennstiel-Ratzel U.'

'Landesamt für Gesundheit und Lebensmittelsicherheit, GE 4, Oberschleißheim

Fragestellung. Die Zytomegalievirus (CMV)-Infektion hat als eine der häufigsten konnatalen Infektionen eine hohe medizinische Bedeutung. In ihrer Folge treten häufig Entwicklungsverzögerungen sowie Hörund Augenschäden bei Kindern auf. Dennoch zeigen Umfragen in anderen Ländern ein geringes Wissen über CMV bei Ärzten, medizinischem Personal und Schwangeren. Geeignete Präventionsstrategien wie einfache Hygienemaßnahmen sind oft nicht bekannt. Untersuchungen dazu liegen in Deutschland bisher nicht vor.

Material und Methoden. Anhand eines eigens entwickelten Fragebogens für Schwangere und medizinisches Personal wurden die Kenntnisse und das Problembewusstsein für eine CMV-Infektion erhoben. Langfristiges Ziel ist es, die Aufklärung über CMV zu verbessern und geeignete Präventionsmaßnahmen zu entwickeln.

Ergebnisse. An drei großen Münchner Geburtskliniken wurden im Rahmen der Schwangerensprechstunden bisher ca. 400 Schwangere befragt. Ebenso liegen ca. 9o Fragebögen von medizinischem Personal vor. Nach ersten Auswertungen sind nur wenige Kenntnisse über die möglichen Folgen, Übertragungsrisiken und Vermeidung einer konnatalen CMV-Infektion vorhanden. Die meisten Schwangeren haben noch nie etwas von CMV gehört. Auch bei Ärzten und medizinischem Personal ist das Wissen in vielen Fällen lückenhaft.

Schlussfolgerung. Das Wissen über die Folgen und Vermeidung einer konnatalen CMV-Infektion ist in Deutschland bei Schwangeren und Medizinischem Personal meist nur gering. Geeignete Aufklärungsund Präventionsmaßnahmen sollten entwickelt werden.

\section{DGKJ-PO-I1-3}

Populationsbasierte Studie zum Outcome Neugeborener abhängig vom Geburtsmodus (SNiP-Studie)

Lange A. ', Zindel K. ${ }^{2}$, Thyrian R.J. ${ }^{3}$, Hoffmann W. ${ }^{3}$, Heckmann M. ${ }^{1}$

'Universitätsmedizin Greifswald, Neonatologie und Pädiatrische Intensivmedizin, Greifswald, ${ }^{2}$ Universitätsmedizin, Greifswald, ${ }^{3}$ Universitätsklinik Greifswald, Community-Medicine, Greifswald

Hintergrund. Das Ziel der Studie ist es, den Zusammenhang vom Geburtsmodus zum neonatalem Schwangerschaftsoutcome zu beschreiben.

Methode. Von 03/2003-11/2208 untersuchten wir Im Rahmen der SNiPStudie $n=5394$ Mütter und ihre Kinder. Es wurden $n=3989$ Kinder spontan und $n=1387$ per Sectio geboren. Ein pathologischer Ultraschall präpartal führte signifikant häufiger in den höheren Schwangerschaftswochen zur Sectio ( $<32$ SSW: $<<0,126 ; 32-34$ SSW: $p<0,086,35-37$ SSW: $\mathrm{p}<0,001,>37$ SSW: $\mathrm{p}<0,001)$.

Ergebnisse. Die Prävalenz, per Sectio entbunden zu werden, betrug $25,7 \%$. Als Ursachen einer Sectio fanden sich die pathologische Geburtslage, ein pathologischer Ultraschallbefund bei der Mutter und Mehrfachgebären. Als fetale Risikoparameter konnten die Frühgeburtlichkeit und ein Gewicht des Kindes $>3500$ g aufgezeigt werden. Als negatives Outcome zeigt sich bei den Neugeborenen, die per Sectio entbunden wurden, häufiger ein 5 Minuten APGAR-Wert $<5$ ( $\mathrm{p}<0,007)$, sie wurden häufiger primär erstversorgt [Spontangeboren 217/3931(5,5\%) vs. Sectio 162/1252 (12\%) >35 SSW; p<0,001] sowie stationär aufgenommen [SG 566/3925 (14\%) vs. 317/1255 (25\%) >35 SSW; p<0,002]. Der arterielle Nsph war bei den Reifgeborenen Kinder die spontan entbunden wurden, signifikant häufiger azidotisch; $(<32$ SSW: $<<0,914,32-34$ SSW: $\mathrm{p}<0,797,35-37$ SSW: $\mathrm{p}<0,007,>37$ SSW: $\mathrm{p}<0,001)$.

Fazit. Jedes 4 . Neugeborene einer Mutter die per Kaiserschnitt entbunden wird, wurde stationär aufgenommen und erhielt eine erweiterte 
Neugeborenen-Erstversorgung obwohl die Fruchtwasserqualität und der 5-min-Apgar bei den spontangeborenen Kindern schlechter waren. Die Daten unterstützen die hochaktuelle Diskussion über die Sicherheit und Indikationsstellung der Sectio-Entbindung.

\section{DGKJ-PO-I1-4 Identifying trajectories for healthy postnatal growth of preterm infants}

Raja P. ${ }^{1}$, Rochow N. ${ }^{1}$, Göttler S. ${ }^{2}$, Olbrich A. ${ }^{3}$, Seigel S. ${ }^{4}$, Campbell D. ${ }^{5}$, Heckmann M. ${ }^{3}$, Poeschl J. ${ }^{2}$, Thabane L. ${ }^{6}$, Fusch C. ${ }^{1}$

${ }^{1}$ McMaster University, Pediatrics, Hamilton, Kanada, ${ }^{2}$ Heidelberg University Hospital, Pediatrics, Heidelberg, ${ }^{3}$ Greifswald University Hospital, Pediatrics, Greifswald, ${ }^{4}$ St. Joseph's Healthcare, Pediatrics, Hamilton, Kanada, ${ }^{5}$ St. Michael's Hospital, Toronto, Pediatrics, Toronto, Kanada, ${ }^{6}$ McMaster University, Clinical Epidemiology \& Biostatistics, Hamilton, Kanada

Background. Postnatally VLBW infants should continue to achieve intrauterine growth rates. However, due to irreversible postnatal contraction of extracellular water space, postnatal growth trajectories shift to a "new" percentile below the one in-utero. Which "new" trajectory a preterm infant should ideally adjust to after completed postnatal adaptation is unknown.

Objective. To develop a model for "healthy" postnatal growth references of preterm infants by 1) Characterizing growth of such infants which required only minimal postnatal support; 2) Developing a model to predict/identify the trajectory for healthy postnatal weight in any given infant by including clinical data available at birth.

Methods. Inclusion criteria: 30-35 weeks GA, admitted 2008-2012 to participating hospitals. Exclusion criteria: maternal diabetes/substance use, major malformation, nCPAP $>3$ days, not on full enteral feeds by day of life (DoL) 10, unavailable growth data until DoL 14, proven sepsis. Models to predict body weight trajectories on DoL 7, 14, 21 were developed using SPSS v.21.

Results. 600 infants were eligible of 4319 that met inclusion criteria. On average, infants had a maximum weight loss by DoL 5 , regained their BW by DoL11 and had stable growth during DoL 7-21. At birth, infants were $95 \pm 18 \%$ of 5 oth BW\%ile, but adjusted to $83 \pm 13 \%$ by DoL14. The zscore difference from birth was $-0.8 \pm 0.3$ at DoL14. Preliminary linear regression models accurately predicted weight at DoL 7, $14(\mathrm{n}=600$; $\left.\mathrm{R}_{2}=0.94,0.88\right)$ and $21\left(\mathrm{n}=306\right.$; $\left.\mathrm{R}_{2}=0.83\right)$.

Conclusions. 1) These results provide robust estimates of postnatal growth trajectories for preterm infants. 2) The model needs to be extended to 24 weeks of gestation. 3) The impact on long-term outcome needs to be assessed, ideally in an RCT.

\section{DGKJ-PO-I1-5 \\ Neonatale Prädiktoren spezifischer Mathematikleistungen bei Frühgeborenen}

Jäkel J., ${ }^{1,2}$, Wolke D. ${ }^{2}$

${ }^{1}$ Ruhr-Universität Bochum, Entwicklungspsychologie, Bochum, ${ }^{2}$ The University of Warwick, Coventry, UK

Fragestellung. Aktuelle Studien zeigen, dass Frühgeborene spezifische Defizite in mathematischen Fähigkeiten aufweisen, die nicht durch allgemeine kognitive Probleme erklärbar sind. Wir untersuchen den $\mathrm{Zu}$ sammenhang zwischen Gestationsalter, neonatalem Risiko und spezifischen Mathematikleistungen im Alter von 8;5 Jahren.

Material und Methode. 947 Kinder (Gestationsalter 27-41 Wochen) wurden von der Geburt bis zum Alter von 8;5 Jahren im Rahmen einer prospektiven populationsbasierten Längsschnittstudie neonataler Risikokinder (Bayrische Entwicklungsstudie, BESt) untersucht. Kognitive Fähigkeiten wurden im Alter von 8;5 Jahren anhand der K-ABC gemessen. Mathematische Leistungen in den Bereichen Schätzen, Schlussfol- gern, Kopfrechnen sowie Mentale Rotation (insgesamt 79 Items) wurden mit einem standardisierten Test erfasst.

Ergebnisse. Spezifische kindliche Mathematikleistungen, die unabhängig von allgemeinen kognitiven Fähigkeiten sind, werden mit abnehmendem Gestationsalter schlechter. Diese Beziehung zwischen mathematischen Fähigkeiten und Gestationsalter ist kurvilinear, da vor der 33. Gestationswoche jede verlorene Woche einen zunehmend negativen Effekt hat. Spezifische mathematische Defizite werden durch frühe neonatale Risiken (z. B. Dauer der Beatmung, neurologische Probleme) vorhergesagt, nicht aber durch Geschlecht, sozioökonomischen Status, kognitive und motorische Fähigkeiten oder Aufmerksamkeitsprobleme.

Schlussfolgerung. Wir benötigen mehr Studien zu den Entwicklungsmechanismen und besonderen Bedürfnissen neonataler Risikokinder mit mathematischen Defiziten. Forschung zu spezifischen Mathematikleistungen kann uns helfen, die unterschiedlichen Facetten des Phänotyps ehemaliger Frühgeborener besser zu verstehen.

\section{DGKJ-PO-I1-6}

Analyse der Entzugssymptomatik von Kindern opiatabhängiger Frauen am Perinatalzentrum Innenstadt der LMU in den Jahren 2003 bis 2011 und Entwicklung eines neuen Screeninginstruments für das neonatale Abstinenzsyndrom

\section{Rößlein A. ${ }^{1}$, Genzel-Boroviczény $0 .{ }^{2}$}

'Ludwig-Maximilians-Universität München, Kinderkardiologie, München, ${ }^{2}$ Ludwig-Maximilians-Universität München, Neonatologie, München

Fragestellung. Ziel dieser Studie war es die Symptome des neonatalen Entzugssyndroms statistisch auszuwerten und aus diesen Erkenntnissen ein Screeninginstrument zu entwickeln.

Material und Methode. Diese Studie war eine retrospektive Fallanalyse aller Kinder, die mit Verdacht auf Entzugssyndrom im Perinatalzentrum Innenstadt des Klinikum der LMU, Maistraße 11, München, in den letzten 9 Jahren behandelt worden sind. Insgesamt wurden 97 Fälle und 920 einzelne Finneganscores ausgewertet.

Ergebnisse. Anhand der statistischen Auswertung der verschiedenen Symptome wurde ein neuer Screeningtest entwickelt. Dieser Score besteht aus sieben Items: Tremor in Ruhe, Muskeltonus erhöht, Myoklonien, vermehrtes Gähnen, Schwitzen, verstärkter Moro-Reflex und schrilles Schreien. Für jedes vorhandene Symptom wird ein Punkt vergeben. In der ROC- Analyse ist dieser Test dem Finnegan Score in der frühen Identifizierung von behandlungsbedürftigen Kindern überlegen $[A U C=0,66(p<0,001)$ bzw. 1,o $(p<0,0001)]$. Bei einem Cut-off von drei oder mehr Punkten errechnet sich eine Spezifität von $98 \%$ und eine Sensitivität von $100 \%$, der positiv prädiktive Wert beträgt $99 \%$, der negativ prädiktive Wert $95 \%$.

Schlussfolgerung. Insgesamt stehen zentralnervöse Symptome beim NAS im Vordergrund. Vor allem bei der Identifizierung behandlungsbedürftiger Neugeborener ist es möglich sich nur auf einen Teil der Symptome zu beschränken, da nicht alle Symptome in den ersten Tagen nach Geburt eine zuverlässige Unterscheidung erlauben.

\section{DGKJ-PO-I1-7}

Ecstasy als „sichere Partydroge“? Hyponatriämie mit generalisiertem Krampfanfall nach MDMA-Intoxikation bei einem 15-Jährigen

Rath A.', Creutzfeldt R. ', Stedtler U.', Krüger M. ${ }^{\text {' }}$

'Universitätsklinikum Freiburg, Zentrum für Kinder und Jugendmedizin, Freiburg

Hintergrund. Ecstasy gehört zur Gruppe der zentral stimulierenden Amphetamine und zu den am häufigsten konsumierten illegalen Drogen in Deutschland. Von vielen Konsumenten wird es bei sporadischer Einnahme als „sichere Partydroge“ angesehen. Bei Langzeitkonsum 
treten u. a. Leistungsminderung und psychische Störungen auf, aber auch akut können sich gefährliche Komplikationen entwickeln. Fallbericht. Ein 15-jähriger Junge wurde nach einem Krampfanfall auf der pädiatrischen Intensivstation aufgenommen. Er hatte den Vorabend mit Freunden verbracht und es bestand der Verdacht auf einen Substanzenkonsum bei bereits wiederholtem Drogenabusus. Morgens ereignete sich ein 2-minütiger generalisierter Krampfanfall mit Zyanose; es fand eine Laien-Mund-zu-Mund-Beatmung statt. Bei Eintreffen des Notarztes war der Junge kardiorespiratorisch stabil, aber somnolent und es traten erneut kurzzeitige Zuckungen auf. Im Labor bestanden eine Hyponatriämie (122 mmol/l), eine erniedrigte Serumosmolalität $(269 \mathrm{mosm} / \mathrm{kg})$ und eine metabolische, respiratorisch kompensierte Azidose ( $\mathrm{pH} 7,34, \mathrm{pCO}_{2} 38 \mathrm{mmHg}, \mathrm{BE}-6 \mathrm{mmol} / \mathrm{l}$, Laktat $\left.9 \mathrm{mmol} / \mathrm{l}\right)$. Das Serum-Drogenscreening ergab $250 \mathrm{ng} / \mathrm{ml}$ MDMA (3,4-Methylendioxy-N-methylamphetamin, Ecstasy), $17 \mathrm{ng} / \mathrm{ml}$ MDA (MDMA-Metabolit) und $36 \mathrm{ng} / \mathrm{ml}$ Amphetamin. Unter einer Natriumsubstitution und dem spontanen Einsetzen der Diurese normalisierten sich die Serumwerte zügig. Es bestand eine Amnesie für den vergangenen Abend bei sonst unauffälliger Neurologie.

Schlussfolgerung. Trotz des verbreiteten Rufs als „sichere Partydroge“ beinhaltet der Konsum von Ecstasy akute Risiken insbesondere durch das Auftreten von einem Serotonin-Syndrom, Herz-Kreislauf-Störungen, einer Hyperpyrexie mit Rhabdomyolyse, aber auch wie unser Fall zeigt einer (Verdünnungs-)Hyponatriämie mit Hirnödem.

\section{DGKJ-PO-I1-8}

\section{Akute nekrotisierende Enzephalopathie bei einem 6-jährigen Jungen - eine Kasuistik}

\section{Kühn A. ', Warncke G. ${ }^{1}$, Vollrath G. ${ }^{2}$, Wigger M. ${ }^{3}$ \\ 'Universitäts-Kinder- und Jugendklinik, Interdisziplinäre pädiatrische Intensivmedizin, Rostock, ${ }^{2}$ Universitäts-Kinder- und Jugendklinik, Neuro- pädiatrie, Rostock, ${ }^{3}$ Universitäts-Kinder- und Jugendklinik, Nephrologie und Dialyse, Rostock}

Einleitung. Die akute nekrotisierende Enzephalopathie ist eine seltene rasch progrediente Enzephalopathie. Sie tritt als sporadische Form parainfektiös bei ansonsten gesunden Kindern auf oder wird als Defekt im RAN-binding protein 2 autosomal dominant vererbt. Klinische Zeichen sind Krampfanfälle, Verwirrtheitszustände und Koma. Diagnostisch wegweisend ist die Bildgebung mittels cMRT, welches multiple symmetrische Läsionen, vornehmlich bithalamisch zeigt. Die Therapieoptionen beinhalten eine therapeutische Hypothermie, die Therapie mit Immunglobulinen (IVIG) sowie Methylprednisolon.

Kasuistik. Ein 6-jähriger Junge wurde durch den Rettungsdienst in unsere Klinik eingewiesen, da er am Morgen nicht erweckbar war. Bei Ankunft in der Klinik war der Patient komatös (GCS 4) und zeigte Kloni der oberen Extremität. Im cMRT zeigten sich bithalamische und mesenzephale Läsionen. Aufgrund des Komas und der nicht vorhersehbaren Progredienz der Läsionen erfolgte die elektive Intubation und Beatmung. Unter der Verdachtsdiagnose einer akuten nekrotisierenden Enzephalopathie (ANE) führten wir eine Immunglobulintherapie und eine Methylprednisolonstoßtherapie durch, woraufhin der Patient sich stabilisierte und keine weitere Befundzunahme im cMRT zu beobachten war. Der Junge wurde insgesamt wacher und konnte komplikationslos extubiert werden. Es erfolgte die Verlegung in eine Rehabilitationsklinik. Zum Verlegungszeitpunkt bestanden ein totaler Spracharrest und rezidivierende Krampfanfälle.

Schlussfolgerung. Das frühzeitige Erkennen der Symptome und eine gezielte Diagnostik wie das cMRT ermöglichen aufgrund der typischen Befunde eine rasche Diagnosestellung und daraus folgend eine maximale Ausschöpfung der therapeutischen Optionen.

\section{DGKJ-PO-I1-9 \\ Clostridium perfringens (C.p.) Typ A bei Frühgeborenen: Gastro- enteritis bis nekrotisierende Enterocolitis (NEC)}

\section{Schlecht M. ${ }^{1}$, Kiesewetter M. ${ }^{\prime}$, Kidszun A. ${ }^{1}$, Uebler A. ', Whybra C. ', Schwanz} $T^{2}{ }^{2}$, Mildenberger $E^{2}$

'Universitätsmedizin der Johannes Gutenberg-Universität Mainz, Kinderklinik, Perinatologische Intensivstation, Mainz, ${ }^{2}$ Universitätsmedizin der Johannes Gutenberg-Universität Mainz, Institut für medizinische Mikrobiologie und Hygiene, Mainz

Hintergrund. C.p. Typ A kann bei einigen asymptomatischen Individuen, z. B. Frühgeborenen (FG), zur Darmflora gehören. Die Kolonisation scheint eine Rolle bei der multifaktoriellen Genese einer NEC zu spielen oder aber die C.p.-assoziierte NEC stellt eine eigene Entität dar. C.p. ist darüber hinaus Erreger akuter Gastroenteritiden. Wir berichten von zwei FG mit unterschiedlichen C.p.-assoziierten abdominellen Infektionen.

Fallberichte. Patient A (FG 28+6 SSW) entwickelte am 11. Lebenstag (LT) perakut das Vollbild einer NEC. Als Ultima ratio erfolgte die Laparatomie, bei der sich eine massive Nekrose (Mitte des Colon transversum bis zum Sigmoideum) und eine Perforation am terminalen Ileum zeigten. Das Kind verstarb $7 \mathrm{~h}$ postoperativ. Im intraperitonealen Abstrich fand sich C.p. (keine Typisierung). Die Übernahme von Patientin B (FG $33+4$ SSW) erfolgte am 2. LT bei V. a. auf distalen Dünndarmileus. Nach konservativem Therapieversuch wurden am 7. LT in der Laparoskopie Briden dargestellt und gelöst. Nach symptomfreier Latenz entwickelte das Kind am 16. LT eine wässrige Enteritis mit massiver Dehydratation. Im Stuhl wurde C.p.-Toxin sowohl in der Akutphase als auch nach der raschen Genesung nachgewiesen.

Diskussion. Bei Patient A lag möglicherweise eine präexistente Kolonisation vor, die die Entstehung und den fulminanten Verlauf der NEC begünstigte. Bei Patientin B gehen wir von einer typischen akuten Enteritis aus. Eine Enteritis durch einen nicht identifizierten Erreger bei C.p.-Kolonisation ist dennoch ebenfalls möglich.

Schlussfolgerung. Der Kenntnisstand bezüglich einer Kolonisation mit C.p. und deren Folgen bei FG ist lückenhaft. Bei abdomineller Symptomatik sollte aufgrund des dramatischen Verlaufs einer C.p.-assoziierten NEC stets auch nach diesem Erreger gesucht werden.

\section{DGKJ-PO-I1-10 Tracheoösophageale Fistel nach Knopfbatterieingestion}

Alt F. ${ }^{1}$, Poplawska K. ${ }^{2}$, Schwind M. ${ }^{3}$, Turial S. ${ }^{3}$, Huth R.G. ${ }^{2}$, Gehring S. ${ }^{2}$

${ }^{1}$ Universitätsmedizin der Johannes Gutenberg-Universität Mainz, Kinderklinik, Interdisziplinäre Intensivmedizin, Mainz, ${ }^{2}$ Universitätsmedizin der Johannes Gutenberg-Universität, Mainz, ${ }^{3}$ Kinderchirurgie, Mainz

Einleitung. Die Ingestion von Lithium-Batterien stellt eine besondere Herausforderung da; der alkalische Inhalt wird durch den sauren $\mathrm{pH}$ des Magen-Darm-Traktes beschleunigt freigegeben und verursacht je nach Verweildauer Nekrosen und Ätzungen. Todesfälle sind beschrieben worden.

Fallbericht. Wir berichten über einen zehn Monate alten Säugling mit sekundärer tracheoösophagealer Fistel (TEF) nach Batterieingestion. Die Entfernung erfolgte in Intubationsnarkose mit starrem Endoskop, die Schleimhaut wies nekrotisch belegte Areale auf. Eine zweite Gastro/Bronchoskopie zeigte eine ausgeprägte TEF. Im Thorax-CT konnten ein Ösophaguseinriss mit Bildung einer TEF auf Höhe von BWK1, Lufteinschlüsse um den Ösophagus auf Höhe BWK 3 und BWK 8/9 und beidseits pneumonische Infiltrate nachgewiesen werden. Die Trachea-Rückwand und der Ösophagus wurden durch Einzelknopfnähte verschlossen und überschüssiges Thymusgewebe interponiert $\left(360^{\circ}\right.$ Thymoplicatio). Intraoperativ wurde die Trachea mehrmals bei entblocktem Tubus einer Dichtigkeitsprobe unterzogen. Postoperativ fiel eine einseitige Recurrensparese auf. Die Kontrolle des postoperativen Befundes erfolgte nach drei Wochen endoskopisch. Trotz Behebung der 
TEF gelang bei bestehender Recurrensparese mit ausgeprägter Schluckstörung ein enteraler Kostaufbau nur zögerlich.

Ergebnisse und Schlussfolgerung. Die Ingestion von Knopfbatterien kann innerhalb sehr kurzer Zeit (ab 2 h nach Ingestion) Schleimhauterosionen und Fisteln verursachen. In dem hier vorgestellten Fall beobachteten wir einen ausgeprägten Schleimhautdefekt und Knorpelnekrose in einem Zeitraum von 4 Stunden. Spätfolgen wie Stenosen und Stimmbänderparesen werden oft erst im Verlauf manifest. Die Indikation zur Endoskopie sollte großzügig und zeitnah gestellt und ein engmaschiges Follow-up etabliert werden.

\section{DGKJ-PO-I1-11}

\section{Infantile hepatische Hämangiomatose - neuer Therapieweg?}

Retter M. ', Stuhrmann S. ${ }^{1}$, Asmussen M. ${ }^{2}$, Kühr J. ${ }^{1}$

${ }^{1}$ Klinikum für Kinder- und Jugendmedizin, Städtisches Klinikum, Karlsruhe, 2Zentralinstitut für Bildgebende Diagnostik, Städtisches Klinikum, Karlsruhe

Fragestellung. Die hepatische Hämangiomatose ist ein potentiell lebensbedrohliches Krankheitsbild. Durch arteriovenöse Shuntbildung kann eine Linksherzbelastung bis zur Herzinsuffizienz resultieren. Die bisherige etablierte Therapie bestand aus Steroiden, Interferon, Vincristin oder chirurgischen Maßnahmen. Aktuelle Studien weisen darauf hin, dass eine Monotherapie mit Propranolol eine effektive, nebenwirkungsarme Behandlungsstrategie darstellen könnte. Bei zwei von hepatischer Hämangiomatose betroffenen Patienten legten wir diesen Therapieansatz zugrunde.

Material und Methode. Wir berichten von zwei Kleinkindern, bei denen im Rahmen der $\mathrm{U}_{2}$ bzw. der $\mathrm{U}_{3}$ sonographisch multiple, rundliche, gut perfundierte Tumore in der Leber festgestellt wurden. Bei Verdacht auf Leberhämangiome begannen wir nach einem EKG und einer Echokardiographie eine Therapie mit Propranolol (1,5-2 mg/kg Körpergewicht). Ergebnisse. Ein Jahr nach Therapiebeginn zeigten sich bei dem Mädchen noch minimale Hämangiome der Haut, Leberhämangiome waren sonographisch nicht mehr nachweisbar, bei dem Jungen waren sonographisch keine, im MRT noch drei Leberhämangiome nachweisbar. Die Therapie wurde nebenwirkungsfrei vertragen und über insgesamt 10 bzw. 15 Monate fortgeführt. In den nachfolgenden Kontrollen wurden bei beiden Kindern keine Hämangiome mehr nachgewiesen.

Schlussfolgerung. Die klinischen Verläufe der beiden Fallbeispiele decken sich mit in der Literatur beschriebenen Verläufen. Hämangiome unter Propranololtherapie zeigen eine raschere Regredienz als im Spontanverlauf. Die Propranololtherapie ist eine effektive, nebenwirkungsarme Alternative in der Therapie der IHH. Propranolol ist aktuell in Deutschland noch nicht für die Therapie von Hämangiomen im Kindesalter zugelassen.

\section{DGKJ-PO-I1-12}

Endoskopische Therapie von Varizen nach erster $\mathrm{Hb}$-wirksamer oberer Gastrointestinalblutung bei einem 3-jährigen Mädchen Intervention nach interdisziplinärer Absprache

\section{Heimann K.', Tischendorf J.' ${ }^{2}$ Trepels-Kottek S. ', Schoberer M. ', Nguyen H. ${ }^{3}$, Wagner N. ${ }^{4}$, Orlikowsky T.?}

'Universitätsklinikum RWTH Aachen, Klinik für Kinder- und Jugendmedizin, Sektion Neonatologie, Pädiatrische Intensivmedizin, Aachen, ${ }^{2}$ Universitätsklinikum RWTH Aachen, Medizinische Klinik III, Aachen, ${ }^{3}$ Städtische Kliniken Mönchengladbach, Allgemeine Innere Medizin, Mönchengladbach, ${ }^{4}$ Universitätsklinikum RWTH Aachen, Klinik für Kinder- und Jugendmedizin, Aachen

Einleitung. Blutungen des oberen Gastrointestinal(GI)-Traktes machen bei Kindern $15 \%$ aller GI-Blutungen aus. Hämatemesis findet sich in $12 \%$, schwere Anämien in $18 \%$. Angaben zur Häufigkeit von Varizen als Blutungsursache ohne Vorerkrankungen variieren. Angaben zu Ri- siken und Erfolg einer endoskopischen Therapie von Ösophagus- und Fundusvarizen schwanken.

Patientin. Dreijähriges Mädchen mit akuten Bauchschmerzen und erstmaliger Hämatemesis. Keine Schockzeichen, jedoch Hb-Abfall von 12 auf $8,5 \mathrm{~g} / \mathrm{dl}$ in 4 Stunden; Einmalige Transfusion. Endoskopisch Ösophagusvarizen Grad II-III, 2 junktionale Fundusvarizen. Beginn Propranolol-Therapie oral. Sonographie, CT, MRT: hochgradiger Verdacht auf hepatische kavernöse Transformation der Pfortader. Anamnestisch kein Nabelvenenkatheter. Interdisziplinäre Fallkonferenz (Pädiatrische Intensivmedizin, Abdominalchirurgie, Pädiatrische und Internistische Gastroenterologie): Abwägung operative (splenorenaler Shunt) und endoskopische Therapieoption vs. Risiken von Zuwarten. Einigung auf endoskopische Sichtung. 1. Sitzung: Obliterierung der junktionalen Varizen mit Histoacryl, 2. Sitzung: Sklerosierung der Ösophagusvarizen mit Äthoxysklerol. Aufgrund des Alters der Patientin Entscheidung gegen Gummibandligatur wg. erhöhten Komplett-Nekroserisikos der Ösophaguswand. Entlassung nach fünf Tagen in gutem Allgemeinzustand. Keine weiteren Blutungsereignisse mehr.

Schlussfolgerungen. Hb-wirksame Blutungen des oberen GI-Traktes durch Ösophagus- und Fundusvarizen im Kindesalter sind selten. Nach Abklärung von Ursache und Ausmaß empfiehlt sich ein interdisziplinärer Ansatz, um Chancen und Risiken abzuwägen. Die endoskopische Therapie kann bei anatomisch gut zugänglichen Varizen auch bei Kindern unter 5 Jahren eine risikoarme therapeutische Maßnahme sein.

\section{DGKJ-PO-I1-13}

Beidseitige fulminante Lungenarterienambolie bei steroidsensiblem nephrotischem Syndrom

\section{Wichmann B. ', Warncke G. ${ }^{1}$, Staude H. ${ }^{2}$, Wigger M. ${ }^{2}$}

'Universitätsklinik Rostock, Pädiatrische Intensivmedizin, Rostock, ${ }^{2}$ Universitätsklinik Rostock, Pädiatrische Nephrologie, Rostock

Einleitung. Thrombosen und Embolien im Kindes- und Jugendalter sind mit einer jährlichen Inzidenz von 1:10o.ooo seltene Ereignisse und entstehen fast immer sekundär bei gravierenden Grunderkrankungen oder in Zusammenhang mit exogenen Risikofaktoren. Neben der medikamentösen und apparativen Rekanalisation der verschlossenen Gefäße und der Prophylaxe neuer Thromben ist die Erkennung und Therapie der auslösenden Grunderkrankung die zweite wesentliche Behandlungssäule.

Kasuistik. Ein 16 Jahre alter Junge stellte sich wegen atemunabhängiger, rechtsthorakaler Schmerzen in der Klinik vor. Bei subfebrilen Temperaturen erfolgte die stationäre Aufnahme bei Verdacht auf eine atypische Pneumonie. Am Folgetag trat beim Aufstehen plötzlich ein starker Thoraxschmerz auf, der Patient zeigte Kreislaufzentralisation und Tachypnoe, sodass die Verlegung auf die Kinder-ITS erfolgte. Im CT-Thorax stellte sich eine beidseitige fulminante Lungenembolie dar. Es erfolgte die systemische Thrombolyse sowie therapeutische Heparinisierung. Nach Stabilisierung der Akutsituation erfolgte die Suche nach der auslösenden Grunderkrankung. Eine mehrfach nachgewiesene Proteinurie wies dabei auf ein nephrotisches Syndrom hin. In der Diagnostik bestätigte sich die Diagnose eines nephrotischen Syndroms, sodass eine Prednisolontherapie begonnen wurde. Bei zusätzlich nachgewiesener Heterozygotie einer Faktor-V-Leiden-Mutation erfolgt eine kontinuierliche Thromboseprophylaxe mit Enoxaparin.

Schlussfolgerung. Bei thromboembolischen Ereignissen im Kindesund Jugendalter muss nach der auslösenden Grunderkrankung gesucht werden, da die kausale Therapie eine effektive Prophylaxe zur Verhinderung weiterer Ereignisse darstellt. 
DGKJ-PO-I1-14

Infantile pulmonale arterielle Hypertonie als diagnoseweisendes Symptom eines NFU1-assoziierten multiplen mitochondrialen Dysfunktionssyndroms

Hempel M. ${ }^{1}$, Engelsberger I. ${ }^{2}$, Ahting U. ', Santra S. ${ }^{3}$, Spranger S. ${ }^{4}$, Makowski C. ${ }^{2}$, Jünger $H^{2}{ }^{2}$, Wagner $C .{ }^{2}$, Rohrbach M. ${ }^{5}$, Chakrapant A.B. ${ }^{3}$, Preece M.A. ${ }^{6}$, Rolinski B. ${ }^{7}$, Alston C.L. ${ }^{8}$, Haack T.B. ${ }^{9}$, Sperl W. ${ }^{10}$, Plecko B. ${ }^{11}$, Mayr J. ${ }^{10}$, Taylor R.W. ${ }^{8}$, Freisinger P. ${ }^{12}$, Prokisch $H^{9}{ }^{9}$

${ }^{1}$ Technische Universität München, Institut für Humangenetik, München, ${ }^{2}$ Städtisches Krankenhaus München Schwabing, Kinderklinik, München, ${ }^{3}$ Birmingham Children's Hospital, Department of Clinical Inherited Metabolic Disorders, Birmingham, UK, ${ }^{4}$ Praxis für Humangenetik, Bremen, ${ }^{5}$ Kinderspital Zürich, Abt. Stoffwechselerkrankungen, Zürich, Schweiz, ${ }^{6}$ Birmingham Children's Hospital, Department of Newborn Screening \& Biochemical Genetics, Birmingham, UK, ${ }^{7}$ Elblandklinikum Riesa, Abt. für Klinische Chemie, Riesa, ${ }^{8}$ Newcastle University, Wellcome Trust Centre for Mitochondrial Research, Newcastle, UK, ${ }^{9} \mathrm{Helmholtz}$ Zentrum München, Institut für Humangenetik, Neuherberg, ${ }^{10}$ Universitätsklinik für Kinder- und Jungendheilkunde, Salzburg, Österreich, "Kinderspital Zürich, Neurologie, Zürich, Schweiz, ${ }^{12}$ Klinikum am Steinenberg, Klinik für Kinder- und Jugendmedizin, Reutlingen

Einleitung. Eine im frühen Säuglingsalter auftretende pulmonale arterielle Hypertonie (PAH) ist eine häufig lebenslimitierende Erkrankung Fallbericht. Wir berichten über ein Frühgeborenes der 29. SSW, das im dritten Lebensmonat mit einem Apnoe-Bradykardie-Syndrom und einem erhöhten pulmonalarteriellen Druck in die elterliche Betreuung entlassen wurde. Vier Wochen später verstarb das Kind bei akuter Verschlechterung der PAH und Rechtsherzinsuffizienz. Eine deutliche Laktaterhöhung führte zur Verdachtsdiagnose Mitochondriopathie. In der Muskelbiopsie zeigte sich eine deutliche Verminderung der Atmungskettenkomplexe I-IV und der Pyruvatdehydrogenase (PDH), vereinbar mit einem multiplen mitochondrialen Dysfunktionssyndrom (MMDS). Die Liponsäure-Färbung war bei den E2 Untereinheiten von PDH und Ketoglutaratdehydrogenase vermindert. Die Analyse des NFU1-Gens identifizierte zwei heterozygote Mutationen. NFU1 kodiert für ein mitochondrial lokalisiertes Protein, das an der Biogenese der Eisen-Schwefel-Cluster (FeS-Cluster) beteiligt ist. FeS-Cluster sind unter anderem Kofaktoren für die Assemblierung der Atmungskettenkomplexe I-III und notwendig für Liponsäuresynthese (PDHKofaktor). Bis Mai 2013 haben wir bei fünf weiteren Patienten aus drei Familien homozygote bzw. compound heterozygote NFU1-Mutationen identifiziert. Ihnen waren klinisch gemeinsam ein frühes Erkrankungsalter, ein rasch progredienter Verlauf mit fatalem Ausgang und die primäre Manifestation mit muskulärer Hypotonie, Gedeihstörung und Apnoen. Bei drei der vier Familien manifestierte sich das MMDS mit einer PAH.

Schlussfolgerung. Unsere Ergebnisse bestätigen bisherige Erkenntnisse, dass die PAH eine häufige Manifestation der NFU1-assoziierten MMDS ist. Umgekehrt sind Mutationen in NFU1 möglicherweise eine häufige Ursache einer PAH im Säuglingsalter.

\section{Samstag, 14.09.2013}

\section{Kinderschutz und Lehre}

DGKJ-PO-LW-1

Der Brandenburger Leitfaden zur Früherkennung von Gewalt bei Kindern und Jugendlichen

Ellsäßer G. ${ }^{\prime}$, Lang A. ${ }^{\text {}}$

'Landesamt für Umwelt, Gesundheit und Verbraucherschutz, Gesundheit, Zossen

Hintergrund. Seit dem Jahr 2003 unterstützt der Leitfaden das Erkennen von Gewalt, das Fallmanagement und besonders auch die interdisziplinäre Zusammenarbeit. Die Weiterentwicklung des Leitfadens ist eines der Ziele der Arbeitsgruppe Unfall- und Gewaltprävention im Bündnis Gesund Aufwachsen des Landes Brandenburg. Im Vortrag werden sowohl die inhaltlichen Schwerpunkte des Leitfadens vorgestellt als auch die Beweggründe für maßgebliche Veränderungen im Laufe der Zeit deutlich gemacht (derzeit 4. Auflage).

Zielgruppe und Inhalte. Die Zielgruppe der Kinderärzt/innen wurde unter Einbeziehung der Hebammen, dem Kinder- und Jugendgesundheitsdienst (2007) sowie dem zahnärztlichen Dienst im Gesundheitsamt und der Jugendhilfe auf Akteure im Bereich der Frühen Hilfen (2013) erweitert. Ziel ist einerseits, die Ressourcen dieser Akteure im Rahmen des Kinderschutzes vorzustellen, Schnittstellen zu anderen Berufsgruppen - explizit zur Jugendhilfe - darzustellen und somit die Zusammenarbeit zu fördern und andererseits auch die Kooperation mit der Jugendhilfe zu verbessern. Die rechtlichen Rahmenbedingungen für die Kooperation zwischen Gesundheitswesen und Jugendhilfe wurden gemäß dem neuen Bundeskinderschutzgesetz aktualisiert. Ein weiterer Schwerpunkt wurde auf die präventiven und familienunterstützenden Hilfesysteme im Land Brandenburg gelegt.

Nutzen für die Praxis. Die Evaluation des ersten Leitfadens im Jahr 2003 konnte zeigen, dass dieser der kinderärztlichen Praxis nützliche Informationen zum Vorgehen bei Kinderschutzfällen zur Verfügung stellt (Ellsäßer \& Carteuser 2006). Mit der Einbeziehung der fachlichen Expertise der verschiedenen Akteure, diente der Leitfaden als eine wichtige Grundlage für die sich im Land Brandenburg gründenden Arbeitsgemeinschaften für den Kinderschutz.

\section{DGKJ-PO-LW-2}

Die Leitfäden der Bundesländer zur Früherkennung von Gewalt gegen Kinder und Jugendliche - ein systematischer Vergleich

Lang A.S.', Ellsäßer G. ${ }^{1}$

'Landesamt für Umwelt, Gesundheit und Verbraucherschutz, Gesundheit, Zossen

Hintergrund. Um bei Gewalt gegen Kinder und Jugendliche frühzeitig eingreifen zu können, wurden in enger Zusammenarbeit der Landesverbände der Kinder- und Jugendärzt/innen und der Techniker Krankenkasse Leitfäden zur Früherkennung von Gewalt für die kinderärztliche Praxis auf Länderebene entwickelt. Inzwischen sind überarbeitete Auflagen entstanden, die angesichts eines veränderten Problembewusstseins verstärkt berufsübergreifende Ansätze beinhalten.

Zielsetzung. Strukturierter Vergleich der Leitfäden, um Standards und Beispiele guter Praxis zu identifizieren

Methode. Leitfäden von 15 Bundesländern werden anhand von Inhalt, Struktur und Nutzerkreis verglichen und in einem zweiten Schritt der Nutzen für die jeweiligen Akteure der Frühen Hilfen bewertet.

Ergebnisse. In fast allen Leitfäden wurden zunächst die verschiedenen Formen von Gewalt definiert und in einem anschließenden Kernteil das diagnostische Vorgehen und das Fallmanagement dargestellt. Große Unterschiede konnten bezogen auf die Adressat/innen und den 
Praxisbezug festgestellt werden. Die Beispiele guter Praxis unter den Leitfäden zeichnen sich durch eine hohe Anschaulichkeit (Nutzen von exemplarischen Fällen) und einen kooperationsorientierten Ansatz aus. Schlussfolgerung. Die Systematisierung und Optimierung von Leitfäden eröffnet neue Potenziale für ein frühes und professionelles Erkennen von Gewalt.

\section{DGKJ-PO-LW-3}

Die Stärkung der gesundheitlichen Vorsorge im Rahmen des bayerischen Gesamtkonzepts zum Kinderschutz - Daten aus der Schuleingangsuntersuchung zum Schuljahr 2011/12

Morlock G. ', Hölscher G. ', Nennstiel-Ratzel U.'

'Bayerisches Landesamt für Gesundheit und Lebensmittelsicherheit, Oberschleißheim

Einleitung. Die frühzeitige Förderung einer guten und gesunden Entwicklung von Kindern und Jugendlichen sowie der effektive Schutz des Kindeswohls stehen im bayerischen Gesamtkonzept zum Kinderschutz im Mittelpunkt. Dieses Konzept verfolgt einen wichtigen präventiven Ansatz zur Stärkung der Elternkompetenz. In Verdachtsfällen von Kindeswohlgefährdung greifen Hilfe- und Interventionsprozesse. Wichtig hierbei ist die enge Zusammenarbeit aller im Bereich der Kindervorund -fürsorge tätigen Einrichtungen.

Methoden. Früherkennungsuntersuchungen sind präventive Leistungen des Gesundheitssystems. Sie bieten neben der Früherkennung von Erkrankungen und Entwicklungsverzögerungen die Möglichkeit, Verdachtsfälle von Gefährdung zu identifizieren. Seit Einführung des Artikels 14 Gesundheitsdienst- und Verbraucherschutzgesetz ist die Teilnahme an den Früherkennungsuntersuchungen in Bayern Pflicht; ein Trackingsystem existiert jedoch nicht. Dafür ist der Nachweis der U6 und $U_{7}$ Voraussetzung zum Erhalt des Landeserziehungsgeldes. Bei der Anmeldung in einer Kindertageseinrichtung ist die Teilnahme an der U7a und U8, bei der Schuleingangsuntersuchung die durchgeführte U9 nachzuweisen. Fehlt letztere, ist eine schulärztliche Untersuchung verpflichtend. Nimmt ein Kind nicht an einer schulärztlichen Untersuchung teil, wird das Jugendamt darüber informiert.

Schlussfolgerung. Die Daten der Schuleingangsuntersuchung zum Schuljahr 2011/12 belegen die hohe Akzeptanz dieser Untersuchungen in der Bevölkerung (ca. 98\% U1-U4 ; ca. 97\% U5-U6; ca. 96\% U7 und U9; ca. 94\% U8 - bezogen auf Kinder mit vorgelegtem Vorsorgeheft). Hohe Teilnahmeraten an den U-Untersuchungen lassen sich durch ein differenziertes Gesamtkonzept erzielen, auch ohne Tracking.

\section{DGKJ-PO-LW-4}

\section{Die Kinderschutzgruppe Neuss (KSGN) - Management am Lukas-} krankenhaus Neuss

\section{Schroers E.M. ${ }^{1}$, Wendt V. ${ }^{2}$, Jansen-Wetzels G. ', Hoheisel R. ${ }^{3}$, Engelmann G. 'Lukaskrankenhaus Neuss, Kinderklinik, Neuss, ${ }^{2}$ Johanniter Unfallhilfe, Neuss, ${ }^{3}$ Helios Kliniken Krefeld, Kinderklinik, Krefeld}

Einleitung. Kinderschutz ist ein Thema, das grundsätzlich alle betrifft, die beruflich mit Kindern zu tun haben. Am 01. Januar 2012 ist das neue Bundeskinderschutzgesetz in Kraft getreten. Mitarbeiter im Kinder- und Jugendgesundheitsdienst sind besonders gefordert Risiken zu erkennen und rechtzeitig zu intervenieren. Hierbei ist die Vernetzung der verschiedenen medizinischen Fachbereiche, des psychosozialen Dienstes, der Jugendämter sowie der Polizei von besonderer Bedeutung. Methoden. Um diesen Anforderungen gerecht zu werden, wurde am Lukaskrankenhaus Neuss eine Kinderschutzgruppe gegründet, deren Konzept wir hier gerne vorstellen möchten. Die Kinderschutzgruppe hat für unser Haus verbindliche Abläufe erarbeitet, welche das Vorgehen vereinheitlichen sollen, um insbesondere forensische Fehler zu vermeiden. Das Konzept ist so gefasst, dass es auch bei Fällen sexueller Gewalt bei Erwachsenen in unserer Zentralambulanz Anwendung fin- den kann. Eine für das gesamte Krankenhaus zur Verfügung stehende Akutbox mit den für die Gerichtsmedizin erforderlichen Utensilien wurde entwickelt.

Schlussfolgerung. Im Rahmen einer Fachtagung wurden die neuen Standards mit Vertretern der Sozialämtern, der Polizei und der Jugendämter diskutiert und abgestimmt. Wir glauben, dass unser Konzept gut geeignet ist, an einem Krankenhaus mit 580 Betten den Erfordernissen der neuen Gesetzgebung Rechnung zutragen.

\section{DGKJ-PO-LW-5 \\ Die Zirkumzisionsdebatte nach Verabschiedung des Beschnei- dungsgesetzes}

\section{Schreiber M. ${ }^{\prime}$}

${ }^{1}$ Klinikum Esslingen, Kinderchirurgie, Esslingen

Einleitung. Im Mai 2012 wurde durch ein Urteil des Landgerichts Köln die sogenannte "deutsche Beschneidungsdebatte" angestoßen. Das im Dezember 2012 vom Deutschen Bundestag verabschiedete Gesetz1 besagt, dass medizinisch nicht erforderliche Beschneidungen von nicht einsichts- und urteilsfähigen männlichen Kindern zulässig sein sollen, wenn die Eingriffe nach den Regeln der ärztlichen Kunst erfolgen. Knaben in den ersten sechs Lebensmonaten dürfen auch von Angehörigen einer Religionsgemeinschaft beschnitten werden, ohne Arzt zu sein, wenn sie für das kulturelle Ritual besonders ausgebildet wurden.

Material und Methode. Durch Befragung des Zentralrats der Juden, des Zentralrats der Muslime und der Kinderbeauftragten des Deutschen Bundestages, und auch nach aktiver Teilnahme als geladener Experte an Sitzungen von Unterausschüssen des Europarats zu diesem Thema soll die aktuelle Situation dargestellt und eine Prognose für die Zukunft erarbeitet werden.

Ergebnisse. Die Beschneidungsdebatte hat mit dem erlassenen Gesetz noch zu keinem Ende gefunden. Im Gegenteil, sie wird nun in allen europäischen Ländern und darüber hinaus weitergeführt.

Schlussfolgerung. Um ein umfassendes Verständnis des Grundrechtskonfliktes der rituellen Beschneidung minderjähriger Kinder zu erhalten, ist eine grundlegende Erörterung und ein echtes gegenseitiges Verständnis notwendig: zwischen den Eltern, Religionsvertretern, erwachsenen Betroffenen, Medizinern, Juristen, Ethikern, Psychoanalytiker und Politikern. Höchstes Ziel aller Überlegungen ist und bleibt, das Kindeswohl zu schützen.

Literatur

1. § 1631 d, Beschneidung des männlichen Kindes, Bürgerliches Gesetzbuch

\section{DGKJ-PO-LW-6}

Evaluation des Lernerfolgs von Medizinstudenten nach unterschiedlichen Lehrmethoden anhand eines OSCE unter Verwendung von detaillierten Checklisten nach Zusammenfassung der Lehrinhalte der Leitlinien zur Erstversorgung von Neugeborenen

Reus E. ', Volk T.', GrafN. ${ }^{2}$, Gortner L. ${ }^{3}$, Tutdibi E. ${ }^{3}$

'Universitätsklinikum des Saarlandes, Klinik für Anästhesie, Intensivmedizin und Schmerztherapie, Homburg, ${ }^{2}$ Universitätsklinikum des Saarlandes, Klinik für Pädiatrische Onkologie und Hämatologie, Homburg, ${ }^{3}$ Universitätsklinikum des Saarlandes, Klinik für Allgemeine Pädiatrie und Neonatologie, Homburg

Einleitung. Die Leitlinien des ERC 2010 beinhalten in Sektion 7 die Erstversorgung von Neugeborenen. Um Leitlinien zu unterrichten und den Lernerfolg zu messen gibt es unterschiedliche Lehr-, Lern- und Prüfungsmodelle. Im Bereich der Notfallmedizin stehen zur Lehre und Überprüfung von Lerninhalten moderne Patientensimulatoren in speziell eingerichteten Simulationszentren bereit. Vermittlung der theoretischen und praktischen Fertigkeiten finden hierbei oft nach Peyton's Four-Step Approch statt. Die Lernerfolgskontrolle kann dabei mittels OSCE erfolgen. In der folgenden Studie wurde die Umwandlung der 
Lehrinhalte der Leitlinien in detaillierte Checklisten für einen OSCE und der Evaluation des Lernerfolgs von Medizinstudenten nach unterschiedlichen Lehrmethoden untersucht.

Material und Methoden. Insgesamt 49 freiwillige Studierende der $\mathrm{Hu}-$ manmedizin wurden randomisiert in zwei Gruppen $\left(\mathrm{G}_{1}, \mathrm{G}_{2}\right)$ aufgeteilt. Unterweisung der Lehrinhalte in Kleingruppen zu vier Personen. G1 erhielt eine Unterweisung in die aktuellen ERC Leitlinien 2010 Sektion 7 in Form des Frontalunterrichts. In G2 wurde als Lehrmethodik Peyton's Four-Step Approach verwendet. Beide Gruppen durchliefen nach 3 Tagen einen OSCE anhand detaillierter Checklisten, mit je 2 möglichen Punkten (P) pro Einzellösung. Im praktischen Teil des OSCE (pOSCE) waren $118 \mathrm{P}$ zu erreichen und im theoretischen Teil (tOSCE) 74 P. Daten als Mittelwerte \pm Standardabweichung, statistische Unterschiede mit $\mathrm{p}<0,05$.

Ergebnisse. Signifikante Unterschiede G2vsG1 pOSCE (113 $\mathrm{P} \pm 4,7$ vs. 67,6 $\mathrm{P} \pm 23,2)$; tOSCE (66,2 $\mathrm{P} \pm 4,7$ vs. 40,2 $\mathrm{P} \pm 22,6)$.

Schlussfolgerung. Die Kombination aus Peyton's Four-Step Approach und OSCE an Simulatoren anhand detaillierter Checklisten sind ein gutes Mittel, um den Lernerfolg von Medizinstudenten signifikant zu verbessern

\section{Pneumologie}

\section{DGKJ-PO-P-1}

\section{Atemwegsdehydratation erhöht im Mausmodell das Risiko für} allergische Atemwegsentzündung

\section{Fritzsching B. ${ }^{1,2}$, Dai L. ${ }^{2}$, van Bodegom C. ${ }^{2}$, Schatterny J. ${ }^{2}$, Hirtz S. ${ }^{2}$, Zhou Z. ${ }^{2}$, Mall M.A. ${ }^{1,2}$}

'Universitätsklinikum Heidelberg, Zentrum für Kinder- und Jugendmedizin, Sektion Pädiatrische Pneumologie, Allergologie und Mukoviszidose Zentrum, Klinik III, Heidelberg, '2Universität Heidelberg, Zentrum für Translationale Lungenforschung, Mitglied im Deutschen Zentrum für Lungenforschung (DZL), Abteilung Translationale Pneumologie, Heidelberg

Fragestellung. Unsere Vorarbeiten an Mäusen mit atemwegsspezifischer Überexpression des epithelialen $\mathrm{Na}+$-Kanals $(\beta \mathrm{ENaC}-\mathrm{Tg})$ und Mäusen mit Deletion des Cl--Kanals SCL26A9 deuten darauf hin, dass die Atemwegsdehydratation durch gestörten Ionentransport möglicherweise eine bedeutsame Rolle in der Pathogenese der allergischen Atemwegsentzündung spielt (Anagnostopoulou et al., J Clin Invest 2012). Diese Hypothese wurde in der vorliegenden Arbeit weiter untersucht.

Material und Methode. Durch intratracheale Sensibilisierung mit Aspergillus fumigatus Extrakt induzierten wir in $\beta \mathrm{ENaC}-\mathrm{Tg}$-Mäusen eine allergische Atemwegsentzündung und führten Lungenfunktionsuntersuchungen mit Metacholinprovokation, zytologische Analysen der BAL und morphologische Untersuchungen durch. Per 11-Farben FACS-Analyse charakterisierten wir die pulmonale Immunantwort.

Ergebnisse. $\beta \mathrm{ENaC}$-Tg-Mäuse mit Atemwegsdehydration wiesen eine signifikante Atemwegshyperreagibilität (AHR) auf. Nach Allergenexposition zeigte sich eine verstärkte eosinophile Entzündung mit gesteigerter pulmonaler IL-13-Expression und gesteigerter AHR. In der FACS-Analyse prouduzierten Th2-Zellen, kürzlich entdeckte ILC-2Zellen und Atemwegsepithelzellen signifikante Mengen an IL-13. Um die Relevanz dieser Beobachtung weiter zu überprüfen, inhibierten wir den IL-13-Signalweg durch Deletion des STAT6-Gens in vivo. Tatsächlich wiesen STAT6-/- $\beta \mathrm{ENaC}$-Tg Mäuse keine eosinophile Atemwegsentzündung nach Allergenexposition auf.

Schlussfolgerung. Atemwegsehydration und gestörte mukoziliäre Clearance sind im Mausmodell Risikofaktoren für die Entstehung einer allergischen Atemwegsentzündung.

Gefördert durch: DFG MA 2081/3-2 und DZL82DZLoo401.

\section{DGKJ-PO-P-2}

Konservatives Management einer bilateralen Tracheallazeration durch akzidentelle Messerstichverletzung bei einem 14-Jährigen

Steindor M.', WulfD. ', Delißen J.', Schuster A. ', Santos M. ${ }^{2}$, Angenendt S. ${ }^{3}$, Schramm D. ${ }^{\prime}$

'Universitätsklinikum Düsseldorf, Klinik für Allgemeine Pädiatrie, Neonatologie und Kinderkardiologie, Düsseldorf, ${ }^{2}$ Universitätsklinikum Düsseldorf, Klinik für Allgemein-, Viszeral- und Kinderchirurgie, Funktionsbereich Kinderchirurgie, Düsseldorf, ${ }^{3}$ Universitätsklinikum Düsseldorf, Klinik für Allgemein-, Viszeral- und Kinderchirurgie, Funktionsbereich Thoraxchirurgie, Düsseldorf

Einleitung. In der Literatur wird die Frage nach konservativem vs. chirurgischem Vorgehen bei Tracheallazerationen kontrovers diskutiert. Fallbericht. Wir berichten über einen 14 Jahre alten Patienten mit akzidenteller Messerstichverletzung mit Klingeneintritt zervikal links, Stichkanal ca. $10 \mathrm{~cm}$. Initial bestand ein linksseitiges Halsemphysem. Die Erstversorgung mit Entfernung des Messers im OP, Tracheoskopie und lokaler Wundversorgung mit Lascheneinlage erlaubte den Ausschluss relevanter Nerven- oder Gefäßverletzungen. Aufgrund eines Pneumothorax rechts sowie eines mäßigen Pneumoperikards erfolgte die Versorgung mittels Pigtail-Drainage. Weiterhin wurde der Patient invasiv über einen distal der Lazeration gecufften Trachealtubus beatmet und intravenös antibiotisch therapiert. Eine Tracheoskopie an Tag 3 und ein Thorax-CT an Tag 4 zeigten eine den rechtsseitigen Pneumothorax unterhaltende persistierende Luftleckage der rechtsseitigen Tracheallazeration bei verschlossenem Defekt links. Eine sich im Verlauf entwickelnde Mediastinitis mit CRP-Anstieg wurde durch Eskalation der antibiotischen Therapie erfolgreich behandelt. An Tag 7 erfolgten eine thorakoskopisch gestützte Pleuraschwarten-Dekortikation und die gezielte Anlage zweier rechtsseitiger Thoraxdrainagen. Daraufhin zeigte sich der Pneumothorax deutlich rückläufig, tracheoskopisch war keine Luftleckage der Tracheallazerationen mehr nachweisbar, so dass der Patient nach 7 Tagen am Respirator extubiert werden konnte und im Verlauf eine stabile Restitutio erreichte.

Schlussfolgerung. Unser Fallbericht zeigt, dass ein konservatives Vorgehen bei traumatischen Tracheallazerationen mittels distal der Lazeration gecufftem Tubus und längerfristiger kontrollierter Beatmung möglich ist und für die Behandlung betroffener Patienten in Betracht gezogen werden sollte.

\section{DGKJ-PO-P-3}

Verkannte Fremdkörperaspiration als Ursache chronischen Hustens

Wulf D. ', Steindor M. ', Delißen J.', Schuster A. ', Schramm D. ${ }^{1}$

'Universitätskinderklinikum Düsseldorf, Klinik für Allgemeine Pädiatrie, Neonatologie und Kinderkardiologie, Düsseldorf

Einleitung. Chronischer Husten ist ein häufiger Vorstellungsgrund in der Kinderklinik. Ein unbeobachtetes Aspirationsereignis kann klinisch oft nicht von einem hyperreagiblen Bronchialsystem unterschieden werden.

Fallbericht. Ein vier Jahre alter Junge präsentierte sich mit seit zwei Jahren bestehendem chronisch-produktivem Husten, mit Zunahme der Symptomatik nachts, bei körperlicher Belastung und während der Pollenflugzeit. Mit der Diagnose einer bronchialen Hyperreagibilität erfolgte eine bedarfsorientierte Therapie mit Salbutamol und Montelukast. Dies führte nur passager zur Besserung der Symptomatik. Ein mögliches Aspirationsereignis zu Beginn der Symptomatik war den Eltern nicht erinnerlich. Auf eine weiterführende kinderpneumologische Diagnostik wurde verzichtet.

Ergebnisse. Bei Vorstellung unauffällige Lungenauskultation. Im Röntgen-Thorax zeigte sich überraschend der Befund einer aspirierten $\mathrm{Ku}$ gelschreiberfeder im linken Hauptbronchus. Retrospektiv habe der Junge zwei Jahre zuvor mit einem Kugelschreiber gespielt, bei dem anschließend Einzelteile fehlten. Es erfolgte die komplikationslose Entfer- 
nung der Feder mittels starrer Bronchoskopie. Abschließend zeigte sich Granulationsgewebe im Bereich des Fremdkörperbettes, welches den linken Hauptbronchus zu 50\% stenosierte. In der Kontrolle zögerliche Rückbildung des Granulationsgewebes unter Maßnahmen zur Verbesserung der mukoziliären Clearance. Seit Entfernung des Fremdkörpers wurden keine bronchialen Beschwerden mehr beobachtet.

Schlussfolgerung. Die Fremdkörperaspiration stellt eine relevante Differenzialdiagnose bei Kindern mit chronischem Husten dar. Die genaue Hustenanamnese kann entscheidende Hinweise zur Diagnose liefern. Bei mangelndem Ansprechen auf die Therapie sollte die Diagnose überprüft werden.

\section{DGKJ-PO-P-4}

Diagnostische Unterstützung bei Kindern mit Husten: Der Einsatz von Fragebögen und Computern hilft, auch seltene Lungenerkrankungen besser zu erkennen

Rother A.-K. ${ }^{1}$, Brinkmann F. ${ }^{2}$, Schwerk N. ${ }^{2}$, Klawonn F. ${ }^{3}$, Lechner W. ${ }^{4}$, Grigull L. 'Medizinische Hochschule Hannover, Pädiatrische Hämatologie und Onkologie, Hannover, ${ }^{2}$ Medizinische Hochschule Hannover, Pädiatrische Pneumonologie, Hannover, ${ }^{3}$ Helmholtz-Zentrum für Infektionsforschung, Braunschweig, ${ }^{4}$ IMD (Improved Medical Diagnostics) Pte Ltd, Singapore, Singapur

Fragestellung. Kindliche Lungenerkrankungen können eine diagnostische Herausforderung sein. Wir erfragten elterliche Beobachtungen, um den Weg zur Diagnose computerbasiert zu unterstützen.

Material und Methoden. 16 offene Interviews wurden mit Eltern durchgeführt, deren Kinder an cystischer Fibrose $(C F, n=3)$, Asthma $(n=3)$, primärer ciliärer Dyskinesie $(\mathrm{PCD}, \mathrm{n}=3)$, Pneumonie $(\mathrm{n}=3)$, akuter Bronchitis $(\mathrm{n}=2)$ oder persistierender bakterieller Bronchitis $(\mathrm{PBB}, \mathrm{n}=2)$ erkrankt waren. Die Interviews wurden digital aufgenommen, verschriftlicht und systematisch ausgewertet. Aus den Interviews entwickelten wir einen Fragebogen (FB) bestehend aus 45 Fragen. Insgesamt wurde der FB dann von 141 Eltern eines Kindes mit pulmonologischer Erkrankung und 24 Eltern eines gesunden Kindes beantwortet. Mit diesem Datensatz trainierte ein spezifisches Computer-Programm, um unterschiedliche Antwortmuster der verschiedenen Diagnosegruppen durch Data Mining Verfahren zu unterscheiden.

Ergebnisse. Die diagnostische Treffsicherheit des Computers schwankte je nach vorliegender Datenmenge. Gesunde Kinder wurden zu 95\% erkannt, das Antwortmuster von Kindern mit einer PCD wurde mit einer Sicherheit von $93 \%$ erkannt. Kinder mit CF konnte der Computer mit 86\%iger und Asthma-Patienten mit 94\%iger Sicherheit erkennen.

Diskussion und Schlussfolgerung. Wir konnten zeigen, dass die diagnostische Unterstützung pulmonologischer Erkrankungen durch Fragen und Data-Mining-Anwendungen möglich ist. Die diagnostische Zuverlässigkeit war abhängig von der Größe des Datensatzes, mit dem der Computer trainiert hatte. Auch seltene Erkrankungen wie PCD waren anhand der Antwortmuster erkennbar. Dieses Potenzial einer Computer-gestützten Diagnostik wäre zur Verkürzung der diagnostischen Latenz seltener Erkrankungen nutzbar.

\section{DGKJ-PO-P-5}

Angeborene Störungen der Lungen und Atemwege - Übersicht der Krankheitsfälle der Kinderklinik Erlangen aus den Jahren 2000 bis 2011

\section{Meyer S.'}

'Friedrich Alexander Universität Erlangen, Erlangen

Einleitung. Kongenitale Lungen- und Atemwegsfehlbildungen können durch die heutigen diagnostischen und therapeutischen Möglichkeiten zunehmend früher diagnostiziert und therapiert werden.

Fallberichte. Es wird über Kinder mit angeborenen Lungen- bzw. Atemwegsfehlbildungen aus den Jahren 2000 bis 2011 berichtet und auf die mit der Krankheit einhergehende Symptomatik, die diagnostischen und therapeutischen Maßnahmen und assoziierte Missbildungen eingegangen. Die Analyse erfolgte retrospektiv anhand der Krankenakten von Kindern, die im Zeitraum 01.01.200o bis 15.4.2011 an der Kinderklinik Erlangen stationär bzw. teilstationär aufgrund einer Lungen- bzw. Atemwegsfehlbildung therapiert wurden. Die Auswahl der Patienten erfolgte nach den jeweiligen ICD-Codierungen.

Methoden. Es wurden 121 Kinder aufgrund einer Lungen- bzw. Atemwegsfehlbildung in Erlangen therapiert. 68,6\% der Kinder waren männlich und $31,45 \%$ weiblich. Folgende Fehlbildungen werden näher beschrieben: Lungenhypoplasie $(n=36)$, Tracheomalazie $(n=26)$, Trachealstenose $(n=21)$, Atelektasen $(n=21), A V-F i s t e l n(n=15)$, Lungensequester $(n=14)$, Lungenzysten $(n=12)$, Chylothorax $(n=8)$, Bronchomalazie $(n=6)$, Trachealbronchus $(n=6)$, Lappungsanomalien $(n=3)$, H-Fistel $(n=3), \operatorname{PCD}(n=3)$, alveolokapilläre Dysplasie $(n=2)$, Bronchusstenose $(n=2)$, Lungenagenesie $(n=1)$, Wilson-Mikity-Syndrom $(n=1)$, hepatopulmonale Fusion $(n=1)$, Surfactant-Protein C-Defizienz $(n=1)$, Bronchiektasie $(\mathrm{n}=1)$, Williams-Campbell-Syndrom $(\mathrm{n}=1)$.

Ergebnisse. Bei ca. 85\% der 121 Patienten waren die Anomalien mit weiteren Fehlbildungen, wie angeborenen Herzfehlern, assoziiert. 23.1\% der beschriebenen Kinder litten an mehr als einer Lungenfehlbildung. Schlussfolgerung. Die diagnostischen und therapeutischen Maßnahmen werden beschrieben. Eine interdisziplinäre Zusammenarbeit ist für einen guten Outcome der Patienten erforderlich.

\section{DGKJ-PO-P-6 \\ Persistierendes pulmonales Infiltrat bei einem 8 Wochen alten Säugling - differenzialdiagnostisch betrachtet}

Sulistyo J., Korsch E. ${ }^{,}$, Kellner M. ${ }^{2}$, Weiß M. ${ }^{\text {' }}$

${ }^{1}$ Kliniken der Stadt Köln, Kinder- und Jugendmedizin, Köln, ${ }^{2}$ Kliniken der Stadt Köln, Kinderradiologie, Köln

Einleitung. MPS II ist eine seltene X-chromosomal vererbte lysosomale Speichererkrankung mit Multisystembeteiligung. Zugrunde liegt ein Mangel oder Fehlen des lysosomalen Enzyms Iduronat-2-Sulfatase, welches am Abbau von Mukopolysacchariden beteiligt ist. Die kardiale Beteiligung nimmt wegen der frühen Morbidität und Mortalität der Patienten eine wichtige Rolle ein.

Methoden. Von den 61 in Mainz untersuchten Hunter Patienten weisen $85 \%$ eine kardiovaskuläre Beteiligung auf. Die häufigste Manifestation mit bis zu 67\% der Patienten ist eine Klappeninsuffizienz mit Überrepräsentation der linksventrikulären Klappen. Eine milde - moderate Kardiomyopathie zeigen $57 \%$ des Kollektivs. Nur $26 \%$ der Patienten haben eine normale Ventrikelkonfiguration, fast die Hälfte zeigt Merkmale einer konzentrischen Hypertrophie. Im Gegensatz dazu haben 97\% der Patienten eine gut erhaltene systolische Funktion, nur ein Patient zeigt Merkmale einer schweren Kardiomyopathie. Bis zur Einführung der Enzymersatztherapie waren alle Behandlungen rein symptomatisch.

Ergebnisse. Seit 2007 ist das Enzym Elaprase ${ }^{\circ}$, der Firma Shire auf dem Markt und ermöglicht eine kausale Therapie. Über fünf Jahre wurden 35 Patienten unter Enzymersatztherapie kardiologisch Betreut. Die ERT scheint die Progression einer Klappeninsuffizienz aufzuhalten. Bei über $80 \%$ der Patienten bleibt diese stabil. Auch ein Rückgang der Kardiomyopathie lässt sich beobachten. Von anfangs $63 \%$ zeigen nach 3 Jahren ERT nur noch $41 \%$ der Patienten eine vergrößerte linksventrikuläre Muskelmasse.

Schlussfolgerung. Von dem Mainzer Hunter Patienten-Kollektiv weisen $85 \%$ eine kardiale Beteiligung auf und es konnte gezeigt werden, dass wöchentliche Enzymgaben einen positiven Einfluss auf die kardiale Beteiligung haben. 


\section{DGKJ-PO-P-7}

\section{Einfluss von Östrogen auf Exazerbationen bei cystischer Fibrose -} ein Therapieversuch

\section{Strohschein A.', C. Körner-Rettberg, N. Teig, E. Hamelmann, M. Ballmann ${ }^{1}$ Ruhr-Universität Bochum, St. Josef Hospital, Klinik für Kinder- und Jugend- medizin, imBochum}

Einleitung. Bei Patienten mit cystischer Fibrose (CF) sind deutliche Geschlechtsunterschiede bekannt: Frauen sind im Vergleich zu Männern früher mit Pseudomonas aeruginosa besiedelt und leiden unter einer häufigeren, frühzeitigeren Umwandlung in mukoide, virulentere Stämme. Weibliche Patienten haben eine schlechtere Lungenfunktion und schlechtere Überlebensraten. Als eine Ursache für diese Unterschiede wird der Einfluss von Östrogen vermutet (NEJM, Mai 2012 „Effect of estrogen on pseudomonas mucoidy and exacerbations in cystic fibrosis"). So konnte eine Korrelation zwischen der Höhe der Östrogenspiegel und Infektexazerbationen nachgewiesen werden. Unter dem Einfluss von Östrogen kommt es zu einer rascheren Umwandlung in mukoide Stämme, wahrscheinlich als Folge einer vermehrten Alginatproduktion. Frauen mit einem oralen Kontrazeptivum litten unter weniger Exazerbationen und benötigten weniger antibiotische Therapien. Fallbericht. Eine an unserer Klinik betreute 15-jährige Patientin mit CF und chronischer Pseudomonasbesiedlung berichtete regelmäßig von zyklusabhängigen deutlichen Verschlechterungen des Allgemeinzustandes mit schwerem Krankheitsgefühl bis Bettlägerigkeit während der Menstruation. Wir starteten einen Therapieversuch mit einem Östrogen/Gestagen-Kombinationspräparat. Hierunter kam es nur subjektiv zu einer klinischen Verbesserung. Mit Unterdrückung der Menstruation sistierten die Beschwerden, jedoch ohne erkennbare pulmonale Verbesserung (FEV1 schwankend zwischen $54-64 \%$ / Juni bis November 2012). Auch der Wechsel des Präparats blieb ohne weiteren Erfolg. Der Therapieansatz, den Östrogeneinfluss auf Exazerbationen bei CF zu unterdrücken, bestätigte sich bei unserer Patientin nicht. Dieser wichtige Ansatz bedarf dringend der Klärung in prospektiven, randomisierten Studien.

\section{DGKJ-PO-P-8 \\ Erstdiagnose eines variablen Immundefektsyndroms (CVID) bei einem 16-jährigen Jugendlichen mit chronischer Sinusitis}

\section{Zeller L.T.', Notheis G. ${ }^{2}$, Rosenecker J.'}

${ }^{1}$ Alpenklinik Santa Maria, Bad Hindelang Oberjoch, ${ }^{2} \mathrm{v}$. Haunersches Kinderspital, Pädiatrische Immunologie, München

Fallbericht. Der 16-jährige Patient wurde im Rahmen einer Rehabilitation wegen seit ca. 8,5 Jahren bestehender, chronischer Sinusitis vorgestellt. Anamnestisch finden sich Infektionen der Nasennebenhöhlen, die einen chirurgischen Eingriff an den Nasennebenhöhlen im Alter von 15 Jahren notwendig machten. Über acht Jahre wurde der Patient mit topischen Steroiden behandelt. Bei Aufnahme standen rez. Rhinorrhoe, frontale Kopfschmerzen sowie retronasaler Schleimfluss im Vordergrund. Auffällig war die Wachstumsretardierung des Patienten (Gewicht <1. Perz., Körperlänge 9. Perz., KU 45. Perz.).

Ergebnisse. Die ausführliche Anamnese ergab im Kleinkindesalter häufige, langandauernde Durchfallepisoden ohne Keimnachweis mit Wachstumsretardierung, später rezidivierende Otitiden mit Paukenröhrcheneinlage im zweiten Lebensjahr. In der Labordiagnostik fiel dann das komplette Fehlen der gamma-Bande in der Serumeiweißelektrophorese auf. Die Immunglobuline waren deutlich erniedrigt [IgA $11 \mathrm{mg} / \mathrm{dl}$ (70-400), IgG<108 mg/dl (700-1600), IgM $9 \mathrm{mg} / \mathrm{dl}(22-240$, IgE nicht nachweisbar)]. Impfantikörper gegen Haem. infl. und Tetanus waren ebenso nicht nachweisbar. In der Lymphozytendifferenzierung ergab sich ein unauffälliger Befund. So wurde die Verdachtsdiagnose eines CVID gestellt, die später durch die immunologische Ambulanz der Uniklinik Mainz (Fr. PD Dr. Mannhardt) bestätigt wurde.
Schlussfolgerung. Der hier präsentierte Fall zeigt, dass bei CVID nicht nur Atemwegsinfektionen der tiefen Atemwege, sondern auch der oberen Atemwege (Nasennebenhöhlen) in Kombination mit Wachtsumsretardierung an eine immunologische Abklärung denken lassen sollten.

\section{DGKJ-PO-P-9}

Vier Lungenrundherde bei einer jugendlichen Leistungsturnerin

Delißen J.', Wulf D. ', Steindor M. ', Schramm D. ', Schuster A. ${ }^{1}$

'Universitätsklinikum Düsseldorf, Klinik für Allgemeine Pädiatrie, Neonatologie und Kinderkardiologie, Düsseldorf

Fragestellung. Jugendliche mit Thoraxschmerzen und pulmonalen Rundherden.

Patienten und Methoden. 16-jährige Leistungsturnerin ohne Vorerkrankungen. Thorakale Schmerzen, Gewichtsverlust, Nachtschweiß und „Leistungsknick“. CT Thorax: vier subpleurale granulomartige Rundherde. Probatorische antibiotische Therapie. Verlegung in unsere Klinik.

Ergebnisse. Diagnostik. CRP 1,6 mg/dl, BSG 25 mm/h, D-Dimere leicht erhöht. Unauffällig: Rheumatologische Diagnostik, Thrombophiliediagnostik, Tumormarker, Tuberkulosediagnostik, Rachenabstrich, EKG, Echokardiographie, Abdomensonographie, Lungenfunktion vor und nach Laufbelastung. Bronchoskopie makroskopisch unauffällig;

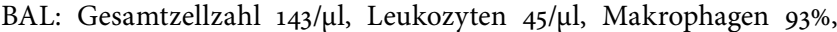
Lymphozyten $3 \%$, Neutrophile $4 \%$, CD $4 / C D 8$-Ratio 1,3. CT-gesteuerte Lungenbiopsie: fokal granulozytär überlagerte Nekrosen, chronisch fibrosierende Entzündung: Bronchiolitis obliterans-organisierende Pneumonie.

Schlussfolgerungen. Diagnose: Bronchiolitis obliterans mit organisierender Pneumonie (BOOP). Synonym: kryptogen organisierende Pneumonie (COP). Obwohl Lungenfunktion und BAL nicht wegweisend verändert, stellten wir bei vorliegendem Beschwerdebild, histopathologischem und radiologischem Befund (nach Ausschluss möglicher Auslöser wie Infektionen, rheumatologische Erkrankungen, EAA, eosinophile Lungenerkrankungen, Z. n. KMT oder Medikamentenwirkung) die Diagnose einer idiopathischen BOOP. Da Beschwerden rückläufig Entscheidung gegen die übliche mehrmonatige systemische Steroidtherapie. Nach drei Monaten: Beschwerdefreiheit, im MRT nur noch minimale Residuen nachweisbar.

Fazit. Bei Vorliegen von vier peripheren Lungenrundherden ohne weitere pathologische Befunde histopathologische Sicherung der Diagnose idiopathische BOOP. Gutartiger Verlauf mit Spontanremission.

\section{Infektiologie (2)}

\section{DGKJ-PO-J2-1}

Antibiotika-Verordnungen in einer Kinderklinik: Erfahrungen der Jahre 2009-2012

Kunze W. ${ }^{1}$, Gastmeier P. $^{2}$, Ratajczak K. ${ }^{1}$, Klemm T. ${ }^{3}$

${ }^{1}$ Muldentalkliniken, Krankenhaus Wurzen, Abteilung Kinder- und Jugendmedizin, Wurzen, ${ }^{2}$ Charité - Universitätsmedizin Berlin, Institut für Hygiene und Umweltmedizin, Berlin, ${ }^{3}$ MVZ Labor Dr. Reising-Ackermann und Kollegen, Leipzig

Hintergrund. Die Behandlung bakterieller Infektionen wird durch den Anstieg der Rate resistenter Erreger zunehmend erschwert. Um diesem Trend entgegen zu wirken wurde die Deutsche Antibiotika-Resistenzstrategie DART ins Leben gerufen. Untersuchungen erfolgten in einer Abteilung für Kinder- und Jugendmedizin. Die Studie hat zum Ziel, Antibiotika-Verordnungen zu erfassen, zu analysieren und bzgl. indikationsgerechter Verordnung zu bewerten.

Patienten und Methoden. Grundlage der Auswertung sind die Daten von 5849 Patienten, die in einem 4 -Jahres-Zeitraum stationär behan- 
delt wurden. Erfasst wurden Diagnose, Alter, Art des Antibiotikums. Die Bewertung erfolgte unter dem Aspekt einer indikationsgerechter Verordnung durch 2 externe Infektiologen und einen Mikrobiologen. Diagnostik. CRP, Leukozyten; mikrobiologische Befunde: Kultur (Blut, Liquor, Urin), PCR, Antikörper.

Ergebnisse. Von 5849 Patienten erhielten 595 (10,2\%) stationär ein Antibiotikum. Bei 85,9\% der Patienten kamen mikrobiologische Methoden zum Einsatz. Die PCR wurde mit 69,7\% am häufigsten angewandt, gefolgt von Urinkulturen mit 20,2\%. Diagnoserelevante Befunde wurden bei $65,6 \%$ erhoben mit Nachweis von Bakterien in $74,6 \%$, Viren in $25,4 \%$. Verordnete Antibiotika: Cephalo-sporine 66,4\%, Makrolide 15,8\%, Ampicillin (+BLI) $11,3 \%$, Penicillin $4,4 \%$, andere $2,1 \%$. Bei leitliniengerechter Prüfung der Indikation erwiesen sich 59,3\% als indiziert, 30,8\% als nicht, 9,9\% als bedingt indiziert. Bei 95,2\% nicht oder bedingt indizierten Verordnungen wurde die Therapie nach Vorliegen diagnostischer Befunde vorzeitig beendet.

Schlussfolgerungen. Die Rate nicht indizierter Verordnungen wird allgemein mit 30\% angegeben. Der hohe Einsatz bei Infektionen der oberen Atemwege ist zu beklagen. Weiterbildungen sind geboten.

\section{DGKJ-PO-J2-2}

Immunologischer Nachweis von Mycobakterium-abscessus-Infektionen bei Patienten mit cystischer Fibrose

Holz M.', Kohns M., Seyfarth J.', Nkwouano V.', Seibt A.', Steindor M.', Mayatepek E.', Schramm D. ', Jacobsen M.'

'Universitätsklinikum Düsseldorf, Klinik für Allgemeine Pädiatrie, Neonatologie und Kinderkardiologie, Düsseldorf

Einleitung. Patienten mit cystischer Fibrose (CF) leiden häufig unter Infektionen durch atypische Mycobakterien (u. a. M. abscessus, M. avium). Infektionen mit M. abscessus (Mab) bei CF-Patienten nehmen seit einiger Jahren zu, sind schlecht therapierbar und haben negative Auswirkungen auf den CF-Krankheitsverlauf. Immunologische Nachweismethoden für Infektionen mit Mab sind nicht verfügbar. Ziel dieser Pilotstudie war die Etablierung eines immunologischen Tests zur Detektion von Infektionen mit Mab bei Kindern mit CF.

Methoden. Insgesamt wurden 7 CF-Patienten rekrutiert. Ein Patient hatte zum Zeitpunkt der Untersuchung einen positiven Nachweis von Mab im Sputum und ein anderer Patient hatte Infektionen mit Mab in der Krankheitsgeschichte. Keiner der anderen Patienten war positiv für Mab getestet worden. Aufgrund der antimycobakteriellen Kreuzreaktionen wurden Vollblut In-vitro-Restimulationen gegen Proteingemische (PPD) von verschiedenen Mycobakterien [Mab (Abscessin), M. avium (Sensitin), M. tuberculosis (Tuberculin)] durchgeführt. Zytokine wurden intrazellulär und extrazellulär bestimmt.

Ergebnisse. Alle mycobakteriellen Antigene induzierten eine T-Zellzytokinantwort in den beiden CF Patienten mit akuter bzw. früherer Infektion mit Mab. Hierbei war die Reaktion auf Abscessin wesentlich stärker als gegen Sensitin und Tuberculin. Ein weiterer Patient zeigte eine positive Immunreaktion gegen mycobakterielle Antigene, wobei auch hier die Reaktion gegen Abscessin am stärksten war.

Schlussfolgerung. Die Ergebnisse dieser Pilotstudie legten nahe, dass eine immunologische Methode zum Nachweis einer akuten oder früheren Infektion mit Mab bei Patienten mit CF möglich ist und dass man durch den Vergleich zu Immunantworten gegen andere Mycobakterien zwischen spezifischen und kreuzreaktiven Testergebnissen unterscheiden kann.

\section{DGKJ-PO-J2-3}

Toxic-Shock-Syndrom (TSS) unter Therapie mit Tocilizumab bei einer 14-jährigen Patientin mit systemischer juveniler idiopathischer Arthritis

\section{Sonnenschein A. ', Kirchner M. ', Derichs U. ${ }^{1}$, Strothmann L. ${ }^{2}$, Mannhardt- Laakmann W. ${ }^{1}$ \\ 'Universitätsmedizin Mainz, Pädiatrische Rheumatologie und Immunolo- gie, Mainz, ${ }^{2}$ Unikinderklinik, Freiburg}

Fallbericht. Seit dem 9.Lebensmonat leidet die 14-jährige Patientin an einer systemischen juvenilen idiopathischen Arthritis (sJIA). Sie ist von rezidivierend auftretenden schweren Schüben betroffen, so dass verschiedene DMARDs, TNF-alpha-Blocker sowie der IL-1-Rez-Antagonist Anakinra über viele Jahre angewandt wurden. Zuletzt traten unter Anakinra zunehmend rezidivierende Infektionen auf, die eine Beendigung der Therapie erforderlich machten. Im Oktober 2011 wurde eine Therapie mit Tocilizumab (RoActemra $\left.{ }^{\circledR}\right)$, dem humanisierten, monoklonalen Anikörper gegen den Interleukin-6-Rezeptor, begonnen. Hierunter kam es zu einer raschen Remission. Nach 3 Monaten unter Tocilizumab erfolgte die akute stationäre Aufnahme der Patientin aufgrund von Kreislaufproblemen, Schüttelfrost, Hautabschälungen - kein Fieber. Seit 3 Tagen hatte die Patientin ihre Menstruation. Laborchemisch zeigte sich eine Leukozytose mit Linksverschiebung, CRP und BSG im Normbereich. Es entwickelte sich perakut das Vollbild eines toxischen Schocksyndroms (TSS) mit Nachweis von S. aureus im Vaginalabstrich. Die Therapie mit Tocilizumab wurde abgebrochen. Unter Therapie mit IL-6-Blockade wurde die klassische Entzündungsreaktion unterbunden (laborchemisch kein Anhalt für erhöhtes CRP) sowie klinische Symptome (Fieber) lange reduziert. IL-6 konnte retrospektiv massiv erhöht $(>10.000 \mathrm{pg} / \mathrm{ml})$ nachgewiesen werden.

Schlussfolgerung. Dieser Fall zeigt, dass eine Tocilizumab-Therapie (Anti-IL-6-Rezeptor) stets sehr engmaschig überwacht werden sollte. Aufgrund der IL-6-Antagonisierung wird die signalvermittelte IL-6Wirkung mit Ausbildung des Parameters CRP blockiert und Fieber als klinisches Symptom unterdrückt. Daher ist bei schweren Infektionen eine genaue Anamnese sowie ausführliche Untersuchung für die Diagnosefindung entscheidend.

\section{DGKJ-PO-J2-4}

\section{Schwere RSV-assoziierte Atemwegserkrankungen bei Kindern in} pädiatrischen Intensivstationen in Bayern

Benjamin R.', Streng A. ', Hanke S. ', Prifert C. ${ }^{2}$, Weißbrich B. ${ }^{2}$, Liese J.G.', Bavarian PICU Study Group on Influenza and Other Viral ARI

'Universitätsklinikum Würzburg, Kinderklinik und Poliklinik, Würzburg, ${ }^{2}$ Universität Würzburg, Institut für Virologie und Immunbiologie, Würzburg

Fragestellung. RSV ist eine der häufigsten Ursachen für akute Atemwegserkrankungen (ARE) bei Kindern <2 Jahren. Wir untersuchten RSV-Erkrankungen bei ARE-Kindern auf pädiatrischen Intensivstationen (PICUs).

Methode. Prospektive Surveillance-Studie (Okt 2010 bis Apr 2012) in 22 PICUs in Bayern bei Kindern im Alter ab 1 Monat und <17 Jahren; Untersuchung (Nasen-)Rachenabstrich mittels Multiplex-PCR auf 19 virale ARE-Einzelerreger; zusätzlich Erhebung klinischer Daten.

Ergebnisse. Von 279 Kindern hatten 86 (31\%) eine RSV-Infektion $(82 \%$ PCR-bestätigt, $18 \%$ mit Schnelltest bzw. IFT). Das Alter lag im Median bei 2 Monaten (IQR 2-16). Der PICU-Aufenthalt dauerte 3 Tage (Median; IQR 2-5), im Krankenhaus insgesamt 7 Tage (IQR 6-10). Von 59 Multiplex-PCR-bestätigten Kindern hatten 17 (29\%) eine Koinfektion mit anderen viralen ARE-Erregern (14 doppelt, 3 dreifach); am häufigsten mit Rhinovirus und Coronavirus. RSV-Koinfektionen unterschieden sich bei diesem Patientenkollektiv im Schweregrad nicht von RSV-Monoinfektionen. Bei Aufnahme wurde der Zustand bei 16 (19\%) Kindern als lebensbedrohlich eingestuft. Die häufigsten Diagnosen waren Bronchitis/Bronchiolitis $(91 \%, \mathrm{n}=78)$ und Pneumonie $(57 \%, \mathrm{n}=49)$. Sauerstoffgabe benötigten 74 (87\%), CPAP 22 (26\%), und endotracheale 
Beatmung 10 (12\%) Kinder. Mindestens eine chronische Grunderkrankung lag bei $43 \%$ der Kinder vor, u. a. 18 (21\%) mit Frühgeburtlichkeit, 15 (17\%) mit neurologischer Grunderkrankung und 14 (16\%) mit einer chronischen Erkrankung der Lunge. 2 (2\%) Kinder hatten bleibende Folgeschäden, 2 (2\%) verstarben.

Diskussion. RSV war mit einem Anteil von 31\% der am häufigsten nachgewiesene virale ARE-Erreger bei PICU-Patienten. Bei diesen schwer erkrankten Patienten verliefen RSV-Koinfektionen ähnlich wie RSVMonoinfektionen.

\section{DGKJ-PO-J2-5}

Therapeutisches Management bei parapneumonischen Pleuraergüssen und Pleuraempyemen (PPE) im Kindesalter - Ergebnisse aus der ESPED-Studie 2010-2012

\section{Segerer F.', Hagemann C. ${ }^{1}$, Keller S. ${ }^{1}$, Schoen C. ${ }^{2}$, van der Linden M.P.G. ${ }^{3}$ Streng A. ${ }^{\prime}$, Rose M.A. ${ }^{4}$, Liese J.G. ${ }^{\text {' }}$ \\ 'Universitätsklinik Würzburg, Kinderklinik und Poliklinik, Würzburg, 2Universität Würzburg, Institut für Hygiene und Mikrobiologie, Würzburg, ${ }^{3}$ Universitätsklinikum RWTH Aachen, Nationales Referenzzentrum für Streptokokken Abteilung Medizinische Mikrobiologie, Aachen, ${ }^{4}$ J.W. Goe- the Universität, Zentrum der Kinder- und Jugendmedizin, Frankfurt}

Einleitung. Die Behandlung des PPE und insbesondere die Entscheidung für ein konservatives oder operatives Management bleibt Gegenstand kontroverser Diskussion.

Methoden. Surveillance-Studie in allen 472 deutschen Kinderkliniken mittels der „Erhebungseinheit für seltene pädiatrische Erkrankungen (ESPED)“. Eingeschlossen sind Kinder $<18$ Jahren mit PPE/PE, die $\geq 1$ Woche persistieren oder mittels Drainage behandelt werden.

Ergebnisse. Von 400 Kindern mit PPE (10/2010-06/2012) wurden 111 (28\%) ohne Punktion des Pleuraraums behandelt. Eine nichtoperative Entlastung (NOE) erfolgte bei 190 (48\%) Kindern mittels Punktion/ Drainage (33\%) oder Drainage plus Pleuraspülung/intrapleurale Fibrinolyse (15\%). Operative Entlastung (OE) wurde bei 99 (25\%) Kindern durchgeführt, entweder durch videoassistierte Thorakoskopie (VATS, $n=69$ ) oder offene Thorakotomie $(\mathrm{n}=30)$. Vierundachtzig der 99 (85\%) Kinder mit $\mathrm{OE}$ wurden intensivstationär behandelt, im Vergleich zu 115 von 190 (61\%) Kindern mit NOE ( $\mathrm{p}<0,001) .22 \%$ der Kinder mit OE wurden in den ersten drei Tagen des stationären Aufenthalts operiert (frühe OE; Median 1, IQR 1-2 Tage) und 78\% nach dem dritten Tag (späte OE; Median 12, IQR 7-17 Tage). Kinder mit früher OE waren älter [Median 10 Jahre (IQR 5-15) vs. 3 Jahre (IQR 3-7) p=o,oo1], und die Aufenthaltsdauer war kürzer [Median 15 Tage (IQR 11-26) vs. 25 Tage (IQR 20-38) p=o,001].

Diskussion. OE erfolgte bei Kindern mit PPE entweder in den ersten Tagen nach Aufnahme oder bei ausbleibender Besserung anderer Maßnahmen. Späte $\mathrm{OE}$ war assoziiert mit jungem Alter, während frühe $\mathrm{OE}$ vor allem bei älteren Kindern gewählt wurde. Grund dafür könnte entweder ein eher zurückhaltendes Vorgehen bei jungen Kindern oder ein initial schwereres Krankheitsbild bei älteren Kindern mit PPE sein.

\section{DGKJ-PO-J2-6}

Invasive Hämophilus-Influenzae-F-Infektion mit Entwicklung einer sekundären hämophagozytischen Lymphohistiozytose

Özcan S. ', Losch H. ${ }^{\prime}$, Renneberg A. ${ }^{\prime}$

'Kinderklinik Am Bürgerpark, Bremerhaven

Fragestellung. Die hämophagozytische Lymphohistiozytose (HLH) entspricht einem schweren Krankheitsbild, das einer überschießenden, jedoch ineffektiven Immunantwort entspringt. Man unterscheidet die primäre, genetische Form, die unbehandelt stets tödlich endet, und eine sekundäre Form. Eine frühe immunsuppressive, bzw. immunmodulatorische Therapie erfolgt nach dem Protokoll HLH 94. Ist eine Therapie bei infektiologischer erkannter und behandelter Ursache in jedem Fall notwendig?
Materialien und Methoden. Wir präsentieren den Fall eines 3-jährigen Mädchens, das aufgrund einer Meningitis durch Hämophilus influenzae Typ F behandelt wurde. Es handelt sich um ein zuvor gesundes Kind mit vollständigem Impfschutz auch gegen Hib. Zusätzlich bestand eine Mastoiditis linksseitig.

Ergebnisse. Nach zunächst klinischer Besserung und Entfieberung unter antibiotischer Therapie fieberte unsere Patientin erneut hoch. Sie entwickelte eine Splenomegalie und folgende laborchemische Befunde: Ferritin 95.323 $\mu \mathrm{g} / \mathrm{l}$, Hämoglobin 7,8 g/dl, Thrombozyten $72.000 / \mu \mathrm{l}$, Triglyceride $285 \mathrm{mg} / \mathrm{dl}$. Wir stellten die Diagnose eines sekundären HLH, verzichteten jedoch bei rascher klinischer Besserung unter weiterer antibiotischer Therapie und bekanntem Erreger auf eine immunsuppressive Therapie nach Protokoll.

Diskussion. Laut dem Protokoll HLH 94/o4 wird empfohlen alle Patienten mit HLH früh immmunsuppressiv bzw. immunmodulatorisch zu behandeln. Unter Berücksichtigung einzelner Publikationen zur Therapie bei Erwachsenen und der anglikanischen Literatur therapierten wir bei mildem Verlauf und gut behandelbarer Grunderkrankung nicht immunsuppressiv. Unter welchen Voraussetzungen ist ein solches Vorgehen verantwortlich und ermöglicht uns, ausgewählten Patienten ein weites Nebenwirkungsspektrum zu ersparen?

\section{DGKJ-PO-J2-7}

Späte Diagnose einer konnatalen Toxoplasmose bei einem HIVnegativem Kind nach Reaktivierung in der Schwangerschaft bei einer dialysierten HIV-positiven Frau

Kobbe R. ', Brolund A. ', Buhk J.-H. ${ }^{2}$, Groß U. ${ }^{3}$, Hentschke M. ${ }^{4}$, Ganschow R. ${ }^{1}$, Ruckdeschel $\mathrm{K}^{4}$

'Universitätsklinikum Hamburg-Eppendorf, Klinik und Poliklinik für Kinderund Jugendmedizin, Hamburg, ${ }^{2}$ Universitätsklinikum Hamburg-Eppendorf, Klinik und Poliklinik für Neuroradiologische Diagnostik und Intervention, Hamburg, ${ }^{3}$ Universitätsmedizin Göttingen, Institut für Medizinische Mikrobiologie, Göttingen, ${ }^{4}$ Universitätsklinikum Hamburg-Eppendorf, Institut für Medizinische Mikrobiologie, Virologie und Hygiene, Hamburg

Hintergrund. Die konnatale Toxoplasmose ist weltweit ein ernsthaftes Problem und kann zu Blindheit und neurologischen Folgeerscheinungen führen. Die Serologie identifiziert normalerweise Erstinfektionen in der Schwangerschaft, sowie infizierte Neugeborene. Leider können serologische Tests im Falle einer Reaktivierung bei immundefizienten Schwangeren versagen und so die Diagnose verzögern.

Kasuistik. Ein hypotrophes Frühgeborenes der 34. SSW einer HIV-positiven, auf Grund einer terminalen HIV-Nephropathie hämodialysierten Mutter, entwickelte postnatal ein schweres Sepsis-ähnliches Krankheitsbild ohne Erregernachweis. Das klinische Ansprechen auf eine breite antimikrobielle Therapie war schlecht. Trotz hoher anti-T.gondii-IgG-Titer bei der fiebernden Mutter wurde keine Reaktivierung vermutet, da gleichzeitig eine Pneumonie und eine Dialysekatheterinfektion vorlag. Bei einer Kontrolluntersuchung des Kindes im Alter von 3 Monaten zum Ausschluss einer HIV-Infektion berichtete die Pflegemutter einen afebrilen Krampfanfall bei unauffälligem EEG. Zu diesem Zeitpunkt war anti-T.-gondii-IgM-positiv, ein MRT und die Lumbalpunktion pathologisch mit positivem Liquor-Serum-anti-T.-gondiiAntikörper-Quotienten. Retrospektiv fanden wir in aufbewahrten Plasmaproben sowohl serologische Anzeichen für eine Reaktivierung, als auch positive T.-gondii-PCRs bei Mutter und Kind. Trotz sofortiger Behandlung mit Pyrimethamin und Sulfadiazin entwickelte das HIVnegative Kind im Verlauf eine beidseitige Chorioretinitis.

Schlussfolgerung. Hohe anti-T.-gondii-IgG-Titer sollten bei immundefizienten Schwangeren eine Reaktivierung vermuten lassen und eine detaillierte Untersuchung des Neugeborenen nach sich ziehen. 


\section{DGKJ-PO-J2-8}

Impfstatus und Impfbereitschaft von Medizinstudenten zu Beginn des klinischen Studienabschnitts

\section{Herbst M. ${ }^{1}$, Schönlaub J.', Streng A.', Kreth H.-W. ${ }^{1}$, Frosch M. ${ }^{2}$, Weißbrich B. ${ }^{3}$ Liese J.' \\ 'Universitätsklinikum Würzburg, Kinderklinik, Pädiatrische Immunologie und Infektiologie, Würzburg, ${ }^{2}$ Universitätsklinikum Würzburg, Institut für Hygiene und Mikrobiologie, Würzburg, ${ }^{3} U$ niversitätsklinikum Würzburg, Institut für Virologie und Immunbiologie, Würzburg}

Einleitung. Impfempfehlungen für medizinisches Personal werden von der ständigen Impfkommission (STIKO) herausgegeben. Im „Praktikum Impfkurs“ am Universitätsklinikum Würzburg wurde der Impfstatus von Medizinstudenten erfasst und die Möglichkeit zur Komplettierung des Impfstatus gegeben.

Material und Methoden. Mithilfe eines Fragebogens wurde anhand des Impfpasses der Impfstatus erfasst. Vollständiger Impfschutz gemäß STIKO definierte sich durch mindestens 1 Tetanus-/Diphtherie- (T/D) und Pertussis-Impfung in den letzten 10 Jahren, einen dokumentierten Hepatitis (HBV) Hbs-Antikörper-Titer $>100$ IE/l und eine 2-malige Impfung gegen Mumps-Masern-Röteln (MMR). Bei Varizellen (VZV) wurde eine positive Anamnese, 2-malige Impfung oder ein VZV-Titer als schützend angesehen. Die Bereitschaft für eine Auffrischimpfung wurde erfasst.

Ergebnisse. 128 von 157 Studenten (82\%) wurden in die Auswertung aufgenommen (6. Semester; Altersmedian 23,4 Jahre). Einen inkompletten Impfstatus laut Impfpass wiesen 83 Teilnehmer (65\%) auf; für Pertussis $52 \%$, T/D $18 \%$ sowie für MMR $17 \%$. Gegenüber HBV hatten $16 \%$ und gegen VZV 2\% keinen definierten Schutz. Von 83 Studenten mit empfohlener Auffrischimpfung ließen sich 46 (55\%) im Kurs durch Kommilitonen impfen; 12 erhielten zwei zeitgleiche Impfungen.

Diskussion. Insgesamt fand sich eine hohe Anzahl von Medizinstudenten mit unvollständigem Impfschutz. Bei Pertussis könnte dies an der unzureichenden Umsetzung der empfohlenen Auffrischimpfung mit Tdap-Impfstoff bei Jugendlichen liegen. Die Impfbereitschaft nach Impfempfehlung war hoch. Eine Vervollständigung des Impfstatus ist anzustreben. Impfkurse im Rahmen des Medizinstudiums bieten neben der Lehre die Möglichkeit Impflücken zu schließen.

\section{DGKJ-PO-J2-9}

Primäre kutane Kryptokokkose bei einem 8 Jahre alten immunkompetenten Jungen - ist eine systemische antimikrobielle Therapie notwendig?

\section{Lenz D. ${ }^{1}$, Held J. ${ }^{2}$, Goerke S.M. ${ }^{3}$, Wagner D. ${ }^{4,5}$, Tintelnot K. ${ }^{6}$, Henneke P. ${ }^{1,5}$, Hufnagel M.}

'Universitätsklinikum Freiburg, Zentrum für Kinder- und Jugendmedizin, Freiburg, ${ }^{2}$ Universitätsklinikum Freiburg, Institut für Medizinische Mikrobiologie und Hygiene, Freiburg, ${ }^{3}$ Universitätsklinikum Freiburg, Department Chirurgie, Abteilung Plastische und Handchirurgie, Freiburg, ${ }^{4}$ Universitätsklinikum Freiburg, Department Medizin, Abteilung Infektiologie und Reisemedizin, Freiburg, ${ }^{5}$ Universitätsklinikum Freiburg, Zentrum für Chronische Immundefizienz, Freiburg, ${ }^{6}$ Robert Koch Institut, Konsiliarlabor für Cryptococcus neoformans, Berlin

Einleitung. Infektionen mit Hefepilzen der Gattung Cryptococcus sind in der Regel opportunistische Infektionen bei immunsupprimierten Patienten und ziehen eine lange antimykotische Therapie nach sich. Eine primäre kutane Kryptokokkose kann nach traumatischer Erregerinokulation bei Immungesunden auftreten. Die Notwendigkeit einer systemischen antimykotischen Therapie wird in der Literatur kontrovers diskutiert. Wir berichten über eine primäre kutane Kryptokokkose bei einem immungesunden Kind, dessen Infektion durch chirurgische Sanierung ohne systemische antimykotische Therapie vollständig abheilte.
Fallbericht. Ein 8-jähriger deutscher Junge stellte sich mit einem subkutanen Abszess des rechten palmaren Daumenweichteils vor. Dieser hatte sich nach Verletzung in einem Gestrüpp entwickelt. Eine 5-tägige antibiotische Therapie mit Cefuroxim zeigte keine Wirkung. Im Drainagesekret nach chirurgischer Inzision und Drainage wurde Cryptococcus neoformans als einziger Krankheitserreger kultiviert. In der Tuschefärbung war nur eine dünne Kapsel zu erkennen. Eine diagnostische Evaluation bei dem Patienten erbrachte keinen Hinweis auf eine systemische Infektion und keine zugrundeliegende Immundefizienz. Auf eine systemische antimykotische Therapie wurde deshalb verzichtet. Klinische Nachkontrollen nach 1 und 4 Monaten zeigten eine vollständige Heilung und ein anhaltend negatives Cryptococcus-Antigen im Serum. Die fehlende systemische Ausbreitung bei primärer kutaner Kryptokokkose wird mit einer nur geringen Kapselbildung nach kutaner Inokulation erklärt.

Schlussfolgerung. Bei primärer kutaner Kryptokokkose und chirurgischer Sanierung scheint nach Ausschluss einer systemischen Infektionen sowie einer zugrundeliegenden Immundefizienz eine systemische antimykotische Therapie verzichtbar zu sein.

\section{Infektiologie (3) und Reisemedizin/Tropenpädiatrie}

\section{DGKJ-PO-J3-1 \\ Nüchternzeiten in der pädiatrischen Anästhesie eines großen afrikanischen Krankenhauses}

Pollach G. ${ }^{1}$, Kapenda R. ${ }^{2}$, Wiesener S. ${ }^{2}$, Arana A. ${ }^{2}$, Namboya F. ${ }^{\prime}$

'University of Malawi, Anaesthesia and Intensive Care, Blantyre, Malawi, ${ }^{2}$ Queen Elizabeth Central Hospital, Anästhesie, Blantyre, Malawi

Fragestellung. Queens Hospital ist das größte Krankenhaus Malawis. Häufig sehen wir dehydrierte Säuglinge und Kinder bei elektiven Eingriffen. Wir fragten uns, ob die realen Nüchternzeiten (NZ) mit den Vorgaben der Anästhesie übereinstimmen (klare Flüssigkeiten bis $2 \mathrm{~h}$ vor dem Eingriff).

Methode. Wiederholte, intensive Befragungen der Angehörigen nach der wirklich letzten Nahrungsaufnahme durch unsere nichtärztlichen Anästhesisten (in Chichewa).

Ergebnisse. 1) Die Befragung 2008 ergab für Kinder unter einem Jahr $(\mathrm{n}=18) \mathrm{NZ}$ von im Schnitt 9,6 h (max. $20 \mathrm{~h}$ ). Nach Ausbildungsmaßnahmen auf der pädiatrisch-chirurgischen Station konnten diese Zeiten lediglich auf 8,7 h verkürzt werden ( $n=73$, Durchschnittsalter: 2,8 Jahre). Fortbildungen mit verschiedenen Schwerpunkten konnten die mittlere NZ im Jahre 2009 auf ca. 4,6 h senken ( $n=42$, Durchschnittsalter 4 Jahre). Die Befragung im Frühling 2012 ergab für Säuglinge unter einem Jahr $(\mathrm{n}=19)$ eine durchschnittliche NZ von $7,5 \mathrm{~h}$ (max. $14 \mathrm{~h})$. Sommer $2012(n=41)$ konnte dann für Säuglinge eine durchschnittliche NZ von 7,4 Stunden ermittelt werden (max. $17 \mathrm{~h}$ bei einem 7 Monate alten Kind). 2) Verschiedenen Versuche mit Fortbildungen für Schwestern und „guardians" (meistens Mütter oder Großmütter) mit Vorlesungen, Gesprächen, Hinweistafeln und bedruckten T-Shirts für die Kinder („give me water at 6 a.m.") zeitigten Verbesserungen.

Schlussfolgerung. Die NZ waren sehr lang. Die Ursachen scheinen multifaktoriell zu sein. Knappheit an Schwestern (dutzende Patienten je Schwester) trifft auf Unkenntnis der (Groß-)Mütter. Sie haben häufig keine Vorstellung physiologischer Vorgänge. Die ständige Versetzung des Personals zerstört alle Fortschritte in der Ausbildung. Wir müssen die Reduktion der NZ als kontinuierliche Aufgabe akzeptieren. 
DGKJ-PO-J3-2

„Fluid expansion as a supportive therapy" (eine Studie an 3000 afrikanischen Kindern mit septischen Krankheitsbildern) - was hat sich nach 2 Jahren für die Klinik geändert?

\section{Pollach $G{ }^{\prime}$}

'University of Malawi, Anaesthesia and Intensive Care, Blantyre, Malawi

Fragestellung. Die im New England Journal of Medicine 2011 veröffentlichte Studie sorgte für Unruhe in der tropisch-pädiatrischen Intensivmedizin. Standard der Volumentherapie schwerer Infektionen (auch reicher Länder und anderer Kontinente) werden in Frage gestellt.

Methodik. Evaluation der Ergebnisse aus klinischer Sicht für ressourcenarme und ressourcenreiche (ra/rr) Länder sowie der klinischen Implementierung.

\section{Ergebnisse.}

1. Kontroll- und Bolusgruppen zeigten niedrige Mortalitäten (7,3\%/10,6\%). Unabhängig von der Bedeutung der Bolusgabe, konnte so die Letalität von Kindern im ra-Umfeld durch einfache Verbesserungen der Notaufnahme gesenkt werden.

2. Die Studie ist (verschiedene Prävalenz von Dengue u. Malaria) schwer auf ra-Länder Asiens und Südamerikas zu übertragen.

3. Die Bedeutung von FEAST für die Mortalität in der Pädiatrie rr-Länder wird durch die Verfügbarkeit von CPAP, Beatmung u. Intensivstationen eingeschränkt.

4. Krankheitsgruppen wurden eingeschlossen, bei denen Bolusgaben relativ kontrandiziert sind.

5. „Intention to treat“ wurde nicht genügend hinterfragt bei der Datenanalyse. Die Randomisierung wurde durch den zeitlichen Ablauf der Therapie verändert.

6. Feast ist noch nicht implementiert und wird bei der WHO intensiv beraten.

Schlussfolgerung. Behandlungsschemata zu ändern lehnen wir momen$\tan$ ab (Uni Malawi). Eingeübte Therapiemaßnahmen des „first line staff“ zu verändern und ihn total zu verwirren muss besser begründet werden. Die positiven Effekte von FEAST für die Letalitätssenkung in ra-Ländern durch das kontinuierliche Vorhandensein von Basismaßnahmen sollte herausgestellt werden. Die Pädiatrie rr-Länder kann durch mehr Vorsicht bei aus den Tropen migrierten Kindern mit der Diagnose "Sepsis“ und Zeichen von Unterernährung, Anfällen oder starker Anämie profitieren.

\section{DGKJ-PO-J3-3}

Malaria in der pädiatrischen Anästhesiologie und Intensivmedizin

Pollach G. ${ }^{1}$

'University of Malawi, Anaesthesia and Intensive Care, Blantyre, Malawi

Fragestellung. Malaria (M) ist weltweit eine der wichtigsten pädiatrischen Erkrankungen. Migrations- und Fluchtbewegungen sorgen für ihre Verbreitung. Wir informieren über ihre Besonderheiten für den pädiatrischen Anästhesisten/Intensivmediziner.

Methode. Auswertung eigener Erfahrungen in einem der größten Krankenhäuser Afrikas.

Ergebnisse. 1) M. stellt immer einen medizinischen Notfall dar. Kinder (sowie Schwangere, Patienten mit „komplizierter“ M., Doppelinfektion, Sichelzellanämie, schlechtem Allgemeinzustand) gehören auf die Intensivstation. 2) Keine Narkose für elektive Operationen bei M. Dringliche Eingriffe mit niedriger Parasitämie stellen Einzelfallentscheidungen dar. 3) Eine chirurgische Notfallindikation bedeutet 2 Notfälle gleichzeitig bei einem Kind zu haben. Eine Allgemeinanästhesie wird bevorzugt. 4) Die bedeutendsten intensivmedizinischen Komplikationen dieser primär multisystemischen Krankheit sind die cerebrale M. die Anämie, die respiratorische Insuffizienz, die kardiovaskuläre Dekompensation, die Hypoglykämie, die Hyperpyrexie, die E'lytentgleisung, die Niereninsuffizienz, eine gleichzeitige Sepsis, Hyperparasitämie sowie die Azidose. 5) Die Initialtherapie der komplizierten M. erfolgt mit Chinin (+ Doxycyclin/Clindamycin) oder parenteralem Artesunate. Die NW bes. des Chinins, sind zu beachten (akut: Hypotonie, Hypoglykämie, Herzrhythmusstörungen Thrombozytopenie u. Hämolyse.6 Das Monitoiring umfasst (neben klein. Untersuchung u. Parasitenidentifikation) Hb, Thrombozyten, BZ, E'yte, BE, Kreatinin, EKG, $\mathrm{SaO}_{2}$ und Rö-Thorax.

Schlussfolgerung. M. bedeutet für den Anästhesisten und den pädiatrischen Intensivmediziner eine große Herausforderung. Schnelle Behandlung, liberale Aufnahme auf Intensiv und strenge Indikationsstellung für jede Operation sichern das Überleben des Kindes.

\section{DGKJ-PO-J3-4}

Interleukin-7-induzierte polyfunktionale T-Zellen sind bei Kindern mit Tuberkulose inhibiert

\section{Kohns M. ${ }^{1}$, Schattling S. ${ }^{2}$, Kleinsteuber K. ${ }^{2}$, Marx F.M. ${ }^{3}$, Mayatepek E. ', Jacobsen $M$.}

'Universitätsklinikum Düsseldorf, Klinik für Allgemeine Pädiatrie, Neonatologie und Kinderkardiologie, Düsseldorf, ${ }^{2}$ Bernhard-Nocht-Institut für Tropenmedizin, Abteilung Immunologie, Hamburg, ${ }^{3}$ Charité - Universitätsmedizin Berlin, Klinik für Pädiatrische Pulmonologie und Immunologie, Berlin

Einleitung. Unzureichende T-Zell-Immunität gegen M. tuberculosis $(\mathrm{Mtb})$ ist vermutlich die Ursache für die Progression zur aktiven Tuberkulose und wiederholte Erkrankung. Interleukin-7 (IL-7) ist ein zentraler Faktor für die Ausbildung eines T- Zellgedächtnisses. IL-7 erhöht die Sensitivität von Interferon- $\gamma($ IFN $\gamma)$ release assays zur Detektion M.tbspezifischer T-Zellen und induziert Immunpolarisierung durch Inhibition von Suppressor of Cytokine Signalling(SOCS) 3 . SOCS 3 wurde als Marker einer aktiven Tuberkulose beschrieben.

Methoden. In dieser Studie wurden Unterschiede in der IL-7-abhängigen T-Zellantwort von Kindern mit Tuberkulose charakterisiert. Hierfür wurden Kinder mit aktiver Tuberkulose $(\mathrm{n}=\mathbf{2 2})$ und gesunde latent Mtb-infizierte (LTBI) Kinder ( $\mathrm{n}=14)$ untersucht. Bei Diagnosestellung (do), während der Therapie (d9o) und nach abgeschlossener Therapie $\left(\mathrm{d}_{3} 65\right)$ wurden Blutentnahmen durchgeführt und aufgereinigte Immunzellen in vitro restimuliert.

Ergebnisse. Kostimulation mit IL-7 und M.tb-Antigenen induzierte eine relative Zunahme der IFN $\gamma$-produzierenden T-Zellen im Vergleich zur Kontrolle ohne IL-7. Dieser Effekt trat verstärkt nach Therapie auf. IFN $\gamma / \mathrm{TNF} \alpha / \mathrm{GM}$-CSF mehrfach-positive („polyfunktional“) T-Zellen wurden ausschließlich nach abgeschlossener Therapie verstärkt induziert. Die Expression von $\mathrm{SOCS}_{3}$ korrelierte negativ mit der IL-7-vermittelten Induktion polyfunkt. T-Zellen. Überexpression von $\mathrm{SOCS}_{3}$ hemmte die IL-7-induzierten positiven Effekte auf Proliferation und Viabilität von T-Zellen.

Schlussfolgerung. Diese Studie zeigt Tuberkulose-spezifische Unterschiede in der T-Zellantwort gegen IL-7 auf, welche durch erhöhte $\mathrm{SOCS}_{3}$ Expression während der akuten Erkrankung verursacht sein könnten. Vor dem Hintergrund klinischer Studien zur therapeutischen IL-7 Gabe sollten diese Ergebnisse Berücksichtigung finden.

\section{DGKJ-PO-J3-5}

Keratoiritis als ophtalmologische Manifestation bei KawasakiSyndrom eines 4-jährigen Mädchens

Junge S. ', Moser J. ', Löwe I. ${ }^{2}$, Lorenz N. ${ }^{1}$, Heubner G. ${ }^{1}$

${ }^{1}$ Klinikum Dresden Neustadt, Klinik für Kinder und Jugendmedizin, Dresden, ${ }^{2}$ Klinikum Dresden Friedrichstadt, Klinik für Augenheilkunde, Dresden

Einleitung. Morphologisch entspricht das Kawasaki-Syndrom einer systemischen Vaskulitis, die insbesondere kleine und mittelgroße Gefäße betrifft. Neben der bekannten Konjunktivitis bestehen allerdings weitere augenärztlich zu berücksichtigende Manifestationen. 
Kasuistik. Vier Jahre altes, seit 3 Tagen fieberndes Mädchen in reduziertem AZ, Exanthem am Gesäß, Extremitäten, Händen und Füßen. Zervikale Lymphkontenschwellung, Konjunktivitis bds., Lacklippen. Mit Cefuroxim anbehandelt. Vorstellung bei persistierendem Fieber.

Diagnostik. Röntgenthorax, Echo, EKG, Abdomensono o. p. B. CrP 159,1; Linksverschiebung, Na 129, BSG 130. Rheumatologische BasisDiagnostik. o. p. B.

Therapie und Verlauf. Bei Verdacht auf ein Kawasaki-Syndrom Gabe von Immunglobulin $(2 \mathrm{mg} / \mathrm{kg})$ sowie ASS. In den echokardiographischen Kontrollen keine Koronarveränderungen feststellbar. $30 \mathrm{~h}$ nach Immunglobulingabe kam es zu einer Entfieberung und einen stetigen Rückgang der Entzündungsparameter. Am 8. Tag fiel eine Hornhauttrübung auf. In der augenärztlichen Untersuchung zeigten sich eine Keratoiritis sowie ein erhöhter Augeninnendruck. Die Therapie erfolgte mit Azetazolamid, Prednisolon und Cyclopentolat. Darunter Befundrückgang.

Diskussion. Häufig bestehen ophtalmologische Manifestationen neben der bilateralen Konjunktivitis. Unser Fall unterstützt die Kenntnis, dass es darüber hinaus auch zu entzündlichen Veränderungen der übrigen Augenhäute kommen kann. Die Pathogenese, der Inflammation kleiner Blutgefäße, die beim Kawasaki-Syndrom beschrieben wird, stellt einen möglichen Erklärungsansatz dar.

Schlussfolgerung. Dieser Häufung Rechnung tragend, sollte die augenärztliche Untersuchung, Bestandteil des diagnostischen Vorgehens beim Kawasaki-Syndrom sein.

\section{DGKJ-PO-J3-6}

\section{Die Rolle von CISH in der T-Zellantwort gegen Tuberkulose}

Seyfarth J.', Kohns M. ', Seibt A. ', Mayatepek E. ', Jacobsen M. ${ }^{1}$ 'Universitätsklinikum Düsseldorf, Klinik für Allgemeine Pädiatrie, Neonatologie und Kinderkardiologie, Düsseldorf

Einleitung. CISH (Cytokine-Inducible SRC Homology 2 domain) gehört zur Familie der Suppressor-of-cytokine-signaling-Proteine und fungiert als negativer Feedback Regulator bestimmter Zytokinrezeptoren. Eine Assoziation verschiedener CISH-Polymorphismen mit einer erhöhten Suszeptibilität gegen Mycobakterium (M.) tuberculosis Infektionen ist beschrieben. Transkriptomanalysen an T-Zellen von M. tuberculosis infizierten Menschen ergaben eine erhöhte CISH-Expression in Tuberkulose-Patienten im Vergleich zu gesunden latent M. tuberculosis infizierten Kontrollen. Ziel dieser Studie war die Charakterisierung der CISH Expression in T-Zellen nach in vitro Aktivierung, sowie die Analyse der phänotypischen und funktionalen Veränderungen von T-Zellen nach Modulation der CISH Expression.

Methoden. Zur quantitativen Analyse von zellspezifischen CISH-Proteinkonzentrationen wurde zunächst eine durchflusszytometrische Methode etabliert und mittels quantitativer PCR und Westernblot verifiziert. In vitro T-Zellrezeptorstimulation induzierte eine Hochregulation von CISH in T-Zellen, während Interleukin-2 und -7 nur eine frühe transiente Expression von CISH mRNA induzierten. Zur Modulation der CISH-Expression in humanen T-Zellen wurde eine lentivirale Methode zur stabilen Expression sowohl von CISH als auch von inhibitorischer shRNA gegen CISH (jeweils zusammen mit GFP) verwendet. Erste Ergebnisse legten keinen Einfluss einer CISH-Überexpression auf die Proliferation und das Zytokinprofil der T-Zellen nahe.

Schlussfolgerung. Neben der Charakterisierung des Einflusses von CISH auf den Phänotyp und die Funktion werden mittels globaler Transkriptomanalysen die Genexpressionsprofile von T-Zellen mit modulierter CISH Expression bestimmt. Diese Experimente sollen die exakte Rolle von CISH in der T-Zellantwort charakterisieren.
DGKJ-PO-J3-7

\section{Anhaltende Apnoen bei Zustand nach Adenoviren-Enzephalitis}

Weber K.', Schum C. ${ }^{\prime}$, Fiedler A. ${ }^{1}$

'Klinikum St. Marien Amberg, Amberg

Einleitung. Anhaltende Apnoen bei Zustand nach Adenoviren-Enzephalitis im Säuglingsalter sind ein bisher in der Literatur nicht beschriebenes Krankheitsbild.

Fallbericht. Wir berichten über einen zum Zeitpunkt der Diagnosestellung 2 Monate alten männlichen Säugling, der uns mit Apnoen unklarer Genese und Ophisthotonus vorgestellt wurde. Bei Aufnahme kein Fieber. Die durchgeführte Liquordiagnostik erbrachte den Nachweis von Adenoviren-DNA. Zudem konnten wir die Adenoviren im Nasenabstrich und im Stuhl nachweisen. Wir behandelten den Patienten symptomatisch und entließen ihn symptomfrei nach Hause. Zehn Tage nach Entlassung erfolgte die Wiedervorstellung mit erneut rezidivierenden Apnoen.

Ergebnisse. Die umfassende Diagnostik einschließlich EEG, MRT Schädel, Polysomnographie im Schlaflabor, Stoffwechseldiagnostik erbrachte keine wegweisenden Befunde. Verschiedene Therapieansätze blieben erfolglos und brachten keine Besserung der Apnoen.

Schlussfolgerung. Wir sehen daher die Apnoen als direkte Folge der stattgehabten Adenoviren-Enzephalitis.

\section{DGKJ-PO-J3-8}

Petechien, Eosinophilie, transiente Hemiplegie und vermindertes IgM im Serum - eine atypische Präsentation eines Hyper-IgM-Syndroms aufgund von CD-40-Liganden-Defizienz

Hensel K. ', Heldmann M. ', Heusch A.', Piroth W. ', Primke R.', Urgatz B.', Sinha $K{ }^{\text {? }}$

${ }^{1} \mathrm{HELIOS}$ Klinikum, Wuppertal

Fallbericht. Wir berichten über ein ehemaliges Frühgeborenes der 34.+4. Schwangerschaftswoche, das im Laufe des ersten Lebensjahres wiederholt aufgrund von scheinbar nicht in Zusammenhang stehenden Symptomen hospitalisiert werden musste. Es zeigten sich rezidivierene Atemwegsinfekte, Petechien im Gesicht und am weichen Gaumen, Eosinophilie, sowie eine Hypogammaglobulinämie mit vermindertem IgM, IgE und IgG auf. Im Alter von 6 Monaten erkrankte der Junge an einer schweren interstitiellen Pneumonie mit respiratorischer Insuffizienz, die sich trotz antibiotischer Therapie zunehmend verschlechterte. Knochenmarkspunktion, Bronchoskopie und CT erbrachten keine wegweisenden Befunde. Klinische Besserung blieb auch unter Cortisonstoßtherapie und Surfactant e.t. aus. Bei akuter, transienter Halbseitensymptomatik wurde ein Notfall-MRT durchgeführt, das einen Normalbefund zeigte. Nach Erhalt der positiven Pneumocystis carinii Serologie erfolgte die Therapie mit Co-trimoxazol und Pentamidin. Darüber hinaus konnte Candida-Antigen im Serum sowie CMV-Antigen im Urin, Serum und Bronchialsekret nachgewiesen werden. Eine zyklische Neutropenie erforderte wiederholte Wachstumsfaktorbehandlungen. Immunologisch ergaben schließlich T-Zell-Typisierung und Durchflusszytometrie das Bild eines CD-40-Liganden-Mangels.

Schlussfolgerung. Wir beschreiben einen atypischen Verlauf eines HyperIgM-Syndromes, das in seltenen Fällen mit vermindertem IgM einhergehen kann. 


\section{DGKJ-PO-J3-9}

\section{Diagnose einer Hämoglobinopathie im Rahmen einer akuten} Osteomyelitis - ein Fallbericht

\section{Junk L. ', Hammer E. ', Leenen A. ${ }^{2}$, Bohn B. ${ }^{3}$, Escherich G. ${ }^{4}$, Höger P. ${ }^{\text {' }}$}

${ }^{1}$ Kath. Kinderkrankenhaus Wilhelmstift, Pädiatrie, Hamburg, ${ }^{2}$ Kath. Kinderkrankenhaus Wilhelmstift, Radiologie, Hamburg, ${ }^{3}$ Berufsgenossenschaftliches Unfallkrankenhaus Hamburg, Unfallchirurgie, Hamburg, ${ }^{4} U K E$ Hamburg, Klinik für Pädiatrische Hämatologie und Onkologie, Hamburg

Einleitung. Die Diagnose einer Osteomyelitis kann im Kindesalter anhand typischer klinischer, laborchemischer und radiologischer Befunde gestellt werden. In seltenen Fällen liegt der entzündlichen Knochenveränderung eine Systemerkrankung zugrunde.

Fallbericht. Ein 7-jähriger Junge südamerikanischer Herkunft stellte sich mit akut aufgetretenen starken Schmerzen im Oberschenkel rechts und Fieber in unserer Klinik vor, leichte Schmerzen habe er seit mehreren Monaten. Klinischer und sonographischer Befund waren mit einer Osteomyelitis des rechten Femurs vereinbar. Labor: Leukozyten 13,1/nl $\mathrm{Hb}$ 11,9 g/dl, LDH 475 U/l, CrP 14,7 mg/. Im MRT zeigten sich Osteomyelitis-typische Veränderungen und Hinweise auf Knocheninfarzierung. Auch in den angrenzenden Knochen war die Signalintensität verändert. Im Knochenmarkausstrich fanden sich entzündliche Veränderungen. Die histologische Untersuchung des Knochenbiopsates zeigte Granulationsgewebe mit nekrotisierender, granulozytärer Entzündung. Ein Erregernachweis gelang weder aus dem Biopsat noch in der Blutkultur. Die Hb-Elektrophorese war hinweisend auf eine HbS/Beta+Thalassämie, die molekulargenetisch bestätigt wurde. Unter der antibiotischen Therapie besserte sich der klinische Befund, im MRT nach 6 Wochen war die erhöhte Signalintensität des rechten Femurs persistierend, die entzündlichen paraossären Veränderungen rückläufig.

Schlussfolgerung. Bei unserem Patienten wurde die Diagnose einer $\mathrm{HbS} /$ Beta + Thalassämie mit dem Auftreten einer Osteomyelitis gestellt. Hinweisend waren ausgedehnte Knochenveränderungen des gesamten Skeletts, die auf eine Systemerkrankung hindeuteten. Da insbesondere eine Sichelzellanämie zu infektiösen ossären Prozessen prädisponiert, sollte bei einer Osteomyelitis auch an eine Hämoglobinopathie gedacht werden.

\section{Endokrinologie/Gastroenterologie}

\section{DGKJ-PO-EG-1 \\ "kinetiKIDS", Ergebnisse eines Interventionsprogrammes für über- gewichtige Kinder}

\section{Mönchmeier B. ', Kühl P.G.', Fleischer M.', Engelmann G.', Weise-Bell J.'}

'Lukaskrankenhaus Neuss, Klinik für Kinder und Jugendliche, Neuss

Fragestellung. Das Kinder- und Jugendgesundheits-Survey fand unter den deutschen 11- bis 13-jährigen Jugendlichen eine Prävalenz für Übergewicht (BMI >90. PC, BMI-SDS >1,3) von $19 \%$. Die Behandlung ist langwierig und oft frustrierend. Deshalb wurden in den letzten 1o Jahren zahlreiche Programme entwickelt um sich dieser Patienten und ihrer Behandlung nachhaltig anzunehmen. Wir berichten hier über erste Ergebnisse eines ambulanten einjährigen Schulungsprogramms „kinetiKIDS“ für adipöse Kinder zwischen 8 und 12 Jahren.

Material und Methoden. Das Programm ist ein interdisziplinäres 1-jähriges Schulungsprogramm nach einem Manual der KgAs: Ein Team aus Pädiatern, Psychologinnen, Oecotrophologinnen und Sportlehreren bietet in den Bereichen Bewegung, Ernährung, Psychosoziales und Medizin theoretische und praktische Lehreinheiten für Eltern und Kinder an. Kern des Programms ist ein intensiver mehrmals wöchentlicher Kontakt zu den Kindern und Eltern.

Ergebnisse. 45 Kinder (19 Jungs, 26 Mädchen) haben bis heute kinetiKIDS durchlaufen. Es gab bislang 8 Dropouts (2 Jungs, 6 Mädchen), davon $4 \mathrm{im}$ ersten von 3 Kursen. Von den 37 Kindern, welche bislang das komplette Programm absolvierten, konnten 28 ihren BMI-SDS entweder halten oder reduzieren (davon $18 \mathrm{um} \geq 0,2$ BMI-SDS). Bei drei Teilnehmern sank der SDS auf Werte normalgewichtiger Kinder.

Schlussfolgerung. kinetiKIDS ermöglicht es, durch eine nachhaltige Betreuung von adipösen Kindern über einen Zeitraum von 1 Jahr bei $75 \%$ der Teilnehmer erfolgreich dem Trend der zunehmenden Adipositas entgegenzuwirken. In 3 Fällen kam es zu einer Normalisierung des SDS, welche allerdings bei einer Patientin nicht nachhaltig war.

Wir danken der Charlotte und Alfred Pierburg Stiftung für die großzügige Unterstützung dieser Arbeit.

\section{DGKJ-PO-EG-2}

\section{Autoimmunes polyglanduläres Syndrom Typ 2 bei einem 10-jährigen Mädchen}

Hagemann R. ${ }^{1}$ Kuhnigk M. ${ }^{1}$, Bienemann K. ${ }^{1}$, Michna D. ${ }^{1}$, Hauffa B.P. ${ }^{2}$ ${ }^{1}$ Elisabeth-Krankenhaus Essen, Allgemeine Pädiatrie, Essen, ${ }^{2}$ Unikinderklinik Essen, Pädiatrische Endokrinologie, Essen

Hintergrund. Autoimmune Endokrinopathien sind durch eine immunvermittelte Zerstörung endokriner Gewebe gekennzeichnet. Das autoimmune polyglanduläre Syndrom Typ 2 (APS-2) ist durch das Auftreten einer Nebennierenrindeninsuffizienz, autoimmuner Schilddrüsenerkrankung und/oder Diabetes mellitus Typ 1 definiert. Daneben können noch andere endokrine und nicht endokrine Autoimmunerkrankungen auftreten.

Kasuistik. Wir berichten über ein 10-jähriges Mädchen mit Gewichtsverlust und zunehmenden Leistungsknick. Bei der klinischen Untersuchung fielen trockene Schleimhäute und eine Hyperpigmentierung der Haut auf. Bei Hyponatriämie und Hyperkaliämie wurde unter dem Verdacht auf eine primäre Nebenniereninsuffizienz mit der Substitution von Hydrocortison und Fludrocortison begonnen. In der weiteren Labordiagnostik bestätigte sich dieser Verdacht (ACTH $>1250 \mathrm{pg} / \mathrm{ml}$, Renin $5460 \mathrm{ng} / \mathrm{l}$, Cortisol 44,8 $\mu \mathrm{g} / \mathrm{l}$, Aldosteron $<11 \mathrm{pg} / \mathrm{ml}$ ). Zusätzlich fiel eine Autoimmunthyreopathie mit erhöhtem TSH $(18,48 \mu \mathrm{lU} / \mathrm{ml})$ und positiven TPOAntikörpern (129,1 U/ml) auf. Hinweise auf andere Organbeteiligungen fehlten (keine mukokutane Candidiasis, kein Nachweis von DiabetesTyp-1-Antikörpern). In der Familienanamnese stellte sich heraus, dass der Vater unserer Patientin im Alter von 6 Jahren ebenfalls an einer Nebenniereninsuffizienz und einer Autoimmunthyreopathie erkrankt war. Fehlender Candidabefall der Schleimhäute und positive Familienanamnese lassen das Vorliegen eines APS-2 möglich erscheinen.

Fazit. Nicht nur bei Erwachsenen, sondern auch bei Kindern kann das autoimmune polyglanduläre Syndrom Typ 2 auftreten. Deswegen sollte bei Kindern, die mit einer autoimmunen Endokrinopathie auffallen, an zusätzliche Autoimmunerkrankungen gedacht und eine entsprechende Diagnostik durchgeführt werden.

\section{DGKJ-PO-EG-3}

\section{1-jähriges Mädchen mit Ösophagusnekrose durch Verschlucken einer Knopfbatterie}

\section{Wiese J.', Thiel K. ', Gründemann S. ${ }^{2}$, Laschat M. ${ }^{3}$, Niehues T.}

'Helios Kliniken Krefeld, Zentrum für Kinder- und Jugendmedizin, Krefeld, ${ }^{2}$ Helios Kliniken Krefeld, Klinik für Hals-, Nasen-, Ohrenheilkunde, Krefeld, ${ }^{3}$ Kinderkrankenhaus Amsterdamerstraße, Kinderanästhesiologie, Köln

Einleitung. Etwa 2\% der verschluckten Fremdkörper sind Batterien. In den letzten Jahren kam es zum Anstieg von Ingestionsfällen durch Lithium-Knopfbatterien $>\mathbf{2 0} \mathrm{mm}$. Neben der möglichen Drucknekrose und Auslaufen der Batterie spielt hier eine Gewebsschädigung durch fließenden elektrischen Strom die entscheidenste Rolle. Anhand des Falls eines 1-jährigen Mädchens mit einer verschluckten 20-mmKnopfbatterie und Ösophagusnekrose möchten wir die elektrische Gewebsschädigung darstellen und Behandlungsschemata diskutieren.

Fallvorstellung. Vorstellung einer 1-jährigen Patientin in der hiesigen Notfallpraxis ca. $1 \mathrm{~h}$ nach Ingestion einer $20 \mathrm{~mm}$ großen Knopfbatte- 
rie. Klinisch zeigte sich Hypersalivation und mehrfaches Erbrechen. Im Röntgen Darstellung in der oberen Ösophagusenge. Entfernung mittels starrer Ösophagoskopie, anschließend Spülung und Schienung mittels nasogastraler Sonde. Die Ösophagusschleimhaut war bereits grün-schwärzlich verfärbt. Es erfolgte eine intravenöse Behandlung mit Prednisolon und Ampicillin/Sulbactam nach Verätzungsschema, sowie initial eine Ernährung über die Magensonde. Im Verlauf war der orale Kostaufbau gut möglich. In endoskopischen Verlaufskontrollen äußerten wir den Verdacht auf eine beginnende Stenosierung.

Schlussfolgerung. Der Stromfluss, der im Ösophagus steckengebliebenen Batterie, ist der Mechanismus zur Nekroseentstehung. Die schnellstmögliche Entfernung ist anzustreben, um mögliche Komplikationen zu verhindern. Die Schienung mittels Magensonde bis zum Ausschluss einer Perforation erscheint sinnvoll. Zur Diskussion steht der Einsatz von Steroiden und prophylaktischer Antibiotikagabe, zu der in der Literatur unterschiedliche Empfehlungen bestehen.

\section{DGKJ-PO-EG-4}

\section{Fremdkörperingestion bei Kindern in Deutschland und Tansania}

\section{Krüger C. ${ }^{1}$, Toschke C. , Malleyeck I. ${ }^{2}$}

${ }^{1}$ St. Franziskus Hospital, Klinik für Kinder und Jugendliche, Ahlen, ${ }^{2}$ Haydom Lutheran Hospital, Haydom, Tansania

Fragestellung. Fremdkörper(FK)-Ingestionen kommen besonders bei jungen Kindern häufiger vor und erfordern $z$. T. eine endoskopische Intervention. Hierzu untersuchten wir Kohorten an 2 Krankenhäusern $(\mathrm{KH})$ der Grundversorgung in Deutschland (D) und Tansania (TZ).

Methoden. In die retrospektive Analyse (D: 09/2004-12/2012; TZ: 01/1998-09/2000) wurden alle Kinder <16 J. mit einer anamnestisch möglichen FK-Ingestion, die an dem jeweiligen $\mathrm{KH}$ endoskopiert wurden, eingeschlossen. Daten zu Alter, Geschlecht, Symptomen, Dauer, Art und Lokalisation des FK und Entlassungsstatus wurden erhoben. Ergebnisse. Bei 30 Kindern in D [m=12; Median 3,1 J. (0,9-14,8)] wurden 11 Münzen, 3 Haarspangen, 3 Apfelstücke, 1 Gräte, 1 Fleischstück, 1 Stecknadel, 1 Glasscherbe, 1 Plastikteil und Kaliumpermanganat entfernt (Magen 8-mal, Ösophagus 13-mal, Pharynx 3-mal). Bei 7 Patienten war kein FK zu finden. Die Endoskopie erfolgte zu 50\% am Tag der Ingestion [Median 1,5 T. (1-10)]. Bei 13 Kindern in TZ [m=10; Median 2,6 J. (o,3-15)] wurden 6 Münzen, 3 Metallteile und 3 Fruchtstücke entfernt (Ösophagus 6-mal, Pharynx 6-mal). Bei 1 Säugling, dem ein Stein in Tötungsabsicht in den Ösophagus gepresst worden war, gelang die Extraktion nicht; er verstarb an den Folgen der Tat. Die Symptomdauer lag zwischen 1 T. und 3 J. (Median: 6 T.). In beiden Gruppen waren Hypersalivation und Schluckbeschwerden die häufigsten Symptome.

Diskussion. In TZ waren mehr Jungen betroffen, die Symptomdauer länger, und die Therapie erfolgte später. In beiden Kohorten wurden überwiegend Münzen und Hartprodukte verschluckt, und $>50 \%$ der Kinder war jünger als 3 J., was die Notwendigkeit der häuslichen Prävention unterstreicht. Bis auf einen konnten alle FK entfernt werden; somit ist diese Intervention auch in KH der Grundversorgung möglich.

\section{DGKJ-PO-EG-5}

\section{Fallbeispiel toxisches Megacolon durch Koprostase}

Proprentner M.', Geier N.', Ruef P.'

${ }^{1}$ SLK Kliniken Heilbronn, Heilbronn

Hintergrund. Das toxische Megacolon ist eine seltene, jedoch lebensbedrohliche Komplikation einer Colitis die zu einer akuten Dilatation des Colons führt und systemisch septisch-toxische Auswirkungen hat. Zugrunde liegen kann ein akuter Schub einer Colitis ulcerosa oder einer pseudomembranösen Colitis, eines Morbus Crohn [1] oder auch die Chagas-Krankheit. Infektiöse Ursachen sind eine Infektion durch enterotoxische E.-coli-Stämme [2] und durch Clostridium difficile [3].
Anamnese. Übernahme auf die pädiatrische Intensivstation bei akuter Verschlechterung des Allgemeinzustandes mit Bauchschmerzen und metabolischer Azidose. Anamnestisch bestand seit 2 Tagen Durchfall und Erbrechen. Die bisherige Therapie erfolgte lediglich medikamentös mit Immodium. Eine Enkopresis seit dem 13. Lebensjahr wurde verheimlicht und bisher nicht behandelt.

Klinik. Akutes Abdomen, Koprostase, Sepsis mit DIC, Lungenödem, ARDS, Peritonitis.

Therapie. Diskontinuitätsresektion nach Hartmann mit Deszendostomie und Rektumblindverschluss am 17.02.2012, Revision mit Stuhlausräumung und Spülung des Rektumblindsack; Rektumvollwand-PE ohne enzymhistochemische Hinweise auf eine Innervationsstörung im Sinne eines Morbus Hirschsprung am 03.04.2012.

Diskussion. Unser Fallbeispiel zeigt eindrücklich, dass es auch aufgrund einer Koprostase zu einer fulminanten Entwicklung eines toxischen Megacolons mit Sepsis und ARDS kommen kann.

Literatur

1. Autenrieth DM, Baumgart DC (2012) Toxic megacolon. Inflamm Bowel Dis 18(3):584-591

2. Nayar DM, Vetrivel S, Mc Elroy J et al (2006) Toxic megacolon complicating Escherichia coli infection. J Infect 52(4):S103-106

3. MC Farland LV (2005) Alternative treatments for clostridium difficile disease: what really works? J Med Microbiol 52(2):101-111

\section{DGKJ-PO-EG-6}

Rapunzel-Syndrom - Fallbericht eines seltenen Phänomens

Rickert A.-T.', Düker G. ', Bachour H. ${ }^{2}$, Korczyk J. ${ }^{2}$, Born M. ${ }^{3}$, Franke I. ${ }^{1}$

${ }^{1}$ Klinik und Poliklinik für Allgemeine Pädiatrie, Zentrum für Kinderheilkunde, Universitätsklinikum, Bonn, ${ }^{2}$ Abteilung für Kinderchirurgie, Klinik und Poliklinik für Allgemein-, Viszeral-, Thorax- und Gefäßchirurgie, Universitätsklinikum, Bonn, ${ }^{3} \mathrm{FE}$ Kinderradiologie, Klinik für Radiologie, Universitätsklinikum, Bonn

Einleitung. Das Rapunzel-Syndrom beschreibt das seltene Phänomen eines bis in den Dünndarm reichenden Trichobezoars.

Patientin. Bei dem 11-jährigen Mädchen chinesischstämmiger Eltern war 4 Tage zuvor eine Verhärtung im Bauch aufgefallen. Neben etwas reduziertem Appetit bestanden keine weiteren Symptome. Die körperliche Untersuchung war bis auf die Verhärtung im linken Oberbauch blande. Sonographisch und radiologisch zeigte sich ein stark dilatierter Magen mit echogenem Inhalt ohne Nachweis einer die Magenkontur durchbrechenden Raumforderung. Auf Nachfrage gab die Patientin zu, vor einigen Jahren Haare geschluckt zu haben. Ob sie dies aktuell immer noch tue, konnte das Mädchen nicht beantworten. Endoskopisch stellte sich ein bis ins Duodenum reichendes Trichobezoar dar. Bei wie erwartet endoskopisch frustraner Mobilisation erfolgte die offen-chirurgische Bezoarentfernung.

Diskussion. Das Rapunzel-Syndrom wurde erstmals 1968 beschrieben. Bislang wurde weltweit von weniger als 40 Fällen - häufig aus Asien - berichtet, fast ausschließlich waren Mädchen betroffen. Häufig werden Trichotillomanie und Trichophagie von den Patientinnen verneint. Auf psychiatrische Auffälligkeiten sollte in der Anamnese und Untersuchung geachtet werden. Neben asymptomatischen Verläufen können ein palpabler Tumor, Bauchschmerzen, Erbrechen oder ein Gewichtsverlust auftreten; Obstruktion, Perforation, Invagination und Peritonitis wurden beschrieben. In den meisten berichteten Fällen war eine operative Entfernung des Trichobezoars erforderlich.

Schlussfolgerung. Obwohl sehr selten, sollten Trichobezoare bei Patienten mit unspezifischen Abdominalbeschwerden in die differenzialdiagnostischen Überlegungen einbezogen und eine entsprechende Diagnostik eingeleitet werden. 
DGKJ-PO-EG-7

\section{Zu klein für einen Meckel?}

\section{Josiger N. ', Kiel T.', Trenkel S.', Radke M.'}

${ }^{1}$ Ernst von Bergmann Klinikum, Klinik für Kinder- und Jugendmedizin, Potsdam, ${ }^{2}$ Ernst von Bergmann Klinikum, Klinik für Kinderchirurgie, Potsdam

Hier präsentiert wird ein 9-jähriger Junge mit rezidivierendem rektalem Blutabgang. Hinweise für eine infektiologische Ursache gab es nicht. Durch eine endoskopische Untersuchung des oberen und unteren Magen-Darm-Trakts konnte die Blutungsquelle nicht lokalisiert werden. Allerdings zeigte sich eine von Teerstuhl obstruierte Bauhin-Klappe, die ein Meckel-Divertikel als Ursache der Blutung nahelegte. Die anschließend durchgeführte szintigraphische Untersuchung konnte ein Meckel-Divertikel jedoch nicht verifizieren. Auch durch Kapselendoskopie und explorative Laparoskopie konnte die Blutungsquelle nicht gefunden werden. Im Verlauf kam es infolge einer neuerlichen schweren Hämatochezie zu einer deutlichen Verschlechterung des Allgemeinzustandes. Eine nochmalige Koloskopie erbrachte den Nachweis massiver frischer Blutansammlungen ohne Nachweis der Blutungsquelle. Weder durch eine nachfolgende Sonographie des Abdomens, noch durch eine intraarterielle digitale Substraktionsangiographie konnte eine Klärung herbeigeführt werden. Als Ultima ratio erfolgte eine explorative Laparatomie. Bei der chirurgischen Exploration des Dünndarms fand sich etwa $60 \mathrm{~cm}$ oral der Bauhin-Klappe auf der Mesenterialseite eine auffällige Gewebsschwellung, die als einzig fassbare Veränderung im Dünndarmbereich als Blutungsquelle in Betracht kam. Daraufhin erfolgte die Resektion des tumortragenden Dünndarmabschnitts. Histologisch fand sich im Op-Präparat ein kongenitales, $4 \mathrm{~mm}$ großes Divertikel der Dünndarmwand mit heterotoper Magenschleimhaut, kleinherdigen Ulzerationen sowie eine fokale follikuläre lymphatische Hyperplasie. Sollte der histologische Befund im Sinne eines atypischen „Mikromeckeldivertikels“ gewertet werden?

\section{DGKJ-PO-EG-8}

Gegenüberstellung intravenöser und oraler (enteraler) Rehydratation bei gastrointestinalem Infekt: die GIORGI-Studie

Marquard J. ${ }^{\prime}$, Lerch C. ${ }^{2}$, Rosen A. ${ }^{1}$, Wieczorek H. ${ }^{1}$, Mayatepek E. ${ }^{\prime}$, Meissner T. 'Universitätsklinikum Düsseldorf, Klinik für Allgemeine Pädiatrie, Neonatologie und Kinderkardiologie, Düsseldorf, ${ }^{2}$ Heinrich-Heine-Universität Düsseldorf, Institut für Allgemeinmedizin

Fragestellung. Bei Kindern mit moderater Dehydratation, akuter Gastroenteritis (aGE) und Nahrungsverweigerung wird trotz mangelnder Evidenz eine nasogastrale Rehydratationstherapie (NRT) empfohlen. In der klinischen Praxis wird jedoch häufig eine intravenöse Rehydratationstherapie favorisiert (IRT). Wir untersuchten im Rahmen einer randomisierten klinischen Studie, ob bei Kindern mit moderater Dehydratation und aGE eine NRT der IRT hinsichtlich der Parameter Erfolg der Rehydratation, Länge des Krankenhausaufenthaltes und unerwünschten Ereignissen (UE) überlegen ist.

Material und Methode. Eingeschlossen wurden Patienten der Universitätskinderklinik Düsseldorf im Alter von 3 Monaten bis 6 Jahre mit moderater Dehydratation, aGE und Nahrungsverweigerung. Nach klinischer Einschätzung des Schweregrades der Dehydratation wurden die Patienten randomisiert dem Behandlungsarm NRT oder IRT zugeteilt und über 6 Stunden unter stationären Bedingungen rehydriert.

Ergebnisse. Insgesamt wurde 97 Patienten in die Studie eingeschlossen (46 NRT, 51 IRT). Es zeigten sich keine Unterschiede beim Erfolg der Rehydratationstherapie in Prozent (90\% NRT vs. 92\% IRT), Länge des Krankenhausaufenthaltes im Median [2 (1-3) Tage IRT vs. $2(1,3-3)$ Tage NRT] sowie UEs. Erbrechen war signifikant häufiger in der Gruppe NRT, insgesamt mussten $26 \%$ der Patienten aus der Gruppe NRT auf eine IRT umgestellt werden, jedoch keine Patienten von IRT auf NRT. Schlussfolgerung. IRT ist der NRT hinsichtlich Erfolg und Länge des Krankenhausaufenthaltes gleichwertig, die Häufigkeit von Erbrechen jedoch deutlich geringer. Es sollte erwogen werden, ob IRT neben NRT zur Behandlung einer moderaten Dehydratation bei Kindern mit aGE und Nahrungsverweigerung ebenfalls empfohlen werden sollte.

\section{DGKJ-PO-EG-9}

Verzögerte Diagnose einer Purpura-Schönlein-Henoch-Kolitis bei fehlender Hautmanifestation

\section{Dinkelborg M. ', K. Thiel, K. Lawrenz, N. Uz, A. Ballauff}

${ }^{1}$ Helios Kliniken Krefeld, Kinder- und Jugendmedizin, Krefeld

Einleitung. Die Purpura-Schönlein-Henoch (PSH) ist ein typisches Krankheitsbild der Pädiatrie. Die Inzidenz liegt bei 20/100.00o Kindern $<17$ Jahre. In der Regel wird die Diagnose nach Auftreten der typischen Hautveränderungen (HV) gestellt. Wir möchten einen Jungen mit einer ausgeprägten Colitis vorstellen, bei dem die Diagnose erst verzögert gestellt wurde.

Fallvorstellung. Ein 6,5 Jahre alter Junge stellte sich bei uns mit akuten, seit 3 Tagen zunehmenden, periumbilikal betonten Bauchschmerzen vor. Der Bauch war diffus druckschmerzhaft, jedoch nicht peritonitisch. Im Labor zeigte sich eine Leukozytose, Thrombozytose und ein leicht erhöhtes CrP. Der initiale Ultraschall zeigte verdickte Dünndarmwände im re. Hemiabdomen, partiell wie ein Invaginat imponierend (Kokardenphänomen) und freie Flüssigkeit im kl. Becken. Bei initialem V. a. infektiöse Enteritis (z. B. Yersinien-Infektion) wurde eine Antibiotikabehandlung begonnen bis zum Erhalt negativer Ergebnisse (Stuhlprobe + Serologie). Nach einigen Tagen traten Ekkchymosen an beiden Füßen und Händen auf, dann entwickelte der Junge blutige Stühle. Eine Koloskopie z. A. einer CED zeigte hämorrhagische Schleimhautveränderungen, sowie eine leichte Dünndarminvagination ins Coecum. Die Histologie ergab eine akute erosive Colitis mit lymphofollikulärer Hyperplasie ohne Hinweise für eine Vasculitis, dennoch stellten wir die Diagnose einer Darmbeteiligung bei PSH. Nach Therapiebeginn mit Prednisolon besserte sich rasch die Symptomatik.

Schlussfolgerung. Die Schwierigkeit in diesem Fall war die Diagnose einer Purpura ohne initilale HV zu stellen. Retrospektiv hinweisend war das Kokardenphänomen. Die Colitis bei PSH entsteht in 12\% der Fälle vor den HV. Sie ist neben einer akuten Infektion oder CED eine wichtige Differenzialdiagnose.

\section{DGKJ-PO-EG-10 Schulungstag als Frühintervention bei funktionellen Bauchschmerzen}

Sukiennik J.', Bläsing G. ', Neubersch C. ', Krause R. ', Thiel K. ', Ballauff A. ${ }^{1}$

'Helios Kliniken Krefeld, Kinder- und Jugendmedizin, Krefeld

Einleitung. Funktionelle Bauchschmerzen bei Kindern und Jugendlichen sind ein häufiges Problem. Wir bieten Kindern und ihren Eltern einen Schulungstag an, an dem wir anatomische Grundlagen, Ursachen und Pathophysiologie, sowie Behandlungsansätze vermitteln.

Ergebnisse. Mittels Fragebogen haben wir 3-6 Monate $(n=42)$ und etwa 12 Monate nach Schulung $(\mathrm{n}=29)$ den weiteren Beschwerdeverlauf erfragt. Es zeigten sich keine Unterschiede nach 3-6 vs.12 Monaten, so dass wir die Ergebnisse für die gesamte Gruppe $(n=71)$ darstellen. $85 \%$ der Familien fanden die Schulung hilfreich, 12\% nicht, 3\% teilweise. $73 \%$ hatten zum Zeitpunkt der Befragung geringere Bauchschmerzen und kamen besser damit zurecht. $6 \%$ konnten, bei gleichbleibenden Beschwerden, besser damit umgehen. 21\% zeigten gleichbleibende Beschwerden und unveränderten Umgang damit. 80\% der Patienten hatten vor der Schulung wiederholt in der Schule gefehlt, bei $77 \%$ verringerten sich die Fehlzeiten. Weitere Besuche bei Ärzten oder Heilpraktikern auf Grund der Bauchschmerzen erfolgten nach der Schulung bei $\mathbf{2 6 \%}$. $21 \%$ setzten alternative Therapiemaßnahmen ein. 30\% machten keine, 58\% zeitweilig eine medikamentöse Therapie (meist Iberogast). $23 \%$ führten diätetische Maßnahmen durch. $3 \%$ nahmen an einem von uns 
empfohlenen Entspannungstraining teil, 38\% folgten selbst erarbeiteten stressvermindernden Strategien.

Schlussfolgerung. Die Diagnosestellung und -benennung „funktionelle Bauchschmerzen" ist für die Akzeptanz der chronischen Beschwerden von großer Bedeutung. Der Schulungstag scheint für viele Familien eine gute Hilfe zu sein. Das Verständnis der Ursachen, der Pathophysiologie und der Behandlungsmöglichkeiten, ist wahrscheinlich der Grund für die hohe Besserungsrate.

\section{Verschiedenes (2)}

\section{DGKJ-PO-V2-1}

Nichtinvasive Beatmung und Sekretmanagement bei Kindern mit spinaler Muskelatrophie Typ 1 (SMA 1), Beratung und Begleitung der Familien durch ein Team der spezialisierten ambulanten Palliativversorgung für Kinder und Jugendliche (SAPV)

\section{Pyper A. ', Heisch K. ${ }^{2}$, Richter M. ${ }^{1}$, Nolte-Buchholtz S.' \\ 'Universitätsklinikum Carl Gustav Carus Dresden, Klinik für Kinder- und Ju- gendmedizin, Brückenprojekt, Dresden, ${ }^{2}$ Universitätsklinikum Carl Gustav Carus Dresden, Klinik für Kinder- und Jugendmedizin, Kinderschlaflabor, Dresden}

Einleitung. Die SMA1 wird autosomal rezessiv vererbt und $\mathrm{zu} 98 \%$ durch eine Mutation im SMN1-Gen hervorgerufen. Unbehandelte $\mathrm{Pa}-$ tienten versterben in den ersten zwei Lebensjahren an den Folgen einer chronischen respiratorischen Insuffizienz die durch den fortschreitenden Untergang von motorischen Nervenzellen im Vorderhorn des Rückenmarks mit Denervierung der Muskelzellen verursacht ist. Abgeschwächte Hustenstöße mit schlechter Clearance der distalen Atemwege, Hypoventilation im Schlaf, unzureichende Lungen und Rippenausreifung und im Verlauf rezidivierende pulmonalen Infektionen sind lebenslimitierend. Inzwischen kommt es durch den Einsatz atemunterstützender Maßnahmen zu einer Verlängerung der Überlebenszeit bei besserer Lebensqualität. Durch Sekretmanagement (Atemtherapie, Hustenassistenz) wird die Expiration verbessert und eine Reduktion der Infektionen erreicht. Die Inspiration und nächtliche Hypoventilation wird durch CPAP oder nicht invasive Beatmung (NIV) verbessert. Methoden. Neun Kinder mit SMA 1, wurden durch Zusammenarbeit des SAPV-Team mit dem Kinderschlaflabor beraten und begleitet. Fünf Familien entschieden sich gegen atemunterstützende Maßnahmen, alle verstarben vor Erreichen des ersten Geburtstages. Zwei Patienten erhielten bei beginnender Ateminsuffizienz eine CPAP. Eine Familie entschied sich im Verlauf gegen NIV, der zweite Patient wurde im Verlauf nichtinvasive beatmet. Beide Patienten starben mit ca. zwei Jahren. Zwei weitere Patienten erhielten bzw erhalten eine NIV, z. T. ergänzt durch mechanische Hustenassistenz („,cough-assist").

Schlussfolgerung. Familien steht bei einer lebensverkürzenden Erkrankung wie der SMA 1 eine bedarfsgerechte umfassende Begleitung durch ein SAPV Team, sowie ein Kinderschlaflabor zu. Entscheidungswege sollen vom Betreuungsteam mit getragen und begleitet werden.

\section{DGKJ-PO-V2-2}

Das akute Abdomen als Leitsymptom des hereditären Angioödems

Koestlin L. ', Dahlinger N. ${ }^{\text {' }}$

'Havellandklinik Nauen, Pädiatrie, Nauen

Einleitung. Das hereditäre Angioödem (HAE) ist eine autosomal dominant vererbte Erkrankung mit einer geschätzten Inzidenz von 1:10.ooo bis 1:150.000, davon sind etwa $20 \%$ Spontanmutationen. Durch die Genmutation entsteht ein Mangel an C1-Inhibitor-Protein, welches normalerweise eine hemmende Funktion auf das Komplementsystem ausübt. Durch die reduzierte Aktivität oder Abwesenheit des Proteins kommt es zu einer Aktivierung der Komplementkaskade, welche wie- derum durch die Aktivierung des Kallikrein-Kinin-Systems zu einem erhöhten Bradykininspiegel führt. Dieser ist letztendlich im akuten Schub verantwortlich für eine erhöhte Permeabilität und dadurch bedingt Ödeme, vor allem der Haut, des Magen-Darm-Traktes und der Weichteilorgane. Eine besondere Gefahr stellen mögliche Ödeme der Luftwege dar. Bekannte Triggerfaktoren für Schwellungen bei HAE sind Traumata und Infektionen.

Fallbericht. Wir diskutieren einen Fall aus unserer Klinik, in der sich das HAE über Jahre allein durch heftige Bauchschmerzen und zuletzt im Rahmen eines akuten Abdomens mit ausgeprägter Aszites präsentierte. Bei wenigen Patienten treten die abdominellen Beschwerden isoliert ohne Hautsymptome auf. Dies kann, wie in unserem Fall dazu führen, dass die Symptomatik nicht als Ursache eines HAE in Betracht gezogen wird, und die Erkrankung unerkannt bleibt. In manchen Fällen führt dies auch zu unnötigen Operationen, da die Erkrankung auch in der Differenzialdiagnose des akuten Abdomens im Regelfall nicht berücksichtigt wird.

Schlussfolgerung. Anhand unserer Fallvorstellung betonen wir noch einmal die Bedeutung der Erkrankung im klinischen Alltag. Um eine korrekte Therapie zu gewährleisten, ist es wichtig die Diagnose frühzeitig zu sichern. Die aktuell empfohlenen Möglichkeiten der Diagnose und Therapie werden erläutert.

\section{DGKJ-PO-V2-3}

Multiple Exostosen als seltene Ursache für Thoraxschmerzen im Kindes- und Jugendalter

Thamer A. ', Datz N. ${ }^{1}$, Jokuti L. ${ }^{2}$, Engelcke G. ${ }^{2}$, Kujath C. ${ }^{3}$, Sinnig M. ${ }^{3}$, Ludwikowski B. ${ }^{3}$, Kordonouri $0 .{ }^{1}$

${ }^{1}$ Kinderkrankenhaus auf der Bult, Allgemeinpädiatrie, Hannover, ${ }^{2}$ Kinderkrankenhaus auf der Bult, Kinderradiologie, Hannover, ${ }^{3}$ Kinderkrankenhaus auf der Bult, Kinderchirurgie, Hannover

Hintergrund. Thoraxschmerzen sind ein häufiges Symptom im Kindes- und Jugendalter. Differenzialdiagnostisch sollten insbesondere pulmonale, kardiale, gastroösophageale oder traumatische Ursachen abgeklärt werden.

Material und Methoden. Wir berichten über einen 10-jährigen Jungen, der sich mit akuten Thoraxschmerzen in unserer Notfallambulanz vorstellte. Es bestand kein Fieber und kein Husten, ein Trauma war nicht erinnerlich. Eine Dys- oder Tachypnoe lag nicht vor. Bei der körperlichen Untersuchung fiel ein abgeschwächtes Atemgeräusch mit gedämpftem Klopfschall rechts basal auf. Anamnestisch lag eine operative Entfernung einer Exostose an der linken Schulter im Alter von 5 Jahren vor.

Ergebnisse. Im Röntgen-Thorax-Darstellung eines rechtsseitigen Pleuraergusses sowie nebenbefundlich einer unklaren Rippenfehlbildung rechts. Die sonographische Untersuchung der Pleura zeigte einen rechtseitigen echoarmen Erguss mit Kammerungstendenz. Laborchemisch keine Entzündungszeichen und kein Anhalt für eine hämatologische Genese. Nach diagnostischer Punktion von hämorraghischem Punktat plötzlich einsetzende Atemnot. In der Computertomographie Darstellung eines Spannungspneumothorax rechts mit Pleuraerguss aufgrund einer Pleuraverletzung durch innenseitige Rippenexostose sowie lokale Verwachsungen der parietalen und viszeralen Pleura an der 7. Rippe und Rippenexostose links mit Kontakt zum Perikard. Nach Stabilisierung erfolgte therapeutisch eine Thorakoskopie mit erfolgreicher partieller Resektion der Exostosen.

Schlussfolgerung. Bei Thoraxschmerzen ist neben einer pulmonalen, kardialen, gastroösophagealen oder traumatischen Genese auch an seltenere Ursachen zu denken. Bei bekannten Exostosen sind regelmäßige Kontrollen, insbesondere während des Wachstums, zu empfehlen. 
DGKJ-PO-V2-4

Riga-Fede-Krankheit bei einem Säugling

Spyridonos T. ${ }^{1}$, Menke T. ${ }^{\text {, }}$ Paulussen M. ${ }^{1}$

'Vestische Kinder- und Jugendklinik Datteln, Universität Witten/Herdecke, Datteln

Einleitung. Charakterisiert wird die Riga-Fede-Krankheit durch persistierende Geschwürbildung ausschließlich auf der Zunge, bedingt durch mechanische kontinuierliche Irritation durch die Zähne. Mikroskopisch lässt sich ein Entzündungsinfiltrat aus Lymphozyten, Makrophagen, Mastzellen und eine reichliche Anzahl von Eosinophilen ausmachen. Die Krankheit kann mit konservativen Maßnahmen behandelt werden.

Fallbericht. Ein 11 Monat alter männlicher Säugling mit einer Entwicklungsverzögerung wurde mit einer Ulzeration im Bereich der ventralen Oberfläche der Zunge vorgestellt. Die Läsion schien schmerzhaft zu sein, da es Fütterung Schwierigkeiten gab sowie Unruhezustände. Beim Säugling wurde die Diagnose Riga Fede gestellt.

Fazit. Eine persistierende Ulzeration auf der Zunge kann zu unzureichender Nahrungsaufnahme führen, Wachstumsstörungen, Entwicklung einer Superinfektion bis zur Verstümmelung der Zunge. Frühzeitige Diagnose und Behandlung kann mögliche Komplikationen vermeiden.

\section{DGKJ-PO-V2-5}

In-vitro-Einfluss von TNFa-, IL1- und IL6-Antagonisten (Biologika) auf das Zytokin-Netzwerk bei Patienten mit systemischer juveniler idiopathischer Arthritis (sJIA)

Robinson B. ', Kirchner M. ', Sonnenschein A. ', Mannhardt-Laakmann W. ${ }^{1}$ 'Universitätsmedizin der Johannes Gutenberg-Universität Mainz, Pädiatrische Immunologie und Rheumatologie, Mainz

Fragestellung. Die Zytokine IL1, IL6 und TNFa gelten als Mediatoren der Inflammation bei sJIA. Wir untersuchten in einem In-vitro-Zellkulturmodell, inwieweit die selektive Zytokinblockade das übrige Zytokinnetzwerk beeinflusst.

Material und Methode. Periphere mononukleäre Zellen von 10 Patienten mit sJIA und 10 Gesunden wurden mit Lipopolysacharid (LPS), in weiteren Ansätzen zusätzlich mit Tocilizumab (IL6)-, Anakinra und Canakinumab (IL1)-, Adalinumab (TNF)-Blocker in vitro kultiviert. Nach 24 Stunden wurden im Überstand IL-1 $\beta,-2,-4,-5,-6,-8,-10,-12 \mathrm{p} 70,-17 \mathrm{~A}$, IFN $\gamma$, TNF $\alpha$ durchflusszytometrisch quantitativ bestimmt. Der Quotient der Zytokinkonzentration aus LPS-Biologika- zu unstimulierter Kultur verdeutlicht den Einfluss der einzelnen Biologika auf das übrige Zytokinnetzwerk.

Ergebnisse. Im Vergleich zu Gesunden (KO) finden sich bei sJIA-Patienten nach LPS-Stimulation höhere Konzentrationen von IL1 und IL6, während TNFa signifikant vermindert sezerniert wird. Tocilizumab und Adalimumab supprimieren IL- 6 und TNFa, steigern jedoch IL1 bei sJIA. Demgegenüber hemmen Anakinra und Canakinumab sowohl IL1, IL6 als auch TNFa, sowohl bei sJIA als auch KO. Das antiinflammatorische Zytokin IL-10 wird bei sJIA in geringerer Konzentration ausgeschüttet als bei KO. Alle untersuchten Biologika hemmen IL-10 zusätzlich. Die Zytokine IL-4 und IL-17A werden bei sJIA nicht sezerniert.

Diskussion. Tocilizumab, Anakinra und Canakinumab wirken signifikant, allerdings nicht selektiv antiinflammatorisch auf die Zytokinexpression bei sJIA. Canakinumab zeigt eine höhere IL1-Spezifität als Anakinra. TNFa, IL4 und IL17 spielen, im Vergleich zur Oligoarthritis, bei sJIA keine Rolle. Allerdings scheint die antiinflammatorische Autoregulation durch ILıo signifikant eingeschränkt zu sein.

\section{DGKJ-PO-V2-6}

Unterschiede bezüglich der Oberflächenmarker und der Zytokinexpression dendritischer Zellen zwischen Patienten mit juveniler Oligoarthritis (oJIA) und Gesunden nach In-vitro-Stimulation mit Toll-like-Rezeptor (TLR)-Liganden

BosserhoffA.-K. ${ }^{1}$, Kirchner M. ${ }^{1}$, Sonnenschein A. ${ }^{1}$, Mannhardt-Laakmann W. 'Universitätsmedizin der Johannes Gutenberg-Universität Mainz, Pädiatrische Immunologie und Rheumatologie, Mainz

Fragestellung. Dendritische Zellen erkennen körpereigene Strukturen und stehen deshalb im Fokus neuerer Hypothesen zu Entstehung der oJIA. Wir untersuchten bei 10 Gesunden (KO) und 10 oJIA-Patienten, inwieweit sich die Aktivierungsmerkmale dendritischer Zellen [Oberflächenantigene (OA) CD8o, CD83, CD86, HLA-DR und CD209, Zytokinexpression] unterscheiden.

Material und Methode. Aus peripheren mononukleären Zellen wurden CD14+-Monozyten isoliert und durch Inkubation mit GM-CSF und IL-4 zu unreifen dendritischen Zellen (DZ) differenziert. Die kultivierten DZ wurden mit TLR-Liganden (Zymosan, PolyIC, LPS, Flagellin, Malp2, CPG A und B, Loxoribin, R848 und PamCys) stimuliert. Kulturen ohne Pathogene dienten als Vergleich. Nach 24 h erfolgte die durchflusszytometrische Detektion der genannten OA sowie die quantitative Analyse der Zytokine IL-1b, IL-2, IL-4, IL-6, IL-8, IL-10 und TNFa.

Ergebnisse. Im Vergleich zu KO findet sich nach Stimulation mit allen TLR-Liganden eine höhere Expression der OA CD8o, CD83 und HLADR. Bei Patienten und KO zeigt sich gleichermaßen ein signifikanter Anstieg der Zytokine IL-10, IL-1b und TNFa nach Stimulation. Zusätzlich steigen IL-10 und TNFa nach Stimulation bei KO signifikant stärker an als bei Patienten. Nach Stimulation sinkt die Konzentration von IL-8 nur bei KO und IL-4 nur bei Patienten signifikant.

Diskussion. Die DZ der KO reagieren generell stärker auf eine Stimulation mit TLR-Liganden. Die verminderte Stimulierbarkeit der oJIA-DZ im Vergleich zu KO-DZ könnte Ausdruck einer Überaktivierung durch endogene TLR-Liganden sein. Zudem scheint eine adäquate Hemmung der Th1-Antwort durch die gesteigerte Ausschüttung des immunregulatorischen IL-10 nur bei KO zu erfolgen.

\section{DGKJ-PO-V2-7}

Die eosinophile Fasziitis - eine seltene Differenzialdiagnose von Arthritis im Kindesalter

Dimitrova T.', Ganser G. ${ }^{1}$

${ }^{1}$ St. Josef-Stift, Kinderrheumatologie, Sendenhorst

Fallbericht. Ein 13-jähriger Patient wird drei Monate nach Krankheitsbeginn vorgestellt. Allgemeinsymptome sind Müdigkeit und Leistungsabfall. Initial treten Schmerzen in den Fingern, Handgelenken, Ellenbogengelenken, Rücken auf, im Verlauf progrediente Bewegungseinschränkungen an allen großen und kleinen Gelenken mit Überwärmung. Arthrosonographisch sind keine Synovialitis oder Ergussbildung an den Gelenken nachweisbar. Sklerodermiforme Hautverdickung um die Hand- und Sprunggelenke mit livider Verfärbung. Familienanamnese: negativ für rheumatische Erkrankungen, ein Zwillingsbruder (zweieiig) und die Eltern sind gesund.

Methoden. Labor-Diagnostik. CRP: $2,31 \mathrm{mg} / \mathrm{dl}$, BSG: 11/35 mm, Eosinophilie im Blut: $24,5 \%$. Immunpathologisch ergibt sich kein Hinweis auf eine Kollagenerkrankung. Die Knochenmarkspunktion ist unauffällig bis auf eine Eosinophilie von 22\%. Magnetresonanztomographisch das Bild eines unspezifischen Weichteilödems am Unterschenkel. Eine Biopsie bestätigt die Verdachtsdiagnose Eosinophile Fasziitis.

Therapie. Prednisolon p.o., Methotrexat s.c., Methylprednisolonstöße, begleitend intensive Physio- und Ergotherapie. Vier Monate nach Therapiebeginn sind die Bewegungseinschränkungen und die Hauterscheinungen weitgehend unverändert. Bislang keine Beteiligung von inneren Organen. 
Schlussfolgerung. Die eosinophile Fasziitis ist eine seltene Erkrankung im Erwachsenenalter, in der Pädiatrie eine Rarität. Als Standardtherapie in der Rheumatologie gilt die orale Cortisontherapie. Bei unzureichendem Ansprechen wird Methotrexat empfohlen. Einzelne Fallberichte in der Pädiatrie berichten das Erreichen einer Remission unter der Therapie mit Cortison und Methotrexat. Bei Therapieresistenz stellen Biologica möglicherweise eine Alternative zu Methotrexat dar, um das Fortschreiten der Erkrankung zu verhindern.

\section{DGKJ-PO-V2-8}

Cryopyrin-assoziierte periodische Syndrome (CAPS): Heterozygotie für eine von Exon 3 des NLRP3-Gens kodierte Q703K-Substitution mit unklarer phänotypischer Relevanz

\section{Schuster K.', Lohse P. ${ }^{2}$, Speckmann C. ${ }^{3}$, Ehl S. ${ }^{3}$, Kümmerle-Deschner J. ${ }^{4}$} Schulze $I^{3}$

${ }^{1}$ University Hospital Freiburg, Center for Pediatrics and Adolescent Medicine, Freiburg im Breisgau, ${ }^{2}$ Institut für Laboratoriumsmedizin, Singen, ${ }^{3} \mathrm{CCl}-$ Center for Chronic Immunodeficiencies, Freiburg, ${ }^{4}$ Klinik für Kinder- und Jugendmedizin, Abteilung für pädiatrische Rheumatologie, Autoinflammation Reference Center Tübingen, Tübingen

Einleitung. Das Muckle-Wells-Syndrom (MWS) ist eine autoinflammatorische Krankheit, die durch rezidivierende Fieberschübe, Arthralgien, Exantheme und eine progressive Innenohrschwerhörigkeit gekennzeichnet ist. Die Erkrankung gehört zu den Cryopyrin-assoziierten periodischen Syndromen (CAPS), die auf einer Mutation im NLRP3-Gen auf Chromosom 1 beruhen und autosomal dominant vererbt werden. Fallbericht. Vorgestellt wird ein 13-jähriger Patient mit rezidivierenden Fieberepisoden, schwerer Abgeschlagenheit, Kopfschmerzen und Myalgien sowie einer Konjunktivitis. Beginn ab dem 8. Lebensjahr, seither mit Unterbrechungen alle 2-3 Monate Fieber über 3 Wochen. Bekannte Innenohrschwerhörigkeit seit dem 3. Lebensjahr. Eine Schwester leidet ebenfalls an Innenohrschwerhörigkeit, zeigt jedoch keine Fieberschübe. Die Symptomatik spricht auf Decortin an. In der molekulargenetischen Untersuchung zeigt sich beim Indexpatienten ein heterozygoter Trägerstatus für eine Q703K-Substitution, jedoch nicht bei seiner Schwester. Diskussion. Die Allelfrequenz dieser Mutation beträgt ca. 4-5\%, was eher auf einen benignen Polymorphismus hinweist. Einige Fallberichte unterstützen jedoch den Verdacht, dass es sich hierbei um eine krankheitsrelevante Mutation mit niedriger phänotypischer Penetranz und variabler Expression handelt. Eine Innenohrschwerhörigkeit ist bei symptomatischen Trägern dieser Mutation bislang nicht beschrieben. Ein diagnostischer Therapieversuch mit dem Il-1 $\beta$-Antagonisten Canakinumab wird derzeit eingeleitet.

Fazit. Die Bedeutung der Q703K-Variante ist bislang nicht eindeutig geklärt. Ein erfolgreicher diagnostischer Therapieversuch könnte dazu beitragen, die Hypothese einer krankheitsrelevanten Mutation mit niedriger phänotypischer Relevanz zu stützen.

\section{DGKJ-PO-V2-9 \\ "Allergische" Proktokolitis des Säuglings als Erstmanifestation einer septischen Granulomatose (CGD) bei zwei Brüdern}

\section{Springer J.', Ballauff A. ', Dückers G. ', Hemmerlein B. ${ }^{2}$, Niehues T. ${ }^{1}$ \\ ${ }^{1}$ Helios Klinikum Krefeld, Zentrum für Kinder- und Jugendmedizin, Krefeld, ${ }^{2}$ Helios Klinikum Krefeld, Institut für Pathologie, Krefeld}

Einleitung. Blutauflagerungen auf dem Stuhl bei sonst gesunden Säuglingen sind oft durch eine allergische Proktokolitis bedingt, meist als Reaktion auf Kuhmilcheiweiß. Die Diagnose wird ex juvantibus gestellt durch Besserung unter Eliminationsdiät. Ausheilung bei $>90 \%$ der Kinder im 1. LJ. Wir präsentieren zwei Brüder mit blutigen Stühlen im ersten Lebenshalbjahr, die sich unter einer Aminosäurediät normalisierten, bei denen aber weitere Symptome im Verlauf zur Diagnose septische Granulomatose führten.
Kasuistik. 5 Monate alter, gut gediehener Junge mit blutigen Stühlen nach einem Infekt. Aufgrund erhöhtem CRP und Eisenmangelanämie Indikation zur Koloskopie. Befund vereinbar mit einer allergischen Proktokolitis. Unter Aminosäurediät Normalisierung von Stuhl u. Labor. Bei wiederholten leichten Infekten (10x/J) erneut blutige Stühle. Beim jüngeren Bruder ebenfalls blutige Stühle mit 3 Monaten unter Muttermilch, sofortige Besserung unter Aminosäurediät. Ebenfalls CRP- sowie Transaminasenerhöhung. Als beide Brüder eine Lymphadenitis entwickeln, wird eine immunologische Diagnostik eingeleitet: Leukozytendifferenzierung, Ig-Hauptklassen und Komplementfaktoren normwertig. Pathologischer Granulozytenfunktionstest (DHR-Test), der V. a. eine CGD wurde molekulargenetisch in beiden Fällen bestätigt.

Diskussion. Verschiedene immunologisch bedingte Kolitiden des Säuglings können auf Antigenreduktion der Nahrung ansprechen. Die Fehldiagnose allergische Proktokolitis bei seltenen Formen der Earlyonset-CED oder Kolitiden bei Immundefektsyndromen führt oft $\mathrm{zu}$ einer verzögerten Diagnosestellung. Bei schwerer Symptomatik oder untypischen Befunden bei blutigen Stühlen im Säuglingsalter sollte trotz gutem Ansprechen auf eine Eliminationsdiät eine weiterführende immunologische Diagnostik erfolgen.

\section{DGKJ-PO-V2-10}

Complementary and alternative medicine in pediatrics: a systematic overview/synthesis of Cochrane Collaboration reviews

\section{Schroeder N.', Meyer S. ${ }^{2}$}

${ }^{1}$ Universitätskinderklinik, Homburg, ${ }^{2}$ Universität des Saarlandes, Homburg

Background. A high prevalence of complementary and alternative medicine (CAM) use has been documented in children with chronic illnesses. Conversely, evidence based medicine is considered an important contributor in providing the best quality of care.

Methods. We performed a systematic overview/synthesis of all Cochrane Reviews published between 1996 and 2012 in pediatrics, assessing the efficacy, and clinical implications and limitations of CAM use in children. Main outcome variables: Percentage of reviews that concluded that a certain intervention provides a benefit, percentage of reviews that concluded that a certain intervention should not be performed, and percentage of studies that concluded that the current level of evidence is inconclusive. Results. 135 reviews were enrolled - most often from the United Kingdom (29/135), Australia (24/135) and China (24/135). In only 5/135 (3.7\%) of reviews a recommendation in favour of a certain intervention was given; $26 / 135(19.3 \%)$ issued a conditional positive recommendation, while $9 / 135$ (6.7\%) reviews concluded that certain interventions should not be performed. Ninety-five reviews (70.4\%) were inconclusive. The proportion of inconclusive reviews increased during 3 , a priori defined time intervals [1995-2000: 15/27 (55.6\%); 2001-2006: 33/44 (75\%); and 2007-2012: 47/64 (73.4\%)]. The 3 most common criticisms with regard to quality of enrolled studies were: more research needed (82/135), low methodological quality (57/135) and small number of study participants (48/135).

Conclusions. Given the disproportionate number of inconclusive reviews, there is an ongoing need for high quality research to assess a potential role of CAM in children.

\section{DGKJ-PO-V2-11}

Anwendungshäufigkeit von Komplementärmedizin bei Kindern in Europa

\section{Zuzak T.J. ${ }^{1,2}$, Längler A. ${ }^{1,3}$}

'Gemeinschaftskrankenhaus, Kinder- und Jugendmedizin, Herdecke, ${ }^{2}$ Unikinderklinik Essen, Kinder- und Jugendmedizin, Essen, ${ }^{3}$ Universität Witten/Herdecke, Lehrstuhl für Medizintheorie, Integrative und Anthroposophische Medizin, Witten

Einführung. Es sind nur wenige Daten über die Anwendung von komplementärer und alternativer Medizin (CAM) in Europa bekannt; von 
diesen behandeln die wenigsten die Anwendung von CAM bei Kindern. Eine gesamteuropäische Übersicht gab es bisher noch nicht.

Methoden. Es wurde eine nicht-systematische, narrative Untersuchung der Anwendung von CAM in Europa durchgeführt, indem Daten aus veröffentlichten Befragungen mit Expertenmeinungen aus 20 Ländern kombiniert wurden. Dabei wurden lokal, als auch international veröffentlichte Umfragen ausgewertet, zusammengefasst und die Prävalenz des CAM-Gebrauchs berechnet. Einschränkungen durch den Mangel an repräsentativen Studien und durch unterschiedliche Definitionen des CAM-Gebrauchs in den verschiedenen Ländern konnten durch den Einbezug von 18 lokalen CAM-Expertenmeinungen größtmöglich kompensiert werden.

Ergebnisse. Es wurden Daten aus 20 europäischen Ländern ausgewertet. Umfragen über die Anwendung von CAM bei Kindern waren in $55 \%$ der untersuchten Länder verfügbar. Die herausgearbeitete Prävalenz des CAM-Gebrauchs von Kindern in Europa war 54\%. Die befragten CAM-Experten in der Pädiatrie berichteten über eine steigende Anwendung von CAM und dessen Wahrnehmung in Gesundheitswesen in den meisten Ländern.

Schlussfolgerung. In Europa scheint das Anwenden von CAM nicht nur unter Erwachsenen sondern auch unter Kindern weit verbreitet zu sein. Durch den steigenden Gebrauch von CAM bei Kindern in Europa wird zusätzliche Forschung über die Anwendung, aber auch über die Effizienz und potenzielle Nebenwirkungen der CAM-Therapien notwendig. In einem nächsten Schritt sollte eine gesamt europäische Definition von CAM gefunden werden, um repräsentative, zwischen den einzelnen Ländern vergleichbar Studien erarbeiten zu können.

\section{DGKJ-PO-V2-12}

familycare - Ein neues Modell der Familienärztlichen Versorgung

\section{König B. ', Reichardt J.' \\ 'familycare, Berlin, Deutschland}

Pädiatrie ist immer auch Familienmedizin. Um den Anspruch der generationenübergreifenden Versorgung von Familien zu realisieren, haben wir ein Konzept - familycare - entwickelt. Dabei sind Pädiater sowie Allgemeinmediziner in der Betreuung von Kindern, Eltern und Großeltern in gemeinsamen Praxisräumen tätig. Dies bedeutet für Pädiater und Allgemeinmediziner, die jeweils andere hausärztliche Fachrichtung als Kooperationspartner wahrzunehmen. Mit der Marke familycare als Organisationsform werden fortlaufend Ideen konkretisiert und Abläufe optimiert. Wir bieten für Familien eine Versorgung mit besonderer Praxislogistik:

- Separate Wartebereiche für die verschiedenen Altersgruppen;

- Behandlungszimmer für Neugeborene und Säuglinge (mit professioneller Wärmelampe, Hüft- und Schädelsonografie, transkutaner Bilirubinmessung) und Stillzimmer;

- hausärztliche Betreuung von Schwangeren und deren postpartale Versorgung;

- Kettentermine für alle Familienmitglieder, welche die Wartezeiten deutlich reduzieren;

- zusätzlich additive Effekte wie Kontrollen des Impfstatus der gesamten Familie;

- die Transition als Überführung von Jugendlichen in die Erwachsenenmedizin ist bei uns bereits konstituiert;

Dieses Praxiskonzept ist attraktiv für Familien, da das begrenzte Zeitkontingent berücksichtigt wird. Es werden bei uns im Vergleich deutlich mehr Vorsorgeuntersuchungen und Impfungen durchgeführt. Geplant ist, unser Praxiskonzept um weitere Fachgruppen (z.B. Gynäkologe/ Hebamme/ HNO/Augenarzt) im Rahmen eines Praxisverbundes zu erweitern und dies als neuen Standard zu etablieren. Zusammenfassend bieten wir, in dieser Form und unter der Marke familycare, erstmals ganz konkret und umfassend eine wirkliche Versorgung für die ganze Familie (drei Generationen) „aus einer Hand“ an.

\section{Gastroenterologie/Ernährung}

\section{DGKJ-PO-G-1}

Darmreinigungsverfahren in der pädiatrischen Koloskopie: Ergebnisse einer multizentrischen Beobachtungsstudie

Berger T. , Claßen M. ${ }^{2}$, Engelhardt H. ${ }^{3}$, Keller K.-M. ${ }^{4}$, Laaß M. ${ }^{5}$, Melchior R. ${ }^{6}$, Posovszky C. ${ }^{7}$, Rodeck B. ${ }^{8}$, Schaper K. ${ }^{9}$, Behrens R. $^{10}$

'Vestische Kinder- und Jugendklinik - Universität Witten/Herdecke, Datteln, ${ }^{2}$ Klinikum Links der Weser gGmbH, Bremen, ${ }^{3}$ Kinderkrankenhaus St. Marien, Landshut, ${ }^{4}$ Deutsche Klinik für Diagnostik $\mathrm{GmbH}$, Wiesbaden, ${ }^{5}$ Universitätsklinikum Carl Gustav Carus, Dresden, ${ }^{6}$ Facharztpraxis für Kinder und Jugendliche, Kassel, ${ }^{7}$ Universitätsklinikum, Ulm, ${ }^{8} \mathrm{Christliches}$ Kinderhospital, Osnabrück, ${ }^{9}$ Universität Witten/Herdecke, Institut für Medizinische Biometrie und Epidemiologie (IMBE), Witten, ${ }^{10}$ Klinikum, Nürnberg

Fragestellung. Analyse der Koloskopievorbereitung und deren Einfluss auf die Ergebnisqualität.

Methode. Von November 2011 bis Oktober 2012 meldeten 29 Zentren über eine Online-Datenbank insgesamt 769 Koloskopien, davon waren 95\% komplette Koloskopien. Der Einfluss der erfassten Parameter auf den Reinigungseffekt (Aronchick-Score), die Komplikationsrate, die Untersuchungsdauer und die Beurteilbarkeit der Koloskopie wurde mittels logistischer bzw. linearer Regression untersucht.

Ergebnisse. Die verwendeten Maßnahmen verteilten sich wie folgt: Picosulfat 54\%, rektale Abführmaßnahmen 44\%, Macrogol 41\%, phosphathaltige Laxantien 9\%, Sonstige 12\% (Mehrfachnennungen). Der Reinigungseffekt war bei $73 \%$ der Untersuchungen gut bis exzellent, mit deutlichen Unterschieden zwischen den einzelnen Zentren. Die Komplikationsraten betrugen $22 \%$ während der Vorbereitungsphase und 12\% während der Endoskopie selbst, diese waren überwiegend leichter Natur. Weder die Vorbereitungsdauer noch die eingesetzten Medikamente hatten einen Einfluss auf die Parameter "Reinigungseffekt", „Komplikationsrate während der Endoskopie“ und "Gesamtbeurteilung“. Dagegen war das Risiko für Komplikationen in der Vorbereitungsphase bei Einsatz von Macrogol erhöht (OR 3,46; $<<0,01)$ und bei Einsatz von Picosulfat erniedrigt (OR o,416; $\mathrm{p}<0,01)$. Insbesondere war das Risiko, eine Magensonde zu erhalten, bei Anwendung von Macrogol um das 27,6-fache erhöht.

Schlussfolgerung. Es handelt sich um die erste Auswertung dieser Art in Deutschland. Wir konnten in Übereinstimmung mit der Literatur deutliche Zusammenhänge zwischen den verwendeten Medikamenten und dem Komplikationsrisiko in der Vorbereitungsphase finden. Die Unterschiede im Reinigungsergebnis lassen sich dagegen durch die von uns erfassten Faktoren nicht erklären.

\section{DGKJ-PO-G-2}

Gedeihstörung und ausgeprägte mesenteriale Lymphadenopathie durch chronische Helicobacter-pylori-Duodenitis bei 1-jährigem Jungen - ein Fallbericht

Thomas V. ', Noss J.', Saadi S. ', Leiz S.

'Klinikum Dritter Orden München, Klinik für Kinder- und Jugendheilkunde, München

Fallbericht. Wir berichten über einen $13 / 12$-jährigen Jungen mit ausgeprägter mesenterialer Lymphadenopathie, ausgelöst durch eine Helicobacter-pylori-positive Duodenitis. Der Patient war bereits im 3. Lebensmonat von der 50. auf die 3. Gewichtsperzentile abgewichen und daher mit der Diagnose einer frühkindlichen Fütterstörung in Betreuung. In der Woche vor Aufnahme war er appetitlos und hatte 1,2 kg Körpergewicht verloren, ohne andere akute Symptome. Im Rahmen der Abklärung der Gedeihstörung wurde eine Abdomensonographie durchgeführt, welche eine auffallend paketartige mesenteriale Lymphadenopathie zeigte. In einer breiten Diagnostik fand sich als einzig weiterer pathologischer Befund eine deutlich erhöhte Calprotectin- 
Konzentration im Stuhl. Eine daraufhin durchgeführte Ösophagogastroduodenoskopie (ÖGD) erbrachte eine chronische Duodenitis und eine wahrscheinlich refluxbedingte Ösophagitis. Interessanterweise konnten Helicobacter pylori im Duodenum nachgewiesen werden. Nach Eradikationstherapie über 7 Tage (Amoxicillin, Clarithromycin) sowie Omeprazol-Therapie war der abdominelle Lymphknotenbefund deutlich rückläufig.

Schlussfolgerung. Eine derart ausgeprägte mesenteriale Lymphadenopathie im Kindesalter ist ein seltener Befund und sollte immer eine ÖGD als essentiellen Bestandteil der Diagnostik mit umfassen. Eine Helicobacter-pylori-Infektion sollte bereits bei unspezifischen Symptomen wie Gedeihstörung und wiederkehrendem Erbrechen in Betracht gezogen werden.

\section{DGKJ-PO-G-3}

\section{Pneumatosis intestinalis im Neugeborenenalter - nicht immer eine NEC - ein Fallbericht}

\section{Franzel J.', Welsch S.', Schaper J.', Schoppe M. ${ }^{3}$, Mayatepek E.', Friedt M. ${ }^{1}$} 'Universitätsklinikum Düsseldorf, Klinik für Allgemeine Pädiatrie, Neonatologie und Kinderkardiologie, Düsseldorf, ${ }^{2}$ Universitätsklinikum Düsseldorf, Institut für diagnostische und interventionelle Radiologie, Düsseldorf, ${ }^{3}$ Universitätsklinikum Düsseldorf, Institut für Pathologie, Düsseldorf

Fallbericht. Wir berichten den Fall eines ehem. Zwillings-FG der $35+6$ SSW, welches per prim. Sectio nach komplikationsloser SS entbunden wurde. Gute postnatale kardiopulmonale Adaptation. Es erfolgte der Nahrungsaufbau mit Pre-Nahrung. Am 8. Lebenstag Auftreten von blutigen, dünnen Stühlen und pathologischen Abdominalbefund sowie Bauchschmerzen. Abdomensonographisch zeigte sich eine Gasansammlung im portalvenösen System sowie in der Wand des C. desc. Die Röntgen Abdomenübersicht blieb unauffällig. Bei V. a. eine NEC erfolgte die Verlegung auf die neonatologische Intensivstation und eine initiale orale Nahrungskarenz. Mikrobiologische und virologische Stuhluntersuchungen blieben unauffällig. Bei weiterhin negativen Entzündungsparametern und klinisch gebesserten Abdomen wurde erneut mit dem enteralen Nahrungsaufbau begonnen. Bei wieder auftretender blutiger Diarrhoe und Bauchschmerzen folgte die Durchführung einer Sigmoidoskopie, welche makroskopisch eine ausgeprägte hämorrhagisch-ödematöse Colitis im distalen Sigma sowie histologisch eine eosinophile Colitis zeigte. Bei V. a. eine Kuhmilchproteinallergie (KMPA) erfolgte die sofortige Umstellung auf eine aminosäurebasierte Formulanahrung. Hierunter rasche Besserung der klinischen Symptomatik. Zur Diagnosesicherung erfolgte eine Kuhmilchprovokation nach 6 Wochen. Hierunter erneut Koliken und vermehrt flüssige Stühle, so dass die KMPA gesichert werden konnte. Unter aminosäurebasierter Nahrung zeigte der Patient im Weiteren einen erfreulichen Verlauf mit guter Gewichtsentwicklung.

Schlussfolgerung. Bei geschilderter Symptomatik im Neugeborenenalter mit blutiger Diarrhoe, Koliken und Pneumatosis intestinalis ist neben einer NEC differenzialdiagnostisch auch an eine KMPA zu denken. Ein möglicher kausaler Zusammenhang von NEC und KMPA wird aktuell diskutiert.

\section{DGKJ-PO-G-4 \\ Infliximabtherapie bei einer Patientin mit Hermansky-Pudlak- Syndrom und CED}

Tyman S. ', Völker A. ', Pilic D. ', Hamelmann E. ', Lücke T.', Ballmann M.', Epplen I. ${ }^{2}$, Schmidt-Choudhury $A .{ }^{\prime}$

${ }^{1}$ Kinder- und Jugendklinik der Ruhr-Universität im St. Josef Hospital, Bochum, ${ }^{2}$ Humangenetik der Medizinischen Fakultät der Ruhr-Universität, Bochum

Einleitung. Verlegung einer 12-jährigen Patientin in unsere Klinik wegen einer therapierefraktären Colitis ulcerosa und Vorliegen eines schmerzhaften Analprolapses. Die Initialtherapie mit Steroiden und Metronidazol verbesserte die Beschwerdesymptomatik geringfügig. Nebenbefundlich bestehen ein seit Geburt bekannter Albinismus sowie ein horizontaler Nystagmus mit Visusverlust beider Augen.

Methode. Die beiden beschriebenen Charakteristika in Assoziation mit dem Vorliegen einer chronisch entzündlichen Darmerkrankung sind charakteristisch für das Hermansky-Pudlak-Syndrom (HPS). In der Literatur sind Fälle bei Erwachsenen beschrieben, darunter 8 Berichte einer erfolgreichen Infliximabtherapie. Es gibt bisher nur 1 publizierten pädiatrischen Patienten mit Hermansky-Pudlak-Syndrom, bei dem eine CED beschrieben wurde. Dieser Patient wurde ebenfalls mit Infliximab behandelt.

Verlauf. Bei der Patientin wurde die systemische Therapie fortgeführt und bei ausgeprägtem Anal-/Rektumprolaps mit tiefer, sehr schmerzhafter Fissur eine operative Intervention erwogen und wegen der floriden Entzündung verworfen. Trotz einer Therapieintensivierung mit Azathioprin exazerbierte acht Wochen später die Symptomatik. Bei der Re-Endoskopie lautet die histologische Beurteilung nun Morbus Crohn. Zusätzlich zur bisherigen Medikation begannen wir mit einer Infliximabtherapie (Dosis $5 \mathrm{mg} / \mathrm{kgKG}$ ). Diese Gaben wurden gut vertragen und der Zustand der Patientin verbesserte sich rapide.

Diskussion. $\mathrm{Ob}$ es sich bei unserer Patientin um einen Morbus Crohn handelt oder die CED bei HPS doch eher als "Crohn's like disease“ einzuordnen ist, bleibt offen. Da Therapieempfehlungen fehlen, können Optionen nur nach Literaturrecherche und im Einzelfall diskutiert werden. Die Diagnose HPS wurde genetisch gesichert.

\section{DGKJ-PO-G-5}

Valproat-assoziierte Pankreatitis - eine seltene, aber schwerwiegende Komplikation mit unspezifischen Symptomen

\section{Hofmeister R.', Finetti C.'}

'Elisabeth Krankenhaus Essen, Kinderneurologisches Zentrum, Essen

Einleitung. Valproat hat trotz neuer Antikonvulsiva auch heute in der Behandlung von Epilepsien im Kindesalter einen hohen Stellenwert. Häufig werden Eltern ausführlich über eine mögliche schwere Schädigung der Leber mit potentiell tödlichem Ausgang unter Valproattherapie aufgeklärt. Eine Valproat-assoziierte Pankreatitis findet dabei wenig Beachtung.

Fallbeschreibung. Wir berichten über einen 21 Monate alten Jungen, der aufgrund einer hypoxisch ischämischen Enzephalopathie eine therapieschwierige Epilepsie entwickelte. Seit 3 Monaten wurde eine Therapie mit Valproat ( $45 \mathrm{mg} / \mathrm{kgKG} /$ die in $2 \mathrm{ED}$ ) und Levetiracetam durchgeführt. Der letzte Valproat-Talspiegel betrug $67 \mu \mathrm{g} / \mathrm{ml}$ (Norm 50-100). Die Vorstellung des Jungen erfolgte bei plötzlicher Verschlechterung des Allgemeinzustandes. Der Junge war blass, appetitlos, verlangsamt und wesensverändert.

Ergebnisse. Laborchemisch zeigte sich eine erhöhte Lipase (1272 U/l). Die Leberwerte und die Entzündungsparameter waren unauffällig. Bei Verdacht auf eine Valproat-assoziierte toxische Pankreatitis wurde das Valproat sofort abgesetzt. Darunter kam es rasch zur Besserung des Allgemeinzustands und deutlichem Rückgang der Lipasewerte mit Restitutio ad integrum.

Schlussfolgerung. Die kausale Therapie der Valproat-assoziierten Pankreatitis ist das Absetzen des Valproats. Entscheidend dafür ist die Kenntnis über diese seltene, schwerwiegende Komplikation. Neben der Bestimmung der Leberwerte sollte daher auch immer eine Bestimmung der Lipase erfolgen. Dies gilt für Routineblutuntersuchungen und insbesondere für die Notfalldiagnostik. 


\section{DGKJ-PO-G-6}

\section{Chronische Cheilitis und Gingivahyperplasie als Primärmanifesta-} tion bei Morbus Crohn

\section{Welsch S. ', Franzel J.', Uche-Holub E. ${ }^{2}$, Frank J. ${ }^{2}$, Mayatepek E. ${ }^{3}$, Friedt M. ${ }^{1}$ 'Universitätsklinikum Düsseldorf, Klinik für Allgemeine Pädiatrie, Neonato- logie und Kinderkardiologie, Pädiatrische Gastroenterologie, Düsseldorf, ${ }^{2}$ Universitätsklinikum Hautklinik, Düsseldorf, ${ }^{3}$ Universitätsklinikum Düssel- dorf, Klinik für Allgemeine Pädiatrie, Neonatologie und Kinderkardiologie, Düsseldorf}

Einleitung. Die Cheilitis granulomatosa zeigt sich durch akute reversible, später persistierende, Schwellung der Lippen und der Perioralregion. Sie wird als Symptom verschiedener Entitäten wie der Sarkoidose oder des M. Crohn verstanden. Sie kann einer intestinalen Manifestation um Jahre vorausgehen. Wir beschreiben zwei Patienten mit M. Crohn, welche initial durch eine chronische Cheilitis auffielen. Bis zur Diagnose vergingen in einige Jahre ausführlicher multidisziplinärer Abklärungen.

Patientin A. Zwei Jahre vor ED fiel eine progrediente Lippenschwellung auf. Bei V. a. Weichteilinfektion erfolgte zunächst eine Therapie mit Antibiotika und später mit Steroiden. Letztere erbrachte Befundbesserung. Drei Jahre vor Erstvorstellung wurde bei der Abklärung einer Gingivahyperplasie eine Plasmazellgingivitis diagnostiziert. Die Lippenbiopsie zeigte eine granulomatöse Entzündung. Bei erhöhten fäkalen Calprotectin und nur vereinzelten Bauchschmerzen zeigte die endoskopische Abklärung eine diskontinuierliche Entzündung mit Epitheloidzell-Granulomen mit im Sigma und im terminalen Ileum. Patientin B. Rezidivierende Lippen- und Mittelgesichtsschwellung mit Aphten der Mundschleimhaut seit $>3$ Jahren. Bei gastroenterologischer Erstvorstellung war sie mit einem $\mathrm{BMI}<\mathrm{P}_{3}$ bereits deutlich dystroph. Eine Woche vor Erstvorstellung traten Erythema nodosum, Bauchschmerzen und Diarrhö auf. Endoskopisch zeigte sich eine Entzündung in terminalem Ileum und Kolon, zusätzlich eine perianale Fistel.

Schlussfolgerung. Bei chronischer Cheilitis oder Gingivahyperplasie ist auch beim Fehlen gastrointestinaler Beschwerden an die extraintestinale Manifestation eines M. Crohn zu denken und weitergehende Diagnostik zu veranlassen, um Komplikationen vorzubeugen und eine rechtzeitige Therapie einzuleiten.

\section{DGKJ-PO-G-7}

Langzeitverlauf und Erfolg von Lebertransplantationen bei Kindern mit progressiver familiärer intrahepatischer Cholestase (PFIC): Gibt es eine Korrelation zwischen Genotyp und Outcome?

Herbst S.M. ${ }^{1}$, Vermehren J. ${ }^{2}$, Hehr U. ${ }^{1}$, Melter M. ${ }^{2}$

'Zentrum für Humangenetik am Universitätsklinikum Regensburg, Regensburg, ${ }^{2}$ Klinik und Poliklinik für Kinder- und Jugendmedizin, Universitätsklinikum Regensburg, Regensburg

Fragestellung. Charakterisierung der Genotyp-Phänotyp-Korrelation sowie Identifizierung prädiktiver genetischer Parameter für den Langzeitverlauf und den Erfolg einer Lebertransplantation bei Patienten mit progressiver familiärer intrahepatischer Cholestase (PFIC).

Methodik. 52 Patienten mit PFIC wurden in unserem Labor auf $\mathrm{Mu}-$ tationen in den Genen ATP8B1, ABCB11 und ABCB4 untersucht. Die Langzeitdaten (2-25 Jahre) von 8 Patienten mit genetisch gesicherter PFIC werden exemplarisch vorgestellt, um die spezifischen Probleme in der interdisziplinären Versorgung dieser Patienten zu illustrieren.

Ergebnisse. Die meisten pathogenen PFIC Mutationen wurden in $\mathrm{ABCB} 11$ identifiziert (56\%), gefolgt von $\mathrm{ATP} 8 \mathrm{~B}_{1}$ (32\%) und $\mathrm{ABCB} 4$ (12\%). Missense-Mutationen wurden am häufigsten beobachtet (73\%), gefolgt von trunkierenden Mutationen (17\%), Splice ( $7 \%$ ) und kleinen In-frame-Deletionen (3\%). Neun Mutationen werden neu beschrieben Bei 5 dieser 8 Patienten wurde eine Lebertransplantation durchgeführt, ein weiterer Patient ist im Alter von 17 Monaten für eine LTX gelistet. Lebensbedrohliche Komplikationen (akute Organabstoßung und Tod) wurden bei zwei Patienten beobachtetet, die beide Träger mindestens einer trunkierenden Mutation waren. Nach erfolgreicher Lebertransplantation traten langfristige Komplikationen v. a. bei ATP8B1 Mutationsträgern auf, diese umfassten u. a. chronische Diarrhö, Dystrophie, Nierenversagen, Pankreatitis und Polyneuropathie.

Diskussion. Trunkierende Mutationen gehen möglicherweise mit einer höheren Komplikationsrate nach Lebertransplantationen einher. In einer aktuellen Studie verfolgen wir derzeit zwei Ziele: (1) Evaluation dieser Hypothese in einer größeren Kohorte und (2) genomweite Sequenzierung zur Identifizierung weiterer Kandidatengene für die PFIC.

\section{DGKJ-PO-G-8}

Zusammenhang zwischen Food-Neophobie der Mutter und der Akzeptanz neuer Breie beim Säugling

Schmidt I.V.', Hilbig A. ${ }^{\prime}$, Kunert J. ${ }^{2}$

${ }^{1}$ Forschungsinstitut für Kinderernährung, Dortmund, ${ }^{2}$ Technische Universität Dortmund, Fakultät Statistik, Dortmund

Fragestellung. Das FKE entwickelt im Forschungsprojekt Baby Gourmet (gefördert durch das Land NRW und die EU) tiefgefrorene Breie als Innovation in der Säuglingsernährung in Deutschland und testet diese sensorisch mit Eltern und Babys. Die sensorischen Vorteile von Tiefkühlkost sollen im Sinne einer präventiven Ernährung so für Säuglinge nutzbar gemacht werden. In einem Pretest zur Methodenentwicklung wurde u. a. die Frage untersucht, ob Babys von neophoben Müttern ebenfalls neophobe Tendenzen erkennen lassen.

Methode. 18 Mütter nahmen mit ihren Babys am Pretest teil. Sie fütterten an zwei unterschiedlichen Tagen einen Brei mit bekanntem (bB) bzw. einen mit unbekanntem Gemüse $(\mathrm{uB})$ und gaben auf einer 9-Pt.Skala an, wie gut er ihrem Baby und ihnen selbst schmeckt. Die Reihenfolge $b B$ und $u B$ wurde balanciert. Die verzehrten Mengen der Breie wurden jeweils abgewogen. Zusätzlich füllten die Mütter einen Food Neophobie Fragebogen aus.

Ergebnisse. Alle (bis auf einen) Säuglinge verzehrten mehr von bB als vom uB. Die Differenz der Verzehrsmengen verringerte sich mit der Neophobie der Mütter signifikant. Die Steigung der linearen Regression ist negativ (p-Wert: o,02). Bei der Einschätzung der Akzeptanz des Breis durch die Mutter ergab sich hingegen kein signifikanter Unterschied zwischen $\mathrm{uB}$ und $\mathrm{bB}$.

Diskussion. Zunächst zeigen die Ergebnisse, dass die Akzeptanz von Breien bei Säuglingen durch die Verzehrsmenge gut gemessen werden kann, noch besser als durch die Einschätzung durch die Mütter. Weiterhin deuten diese Ergebnisse darauf hin, dass Babys von neophilen Müttern noch weniger bereit sind, neue Lebensmittel zu essen, als Babys von neophoben Müttern. Weitere Untersuchungen mit mehr Teilnehmern werden folgen.

\section{DGKJ-PO-G-9}

Gesundheitsbezogene Lebensqualität von Kindern mit funktionellen und organisch bedingten gastrointestinalen Störungen

Warschburger P.', Brücker J.', Friedt M. ${ }^{2}$, Lenhartz H. ${ }^{3}$, Posovszky C. ${ }^{4}$, Calvano C. $^{\prime}$

${ }^{1}$ Universität Potsdam, Beratungspsychologie, Potsdam, ${ }^{2}$ Universitätsklinikum Düsseldorf, Klinik für Allgemeine Pädiatrie, Neonatologie und Kinderkardiologie, Düsseldorf, ${ }^{3}$ Kreiskrankenhaus Wilhelmstift, Hamburg, ${ }^{4}$ Universitätsklinikum Ulm, Abteilung für Kinder- und Jugendmedizin, Ulm

Fragestellung. Ziel der Studie war ein Vergleich der gesundheitsbezogenen Lebensqualität (LQ) zwischen Kindern mit funktionellen und organisch bedingten gastrointestinalen Störungen sowie gesunder und chronisch kranker Kinder (Neurodermitis, Asthma bronchiale, Adipositas). Zudem sollten Prädiktoren der gesundheitsbezogenen LQ ermittelt werden.

Material und Methoden. Fragebogendaten wurden in pädiatrisch-gastroenterologischen Ambulanzen querschnittlich im Kindesurteil erho- 
ben. Kinder mit funktionellen ( $\mathrm{n}=70$, FGIS) und organisch bedingten gastrointestinalen Störungen ( $\mathrm{n}=100$; OGIS) im Alter von 8-18 Jahren machten Angaben zum Schmerzerleben, Coping und gesundheitsbezogener LQ.

Ergebnisse. Kinder mit FGIS sowie OGIS zeigten eine vergleichbar beeinträchtigte gesundheitsbezogene LQ. Kinder mit gastrointestinalen Schmerzen zeigten im Vergleich mit chronisch kranken Kindern die geringste LQ. Alter, Geschlecht, Erkrankungsdauer und Diagnose (FGIS vs. OGIS) wiesen keinen signifikanten Zusammenhang zur gesundheitsbezogenen LQ auf. Schmerzerleben und Katastrophisieren jedoch waren signifikante Prädiktoren der gesundheitsbezogenen LQ, wobei Katastrophisieren die Beziehung zwischen Schmerzerleben und gesundheitsbezogener LQ vollständig vermittelte.

Diskussion/Schlussfolgerungen. Es besteht eine deutliche emotionale Belastung in Zusammenhang mit chronischen Bauchschmerzen - unabhängig von ätiologischen Faktoren. Interventionen sollten auf eine Bearbeitung der Copingstrategien zielen, da eine katastrophisierende Verarbeitung und Bewertung der Schmerzen die kausale Verbindung zwischen Schmerzerleben und gesundheitsbezogener LQ darstellt.

\section{Kardiologie und Verschiedenes}

\section{DGKJ-PO-V3-1 \\ Körperliches Training verursacht konzentrische kardiale Hypertro- phie bereits bei jugendlichen Leistungssportlern}

Gilbert N. ', Machens P.', Engl G. ', Oberhoffer R. ${ }^{1}$

'TU München, Lehrstuhl für präventive Pädiatrie, München

Methoden. Wir untersuchten ein Kollektiv von 65 jugendlichen männlichen Leistungssportlern aus einem Münchner Fußballverein im Alter zwischen 13 und 19 Jahren ( $M=14,4$ Jahre). Anthropometrische Daten, Trainingsdauer und -intensität, kardiovaskuläre Parameter und Daten aus der Spiroergometrie wurden über 6 Monate gesammelt. Dabei ergab sich ein signifikanter Zusammenhang zwischen der Anzahl der leistungssportlichen Trainingsjahre $(\mathrm{M}=4,7 \mathrm{y}$, Range 1-9 y) und der linksventrikulären Hinterwanddicke $(\mathrm{p}=0,025)$ sowie ein Trend $z w i-$ schen den Trainingsjahren und der interventrikulären Septumdicke $(\mathrm{p}=\mathrm{o}, 093)$, nicht jedoch zwischen Trainingsjahren und linksventrikulärem enddiastolischen Durchmesser. Intensives Fußballtraining führt damit vermutlich zur konzentrischen kardialen muskulären Anpassung, nicht jedoch zur Vergrößerung des linksventrikulären Lumens. Die Septumverdickung (IVSd) bzw. Hinterwandverdickung (PWd) lag bei $15 \%$ (IVSd) bzw. 4\% (PWd) der Sportler oberhalb des oberen Normwertes. Eine signifikante, klinisch relevante linksseitige Ausflusstraktobstruktion konnte (noch) nicht gefunden werden.

Schlussfolgerung. Diese Beobachtung bestätigt unsere Forderung nach kinderkardiologischem Screening inklusive Echokardiographie vor und unter leistungssportlicher Tätigkeit bereits im Jugendalter. Man muss allerdings auch kritisch über die Erstellung neuer Normwertetabellen für Leistungssportler nachdenken. Zukünftig sollen nun auch Gewebedoppler-Untersuchungen als funktionelle Myokarduntersuchungen in unsere Routine integriert werden, um noch genauere Differenzierungen der myokardialen Anpassung an Training registrierbar $\mathrm{zu}$ machen und zwischen longitudinalen, circumferenziellen und radialen myozytären Antworten auf körperliches Training unterscheiden zu können.

\section{DGKJ-PO-V3-2}

Charakteristika und Überleben von erwachsenen Patienten mit angeborenen Herzfehlern und pulmonalarterieller Hypertonie: COMPERA-CHD Register

Kaemmerer H. ${ }^{1}$, Pittrow D. ${ }^{2}$, Huscher D. ${ }^{3}$, Tiede H. ${ }^{4}$, Delcroix M. ${ }^{5}$, Hoeper M.M. ${ }^{6}$, Ewert P. ${ }^{1}$, für die COMPERA-Studiengruppe

'Deutsches Herzzentrum, München, ${ }^{2}$ Institut für Klinische Pharmakologie, Technische Univ., Dresden, ${ }^{3}$ Epidemiologie, Deutsches Rheumaforschungszentrum, Berlin, ${ }^{4}$ Med. Klinik II der Universität, Gießen, ${ }^{5}$ Dept. for Pneumology, University Hospital, Leuven, Niederlande, ${ }^{6} \mathrm{Abt}$. für Pneumologie, $\mathrm{MHH}$, Hannover

Fragestellung. Aktuelle Daten zu Charakteristika und Behandlungssituation von Patienten mit pulmonalarterieller Hypertonie (PAH) assoziiert mit angeborenen Herzfehlern (CHD, Dana Point Klassifikation Gruppe 1.4.4.) sind erforderlich.

Methoden. In der Registerstudie COMPERA (Prospective Registry of Newly Initiated Therapies for Pulmonary Hypertension, ClinTrials. gov Identifier NCTo1347216) werden seit 2007 erwachsene Patienten mit allen Formen der PAH-CHD prospektiv dokumentiert (inklusive Eisenmenger-Physiologie; „pulmonal-vaskuläre Dysfunktion“ bzw.“ relative PAH" nach cavo-pulmonaler Anastomose oder modifizierter Fontan-Operation).

Ergebnisse. Im März 2013 waren in COMPERA 1542 Patienten mit PH und 2373 Patienten mit PAH eingeschlossen, davon 322 mit PAH-CHD. Die Patienten waren im Mittel 46,5 Jahre alt, in 63\% Frauen, in NYHA funktioneller Klasse I in $5 \%$, II in $23 \%$, III in $68 \%$, und IV in $3 \%$. Die Lebensqualität auf der EQ-5D visuellen Analogskala (o sehr schlecht, 100 sehr gut) lag bei 50 Punkten. Die Mehrheit der CHD-Patienten wurde bei Einschluss mit PAH-spezifischen Medikamenten behandelt: Endothelinrezeptorantagonisten erhielten $64 \%$ der Patienten, Phosphodiesterase-V-Hemmer 49\%, und Prostazykline 6\%. Unter oraler Antikoagulation standen $42 \%$ aller CHD-Patienten (Eisenmenger 21\%, Fontan $88 \%$ ). Bei den Eisenmenger-Patienten lag die Überlebensrate 4 Jahre nach Einschluss bei $84,4 \%$.

Diskussion. In Hinblick auf die zu Grunde liegenden Ätiologie und der speziellen Hämodynamik der angeborenen Herzfehler sollten PAHCHD-Patienten getrennt von anderen PAH-Formen und differenziert nach Subgruppen dargestellt werden, wofür sich COMPERA aufgrund der Fallzahl und Detailtiefe eignet.

\section{DGKJ-PO-V3-3}

\section{Besonderheiten von Impfungen bei herzkranken Kindern}

\section{Eyermann . $^{\prime}$}

'Dr. Richard Eyermann, Kinder- und Jugendmedizin, Kinderkardiologie, Sportmedizin, München

Fragestellung. Impfungen sind hocheffizient gegen viele Infektionskrankheiten. Was ist bei herzkranken Kindern zu beachten?

Methode. Literaturrecherche. Empfehlungen EbM.

RSV-Prophylaxe. Kinder mit HSCHD in RSV-Saison 4-wö. mit Palvizumab: $<1$ J. Muß-/1<2 J. Kann-Bestimmung (neu).

Herzoperation. Bei elektiver OP: Mindestabstand nach Tot- /Lebendimpfstoffen 3 bzw. 14 die. Nach OP Impfungen gleiche Mindestabstände. Vitale Indikation: weder Impfung noch OP verschieben. Zwischen Gabe Ig-haltiger Präparate u. Lebendimpfstoffe Abstand 3 Mo. Vor OP Hep B-Immunisierung vollenden.

HTX. Vor HTX Grundimmunisierung komplett vollenden, ggf. Impfungen vorziehen: Hep B beim NG, MMR u. Varizellen ab 9. Mo; DPT, Polio, Hib mit 6 Wo. Nach HTX unter Immunsuppression KI für Lebendimpfstoffe, Ausnahmen n. Konsil; unter Hochdosis-Steroidtherapie nach Impfung kein suffizienter AK-Titer; Kontrolle Impftiter!

Asplenie, angeboren. Zum Beispiel Heterotaxie-S.; v. a. Impfungen gegen Pneumo-, Meningokokken u. Hib. Pneumokokken: Immunisierung lt. STIKO, später ggf. weitere Wiederholungsimpfungen - Kinder 
$>5<10 \mathrm{~J}$. in mindestens 3-, Erwachsene 5-J.-Abständen. Ausgeprägte Impfreaktionen möglich (individuelle Nutzen-Risiko-Abwägung, Impftiter!). Hib: Immunisierung lt. STIKO. Meningokokken: M.-C-Impfung <2 J., B-Impfstoff aktuell zugelassen, Impfschema in Diskussion. Ggf. 6-12 Mon. nach 2. Lj. Impfung gegen Serotypen A, C, W135, Y. DiGeorge-Syndrom. Partiell/komplett, Immunschwächespektrum breit. Totimpfstoffe lt. STIKO. Impftiter! Lebendimpfstoffe nach immunologischer Basisuntersuchung u. Konsil. RSV-Prophylaxe in RSV-Saison. Bei Varizellenexposition Varizellen-Ig.

Influenza-Impfung. Chronisch Herzkranke jeden Alters, DiGeorgeSyndrom u. n. HTX lt. STIKO jährlich.

Schlussfolgerung. Prinzipiell gilt der STIKO-Impfkalender. Besonderheiten sind aber zu beachten.

\section{DGKJ-PO-V3-4}

Bedeutung kardiovaskulärer Risikoreduktion bereits im Kindesund Jugendalter für spätere kardiovaskuläre Erkrankungen (CVD), für KHK und major kardiovaskuläre Ereignisse (MACE) als Todesursache Nr. 1, unter besonderer Berücksichtigung der Dyslipidämien

\section{Eyermann $R$.}

'Dr. Richard Eyermann, Kinder- und Jugendmedizin, Kinderkardiologie, Sportmedizin, München

Einleitung. Die Hälfte aller ersten MACE sind fatal, CVD-Prävention daher essentiell. Dyslipidämien: Hohe LDL-C u. TG u. niedrige HDL-C sind sensitivste u. spezifischste Risikofaktoren für frühe CVD; International klassifiziert in: 1) FH, 2) FCH, 3) „Mixed environmental hyperlipidemia“", 4) „metabolic syndrome“.

Methoden. Diät und therapeutische Lifestyleänderungen (TLC) sind Säulen in Prävention und Therapie von HLP. Additiv sind Pharmaka hilfreich. Diät: reduziert an Fett, Cholesterol und gesättigtem Fett, aber suffizient an Kalorien, um Wachstum und Entwicklung der Kinder zu fördern (NECP Step One und ggf. nach 3 Mo. Step Two Diet). NECP, AHA Scientific Statement on Cardiovascular Health in Childhood, AAP Committee on Nutrions's „Cholestrol in Childhood" Statement empfehlen 2 Strategien: 1) Populationsbasierte Strategie aller Kinder >2 Jahre zur Förderung herzgesunder Ernährung, 2) Individualisierte Strategie für Kinder mit pos. FA für frühe CVD, elterliche Hyper-Chol oder Kinder mit anderen CVD-Risikofaktoren. Pharmakotherapie ist Adoleszenten vorbehalten, die trotz TLC die Lipidzielwerte in der CVDPrävention LDL-C $<130 \mathrm{mg} / \mathrm{dl}$ und TG $<150 \mathrm{mg} / \mathrm{dl}$ nicht erreichen. Neue AAP-Guidelines empfehlen Intervention ab $8 \mathrm{~J}$. bei LDL-C $>190 \mathrm{mg} / \mathrm{dl}$, bei pos. FA oder 2 additiven Risikofaktoren $>160 \mathrm{mg} / \mathrm{dl}$ bzw. $>130 \mathrm{mg} /$ dl bei Dm. Zur LDL-C-Senkung sind n. FDA einige Statine (>12 J.) und Harze (nicht alle <18 J.) zugelassen, Niacin, Fibrate und Ezetimibe nicht $<18 \mathrm{~J}$. EMA-Zulassung für einige Statine und Ezetimib ab 10 J. FH bes. Interventionsschwerpunkt (ESC/ESA/DGK IA).

Schlussfolgerung. Kindheit und Adoleszenz sind Schlüsselalter für Beginn atherosklerotischer Lastreduktion. Dyslipidämien sind sensitivste und spezifischste Risikofaktoren für frühe KHK und MACE im globalen kardiovaskulären Risikokonzept (Score-Charts, Guidelines ESC/ ESA/DGK 2011)

\section{DGKJ-PO-V3-5}

Plötzlicher Herztod (SCD) und Empfehlungen zur Prävention in der Kinder- und Jugendmedizin

\section{Eyermann $R^{?}$ \\ 'Dr. Richard Eyermann, Kinder- und Jugendmedizin, Kinderkardiologie, Sportmedizin, München}

Einleitung. Inzidenz bei scheinbar gesunden Adoleszenten pro Jahr sportlicher Aktivität bei 1:250.0oo,häufiger bei Jungen, Afro-Amerikanern, Wettkämpfern von Football und Basketball. Ätiologisch SCD bei jüngeren Sporttreibenden präexistente nichterkannte Herzerkrankun- gen (90\% strukturelle Herzerkrankungen, $10 \%$ primär elektrophysiologische Störungen): Häufig dabei HCM $36 \%$, Koronaranomalien $23 \%$, idiopathische $\mathrm{LVH}$ 10\%; weniger häufig rupturiertes Aortenaneurysma, Myokarditis, AS, KHK, ARVD; selten WPW-Syndrom, LQTS, MKPS, Commotio cordis, Drugs. In Screeningevaluationen (n-115) bei SCD-Betroffenen in vorherigen medizinischen Evaluationen nur in 3\% kardiovaskuläre Erkrankungen aufgedeckt, in $0,9 \%$ korrekte Korrelationen zum SCD hergestellt worden!

Kardiovaskuläre Anamnese. Bedeutsamstes Screeningelement, Mindestinhalt: 1) früherer Thoraxschmerz, Synkope oder Near-Synkope, unerwartete unklare Dyspnoe oder Fatigue assoziiert mit Belastung, 2) früheres Herzgeräusch oder Hypertonie, 3) positive FA auf SCD, MACE $<50$ Jahre sowie HCM, Marfan-Syndrom, LQTS, signifikante Arrhythmien.

Medizinische Untersuchung. Mindestinhalt: 1) Auskultation im Liegen und Stehen, v. a. zur Detektion von Geräuschen dynamischer LVOTO, 2) Femoralispulse zum Ausschluss CoA, 3) Evaluation auf Stigmata Marfan-Syndrom, 4) RR-Messung sitzend.

Weitere Diagnostik. EKG und Echo in USA im Routine-Screening wegen niedriger Inzidenz, hoher Rate falsch-positiver Befunde und Kosten nicht empfohlen (IIIC). Zukünftige Involvierung von Gentests bei jungen High-risk-Sporttreibenden geplant.

Konklusion. Junge Sporttreibende screenen und bei kardiovaskulären Abnormitäten kardiologisch evaluieren und Belastbarkeit nach Guidelines von ACC/ACSM einstufen (Europa bis IB). Basic und „advanced life support"-Schulen. Protektoren gegen Commotio cordis unsicher.

\section{DGKJ-PO-V3-6}

Dysmorphiezeichen und Fehlbildungen - fetales Valproat-Syndrom auch heute noch eine wichtige Differenzialdiagnose

Merkle B. ', Wild F.', Seeliger S. ', Herrmann L. ${ }^{1}$

${ }^{1}$ Kliniken St. Elisabeth, Klinik für Kinder- und Jugendmedizin, Neuburg

Fragestellung. Aufgrund seiner teratogenen Wirkung wird Valproat in der Schwangerschaft heute nicht mehr empfohlen. Dadurch sind Fälle des fetalen Valproat-Syndroms selten geworden. Im Hinblick auf Spätfolgen und eine optimale Nachbetreuung sollte bei Dysmorphie Zeichen jedoch immer auch an Folgen einer Medikamenteneinnahme wie Valproat während der Schwangerschaft gedacht werden.

Falldarstellung. Bei dem Patienten handelt es sich um ein männliches Frühgeborenes der 32. SSW, das postpartal zunächst durch eine auffällige Fazies auffiel. Anamnestisch ergab sich eine pränatale Valproat-Exposition von $1000 \mathrm{mg} / \mathrm{Tag}$, sodass gezielt nach weiteren Fehlbildungen im Sinne eines Valproat-Syndroms gesucht wurde. Es zeigten sich eine weite vordere Fontanelle, Hypertelorismus, flache Nasenwurzel mit nach oben gerichteter Nase, niedrig angesetzte Ohren und weit auseinander stehende Brustwarzen. In der Literatur werden zudem weitere Dysmorphiezeichen und Fehlbildungen beschrieben. Zu den häufigsten gehören Spina bifida, Herzfehler, Lippen-Kiefer-Gaumen-Spalte, genitale Fehlbildungen wie Hypospadie und Extremitäten-Fehlbildungen. Diskussion. Trotz der neuen Antikonvulsiva, muss man auch heute noch an ein fetales Valproatysndrom bei geschlechtsreifen Frauen denken. Eine antikonvulsive Therapie mit Valproat während der Schwangerschaft erhöht das Fehlbildungsrisiko um das 2- bis 3-fache, besonders wenn die Dosis über $1000 \mathrm{mg} / \mathrm{d}$ liegt. Daher sollte bei Mädchen ab der Pubertät die Therapie umgestellt werden auf ein unbedenkliches Präparat. Sollte Valproat das einzig wirksame Antikonvulsivum sein, müssen engmaschige sonographische Kontrollen während der Schwangerschaft erfolgen. Auch ein Langzeit-Follow-up der Kinder ist auf Grund der möglichen langfristigen Auswirkungen auf das Verhalten notwendig. 


\section{DGKJ-PO-V3-7}

\section{Beratungspraxis der Kinderärzte zum Umgang mit Mehrsprachig-} keit in der Familie - eine Fragebogenerhebung

\section{Radtke E. ${ }^{1}$, Bockmann A.-K.', Buschmann A. ${ }^{2}$ \\ 'Universität Hildesheim, Institut für Psychologie, Hildesheim, ${ }^{2}$ Pädagogi- sche Hochschule Heidelberg, FRIZ Frühinterventionszentrum, Heidelberg}

Hintergrund. Mehrsprachig aufwachsende Kinder gehören zunehmend zum alltäglichen Bild in Deutschland. Jedoch stellt der Umgang mit den verschiedenen Sprachen innerhalb einer Familie noch immer eine Herausforderung sowohl für die Familien selbst als auch für Personen, die diese Familien diesbezüglich beraten, dar.

Methode. Im Rahmen des Modellprojekts „Sprachkompetent von Anfang an" (Kooperation Frühinterventionszentrum Heidelberg und Universität Hildesheim) wurde eine Fragebogenerhebung zur Erfassung der kinderärztlichen Beratungspraxis zum Thema Mehrsprachigkeit durchgeführt. Hierfür wurde eine Zufallsstichprobe von 306 Pädiatern in niedergelassener Tätigkeit aus ganz Deutschland gezogen.

Ergebnisse. Die Rücklaufquote betrug 44,8\%. Ein Drittel der Pädiater gab an, dass mehr als 30\% der von ihnen betreuten Familien einen Migrationshintergrund aufweisen. Es zeigte sich u. a., dass die Mehrheit der Befragten bereits routinemäßig zum Umgang mit Mehrsprachigkeit berät. Häufig ist jedoch der Beratungszeitpunkt zu spät gewählt und es werden auch nicht förderliche Ratschläge erteilt. Zwei Drittel der Pädiater gab an, sich nicht ausreichend über das Thema Mehrsprachigkeit informiert zu fühlen.

Schlussfolgerung. Als erste Ansprechpartner für Entwicklungsfragen und somit auch für Fragen zur mehrsprachigen Erziehung tragen Pädiater in niedergelassener Praxis eine große Verantwortung und sollten zu kompetenten Ansprechpartnern für viele Familien zum Thema Mehrsprachigkeit befähigt werden. Aus diesem Grund sind in der Arbeitsgruppe Blätter zur Mehrsprachigkeit für den Einsatz im Rahmen der kinderärztlichen Vorsorgeuntersuchungen entwickelt und in zehn Sprachen übersetzt worden.

\section{DGKJ-PO-V3-8}

Einführung eines neuen Dienstmodells für Ärzte in zwei Kliniken für Kinder- und Jugendmedizin: Einhaltung der arbeitszeitrechtlichen Vorgaben und Befragung der Betroffenen

Maschmann J.', Rieger M.A. ${ }^{2}$, Michaelis M. ${ }^{2,3}$, Lillig J.S. ${ }^{2}$, Wilke M. ${ }^{4}$, Hand gretinger $R{ }^{5}{ }^{5}$, Krägeloh-Mann I. ${ }^{4}$

'Universitätsklinikum Tübingen, Stabsstelle Medizinische Strukturplanung und Qualitätsmanagement, Tübingen, ${ }^{2}$ Institut für Arbeitsmedizin, Sozialmedizin und Versorgungsforschung, Tübingen, ${ }^{3}$ Freiburger Forschungsstelle für Arbeits- und Sozialmedizin, Freiburg, ${ }^{4}$ Department für Kinderheilkunde, Neuropädiatrie, Tübingen, ${ }^{5}$ Department für Kinderheilkunde, Hämatologie, Onkologie und Allg. Pädiatrie, Tübingen

Einleitung. Die Arbeitszeitbelastung im ärztlichen Dienst ist hoch und kollidiert oft mit arbeitszeitrechtlichen Vorgaben. Die Frage war, ob ein modifiziertes Dienstmodell zur besseren Einhaltung der Vorgaben führen kann und wie die Betroffenen das neue Modell einschätzen.

Methoden. Mit Vertretern der Kliniken für Neuropädiatrie und Hämatologie/Onkologie wurde gemeinsam ein modifiziertes Dienstmodell entwickelt und im Februar 2011 eingeführt. Zu Beginn wurden alle Ärzte per Fragebogen zu ihren Arbeitsbedingungen befragt (to). Dies wurde im Februar 2012 wiederholt (t1). Die Fragen wurden $u$. a. dem ArbiK-Fragebogen entnommen. Die durchschnittliche Wochenarbeitszeit (dWAZ) und die Einhaltung der 10-h-Tageshöchstarbeitszeitgrenze (10-h-TAZ) wurden analysiert.

Ergebnisse. Die Rücklaufquoten lagen bei $45 \%$ (to) und bei $47 \%$ (t1) bei $\mathrm{n}=53$ bzw. 55 Befragten. Die Dokumentationsrate aller Überstunden stieg von $58,3 \%(14 / 24$, to) auf $92,3 \%(24 / 26, t 1)$. Kurzfristige Änderungen an der Dienstplanung reduzierten sich von to nach t1 ( $9 / 24$ auf 5/24), wurden aber zu t1 als belastender empfunden (4/24 vs. 8/24). Ebenfalls nahm die Notwendigkeit ab, nach dem Bereitschaftsdienst weiter arbeiten zu müssen. Tendenziell gestiegen waren die Aussagen „musste auf freies Wochenende verzichten“ und „wurde aus dem Frei geholt“. Die dWAZ wurde von 18 der 55 analysierten Beschäftigten in 2011 nicht eingehalten (33\%). 2012 sank der Wert auf 25\%. Die 10-h-TAZ wurde in $26 \%$ der Fälle überschritten (2012: 28\%).

Schlussfolgerung. Im ersten Jahr der Einführung war die Beurteilung des modifizierten Dienstmodells im Vergleich zum Vorzustand nicht wesentlich unterschiedlich. Erfreulich war die deutliche Zunahme der Dienstzeitendokumentation. Die Einhaltung der dWAZ und der 10-hTAZ war nur ungenügend gegeben. Die dWAZ hat sich im Folgejahr aber verbessert.

\section{DGKJ-PO-V3-9}

\section{Paternale uniparentale Disomie 14}

Schilling S. ', Gebauer C. ${ }^{,}$, Knüpfer M. ${ }^{2}$, Pulzer F. ${ }^{2}$, Bläser A. ${ }^{2}$, Mitter D. ${ }^{3}$, Heinritz W. ${ }^{3}$, Pernice W. ${ }^{4}$, Hirsch W. ${ }^{5}$, Thome U.'

${ }^{1}$ Universität Leipzig, Neonatologie, Leipzig, ${ }^{2}$ Universität, Leipzig, ${ }^{3}$ Institut für Humangenetik, Leipzig, ${ }^{4}$ Kreiskrankenhaus Torgau, Pädiatrie, Torgau, ${ }^{5}$ Universität Leipzig, Pädiatrische Radiologie, Leipzig

Hintergrund. Uniparentale Disomie (UPD) beschreibt das Vorliegen beider Homologen eines Chromosoms von einem Elternteil. Bei der paternalen UPD 14 (UPD14pat) fehlt das mütterliche Chromosom 14, stattdessen sind zwei väterliche Chromosomen 14 vorhanden.

Kasuistik. eutrophes, weibliches Frühgeborenes der 31. SSW, Übernahme aus der Geburtsklinik wegen Frühgeburtlichkeit. Klinisch fiel das Frühgeborene durch eine schaukelnde, paradoxe Atmung mit Tachypnoe und Einziehungen auf. Abdominal fand sich eine große Rektusdiastase mit ca. $5 \mathrm{~cm}$ Durchmesser. Außerdem sahen wir auffällige Dysmorphiezeichen, die uns zu einer humangenetischen Untersuchung veranlassten. Die Chromosomenanalyse ergab einen Karyotyp 45,XX mit einer Robertson'schen Translokation rob(14;14)(q10;q10). Die Mikrosatellitenanalyse zeigte eine paternale Isodisomie für das Chromosom 14.

Verlauf. Das Mädchen zeigte stets ausgeprägte Dyspnoezeichen bei glockenförmigem Thorax und breiter Rektusdiastase, so dass kontinuierlich eine CPAP-Atemunterstützung und geringe Sauerstoffsubstitution notwendig waren.

Schlussfolgerung. Uniparentale Disomien von einigen Chromosomen beeinflussen den Phänotyp. Wie unsere kleine Patientin haben Betroffene mit einem paternalen UPD(14)-Syndrom einen engen, glockenförmigen Thorax mit kurzen, gebogenen Rippen, eine Kyphose und kurze Extremitäten. Die Erkrankung ist sehr selten, in der Literatur findet man lediglich 12 beschriebene Fälle. Die Kinder versterben meist im Säuglings- und Kleinkindalter an respiratorischer Insuffizienz. Für den ältesten lebenden Patient wird ein Alter von 9 Jahren berichtet, dieser Patient hatte zusätzlich eine schwere mentale Retardierung. Für das Neugeborenen- und frühe Säuglingsalter scheint eine Atemunterstützung unabdingbar.

\section{DGKJ-PO-V3-10}

Alternative und komplementäre Therapien in der Neonatologie: keine Evidenz für die Wirkung von Homöopathie

Thiel M. ${ }^{1}$

'Sana-Klinikum Remscheid, Klinik für Kinder und Jugendliche, Remscheid

Hintergrund. Alternative und komplementäre Methoden sind in der Medizin weltweit sehr beliebt. Wirkung, auch Wirkungsweisen sowie potentielle Nebenwirkungen sind nicht geklärt. Theoretisch sind Neugeborene auch aus wissenschaftlicher Sicht eine sehr interessante $\mathrm{Pa}$ tientengruppe, da der Placebo-Effekt außer durch die Beeinflussung durch die Eltern oder die verabreichende Bezugsperson sehr gering ist. Methodik. Aus diesem Grund führten wir eine systematische Review der Literatur zu diesem Thema durch. 
Ergebnisse. Die Medline-Recherche nach den PRISMA-Kriterien lieferte bei der Suche nach Neonates, newborn, neonatology und homeopathy insgesamt 61 Studien. Davon waren 41 in den letzten 10 Jahren publiziert worden. Insgesamt beschäftigten sich aber nur 4 mit Neonaten i. e. S. Dabei handelte es sich um Fallberichte und Übersichtsarbeiten. Es fanden sich 7 klinische Studien, von denen keine sich mit Neonaten beschäftigte. Systematische Reviews zum Thema fehlen.

Schlussfolgerung. Für den Einsatz der Homöopathie in der Neonatologie gibt es keine durch Studien abgesicherte Grundlage. Vereinzelten anekdotischen Erfolgsgeschichten stehen auch Berichte über Nebenwirkungen gegenüber.

\section{DGKJ-PO-V3-11}

\section{Arthritis als Beginnsymptomatik der Wegener Granulomatose?}

\author{
Kerschgens B. ', Loh N.', Lassay L.', Wagner N.'
}

'Universitätsklinikum RWTH Aachen, Kinder- und Jugendmedizin, Aachen

Einleitung. Die Wegener Granulomatose ist eine systemisch nekrotisierende Vaskulitis. Im Kindesalter müssen für die Diagnosestellung drei der folgenden sechs Kriterien erfüllt sein (Ozen et al. 2010): Histologisch granulomatöse Vaskulitis, Beteiligung der oberen Atemwege, laryngo-tracheo-bronchiale Stenose, pulmonale Beteiligung, positive ANCA, Beteiligung der Niere.

Fallbericht. Ein 17-jähriger bis dahin gesunder Patient wurde eine Woche mit ausgeprägten Arthralgien und Schwellungen von Knie- und Sprunggelenken in der orthopädischen Klinik eines externen Krankenhauses behandelt. Laborchemisch zeigte sich ein erhöhtes $\mathrm{CrP}$, eine Leukozytose und Thrombozytose sowie eine maximal beschleunigte BSG. ANA, ENA, und Rheumafaktor waren negativ. Unter symptomatischer Behandlung und antibiotischer Therapie bei Verdacht auf Sinusitis war die Symptomatik progredient. Im Verlauf fiel eine Mikrohämaturie und leichte Proteinurie auf. Der Patient wurde mit V. a. Morbus Still DD rheumatisches Fieber in unsere Klinik verlegt.

Ergebnisse. Hier zeigten sich vaskulitische Effloreszenzen im Bereich beider Sprunggelenke und positive cANCA. Erst auf gezielte Nachfrage berichtete der Patient über seit einigen Monaten bestehende blutige nasale Sekretion. Mit nun drei positiven Diagnosekriterien wurde eine Wegener Granulomatose diagnostiziert. Unter intravenöser Therapie mit Steroiden und Cyclophosphamid zeigte sich ein rasches Therapieansprechen. Nach Erreichen einer Remission erfolgte die Umstellung auf Methotrexat.

Schlussfolgerung. Durch die scheinbar ungewöhnliche Beginnsymptomatik wurde die Diagnosestellung einer Wegener Granulomatose erschwert. Sie war erst durch das gezielte Erfragen des dem Patienten unbedeutend erscheinenden Symptoms eines blutigen Schnupfens möglich.

\section{DGKJ-PO-V3-12}

\section{Differenzialdiagnose Knochentumor: fibröse Dysplasie}

Armbrust S. ${ }^{\prime}$, Pietruschka S.A. ${ }^{2}$, Decker T. ${ }^{3}$, Gilberg E. ${ }^{1}$, Dittes $C .{ }^{4}$ 'Dietrich-Bonhoeffer-Klinikum, Klinik für Kinder- und Jugendmedizin, Neubrandenburg, ${ }^{2}$ Dietrich-Bonhoeffer-Klinikum, Klinik für Radiologie und Neuroradiologie, Neubrandenburg, ${ }^{3}$ Dietrich-Bonhoeffer-Klinikum, Institut für Pathologie, Neubrandenburg, ${ }^{4}$ Dietrich-Bonhoeffer-Klinikum, Klinik für Mund-, Kiefer- und Gesichtschirurgie und Plastische Operationen, Neubrandenburg

Hintergrund. Fibröse Dysplasie (FD): früh embryonal entstehende Störung durch somatische Mutation der $\alpha$-Untereinheit des G-Proteins. Wir beschreiben den Verlauf eines 9-jährigen Mädchens.

Fallbeschreibung. Schwellung der rechten unteren Gesichtshälfte mit rezidivierenden Schmerzen im Unter- und Oberkiefer. MRT/CT: Gemischter osteolytisch-osteosklerotischer knöcherner Prozess im Ramus mandibulae rechtsseitig mit solider Periostitis und ödematösen Verände- rungen in den Weichteilen. Szinti: deutlich verstärkte Radionuklidspeicherung a. a. O. Histo: Unregelmäßig geformter trabekulärer Geflechtknochen mit randlichem spärlichem plumpem Osteoblastensaum aus monomorphen Osteoblasten mit chromatindichten, scharf abgegrenzten Zellkernen. Anteile von unreifem, unregelmäßig angeordnetem Geflechtknoten. Diagnose: fibröse Dysplasie. Im Verlauf bei progredienten Schmerzen und Mundöffnungsbehinderung OP notwendig.

Diskussion. Die FD ist eine benigne Knochenerkrankung. Spongiöser Knochen wird lokal durch fibröses Knochengewebe ersetzt. Häufigkeit 1:400o bis 1:10.0oo. Keine maligne Entartungsgefahr. Mehrheitlich monostotische Varianten. Polyostotische Varianten exisitieren, in Kombination mit Pubertas praecox und Pigmentanomalien der Haut bilden sie das McCune-Albright-Syndrom. Keine medikamentöse Therapie, ggf. Versuch mit Bisphosphonaten, Strahlentherapie ist kontraindiziert. Therapeutisches Vorgehen: beobachtendes Zuwarten, ggf. operative Abtragung des exostotischen Anteils. Wachstum der FD kommt nicht selten in Pubertät zum Stillstand. Genetische Diagnostik nur bei einzelnen Sonderformen sinnvoll, nicht aber bei einer klassischen fibrösen Dysplasie.

Schlussfolgerung. Bei osteolytisch-osteosklerotischen knöchernen Prozessen ist neben Ewing-Sarkom auch die fibröse Dysplasie zu erwägen.

\section{Hämatologie und Onkologie (2)}

\section{DGKJ-PO-02-1}

Das Girdle-Syndrom - eine seltene Komplikation der Sichelzellkrankheit

Bienemann K.', Knorr M. ${ }^{2}$, Wieczorek H. ${ }^{1}$, Michna D. ${ }^{1}$, Schündeln M. ${ }^{2}$

${ }^{1}$ Elisabeth-Krankenhaus Essen, Allgemeine Pädiatrie, Essen, ${ }^{2}$ Unikinderklinik Essen, Pädiatrische Hämatologie und Onkologie, Essen

Hintergrund. Die Sichelzellkrankheit ist eine autosomal rezessiv vererbte Hämoglobinopathie. Bei Homozygotie bilden sich gesichelte Erythrozyten, die Sichelzellen. Die Patienten haben eine chronisch hämolytische Anämie und rezidivierende Vasookklusionen verschiedener Organsysteme. Führendes Symptom sind Schmerzkrisen, die durch Mikroinfarkte im Knochen ausgelöst werden. Als typische Komplikationen treten Milzsequestrationen, Milzinfarkte und das akute Thoraxsyndrom auf. Eine eher seltene Komplikation ist das Girdle-Syndrom, bei dem es zu einem paralytischen Ileus durch Vasookklusionen im Bereich der Mesenterialgefäße kommt.

Kasuistik. Wir berichten über einen 6-jährigen Jungen ghanaischer Abstammung ohne bekannte Vorerkrankungen, der innerhalb von wenigen Stunden stärkste abdominelle Schmerzen mit dem klinischen Bild eines paralytischen Ileus entwickelte. Im Blutbild fiel eine mikrozytäre, hypochrome Anämie und eine Retikulozytose auf. Im Blutausstrich waren 30\% Sichelzellen erkennbar. Mit Verdacht auf ein Girdle-Syndrom wurde der Patient hydriert, erhielt eine adäquate Schmerztherapie und abführende Maßnahmen. Da nach 24 Stunden weiterhin ein paralytischer Ileus bestand wurde eine Blutaustauschtransfusion durchgeführt und es kam innerhalb weniger Stunden zur Normalisierung der Darmperistaltik.

Fazit. Das Girdle-Syndrom ist eine seltene Komplikation der Sichelzellkrankheit im Kindesalter. Durch Mikroinfarkte in der Mesenterialstrohmbahn kommt es zu einem paralytischer Ileus. Damit kann es bei Patienten aus Risikogebieten eine Differenzialdiagnose des akuten Abdomens sein. Chirurgische Maßnahmen sind kontraindiziert. Bei prolongierten Verläufen ist eine Austauschtransfusion die Therapie der Wahl. 
DGKJ-PO-02-2

Langzeittherapie mit monatlichen Immunglobulingaben bei Parvovirus-B19-Infektion und rezidivierenden aplastischen Krisen nach hämatopoetischer Stammzelltransplantation: ein Fallbericht

Fouz H. ', Friemann V. ', Siepermann M. ${ }^{1}$, Schuster F.', Meisel R. ${ }^{1}$

'Universitätsklinikum Düsseldorf, Klinik für Kinder-Onkologie, -Hämatologie und Klinische Immunologie, Düsseldorf

Fragestellung. Führt eine Langzeittherapie mit monatlichen Immunglobulingaben zu einer Stabilisierung der Viruslast und des Hämoglobinwertes bei rezidivierenden Exazerbationen einer Parvovirus-B19-Infektion mit konsekutiven aplastischen Krisen bei einem immunkompromittierten Kind?

Material und Methode. Sechsjähriger Patient ein Jahr nach haploidentischer hämatopoetischer Stammzelltransplantation bei Neuroblastomrezidiv mit rezidivierend hoher Parvovirus-B19-Kopienzahl und konsekutiven aplastischen Krisen. Therapie mit humanem Immunglobulin-Präparat (o,5 g/kg i.v.) alle 4 Wochen.

Ergebnisse. Trotz initialer, durch Parvovirus-B19-Exazerbationen getriggerte Immunglobulingaben, persistierte bei dem Patienten die chronische Parvovirus-B19-Infektion mit hoher Kopienzahl und konsekutiven aplastischen Krisen mit Transfusionsbedarf. Nach Einleitung einer regelmäßigen, monatlichen Immunglobulintherapie zeigten sich eine eindeutige Stabilisierung des Hämoglobinwertes auf fast altersentsprechende Normwerte sowie ein anhaltender Rückgang der Parvovirus-B19-Kopienzahl über ein Jahr. Erythrozytentransfusionen waren nicht mehr erforderlich. Bei zu erwartender Immunrekonstitution ist ein Auslassversuch der Immunglobulintherapie begonnen worden, worunter sich bisher ein stabiler Verlauf zeigt.

Diskussion. Eine monatliche Langzeittherapie mit intravenösen Immunglobulinen kann bei immunkompromittierten Patienten mit chronischer Parvovirus-B19-Infektion und konsekutiven rezidivierenden aplastischen Krisen möglicherweise eine Stabilisierung des Hämoglobinwerts und eine effiziente Suppression der Parvovirus-B19-Last bewirken. Ein Auslassversuch unter Laborkontrollen des Hämoglobinwertes sowie der Parvovirus-B19-Viruslast erscheint möglich, sobald eine Immunrekonstitution zu erwarten ist.

\section{DGKJ-PO-02-3}

Idiopathisches hypereosinophiles Syndrom (HES) nach Lebertransplantation

\section{Aulbert W. ${ }^{1}$, Breuer C. ${ }^{2}$, Oh J. ${ }^{1}$, Richter A. ${ }^{3}$, Kobbe R. ${ }^{1}$, Ganschow R. ${ }^{3}$}

'Universitätsklinikum Hamburg-Eppendorf, Kinderklinik, Hamburg, ${ }^{2}$ Universitätsklinikum Hamburg-Eppendorf, Pädiatrische Gastroenterologie, Hamburg, ${ }^{3}$ Universitätklinikum Hamburg-Eppendorf, Pädiatrische Hepatologie und Lebertransplantation, Hamburg

Hintergrund. Hypereosinophile Syndrome (HES) sind bei Kindern selten und werden in 6 verschiedene Varianten eingeteilt. Das idiopathische HES kann sich nach Lebertransplantation mit einer Transaminasenerhöhung präsentieren, die teilweise schwierig von einer akuten Rejektion zu unterscheiden ist. Die Diagnose gelingt über den Ausschluss einer sekundären Hypereosinophilie.

Kasuistik. Ein 12-jähriger Junge stellte sich nach Lebertransplantation bei extrahepatischer Gallengangsatresie unter intensivierter Immunsuppression mit Cyclosporin A und Everolimus aufgrund seit drei Monaten persistierender Beschwerden vor. Im Vordergrund standen Fieber $>39^{\circ} \mathrm{C}$, Abgeschlagenheit und Gewichtsverlust. Laborchemisch fielen erhöhte Transaminasen (GOT 75 U/l, GPT 70 U/l) sowie im Blutbild eine signifikante und konstante Eosinophilie von $20 \%$ (2196/ $\mu$ l Eosinophile) auf. Eine Leberbiopsie ergab keinen Hinweis auf eine akute oder chronische Abstoßung des Transplantats oder eosinophile Infiltrate. Stuhlproben, Autoantikörperbestimmung (ANA, ANCA), Serologien, Endoskopie, Röntgen-Thorax, MRT und PET-CT zum Ausschluss einer sekundären Hypereosinophilie ergaben unauffällige Befunde. Im Kno- chenmark zeigte sich eine deutliche Eosinophilie ohne Dysmorphie. Es erfolge bei Verdacht auf ein idiopathisches HES die Therapie mit Steroiden. Der Eosinophilie-vermindernde Effekt der Steroide zeigte sich rasch: bereits nach dreitägiger Gabe von Prednisolon in einer Dosierung von $2 \mathrm{mg} / \mathrm{kg}$ KG besserte sich der Allgemeinzustand des Patienten deutlich und es kam zu einer Normalisierung des Blutbildes.

Schlussfolgerung. Bei pädiatrischen Patienten mit idiopathischem HES nach Lebertransplantation zeigen Steroide einen guten Therapieerfolg mit Rückgang der Eosinophilie und Besserung des klinischen Allgemeinzustands.

\section{DGKJ-PO-02-4}

Kaposiformes Hämangioendotheliom mit Kasabach-MerrittSyndrom: eine neue Therapieindikation für Propranolol

\section{Jürgens T.', Knöfler R. ', Wagner C. ', Hahn G. ${ }^{2}$, Suttorp M. ${ }^{\text {' }}$}

'Universitätsklinik Carl Gustav Carus, Klinik und Poliklinik für Kinder- und Jugendmedizin, Dresden, ${ }^{2}$ Universitätsklinik Carl Gustav Carus, Institut und Poliklinik für Radiologische Diagnostik, Dresden

Einleitung. Das Kaposiforme Hämangioendotheliom (KHE) ist ein seltener, niedergradig maligner Gefäßtumor der Haut und der inneren Organe, der bei Kindern mit Verbrauchskoagulopathie und schwerer Thrombopenie (Kasabach-Merritt-Syndrom, KMS) einhergehen und einen lebensbedrohlichen Verlauf nehmen kann. Der Tumor kann in jedem Alter auftreten, ist aber bei Kleinkindern am häufigsten. Abhängig vom Ort des Entstehens präsentieren sich die Gefäßtumoren als blau-livide, druckempfindliche Plaques, tastbare Gewebsmassen oder sie werden als Tumor-Kompressionssyndrom manifest. Mit einer MRT muss die Ausdehnung des Tumors erfasst werden. Die Behandlung hängt von der klinischen Ausprägung ab. Unkomplizierte kutane Formen können lokal mit Kortikoiden behandelt werden. Wenn die Läsionen Funktionen beeinträchtigen, kann eine Behandlung mit Vincristin erforderlich sein, wobei eine mehrmonatige Therapie notwendig ist. Weitere therapeutische Optionen sind Embolisation, chirurgische Exzision und Strahlentherapie.

Fallbeschreibung. Wir präsentieren eine Patientin, bei der im Alter von zwei Monaten die Diagnose eines KHE des Oberschenkels rechts (ca. 10×4 cm) mit KMS gestellt wurde. Nach zwei Therapiezyklen mit Vincristin (VCR) und Actinomycin D (Ad) haben wir bei gutem Ansprechen eine Propranolol-Monotherapie begonnen, welche zu einer mittlerweile 18 Monate anhaltenden inkompletten Remission geführt hat. Therapiebedingte Nebenwirkungen sind nicht aufgetreten und die Patientin hat sich altersentsprechend entwickelt.

Schlussfolgerung. Bei dieser lebensbedrohlichen Erkrankung kann mit VCR und Ad eine Regression induziert werden und Propranolol als Therapieoption kann zu einer langanhaltenden Remission führen. $\mathrm{Ob}$ Propanolol beim KMS auch primär eingesetzt werden könnte, ist noch unklar.

\section{DGKJ-PO-02-5}

Helicobacter-pylori (HP)-positive Gastritis mit Eisenresorptionsstörung bei Eisenmangelanämie

\section{Benzrath S.', Berlemann B. ', Seiffert P.'}

${ }^{1}$ Helios St. Johannes Hospital, Kinder- und Jugendmedizinische Klinik, Duisburg

Fragestellung. Ein bisher gesundes 5 Jahre altes Mädchen mit ausgeprägter Eisenmangelanämie ( $\mathrm{Hb} 4,9$ g/dl, MCV 52 fl, Transferrinsättigung $2,3 \%$ ) zeigte eine enterale Eisenresorptionsstörung trotz adäquater oraler Substitution. Frage nach Genese.

Material und Methoden. Ausbleibender Anstieg des Hb-Werts unter oraler Eisen-II-Therapie. Pathologischer Eisenresorptionstest mit fehlendem Anstieg des Eisenspiegels ( $2,7 \mu \mathrm{mol} / \mathrm{l}$ vor, 2,8 $\mu \mathrm{mol} / \mathrm{l} 2$ Stunden nach Gabe). ParvoB19-negativ, kein Hinweis auf chronische Blutung, 
ÖGD mit HP-positiver Gastritis, kein Enzymmangel oder -defekt, unauffällige Erythrozytenmorphologie. Folglich i.v.-Substitution mit zweiwertigem Eisen i.v. 3-mal/Woche über 4 Wochen sowie HP-Eradikationstherapie mit Amoxicillin, Clarithromycin und Pantozol über 7 Tage. Anstieg des Hb-Wertes bis auf 11,2 g/dl. Im Anschluss Substitution mit Eisen oral und fortan stabile Werte. Beendigung der Therapie nach 12 Wochen. Im Verlauf nie mehr Resorptionsproblematik oder Anämie. Ergebnisse. Die HP-Infektion musste zunächst beseitigt werden, wonach eine orale Eisensubstitution erfolgreich durchgeführt werden konnte. Zwischenzeitlich musste intravenös Eisen zugeführt werden. Eine Transfusion konnte vermieden werden.

Diskussion. Bei gesicherter Eisenmangelanämie mit fehlender Besserung trotz adäquater oraler Eisensubstitution ist eine Resorptionsstörung möglich. Häufigste Ursache ist eine Non-Compliance. In unserem Fall ist anzunehmen, dass die HP-positive Gastritis die orale Eisenresorption vermutlich über die Rückkopplung mittels Hepcidin störte. Nach Eradikation und i.v.-Gaben von Eisen besserte sich die Resorptionsstörung und eine orale Therapie wurde möglich. Eine HP-Testung erscheint somit differenzialdiagnostisch ergänzend sinnvoll.

\section{DGKJ-PO-02-6}

Antimykotische Kombinationstherapie mit supportiven Granulozytentransfusionen bei Candidämie mit kutanen Absiedlungen und ZNS-Befall in Aplasie nach hämatopoetischer Stammzelltransplantation: ein Fallbericht

\section{Fouz H. ', Schuster F.', Meisel R. ${ }^{\text {' }}$ \\ 'Universitätsklinikum Düsseldorf, Klinik für Kinder-Onkologie, -Hämatolo- gie und Klinische Immunologie, Düsseldorf}

Fragestellung. Kann eine fortschreitende Candida-tropicalis-Sepsis mit kutanen Absiedlungen und ZNS-Beteiligung in der Panzytopenie nach hämatopoetischer Stammzelltransplantation durch eine Kombination von Antimykotika mit Granulozytentransfusionen erfolgreich therapiert werden?

Material und Methode. 8,5-jähriger Patient in Aplasie nach allogener hämatopoetischer Stammzelltransplantation bei myelodysplastischem Syndrom mit Candida tropicalis-Sepsis, papulösen Candida-Absiedlungen der Haut und Candida-Nachweis im Liquor. Eskalierende Therapie mit liposomalem Amphotericin B, Caspofungin sowie Voriconazol und frühzeitige Entfernung des Broviakkatheters. Bis zum neutrophilen Engraftment erhielt der Patient dreimalig Granulozytentransfusionen vom Vater.

Ergebnisse. Trotz sofortiger Initiierung einer antimykotischen Therapie mittels liposomalem Amphotericin B nach Erhalt der Blutkulturen, war ein Fortschreiten der Erkrankung mit Ausbildung von kutanen Candidaläsionen nachweisbar, so dass die Therapie um Caspofungin erweitert wurde. Zwei Tage später erfolgte der Nachweis von Candida tropicalis im Liquor. Aufgrund weiterhin zu erwartender Aplasie, wurden neben der Medikamentenerweiterung um das liquorgängige Voriconazol, dreimalig Granulozytentransfusionen vom Vater bis zur Erholung aus dem Zelltief verabreicht. Im weiteren Verlauf bildeten sich die Hautinfiltrate vollständig zurück, Blut- und Liquorkulturen blieben steril. Schlussfolgerung. Bei immunkompromittierten Patienten in Aplasie nach allogener hämatopoetischer Stammzelltransplantation kann eine Candidasepsis, selbst bei Haut- und ZNS-Beteiligung, mittels der Kombination aus mehreren Antimykotika und Granulozytentransfusionen eine klinische Stabilisierung und Ausheilung der Infektion bewirken.

\section{DGKJ-PO-02-7}

Follikuläres Lymphom bei einer 6-jährigen Patientin am Ohrläppchen?

\section{Hübsch M.', Lange B.S.', Knöfler R.', Suttorp M.'}

'Universitätsklinikum Carl Gustav Carus Dresden, Klinik und Poliklinik für Kinder- und Jugendmedizin, Bereich Pädiatrische Hämatologie und Onkologie, Dresden

Einleitung. Follikuläre Lymphome (FL) sind in der pädiatrischen Hämato-Onkologie extrem selten. Histologisch ist ein FL durch Zentrozyten und Zentroblasten mit Expression von B-Zellmarkern sowie BCL-2- und -6-Positivität charakterisiert. In $75 \%$ aller Fälle kann die chromosomale Translokation t(14/18) nachgewiesen werden. Ein klonales Immunglobulin-Schwerketten-Gen-Rearrangement beweist die Diagnose.

Fallbericht. Ein 6-jähriges Mädchen zeigte ohne sonstige klinische Auffälligkeiten eine gerötete, indolente Schwellung des rechten Ohrläppchens. Nach erfolgloser lokaler Antibiotikatherapie erfolgte die Biopsie, welche (referenzpathologisch bestätigt) die typische Histologie eines FL zeigte. Im Staging ergaben sich keine weiteren pathologischen Befunde. Aufgrund des klinischen Bildes und der Seltenheit der Diagnose erweiterten wir die Diagnostik. Es fiel eine positive Borrelienserologie im Sinne eines späten Infektionsstadiums auf und in einer zweiten Referenzpathologie konnte bei Untersuchung des Ig-Schwerketten-Gens ein FL nicht bewiesen werden. Deshalb wurde der Befund als Borrelien-Lymphozytom gewertet. Die Therapie mit Amoxillin führte zum Rückgang des Befundes am Ohrläppchen.

Schlussfolgerung. Unser Fallbericht unterstreicht die Schwierigkeit der histologischen Unterscheidung von FL und Borrelien-Lymphozytom. Ein Lymphozytom im Kindesalter sollte klinisch diagnostiziert werden, um belastende diagnostische Prozeduren zu vermeiden.

\section{DGKJ-PO-02-8}

Hereditäres-nonpolypöses Kolonkarzinom (HNPCC) - eine Fallvorstellung

Haber B. ', Trechow R.', Fellbaum C. ${ }^{2}$, Kaiser R. ', Trotter A. ${ }^{\prime}$

${ }^{1} G$ esundheitsverbund HBH-Kliniken, Klinik für Kinder und Jugendliche, Singen, ${ }^{2}$ Gesundheitsverbund HBH Kliniken, Institut und Gemeinschaftspraxis für Pathologie, Singen

Hintergrund. Das HNPCC ist eine autosomal-dominate Form des Kolonkarzinoms, dessen mittleres Erkrankungsalter bei 48 Jahren liegt und bevorzugt im rechten Hemikolon lokalisiert ist. Ursächlich ist eine Keimbahnmutation in einem der DNA-Mismatchrepair Gene.

Anamnese. Bei einem 10-jährigen Jungen Beginn der Symptomatik 3 Monate vor Aufnahme. Seitdem bestehe Dysphagie und ein reduzierter Appetit, teilweise Erbrechen nach der Nahrungsaufnahme. Ernährung seit vier Wochen mit zwei hochkalorischen Getränken täglich, feste Nahrung sei kaum möglich. Gewichtsverlust 9 kg, kein Nachtschweiß, kein Fieber. Familiär HNPCC bekannt.

Befunde. Reduzierter AZ, schlanker EZ, blasses Kolorit. Gewicht $27,8 \mathrm{~kg}(\mathrm{knapp}<3$. P). Abdomen: weich, diffuser Druckschmerz gesamter Oberbauch, keine Resistenz. Keine Organomegalie.

Labor. Hb 10,2 g/dl, CrP 1,84 mg/dl, BSG $38 \mathrm{~mm} / \mathrm{h}$. Harnsäure 3,6 mg/ dl, LDH $278 \mathrm{U} / \mathrm{l}$.

Verlauf. Bei primärem Verdacht auf Achalasie wurde eine MDP durchgeführt mit unauffälligem Ergebnis. In der Abdomensonographie zeigte sich eine massiv verdickte Darmwand im linken Oberbauch mit verwaschener Struktur. Daraufhin wurde zur näheren Klärung eine MRT durchgeführt, welche die Raumforderung in der linken Kolonflexur mit Lumeneinengung zeigte. Eine nähere Einordnung konnte nicht erfolgen. Daher erfolgte eine Koloskopie, die eine Stenose der linken Kolonflexur bei zirkulär/exophytisch wachsender Raumforderung mit Nekroseanteilen zeigte. Histologisch zeigte sich ein invasives mittelgradig differenzier- 
tes Adenokarzinom, passend zum HNPCC-Typ. Daraufhin Verlegung in ein onkologisches Zentrum. Das Follow-up steht aus.

Schlussfolgerung. Bei Gewichtsabnahme und Dysphagie muss auch im Kindesalter an Raritäten wie ein Kolonkarzinom gedacht werden.

\section{DGKJ-PO-02-9}

Die komplexe Differenzialdiagnostik retroperitonealer Tumoren mit Bezug zur Niere bei Adoleszenten - exemplarisch anhand des Falls eines 11-Jährigen

Schöndorf D. ', Dantonello T. ${ }^{2}$, Vokuhl C. ${ }^{3}$, Leuschner I. ${ }^{3}$, Kim Y.-J. ${ }^{4}$, Schenk J.-P. ${ }^{5}$, Schneider G. ${ }^{6}$, Graf N. ${ }^{1}$, Furtwängler R. ${ }^{1}$

'Universitätsklinikum des Saarlandes, Klinik für Pädiatrische Onkologie und Hämatologie, Homburg, ${ }^{2}$ Olgahospital Stuttgart, CWS-Studienzentrale, Stuttgart, ${ }^{3}$ Universitätsklinikum Schleswig-Holstein, Campus Kiel, Institut für Pathologie, Kiel, ${ }^{4}$ Universitätsklinikum des Saarlandes, Institut für Allgemeine und Spezielle Pathologie, Homburg, ${ }^{5}$ Universitätsklinikum Heidelberg, Pädiatrische Radiologie, Heidelberg, ${ }^{6}$ Universitätsklinikum des Saarlandes, Klinik für Diagnostische und Interventionelle Radiologie, Homburg

Einleitung. Wir berichten von einem Adoleszenten mit retroperitonealem Tumor und Bezug zur Niere. Trotz umfangreicher Diagnostik inklusive Stanzbiopsie erbrachte erst die vollständige Histopathologie die richtige Diagnose.

Fallbericht. Starke Rücken- und Bauchschmerzen führten bei einem 11-Jährigen zur Diagnose eines in der MRT heterogenen, teils zystischen Tumors, lokalisiert zwischen linker Niere und dorsaler Gerota-Faszie (Diameter $12 \mathrm{~cm}$; Volumen $400 \mathrm{ml}$, wovon $>95 \%$ extrarenal; $1,5 \mathrm{~cm}$ langer Anteil im dorsalen Parenchym). Bildgebend konnte nicht zwischen Weichteilsarkom und Nephroblastom differenziert werden. Die Stanzbiopsie zeigte einen spindelzelligen Tumor, passend zu einem embryonalen Rhabdomyosarkom (RME). Die Therapie mit Vincristin, Ifosfamid und Actinomycin D gemäß CWS (Hochrisiko) führte zu einer Regression auf $60 \mathrm{ml}$. Nach Nephrektomie ergab sich ein stromareiches Nephroblastom mit perilobärer Nephroblastomatose. Die Kumulativdosen von Vincristin und Actinomycin D für ein Nephroblastom intermediären Risikos des Stadiums I waren bereits erreicht, die Therapie wurde beendet. Nach 2 Jahren besteht eine anhaltende Erstremission. Die bildgebende Differenzialdiagnose eines Nephroblastoms wurde aufgrund der Biopsie zugunsten des RME verworfen. Retrospektiv hätte die Referenzpathologie auch ein stromareiches Nephroblastom bei Kenntnis der räumlichen Beziehung zur Niere erwogen, sich aber nicht festlegen können.

Schlussfolgerung. Die Wertigkeit der Stanzbiopsie bei der Einordnung retroperitonealer Tumoren bleibt auch infolge ihrer Risiken (Blutung, Stichkanalmetastasierung) kontrovers. Insbesondere bei spindelzelligen Tumoren und bei der Abgrenzung blastemreicher Tumoren gegenüber einer Nephroblastomatose gelingt dies selten. Das vollständige Informieren des Pathologen ist gerade in komplexen Fällen wichtig.
DGKJ-PO-02-10

Einfluss einer sporttherapeutischen Intervention während der Akuttherapie auf die Entwicklung der Knochendichte und Alltagsaktivität bei pädiatrischen Knochentumorpatienten

Müller C. ', Winter C.C. ${ }^{1}$, Boos J. ${ }^{2}$, Gosheger G. ${ }^{3}$, Hardes J. ${ }^{3}$, Vieth V. , Rosenbaum $D .{ }^{\prime}$

'Universitätsklinikum Münster, Institut für Experimentelle Muskuloskelettale Medizin (IEMM), Funktionsbereich Bewegungsanalytik, Münster, 2Universitätsklinikum Münster, Klinik für Kinder- und Jugendmedizin Pädiatrische Hämatologie und Onkologie, Münster, ${ }^{3}$ Universitätsklinikum Münster, Klinik für Allgemeine Orthopädie und Tumororthopädie, Münster, ${ }^{4}$ Universitätsklinikum Münster, Institut für Klinische Radiologie, Münster

Fragestellung. Zunehmend rücken Spätfolgen der Behandlung einer Knochentumorerkrankung im Kindesalter wie ein erhöhtes Frakturrisiko in den Vordergrund. Der Beitrag untersucht den Einfluss einer bewegungsfördernden Maßnahme in der pädiatrischen Onkologie zur Vermeidung therapiebedingter Knochendichteverluste.

Material und Methode. Untersucht wurden 21 Teilnehmer $(14,4 \pm 2,9 \mathrm{~J}$.) mit Knochentumoren an der unteren Extremität. Elf Patienten der Kontrollgruppe erhielten standardisierte Physiotherapie, 1o Patienten der Interventionsgruppe (IG) wurden zusätzlich sporttherapeutisch während der Akuttherapie betreut (Schwerpunkt Krafttraining). Die Knochendichte der Lendenwirbelsäule (LWS) und des nicht betroffenen Femurs wurde mittels DXA nach Abschluss der neoadjuvanten Chemotherapie, nach sechs und nach zwölf Monaten bestimmt. Zeitgleich erfolgte die objektive Erfassung der Alltagsaktivität über einen Aktivitätsmonitor.

Ergebnisse. Die Knochendichte nahm im Therapieverlauf generell ab, in der IG fielen die Verluste (teils signifikant) geringer aus. An der LWS wurden für die Sportintervention Effektstärken zwischen $d=0,71-0,96$ ermittelt, am Femur zwischen $\mathrm{d}=0,42-0,71$, wobei nach Cohen bei $\mathrm{d}=0,5$ ein mittlerer und bei $\mathrm{d}=0,8$ ein starker Effekt zugrunde liegt. $\mathrm{Zu}$ sämtlichen Messzeitpunkten wies die Interventionsgruppe ein signifikant höheres Aktivitätsniveau auf. Die Effektstärken lagen bei: Schritte pro Tag $d=1,38-1,64$; Schritte pro Stunde $d=1,30-1,42$ und Phasen hoher körperlicher Aktivität $\mathrm{d}=1,25-1,49$ (jeweils $\mathrm{p}<0,05$ ).

Schlussfolgerung. Pädiatrische Knochentumorpatienten profitieren von einer sporttherapeutischen Intervention bereits während der Akuttherapie. Die Ergebnisse belegen sowohl Notwendigkeit als auch Durchführbarkeit dieser Maßnahmen in der pädiatrischen Onkologie.

DGKJ-PO-02-11

Entwicklung des Gangbilds bei pädiatrischen Hirn- und Knochentumorpatienten im Verlauf einer vierwöchigen stationären Rehabilitationsmaßnahme

Müller C. ${ }^{1}$, Rosenbaum D. ${ }^{1}$, Kelter-Klöpping A. ${ }^{2}$, Mailand P. ${ }^{2}$, Lindkamp K. ${ }^{2}$, Krauth $K^{2}$

'Universitätsklinikum Münster, Institut für Experimentelle Muskuloskelettale Medizin (IEMM), Funktionsbereich Bewegungsanalytik, Münster, ${ }^{2}$ Klinik Bad Oexen, Kinderhämatologie und Onkologie, Bad Oeynhausen

Fragestellung. Der Beitrag untersucht, in welchem Maße Kinder nach einer Knochen- bzw. Hirntumorerkrankung in ihrem Gangbild eingeschränkt sind. Es werden Unterschiede zwischen den Diagnosegruppen und Entwicklungen beschrieben, die sich im Anschluss an eine vierwöchige stationäre Rehabilitationsmaßnahme erwarten lassen.

Material und Methode. 58 Hirn- und 39 Knochentumorpatienten zwischen 4-18 Jahren $(11,5 \pm 3,9$ J.) wurden zu Beginn und vor Abschluss ihres Aufenthalts ganganalytisch mittels Videoanalyse (Fa. Contemplas, erhobene Parameter: Standphase, Schrittlänge) und Druckverteilungsmessung, DVM, untersucht (Fa. Novel, Parameter: Kontaktfläche, Kraftmaximum, Druck-Zeit-Integral; zusätzlich Einbeinstand zur Beurteilung der Gleichgewichtsfähigkeit). Der Vergleich der Messergeb- 
nisse erfolgte über die Berechnung des Absoluten Symmetrie-Indexes (ASI,\%). Ein höherer Wert zeigt eine größere Asymmetrie im betroffen/ nicht-betroffen-Vergleich an.

Ergebnisse. Die videobasierte Ganganalyse demonstrierte eine signifikante Abnahme des ASI im Verlauf der Rehabilitation für die Parameter Standphase von 5,2 auf 4,1\% (Cohen's $d=0,22, p=0,022$ ) und Schrittlänge von 6,7 auf $3,9 \%(\mathrm{~d}=0,32 ; \mathrm{p}<0,001)$. In den Untersuchungen zur DVM wiesen Knochen- gegenüber Hirntumorpatienten signifikant höhere ASI-Werte auf $(\mathrm{p}<0,05)$. Die Ergebnisse des Einbeinstands auf der Druckmessplatte belegten eine signifikant verbesserte Gleichgewichtsfähigkeit der Patienten in der Abschlussmessung $(\mathrm{p}<0,05)$.

Schlussfolgerung. Die Untersuchungen zeigen den positiven Einfluss der Rehamaßnahme auf das Gangbild pädiatrisch-onkologischer Patienten. Insbesondere für Knochentumorpatienten ist sie aufgrund charakteristischer Einschränkungen im Gangbild nach operativen Eingriffen von Bedeutung.

Projektförderung: ARGE Krebs NW.

\section{DGKJ-PO-02-12}

Auswirkungen einer stationären Rehabilitationsmaßnahme auf Aktivitätsniveau und Lebensqualität von Kindern und Jugendlichen nach onkologischer Erkrankung

\section{Krauth K.A. ', Rosenbaum D. ${ }^{2}$, Kelter-Klöpping A. ', Mailand P. , Lindkamp K. ${ }^{1}$, Müller $C^{2}$}

'Klinik Bad Oexen, Pädiatrie, Bad Oeynhausen, ${ }^{2}$ Universitätsklinikum Münster, Institut für Experimentelle Muskuloskelettale Medizin (IEMM), Funktionsbereich Bewegungsanalytik, Münster

Fragestellung. Ziel der Studie ist die Evaluation stationärer Rehabilitationsmaßnahmen (Reha) für Kinder und Jugendliche in der Klinik Bad Oexen hinsichtlich der angestrebten nachhaltigen Verbesserung im Bereich der Alltagsaktivität und Lebensqualität.

Material und Methoden. Es wurde ein kontrolliertes Prä-post-Studiendesign gewählt. Die vier Messzeitpunkte waren kurz vor, direkt nach, sowie 6 und 12 Monate nach der Reha in Bad Oexen. Zur Erfassung der Alltagsaktivität wurde der StepWatch3 Aktivitätsmonitor für jeweils sieben Tage getragen. Mit dem KINDL-Fragebogen wurde die Lebensqualität erfasst. 214 Patienten im Alter von 4 bis 18 Jahren konnten in die Studie eingeschlossen werden (59 Hirn-, 42 Knochentumoren, 113 Leukämien/Lymphome).

Ergebnisse. Nach Abschluss der Reha zeigt sich ein Trend zu einer höheren Alltagsaktivität: Die Patienten steigerten ihren Aktivitätsumfang von durchschnittlich 11.100 Schritten direkt nach der Reha auf 11.600 Schritte nach zwölf Monaten. Phasen hoher Bewegungsintensität verlängerten sich von 31,0 auf 36,o Minuten. Diese vorläufigen Ergebnisse deuten zumindest bis zur Messung 6 Monate nach der Reha auf eine kontinuierliche Steigerung der Lebensqualität hin, die zwischen den ersten beiden ( $\mathrm{p}<0,001)$, sowie zwischen der ersten und dritten Erhebung $(\mathrm{p}=0,003)$ jeweils auf dem nach Bonferroni korrigierten Signifikanzniveau statistisch signifikant ausfällt.

Schlussfolgerung. Die vorläufigen Ergebnisse deuten auf einen positiven und nachhaltigen Einfluss der Reha hinsichtlich der oftmals eingeschränkten Alltagsaktivität hin. Ebenso lässt sich ein Trend zugunsten einer höheren gesundheitsbezogenen Lebensqualität der teilnehmenden Kinder und Jugendlichen im Anschluss an die Maßnahme erkennen.

Mit Unterstützung der ARGE Krebs NW.

\section{Neuropädiatrie (2)}

\section{DGKJ-PO-N2-1}

Akuter ischämischer Hirnstamminfarkt mit atypischen Wallenbergsyndrom im Rahmen einer ZNS-Vaskulitis bei einem 14-jährigen Jungen mit Neuroborreliose

Hetzer B. ', Baumann M.', Brunner J.', Cartes-Zumelzu F. ${ }^{2}$, Rostasy K. ${ }^{1}$

${ }^{1}$ Medizinische Universität Innsbruck, Department für Kinder- und Jugendheilkunde, Universitätsklinik für Pädiatrie I, Innsbruck, Österreich, ${ }^{2}$ Medizinische Universität Innsbruck, Department für Neuroradiologie, Innsbruck, Österreich

Einleitung. Wir berichten über einen 14-jährigen Jungen, der sich mit Gleichgewichtsstörung und Gangunsicherheit nach dem Aufstehen am Morgen vorstellte. Die neurologische Untersuchung zeigte ein HornerSyndrom mit Miosis und milder Ptosis auf der rechten Seite. Zudem fiel eine rechtsseitige Ataxie mit Fallneigung auf die rechte Seite, eine Abweichung des weichen Gaumens zur linken Seite als auch eine Dysarthrie auf. Zudem hatte er eine Hypästhesie (vor allem Temperaturempfindungsstörung) der linken Körperseite und der linken Gesichtshälfte, sodass die klinische Diagnose eines atypischen dorsolateralen Oblongatasyndroms (Wallenberg-Syndrom) gestellt wurde.

Ergebnisse. In der durchgeführten MRT-Untersuchung zeigte sich ein Infarkt in der lateralen Medulla oblongata rechts. Die CSF-Analyse ergab eine pleomorphe Pleocytose (116 Zellen/ $\mu$ l) als auch einen hohen Proteingehalt $(101 \mathrm{mg} / \mathrm{dl})$. Der spezifische IgG-Antikörper-Index für Borrelia burgdorferi im CSF war mit 38,7 erhöht und bestätigte die Diagnose einer Neuroborreliose. Die Behandlung mit Ceftriaxon i.v. über 14 Tage sowie $200 \mathrm{mg}$ Acetylsalicylsäure über drei Monate wurde begonnen. Die neurologischen Symptome verbesserten sich bereits innerhalb von zwei Wochen. In einer Kontrolluntersuchung nach zwei Monaten zeigte sich ein leicht sensorisches Defizit der linken Körperseite mit Dysaesthesien.

Schlussfolgerung. Der ischämische Schlaganfall bei Kindern auf Grund einer ZNS-Vaskulitis im Rahmen einer Neuroborreliose ist selten. Die Präsentation als atypisches Wallenberg-Syndrom wurde unseres Wissens nach bisher im Kindesalter noch nicht beschrieben. Die Neuroborreliose sollte daher als Differenzialdiagnose bei einem Schlaganfall im Kindesalter einbezogen werden.

\section{DGKJ-PO-N2-2}

Erfolgreiche Katheter-interventionelle Rekanalisation eines thrombembolischen Verschlusses der Arteria cerebri media infolge eines Herzkatheters

Kehl H.G. ${ }^{1}$, Kurlemann G. ${ }^{2}$, Verfürth A. ${ }^{1}$, Stege D. ${ }^{1}$, Niederstadt T. ${ }^{3}$, Köhler M. ${ }^{3}$

'Universitätsklinikum Münster, Klinik für Kinderheilkunde - Pädiatrische Kardiologie, Münster, ${ }^{2}$ Universitätsklinikum Münster, Klinik für Kinderheilkunde - Allgemeinpädiatrie, Münster, ${ }^{3}$ Universitätsklinikum Münster, Institut für klinische Radiologie, Münster

Einleitung. Akute zerebrale Gefäßverschlüsse sind zwar seltene, aber gut belegte Risiken von Herzkatheteruntersuchungen, insbesondere bei Interventionen und/oder hämostasiologischen Risikofaktoren.

Kasuistik. Eine 15-jährige Patientin mit Fontankreislauf bei Tricuspidalatresie Tpy IIc wurde wegen Zyanose $\left(\mathrm{SaO}_{2} 85 \%, \mathrm{Hb} 18,8 \mathrm{~g} / \mathrm{dl}\right)$ kathetert. Neben der bekannten Fenestrierung des extrakardialen Konduits fanden sich mehere Kollateralen von der V. anonyma zu den Lungenvenen. Die Fenestrierung und die Kollateralen konnten problemlos mit einem Amplatzer ASD-Okkluder und 2 Vascular-Plug-IV-Okkludern verschlossen werden. Nach Erwachen aus der Narkose fiel eine $\mathrm{He}$ miparese links auf, als Ursache fand sich im CCT ein subtotaler M1Verschluss der A. cerebri media rechts. Sofort nach Diagnosestellung wurde endovaskuläre Rekanalisierung versucht. Es gelang mit dem pREset ${ }^{\oplus}$-Thromb-Stent den Thrombus zu bergen. Histologisch fanden 
sich alte und frische Thrombusanteile. Die Hemiparese besserte sich innerhalb von wenigen Stunden und sistierte bis zur Entlassung am 8. Tag vollständig.

Schlussfolgerung. Die schnelle Diagnostik der Klinik und Bildgebung einer möglichen zerebralen Thrombembolie nach Herzkatheteruntersuchung ist entscheidend für eine erfolgreiche endovaskuläre Thrombusextraktion mittels pREset ${ }^{\oplus}$-Stent.

\section{DGKJ-PO-N2-3}

Tücken in der Diagnostik bei pädiatrischen Patienten mit zerebrovaskulären Erkrankungen (ZVE)

\section{Harmsen S. ', Karenfort M. ', Assmann B. ${ }^{2}$, Mayatepek E. ${ }^{\prime}$}

'Universitätsklinikum Düsseldorf, Klinik für Allgemeine Pädiatrie, Neonatologie und Kinderkardiologie, Düsseldorf, ${ }^{2}$ Universitätsklinikum Heidelberg, Zentrum für Kinder- und Jugendmedizin, Heidelberg

Fragestellung. ZVE treten im Kindesalter viel seltener als bei Erwachsenen auf und können sich mit einer Vielzahl von Symptomen manifestieren. Das wichtigste ist deren rasche Erkennung, wobei die Identifikation jener Symptome, die auf eine ZVE weisen, oftmals sehr schwierig sein kann. Die bei Erwachsenen häufigen Erkrankungen stellen im Kindesalter Ausnahmen dar. Hier sind Herzfehler, vaskuläre Läsionen, hämatologische Erkrankungen, Infektionen und Dissektionen, auch nach Bagatelltraumen, neben genetischen Erkrankungen, die häufigsten zugrundeliegenden Ätiologien.

Material und Methode. Um die klinischen und diagnostischen Schwierigkeiten zu identifizieren, die zu verzögerter Behandlung oder gar Fehldiagnose bei pädiatrischen Patienten mit ZVE führen können, analysierten wir retrospektiv die klinischen Symptome sowie die Ergebnisse der bildgebenden und Laboruntersuchungen von 16 Patienten mit ZVE (Alter 5-16 Jahre)

Ergebnisse. Die Initialsymptome, die teilweise bereits Monate vor der akuten Verschlechterung bestanden, waren heterogener als zuvor angenommen. Am häufigsten fanden sich kurze fokal-neurologische Zeichen unterschiedlicher Lokalisation. Im Verlauf traten oft Kopfschmerzen auf. Keiner der 16 Patienten ist verstorben. Sechs Patienten erhielten eine neurochirurgische Intervention.

Schlussfolgerung. Bei Kindern mit ZVE finden sich selten typische Beschwerden, wie sie im Erwachsenenalter auftreten. Die initiale klinische Symptomatik variierte von unspezifischem verschwommen sehen und plumpem Gangbild Monate zuvor bis hin zu schwerstem Kopfschmerz nur Minuten vor einem anschließenden Koma. Folglich gibt es bei pädiatrischen Patienten keine typische Anamnese oder klinische Symptomatik welche eine eindeutige Identifikation einer zugrundeliegenden ZVE erlaubt.

\section{DGKJ-PO-N2-4}

\section{Spitzfuß durch arteriovenöse Malformation}

\section{Aktas-Koptagel M. ${ }^{1}$, Delbrück H. ${ }^{2}$, Mahnken A. ${ }^{3}$, Häusler M. ${ }^{1}$} 'Universitätsklinikum RWTH Aachen, Klinik für Kinder- und Jugendmedizin, Aachen, ${ }^{2}$ Universitätsklinikum RWTH Aachen, Klinik für Orthopädie, Aachen, ${ }^{3}$ Universitätsklinikum RWTH Aachen, Klinik für Diagnostische und Interventionelle Radiologie, Aachen

Einleitung. Die Differenzialdiagnose des erworbenen Spitzfußes umfasst insbesondere neurogene und myogene Ursachen, wobei eine Schädigung der Pyramidenbahn nach zentraler Durchblutungsstörung, eine Rückenmarkserkrankung und primäre Myopathien zu den häufigen Ursachen zählen.

Fallbericht. Ein 9-jähriger Junge mit unauffälliger Vorgeschichte entwickelte einen rasch progredienten rechtsseitigen Spitzfuß, der auf Physiotherapie und Orthesenbehandlung nicht ansprach. Die Magnetresonanztomographie des Rückenmarks, des Gehirns und des Fußes, ausführliche Laboruntersuchungen (CK negativ) und elektro- physiologische Untersuchungen waren unauffällig. Schließlich zeigte die Magnetresonanztomographie des rechten Unterschenkels eine Gefäßmalformation im lateralen Gastrocnemiuskopf. Sonographisch zeigte dieser Muskel eine erhöhte Echogenität. Therapeutisch erfolgte eine interventionelle Embolisation der Malformation gefolgt von einer Achillessehnenplastik. Dies führte zu einer deutlichen funktionellen Verbesserung. Der sonographische Befund des verbleibenden Muskels normalisierte sich. Eine während der Operation aus dem echogenen Muskelbereich entnommene Biopsie ergab keine strukturellen Schäden. Diskussion. Die Spitzfußbildung durch arteriovenöse Malformationen ist bekannt aber selten. Therapeutisch wurden insbesondere ausgedehnte Resektionen und die Achillessehnenplastik beschrieben. Das hier gewählte zweizeitige Vorgehen ist eine neue Alternative, die mit gutem funktionellem Ergebnis die Gefäßfehlbildung beseitigt und den Restmuskel erhält.

\section{DGKJ-PO-N2-5}

\section{Seltene Ursache einer Okulomotoriusparese}

Elpers C. ', Fiedler B. ${ }^{1}$, Schwindt W. ${ }^{2}$, Henkes H. ${ }^{3}$, Omran H. ', Stummer W. ${ }^{4}$, Kurlemann G.

'Universitätsklinikum Münster, Klinik für Kinder- und Jugendmedizin, Allg. Pädiatrie, Münster, ${ }^{2}$ Universitätsklinikum Münster, Institut für Klinische Radiologie, Münster, ${ }^{3}$ Klinikum Stuttgart, Olgahospital, Klinik für Diagnostische und Interventionelle Neuroradiologie, Stuttgart, ${ }^{4}$ Universitätsklinikum Münster, Klinik für Neurochirurgie, Münster

Einleitung. Die Okulomotoriusparese (OcP) ist meist Erstsymptom eines Hirndrucks oder chiasmatischen Raumforderung. Das Hämangiom ist der häufigste, gutartige Tumor im Kindesalter mit meist kutaner Lokalisation. Eine intracerebrale Manifestation ist selten und tritt vor allem bei multiplen Hämangiomen der Haut auf. Wir präsentieren den Fall einer Adoleszenten mit OcP und Nachweis eines intracerebralen Hämangioms im Bereich des Chiasma opticum.

Fallbericht. Vorstellung eines 17-jährigen Mädchens mit rechtsseitiger OcP, Amaurosis und zunehmender Visusreduktion links (o,15). Funduskopisch beidseitige Opticusatrophie. Anamnestisch und in der klinischen Untersuchung keine kutanen Hämangiome. In der cMRT Nachweis einer ausgedehnten, parasellären, extraaxialen Raumforderung. Daher stereotaktische Biopsie und histologischer Nachweis eines Hämangioms mit immunhistochemisch positivem VEGF-Nachweis. Aufgrund der Tumorgröße initial keine chirurgische Intervention möglich, daher primär konservativer Therapieversuch mit Propranolol zum Erhalt des linksseitigen Visus; hierunter keine Größenreduktion. Daher Erweiterung der Medikation um Prednisolon nach 3 Monaten und Nachweis einer Größenregression in der cMRT. Beendigung der Behandlung bei Steroiddiabetes und Candida-Infektion. Therapieeskalation auf Bevacizumab. Beendigung nach 3 Monaten bei fehlendem Effekt. 15 Monate nach Therapiebeginn erfolgte als Ultima ratio die operative Hämangiomextirpation mit intraoperativer Embolisation. Postoperative Entwicklung von Vasospasmen mit transienter Hemiplegie links, kein Erhalt des linksseitigen Restvisus.

Schlussfolgerung. Eine definitive Therapie des intracerebralen Hämangioms besteht nicht, die jeweilige Behandlung ist individuell und symptomabhängig, der Zeitpunkt einer operativen Intervention Gegenstand aktueller Diskussion. 


\section{DGKJ-PO-N2-6}

\section{Schmerzhafte Augenbewegungen - okuläre Myositis}

Fiedler B.J.', Schwindt W. ${ }^{2}$, Elpers C. ', Kurlemann G. ${ }^{1}$

'Universitätsklinikum Münster, Klinik für Kinder- und Jugendmedizin, Bereich Neuropädiatrie, Münster, ${ }^{2}$ Universitätsklinikum Münster, Institut für klinische Radiologie, Münster

Einleitung. Die okuläre Myositis ist eine seltene entzündliche Erkrankung der extraokulären Muskeln. Führendes Symptom sind schmerzhafte Augenbewegungen. Wie berichten über 9 Patienten aus 3 Familien.

P 1. 13 J. weiblich. Schmerzhafte Bewegungen rechtes Auge, v. a. beim Blick nach links. MRT-Orbita: entzündlich geschwollener M. rectus medialis rechts. Therapie mit $100 \mathrm{mg}$ Methylprednisolon für 5 Tage, Ausschleichen über 8 Wochen. Rasche Besserung innerhalb weniger Tage, MR-tomographisch Remission nach 3 Monaten. Rezidivfreies Follow-up bis aktuell 21 Jahre.

P 2. 15 J. weiblich. Über 2 Jahre undulierender Verlauf mit schmerzhaften Augenbewegungen li. > re., v. a. beim Aufblick links. MRT-Orbita: entzündliche Veränderung der gesamten extraokulären Muskeln, v. a. M. rectus superior links. Steroidtherapie mit 1 mg $/ \mathrm{kg} \mathrm{KG.} \mathrm{Nach} 3$ Tagen nahezu komplett schmerzfrei.

P 3-9. Italienisch-deutsche Familie, 5 weiblich und 2 männlich, in 3 Generationen betroffen. Alle zeigten einen undulierenden Verlauf, beginnend mit schmerzhaften Augenbewegungen zwischen dem 9. und 17. Lj. Bei Großmutter und Mutter der italienischen Seite sistierte die Symptomatik jeweils nach Geburt des 1. Kindes. Alle haben prompt auf Steroide angesprochen. Während die Männer der Familie nur 1 Schub hatten, war der Verlauf bei den Frauen mehrfach rezidivierend. Zwei Frauen der 3. Generation sind seit Einnahme von Kontrazeptiva beschwerdefrei.

Konklusion. Die okuläre Myositis tritt bevorzugt vor der Pubertät auf, weist einen stark undulierenden Verlauf auf und spricht auf Steroide prompt an. Möglicherweise haben Frauen einen schweren Verlauf als Männer, wie unsere 3-Generationen-Familie zeigt. In dieser Familie sind genetische Untersuchungen veranlasst. Die Beobachtung einer anhaltenden Besserung unter weiblichen Hormonen (Antikonzeption) ist neu und könnte auf einen protektiven Effekt hinweise.

\section{DGKJ-PO-N2-7}

Das Eineinhalb-Syndrom - seltener Beginn einer multiplen Sklerose bei einem 13-jährigen Mädchen. Ein Fallbericht

Finetti C. ${ }^{1}$, Horn A. ${ }^{2}$, Utz N. ${ }^{3}$

${ }^{1}$ Elisabeth Krankenhaus Essen, Kinderneurologisches Zentrum, Essen, ${ }^{2}$ Klinikum Duisburg, Klinik für Kinder- und Jugendmedizin, Abteilung Neuropädatrie, Duisburg, ${ }^{3}$ Helios-Klinikum Krefeld, Klinik für Radiologie, Sektion Kinderradiologie, Krefeld

Einleitung. Das Eineinhalb-Syndrom stellt einen seltenen neuroopthalmologischen Symptomenkomplex dar, das durch die Kombination einer horizontalen Blicklähmung („ganze Blicklähmung“) mit einer internukleären Ophthalmoplegie („halbe Blicklähmung“) gekennzeichnet ist. Ursache des Eineinhalb-Syndroms ist eine einseitige pontine Schädigung, infolge eines lakunären Hirninfarktes, eines Entmarkungsherdes bei Multipler Sklerose, einer Hirnblutung oder eines Tumors im Bereich des Pons.

Fallbeschreibung. Wir berichten über ein 13-jähriges Mädchen, das aufgrund von Doppelbildern zur neuropädiatrischen Abklärung vorstellt wurde. Es zeigte sich eine beidseitige horizontale Blicklähmung beim Blick nach rechts. Zusätzlich war die Adduktion beim Blick zur Gegenrichtung des rechten Auges nicht möglich. Ansonsten war der neurologische Untersuchungsbefund unauffällig.

Ergebnisse. In der MRT-Untersuchung des Schädels zeigten sich periventrikuläre Marklagerläsionen sowie eine Läsion links frontal. Weiterhin zeigte sich infratentoriell eine pontine Läsion rechtsseits sowie eine weitere auf Niveau des dorsalen Hirnstamms. Im Liquor Nachweis eine Schrankenstörung und Nachweis oligoklonaler Banden. Damit konnte die Diagnose einer multiplen Sklerose anhand der McDonald-Kriterien gestellt werden. Nach 5-tägiger Therapie mit Cortison kam es zur Besserung der Symptomatik.

Schlussfolgerung. Neuroophthalmologische Symptome sind in der Kinder- und Jugendärztlichen Praxis eine Seltenheit. Umso wichtiger ist es, diese Symptome zu erkennen und sowohl augenärztlich, als auch neuropädiatrisch abzuklären zu lassen, denn manchmal verbirgt sich hinter einem Symptom des Auges eine chronische neurologische Erkrankung.

\section{DGKJ-PO-N2-8}

Post-hoc-Vergleich der Wirksamkeit von Lisdexamfetamindimesilat und Osmotic-Release Oral System Methylphenidate bei Kindern und Jugendlichen mit ADHS

Häge A. ', Banaschewski T.', Lecendreux M. ${ }^{2}$, Soutullo C. ${ }^{3}$, Johnson M. ${ }^{4}$, Zuddas A. ${ }^{5}$, Anderson C.S. ${ }^{6}$, Civil R. ${ }^{6}$, Higgins N. ${ }^{6}$, Bloomfield R. ${ }^{7}$, Squires L.A. ${ }^{6}$, Coghill D. R. ${ }^{8}$

${ }^{1}$ Klinische Psychopharmakologie des Kindes- und Jugendalters, Mannheim, ${ }^{2}$ Robert-Debré University Hospital, Paediatric Sleep Centre and National Reference Centre for Orphan Diseases: Narcolepsy, Idiopathic Hypersomnia and Kleine-Levin Syndrome, Paris, Frankreich, ${ }^{3}$ University of Navarra Clinic, Child \& Adolescent Psychiatry Unit, Department of Psychiatry \& Medical Psychology, Pamplona, Spanien, ${ }^{4}$ Queen Sylvia Children's Hospital, Child Neuropsychiatry Unit, Göteborg, Schweden, ${ }^{5}$ Universität Cagliari, Department of Biomedical Sciences, Section of Neuroscience and Clinical Pharmacology, Cagliari, Italien, ${ }^{6}$ Shire Development LLC, Wayne, USA, ${ }^{7}$ Shire Pharmaceutical Development Ltd, Basingstoke, UK, ${ }^{8}$ Universität Dundee, Division of Neuroscience, Dundee, UK

Zielsetzung. In einer Phase-3-Studie zeigten sich Lisdexamfetamindimesilat (LDX) und Osmotic-Release Oral System Methylphenidate (OROS-MPH) wirksamer als Placebo hinsichtlich der Symptomverbesserung bei Kindern und Jugendlichen mit Aufmerksamkeitsdefizit-/ Hyperaktivitätsstörung (ADHS). In dieser Post-hoc-Analyse wurde die Wirksamkeit von LDX und OROS-MPH miteinander verglichen.

Methoden. Patienten mit ADHS im Alter von 6-17 Jahren wurde in diese 7-wöchige, doppelblinde, dosisoptimierte Parallelgruppenstudie eingeschlossen. Die Patienten wurden in drei Behandlungsarme randomisiert und erhielten einmal täglich LDX (30, 50 oder $70 \mathrm{mg} / \mathrm{Tag})$, OROS-MPH (18, 36 oder 54 mg/Tag) oder Placebo. Die Wirksamkeit wurde anhand der ADHD Rating Scale IV (ADHD-RS-IV) und der Clinical Global Impressions-Improvement (CGI-I) Skala beurteilt. Der Endpunkt wurde definiert als letzter Besuch während der Behandlung mit einer gültigen Beurteilung.

Ergebnisse. Der Gesamtanalysesatz umfasste 317 Patienten (LDX, $\mathrm{n}=104$; Placebo, $\mathrm{n}=106$; OROS-MPH, $\mathrm{n}=107$ ). Der Unterschied zwischen LDX und OROS-MPH bzgl. der Kleinstquadrat-Änderung ]95\% Konfidenzintervall, (KI)] im ADHD-RS-IV Gesamtscore zwischen Startund Endpunkt war statistisch signifikant zugunsten von LDX $[-5,6$ $(-8,4,-2,7) ; \mathrm{p}<0,001$; Effektstärke, 0,541]. Ebenso war der Anteil LDX minus OROS-MPH der Patienten mit einem CGI-I-Score von 1 bzw. 2 am Behandlungsendpunkt statistisch signifikant unterschiedlich und für LDX um 17,4\% höher (95\% KI: 5,0, 29,8; p<0,05).

Schlussfolgerungen. Diese Post-hoc-Analyse deutete darauf hin, dass LDX bei der Verbesserung der Hauptsymptome und der allgemeinen Funktion bei Kindern und Jugendlichen mit ADHS signifikant wirksamer war als OROS-MPH.

Unterstützt durch Forschungsmittel von Shire Development LLC. 


\section{DGKJ-PO-N2-9}

Eine Vergleichsstudie der Phase $3 \mathrm{~b}$ zur Wirksamkeit und Sicherheit von Lisdexamfetamindimesilat und Atomoxetin bei der Behandlung von Kindern und Jugendlichen mit Aufmerksamkeitsdefizit-/ Hyperaktivitätsstörung

Häge A. ${ }^{1}$, Cardo E. ${ }^{2}$, Coghill D.R. ${ }^{3}$, Nagy P. ${ }^{4}$, Anderson C.S. ${ }^{5}$, Bloomfield R. ${ }^{6}$, Caballero B. ${ }^{7}$, Higgins N. ${ }^{5}$, Hodgkins P. ${ }^{5}$, Lyne A. ${ }^{6}$, Civil R. ${ }^{5}$, Dittmann R.W. ${ }^{1}$

${ }^{1} K$ linische Psychopharmakologie des Kindes- und Jugendalters, Mannheim, ${ }^{2}$ Son Llatzer Hospital \& Research Institute on Health Sciences, Palma, Spanien, ${ }^{3}$ Universität Dundee, Division of Neuroscience, Dundee, UK, ${ }^{4}$ Vadaskert Child and Adolescent Psychiatry Hospital and Outpatient Clinic, Budapest, Ungarn, ${ }^{5}$ Shire Development LLC, Wayne, USA, ${ }^{6}$ Shire Pharmaceutical Development Ltd, Basingstoke, UK, ${ }^{7}$ Shire AG, Eysins, Schweiz

Zielsetzung. Vergleich der Wirksamkeit und Sicherheit von Lisdexamfetamindimesilat (LDX) und Atomoxetin (ATX) bei der Behandlung von Kindern und Jugendlichen mit Aufmerksamkeitsdefizit-/Hyperaktivitätsstörung (ADHS).

Materialien und Methoden. In diese 9-wöchige, randomisierte, dosisoptimierte, doppelblinde Vergleichsstudie wurden Kinder und Jugendliche (im Alter von 6-17 Jahren) mit ADHS eingeschlossen, die zuvor unzureichend auf eine Methylphenidat-Therapie angesprochen hatten. Die Patienten wurden in Arme mit einmal täglich LDX (30, 50 oder $70 \mathrm{mg}$ ) bzw. ATX (Patienten <7o kg, 0,5-1,2 mg/kg, max. 1,4 mg/kg; $\geq 70 \mathrm{~kg}, 40,80$ oder $100 \mathrm{mg}$ ) randomisiert (1:1). Der primäre Endpunkt der Studie war die Zeit bis zum klinischen Ansprechen, definiert als Clinical Global Impressions-Improvement-Wert von 1 (stark verbessert) bzw. 2 (sehr verbessert).

Ergebnisse. 200 (74,9\%) der randomisierten 267 Patienten schlossen die Studie ab. Die mediane Ansprechzeit [95\% Konfidenzintervall (KI)] war für LDX signifikant kürzer [12,o Tage $(8,0,16,0)]$ als für ATX [21,o Tage $(15,0,23,0) ; \mathrm{p}=0,001]$. Bis Woche 9 war der Prozentsatz der Patienten (95\% KI), die auf eine Behandlung ansprachen, für LDX höher $[81,7 \%$ $(75,0,88,5)]$ als für ATX $[63,6 \%(55,4,71,8) ; p=0,001]$. Unter der Behandlung aufgetretene unerwünschte Ereignisse wurden von $71,9 \%$ der $\mathrm{Pa}$ tienten unter LDX und 70,9\% der Patienten unter ATX berichtet.

Schlussfolgerungen. LDX führte im Vergleich zu ATX bei Kindern und Jugendlichen mit ADHS, die zuvor unzureichend auf MPH angesprochen hatten, zu einem schnelleren und deutlicheren Ansprechen auf die Behandlung. Die Sicherheitsprofile beider Behandlungsoptionen standen im Einklang mit Ergebnissen aus vorherigen klinischen Studien. Unterstützt durch Forschungsmittel von Shire Development LLC.

\section{DGKJ-PO-N2-10}

Myopathie als einzige Manifestation einer ausgeprägten Hashimoto-Thyreoiditis

\section{Pigulla J.', Becher T.', Duckwitz H.', Weise S. \\ 'Sana Krankenhaus Gerresheim, Kinderneurologisches Zentrum, Düssel- dorf}

Kasuistik. Wir berichten über eine bis dato gesunde 15-jährige Patientin, bei der eine Myopathie das einzige Symptom einer manifesten Hashimoto-Thyreoiditis darstellte. Die Patientin wurde bei V. a. neuromuskuläre Erkrankung neuropädiatrisch vorgestellt. Sie klagte seit 6 Wochen über zunehmende rezidivierende schmerzhafte Krämpfe der Unterschenkel sowie Taubheitsgefühl nach moderater Anstrengung. Im Verlauf zusätzlich Schwäche und Taubheitsgefühl der oberen Extremität nach wenigen Minuten Aktivität. Steigerung der Beschwerden im Tagsverlauf. Zuletzt Einschränkung der Gehstrecke auf $200 \mathrm{~m}$ bzw. 2 Etagen. Keine Stuhlveränderungen, Antriebsarmut, Verlangsamung, Schwindel, Kälteintoleranz, Zyklusveränderungen, Haarausfall, Veränderungen von Haut oder Haar oder Gewichtsveränderung. Klinik: internpädiatrisch und neurologisch unauffällig. Labor: CK 576 U/l, Kreatinin 1,08 mg/dl, GPT 81 U/l, Cholesterin $421 \mathrm{mg} / \mathrm{dl}$. TSH $290 \mathrm{mU} / \mathrm{l}, \mathrm{fT}_{4}$ o,06 ng/dl, T3 o,10 ng/dl, MAK >600 IU/ml (<34), TAK 185 IU/ml (<115),
TRAK 0,54 IU/l (<1,75). Aufgrund der Befundkonstellation wurde eine manifeste Autoimmun-Thyreoiditis Hashimoto diagnostiziert und die Patientin endokrinologisch weiterbetreut.

Schlussfolgerung. Dieser Fall zeigt die Wichtigkeit, bei Myopathien eine Hypothyreose auch bei Fehlen weiterer Kardinalsymptome frühzeitig differenzialdiagnostisch in Betracht zu ziehen. Durch eine rasche Diagnose können eine verlängerte Erkrankungsdauer und invasive Untersuchungen vermieden werden.

\section{DGKJ-PO-N2-11 \\ Junge mit hämolytisch-urämischem Syndrom (HUS) und Hypomye- linisierung: vom HUS zum 4H-Syndrom}

Kotzaeridou U. ${ }^{1}$, WuehI E. ${ }^{2}$, van Spaendonk R. ${ }^{3}$, Hoffmann G.F.', Wolf N.I. ${ }^{4}$

${ }^{1}$ Universitätsklinikum Heidelberg, Zentrum für Kinder- und Jugendmedizin, Kinderheilkunde I, Sektion Neuropädiatrie, Sozialpädiatrisches Zentrum, Heidelberg, ${ }^{2}$ Universitätsklinikum Heidelberg, Zentrum für Kinder- und Jugendmedizin, Kinderheilkunde I, Sektion Pädiatrische Nephrologie, Heidelberg, ${ }^{3}$ VU University Medical Center, Abteilung Klinische Genetik, Amsterdam, Niederlande, ${ }^{4} \mathrm{VU}$ University Medical Center, Amsterdam, Niederlande

Einleitung. 4H-Syndrom (Hypomyelinisierung, Hypodontie und hypogonadotroper Hypogonadismus) ist eine autosomal rezessive neurodegenerative Erkrankung. Die Erkrankung wird neurologisch vor allem durch eine progrediente Ataxie gekennzeichnet; im Verlauf treten eine milde Spastik sowie eine milde kognitive Regression hinzu. Andere, nicht obligate Merkmale können eine verzögerte Dentition, Hypodontie und Hypogonadismus sein.

Fallbeschreibung. Der Indexpatient wurde im Alter von 8 Monaten mit dem klinischen Bild eines hämolytisch-urämischen Syndroms stationär aufgenommen. Schwangerschaft und Geburt waren unauffällig, wie auch die Entwicklung bis zum diesem Zeitpunkt. Im ersten cMRT war bereits eine Myelinisierungsstörung zu sehen. Im Verlauf zeigten sich für HUS-typische vaskulitische Veränderungen im Bereich der Basalganglien Bei der Entlassung zeigte der Patient eine globale Entwicklungsverzögerung und muskuläre Hypotonie, interpretiert als sekundär zur cerebralen Beteiligung des HUS. Ab dem Alter von 2 Jahren fiel eine ataktische Bewegungsstörung mit neu aufgetretenem Nystagmus und Tremor auf. Die Zahnentwicklung verlief auffällig, so blieb die Entwicklung der Vorderzähne bis zum 2. Lebensjahr aus. Das cMRT im Alter von 2,5 Jahren zeigte eine Hypomyelinisierung zusätzlich zu den Nekrosen der Putamina im Rahmen des HUS. Bei V. a. ein ${ }_{4} \mathrm{H}-\mathrm{Syn}-$ drom wurde das $\mathrm{POLR}_{3} \mathrm{~A}$ Gen sequenziert und zwei neue pathogene Mutationen nachgewiesen.

Schlussfolgerung. Die Diagnose einer HLD-7 wurde durch das gleichzeitige Auftreten eines HUS mit cerebraler Beteiligung erschwert. Die auffällige Dentition und die Hypomyelinisierung im MRT waren entscheidend für die Diagnosefindung.

\section{DGKJ-PO-N2-12}

\section{Seltene Nebenwirkung unter Interferon-Therapie bei multipler} Sklerose

\section{Elpers C. ${ }^{1}$ Fiedler B. ${ }^{1}$, Radke I. ${ }^{2}$, Linden T. ${ }^{1}$, Kurlemann $G .{ }^{1}$}

'Universitätsklinikum Münster, Klinik für Kinder- und Jugendmedizin, Allg. Pädiatrie, Münster, ${ }^{2}$ Universitätsklinikum Münster, Klinik für Frauenheilkunde und Geburtshilfe, Münster

Einleitung. Die multiple Sklerose (MS) ist eine chronisch-entzündliche Erkrankung des Zentralnervensystems mit meist schubförmig-remittierendem Verlauf. Zur Reduktion der Krankheitsprogression wird auch bei juveniler Manifestation eine Dauertherapie mit Interferonen empfohlen. Fibroadenome sind gutartige, durch hormonellen Einfluss entstandene Neubildungen in der Brustdrüse. Eine Veränderung dieser Tumoren unter Interferon-Therapie wurde bisher nicht beschrieben. 
Wir präsentieren eine Jugendliche mit MS und rasch zunehmenden Fibroadenomen unter Interferon-Behandlung.

Fallbericht. 17-jähriges Mädchen mit Erstmanifestation der MS im April 2007 mit rechtsseitiger, armbetonter Hemiparese. Unter i.v. Cortisontherapie rasch rückläufige Symptome mit mildem Residualbefund. Erneuter Schub mit gleicher Symptomatik im Oktober 2009. Seit Oktober 2011 Basistherapie mit Interferon-beta-1a. Hierunter seitdem klinisch stabiler Krankheitsverlauf. Anamnestisch bekannte Fibroadenome beider Mammae. Zusätzlich Hirsutismus, polyzystische Ovarien, Adipositas und Zustand nach Thyreoidektomie 2009 bei Struma multinodosa. Wiederholt normwertige Hormonbestimmungen. Unter Interferon-beta-Therapie klinisch und radiologisch rasche Progredienz der Fibroadenome in Anzahl und Größe. Biopsie zur histologischen Sicherung vorgesehen. Dieser Fall beschreibt erstmalig die Fibroadenomatose als seltene Nebenwirkung der Interferon-beta-Therapie, welche gerade für weibliche Patienten von großer Bedeutung ist.

Schlussfolgerung. Die Beendigung der Medikation aufgrund der zunehmenden Fibroadenome bleibt gerade bei stabilem Krankheitsverlauf zu diskutieren. In der Literatur wird ein Zusammenhang zwischen aggressiver Fibromatose und Interferonen beschrieben. Diese Korrelation ist auf eine Erhöhung der Anzahl an Progenitorzellen durch Interferone zurückzuführen.

\section{DGKJ-PO-N2-13}

Chronische Liquorabflusstörung aus dem 4. Ventrikel nach frühgeburtlicher Hirnblutung. Eine Operationsindikation?

Häusler M. ', Deutz U. ${ }^{1}$, Tanrikulu L. ${ }^{2}$, Neuloh G. ${ }^{2}$

'Universitätsklinikum RWTH Aachen, Klinik für Kinder- und Jugendmedizin, Sektion Neuropädiatrie und Sozialpädiatrie, Aachen, ${ }^{2}$ Universitätsklinikum RWTH Aachen Klinik für Neurochirurgie, Aachen

Fragestellung. Die Liquorabflusstörung aus dem 4. Ventrikel ist eine bekannte Folge frühgeburtlicher (FGB) Hirnblutungen. Bei sicherem Hirndruck oder einer sekundären Syringomyelie ist die Operationsindikation klar. Schwierig ist die Entscheidung wenn sichere Druckzeichen fehlen.

Material und Methode. Fallberichte zu zwei ehemaligen FGB von 25 bzw. 26 SSW mit peripartaler Hirnblutung Grad 3 bzw. 4.

Ergebnisse. Beide Jungen zeigten bei Erstvorstellung mit 9 bzw. 16 Jahren eine schwere Tetraspastik und MR-tomographisch plumpe innere Liquorräume mit deutlicher Erweiterung des 4. Ventrikels sowie eine Kleinhirnkompression. Patient 2 war schwerer betroffen. Nach 3- bzw. 1-jähriger Beobachtung wurden bei beiden die den Ausfluss aus dem 4. Ventrikel verlegenden Membranen gefenstert. Danach verkleinerte sich bei Patient 1 der 4. Ventrikel nicht. Er zeigte jedoch eine Verbesserung von Aufmerksamkeit, Konzentration, nonverbaler Kommunikation und Muskeltonus. Patient 2 zeigte postoperativ eine Blutung mit Abflussstörung aus dem 4. Ventrikel, die einen ventrikuloperitonealen Shunt erforderte. Im Verlauf wurde der 4. Ventrikel kleiner. Seine Aufmerksamkeit und nonverbale Kommunikation wurden besser, die Spastik persistierte.

Diskussion. Beide Kinder hatten als Folge einer FGB-Hirnblutung eine membranöse Liquorabflusstörung aus dem 4. Ventrikel ohne eindeutige Druckzeichen. Die späte Operation führte nur zu geringer klinischer Besserung. Es bleibt unklar, ob eine frühere Entlastung effektiver gewesen wäre. Unsere Befunde erweitern das Spektrum von Liquorabflusstörungen nach frühgeburtlicher Hirnblutung. Auch nach Jahren klinischer Stabilität kann bei diesen Kindern eine erneute zerebrale Bildgebung indiziert sein.

\section{Neonatologie/Pädiatrische Intensivmedizin (2)}

\section{DGKJ-PO-I2-1}

Respiratorische Unterstützung während der kardiopulmonalen Reanimation bei neugeborenen Ferkeln: Einfluss verschiedener Beatmungsverfahren auf den Gasaustausch, die Hämodynamik und die zerebrale Oxygenierung

Mendler M.R. ', Maurer M.', Waitz M.', Hassan M.', Huang L.', Hummler H.D.' 'Universitätsklinikum Ulm, Klinik für Kinder- und Jugendmedizin, Sektion Neonatologie und pädiatrische Intensivmedizin, Ulm

Einleitung. Die ILCOR-Richtlinien sehen ein Kompressions-/Ventilationsverhältnis von 3:1 für die Reanimation von Neugeborenen im Kreissaal vor. Allerdings gibt es keine Untersuchungen, die zeigen, dass die Interposition der Atemhübe gegenüber nichtsynchroner kontinuierlicher Fortführung der kardialen Kompression mit 120 Kompressionen/min bzw. die Verwendung von positivem endexpiratorischem Druck (PEEP) vorteilhaft ist.

Ziel. Das Ziel dieser Studie war die Untersuchung der Einflüsse verschiedener Formen der respiratorischen Unterstützung während der CPR auf den Gasaustausch und die Hämodynamik bei neugeborenen Ferkeln im Kreislaufstillstand. Unsere Annahme war hierbei, dass die Verwendung von PEEP und die Interposition der Beatmungshübe den Gasaustausch und die Hämodynamik, u. a. gemessen an der $\mathrm{SaO}_{2}$, verbessert.

Methoden. Prospektive, kontrollierte, randomisierte Studie an 30 intubierten neugeborenen (5d;4-6d)Ferkeln (1875g;168o-220og)in3 Gruppen: - Gruppe 1: Respirator: PIP/PEEP 20/5 cmH2O, $\mathrm{f}=3 \mathrm{O} / \mathrm{min}$, ti o,4 s. Kardiale Kompressionen (CC) werden mit einer Frequenz von 120/min verabreicht, ohne auf Synchronisation mit der Beatmung zu achten. - Gruppe 2: T-piece-System: PIP/PEEP $20 / 5 \mathrm{cmH}_{2} \mathrm{O}, \mathrm{f}=30 / \mathrm{min}$, wobei die Beatmungshübe zwischen CC mit einer 3:1 Ratio interponiert werden. -Gruppe 3:Beatmungsbeutel: $\mathrm{PIP}_{2} \mathrm{O}_{\mathrm{cmH}} \mathrm{H}_{2} \mathrm{O}$ ohnePEEP, $\mathrm{f}=3 \mathrm{O} / \mathrm{min}$, wobei die Beatmungshübe zwischen CC mit einer 3:1 Ratio interponiert werden. Ergebnisse. Es konnte kein signifikanter Unterschied bezüglich der $\mathrm{SaO}_{2}$ festgestellt werden. Allerdings ließ sich ein Trend zu einer höheren $\mathrm{SaO}_{2}$ und $\mathrm{zu}$ niedrigeren $\mathrm{paCO}_{2}$-Werte in der Respiratorgruppe erkennen.

Schlussfolgerung. Mit vorliegender Studie konnte unsere Hypothese nicht bestätigt werden. Möglicherweise hat die erhöhte Rate an Kompressionen in der Respiratorgruppe einen vorteilhaften Einfluss.

\section{DGKJ-PO-12-2}

Trachealagenesie - eine seltene Differenzialdiagnose der Atemnot im Kreißsaal

\section{Klotz D. ', Frölich K. ${ }^{2}$, Zollner U. ${ }^{3}$, Rehn M. ${ }^{3}$, Wirbelauer J.'}

'Universitätsklinikum Würzburg, Kinderklinik und Poliklinik, Würzburg, ${ }^{2}$ Klinik und Poliklinik für Hals-, Nasen- und Ohrenkrankheiten, plastische und ästhetische Operationen, Würzburg, ${ }^{3}$ Frauenklinik und Hebammenschule, Würzburg

Hintergrund. Die pränatale Diagnose kongenitaler Obstruktionen der oberen Atemwege - insbesondere mit ösophagealer Fistulierung - ist ohne begleitende Fehlbildung selten möglich. Von einer Trachealagenesie (TA) als Ursache einer postnatalen Atemnot werden Erstversorgende in aller Regel überrascht.

Kasuistik. Nach vorzeitiger Wehentätigkeit und Spontangeburt eines Frühgeborenen in der 34. Schwangerschaftswoche bot sich postnatal das Bild einer respiratorischen Adaptationsstörung. Eine respiratorische Stabilisierung konnte über einen nasopharyngealen Tubus erreicht, der Beatmungstubus jedoch nicht über die Stimmritze platziert werden. Wir stellten bildgebend die Diagnose einer langstreckigen Trachealagenesie mit bronchoösophagealer Fistel. Das Frühgeborene verstarb im Alter von 4 Lebensstunden an einer ausgeprägten Ventilationsstörung, die Obduktion bestätigte die Diagnose. 
Diskussion. Die TA ist eine seltene kongenitale Fehlbildung. Der Larynx endet blind, die Trachea fehlt unterhalb des normal angelegten Larynx partiell oder wie in unserem Fall vollständig. Enden die Hauptbronchi nicht blind, so können sie getrennt voneinander oder in Form eines gemeinsamen Trachealstumpfs in den Ösophagus fistulieren. Ohne begleitende Fehlbildungen gelingt die pränatale Diagnosestellung selten. Postnatal kann die Obstruktion der Atemwege an den Leitsymptomen Atemnot mit frustranen Atemanstrengungen, fehlender Stimme und der Unmöglichkeit der Intubation erkannt werden. Trotz dieses als typisch beschriebenen Symptomenkomplex ist die Trachealagenesie in der Kreißsaalreanimation eine differenzialdiagnostische Herausforderung. Die Ätiologie ist unbekannt, die therapeutischen Optionen sind limitiert. Fast immer versterben die Neugeborenen innerhalb weniger Stunden an einer Ventilationsstörung.

\section{DGKJ-PO-12-3 \\ Anwendung des Cook-Tubuswechslers zur frühen Surfactant- Applikation}

\section{Petrasch M. ${ }^{\prime}$, Geier N. ${ }^{1}$, Geier A. ${ }^{1}$, Ruef P. ${ }^{1}$}

'SLK Kliniken Heilbronn, Kinder- und Jugendklinik, Heilbronn

Hintergrund. Frühe Surfactantgabe sowie Ventilation per CPAP reduziert die Mortalität sowie das Auftreten pulmonaler Komplikationen. Man unterscheidet die „InSurE“ (Intubate, Surfactant, Extubate) von der „TakeCare“-Methode (Applikation via Katheter unter Spontanatmung).

Material/Methoden. Zehn Frühgeborene (25.-36.SSW, GG 550-1970 g) mit einem $\mathrm{FiO}_{2}>0,40$ am nasalen Rachen-CPAP erhielten wie folgt Surfactant: Präoxygenierung über CPAP; Medikation mit Ketanest (1-2 mg/kg KG) und Atropin (10 $\mu \mathrm{g} / \mathrm{kg} \mathrm{KG);} \mathrm{Einstellen} \mathrm{der} \mathrm{Stimmritze}$ mittels Videolaryngoskop; Einführen des Tubuswechsler (8 Fr/Cook $\left.{ }^{\circledR}\right)$; Surfactantgabe durch einen 2. Helfer; kurzer, noninvasiv/kontrollierter Beatmungszyklus über den noch liegenden NCPAP an einer Beatmungseinheit.

Ergebnisse. Alle Kinder zeigten nach Surfactantgabe einen sinkenden $\mathrm{O} 2$-Bedarf. Sieben der zehn Kinder benötigten keine weiteren Maßnahmen. Zwei Kinder mussten aufgrund unzureichenden Ansprechens im Verlauf intubiert werden; eine 2. Surfactantgabe war nötig. Ein Kind wurde aufgrund resp. Instabilität intubiert, ohne weitere Surfactantgabe. Bei keinem der Kinder kam es unter der Applikation zu Komplikationen oder Verletzungen im Respirationstrakt.

Schlussfolgerungen. Der Tubuswechsler birgt verglichen mit der häufig verwendeten, weichen Magensonde, folgende Vorteile: Einfaches Einführen des Katheters mit dem beiliegenden Führungsdraht; eine Deplatzierung während der Applikation aufgrund der höheren Stabilität wurde nicht beobachtet; Eindringtiefe des Cook-Wechslers mittels seiner Markierungen kontrollierbar. Ein Zurückfließen von Surfactant aus der Trachea während der Gabe kann per Überwachung mit dem Videolaryngoskop vermieden werden. Letzteres erwies sich auch als schonender/stressfreier im Vergleich zur konventionellen Einstellung des Larynx.

\section{DGKJ-PO-I2-4}

Preliminary report: body composition of preterm infants using air displacement plethysmography during the first weeks of life

Chin J.', Fusch G. ', Rochow N.', Radke D. ', Pogorzelski D. ', Fusch C.'

'McMaster University, Pediatrics, Hamilton, Kanada

Aim. Establish longitudinal reference data of preterm infant body composition (BC) and growth using air displacement plethysmography at bedside.

Methods. Ongoing, single-centre, longitudinal, observational study of preterm infants. Inclusion criteria: $24-36$ weeks gestational age (GA), infants without IV lines and stable off respiratory support for $7 \mathrm{~min}$, written and informed consent. Exclusion criteria: chromosomal or congenital abnormalities, hydrops fetalis. BC assessed by PEA POD daily for the first 21 days of life, then twice per week. Weight, length, head circumference collected once per week. Infants assessed from study inclusion to hospital discharge.

Results. A total 180 measurements of 60 preterm infants (GA range at birth: $27-361 / 7$ wks) were performed. Percent fat mass (\%FM) of preterm infants at postmenstrual ages $30,31,32,33,34,35,36$ weeks were $8.1 \pm 3 \%, 6.2 \pm 3 \%, 8.1 \pm 4 \%, 6.8 \pm 4 \%, 8.9 \pm 6 \%, 11.6 \pm 6 \%$ and $10.9 \pm 5 \%$. Fat free mass and FM accretion occurred at different rates leading to an overall \%FM increase after sufficient caloric intakes were established. Preliminary data suggests that \%FM is not predicted by GA at birth. No infant experienced an adverse event relating to a measurement.

Discussion. Successfully established the infrastructure needed to routinely measure preterm infant $\mathrm{BC}$ at bedside in the NICU indicating PEA POD's feasibility for clinical use. To our knowledge, this is the first longitudinal, observational data of preterm infants measured so soon after birth using PEA POD.

\section{DGKJ-PO-I2-5}

Time is Brain: Frühzeitiger Beginn der therapeutischen Hypothermie verbessert das motorische Langzeitoutcome nach perinataler Asphyxie

Thoresen M. ${ }^{1,2,3}$, Tooley J. ${ }^{2}$, Jary S. ${ }^{2}$, Harding D. ${ }^{2}$, Fleming P. ${ }^{2}$, Luyt K. ${ }^{2}$, Jain

A. ${ }^{2}$, Cairns P. ${ }^{2}$, Sabir H. ${ }^{1,4}$

'University of Bristol, Neonatal Neuroscience, School of Clinical Sciences, St Michael's Hospital, Bristol, UK, ²University Hospitals Bristol, Neonatal Unit, St Michael's Hospital, Bristol, UK, ${ }^{3}$ University of Oslo, Department of Physiology, Institute of Basic Medical Sciences, Oslo, Norwegen, ${ }^{4}$ Universitätsklinikum Düsseldorf, Klinik für Allgemeine Pädiatrie, Neonatologie und Kinderkardiologie, Düsseldorf

Hintergrund. Die therapeutische Hypothermie (HT) ist die Standardtherapie für reife Neugeborene nach perinataler Asphyxie. In präklinischen Studien hat sich die HT als besonders effektiv erwiesen, wenn diese frühzeitig begonnen wird, jedoch fehlt die klinische Evidenz hierfür.

Fragestellung und Methodik. Die Daten von 82 asphyktischen Neugeborenen wurden ausgewertet. Die überlebenden Neugeborenen $(n=67)$ wurden in zwei Gruppen eingeteilt: „frühe HT“ (o-18o min nach Geburt) und „späte HT“ (>181 min). Alle 67 Neugeborenen wurden im Alter von 18-20 Monaten nachuntersucht und mittels Bayley II getestet. Wir untersuchten ob die frühe HT mit verbessertem Langzeitoutcome verbunden ist.

Ergebnisse. Die Gruppen unterschieden sich nicht signifikant hinsichtlich des Schweregrades der perinatalen Asphyxie, jedoch erlitten die nicht überlebenden Neugeborenen eine signifikant schwerere Asphyxie. Die verstorbenen Neugeborenen hatten außerdem ein signifikant niedrigeres Geburtsgewicht. Die Zeit bis zum Beginn der therapeutischen Hypothermie war nicht signifikant verschieden zwischen den überlebenden und verstorbenen Neugeborenen. Von den überlebenden Neugeborenen waren 36 in der frühen und 31 in der späten HT Gruppe. Das motorische Outcome im Bayley-II-Test (PDI) war in der frühen HT Gruppe signifikant besser, als in der späten HT Gruppe $(p=0,043)$. Das kognitive Outcome im Bayley-II-Test (MDI) unterschied sich zwischen den beiden Gruppen nicht signifikant.

Schlussfolgerung. Der frühzeitige Beginn der therapeutischen Hypothermie ist sicher und verbessert signifikant das motorische Outcome nach perinataler Asphyxie. Auf Grund dessen sollte die therapeutische Hypothermie nach perinataler Asphyxie so früh wie möglich gestartet werden. 


\section{DGKJ-PO-12-6}

\section{Establishment and validation of a method to detect circulating} endothelial cells in blood of preterm infants

Lee S.-Y.', Brar B. ', Rochow N.', Kalaniti K.', elHelou S.' , Fusch G.', Snider D. ', Fusch $C{ }^{\prime}$

${ }^{1}$ McMaster University, Pediatrics, Hamilton, Kanada, ${ }^{2}$ McMaster University, Pathology, Hamilton, Kanada

Question. Circulating endothelial cells (CEC) have been shown as a biomarker of vascular injury in adults. As such, CECs may be used to assess vascular integrity of preterm infants who undergo invasive medical treatments that may compromise vascular integrity. However, the published methods to enumerate CECs require blood volumes too large $(>4 \mathrm{~mL}$ ) for sampling in preterm infants; the aim is to establish a flow cytometric method feasible for use in preterm population $(0.45 \mathrm{~mL})$.

Method. Adults peripheral blood and cord blood from term placentas were processed by PBMC isolation. CECs were identified as positive for $\mathrm{CD}_{31}, \mathrm{CD} 146$, and Syto16, and negative for CD45, CD14, and CD133. Morphology of these cells was assessed using TEM. Intra-sample variability was evaluated by simultaneously processing 5 aliquots of the same sample $(n=5)$. Precision of enumerating CECs from small volume of blood in reference to the large volume was tested by processing duplicates of $5 \mathrm{~mL}$ and $0.45 \mathrm{~mL}$ of cord blood in parallel $(\mathrm{n}=5)$. To assess the feasibility of the method in the clinical settings, temporal decline in CECs was evaluated from whole blood stored for 0,12 , and $24 \mathrm{~h}$ after sampling $(n=10-12)$ and from stained cells either fixed or unfixed and stored for 0,1 and $2 \mathrm{~d}$ post processing $(\mathrm{n}=6)$. The absolute number of CECs was calculated using a hematological analyzer.

Results. The average CV between 5 aliquots of $0.45 \mathrm{~mL}$ cord blood was $23 \%$ and $5 \mathrm{~mL}$ of adult peripheral blood samples was $19 \%$. On average, enumeration in small volume was 1.5 times the large volume, with R2 value o.9. There was no significant temporal decline in levels of CEC over the course of analysis.

Conclusion. This flow cytometric method is reproducible for enumerating CECs and can be used in clinical studies in preterm infants.

\section{DGKJ-PO-I2-7}

\section{"Artificial placenta" - a lung assist device for neonates}

Rochow N. ', Manan A. ${ }^{2}$, Fusch G. ${ }^{1}$, Wu W.-I. ${ }^{3}$, Selvaganapathy P.R. ${ }^{3}$, Fusch C.

${ }^{1}$ McMaster University, Pediatrics, Hamilton, Kanada, ${ }^{2}$ McMaster University, Biomedical Engeneering, Hamilton, Kanada, ${ }^{3}$ McMaster University, Mechanical Engineering, Hamilton, Kanada

Aims. Overcome restrictions of current respiratory therapies for newborn infants by (i) developing a new low volume lung assist device (LAD) that mimics the functions of the natural placenta. The LAD would be attached to the infant via the umbilical vessels where the in fant would use its own heart to pump the blood. In addition the LAD would provide (ii) $\mathrm{O}_{2}$ exchange rate $0.3 \mathrm{~mL} / \mathrm{kg} / \mathrm{min}$, and (iii) achieves flow rates of $30 \mathrm{ml} / \mathrm{kg} / \mathrm{min}[1]$.

Methods. (i) A low volume LAD composed of stacked microfluidic oxygenators was developed. (ii) The LAD was tested in vitro with four different gas permeable membranes [polycarbonate (PC), pore sizes 0.05 and $0.1 \mathrm{um}$, porous polydimethylsiloxane (PDMS), and Normal PDMS)] to determine the most effective interface for gas exchange. (iii) LAD was tested in vivo using a hypoxic piglet model $(1-2 \mathrm{~kg})$, where flow rate through device was recorded.

Results. (i) The priming volume is $1.4 \mathrm{~mL} / \mathrm{kg}+6 \mathrm{~mL}$ (dead space). (ii) Porous PDMS membrane was superior to PC, uniform PDMS membranes and OXR by demonstrating a 1.6-2.6 times higher $\mathrm{O}_{2}$ and 1.2-2.4 times higher $\mathrm{CO}_{2}$ exchange rate. Porous PDMS membranes have a 2 times lower resistance than PC and 1.3 times lower resistance than uniform PDMS membranes. (iii) PC membrane LAD may be able to increases
$\mathrm{SaO}_{2}$ by $40 \%$ without compromising cardiac output in a hypoxic piglet model. Extracorporeal blood flow rates were up to $57 \mathrm{~mL} / \mathrm{min}$.

Conclusion. Our LAD demonstrates effective gas exchange and has the potential to become a rescue treatment for newborn infants with endstage lung failure. Next steps include improving haemocompatibility through attachment of anti thrombin heparin complex to the inner surface of device.

\section{Literatur}

1. Rochow et al (2013) Artificial placenta- Review Paper. Int J Artif Organs

\section{DGKJ-PO-I2-8}

Target fortification of breast milk for preterm infants - what is the ideal measurement frequency?

Rochow N.', Fusch G. ', Ali A. ', Zapanta B. ', Fusch C. ${ }^{\text {' }}$

${ }^{1}$ McMaster University, Pediatrics, Hamilton, Kanada

Background. Target fortification (TFO) standardizes the macronutrient composition of breast milk (BM). Recently, we have shown that TFO in preterm infants improved growth rates significantly. However, TFO adds considerable amount of work load to the NICU: the total time required to measure BM composition and calculate TFO, documentation, and printing of the prescription is 10-12 min per patient. We acknowledge that daily BM analysis may not be feasible in all locations, particularly in units with limited resources.

Objective. To analyze the variation of macronutrients in BM when TFO is done at different frequencies.

Method. Single-center, prospective study; 10 stable, fully BM fed VLBW infants on TFO. Calories, F, P \& CHO were measured on a daily basis $(\mathrm{n}=295)$. Single additives of F, $\mathrm{P}$ and $\mathrm{CHO}$ were added to routinely fortified BM (F: 0.36, P: 1 \& CHO: $1.8 \mathrm{~g} / 100 \mathrm{~mL}$ ) to achieve a target concentration of $\mathrm{F} 4.4, \mathrm{P} 3, \mathrm{CHO}: 8.8 \mathrm{~g} / 100 \mathrm{~mL}$. The variation in calories and macronutrients was modelled with varying frequency of BM measurements (daily, every weekday, Mo-We-Fr, Mo-Th, and Mo only) and compared to native BM.

Results. Average composition of kcal was $65 \pm 8$, F: $4.1 \pm 0.9$, P: $1.2 \pm 0.2$, CHO: $5.8 \pm 0.2 \mathrm{~g} / 100 \mathrm{~mL}$. A measurement frequence of $1 \times$ per week reliably increased the average intake to the desired level, however still with considerable day-to-day variation. Day-to-day variation of macronutrients decreased as the frequency of milk analysis increased.

Conclusions. The mean macronutrient intake was stable and independent of which approach was used. We believe that even in units with limited resources a weekly measurement of macronutrient content might provide a reasonable balance between workload and outcome. The precise impact of such regimes needs to be studied in future RCTs.

\section{DGKJ-PO-12-9}

Spheno-ethmoidale Encephalocele als seltene Ursache von neonataler Atemnot

\section{Aring C. ${ }^{1}$, Dohmen-Baterovskyy G. ${ }^{1}$, Wenserski F. ${ }^{2}$, Messing M. ${ }^{3}$}

${ }^{1} \mathrm{AKH}$ Viersen $\mathrm{gGmbH}$, Klinik für Kinder- und Jugendmedizin, Viersen, ${ }^{2} \mathrm{AKH}$ Viersen $\mathrm{gGmbH}$, Klinik für diagnostische und interventionelle Radiologie, Viersen, ${ }^{3}$ Asklepios Kinderklinik, Abteilung für Neurochirurgie, St. Augustin

Fallbericht. Reifes AGA-Neugeborenes am Termin, spontane problemlose Entbindung, innerhalb von 10 Minuten post partum zunehmende Atemnot, beatmungspflichtig, Nase für keinen Tubus passierbar, problemlose oro-tracheale Intubation. 1. Kind gesunder, nicht verwandter kaukasischer Eltern, dezente Lippenspalte, keine Gaumenspalte oder sonstigen Dysmorphiezeichen.

Ergebnisse. Unproblematische Beatmung, keine Lungenpathologie, keine kardiale Anomalie, keine Infektion. Die HNO-ärztliche Abklärung ergibt bds. offene Choanae, allerdings eine von oben in den Nasopharynx reichende schlauchartige Struktur. Die MR-tomographische Abklärung führt zu der Diagnose spheno-ethmoidale Encephalocele. 
Assoziiert sind ein kompletter Balkenmangel und andere cerebrale Auffälligkeiten. Nach der postnatalen Anpassung konnte das Kind extubiert werden und spontan atmen.

Schlussfolgerung. Das weitere diagnostische und therapeutische Procedere wird beschrieben, außerdem eine Übersicht über veröffentlichte Kasuistiken und Verläufe erstellt.

\section{DGKJ-PO-I2-10}

\section{Mekoniumobstruktion bei sehr unreifen Frühgeborenen}

Werlein A. ', Zovko D. ${ }^{2}$, Knöppel C. ', Göbert P. ', Zemlin M.', Maier R.F.' 'Philipps Universität Marburg, Kinder- und Jugendmedizin, Marburg, ${ }^{2}$ Philipps Universität Marburg, Klinik für Kinderchirurgie, Marburg

Hintergrund. Eine Mekoniumobstruktion kann bei Frühgeborenen zu intestinaler Perforation, Kurzdarmsyndrom und verlängertem Krankenhausaufenthalt führen.

Fallberichte. Wir berichten über drei Frühgeborene mit einem Gestationsalter $<25$ Wochen und einem Geburtsgewicht $<700 \mathrm{~g}$. Bei allen drei Kindern wurde protokollgemäß am ersten Lebenstag mit dem enteralen Nahrungsaufbau begonnen. Sie setzten in den ersten Tagen geringe Mengen Mekonium ab, entwickelten im Verlauf aber eine Ileussymptomatik. Durch rektales Anspülen mit Kochsalzlösung, Acetylcystein und Gylcerin konnte das Kolon von zähem Mekonium entleert werden. Dennoch kam es im Alter von 8, 10 bzw. 29 Lebenstagen zur intestinalen Perforation. Alle Perforationen waren im termialen Ileum lokalisiert, wo sich intraoperativ „Mekoniumsteine“ zeigten. Wir fanden weder anatomische Fehlbildungen (Morbus Hirschsprung) noch entzündliche Veränderungen (nekrotisierende Enterokolitis), das immunreaktive Trypsin war negativ.

Diskussion. Alle drei Kinder waren sehr unreif, zwei waren eutroph und eines hypotroph. Die als Risikofaktor beschriebene Plazentainsuffizienz mit Minderperfusion des fetalen Darmes fand sich bei unseren Kindern nicht, jedoch war in allen drei Fällen eine vorzeitige Plazentalösung Anlass für die frühe Geburt. Als konservative Maßnahmen sind in Falldarstellungen rektale Einläufe mit verschiedenen Agenzien, u. a. mit Gastrografin ${ }^{\star}$ beschrieben, wobei die Jod-Belastung gerade bei sehr unreifen Frühgeborenen nicht unproblematisch ist.

Schlussfolgerung. Obwohl eine Mekoniumobstruktion bei sehr unreifen Frühgeborenen mit schwerwiegenden Folgen einhergehen kann, fehlen bislang kontrollierte Studien zur Effizienz und Sicherheit von Maßnahmen zur Prophylaxe und Therapie.

\section{DGKJ-PO-I2-11}

\section{Reduktion von Keimlast und Infektionen durch kontinuierliche sonothermale Desinfektion der Geruchsverschlüsse von Wasch- becken auf neonatologischen Intensivstationen}

\section{Fusch C. ${ }^{1}$, Meyer C. ', Gittens C. ', Maine C. ${ }^{2}$, Fusch G. ${ }^{1}$, elHelou S. ${ }^{1}$, Mertz D. ${ }^{2}$ ${ }^{1}$ McMaster University, Pediatrics, Hamilton, Kanada, ${ }^{2}$ McMaster University, Department of Microbiology, Hamilton, Kanada}

Einleitung. Wachbecken-Syphons stellen relevante klinische Keimreservoire dar, die sich als Erregerquellen im Klinikalltag durch kontinuierliche sonothermale Desinfektion ausschalten lassen (Doering 1991). Diese Methode kombiniert thermische Desinfektion mit einer mechanischen Reinigung (Sissiko 2004, 2005).

Methode. Seit 04/12 wird das Desinfektionssystem (Biorec, Lauta) in der NICU der McMaster Universität Hamilton (47 Betten, 1200 Aufnahmen und 15.00o Patiententage p. a., mittlerer Census 42 Betten) eingesetzt: In der 1. Ausbaustufe wurden die 9 meist benutzten Syphons der i 20 Waschbecken (45\%) durch das Desinfektionssystem ersetzt. Vor (05/11-05/12) und nach (05/12-04/13) der Maßnahme wurden mit einem Luftsammler (Impaktor, Klotz, Bad Liebenzell) standardisiert über je 12 Monate 5 ausgewählte Waschbecken zuerst bei geschlossenem, dann bei geöffnetem Wasserhahn beprobt; dazu wurden 5001 Luft über eine
Petrischale gezogen, der Messabstand zum Waschbecken betrug 50 und $100 \mathrm{~cm}$. Ebenso wurden Kolonisationen, Patientenisolationstage sowie die Anzahl invasiver Pseudomonas-Infektionen (Leitkeim) ausgewertet.

Ergebnisse. Für Mai bis Dezember der Jahre 2011 (ohne Desinfektion) und 2012 (mit Desinfektion) ergab folgende Ergebnisse : Die Anzahl keimbildender Units (CFU's) sank von im Mittel 4,5 (Range 1-28) auf 0,15 (Range 0-1), Anzahl kolonisierter/infizierter Patienten sank von 22 auf 11, die der Isolationstage von 777 auf 499.

Diskussion. Die Nasskeim-Besiedlung von NICU-Patienten lässt sich wahrscheinlich durch Syphon-Desinfektion senken. Die Ergebnisse lassen erwarten, dass nach vollständiger Ausrüstung der Station in einer zweiten Ausbaustufe eine weitere Verbesserung der Infektionsprävention erreichbar ist.

\section{DGKJ-PO-I2-12}

TSH-Screening bei Frühgeborenen: Werden kleine Frühgeborene mit Hypothyreose im Screening frühzeitig erkannt?

\section{Nennstiel-Ratzel U.', Lüders A. ', Mohnike K. ${ }^{2}$, Blankenstein 0. ${ }^{3}$}

${ }^{1}$ Bayerisches Landesamt für Gesundheit und Lebensmittelsicherheit, GE ${ }^{4}$ Gesundheitsberichterstattung, Epidemiologie und Sozialmedizin, Oberschleißheim, ${ }^{2}$ Otto-von-Guericke Universität, Universitätskinderklinik, Magdeburg, ${ }^{3}$ Charité - Universitätsmedizin Berlin, Universitätskinderklinik, Berlin

Hintergrund. Das Neugeborenenscreening (NGS) wird seit 2005 entsprechend der Kinderrichtlinie durchgeführt. Danach werden Frühgeborene (FG) unter 32 Schwangerschaftswochen (SSW) im Alter von 36-72 Lebensstunden wie alle Neugeborenen ein erstes mal und im Alter von 32 SSW ein zweites Mal gescreent, um insbesondere konnatale Hypothyreosen nicht zu übersehen, denn eine Hirnschädigung ist bereits bei verspätetem Therapiebeginn nach der zweiten Lebenswoche zu erwarten.

Methode. Die Deutsche Gesellschaft für Neugeborenenscreening (DGNS) evaluiert das NGS für ganz Deutschland. Basis der Auswertung sind Daten von 4 Mio. in den Jahren 2006-2011 geborene Kindern. Ergebnis. Die Prävalenz einer konnatalen Hypothyreose liegt insgesamt bei 1:3530, in der Population der kleinen FG mit 1:830 viermal so hoch. In dieser Gruppe wurden 6o Hypothyreosen entdeckt, davon $16 \mathrm{im}$ Erstscreening, bei der Kontrolle bis 32 SSW weitere 15. Damit wurde die Hälfte der Betroffenen im Screening nicht gefunden. Bei 26 Kindern (43\%) war kein zweites Screening bis zu 32 SSW abgenommen worden, bei 3 Kindern war das Screening mit 32 SSW noch unauffällig.

Diskussion. $\mathrm{Ob}$ die erhöhte Prävalenz der Hypothyreosen passagere oder permanente Formen betrifft ist derzeit unklar. Sicher ist jedoch, dass diese Kinder zumindest vorübergehend behandelt werden müssen. Um mit der Behandlung rechtzeitig d. h. kurz nach dem TSH-Anstieg zu beginnen zu können, wären weitere TSH-Kontrollen vor und auch nach 32 SSW nötig.

Fazit. Eine Kontrolluntersuchung mit $32 \mathrm{SSW}$ wird häufig nicht oder zu spät durchgeführt. Eine zeitgerechte Kontrolle ist aber unbedingt erforderlich. Zur weiteren Abklärung ob zusätzliche TSH-Kontrollen nötig sind und welche Formen der Hypothyreose bei FG vermehrt auftreten, sind weitere Studien notwendig. 


\section{DGKJ-PO-I2-13}

\section{Schwere systemische Vaskulitis bei einem Neugeborenen}

Hilbich J. ${ }^{1,2}$, Hüchering B. ${ }^{3}$, Wild F. ${ }^{3}$, Becher T. ${ }^{4}$, Paul T. ${ }^{2}$, Seeliger S. ${ }^{3}$ ${ }^{1}$ Kliniken St. Elisabeth, Pädiatrie, Neuburg an der Donau, ${ }^{2}$ Universitätsklinikum Göttingen, Klinik für Pädiatrische Kardiologie und Intensivmedizin, Göttingen, ${ }^{3}$ Kliniken St. Elisabeth, Neuburg an der Donau, ${ }^{4}$ Diagnosticum Neuburg, Neuburg an der Donau

Einleitung. Systemische Vaskulitiden sind sehr seltene Erkrankungen in der Neonatalperiode. Bei Vaskulitiden in diesem Alter, handelt sich fast immer um transplazentar übertragene mütterliche Autoantikörper. Die häufigsten klinischen Manifestationen betreffen Herz, Leber und Haut. Therapeutische Ansätze sind beschränkt und leiten sich aus der Behandlung anderer erworbener Autoimmunerkrankungen ab.

Fallbericht. Ein reifes männliches Neugeborenes wurde mit erhöhter Körpertemperatur und dezent erhöhtem IL- 6 aufgenommen. Auffällig waren deutlich erhöhte Blutdruckwerte (MAD 80-100 mmHg), sowie ein feinfleckiges, makulopapulöses Exanthem wechselnder Lokalisation und Intensität. Es wurde umgehend mit einer antihypertensiven Therapie initial mit Metoprolol, später auch mit Nitroprussid begonnen. Im Verlauf kam es zu einer progredienten, kardialen Dekompensation mit ausgeprägter linksventrikulärer Hypertrophie und peripherer Widerstandserhöhung. Der sonographisch auffällige Gefäßstatus, besonders der Nierenarterien, bestätigte sich im MRT. Es zeigten sich langstreckige Stenosen aller großen Arterien z. T. mit perlschnurartigem Charakter, passend zu einer systemischen Vaskulitis. Daraufhin Erweiterung der Therapie antiinflammatorisch mit Hydrokortison, später mit Methylprednisolon, sowie einer Blutaustauschtransfusion, wodurch es zur Stabilisierung des Patienten kam. Im MRT im Alter von 4 Monaten weiterhin schmächtige infrarenale Gefäße.

Schlussfolgerungen. Die Mortalität einer systemischen Vaskulitis des Neugeborenen korreliert mit dem Schweregrad der arteriellen Hypertonie. Die Kontrolle des Blutdrucks hat neben der antiinflammatorischen Therapie oberste Priorität. Beim Neonaten stellt zudem die Austauschtransfusion eine mögliche Therapieoption in der Behandlung der Vaskulitis dar.
DGKJ-PO-I2-14

Neonatale Thalamusblutung - Indikator einer Sinusvenenthrombose

Bialas J. ', Hüning B. ', Sirin S. ${ }^{2}$, Schweiger B. ${ }^{2}$, Felderhoff-Müser U. ${ }^{1}$

'Universitätsklinikum Essen, Klinik für Kinderheilkunde I, Neonatologie, Essen, ${ }^{2}$ Universitätsklinikum Essen, Institut für Diagnostische und Interventionelle Radiologie und Neuroradiologie, Essen

Fallbericht. Wir berichten über zwei reife Neugeborene, die im Alter von 4 und 5 Wochen mit zerebralen Anfällen vorgestellt wurden. Die Symptome Erbrechen, rezidivierende tonisch-klonische Anfälle, sowie ein Sonnenuntergangsphänomen traten plötzlich aus völliger Gesundheit auf. Die initiale sonographische Untersuchung des Schädels zeigte bei beiden eine Blutung im Bereich des Thalamus mit Einbruch in den Seitenventrikel.

Ergebnisse. In der MRT-Untersuchung konnte eine Sinusvenenthrombose (SVT) bestätigt werden. Beide Kinder hatten eine heterozygote Mutation im MTHFR-Gen bei unauffäliger Familienanamnese. Die Entwicklung eines shuntpflichtigen Hydrozephalus ist eine der Komplikationen. Die Thromboseinzidenz von SVT bei Neugeborenen liegt bei 7/1.000.00o. Am häufigsten betroffen ist der Sinus sagittalis superior (62\%) und Sinus transvs. (40-45\%). Die SVT stellt eine vital bedrohliche Komplikation dar: Blutungskomplikationen (14-39\%), fokale oder generalisierte Krampfanfälle (40\%), Tod bei Blutungskomplikationen (32\%). Perinatale Komplikationen (24\%), Dehydratation (25\%), Infektionen mit Kopfbeteiligung (18\%) und Thrombophilie (32\%) sind die häufigsten Risikofaktoren für SVT in der Neonatalperiode und Kindesalter.

Schlussfolgerung. Die SVT kann im Säuglingsalter nicht immer sicher diagnostiziert werden und es bedarf einiger Erfahrung um die Veränderungen in der Bildgebung richtig interpretieren zu können. Die beschriebene Blutungskonstellation sollte dennoch immer den Blick auf eine SVT lenken. Die niedrigmolekulare Heparinisierung gilt es aufgrund von unsicherer Datenlage beim Neugeborenen von Fall zu Fall abzuwägen. Aussagen zur neurologischen Langzeitentwicklung werden diskutiert. In Anbetracht der geringen Fallzahl sollte ein bundesweites Register angelegt werden 


\section{Abstracts der 65. Jahrestagung der Deutschen Gesellschaft für Sozialpadiatrie und Jugendmedizin (DGSPJ)}

\section{Vorträge}

Freitag, 13.09.2013

\section{Neue Medien und virtuelle Welten}

\section{DGSPJ-SY-NM-1}

Computerspiel- und Internetabhängigkeit: seelische Entwicklung in der virtuellen und realen Welt

\author{
Paulus F.W. ${ }^{1}$ \\ ${ }^{1}$ Klinik für Kinder- und Jugendpsychiatrie, Psychosomatik und Psychothera- \\ pie/Universitätsklinikum des Saarlandes, Homburg
}

Computerspiele, Chatten und Surfen im Internet sind im letzten Jahrzehnt für viele Kinder und Jugendliche ein ganz alltäglicher Teil ihres Lebens geworden. Daten zur Mediennutzung von Kindern und Jugendlichen lassen beeindruckende Nutzungszeiten und Verbreitung sowie eine starke Zunahme während der letzten Jahre erkennen.

In jeder Entwicklungsphase sind von Kindern und Jugendlichen bestimmte Entwicklungsaufgaben zu lösen, die mehr oder weniger gut gelingen und die eine günstige weitere Entwicklung ermöglichen oder auch blockieren können. Von exzessiver Bildschirmspielnutzung spricht man ab 4,5 Stunden täglich. Das Konzept der Computerspielabhängigkeit als Verhaltenssucht ist konzeptualisiert in Anlehnung an aus dem Bereich substanzabhängiger Süchte stammender Abhängigkeitskriterien (z. B. Kontrollverlust, Toleranzentwicklung, Interessenseinschränkung...). Internet- und Computerspielabhängigkeit entwickelt sich in einer komplexen und multifaktoriellen Ursachenstruktur. Dabei spielt neben den Einflüssen der sozialen Umwelt (Freundeskreis, Familie, Gesellschaft) und spielseitigen Ursachen und Bedingungen des Mediums Computer und Internet insbesondere die besondere psychische Disposition (Veranlagung und Persönlichkeit) und psychische Störungen der Spieler/ innen eine große Rolle.

Eine psychische Störung mit komorbider Computerspielabhängigkeit wirkt sehr beeinträchtigend auf die kindliche Entwicklung. Die Entwicklungsprozesse in der realen und der virtuellen Welt laufen komplementär und kompensatorisch ab: gescheitert vs. erfolgreich, schwach vs. mächtig, hässlich vs. attraktiv, isoliert vs. sozial beliebt etc. Therapie hat zum Ziel, Ausstiegsszenarien aus diesem dysfunktionalen Teufelskreis zu finden.

\section{DGSPJ-SY-NM-3}

Ethisches Reflektieren in Computerspielen: Was Jugendliche aus Computerspielen lernen können

\section{Görgen A. ${ }^{1}$}

'Institut für Geschichte, Theorie und Ethik der Medizin, Ulm

Im Jahr 2012 gaben in einer von der BITKOM in Auftrag gegeben Forsa-Umfrage $68 \%$ der befragten 14 - bis 29 -Jährigen an, Computerspiele zu nutzen. Die Spiele selbst sind dabei längst den Kinderzimmern entwachsen und ermöglichen durch hohe spielerische und erzählerische Qualität ein intensives und intellektuell anregendes Spielerleben. Im Vortrag sollen allgemein Spiele als wichtiges und unterschätztes Kulturgut vorgestellt werden und dabei im speziellen auf Spiele als kritische
Reflexionsflächen gesellschaftlicher Probleme eingegangen werden. Insbesondere Mechanismen zur Generierung ethischer Reflexion werden erläutert und anhand von Beispielen - vor allem aus dem Bereich der Medizinethik - vermittelt werden.

\section{DGSPJ-SY-NM-4 \\ Web 2.0 und Social Media: Kommunikation als "Neue Religion"}

Richterich $A{ }^{\prime}$

${ }^{1} \mathrm{HELIOS}$ St. Josefs-Hospital Bochum, Kinder- und Jugendpsychiatrie, -psychosomatik und -psychotherapie, Bochum

„Medien bieten Ersatzformen von Allwissenheit und Allgegenwärtigkeit an. An die Stelle religiöser Kommunikation tritt heute Kommunikation als Religion." schrieb der Medien- und Kommunikationstheoretiker Norbert Bolz schon 1996. Im Web 2.0 oder in „Social Media“ veränderte sich die Verwendung des Internets seither rasant weiter - jeder Nutzer ist nicht nur passiver Konsument, sondern generiert selbst Inhalte, es entstehen vielfältige Möglichkeiten für die Selbstdarstellung, Kommunikation und Kooperation. Ende 2012 nutzen beispielsweise mehr als eine Milliarde Menschen Facebook; aber auch Anwendungen wie Wiki, Blog, Podcast, andere soziale Netzwerke und virtuelle Welten werden extensiv genutzt - und verändern die Benutzer und ihr Verhalten. Aus Sicht eines Kinderund Jugendpsychiaters wird in diesem Vortrag dargestellt, wie technische Möglichkeiten Vorstellungen und Haltungen verändern, und welche klinischen Auswirkungen die unüberschaubaren, endlosen und ständig verfügbaren Kommunikationsmöglichkeiten auf Heranwachsende haben. Wenn durch ein kulturelles Phänomen menschliches Handeln, Fühlen und Denken in erheblichem Umfang geprägt und geformt, wenn Wertvorstellungen und Welterklärungen beeinflusst werden, wenn Menschen Trost und Sinn in der ausgiebigen Beschäftigung hiermit finden, so liegt der Vergleich mit Religion nahe und soll hier mit besonderer Berücksichtigung des Stellenwertes von Kommunikation untersucht werden.

\section{Ethik in der Sozialpädiatrie}

\section{DGSPJ-SY-SP-1 \\ Das Kind in der Fürsorge}

Wegmann $\mathrm{H}^{\text {? }}$

'Universitätsarchiv der Humboldt-Universität zu Berlin, Berlin

Wie entwickelte und entfaltete sich die organisierte Fürsorge für Mütter und Kinder?

Die erste, die sich bis dahin in einem nie gekannten Ausmaß dieser Aufgabe annahm war Kaiserin Auguste Viktoria durch das von ihr initiierte und protegierte Kaiserin Auguste Viktoria Haus (KAVH) mit seinen angegliederten Organisationen - dem Organisationsamt für Säuglingsschutz und der Deutschen Vereinigung für Säuglingsschutz im Jahre 1909. Die Mitarbeiter des KAVH, hochmotivierte Kinderärzte und Pflegerinnen, waren in der Arbeit und in der Erarbeitung von wissenschaftlichen Aussagen über den jeweiligen Zustand der jungen Klientel sehr produktiv. Aus den Ergebnissen und Erkenntnissen erarbeiteten sie u. a. Ausstellungen, Lehrund Lernmaterialien und organisierten Fort- und Weiterbildungsprogramme für unterschiedliche Berufsgruppen und Familienangehörige. Systematisch wurde dadurch ein Fundus von Empfehlungen für Maßnahmen und Methoden zur Verbesserung der Kindergesundheit in 
Deutschland aufgebaut. Aus dieser Arbeit resultierten auch die nun einsetzenden staatlichen Maßnahmen wie z. B. Einrichtung von Säuglings- und Kleinkinderfürsorgestellen. Somit wurden allmählich die Chancen der Kinder verbessert.

\section{DGSPJ-SY-SP-2}

Präimplantationsdiagnostik und sozialethische Implikationen

Wunder M. ${ }^{?}$

'Evangelische Stiftung Alsterdorf und Deutscher Ethikrat, Hamburg

Der Bundestag hat im Juli 2011 das Gesetz zur Regelung der Präimplantationsdiagnostik verabschiedet. Damit ist in Deutschland die genetische Untersuchung an pluripotenten Zellen eines in vitro gezeugten Embryos erlaubt, wenn die Eltern ein hohes Risiko einer schwerwiegenden Erbkrankheit haben. Nach dem Gesetz ist PID darüber hinaus auch zur Feststellung einer schwerwiegenden Schädigung des Embryos zulässig, die mit hoher Wahrscheinlichkeit zu einer Tot- oder Fehlgeburt führt. Der Gesetzgeber ist damit in wesentlichen Punkten dem vorangegangenen BGH-Urteil von 2010 gefolgt, in dem die genetische Untersuchung von embryonalen Trophoblasten als mit dem Embryonenschutzgesetz vereinbar angesehen wurde, wenn diese die Herbeiführung einer Schwangerschaft zum Ziel hat.

Die kontroverse Debatte über die Zulässigkeit der PID ist damit aber nicht beendet. Dies zeigte sich zuletzt an den kontroversen Vorschlägen und Einwänden zur Durchführungsverordnung, vor deren Inkrafttreten die PID in Deutschland nicht zulässig ist.

In der ethischen Debatte steht die Frage des Würde- und Lebensschutzes des Embryos und seines moralisch-rechtlichen Status im Mittelpunkt. In der allgemeinen gesellschaftlichen Debatte geht es des Weiteren aber auch um Fragen der möglichen Diskriminierung von Menschen mit Behinderung, des Verständnisses von Leiden und Leidvermeidung und um längerfristige gesellschaftliche Auswirkungen. Mit Blick auf andere Länder, in denen die PID schon länger praktiziert wird, werden auch mögliche Anwendungsausweitungen befürchtet. In dem Vortrag werden die wesentlichen Argumentationslinien in der weiterhin kontrovers geführten Diskussion nachgezeichnet.

\section{DGSPJ-SY-SP-3}

\section{Pränataldiagnostik aus Sicht des Pädiaters}

Held K.R. ${ }^{1}$

${ }^{1} \mathrm{MVZ}$ genteQ GmbH, Hamburg

Die pränatale Diagnostik genetischer Eigenschaften (PND) des Ungeborenen ist seit jeher Gegenstand intensiver ethischer Kontroversen. Kinder- und Jugendärzte fühlen sich primär dem individuellen Wohl eines Kindes und damit auch des Ungeborenen verpflichtet. Hieraus resultiert eine natürliche Skepsis gegenüber der genetischen PND, weil in der Mehrheit aller Untersuchungen mit pathologischem Ergebnis keine Therapieoptionen zur Verfügung stehen. Bei der Einschätzung der PND stehen für Kinder- und Jugendärzte Überlegungen im Zusammenhang mit der Selbstbestimmung der Schwangeren weniger im Vordergrund, als Überlegungen zu den Belastungen, die auf die Familien im Einzelfall mit behinderten Kindern zukommen und der Frage, inwieweit eine PND für die Familie hilfreich sein kann.

Hatte in der Vergangenheit eine PND mehrheitlich eine konkrete Fragestellung zum Anlass, zu deren Beantwortung eine definierte Untersuchungsmethode angewendet wurde, so erweitern die neuen Sequenziertechnologien das Spektrum genetischer Diagnostik bis hin zur Sequenzierung des gesamten fetalen Genoms. Darüber hinaus bietet die Möglichkeit der Isolierung fetaler DNA aus mütterlichem Blut einen nichtinvasiven und damit, niederschwelligen Zugang zum Untersuchungsmaterial. Die heute zur Verfügung stehenden neuen Sequenziertechnologien werden dargestellt und ihr Potenzial in der Diagnostik beschrieben. Die sich aus der Einführung dieser neuen Verfahren zur PND ergebenden ethischen Fragen hinsichtlich des Lebensschutzes des Ungeborenen gegenüber der
Selbstbestimmung der Schwangeren, aber auch der elterlichen Verantwortung gegenüber der Selbstbestimmung des künftigen geborenen Menschen sowie denkbare gesellschaftliche Folgen werden diskutiert.

\section{DGSPJ-SY-SP-4 \\ Ethische Implikationen von Entscheidungen in der Kinderpalliativ- medizin}

Nolte-Buchholtz S. ${ }^{1}$

'Universitätsklinikum Carl Gustav Carus Dresden, Klinik und Poliklinik für Kinder- und Jugendmedizin, Brückenprojekt, Dresden

Entscheidungen bei Kindern mit lebenslimitierenden Erkrankungen zu treffen, ist für alle an der Versorgung Beteiligten eine Herausforderung. Etwa $60 \%$ der in der pädiatrischen Palliativmedizin versorgten Patienten sind an nichtonkologischen Diagnosen erkrankt. Die Situation dieser Patient ist komplex. Die Familien sind Experten für die vorliegende Erkrankung und Indikationen zu Behandlungen können auf Grund der unsicheren Erfolgsaussichten, der Diagnose oder der individuellen Situation des Kindes nicht eindeutig gestellt werden.

Was ist notwendig, um für diese Patienten gemeinsam mit der Familie und allen Versorgern eine individuelle und ethisch richtige Entscheidung treffen zu können?

Der Vortrag geht auf ethisch-moralische und rechtliche Aspekte ein. Anhand von Patientenbeschreibungen und Darstellung von Entscheidungswegen wird die Thematik diskutiert.

\section{Kommunikation in der transkulturellen Pädiatrie}

\section{DGSPJ-SY-TP-1}

\section{Dolmetschen in der medizinischen Versorgung von Familien}

\section{Albrecht N.-J.', Langer T. ${ }^{2}$}

'Universitätsklinikum Hamburg-Eppendorf, Migration und Gesundheit, Hamburg, ${ }^{2}$ Universität Witten/Herdecke, Fakultät für Gesundheit, Witten

Der Beitrag stellt Studien und Projekte in Einrichtungen des Gesundheitssystems vor, die Probleme und Lösungsmodelle der Interkulturellen Kommunikation in der Arzt-Patient-Interaktion aufzeigen. Vorgestellt werden u. a.:

- das Pilotprojekt des Universitätsklinikums Hamburg-Eppendorf (UKE), in dem von 1995 bis 2002 ca. 9000 Dolmetschereinsätze mit jeweils über 100 Items dokumentiert und ausgewertet wurden,

- die Wiener Studie von Franz Pöchhacker, für die ca. 900 Professionelle in stationären Einrichtungen einbezogen wurden,

- die Erhebung von Susanne Deininger im Auftrag des Berliner Senats in 39 Krankenhäusern,

- die Studie von Thorsten Langer et al. während der 105. Jahrestagung der DGKJ in Mannheim.

Darüber hinaus wird das Konzept der Sprach- und Integrationsmittlung (SprInt) dargestellt, das mittlerweile - kontinuierlich überprüft und evaluiert - in diversen Kommunen umgesetzt wurde und bundesweit aufgebaut wird.

Die Zulassung von geeigneten BewerberInnen zur ca. 2000-stündigen SprInt-Ausbildung wird von einer Qualitätssicherungskommission, d. $\mathrm{h}$. drei Hochschulen (Hamburg, UKE; Berlin, ASH; Mainz, JGU) ebenso geprüft und überwacht, wie die Umsetzung des Ausbildungskonzeptes. Die Qualifizierungsprüfungen und die Erteilung des Zertifikates erfolgen ebenfalls durch diese Hochschulen.

Das eingangs erwähnte Pilotprojekt am UKE konnte bereits die z.T. sehr schnell erforderlichen Änderungen im Bereich des Dolmetschsettings, von neuen Zielsprachen und von zusätzlichen Anforderungen an die Dolmetschenden belegen. Um auch aktuell entsprechenden Änderungen umgehend begegnen zu können, steht die Qualitätssicherung Gesundheit hierfür bundesweit in Verbindung mit den kooperierenden Vermittlungspools in den Kommunen. 


\section{DGSPJ-SY-TP-3}

Standards und Best Practice - der Weg des Kinderspitals Zürich zum Kompetenzzentrum Migrant Friendly Hospital

\section{Keller M. ${ }^{?}$}

'Universitätskinderspital Zürich, Fachstelle Interkulturelle Fragen, Zürich, Schweiz

Das universitäre Kinderspital Zürich erfüllt neben der pädiatrischen Grundversorgung eine Zentrumsfunktion für spezialisierte und hochspezialisierte Versorgung von akut oder chronisch erkrankten sowie verunfallten Patientinnen/Patienten. Bereits Ende 1990er betrug der Anteil der Migrationfamilien am Total der behandelten Kinder und Jugendlichen ein Drittel. In Anbetracht der eigenen begrenzten „Interkulturellen Handlungsfähigkeit" wurde auf Initiative der Medizinischen Direktion und in Zusammenarbeit mit dem Schweizerischen Roten Kreuz eine detaillierte Spitalanalyse durchgeführt. Darauf aufbauend sind auf strategischer und operativer Ebene die erforderlichen Strukturen und Stellen geschaffen worden, um eine adäquate Behandlungsund Betreuungsqualität für Kinder, Jugendliche und ihre Familien aus der Migrationsbevölkerung sicherstellen zu können.

Seit drei Jahren ist das Kinderspital Zürich eines der Partnerspitäler des Bundesamtes für Gesundheit (BAG), welche sich im Rahmen der nationalen Strategie „Migration und Gesundheit“ zu Kompetenzzentren Migrant Friendly Hospitals (MFH) entwickeln sollen. Vom erarbeiteten bereichsübergreifenden Aktionsprogramm sind inzwischen die Schwerpunkte Spitaldolmetschen, Empowerment der Patienteneltern sowie Sensibilisierung, Information und Schulung der Mitarbeitenden zu transkultureller Kompetenz umgesetzt und evaluiert worden. Die zukünftige Herausforderung wird sein, die lancierten Projekte zu konsolidieren, weiterzuentwickeln und in der Pädiatrie zu vernetzen.

\section{Update: Adipositas - was hilft wirklich?}

\section{DGSPJ-SY-AP-1}

\section{Obesigene Faktoren in Kontext und Disposition}

\section{Wiegand $S^{1}$}

${ }^{1}$ Charité - Universitätsmedizin Berlin, Kinderklinik, Pädiatrische Endokrinologie und Diabetologie, Berlin

Adipositas bei Kindern und Jugendlichen ist ein multifaktorielles, langfristiges Geschehen. Dabei treffen oft divergierende Positionen zur Bedeutung von genetischer Disposition und Lifestyle- bzw. Umweltfaktoren für die Entstehung und Behandlung der Erkrankung aufeinander. In der gesellschaftlichen Wahrnehmung ist Adipositas stark stigmatisierend und wird als selbstverschuldet bzw. Versagen der Eltern wahrgenommen. Im Gegensatz dazu zeigen die Ergebnisse von Zwillings- und Adoptionsstudien einen Anteil der genetischen Disposition von 40-70\% an der lebenslangen Gewichtsentwicklung. Die in genomweiten Assoziationsstudien (GWA) gefundenen Risikogene für Adipositas erklären allerdings nur ca. $2 \%$ der interindividuellen Variabilität des Gewichts. Zusätzlich ist bekannt, dass sowohl hypertrophe als auch hypotrophe Neugeborene ein erhöhtes Risiko für die Entwicklung von Übergewicht im späteren Leben haben. Deshalb rücken Untersuchungen zur Epigenetik gewichtsrelevanter Genorte aktuell in den wissenschaftlichen Fokus. So unterscheidet sich die Metylierung des Proopiomelanokortin-Gens signifikant bei Adipösen im Vergleich zu Nichtadipösen. Zusätzlich zur (epi-)genetischen Regulation der Gewichtsentwicklung ist für einige Lifestyle-Faktoren ein signifikanter Effekt bezüglich der Prävention von Übergewicht und Adipositas bei Kindern und Jugendlichen gezeigt, so z. B. für das Aufstellen von Trinkwasserspender in Schulen, eine Stunde zusätzliche körperliche Aktivität pro Tag und 3 Stunden weniger Medienkonsum pro Woche. Für die Therapie der Adipositas wurde allerdings in Metaanalysen gezeigt, dass insbesondere multiprofessionelle, familienbasierte Programme einen nachweisbaren Therapieerfolg bringen.

\section{DGSPJ-SY-AP-4}

Energieverbrauch und Energiebilanz beim therapeutischen Bergwandern bzw. Skilanglauf adipöser Kinder und Jugendlicher

Langhof H. ', Gebhardt H. ${ }^{2}$, Groß-Bölting G. ${ }^{2}$, Heß B.L. ${ }^{1}$, Heß K. ${ }^{2}$

${ }^{1}$ Klinik Schönsicht Berchtesgaden, Berchtesgaden, ${ }^{2}$ Universität Mainz, Institut für Sportwissenschaften, Mainz

Einleitung. Im Berchtesgadener Land sind die Ausdauersportarten Bergwandern und Skilanglauf üblich und für Steigerungen des Energieverbrauchs nutzbar. Bei der Ausübung dieser Sportarten durch adipöse Kinder und Jugendliche wurde der Energieverbrauch gemessen und die Energiebilanz berechnet.

Methodik. Bestimmung der O2-Aufnahme (MetaMax) bei 22 Kindern/ Jugendlichen auf 2 Wanderrouten und bei 11 auf einem SkilanglaufRundkurs, Umrechnung auf Energieverbrauch. Energiebilanz anhand der Soll-Zufuhr mit der Nahrungsaufnahme.

Ergebnisse. Der Ruheumsatz lag im Mittel bei 1,59 Js-1kg-1.Hochgerechnet für eine10o-kg-Person ergibt sich ein Tagesbedarf von $3278 \mathrm{kcal}$. Bei einer Reduktionskost von $1800 \mathrm{kcal} / \mathrm{d}$ liegt unter Ruhebedingungen ein Energiedefizit von 1478 kcal vor. Der zusätzliche Energieverbrauch bei den therapeutischen Aktivitäten betrug 13,7 kJ/kg für die kurze (52 min) und $39,6 \mathrm{~kJ} / \mathrm{kg}$ für die lange Wanderroute $(2: 19 \mathrm{~h})$ sowie $9,5 \mathrm{~kJ} / \mathrm{kg}$ für 3 Skilanglauf-Runden (29 min).Für eine 100-kg-Person ergibt sich für die kurze Wanderung ein Energiemehrverbrauch von $327 \mathrm{kcal}$, für die lange von $945 \mathrm{kcal}$ und für 1 Stunde Skilanglauf ca. 500 kcal Dies entspricht $18,1 \%$ bzw. 39,0\% und 25,4\% des Tagesenergiedefizits.

Diskussion. Im Vergleich zum Energiedefizit durch die hypokalorische Diät ist die aktivitätsbedingte Umsatzsteigerung für die Energiebilanz nur zweitrangig.

Danksagung. Dem Mittendorff-Institut Berchtesgaden für finanzielle Unterstützung und H.-V. Ulmer (Mainz) als Betreuer der 3 Mainzer Diplomarbeiten.

Samstag, 14.09.2013

\section{Gesundheit in KiTa und Schule - von der Neurobiologie bis zum Case management (1)}

\section{DGSPJ-SY-NL-3}

PIAF für alle - wie wird aus einem interdisziplinären Präventionsprojekt ein kommunales Regelangebot?

Langenbruch B. ${ }^{1}$, Sosada U. ', Wolpers P. ${ }^{2}$, Wöhler U. ${ }^{3}$

${ }^{1} F^{409}$ Gesundheit LK Hildesheim, Kinder- und Jugendgesundheitsdienst, Hildesheim, ${ }^{2}{ }^{F D}{ }^{406}$ Erziehungshilfe LK Hildesheim, Erziehungsberatung, Hildesheim, ${ }^{3}$ Landkreis Hildesheim, Dezernat Jugend, Gesundheit und Soziales, Hildesheim

Einleitung. Die im Rahmen der Schuleingangsuntersuchungen (SEU) festgestellten Entwicklungs- und Gesundheitsprobleme bedeuten für unsere Kinder erhebliche Risiken für Lernen und Leben. Langfristig ist mit fatalen gesamtgesellschaftlichen Folgen, mittelfristig mit Auswirkungen auf die kommunalen Jugendhilfekosten zu rechnen.

Methoden. 2006 erhielten Kinder- und Jugendgesundheitsdienst KJGD und Psychologe im LK Hildesheim deshalb von Verwaltung und Politik den Auftrag, gemeinsam ein Projekt zur frühzeitigen Prävention und Intervention zu entwickeln. Interdisziplinär - frühzeitig - aufsuchend - nachsorgend - systematisch: Diese Prinzipien stehen für das Programm PIAF $^{\circledast}$. 2 Jahre vor Schulbeginn werden alle Kinder in der KiTa vom Team aus Ärztin/KJGD und BezirkssozialarbeiterIn/Jugendhilfe besucht, die Kinder untersucht und die Eltern mit der Erzieherin gemeinsam beraten. Die Beratungen und Interventionen führten zu einer deutlichen Verbesserung der Gesundheits- und Entwicklungsindikatoren der PIAF-Kinder vs. Kontrollgruppe (Messung KJGD bei SEU). Die 
Evaluation der systemischen PIAF-Ziele erfolgte durch die Universität Hildesheim. Politik und Verwaltung wurden fortlaufend informiert und in die Entwicklung einbezogen.

Ergebnisse. Die Ergebnisse der Evaluationen, sehr positive Erfahrungen aus dem Projektalltag und viele „kleine“ Lebensgeschichten überzeugten im Verlauf alle Verantwortlichen, so dass zunächst die stufenweise Ausweitung des Projektes und schließlich die Etablierung als Regelprogramm für alle Kinder und KiTas fraktionsübergreifend und einstimmig beschlossen wurden. Aus „PiAF = Prävention in Alfeld und Freden" (220 Kinder/Jahr in 15 KiTas, Laufzeit 4 Jahre) wurde im Verlauf von 7 Jahren „PIAF ${ }^{\varpi}$ = Prävention in aller Frühe“ (2300 Kinder/Jahr in 180 KiTas, unbefristetes Regelangebot).

\section{Interdisziplinäre Diagnostik und Beratung bei FASD}

\section{DGSPJ-SY-FS-1}

Inhalt und Implementierung der Leitlinie zur Diagnostik des fetalen Alkoholsyndroms

\section{Landgraf M.N.', Heinen F.'}

'Universitätsklinikum München und Dr. von Haunersches Kinderspital, Abteilung für Pädiatrische Neurologie, Entwicklungsneurologie und Sozialpädiatrie iSPZ München, München

Einleitung. Das fetale Alkoholsyndrom (FAS) weist eine Inzidenz von 130 bis 5400 Geburten pro Jahr in Deutschland auf. Eine hohe Zahl von Fällen bleibt undiagnostiziert. FAS hat schwerwiegende, lebenslange Konsequenzen für die betroffenen Individuen und deren Familien.

Methoden. Auf Initiative des Bundesgesundheitsministeriums wurde von einer multidisziplinären Konsensusgruppe (1o Fachgesellschaften, 4 Berufsverbände, 3 Vertreterinnen von FASD Deutschland e.V. und 16 weitere Experten) eine S3-Leitlinie zur Diagnose des fetalen Alkoholsyndroms entwickelt. Vertreter des BMG und Methodik-Experten nahmen als nicht stimmberechtigte Berater teil. Die Literatur der letzten 10 Jahre wurde evaluiert und hinsichtlich ihrer methodischen Qualität bewertet. Die daraus resultierenden evidenzbasierten Ergebnisse wurden in drei Konsensuskonferenzen hinsichtlich klinischer Relevanz, ethischen Hintergründen und Praktikabilität diskutiert, modifiziert, konsentiert und daraufhin formell verabschiedet. Die diagnostischen Kriterien für das Vollbild FAS sind (unabhängig vom Bestimmungszeitpunkt): mindestens eine Wachstumsauffälligkeit, drei definierte faciale Auffälligkeiten und eine funktionelle oder strukturelle Auffälligkeit des zentralen Nervensystems. Die intrauterine Alkoholexposition muss für die Diagnosestellung nicht bestätigt sein. Schlussfolgerung. Die Leitlinie beinhaltet evidenzbasierte, klinisch relevante und in der Praxis einfach anwendbare diagnostischen Empfehlungen für die Identifikation des Vollbildes FAS bei Kindern und Jugendlichen. Sie ist Grundlage für eine einheitliche Diagnostik und für eine adäquate und individuelle Förderung der betroffenen Kinder und Unterstützung der leiblichen, Pflege- oder Adoptivfamilie.

\section{DGSPJ-SY-FS-2}

Neuropsychologische Diagnostik bei FASD

\section{Wagner J.C. \\ 'Charité Universitätsmedizin Berlin, Campus Virchow-Klinikum, FASD- Zentrum, Berlin}

Hintergrund. Menschen mit fetalen Alkoholspektrumstörungen zeigen häufig Beeinträchtigungen des zentralen Nervensystems, die sich in mäßigen bis erheblichen Dysfunktionen äußern und u. a. mit Wahrnehmungsstörungen, Teilleistungsstörungen, kognitiven Defiziten, Aufmerksamkeitsproblemen, Lern- und Gedächtnisschwierigkeiten, Planungs- und Handlungsschwierigkeiten einhergehen können.

Methoden. Diese neuropsychologischen Aspekte bzw. „Domänen“ können durch speziell entwickelte Tests bzw. Testbatterien untersucht wer- den. Die neuropsychologische Diagnostik ist Bestandteil der Erfassung von ZNS-Dysfunktionen und bildet damit einen wichtigen Baustein in der Diagnosestellung von Fetalen Alkoholspektrumstörungen (FASD). Ziel der neuropsychologischen Untersuchung ist darüber hinaus das Erstellen eines neuropsychologischen Profils, das sowohl Beeinträchtigungen als auch Stärken umfasst und die Grundlage darstellt für ein umfassendes Verständnis der individuellen Beeinträchtigungen von FASD-Betroffenen sowie gezielte Interventionen.

Schlussfolgerung. Der Vortrag soll daher eine kurze Einführung in die neuropsychologische Diagnostik dieser Aspekte liefern, Testverfahren vorstellen und mögliche Anwendungsprobleme diskutieren.

\section{DGSPJ-SY-FS-3}

Besondere Anforderungen an die Beratungspraxis bei fetalen Alkoholspektrumstörungen (FASD)

Becker G.

${ }^{1} E v$. Verein Sonnenhof e.V., FASD spezialisierte integrative Jugend- und Eingliederungshilfe, Berlin

Als integrative Jugendhilfe- und Eingliederungshilfeeinrichtung hat sich der Ev. Verein Sonnenhof e. V. auf FASD spezialisiert und überblickt im Fall- und Beratungsverlauf 42 diagnostizierte Fälle. $69 \%$ der uns anvertrauten FASD Fälle kommen aus der Herkunftsfamilie, davon 42,9\% aus Einelternfamilien (alleinerziehende Mütter). Besonderheiten in der Beratungspraxis zeigen sich bei einem Teil der Mütter in intrapsychischen Konfliktdynamiken, jedoch können auch besondere interpsychische Übertragungs- und Gegenübertragungskonflikte in den Helferfeldern, die mit der ineinander verschränkten Opfer-Täter-Dynamik zwischen Mutter und Kind zu tun haben, sowie der besonderen Thematik der „guten Mutter", zu Spaltungstendenzen führen. Insbesondere in den unteren Statusgruppen tragen Trauma-Folgestörungen zu Alkoholmissbrauch bei, so dass im Beratungsverlauf zu Teilen das MutterKind-Verhältnis als „doppeltes Opferverhältnis“ erscheint. Es ergeben sich besondere Anforderungen für die Behandler in der Differenzierung zwischen Schuldgefühl und Verantwortung, sowie der multiplen Identifikation. Die Spaltungstendenzen können jedoch angesichts einer vermeidbaren Behinderung so ausgeprägt sein, dass Helfersettings mit personeller Aufteilung angestrebt werden müssen. Abgeschlossen wird der Beitrag mit Fallvignetten aus zwei Familien: einmal mit niedrigem und einmal mit hohem Sozialstatus, um die jeweilig anderen Akzente der Beratung anzudeuten, sowie darauf hinzuweisen, dass in Deutschland der Alkoholkonsum während der Schwangerschaft vor allem ein Problem der hohen sozialen Statusgruppen ist.

\section{Gesundheit in KiTa und Schule - von der Neurobiologie bis zum Case management (2)}

\section{DGSPJ-SY-SG-1 \\ Diabetesmanagement in der Schule - wie kann es gehen von 8.00-17.00 Uhr?}

\section{Mönkemöller K.', Abendroth U.', Backes M.', Kluge A.', Mirza J.', Weiss M. ${ }^{1}$} 'Kinderkrankenhaus derStadtKölngGmbH,Kinder-undJugendmedizin, Köln

Einleitung. Die Diabetesbehandlung erfordert ein komplexes Therapiemanagement - von der Messung der Blutzucker über die Gabe von angepassten Insulindosen bis hin zur Einnahme von Kohlehydraten vor dem Sport. Grundschulkinder oder auch Jugendliche in der offenen Ganztagsschule sind meist nicht alleine in der Lage, diese Herausforderungen im Schulalltag zu bewältigen.

Methoden. Deshalb ist es entscheidend, von Anbeginn gemeinsam mit allen Beteiligten zu planen, welche Unterstützung die Patienten brauchen, wie diese innerhalb der jeweiligen Schule gewährleistet werden kann und wo ergänzende Hilfen einbezogen werden müssen. Die Auf- 
klärung der Lehrer über das Krankheitsbild und die Therapie sollte pragmatisch und alltagsnah erfolgen, Notfallsituationen erklären, vor allem aber Ängste reduzieren. Dies umfasst auch die rechtliche Situation der Lehrer, wenn sie das Kind bei der Anpassung der Insulindosis unterstützen oder Medikamente geben wollen. Der Schule muss jederzeit ein Ansprechpartner für Fragen zur Diabetestherapie zur Verfügung stehen.

Schlussfolgerung. Die offene Ganztagsschule - insbesondere das Mittagessen dort - erfordert oft eine umfassendere Herangehensweise: das Schätzen des Mittagessens oder die Schulung von Mitarbeitern, die nicht zur Schule gehören. Hier gilt es umso mehr, alltagsnahe Lösungen gemeinsam mit allen Beteiligten zu finden - und manchmal auch am Nachmittag ein etwas großzügigeres Therapiemanagement einzuplanen.

\section{DGSPJ-SY-SG-3 \\ Kooperationsmodelle in der Schulgesundheitspflege in Kanada}

\section{Kraus de Camargo 0.'}

${ }^{1}$ McMaster University - Chedoke Campus, Hamilton, Kanada

Einleitung. Der Vortrag skizziert wie sonderpädagogische, psychologische, therapeutische und medizinische Bedürfnisse von Schulkindern in der kanadischen Provinz Ontario geregelt sind und die Unterstützung dieser Kinder organisiert wird.

Methoden. Nach einer Beschreibung des kanadischen Schulsystems erfolgt eine Darstellung an einem Fallbeispiel wie medizinisch-pädagogische Leistungen, die zum erfolgreichen Besuch der Schule notwendig sind, von den Schulbehörden sichergestellt werden. Dies beinhaltet konsiliarische therapeutische, psychologische und ärztliche Leistungen sowie sonderpädagogische Leistungen und Pflegeleistungen in der Schule.

Schlussfolgerung. Die Zugangskriterien zur Gewährung und Umfang der Leistungen wird beschrieben und Vor- und Nachteile des Modells werden erörtert.

\section{Kinderbewusstsein - Welche Kinder brauchen Hilfe?}

\section{DGSPJ-SY-KB-2 \\ Volkswirtschaftliche Bedeutung von familien- und schulergänzen- der Kinderbetreuung}

\section{Fritschi $T^{1}$}

'Berner Fachhochschule, Soziale Arbeit, Bern, Schweiz

In diesem Beitrag wird auf Basis verschiedener durch den Autor durchgeführter Forschungsarbeiten (Fritschi/Jann 2009, Fritschi/Strub/Stutz 2007) der Fragestellung nachgegangen, welche volkswirtschaftlichen Auswirkungen von familien- und schulergänzender Kinderbetreuung ausgehen. Hierbei ist eine Unterscheidung verschiedener Akteursgruppen notwendig:

- Kinder: durch die familien- und schulergänzende Betreuung haben Kinder die Möglichkeit, Kompetenzen zu erwerben und Verhaltensweisen zu trainieren, die bei Betreuung zu Hause nicht in gleichem Maß gefördert würden. Insbesondere soziale Kompetenzen sowie Sprachkompetenzen sind dabei zu nennen. Die damit verbundenen Bildungseffekte tragen dazu bei, dass die Kinder höhere Bildungsabschlüsse erzielen können.

- Eltern: durch die Möglichkeit der Betreuung der Kinder zu Zeiten, in denen diese sonst zu Hause von den Eltern betreut würden, können die Elterrn ihre Erwerbstätigkeit ausdehnen, wodurch ein größeres Einkommen erzielt werden kann. Dies hat Auswirkungen auf die in $\mathrm{Zu}$ kunft erzielten Einkommen aufgrund der erhöhten Erwerbserfahrung. Auch das Rollenverständnis von Müttern und Vätern wird beeinflusst. - Staat: die teilweise staatlichen und subventionierten Betreuungsangebote sowie deren Verwaltung und Steuerung führen auf der einen Seite zu staatlichen Ausgaben. Diese werden aufgewogen durch staatliche
Einnahmen in Form von höheren Steuereinnahmen auf den größeren Erwerbseinkommen der Eltern in der Gegenwart sowie in der Zukunft, einschließlich der aufgrund höherer Bildungsabschlüsse gesteigerter Einkommen der Kinder.

Der Beitrag stellt die für die Akteursgruppen anfallenden Kosten und Nutzen gegenüber und leitet daraus Schlussfolgerungen für das Bildungs- und Betreuungssystem ab.

\section{DGSPJ-SY-KB-3}

\section{Wie frühe Bildung zum sozialen Ausgleich beitragen kann}

Berth F.

'Publizist, München

Eine Kleinstadt in den USA im Jahr 1962: An der Perry Preschool beginnt ein Experiment mit früher Bildung für benachteiligte Kinder. Drei- und Vierjährige aus armen Familien werden zwei Jahre lang in einem Halbtags-Kindergarten gefördert. Am Ende des Programms sind die Intelligenzquotienten der Kinder aus der Experimentalgruppe etwas höher als die aus der Kontrollgruppe. Ein Erfolg? Leider kein stabiler, wie es scheint: Im Alter von zehn Jahren sind die IQ-Vorsprünge verschwunden. Ein Misserfolg?

Auch nicht. Denn wenige Jahre später erreichen die Kinder aus der Experimentalgruppe bessere Schulleistungen. Und weil es den Studienmachern gelingt, die „Kinder“ bis zum vierzigsten Geburtstag kontinuierlich weiter zu untersuchen, zeigen sich markante und signifikante Verbesserungen bei den Schulabschlüssen, den Lebenseinkommen, der Sozialhilfe-Bedürftigkeit und der Kriminalität. Ein Wunder?

Der Vortrag nimmt diese einzigartige US-amerikanische Studie zum Anlass, nach Gründen für diesen Erfolg zu suchen. Eine Leitfrage ist, wann Bildungsprozesse im Lebenslauf besonders bedeutsam sind und was diese Erkenntnisse für Bildungsinstitutionen und die deutsche Bildungspolitik bedeuten.

Der Vortrag warnt allerdings auch davor, frühe Bildung als Wundermittel für alle Kinder zu betrachten. Dennoch wird deutlich, dass gerade Kinder aus benachteiligten Verhältnissen enorm von guter Betreuung weit vor Schulbeginn profitieren können. Deshalb plädiert der Vortrag gegen das gebräuchliche Gießkannenprinzip der deutschen Sozial- und Familienpolitik - und für eine Unterstützung, die gerade den schwächsten Kindern besonders zugute kommt.

\section{Universitäre Forschung in der pädiatrischen Rehabilitation}

\section{DGSPJ-SY-FR-1}

Die Rehabilitationsklinik als Forschungspartner aus der Sicht einer Universitätskinderklinik

Rosenecker J.'

'Klinik Oberjoch, Pädiatrie, Bad Hindelang

In der Bundesrepublik Deutschland werden innerhalb eines Jahres etwa 30.000 Rehabilitationsmaßnahmen bei Kindern und Jugendlichen durchgeführt. Der durchschnittliche Krankenhausaufenthalt im Rahmen einer Rehabilitationsleistung beträgt etwa 4-5 Wochen. Damit ergeben sich etwa 1 Million Krankenhaustage, die chronisch-kranke Kinder in Rehabilitationskliniken pro Jahr verbringen. Die überwiegende Mehrzahl der Patienten ist vor Beginn einer Rehabilitation einer umfangreichen Diagnostik unterzogen worden, so dass klar definierte Patientengruppen zu erkennen sind. Die forschungsaktiven Arbeitsgruppen universitärer Einrichtungen haben bislang zu wenig das große Potential genutzt, das aus der Zusammenarbeit mit Rehabilitationseinrichtungen entstehen kann. Neben epidemiologischen Studien können auch grundlagenorientierter Forschungsaktivitäten von der Kooperation mit Rehakliniken profitieren. Die technische Ausstattung der Rehabilitationskliniken ist in der Regel sehr hoch, so dass für Verlaufsbeobachtungen ausreichend Infrastruktur vorhanden ist. Neben den 
häufigen Krankheiten, wie Asthma bronchiale, Neurodermitis und Stoffwechselerkrankungen, werden auch viele seltene Krankheiten in den Rehabilitationseinrichtungen betreut. Eine Vernetzung der Zentren für seltene Erkrankungen, die sich in Deutschland in letzter Zeit konstituiert haben, mit den Rehakliniken würde hier Möglichkeiten schaffen, um Forschung im Bereich seltener Krankheiten zu ermöglichen. Eine Förderung der wissenschaftlichen Zusammenarbeit zwischen den universitären Einrichtungen und den Rehakliniken ist dringend erforderlich zum Wohle der chronisch kranken Kinder und deren Familien.

\section{DGSPJ-SY-FR-1 \\ Häufigkeit von Asthma bronchiale bei adipösen Kindern und Jugendlichen}

Bauer C.P.', Zötl B. ${ }^{1}$

${ }^{1}$ Fachklinik Gaißach, Gaißach

Einleitung. Adipositas im Kindesalter wird als Risikofaktor für die Manifestation eines Asthmas angesehen. Die bisherigen Untersuchungen beziehen sich allerdings mehrheitlich auf anamnestische Angaben ohne Lungenfunktionsuntersuchungen. Als Ursache für das Asthma bei Adipositas werden verschiedene Faktoren wie GÖR, erhöhte Entzündungsaktivität der Adipozyten etc. diskutiert. In nachfolgender Studie sollte mittels Anamnese, klinischer Untersuchung und Lungenfunktion die Häufigkeit von Asthma bei Kindern und Jugendlichen ermittelt werden, die wegen einer Adipositas im Rahmen einer Reha behandelt wurden.

Patienten und Methodik. In der Zeit von 01.01.-31.12.10 wurden 742 Patienten im Alter von 6-18 Jahren zur stat. Reha wegen Adipositas (BMI > 97. P) aufgenommen. Die Diagnose Asthma wurde gestellt, wenn eine Dauermedikation wegen Asthma bzw. anamnestisch der V. a. ein Asthma bestand und dies durch Lungenfunktion bestätigt wurde. Es wurde bei entsprechender Anamnese eine Lungenfunktion in Ruhe durchgeführt. Bei Hinweisen auf eine Obstruktion erfolgte eine Bronchospasmolyse, bei unauffälligen Ausgangswerten eine Laufbelastung.

Ergebnisse. Von 742 erfassten Patienten bestand bei 140 ein Asthma bzw. der V. a. ein Asthma. Von diesen konnte bei 6o Patienten die Diagnose durch Lungenfunktion gesichert werden ( $8 \%$ vom Gesamtkollektiv). Bei 45 Patienten (6\%) bestanden trotz anamnestisch bekannten Asthmas keine Auffälligkeiten in der Lungenfunktion und keine Klinik. Bei 35 Patienten $(4,6 \%)$ bestand nur der anamnestische V. a. ein Asthma, der nicht bestätigt werden konnte.

Fazit. Es bestanden zwar bei 140 Patienten (18,6\%) anamnestisch oder per Lungenfunktion Hinweise auf ein Asthma bronchiale. Klinisch relevante Veränderungen konnten jedoch nur bei $8 \%$ der untersuchten adipösen Patienten gefunden werden. Eine signifikante Erhöhung der Asthmarate konnte in diesem Kollektiv der untersuchten adipösen Kinder und Jugendlichen im Vergleich zur allgemeinen Asthmahäufigkeit bei Kindern und Jugendlichen nicht festgestellt werden. Die Bedeutung der Adipositas als Risikofaktor für ein Asthma wird vielleicht überschätzt.

\section{DGSPJ-SY-FR-2 \\ Das kardiovaskuläre Risiko übergewichtiger und adipöser Kinder und Jugendlicher}

\section{Elmenhorst J.', Oberhoffer R. ${ }^{1}$}

${ }^{1}$ Technische Universität München, Lehrstuhl Präventive Pädiatrie, München

Fragestellung. Kardiovaskuläre Risikofaktoren (RF) treten bereits früh in der Lebenspanne auf und es ist anerkannt, dass Arteriosklerose als Vorbote kardiovaskulärer Erkrankungen im Erwachsenenalter bereits Jahrzehnte zuvor in der Kindheit beginnt. Wissenschaftlich etabliert ist ein „Tracking“ von RF vom Kindes- in das Erwachsenenalter. Auch die Rate von Hypertonikern oder Kindern mit grenzwertig erhöhtem Blutdruck ist bei Übergewichtigen gesteigert. Darüber hinaus konnten wir im Rahmen der Studie: „Catch the (pulse) wave“ weitere unabhängige vaskuläre Prädiktoren bei diesem Risikokollektiv nachweisen.
Material und Methode. Insgesamt wurden 1809 Schüler [50,2\% weiblich, BMI: 11,9-49,3 (kg/m2], 105 übergewichtig, 201 adipös, mittleres Alter: 13,24 $\pm 2,94$ Jahre] mittels vaskulärer Diagnostik (Mobil-O-Graph, IEM) untersucht [Blutdruck, peripher (pSBD)/zentral (zSBD), sowie Pulswellengeschwindigkeit (PWV)]. Die PWV wurde am Oberarm mit 5 adäquaten Manschetten oszillometrisch gemessen.

Ergebnisse. PWV ist bereits im Kindesalter mit dem BMI $(r=0,423)$ korreliert. Da die PWV mit Alter $(r=0,507)$, Körpergröße $(r=0,56)$ und pSBD $(r=0,844)$ korreliert (alle $\mathrm{p}<0,001)$ wurden für die weitere Analyse entsprechend gematchte Paare $(n=327)$ gebildet. Probanden mit $\mathrm{BMI}>90$. Perzentile $(\mathrm{O})$ zeigen höhere PWV als Kontrollen [CO; PWV $\mathrm{O}=4,8 \mathrm{o} \pm 0,38 / \mathrm{PWV} \mathrm{CO}=4,94 \pm 0,4(\mathrm{~m} / \mathrm{s}), \mathrm{p}<0,001]$. Auch der $\mathrm{zSBD}$ ist bei $\mathrm{O}$ höher $[\mathrm{zSBD} \mathrm{O}=104 \pm 10,3 / \mathrm{CO}=108 \pm 10,8(\mathrm{mmHg}) ; \mathrm{p}<0,001]$, obwohl bei pSBD kein Unterschied festzustellen ist.

Schlussfolgerung. Rehamaßnahmen, die zu einer dauerhaften Gewichtsabnahme führen, könnten daher nicht nur als erfolgreich hinsichtlich des Ziels der Gewichtsreduktion, sondern auch als (präventiv) kardiovaskulär sinnvoll, angesehen werden.

\section{DGSPJ-SY-FR-3}

Effektivität stationärer medizinischer Rehabilitation bei Kindern mit expressiven und/oder rezeptiven Sprachstörungen und Komorbidität

\section{Springer S. ', Hecking M. ${ }^{1}$, Grohnfeldt M. ${ }^{2}$}

${ }^{1}$ Klinik Hochried, Murnau, ${ }^{2}$ Ludwig-Maximilians-Universität München, Lehrstuhl für Sprachheilpädagogik und Sprachtherapie, München

Hintergrund. Sprachstörungen bestehen lebenslang, die Symptomatik ist spätestens mit 3. Lebensjahr messbar, bei großer Häufigkeit von Komorbidität und Teilhabebeeinträchtigung. Ziel ist nachzuweisen, dass eine Behandlung der Primärsymptomatik der Sprache im Rahmen stationärer Reha mit einem multimodalen Konzept in der Lage ist, die Primärsymptomatik signifikant zu verbessern, andererseits aber auch messbare Verbesserungen der Anpassungsfähigkeit der Kinder zu erzielen.

Methodik. Randomisiert-kontrollierte Therapiestudie mit Doppelblindung und Follow-up. Unterschiede in sprachspezifischen Maßnahmen der Gruppentherapie. Zur Erhebung SON-R-2,-7, PDSS, sowie CBCL, DISYPS-KJ, ET6-6. Einschlusskriterien 3;0-6;11 Jahre, Ausschlusskriterien Intelligenzminderung, Syndrome und Autismus. Stichprobengröße auf der Basis der Pilotstudie mit $n=75$ je Interventions- und Kontrollgruppe. Auswertung mit Zweistichproben-T-Test für unabhängige Stichproben.

Ergebnisse. In Pilotstudie für Item Mittelwert ( $\left.\mathrm{T}_{2}-\mathrm{T}_{1}\right)$ und Standardabweichung ( $\left.\mathrm{T}_{2}-\mathrm{T}_{1}\right)$ : Wortverständnis Nomen 5.7/10.4142, Wortverständnis Verben 11.9/11.4935, Wortproduktion Nomen 3.6/5.9852, Wortproduktion Verben 18.3/13.2837, BK Ablenker 20.7/19.2645, BK Zielitems 11.5/24.2636. Einseitiger t-Test ergibt p-Werte: WV Nomen 0.0588 nicht signifikant, WV Verben 0.0048 signifikant, WP Nomen 0.0448 signifikant, WP Verben o,000916 signifikant, BK Ablenker 0.0039 signifikant, BK Zielitems o.0841 nicht signifikant.

Diskussion. Kurzfristige Rehaerfolge können für das multimodale Behandlungskonzept sowohl für kindzentrierte als auch elternzentrierte Maßnahmen nachgewiesen werden. Für die elternzentrierten Maßnahme in der Rehabilitation sind bereits kurz- und langfristige Effekte belegt werden, die diese Fragestellung sinnvoll machen. 


\section{Sonntag, 15.09.2013}

\section{Freie Vorträge}

\section{DGSPJ-FV-1 \\ CPCHILD $^{\oplus}$ - Caregiver Priorities and Child Health Index of Live with Disabilities - Validierung in einer deutschen Kohorte}

Jung N. ${ }^{1}$, Brix $0 .^{2}$, Bernius P. ${ }^{3}$, Schröder S. ${ }^{2}$, Kluger G. ${ }^{4}$, Beyerlein A. ${ }^{5}$, Weir $S^{6}$, von Kries R. ${ }^{5}$, Narayanan U. ${ }^{6}$, Mall V., Berweck S. ${ }^{4}$

${ }^{1}$ Lehrstuhl für Sozialpädiatrie, Kinderzentrum München, Pädiatrie, München, ${ }^{2}$ Universitätsklinikum München und Dr. von Haunersches Kinderspital, Klinik für Neuropädiatrie und Sozialpädiatrie, München, ${ }^{3} S c h o ̈ n$ Klinik Harlaching, Klinik für Kinderorthopädie, München, ${ }^{4}$ Schön Klinik Vogtareuth, Klinik für Neuropädiatrie und neurologische Rehabilitation, Vogtareuth, ${ }^{5}$ Ludwig-Maximilians-Universität München, Institut für Soziale Pädiatrie und Jugendmedizin, München, ${ }^{6}$ The Hospital for Sick Children, Division of OrthopedicSurgery, Toronto, Kanada

Fragestellung. Validierung der übersetzten Version des Caregiver Prioritiesand Child Health Index of Live with Disabilities (CP-CHILDఠ) um die gesundheitsbezogene Lebensqualität (HRQOL) in einer deutschen Kohorte von Kindern mit schwerer Cerebralparese (CP) gemäß des Gross Motor Function Classification System (GMFCS Level III-V) zu beurteilen.

Methoden. Es wurden $n=68$ Patienten (w: $n=33, m=35$; Alter: $10,9 \pm 5,1$ Jahre) mit CP und GMFCS Level III $(n=14)$, Level IV $(n=28)$ und Level V $(n=26)$ untersucht. Der Fragebogen und das Handbuch wurden aus dem englischen übersetzt und die deutsche Fassung wieder zurückübersetzt. Der CPCHILD@-Fragebogen besteht aus 37 Punkten, die sich über 6 Sektionen verteilen: 1. Körperpflege/Aktivitäten des täglichen Lebens (ADL), 2. Positionierung, Transfer \& Mobilität, 3. Wohlbefinden \& Gefühle, 4. Kommunikation \& soziale Interaktion, 5. Gesundheit, 6. Lebensqualität insgesamt.

Ergebnisse. Der mittlere Total Score des CP-CHILD॰ für GMFCS Level III betrug $67,1 \pm 14,9$, für GMFCS Level IV $56,6 \pm 11,8$, und für Level V $44,3 \pm 12.9$. Konstruktvalidität (ANOVA, GMFCS) war für den Total Score sowie für die standardisierten Scores für ADL, Transfer, Kommunikation und Gesundheit signifikant. Die Retest-Reliabilität zeigte InterklassenKorrelationskoeffizienten zwischen 0,436 and o,897. Die Augenscheinvalidität zeigte, dass alle Punkte oberhalb des Signifikanzniveaus von 2 lagen Schlussfolgerung. Die deutsche Übersetzung des CP-CHILD@-Fragebogens scheint ein valides Instrument zu sein, um die HRQOL bei Kindern und Jugendlichen mit schwerer $\mathrm{CP}$ zu beurteilen. Die psychometrischen Daten sind zufriedenstellend, eine Implementierung in der klinischen Routine um die HRQOL zu beurteilen scheint möglich.

\section{DGSPJ-FV-2}

\section{Der Fragebogen zu elterlichen Sorgen bei Epilepsien im Kindes- und Jugendalter - Ergebnisse einer Pilotstudie}

\section{Müller-Godeffroy E.', Thyen U. ${ }^{1}$ \\ 'Universitätsklinikum Schleswig Holstein, Campus Lübeck, Kinder- und Jugendmedizin, Lübeck}

Fragestellung. Obwohl Kinder- und Jugendliche mit Epilepsie oft ohne große Einschränkungen leben können, fühlen sich deren Eltern häufig vor allem psychisch sehr belastet. Zur Erfassung dieser psychischen Belastung wurde ein Fragebogen zu epilepsiebezogenen Sorgen von Eltern entwickelt.

Material und Methoden. Die Entwicklung des Fragebogens erfolgte im Rahmen der Evaluation des Epilepsieschulungsprogramms „Flip \&Flap“, das sich an weitgehend altersangemessen entwickelte Kinder/Jugendliche und ihre Eltern richtet. Die Items entstammen Interviews mit betroffenen Eltern und Experten und beziehen sich auf Sorgen über das Anfallsgeschehen, die Entwicklung und soziale Inklusion des Kindes. Die Evalua- tion wurde als multizentrische kontrollierte Längsschnittstudie durchgeführt. 153 Eltern ( $\mathrm{n}=77$ Interventions-, 76 Kontrollgruppe) beantworteten den Fragebogen im Rahmen der Baseline-Befragung; zur Erfassung der Änderungssensitivität wurden die Daten der Interventionsgruppe aus der Nachbefragung nach 6 Monaten $(n=72)$ ausgewertet.

Ergebnisse. Die explorative Faktorenanalyse (Hauptkomponentenanalyse mit anschließender Varimax-Rotation) ergab zwei Skalen „Sorgen über die Behandlung" und "Sorgen über die Entwicklung des Kindes“. Beide Skalen zeigte gute interne Konsistenz (Cronbach's alpha = o,82; $0,85)$ und mittlere Skaleninterkorrelation $(r=0,35)$. Da die Eltern nach 6 Monaten über eine signifikante Abnahme epilepsiebezogener Sorgen berichteten, kann von der Änderungssensitivität des Instruments ausgegangen werden.

Schlussfolgerungen. Mit dem „Fragebogen zu elterlichen Sorgen bei Epilepsie des Kindes“ liegt ein kurzes Instrument vor, das in der Pilotstudie Reliabilität und Änderungssensitivität zeigte und sich damit für den Einsatz in weiteren klinischen Studien empfiehlt.

\section{DGSPJ-FV-3}

Entwicklung von Qualitätsindikatoren für das Krankheitsbild ADHS in Sozialpädiatrischen Zentren

\section{Skrundz M. ${ }^{1,2}$, Hameister K. ${ }^{3}$, Borusiak P. ${ }^{2}$, Geraedts M. ${ }^{4}$}

'Universität Witten/Herdecke, Witten, ${ }^{2} \mathrm{HELIOS}$ Klinikum Wuppertal, Zentrum für Kinder- und Jugendmedizin, Sozialpädiatrisches Zentrum, Wuppertal, ${ }^{3}$ Lebenszentrum Königsborn, Sozialpädiatrisches Zentrum, Unna, ${ }^{4}$ Universität Witten/Herdecke, Institut für Gesundheitssystemforschung, Witten

Einleitung. Zur Überprüfung der Umsetzung von Struktur- und Prozessvorgaben sowie der Ergebnisevaluation einzelner Sozialpädiatrischer Zentren (SPZ) existiert bislang noch keine einheitliche Methodik. Hierfür werden exakt definierte Messgrößen im Sinne von Qualitätsindikatoren (QI) benötigt. Ziel der vorliegenden Arbeit ist es, unter Einsatz erprobter, wissenschaftlich fundierter Methoden, Indikatoren zur Qualitätsbewertung von SPZ, begrenzt auf das Krankheitsbild ADHS, zu entwickeln. Hierzu wurden folgende Schritte durchgeführt: (1) Literatur-, Datenbank- und Leitlinienrecherche zu Ergebnisparametern der Effektivität von SPZ, sowie zu vorhandenen QI in der ADHS-Versorgung, (2) Entwicklung von QI auf Basis der im Bereich der Qualitätssicherung verabschiedeten Beiträge der DGSPJ sowie der Ergebnisse aus Schritt (1). Das so entwickelte Rohset enthielt 95 QI.

Methoden. Die methodische Gütetestung der identifizierten Messgrößen erfolgte im Anschluss schrittweise unter Einsatz des standardisierten und praktisch erprobten QUALIFY-Instrument (Reiter et al. 2008). Das ursprüngliche QI-Rohset konnte im Verlauf zweier Expertenbewertungsrunden nach modifizierter RAND/UCLA-Delphi-Methode (Brook 1994) auf ein Set von 37 QI reduziert werden, welches inhaltlich die Prozess-, Struktur-, sowie Ergebnisqualität in der Diagnostik und Behandlung von ADHS-Patienten in SPZ abdeckt.

Schlussfolgerung. Präsentiert werden das bisherige Vorgehen und die resultierten QI unter Berücksichtigung auf die Versorgungslage in Sozialpädiatrischen Zentren, sowie daraus folgende Schlussfolgerungen für Maßnahmen zur Qualitätssicherung in diesem Versorgungsbereich.

\section{DGSPJ-FV-4}

Machbarkeitsstudie zur Implementierung von Qualitätsindikatoren für das Krankheitsbild ADHS in Sozialpädiatrischen Zentren

\section{Skrundz M.1,2, Hameister K. ${ }^{3}$, Borusiak P.2, Geraedts M. ${ }^{1}$}

'Universität Witten/Herdecke, Institut für Gesundheitssystemforschung, Witten, ${ }^{2} \mathrm{HELIOS}$ Klinikum Wuppertal, Zentrum für Kinder- und Jugendmedizin, Sozialpädiatrisches Zentrum, Wuppertal, ${ }^{3}$ Lebenszentrum Königsborn, Sozialpädiatrisches Zentrum, Unna

Einleitung. Zur Überprüfung der Umsetzung von Leitlinien in Sozialpädiatrischen Zentren (SPZ) existiert bislang noch keine einheitliche 
Methodik. Hierfür werden exakt definierte Messgrößen im Sinne von Qualitätsindikatoren (QI) benötigt. Unter Einsatz erprobter, wissenschaftlich fundierter Methoden, wurden im ersten Teil des Projekts solche Indikatoren zur Qualitätsbewertung von SPZ, begrenzt auf das Krankheitsbild ADHS, unter Einsatz des standardisierten und praktisch erprobten QUALIFY-Instruments (Reiter et al. 2008) entwickelt. Die vorliegende Arbeit hatte zum Ziel das QI-Set von 37 Indikatoren zum Ziel der abschließenden Bewertung hinsichtlich Güte und Machbarkeit in einer Pilotstudie an einer Gruppe teilnehmender SPZ zu erheben.

Methoden. Die Erhebung erfolgte Anfang 2013 an 9 SPZ. Für die QIBerechnung notwendige Daten wurden aus jeweils 20 zufällig ausgewählten Akten pro SPZ erhoben. Alle erhobenen Fälle erfüllten das Kriterium: erstmalige Vorstellung des Patienten zur diagnostischen Abklärung eines ADHS. 10 der 20 Fälle erfüllten zudem das Kriterium: gesicherte ADHS-Diagnose nach Abschluss der störungsspezifischen Diagnostik im SPZ. Die berechneten QI-Werte wurden der weiteren Güte- und Machbarkeitsprüfung unterzogen, hierzu wurden u. a. deskriptive Parameter und Konfidenzintervalle berechnet.

Schlussfolgerung. Es zeigte sich, dass die Bestimmung der entwickelten QI auf Basis vorliegender Daten in SPZ grundsätzlich machbar ist. Nicht alle QI erfüllen das Gütekriterium einer ausreichenden statistischen Unterscheidungsfähigkeit. Es resultiert nach der abschließenden Gütebewertung somit ein nochmals reduziertes QI-Set, welches inhaltlich und im Kontext der praktischen Anwendbarkeit, sowie der bestehenden Notwendigkeit zur Schaffung einer validen Qualitätsbewertung der Versorgung diskutiert wird.

\section{DGSPJ-FV-5}

\section{Diagnostik von Sprachentwicklungsstörungen bei mehrsprachigen} Kindern

\section{Ehl B. ${ }^{1,2}$, Schrey-Dern D. ${ }^{3}$, Willmes $K^{4}$}

'Universität RWTH Aachen, Studiengang Lehr- und Forschungslogopädie, Aachen, ${ }^{2}$ SPZ Rhein-Erft-Kreis, Kerpen, ${ }^{3}$ Universität RWTH Aachen, Lehrbeauftragte im Studiengang Lehr- und Forschungslogopädie, Aachen, ${ }^{4}$ Universitätsklinikum RWTH Aachen, Lehr- und Forschungsgebiet Neuropsychologie an der Neurologischen Klinik, Aachen

Fragestellung. Sprachtests in Deutschland sind in der Regel für monolinguale und nicht für sukzessiv mehrsprachige Kinder normiert. Dies gilt auch für den Aktiven Wortschatztest für 3- bis 5-jährige Kinder (AWST-R). Ziel war, zu überprüfen, inwiefern sich die Normen des AWST-R zur Differenzialdiagnostik bei mehrsprachigen Kindern eignen bzw. inwiefern sie angepasst werden können.

Material und Methode. 28 sukzessiv mehrsprachige Kinder im Alter von 3;0 bis 5;5 Jahren, 14 Kinder mit und 14 Kinder ohne Sprachstörung, wurden hinsichtlich ihrer Ergebnisse im AWST-R verglichen. Zudem wurde die Differenz aus Alter und Entwicklungsalter berechnet sowie der Mittelwert je Gruppe bestimmt.

Ergebnisse. Sowohl alle 14 Kinder mit Sprachstörung, aber auch 12 von 14 Kindern ohne Sprachstörung schnitten unterdurchschnittlich ab. Dies entspricht einer Falsch-positiv-Rate von 85,7\%. Der Gruppenunterschied war nicht signifikant $(\mathrm{p}=481)$. Im Durchschnitt lagen Kinder mit Sprachstörung im Entwicklungsalter 23,5 Monate (19,3-27,7 Monate; $S D=2,0$ ) unter ihrem Alter, Kinder ohne Sprachstörung im Mitte 15,5 Monate $(11,4-19,7$ Monate; $S D=2,0)$. Dieser Unterschied war signifikant $(\mathrm{p}=015)$

Schlussfolgerung. Der Einsatz der altersbasierten, monolingualen Normen des AWST-R führt bei sukzessiv mehrsprachigen Kindern zu einer hohen Falsch-positv-Rate. Die sukzessiven Erwerbsbedingungen sollten bei der Auswertung berücksichtigt werden, indem überprüft wird, ob das zu erwartende Entwicklungsalter erreicht wird. Dieses kann mit folgender Korrekturformel berechnet werden: $\mathrm{Zu}$ erwartendes Entwicklungsalter im Wortschatzumfang $=$ Alter $-15,5( \pm 2)$ Monate .

\section{Poster}

\section{DGSPJ-PO-1 \\ Wie wirksam sind kognitive Trainingsprogramme im Kindes- und Jugendalter? Eine Metaanalyse}

Albers L. ${ }^{\prime}$, Karch $D .{ }^{2}$, Renner G. ${ }^{3}$, Lichtenauer N. ${ }^{4}$, von Kries $R .{ }^{1}$

'Institut für soziale Pädiatrie und Jugendmedizin, München, ${ }^{2}$ Kinderzentrum Maulbronn gGmbH, Maulbronn, ${ }^{3}$ Pädagogische Hochschule Ludwigsburg, Fakultät für Sonderpädagogik, Reutlingen, ${ }^{4} \mathrm{Fach}$ therapeut für kognitives Training, Altötting

Fragestellung. Kognitive Therapien zielen auf eine Verbesserung von Störungen kognitiven Basisfunktionen, unabhängig von ihrer Ursache. Kindzentriert kommen hierbei verhaltenstherapeutische und computergestützte Trainingsprogramme bei Kindern mit unterschiedlichen Krankheitsbildern zum Einsatz. Eine Metaanalyse zur Wirksamkeit dieser Therapien fehlt bislang.

Methoden. Systematischer Review und Metaanalyse kindzentrierter kognitiver Trainings zur Verbesserung von Aufmerksamkeit, Gedächtnisleistung, exekutiven Funktionen (primärer Outcome) und Verhalten/ Psychopathologie, Intelligenz und Schulleistung (sekundärer Outcome). Mittelwertdifferenzen zwischen Therapie- und Kontrollgruppe werden als Standarddeviation-Scores (SD) berichtet.

Ergebnisse. Von 1661 identifizierten Publikationen wurden 22 Studien eingeschlossen. Der Overall Effekt der kognitiven Trainings auf Aufmerksamkeit $[0,18 \mathrm{SD}, 95 \% \mathrm{KI}=(-0,11,0,47)]$ und exekutiven Funktionen $[0,17 \mathrm{SD}, 95 \% \mathrm{KI}=(-0,12,0,46)]$ waren konsistent gering. Ein vergleichsweise hoher Effekt wurde für Gedächtnisleistungen [0,65 SD, $95 \% \mathrm{KI}=(-0,12$, $1,42)$ ] bei starker Heterogenität $(=82 \%)$, bedingt durch zwei Studien, gefunden. In dem Bereich Verhalten/Psychopatholgie wurden die größten Effekte berichtet $[0,58 \mathrm{SD}, 95 \% \mathrm{KI}=(0,31,0,85)]$. Sie basierten jedoch hauptsächlich auf Studien ohne aktive Kontrollgruppe.

Schlussfolgerung. Kindzentriertes kognitive Trainings erzielten generell günstige, vermutlich jedoch unspezifische Effekte im Bereich des Verhaltens. Dagegen waren die Effekte bezüglich der spezifischen Outcomes insgesamt gering. Nur für einzelne Therapien und Therapieindikationen konnten Effekte nachgewiesen werden.

\section{DGSPJ-PO-2}

Impferinnerungssystem (Impf-Recall) bei der Schuleingangsuntersuchung in Bayern - Ergebnisse zum Schuljahr 2011/2012

Hölscher G. ', Schneider T.', Ludwig M.-S. ${ }^{2}$ Fischer R. ${ }^{3}$, Liebl B. ', NennstielRatzel U.'

'Bayerisches Landesamt für Gesundheit und Lebensmittelsicherheit, Oberschleißheim, ${ }^{2}$ Bayerisches Landesamt für Gesundheit und Lebensmittelsicherheit, Erlangen, ${ }^{3}$ Bayerisches Staatsministerium für Umwelt und Gesundheit, München

Hintergrund. Als Bestandteil des Bayerischen Impfkonzepts wurde bei der Schuleingangsuntersuchung (SEU) ein Impferinnerungssystem (Impf-Recall) zum Schuljahr 2010/2011 flächendeckend eingeführt. Ziel des ImpfRecalls ist das Schließen von Impflücken insbesondere bei Masern und die damit verbundene Verbesserung der (Masern-)Impfraten in Bayern.

Methodik. Im Rahmen der SEU wurden anhand der vorgelegten Impfbücher Impflücken auf Grundlage der STIKO-Empfehlungen erfasst. Bei vorhandenen Impflücken erhielten die Eltern eine Impfberatung sowie die Einladung zur freiwilligen Teilnahme am Impf-Recall, bei dem sie in zwei Stufen an das Schließen der Impflücken erinnert wurden. Die nachgeholten Impfungen sollten vom Arzt per Fax an das jeweilige Gesundheitsamt zurückgemeldet und dort entsprechend dokumentiert werden. Ergebnisse. Am ersten flächendeckend durchgeführten Impf-Recall-Jahrgang (Schuljahr 2010/2011) beteiligten sich 68 von 77 Gesundheitsämtern. 2722 Eltern von 8850 Kindern mit einer dokumentierten Masern-Impflücke waren mit der Teilnahme am Impf-Recall einverstanden. Bei 576 Kindern 
wurde die Impflücke nachweislich geschlossen. Die Durchimpfungsrate gegen Masern stieg um o,7 (mind. 2 Masern-Impfungen) Prozentpunkte. Die Ergebnisse zum zweiten flächendeckenden Jahrgang (Schuljahr 2011/2012) sollen auf der diesjährigen DGKJ-Tagung präsentiert werden. Schlussfolgerung. Bisher war die Akzeptanz des Impf-Recalls sowohl bei den Gesundheitsämtern als auch bei den Eltern und niedergelassenen Ärzten noch unzureichend. Es ist davon auszugehen, dass noch nicht alle aufgrund des Impf-Recalls nachgeholten Impfungen von den Ärzten an die Gesundheitsämter zurückgemeldet wurden. Weitere Anstrengungen bzgl. Akzeptanz und Vereinfachung des Ablaufs scheinen erforderlich.

\section{DGSPJ-PO-3}

Übergang vom Elementar- in den Primarbereich: Begleitung durch den Kinder- und Jugendgesundheitsdienst Bremen

Gerken C.', Sadowski G. ${ }^{\prime}$

'Gesundheitsamt Bremen, KJGD, Bremen

Fragestellung. Der Übergang vom Elementar- in den Primarbereich birgt eine Vielzahl neuer Anforderungen. Wie gelingt, besonders für Kinder mit psychosozialen Auffälligkeiten, die sichere und stützende Übergangsgestaltung?

Methoden. Die Aktivität des Kinder- und Jugendgesundheitsdienst besteht in Vernetzung mit Kinderärzten, Schulen und Kindertageseinrichtungen, sowie den lokalen Sozialzentren. Bundesweite Besonderheit ist, neben vorzeitiger Schuleingangsuntersuchung von heilpädagogisch geförderten Kindern, der Austausch mit den Schulleitungen vor Klassenbildung und eine Hospitation nach der Einschulung, in allen ersten Grundschulklassen. Die Schuleingangsuntersuchung erfolgt standardisiert, mittels SOPESS. Zum Screening psychosozialer Auffälligkeiten, wird der SDQ-Fragebogen eingesetzt. Er erfasst emotionale Stabilität, Verhalten, Hyperaktivität und Probleme im Umgang mit Gleichaltrigen. Neben bereits in Therapie befindlichen Kindern (14\% der auffälligen Befunde), werden solche ermittelt, für die eine Unterstützung zum Schuleintritt erforderlich erscheint. Psychologische Testdiagnostik und Therapie ist somit noch vor Schulbeginn möglich.

Ergebnisse. Die seit 2011 erhobenen Daten zeigen in nahezu 20\% auffällige Befunde, bei 5\% in mehr als 1 Unterskala. In 2012 wurden, nach 179 Überweisungen (26,6\% der auffälligen Befunde) und 96 Untersuchungen, 94 Verdachtsdiagnosen gestellt.

Schlussfolgerung. Der SDQ- Fragebogen ist ein sicheres Screeninginstrument für psychosoziale Auffälligkeiten. Die große Akzeptanz bei den Familien (91\% Rücklauf) bahnt die adäquate Versorgung und Begleitung der Kinder an der entscheidenden Schnittstelle Schuleintritt. In standardisierten Befragungen von Eltern und Lehrkräften, soll das Gelingen dieses Übergangs zukünftig evaluiert werden.

\section{DGSPJ-PO-4}

Einfluss der Hüftluxation auf die Lebensqualität bei Kindern und Jugendlichen mit Cerebralparese beurteilt durch den CPCHILD ${ }^{\circledR}$ Fragebogen

Jung N. ${ }^{1}$, Pereira B. ${ }^{1}$, Brix O. ${ }^{2}$, Bernius P. ${ }^{3}$, Schröder S. ${ }^{2}$, Kluger G. ${ }^{4}$, Köhler T. ${ }^{5}$, Beyerlein A. ${ }^{6}$, Weir S. ${ }^{7}$, von Kries $R .{ }^{6}$, Narayanan U. ${ }^{7}$, Berweck S. ${ }^{4}$, Mall V. ${ }^{1}$

'Lehrstuhl für Sozialpädiatrie, Kinderzentrum München, Pädiatrie, München, ${ }^{2}$ Dr. von Haunersches Kinderspital, Ludwig-Maximilians-Universität München, Klinik für Neuropädiatrie und Sozialpädiatrie, München, ${ }^{3}$ Schön Klinik Harlaching, Klinik für Kinderorthopädie, München, ${ }^{4}$ Schön Klinik Vogtareuth, Klinik für Neuropädiatrie und neurologische Rehabilitation, Vogtareuth, ${ }^{5}$ Kinderzentrum Mecklenburg gGmbH, Schwerin, ' ${ }^{6}$ udwig-Maximilians-Universität München, Institut für Soziale Pädiatrie und Jugendmedizin, München, ${ }^{7}$ The Hospital for Sick Children, Division of Orthopedic Surgery, Toronto, Kanada

Fragestellung. Die Hüftlateralisation bei Kindern mit Cerebralparese (CP) hängt von der Schwere der motorischen Beeinträchtigung ab und kann zu einer milden Beeinträchtigung, bis hin zu starken Schmerzen führen. Das Ziel der Studie war es, die gesundheitsbezogene Lebensqualität bei Kindern mit CP und den Einfluss der Hüftlateralisation mit Hilfe eines spezifischen Fragebogens, dem Caregiver Priorities and Child Health Index of Life with Disabilities (CPCHILD ${ }^{\circ}$ ), zu untersuchen.

Material und Methoden. Insgesamt 34 Patienten (mittleres Alter: 10,2 $\pm 4,7$ Jahre; W: $n=16$ ) mit bilateraler spastischer CP und Gross Motor Function Classification System (GMFCS) Level III-V nahmen teil. Es wurden die betreuenden Personen mit Hilfe des CPCHILD ${ }^{\circ}$-Fragebogens zur Lebensqualität der Patienten befragt. Der Migrationsindex nach Reimers wurde als Maß der Hüftlateralisation erhoben. Die Patienten wurden in eine Hochrisikogruppe (MI $>40 \%$ ), eine Risikogruppe (MI 25\% bis $\leq 40 \%$ ) und eine Gruppe mit einem geringen Risiko (MI<25\%) eine Hüftluxation zu entwickeln eingeteilt.

Ergebnisse. Sieben Patienten hatten einen GMFCS Level III, $n=15$ Level IV und $n=12$ Level V. Es zeigte sich ein signifikanter Einfluss der Faktoren GMFCS und MI auf den Total Score des CPCHILD ${ }^{\circ}$ (GMFCS: $\mathrm{p}=0,005$ und MI: $\mathrm{p}=0,006$ ), nicht jedoch für die Interaktion. Das Ausmaß der Lateralisation (MI) korrelierte signifikant mit dem Total Score des CPCHILD $^{\circ}(\mathrm{r} 2=0,146 ; \mathrm{p}=0,026)$.

Schlussfolgerung. Die Ergebnisse deuten darauf hin, dass, neben dem GMFCS-Level, die Lateralisation der Hüfte einen Einfluss auf die gesundheitsbezogene Lebensqualität haben könnte. Die Ergebnisse unterstützten die Bemühungen einer adäquaten Prävention und Therapie der Hüftluxation bei Kindern mit CP.

\section{DGSPJ-PO-5}

\section{Das Sozialpädiatrische Zentrum durch die Augen der Eltern}

Zinn $W^{1,2}$

${ }^{1} \mathrm{H}: \mathrm{G}$ Hochschule für Gesundheit und Sport, Berlin, ${ }^{2}$ Forschungsgruppe Metrik, Bermuthshain

Fragestellung. Das sozialpädiatrische Zentrum steht, wenn es um das Qualitätsmanagement geht, vor besonderen Aufgaben. Anders als in Einrichtungen für Erwachsene, in denen man diese direkt zu ihrer Meinung über die empfangene Leistung Befragung kann, ist dieses in sozialpädiatrischen Zentren, nicht so ohne weiteres möglich.

Methode. Die Forschungsgruppe Metrik nutz die Eltern als Stellvertreter der Kinder und Jugendliche. Diese werden mittels standardisierter Fragebögen über die empfangene Leistung bei Ihren Kindern und bezüglich des Verhaltens des Klinikpersonals ihnen gegenüber befragt. In 11 sozialpädiatrischen Zentren nutzten insgesamt 474 Eltern das standardisierte Instrument, das sowohl konkrete Erlebnisse als auch die Zufriedenheit und die subjektive Wichtigkeit erfasst. Die Ergebnisse werden in Beziehung gesetzt mit den vergleichbaren Befragungsresultaten von 8139 allgemeinpsychiatrischen Patienten aus 30 Abteilungen. Ergebnisse. Das Anspruchsverhalten der Eltern ist bei den Themen Gruppentherapie, Wahrung der Privatsphäre und beim Einbeziehen in das Geschehen der Einrichtung deutlich höher als bei den allgemeinpsychiatrischen Patienten. Bei der Zufriedenheitsmessung wird das Essen kritisiert, jedoch werden u. a. die Fragen zum Einbeziehen der eigenen Person in das Geschehen und die Aufklärung über Wirkung und Nebenwirkung der Medikamente deutlich positiver beurteilt. Auch bei objektiven Erlebnissen, wie die Anzahl der Einzelgespräche und Visiten berichten die Eltern deutlich häufiger von positiven Situationen. Schlussfolgerung. In sozialpädiatrischen Zentren kann aktives Qualitätsmanagement mittels Befragung der Eltern unterstützt werden und liefert mit einem vertretbaren Aufwand wertvoll Informationen für die weitere Verbesserung. 
DGSPJ-PO-6

Morbus Sanfilippo (MPS III) - frühe Erkennung attenuierter Formen

Arash-Kaps L.', Amraoui Y.', Reinke J.', Beck M.', Mengel E.'

'ZKJM der JoGu Mainz, Villa Metabolica, Mainz

Einleitung. Der Mangel an einem von vier Enzymen aus dem Abbauweg des Heparan-Sulfats führt zu MPS III Typ A, B, C oder D. Kennzeichnend für die Erkrankung ist im Kleinkindesalter auftretende unspezifische Verhaltensstörungen, Verlust psychomotorischer Fähigkeiten und Schlafstörungen. Patienten, die eine auffällige Fazies und frühe radiologische Knochenveränderungen haben, werden in der Regel nach sekundärem Verlust von Fähigkeiten diagnostiziert. Patienten ohne äußerliche Auffälligkeiten, Organomegalie oder frühen Skelettveränderungen werden hingegen primär nicht als Speichererkrankung gesehen. Material und Methoden. Wir beschreiben 6 Patienten, bei denen die Erkrankung einen attenuierten Verlauf zeigte.

Ergebnisse. Eine leichte bis mäßige Entwicklungs- und Verhaltensstörung war bei diesen Patienten zu beobachten. Die 10- bis 29 Jahre alten Patienten waren bei Diagnosealter 6-14 Jahre alt. 4 von 6 Patienten sind noch gehfähig, 2 zeigen eine fortgeschrittene Zerebralparese mit Tetraspastik. Keiner dieser Patienten hat eine auffällige Gesichtsmorphologie, eine Hepatosplenomegalie oder frühe skeletale Manifestation.

Schlussfolgerung. Im Unterschied zu Patienten, die eine primäre Entwicklungsstörung aufweisen, haben diese Patienten sekundäre Verluste ihrer Fähigkeiten im Sinne einer frühkindlichen Demenzerkrankung. Sie weisen keine typische Morphologie im Sinne einer Speichererkrankung. Die Diagnose wird häufig mehrere Jahre später als bei Patienten mit den klassischen Symptomen gestellt. Im Hinblick auf neue Therapieoptionen, die z. T. bereits über die präklinischen Phasen hinaus auch für klinische Studien zugelassen sind, sind eine frühe Erkennung der Patienten, sowie zentralisierte Untersuchungen des natürlichen Verlaufs im Rahmen von internationalen Studien von zunehmender Bedeutung.

\section{DGSPJ-PO-7}

Nehmen Kinderärzte eine interprofessionelle Beurteilung der sozialen Entwicklung des Kindes als qualitative Verbesserung der Vorsorgeuntersuchung U8 wahr?

Wygold T.', Wygold C.L. ${ }^{2}$, Warlich-Zach N. ${ }^{2}$

'Regio Kliniken $\mathrm{GmbH}$, Uetersen, ${ }^{2}$ Universität, Vechta

Fragestellung. Können Kinderärzte bei der Beurteilung der sozialen Entwicklung und der sozialen Fertigkeiten vierjähriger Kinder im Rahmen der Vorsorgeuntersuchung U8 durch eine andere Profession unterstützt werden?

Material und Methode. $n=9$ in einer eigener Praxis niedergelassene Kinderärzte und $n=8$ Erzieherinnen aus 3 Kindertagesstätten wurden mit Hilfe eines halbstrukturierten Interviews zu ihren Selbstkonzepten und Erwartungen an die jeweils andere Profession in Bezug auf die Fragestellung evaluiert.

Ergebnisse. Kinderärzte sind mit der Vorsorgeuntersuchung U8 bezüglich der Prüfung von sozialer Entwicklung und Sozialverhalten von Kindern zufrieden und erachten eine Unterstützung durch Erzieherinnen für nicht erforderlich. Andererseits sehen Erzieherinnen genau dies als sinnvoll und notwendig an. Seitens der niedergelassenen Kinderärzte werden Zeitaufwand, unzureichende fachliche Qualifikation von Erzieherinnen und die Gefahr der Pathologisierung von Kindern als Risiken einer zielführenden Zusammenarbeit angeführt. Die Erzieherinnen berichten über einen strukturierten fachlichen Austausch innerhalb ihres Teams und mit vielen verschiedenen Berufsgruppen, aber eben nicht mit Kinderärzten. Sie fühlen sich von diesen nicht wertgeschätzt. Grundsätzlich sind beide Berufsgruppen an einer bedarfsorientierten Kooperation interessiert, wobei unterschiedliche Auffassungen bestehen, wie diese konkret umgesetzt werden soll. Für einen fachlichen Austausch wird dem persönlichen Kontakt der Vorzug vor standardisierten Beurteilungsbögen gegeben.

Schlussfolgerung. Die Ergebnisse erklären das in der Literatur beschriebene hohe Scheiterpotenzial entsprechender Projekte. Die organisatorischen Hürden und fachlichen Vorbehalte zwischen den Berufsgruppen erschweren die Zusammenarbeit.

\section{DGSPJ-PO-8}

Sind modulare Schulungen nach dem ModuS-Konzept bei an Asthma erkrankten Kindern und ihren Familien wirksam?

Menrath I.', Ernst G. ${ }^{2}$, Staab D. ${ }^{3}$, Lange K. ${ }^{2}$, Thyen U.', Szczepanski R. ${ }^{4}$ 'Universität zu Lübeck, Klinik für Kinder- und Jugendmedizin, Lübeck, ${ }^{2}$ Medizinische Hochschule Hannover, Medizinische Psychologie, Hannover, ${ }^{3}$ Charité-Universitätsmedizin, Abteilung für Pädiatrische Pneumonologie und Immunologie, Berlin, ${ }^{4}$ Kinderhospital, Osnabrück

Fragestellung. Auf der Basis qualitätsgesicherter Schulungskonzepte ist ein krankheitsübergreifendes modulares Schulungsprogramm für chronisch kranke Kinder/Jugendliche und deren Familien (ModuS) entwickelt worden. Die Überprüfung der Wirksamkeit erfolgte an der häufigen Erkrankung Asthma. Hierzu wurde untersucht, ob sich die Schulungseffekte der ambulanten Asthmaschulungen nach Modus und nach dem gut evaluierten „konventionellen“ Schulungscurriculum unterscheiden.

Material und Methode. Mit Hilfe standardisierter Fragebögen wurden soziodemographische Daten, Schulungszufriedenheit, gesundheitsbezogene Lebensqualität (HRQoL), Krankheitsbelastung und krankheitsbezogenes Wissen vor und direkt nach den Schulungen sowie 6 Wochen nach Schulungsende erfasst.

Ergebnisse. Insgesamt nahmen an der Untersuchung 491 Kinder und Jugendliche bzw. deren Eltern teil. Sowohl die ModuS-Schulungen als auch die konventionellen Asthmaschulungen wurden von den Familien sehr gut bewertet. Es zeigten sich keine signifikanten Unterschiede in der Wirksamkeit beider Schulungsmodalitäten. Unabhängig von der Schulungsart kam es zu einer Steigerung der allgemeinen HRQoL im Kinderurteil, der Lebenszufriedenheit der Kinder im Elternurteil und des krankheitsspezifischen Wissens. Gleichzeitig nahm die Krankheitsbelastung der Eltern ab.

Schlussfolgerung. Modularisierte Patientenschulungen zeigen bei der Erkrankung Asthma die gleiche Wirksamkeit wie "konventionelle“ Schulungen. Darauf aufbauend wird in Begleitstudien überprüft, ob Schulungen nach ModuS mit ihren krankheitsübergreifenden und krankheitsspezifischen Modulen auch für andere, seltenere Erkrankungen geeignet sind.

\section{DGSPJ-PO-9}

Unterstützungsbedarf bei der Betreuung von Migrantenkindern in Sozialpädiatrischen Zentren?

Soykök S. ${ }^{1}$, Mall V.

'Lehrstuhl für Sozialpädiatrie, Kinderzentrum, München

Fragestellung. In Zusammenhang mit der sozialpädiatrischen Versorgung von Kindern und Jugendlichen mit Migrationshintergrund ergeben sich Herausforderungen für die Mitarbeiter. Im Rahmen des 2. Forums für Sozialpädiatrie 2013 wurden Workshopteilnehmer dazu befragt, welche konkrete Unterstützung ihnen die Arbeit mit Migrantenkindern erleichtern würde.

Material und Methode. Durchgeführt wurde eine anonyme, offene („Welche Unterstützung brauche ich in meiner Arbeit mit Migrantenkindern?"), schriftliche Kurzbefragung mit den Workshopteilnehmern. Mehrfachnennungen waren möglich. Insgesamt wurden 33 Nennungen ausgezählt. Die Antworten wurden auf Karten festgehalten. Alle Workshopteilnehmer $(n=12)$ haben an der Befragung teilgenommen. 
Ergebnisse. Die Nennungen der Teilnehmer wurden in 5 Cluster zusammengefasst: Cluster 1 „Auflösung der Kulturbarrieren der Familien“ (9,1\%), Cluster 2 „Auflösung der Kulturbarriere bei den Mitarbeitern“ $(30,3 \%)$, Cluster 3 „Abhilfe bei der Informationsbarriere der Eltern“ (3\%), Cluster 4 "Abhilfe bei der Informationsbarriere der Mitarbeitern“ (30,3\%), Cluster 5 „Auflösung der Sprachbarriere“ (27,3\%).

Schlussfolgerung. Neben struktureller Unterstützung hinsichtlich der Lösung der Sprachbarriere durch geeignete Dolmetscher besteht ein Bedarf an Weiterbildungen in Kulturkenntnissen und an spezifischen Informationen zur Versorgung von Migrantenkindern. Perspektivisch soll diese Erhebung die Grundlage für eine standardisierte Datenerhebung für SPZs in Deutschland werden, die einen Überblick über die strukturellen Bedürfnisse von Mitarbeitern in der Versorgung von Kindern- und Familien mit Migrationshintergrund in sozialpädiatrischen Zentren geben soll.

\section{DGSPJ-PO-10}

Verbesserung von Zugangswegen zu Asthmaschulungen für Familien mit Migrationsbiographie und/oder sozialer Benachteiligung

Thomsen E.M.', Lehmann C. ${ }^{2}$, Mönkemöller K. ${ }^{3}$, Eberding A. ${ }^{4}$, Müller-Godeffroy E.', Menrath I.', Szczepanski R. ${ }^{5}$, Thyen U.'

'Universität zu Lübeck, Klinik für Kinder- und Jugendmedizin, Lübeck, ${ }^{2}$ Charité Berlin, Pädiatrische Pneumologie und Immunologie, Berlin, ${ }^{3}$ Kliniken der Stadt Köln, Kinderklinik-Kinderrheumatologie, Köln, ${ }^{4}$ Christliches Kinderhospital, Osnabrück, ${ }^{5}$ Kinderhospital, Osnabrück

Fragestellung. Da Familien mit Migrationsbiographie (MB) und/oder sozialer Benachteiligung (SB) bislang in geringerem Ausmaß an $\mathrm{Pa}$ tientenschulungen teilnehmen, wurden mit Hilfe des ModuS-Projekts Maßnahmen zur Erhöhung der Teilnahmeraten ermittelt. Im Rahmen der durchgeführten Asthmaschulungen soll überprüft werden, welche Maßnahmen eine Erhöhung der Teilnahmerate bewirken, welche sich als dauerhaft wirksam und durchführbar erweisen.

Material und Methode. Acht Schulungszentren erfassten über einen Zeitraum von 15 Monaten mit Hilfe eines selbstentwickelten Fragebogens alle Interessenten für eine Asthmaschulung. Dabei wurden MB und SB dokumentiert und die Einschätzung bei Teilnahme durch einen standardisierten Fragebogen überprüft. Bei Teilnahmebarrieren wurden bedarfsgerechte Maßnahmen zur Problemlösung und Teilnahmesicherung ergriffen und ebenso wie Teilnahme und Nichtteilnahme dokumentiert. Zur Plausibilitätsprüfung der Ergebnisse wurde ein Workshop zu diesem Thema mit den teilnehmenden Zentren durchgeführt.

Ergebnisse. Im Vergleich zur durchschnittlichen Teilnahmerate erwiesen sich insbesondere der enge Kontakt zum Kinderarzt, die Klärung der Finanzierung und ein Dolmetscher als wirkungsvoll. Jedoch wurden diese Maßnahmen vergleichsweise selten angewandt. Im Workshop wurden hierfür organisatorische und finanzielle Gründe genannt. Eine verbesserte Überzeugung der zuweisenden Ärzte von der Erreichbarkeit und dem Nutzen der Patientenschulungen könne ebenfalls einen großen Beitrag zur Erhöhung der Teilnahmerate leisten.

Schlussfolgerung. Die Einbettung der erfolgreich evaluierten Maßnahmen in bestehende Strukturen stellt neben der Motivation der Zuweiser einen zentralen Bestandteil zur Verbesserung der Zugangswege zu Patientenschulungen dar.

\section{DGSPJ-PO-11}

Effekte eines modularen Schulungsprogramms (ModuS) bei Kindern und Jugendlichen mit chronischen Erkrankungen sowie deren Familien

Degner M. ', Menrath I.', Wagner P. ${ }^{2}$, Gebert N. ${ }^{3}$, Szczepanski R. ${ }^{4}$, Thyen U. ${ }^{1}$

'Universität zu Lübeck, Klinik für Kinder- und Jugendmedizin, Lübeck, ${ }^{2}$ Charité-Campus Virchow-Klinikum, Berlin, ${ }^{3}$ Medizinische Hochschule, Hannover, ${ }^{4}$ Kinderhospital, Osnabrück

Fragestellung. Ein krankheitsübergreifendes, modulares Schulungsprogramm (ModuS) für chronisch kranke Kinder, Jugendliche und deren Familien zeigte bei Asthmatikern eine qualitätsgesicherte Asthmaschulung vergleichbare Wirksamkeit. Nachfolgend wurde untersucht, ob das neue Konzept bei weiteren chronischen Erkrankungen (Bauchschmerz, chronisch-entzündliche Darmerkrankungen, zystische Fibrose, Harninkontinenz, nephrotisches Syndrom, primäre Immundefekte, Phenylketonurie) ähnlich wirksam ist und welche Effekte es dort hat.

Material und Methoden. Mittels standardisierter Fragebögen wurden soziodemografische Daten, gesundheitsbezogene Lebensqualität, Lebenszufriedenheit, Schulungszufriedenheit und krankheitsspezifisches Wissen vor, direkt nach und sechs Wochen nach der Schulung beurteilt $(n=269)$. Zudem wurden die Schulungsteilnehmer in elf leitfadengestützten Fokusgruppeninterviews befragt, die aufgezeichnet, transkribiert und mittels qualitativer Inhaltsanalyse nach Mayring ausgewertet wurden.

Ergebnisse. Die quantitative Befragung zeigte positive Veränderungen der Zielvariablen sowie vergleichbare positive Schulungseffekte bei Asthma und den weiteren Indikationen. Die qualitative Befragung bestätigte die Effekte und wies zusätzlich Verbesserungen des Krankheitsmanagements, der Symptomatik sowie psychologischer und emotionaler Parameter nach. Die Befragten zeigten sich unter Hervorhebung typischer Merkmale modularer Schulungen sehr zufrieden mit dem neuen Schulungskonzept.

Diskussion. Die vergleichbare, positive Wirksamkeit der Schulung bei Asthma und den weiteren Indikationen zeigt, dass sie die Anforderungen an standardisierte Schulungsprogramme erfüllt. Daher sollte sie in die Behandlungsleitlinien chronischer Erkrankungen integriert werden.

\section{DGSPJ-PO-12}

Elemente multimodaler Behandlung der ADHS - Erwartungen und Einstellungen von Patienten zum Thema Coaching

Weidhaas M.', Schepler P.', Greven P.,2

${ }^{1} \mathrm{H}: G$ Hochschule für Gesundheit und Sport, Fachbereich Psychologie, Berlin, ${ }^{2}$ Institut für Kinder- und Jugendpsychiatrie, Psychotherapie und Soziale Pädiatrie, Berlin

Einleitung. Die multimodale Behandlung von ADHS im Kindes-, Jugend- und Erwachsenenalter stellt alle Beteiligten vor vielfältige Herausforderungen. Vor diesem Hintergrund wurde ein hochschulbasiertes Weiterbildungsprogramm zum ADHS-Coach entwickelt, das sich an Angehörige medizinischer, psychologischer, pädagogischer oder psychosozialer Berufe richtet, die in ihrer Tätigkeit mit Betroffenen umgehen. Es soll auf solider wissenschaftlicher und klinischer Basis eine fundierte individuelle psychosoziale Beratung, Unterstützung, Förderung und Begleitung Betroffener ermöglichen.

Fragestellung. Von Interesse ist in diesem Zusammenhang, wie eine solche zusätzliche, nicht klinisch oder therapeutisch, sondern vielmehr psychosozial ausgerichtete Unterstützung von den Betroffenen im Kontext ihrer multimodalen Behandlung wahrgenommen wird.

Methoden. Es erfolgte eine Fragebogenerhebung bei Betroffenen zur Zufriedenheit mit ihrer laufenden multimodalen ADHS-Behandlung. Erhoben wurden u. a. Daten zu verschiedenen Elementen der multimodalen Behandlung, zur Komorbidität, zum Stellenwert von Coaching in der Behandlung und zu dafür wünschenswerten Inhalten. 
Ergebnisse. Erste Ergebnisse der noch nicht abgeschlossenen Untersuchung deuten auf durchaus positive Einstellungen bzgl. Coaching im Rahmen der Behandlung. Das Angebot einer qualifizierten psychosozialen Unterstützung wird als sinnvolle und auch spezifische Ergänzung in der ADHS-Behandlung wahrgenommen.

Diskussion. Das Programm wird weiterhin wissenschaftlich begleitet und evaluiert werden. Neben einer Erhebung bei ADHS-Behandlern sollen im Verlauf auch Absolventen des Programms zu ihren Erfahrungen einbezogen werden.

\section{DGSPJ-P0-13 \\ Lernspiele als effektive Nachschulungsmaßnahme bei Asthma bronchiale?}

Thiele M.', Steiß J.-O. ${ }^{2}$

'outermedia $\mathrm{GmbH}$, Berlin, ${ }^{2}$ Universitätsklinikum Gießen und Marburg $\mathrm{GmbH}$, Zentrum für Kinderheilkunde und Jugendmedizin-Abt.: Allgemeinpädiatrie und Neonatologie, Gießen

Asthmaschulungen sind wichtiger Bestandteil der evidenzbasierten Asthmatherapie und gehören in ein langfristiges Behandlungskonzept. In Deutschland werden 20.000 Kinder und Jugendliche pro Jahr geschult. Nach den Qualitätsmanagement-Vorgaben der AG Asthmaschulung und der Nationalen Versorgungsleitlinie ist die Durchführung einer Nachschulung sechs bis zwölf Monate nach der Basisschulung sinnvoll und notwendig. Allerdings ist der Anteil der Nachschulungsteilnehmer vergleichsweise gering. Das internetbasierte und pharmaunabhängige Lernspiel Luftikids kann hier Abhilfe schaffen:

Luftikids vermittelt Kindern innerhalb von vier Wochen wesentliche Informationen zum Verständnis von und Umgang mit Asthma. Ein asthmakranker Spielcharakter steht dem Nutzer zur Seite. Das erhöht den Grad der Identifikation und damit den Lerneffekt. Gemeinsam mit ihm sammelt der Nutzer Informationen, löst Minispiele und besiegt schließlich einen Vulkan.

Auch das Asthma des Kindes kann dadurch besser kontrolliert werden. Die von der Universitätsklinik Gießen (PD Dr. J.-O. Steiß) evaluierten Daten, die vom Kinderspital der Universitätsklinik Zürich (PD Dr. A Möller) ausgewertet wurden, lassen positive Erwartungen zu. Demnach führt das interaktive Programm zu einer verminderten Symptomatik, besserem Asthmawissen, häufigerer Beschwerdefreiheit und verminderten Gebrauch von Bedarfsmedikamenten sowie zu weniger Schulfehltagen und Notfallkonsultationen. Diese Effekte sind zurückzuführen auf die Art der niedrigsschwelligen Vermittlung, auf den dadurch erhöhten Lernantrieb des Kindes und auf die zeitliche und räumliche Unabhängigkeit.

Über Wirkung und Nutzen des Lernspiels und die Möglichkeit der flächendeckenden Anwendung soll referiert und anschließend diskutiert werden.

\section{DGSPJ-PO-14}

Das Konzept "Ärztin an der Schule“: Intensivierung der schulärztlichen Versorgung zur Verbesserung der gesundheitlichen Chancengleichheit in den Münchner Mittelschulen

Franz A. ', Reincke M. ${ }^{\text {' }}$

'Referat für Gesundheit und Umwelt, Landeshauptstadt München, Gesundheitsvorsorge für Kinder und Jugendliche, München

Kinder und Jugendliche in den Mittel-(früher Haupt-)Schulen sind eine vorrangige Zielgruppe im Bereich der kommunalen Gesundheitsvorsorge. Diese Schülerinnen und Schüler werden vom bestehenden Versorgungsangebot des Gesundheitswesens oft schwer erreicht, verfügen häufig über nur geringe Bildungs- und andere Ressourcen und haben gleichzeitig mehr gesundheitliche Probleme als Gleichaltrige. Die Gesundheitsvorsorge für Kinder und Jugendliche des Referates für Gesundheit und Umwelt der Landeshauptstadt München begegnete dem da- durch begründeten hohen Bedarf an nachhaltiger Gesundheitsvorsorge für diese Zielgruppe mit der Entwicklung des Konzeptes „Ärztin an der Schule“. Das Konzept beinhaltet eine wöchentliche schulärztliche Sprechstunde vor Ort, ein Angebot an Klassenuntersuchungen und Gesundheitsunterricht sowie eine enge Vernetzung mit anderen Beteiligten an der Schule, vor allem mit Lehrern, Eltern, Schulsozialarbeit und schulpsychologischen Diensten. Um potenzielle und vorhandene gesundheitliche Beeinträchtigungen rechtzeitig erkennen und beseitigen zu können, ist zudem eine intensive Zusammenarbeit mit niedergelassenen Ärzten und anderen fachspezifischen Diensten in der Umgebung notwendig. Neben der direkten Beeinflussung der Gesundheit einzelner Schüler und Schülerinnen bietet das Konzept durch den Zugang zu epidemiologischen Daten dieser Bevölkerungsgruppe auch vielfältige Möglichkeiten für die Entwicklung weiterer passgerechter Präventionsangebote zur Verbesserung der gesundheitlichen Chancengleichheit.

\section{DGSPJ-PO-15}

Wie riskant ist mütterliche Erschöpfung für das Baby in einer No-risk-Population? Psychische Belastung bei gesunden erstgebärenden Mittel- bis Oberschichtseltern und Auswirkungen auf die Eltern-Kind-Interaktion in einem Frühpräventionsprogramm

Brandi D.

"„Von Anfang an", Hamburg

2011 wurden die präventiven Eltern-Säuglings-Beratungen in der Hamburger Beratungsstelle „Von Anfang an. Erste Hilfe und Beratung für Eltern mit Kindern von null bis drei Jahren" durch das Institut für Medizinische Psychologie des Universitätskrankenhaus Hamburg Eppendorf evaluiert. Weder Eltern noch Kinder kamen aus Risikogruppen. Alle Kinder zeigten Anpassungsstörungen. Die Schwere der mütterlichen psychischen Belastung war dennoch überdurchschnittlich hoch. Nach endgültiger Auswertung der Zahlen sollen diese Ergebnisse abschließend vorgestellt und diskutiert werden im Hinblick auf Stressoren, die der Entwicklung einer intuitiven elterlichen Feinfühligkeit entgegenstehen. Darüber hinaus wird diskutiert ob die Folgen für die Affektregulierung des Babys, wenn die Feinzeichen nicht richtig interpretiert werden, bei kurzfristiger Erholung der Mütter reversibel sind. Oder verfügen diese Familien über andere Kompensationsversuche, die die Entwicklung der Interaktion- und Mentalisierungsfähigkeit verhindern?

\section{DGSPJ-PO-16}

\section{Diagnostische Hürden bei der juvenilen Huntington-Erkrankung} (HD)

\section{Thiels C. ${ }^{1}$, Saft $C .^{2}$, Hoffmann R. ${ }^{2}$, Lücke T. ${ }^{1}$}

${ }^{1}$ Universitätsklinik für Kinder- und Jugendmedizin der Ruhr-Universität Bochum, Neuropädiatrie, Bochum, ${ }^{2}$ Universitätsklinik für Neurologie der Ruhr-Universität Bochum, Neurologie, Bochum

Einleitung. Beim M. Huntington (HD, MIM 14310o, Chrom. 4p16.3, autosom-dom) erkranken stat. 50\% der Nachkommen. Aufgrund des schweren Verlaufs ist die Belastung für HD-Familien hoch und Verdrängung häufig. Das Gen-Diagnostik-Gesetz lässt keine Gen-Diagnostik bei frühen, unspezifischen Symptomen zu.

\section{Kasuistiken.}

1) Großvater, Großonkel väterl. und Vater HD-Patienten. Pat, m: motorische Auffälligkeiten mit 1,5 LJ, mit 3,5 LJ: muskuläre Hypotonie, Gangstörung. Mit 9. LJ Huntingtin-Gen: 8o CAG-Repeats. 12-jährig schwere Gangstörung, Rigidität, kognitiver Abbau und Dystrophie; Therapie: Pramipexol und Seroquel.

2) Vater HD-Patient; Pat, w: FG 35. SSW, 9. LJ: progrediente Störung in Fein- und Grobmotorik, Schulprobleme. Vorstellung 13-jährig: Hypomimie und -kinesie, Dysarthrie, Tremor. Huntingtin-Gen: 73 CAGRepeats. Therapie (17-jährig): Pramipexol, Seroquel, Valproat, Lithium, Venlafaxin. 
3) Vater HD-Patient, Suizid 41-jährig; älteste Schwester HD-Pat. (Beginn 15 LJ). Pat. 13-jährig: Leistungsabbau, depressive Verstimmung. Vorstellung auf Druck der Schule. Klinik: depressiv, diskreter feinschlägiger Tremor. Später Bradykinesie beim Fingertapping. Huntingtin-Gen: 48 CAG-Repeats. Therapie: Psychotherapie. 15-jährig: keine Pharmaka. 4) Vater HD. Pat: FG 37. SSW, KK: progrediente motorische und Sprachprobleme, häufiges Stolpern, Lernschwierigkeiten. 9-jährig Analyse Huntingtin-Gen: 81 CAG-Repeats; Therapie (17-jährig): Pramipexol. Schlussfolgerung. Diagnostik bzgl. HD-Erkrankung erfordert Beachtung der familiären Situation/mögliche Antizipation bei Vererbung sowie die Beachtung des Gen-Diagnostik-Gesetzes. Juvenile HD Patienten profitieren deutlich von einer symptomatischen Pharmakotherapie und ggf. Psychotherapie.

\section{DGSPJ-PO-17}

\section{Zugang zur stationären Rehabilitation - Möglichkeiten und Gren-} zen

\section{Berghem S.'}

'Ostseestrandklinik Klaus Störtebeker, Rehabilitationsklinik für Kinder und Jugendliche, Kölpinsee/Usedom

Fragestellung. Die stationäre Rehabilitation chronisch kranker Kinder und Jugendlicher ist ein wesentlicher Beitrag zur gesunden Entwicklung der Bevölkerung. Die Effektivität dieser Behandlungsart wurde vielfach nachgewiesen. Obwohl chronische Krankheiten einen unverändert hohen Stellenwert in der Behandlung einnehmen, ist die Zahl der beantragten und der durchgeführten Rehabilitationsmaßnahmen trotz gleichbleibender Rehabilitationsbedürftigkeit drastisch rückläufig. Der demographische Wandel ist hierfür keine hinreichende Erklärung. Material und Methode. Durch Gespräche mit niedergelassenen Kinderund Jugendärzten, Ärzten in der stationären Rehabilitation, Patienten und Prozessbeteiligten der Kostenträger wurde ein umfassender Überblick über die aktuelle Situation erzielt.

Ergebnisse. Weitere Gründe sind neben dem demographischen Wandel einerseits unzureichende Kenntnisse über Indikationen und $\mathrm{Zu}$ gangswege aber auch Möglichkeiten und Grenzen der Rehabilitation, andererseits Frustrationen durch wiederholt abgelehnte Rehabilitationsanträge trotz nachgewiesener medizinischer Notwendigkeit. Für einen Rehabilitationsantrag, der auch bewilligt wird, ist eine profunde Kenntnis der Zusammenhänge erforderlich. In dem Vortrag werden hilfreiche Empfehlungen für einen erfolgreichen Rehabilitationsantrag gegeben.

Schlussfolgerung. Die rapide sinkende Zahl der durchgeführten stationären Rehabilitationsmaßnahmen für Kinder und Jugendliche mit chronischen Erkrankungen bedroht die Gesundheit der Betroffenen. Durch vertiefte Kenntnisse kann den betroffenen Patienten in vielen Fällen zu einer Rehabilitationsmaßnahme verholfen und so zu ihrer Gesundung beigetragen werden.
DGSPJ-PO-18

Der Herzinfarkt beginnt im Kindesalter! Profitieren auch adipöse Kinder noch von einer Gewichtsreduktion bzw. -normalisierung bis zum Erwachsenenalter hinsichtlich ihres kardiometabolischen Risikos?

Eyermann R. $^{1}$

'Dr. Richard Eyermann, Kinder- und Jugendmedizin, Kinderkardiologie, Sportmedizin, München

Einleitung. Juvenile Adipositas ist Prädiktor für Dm2 und erhöhte kardiovaskuläre Morbidität. Meist werden aus übergewichtigen Kindern dicke Erwachsene.

Methoden. Aktuelle Studiendaten aus internationalen multicentrischen Kohorten-Langzeitbeobachtungen von 6328 Kindern über $>20$ J. (Einschlussalter: 3-18 J., 774 übergewichtig und adipös, 5554 normales KG) belegen eine Persistenz von Übergewicht ins Erwachsenenalter von 65\% und Neuentwicklung der Adipositas als junger Erwachsener (normalgewichtig als Kind) von 15\%, aber auch eine Gewichtsnormalisierung dicker Kinder bis zum Erwachsenenalter von 35\%.

Ergebnisse. Erwartungsgemäß haben die Konstellationen Adipositas als Kind/Adipositas als Erwachsener aber auch Normalgewicht als Kind/ Adipositas als Erwachsener ein mehrfach erhöhtes kardiometabolisches Risiko. Übergewicht und Adipositas waren signifikante Risikofaktoren für die Entwicklung von v. a. Dm2, Hypertonie, hohen TG, niedrigem HDL-C im Erwachsenenalter. Es gab kaum geschlechtsspezifische Unterschiede. Risikofaktor LDL-C u. IMT waren bei Männern mit Übergewicht und Adipositas assoziiert. Überraschend - und erstmals belegt - haben aber dicke Kinder mit Gewichtsnormalisierung bis zum Erwachsenenalter (35\% in Kohorten-Langzeitstudien) ein Risiko wie stets Normalgewichtige (Akademie Finnland et al.).

Schlussfolgerung. Übergewichtige oder adipöse Kinder mit Persistenz der Adipositas ins Erwachsenenalter haben ein erhöhtes Risiko für Dm2, Hypertension, Dyslipidämie und Atherosklerose der Carotiden. Durch Gewichtsnormalisierung kann ihr erhöhtes kardiometabolisches Risiko komplett normalisiert werden. Einmal existente Risikofaktoren persistieren nicht als „metabolisches Gedächtnis“ ins Erwachsenenalter. Die Motivation zur Gewichtsabnahme und Langzeitbegleitung betroffener Kinder und Jugendlicher ist daher wichtige ärztliche Aufgabe. 


\section{Abstracts der 51. Herbsttagung der Deutschen Gesellschaft für Kinderchirurgie (DGKCH)}

\section{Vorträge}

Freitag, 13.09.2013

\section{Kindersicherheit und Unfallprävention}

\author{
DGKCH-SY-KU-1 \\ Prävention von Verletzungen bei Säuglingen und Kleinkindern - \\ was ist evidenzbasiert?

\section{Albrecht M. ${ }^{1}$ \\ 'Runder Tisch Prävention von Kinderunfällen Dortmund, Dortmund}

In den letzen Jahren sind die Methoden und Erkenntnisse der evidenzbasierten Medizin auf Wissenschaft und Praxis der Prävention - speziell auch der Prävention von Verletzungen - übertragen worden.

Grundlage des Vortrags sind die Ergebnisse einer Cochrane-Studie von Kendrick et al. [Kendrick D, Young B, Mason-Jones AJ, Ilyas N, Achana FA, Cooper NJ, Hubbard SJ, Sutton AJ, Smith S, Wynn P, Mulvaney; C, Watson MC, Coupland C.:Homesafetyeducationandprovisionofsafetyequipmentforinjuryprevention. (Review) Cochrane Database of Systematic Reviews 2012, Issue 9. sowie der WHO Bericht "European report on child accident prevention" (2008)]

Für die häufigsten Verletzungen in der Altersgruppe 0-5 Jahre wie Stürze, thermische Verletzungen, Vergiftungen, Erstickung, Ertrinken, Wunden aller Art liegen gute Grundlagen vor, welche Interventionen im Haushalt und Kita gut wirksam sind. In dieser Altersgruppe laufen die meisten Interventionen über die Eltern. Daher wird auch die Cochrane-Studie von Kendrick et al. einbezogen, die untersucht, welche Eltern-Programme sich als wirksam erwiesen haben, um die Rat von Verletzungen bei kleinen Kindern zu senken [Kendrick D, Mulvaney CA, Ye L, Stevens T, Mytton JA, Stewart-Brown S: Parenting interventions for the prevention of unintentional injuries in childhood (Review) The Cochrane Library 2013, Issue 3].

In der Diskussion wird Fragen der Methodik der Cochrane-Reviews und die Übertragbarkeit eingegangen.

\section{DGKCH-SY-KU-2}

Rolle der Kinderärzte in Klinik und Praxis in der Unfallprävention

\section{Böhmann J.' \\ 'Klinikum Delmenhorst, Schierbrok}

Fragestellung. Welche Rolle spielen Kinderärzte in Praxis und Klinik in der Prävention von Verletzungen im Kindesalter? Wie kann die herausragende Bedeutung von Kinder- und Jugendärzten vor allem für Familien mit kleinen Kindern für eine wirksamere Beratung und Vorbeugung intensiver genutzt werden?

Methoden. Verletzungen durch Unfälle und Gewalttaten sind neben dem großen Leid für Betroffene und Angehörige der häufigste Grund für eine stationäre Behandlung, die häufigste Todesursache und haben oft lebenslange Folgen, wie am Beispiel von Verbrennungen leicht darstellbar ist. Im Gegensatz zu vielen anderen Gesundheitsstörungen spielen Unfälle aber in der pädiatrischen Fachöffentlichkeit keine entsprechende Rolle. Die Gründe dafür müssen ebenso diskutiert werden, wie auch die oft mangelhafte Einbindung bzw. Beteiligung von Kinderärzten in Aktivitäten und Projekten zur Prävention, wie es aktuell am
Prozess zur Neuausrichtung des Kinderschutzes deutlich wurde. Die Gründe für eine mangelnde Kooperation von Jugend- und Familienhilfe mit Kinderärzten ist ebenso zu diskutieren. Sowohl strukturelle Besonderheiten des deutschen Gesundheitswesens als auch berufsständische Hindernisse müssen erörtert werden.

Schlussfolgerung. Am Beispiel einer Kommune werden konkrete Alternativen und Lösungsmöglichkeiten aufgezeigt. Die überragende Bedeutung kommunaler Ansätze zur Gesundheitsförderung und Prävention unter Beteiligung von Kinderärzten aber auch anderen Berufsgruppen wird dargestellt.

\section{DGKCH-SY-KU-3 \\ Wie können Pädiater junge Eltern für die Unfallprävention motivieren? Ellsäßer G. ${ }^{\text {? }}$}

'Landesamt für Umwelt, Gesundheit und Verbraucherschutz, Gesundheit, Zossen

Ziel dieses Beitrags ist es, Kinder- und Jugendärzte zu motivieren, Eltern im Rahmen von Vorsorgeuntersuchungen eine präventive Unfallberatung anzubieten. Diese Beratung sollte in einem persönlichen Gespräch stattfinden und die altersbezogenen Unfallschwerpunkte gezielt berücksichtigen. Epidemiologische Erhebungen zeigen, dass Säuglinge und Kleinkinder am stärksten gefährdet und schutzbedürftig sind. Bei ihnen dominieren Verletzungen durch Unfälle im häuslichen Bereich, insbesondere durch Stürze, thermische Verletzungen und Vergiftungen. Schulkinder dagegen erleiden Unfälle, wenn sie draußen spielen, Sport treiben oder als Fahrradfahrer unterwegs sind. Nationale und internationale Studien weisen darauf hin, dass die Lebensumwelt, die familiäre Situation (soziale Lage, Migrationsstatus, elterliche Fürsorge) und kindbezogene Merkmale (Geschlecht, Alter, Hyperaktivität, Aggressivität) bedeutsame Risikofaktoren bei Unfällen im Kindesalter sind. Mit diesem Wissen und den neuen Merkblätter zur Unfallprävention zu den altersspezifischen Unfallschwerpunkten ist der Pädiater in der Lage, eine gezielte Elternberatung vorzunehmen und geeignete $\mathrm{Si}$ cherheitsmaßnahmen zu empfehlen.

\section{Gastroösophagealer Reflux}

\section{DGKCH-GÖR-4}

Zirkuläre und nichtzirkuläre Fundoplicatio - zweigleisiges operatives Anti-Reflux-Konzept

Schnekenburger F.', Bauck M. ${ }^{\text {? }}$

'Klinikum Kassel, Klinik für Kinderchirurgie, Kassel

Fragestellung. Kinder und Jugendliche mit einem gastroösophagealen Reflux (GÖR) haben meist eine wesentlichen Beeinträchtigung des Zentralnervensystems. Dabei besteht sehr oft eine (teilweise) aufgehobene orale Ernährbarkeit. Um diese zu berücksichtigen besteht in unserer Klinik ein zweigleisiges operatives Behandlungskonzept. Wir wenden sowohl eine zirkuläre (Nissen) als auch eine nicht zirkuläre (Thal) Fundoplicatio an, um die Vorteile beider Methoden differenziert einzusetzen.

Material und Methode. Zeitraum: 2008 bis 2012. Patienten: 19 (Altersdurchschnitt: 9 8/12 Jahre), alle mit syndromaler oder posthypoxischer Schädigung des Zentralnervensystems, in 11 Fällen vorbestehend eine Gastrostomie wegen aufgehobener oder eingeschränkter oraler Ernähr- 
barkeit. Operationen: 20 Fundoplicationes, 12-mal nach Thal, 8-mal nach Nissen, jeweils mit Hiatoplastik. 14 Eingriffe laparoskopisch, 4 primär offen, 2 umgestiegen.

Ergebnisse. 17-mal sehr gut (kein Reflux mehr und Erhalt der oralen Ernährbarkeit, wenn gewünscht). 1-mal kein Reflux mehr, aber unbefriedigende orale Ernährbarkeit bei rel. enger Manschette (Nissen), 1-mal Rezidivreflux bei chronischem mechanischem Subileus, 1-mal Leck an der Gastrostomie 17 Tage postoperativ mit foudroyanter letaler Peritonitis.

Diskussion. Patienten mit noch (teilweise) erhaltener Schluckfunktion soll die orale Ernähbarkeit sowie die Möglichkeit des Aufstoßens unbedingt erhalten bleiben; diesbezüglich bietet die nicht zirkuläre ThalFundoplicatio Vorteile. Die Nissen-Methode mit noch zuverlässigerer antirefluxiver Funktion kann bevorzugt bei Patienten mit vollständiger gastrostomaler Ernährung angewendet werden. Da bis auf 1 Fall unsere Komplikationen nicht der Art der Fundoplicatio anzulasten sind, können wir dieses zweigleisige Konzept empfehlen.

\section{Vesikoureteraler Reflux (VUR) und Hydronephrose}

\section{DGKCH-SY-VU-2}

\section{Jahre Erfahrung mit der MR-Urographie im Kindesalter}

\section{Rohrschneider W.K. ${ }^{1}$ \\ 'St.-Annastiftskrankenhaus, Kinderradiologie, Ludwigshafen}

Einleitung. Angeborene Harnwegsfehlbildungen werden oft im Ultraschall durch eine Aufweitung der Harnwege entdeckt, die Ausdruck eines gestörten Harntransportes sein kann, aber nicht muss. Aufgaben der bildgebenden Diagnostik sind zum einen die exakte Darstellung der pathomorphologischen Situation, (traditionell mittels Ultraschall und Ausscheidungsurographie), zum anderen die Ermittlung funktioneller Parameter, (traditionell mittels Szintigraphie).

Methoden. Ziel dieses Vortrages ist die Darstellung eines alternativen MRT-Verfahrens, das neben der übersichtlichen und detaillierten morphologischen Darstellung der Harnwege die zuverlässige Bestimmung von seitengetrennter Nierenfunktion sowie Harnabfluss erlaubt. Die Methode beinhaltet die Kombination eines 3 D-Bildes des Harntraktes mit einer funktionellen post-KM-Diagnostik und zusätzlichen anatomisch exakten multiplanaren Dünnschichten. Nach ihrer technischen Entwicklung wurde sie zunächst im Tiermodell und danach in klinischen Studien getestet, mittlerweile hat sie in die Routine Einzug gehalten. Es werden Situationen aufgezeigt, in denen dieses MRT-Verfahren besondere Vorteile verspricht - wie komplizierte Doppelnieren, ektope Nieren, komplexe, mit herkömmlichen Verfahren nicht zu klärende Pathomorphologie, diskrepante Befunde verschiedener konventioneller Verfahren, perioperative Situation. Darüber hinaus können assoziierte Fehlbildungen anderer Organe durch die Kombination mit Standard- Sequenzen oder einer MRAngiographie erfasst werden.

Schlussfolgerung. Die statisch-dynamische MR-Urographie erlaubt die komplexe bildgebende Diagnostik angeborener Nieren- und Harnwegsfehlbildungen. Neben der fehlenden Strahlenbelastung ist als einzigartiger Vorteil dieser Methode die Ermöglichung einer exakten morphologisch-funktionellen Korrelation hervorzuheben.

\section{DGKCH-SY-VU-3}

Vesikoureteraler Reflux - wie gehen wir mit den neuen Leitlinien um?

Beetz R. ${ }^{1}$

'Universitätsmedizin der Johannes Gutenberg-Universität, Pädiatrische Nephrologie, Mainz

Einleitung. In jüngster Zeit wurden von verschiedenen nationalen und internationalen Gesellschaften neue Leitlinien zur Diagnostik und Therapie von Harnwegsinfektionen (HWI) und vesikoureteralem Reflux (VUR) publiziert. Neben der American Academy of Pediatrics (AAP) und der American Urological Association (AUA) brachten die
European Association of Urology (EAU) und eine italienische Arbeitsgruppe vielbeachtete Guidelines heraus.

Ergebnisse. Nicht zuletzt wegen teils fehlender Evidenzgrundlage zeigen die Strategien in manchen Punkten keine Übereinstimmung. Dennoch zeichnet sich ein Trend zu einer einheitlicheren Konzeption ab. Paradigmenwechsel finden sich in der Einschätzung des Stellenwerts der Sonographie, in der Indikationsstellung zur Refluxdiagnostik nach Pyelonephritis, in der Wertung einer antibakteriellen Infektionsprophylaxe und im Spektrum der operativen Korrekturoptionen. Klar erkennbar ist das Bemühen um eine individualisierte, risiko-adaptierte Diagnostik und Therapie. Als Kriterien für die differenzierte Therapieentscheidung gelten heute nicht nur der Refluxgrad, sondern auch das Alter, das Geschlecht, der Nachweis dysplastischer oder pyelonephritischer Nierenparenchymdefekte, das Vorhandensein von Blasenfunktionsstörungen und die klinische Symptomatik von HWI.

Schlussfolgerung. Neue AWMF-Leitlinien zur Diagnostik, Therapie und Prophylaxe kindlicher HWI und zum VUR stehen in Deutschland aus. Der Wert der kürzlich erschienenen internationalen Guidelines ist dafür in vielen Punkten unschätzbar. Es ist zu hoffen, dass rasch ein Konsens zwischen Kinderurologen, Kinderchirurgen, Kindernephrologen und Radiologen gefunden werden kann. Die Aussichten dafür sind gut, zumal die Zahl der Studien wächst, die eine evidenzbasierte Empfehlung für den deutschsprachigen Raum ermöglichen werden.

\section{Transition}

\section{DGKCH-SY-TS-4 Nachsorgeheft - Anorektale Fehlbildungen}

Schwarzer N.', Grasshoff-Derr S. ${ }^{2}$, Schmidt D. ${ }^{3}$, Reifferscheid P.', Schmiedeke E. ${ }^{4}$, Jenetzky E. ${ }^{5}$, CURE-Net

${ }^{1}$ SoMA e. V., München, ${ }^{2}$ Universitätsklinikum Würzburg, Kinderchirurgie, Würzburg, ${ }^{3}$ Charité - Universitätsmedizin Berlin, Klinik für Kinder und Jugendpsychiatrie, ARM-Arbeitsgruppe, Berlin, ${ }^{4}$ Klinikum Bremen-Mitte, Abteilung für Kinderchirurgie und Urologie, Bremen, ${ }^{5}$ Johannes Gutenberg Universität Mainz, Kinder und Jugendpsychiatrie und -psychotherapie, Mainz

Fragestellung. Die Auswertungen der Patientendaten aus CURE-Net (www.cure-net.de), einem Netzwerk zur Erforschung von Ursachen, Behandlung und Nachsorge bei anorektaler Fehlbildungen (ARM) zeigten enorme Unterschiede in Diagnosestellung, Behandlung und Nachsorge mit entsprechenden Folgen für die Patienten.

Material und Methode. Ein Ziel von CURE-Net war anhand der Erfahrungen aus den erhobenen Daten ein „Nachsorgeheft - Anorektale Fehlbildung" zu entwickeln, das, vergleichbar dem gelben „U-Heft“, als Leitfaden die Nachsorge verbessert.

Ergebnisse. Die erste Version dieses Heftes ist für o- bis 8-jährige ARMPatienten im März 2013 erschienen. Eine Ausgabe für 9- bis 17-jährige sowie für erwachsene Patienten wird noch erstellt. Inhalt des ersten Heftes ist: Diagnoseblatt zu ARM und zu Begleitfehlbildungen; Erfassung von Operationszeitpunkten und -methoden und von Komplikationen; strukturierte Nachsorge einschließlich der Erhebung psychosozialer Aspekte; ergänzend finden sich Stuhlprotokoll, Hinweise zur Bougierung und zu weiteren Hilfen sowie ein Glossar. Das Heft soll Eltern möglichst zum Zeitpunkt der Geburt des Kindes mit ARM ausgehändigt werden. Bei den entsprechenden Terminen wird es von den Eltern dem behandelnden Kinderchirurgen zum Ausfüllen übergeben und dann kontinuierlich der Behandlungsverlauf dokumentiert.

Diskussion. Die Erarbeitung des Nachsorgeheftes barg große Herausforderungen: Prävention vs. Überdiagnostik, Vorsicht vs. Angstmache. Ziel ist, allen am Prozess Beteiligten (Arzt und Patient), eine Orientierung zu geben, wann welche Nachsorge durchzuführen oder abgeschlossen ist. Ob Komplikationen durch bessere Nachsorge reduziert und die psychosoziale Gesundheit der Patienten/Eltern gefördert werden kann, muss in weiteren Studien untersucht werden. 


\section{DGKCH-SY-TS-5}

Studie über die Langzeit-Lebensqualität nach komplizierter Ösophagusatresie

Dingemann C. ${ }^{1}$, Meyer A. ${ }^{1}$, Offenbecher S. ${ }^{2}$, Boemers T.M. ${ }^{3}$, Loff S. ${ }^{4}$, Till H. ${ }^{5}$, Vaske B. ${ }^{6}$, Ure B.M. ${ }^{1}$

${ }^{1}$ Medizinische Hochschule Hannover und Kinderkrankenhaus auf der Bult, Zentrum Kinderchirurgie, Hannover, ${ }^{2}$ Patienten- und Selbsthilfeorganisation für Kinder und Erwachsene mit kranker Speiseröhre (KEKS) e.V., Stuttgart, ${ }^{3}$ Kliniken der Stadt Köln gGmbH, Klinik für Kinderchirurgie und Kinderurologie, Köln, ${ }^{4}$ Klinikum Stuttgart, Olgahospital, Kinderchirurgische Klinik, Stuttgart, ${ }^{5}$ Universitätsklinikum Graz, Klinik für Kinder- und Jugendchirurgie, Graz, Österreich, ${ }^{6}$ Medizinische Hochschule Hannover, Zentrum Biometrie, Medizinische Informatik und Medizintechnik, Hannover

Fragestellung. Die komplizierte Ösophagusatresie (kÖA) kann mit einer erhöhten Morbidität einhergehen. Hypothese der Studie war, dass die kÖA mit einer Einschränkung der Lebensqualität (LQ) verbunden ist. Material und Methode. Alle bei KEKS registrierten Patienten mit kÖA wurden eingeschlossen. Die Einteilung in Untergruppen erfolgte nach Alter und chirurgischem Management. Die Messung der LQ erfolgte altersabhängig mittels validierter Fragebögen (KIDSCREEN27, WHO5, gastrointestinaler LQ Index=GIQLI).

Ergebnisse. Das Follow-up betrug 4,5 Jahre und war für 9o Patienten (98\%) verfügbar (63 Kinder und Jugendliche, 27 Erwachsene). Die Einteilung erfolgte in verzögerte Anastomosierung $(n=28)$, Ösophagus-Ersatzverfahren $(n=27)$, chirurgische Revision $(n=15)$ und $>10$ Dilatationen $(n=20)$. Das allgemeine Wohlbefinden erwachsener Patienten nach kÖA-Korrektur war erheblich eingeschränkt (WHO-Score: 15,5/25). 23\% dieser Patienten wiesen ein stark eingeschränktes Wohlbefinden auf. Der GIQLI erwachsener Patienten war gegenüber einer Kontrollgruppe von gesunden Normalpersonen vermindert (105 vs. 126; p<0,0001). Die LQ von Kindern mit kÖA unterschied sich nicht von der Kontrollgruppe (KIDSCREEN27). Verzögerte Anastomosierung ging mit der günstigsten LQ einher. Das physische Wohlbefinden dieser Kinder war besser im Vergleich zur Kontrollgruppe (64 vs. 52; $p=0,0011$ ), Kindern nach Ösophagus-Ersatz ( $51 ; \mathrm{p}=0,008)$, nach Revision $(52 ; \mathrm{p}=0,026)$ und multiplen Dilatationen (50; $\mathrm{p}=0,04)$.

Schlussfolgerung. Die LQ bei Kindern mit korrigierter kÖA ist exzellent. Beim Erwachsenen geht die kÖA mit einer Einschränkung der LQ einher. Die Langzeit-LQ bei Kindern nach verzögerter Anastomosierung ist besser im Vergleich zu Kindern nach Ösophagus-Ersatz, Revisionen oder multiplen Dilatationen.

\section{Samstag, 14.09.2013}

\section{Traumatologie, Freie Themen}

\section{DGKCH-SY-TR-1}

Die geschlossene Reposition der dislozierten distalen Radiusfraktur. Bei Kindern die Therapie der Wahl?

Wendling-Keim D.S.', Wieser B.', Dietz H.-G.'

'Universitätsklinikum München, Dr. von Haunersches Kinderspital, Kinderchirurgische Klinik, München

Einleitung. Bei der Therapie der dislozierten distalen Radiusfraktur bei Kindern fehlt ein einheitliches akzeptiertes Vorgehen, denn die primäre Therapie soll so wenig invasiv wie möglich sein und zugleich die Fraktur definitiv in achsgerechter Stellung stabilisieren. Hierbei konkurriert die konservative Reposition mit der zusätzlich verwendeten KirschnerDraht-Osteosynthese. Ziel der Arbeit war es daher, herauszufinden, inwieweit die Reposition ohne Kirschner-Draht-Osteosynthese eine definitive Stabilisierung gewährleisten kann.

Methoden. Im Rahmen einer retrospektiven Studie wurden 411 distale dislozierte Radiusfrakturen bei Kindern im Alter von 1 bis 18 Jahren mit radiologisch offenen Wachstumsfugen im Zeitraum von 2005-2011 auf ihre Therapie sowie Komplikationen hin überprüft. Dies erfolgte anhand von Röntgenbildern sowie Krankenunterlagen.

Ergebnisse. Bei 274 primär reponierten Frakturen betrug der Anteil der sekundären Dislokationen zwar 25,4\%, allerdings wurden die Restangulationen hier in $78,3 \%$ der Fälle mit max. $10^{\circ}$ verzeichnet, so dass keine weitere Intervention nötig war. Lediglich bei 32 Frakturen musste eine Nachreposition und bei 12 Frakturen eine Kirschner-Draht-Osteosynthese durchgeführt werden. Hierbei wurde festgestellt, dass das Risiko einer sekundären Dislokation erhöht war bei intraoperativ wiederholten Repositionsversuchen oder einer Restfehlstellung von mehr als $5^{\circ}$ bzw. mehr als einer Kortikalisbreite.

Schlussfolgerung. Die geschlossene Reposition und entsprechende Ruhigstellung der distalen dislozierten Radiusfraktur liefert bei Kindern eine sichere und nichtinvasive Therapie, sofern sie nicht bei erhöhtem sekundärem Dislokationsrisiko bei wiederholten Repositionsversuchen oder Restfehlstellungen von mehr als einer Kortikalisbreite oder mehr als $5^{\circ}$ Restangulation eingesetzt wird.

\section{DGKCH-SY-TR-2}

\section{Kasuistik. Sekundäre Dislokation einer geburtstraumatischen} Humerusfraktur

\section{Schneider A. ', Degenhardt P.', Rothe K. ${ }^{1}$}

'Charité - Universitätsmedizin Berlin, Klinik für Kinderchirurgie, Berlin

Einleitung. Geburtstraumatische Frakturen heilen in der Regel unproblematisch aus, ggf. begleitende Gefäß- oder Nervenläsionen bestimmen Behandlungsaufwand und Prognose. Wir berichten über eine sekundär dislozierte geburtstraumatische Humerusfraktur.

Fallbericht. Bei einem hypertrophen, männlichen Neugeborenen entwickelte sich bei der vaginalen Entbindung eine linksseitige Schulterdystokie. Postnatal wurde eine diaphysäreHumerus- Querfraktur nachgewiesen, die mittels eines Desault-Verbands ruhiggestellt wurde. Nach 11 Tagen zeigte sich radiologisch noch keine Kallusformation sowie eine Dislocatio ad latum, zur Kallusbeurteilung war nur eine Ebene angefertigt worden. Nach 19 Tagen erfolgte die nächste Röntgenkontrolle, jetzt mit reichlich Kallus und einer Achsabweichung von $75^{\circ}$ sowie einem Rotationsfehler. Es erfolgte die geschlossene Reposition der Fraktur in Allgemeinnarkose, eine Oberarm-Gipsschiene wurde appliziert. Bei der Stellungskontrolle am 3. Tag nach Reposition zeigte sich erneut eine tolerable Achsabweichung sowie eine Dislocatio ad latum. Im weiteren Verlauf entwickelte sich eine Fallhand links Die Kontrolle 2 Wochen nach Reposition ergab eine regelrechte Stellung bei reichlicher Kallusformation. Unter Radialisschiene und durch physiotherapeutische Maßnahmen kam es zur kompletten Rückbildung der Fallhand und freien Beweglichkeit binnen 8 Wochen.

Fazit. Auch geburtstraumatische Frakturen können neben neurovaskulären Begleitschäden einer verzögerten Konsolidierung und sekundären Dislokation unterliegen, altersbedingt sind die osteosynthetischen Möglichkeiten begrenzt, so dass die weitere konservative Behandlung erwogen werden sollte.

\section{DGKCH-SY-TR-3}

Weniger ist mehr: mit kleinem Aufwand zu kürzeren Durchleuchtungszeiten

Lindert J.', Duhnke J.', Wünsch L. ${ }^{1}$

'Universitätsklinikum Schleswig-Holstein, Kinderchirurgie, Lübeck

Hintergrund. Unterarmfrakturen gehören auch bei Kindern zu den häufigsten Verletzungen. Neben dem funktionellen Behandlungsergebnis ist die Minimierung der Strahlenexposition ein wichtiges Qualitätsmerkmal. Fragestellung. Können Durchleuchtungs-Zeiten (DL) bei der Versorgung von Unterarm(UA)-Frakturen durch eine einfache Strahlenschutz-Intervention reduziert werden? 
Material und Methoden. Analyse der 2011 in der Kinderchirurgie Lübeck operierten UA-Frakturen (distaler UA mit K-Draht und UA-Schaft mit ESIN-Osteosynthese) als Kontrollgruppe G1, einer Strahlenschutz-Intervention und einer Erfassung der DL nach 3 G2 und 12 Monaten. Intervention: 1. Schulung des OP-Teams, 2. Prä-OP-Briefing, 3. Fußschalter, 4 Ansage der DL-Zeiten bei der Besprechung. Datenanalyse mit SPSS 11.5. Ergebnisse. 44 distale UA-Frakturen: Altersdurchschnitt in G1 10,5 J und in G2 11 J. Durchschnittliche Operationszeit (DOZ) 24 min in G1 und $17 \mathrm{~min}$ in G2. Mittlere DL-Zeit (MDZ) $26 \mathrm{~s}$ in G1 und $9 \mathrm{~s}$ in G2. 86 diaphysäre Unterarmfrakturen. Altersdurchschnitt 8,9 J in G1 und 9,8 in G2. Die DOZ war 33,4 min in G1 und 35,6 min in G2. Die MDZ war 54,9 s in G1 und 42,6 s in G2. In der log. Regression zeigte sich ein signifikanter Einfluss der Operationsdauer $(p=0,000)$ für beide Frakturtypen und der Intervention auf die UA-Schaftfrakturen $(p=0,047)$. Diskussion. Nach 3 Monaten ist eine Reduktion der Durchleuchtungszeiten und Strahlenbelastung nachweisbar. Die Ergebnisse nach 12 Monaten werden im Juni 2013 zur Verfügung stehen. Die Ergebnisanalyse wird zu wirksamen Empfehlungen zur Reduktion der Durchleuchtungszeiten bei und der Verbesserung des Strahlenschutzes bei Unterarmfrakturen führen.

\section{DGKCH-SY-TR-4}

Is a standardized preoperative questionnaire a good tool to detect coagulation disorders in children?

\section{Halimeh $S^{1}$}

'Gerinnungszentrum Rhein/Ruhr, Duisburg

Introduction. In our study 144 children were send to our coagulation centre with a positive anamnesis (such as haematomasornose bleeding's) a positive family anamnesis (p.e. Mother with Menorrhagie) or a prolonged aPTT during a standardized preoperative examination. Methods. We analyzed samples of 144 children by conducting the following tests: Blood count, VWF: RCo, VWF: Ag, VWF:CB, Fibrinogen (Clauss), activities of FII, FV, FVII, FVIII (clotting and chromogenic), FIX, FX, FXI, FXII, FXIII. In 126 of 144 children (87\%) a bleeding disorder could be detected. In those with a bleeding disorder the distribution was as follows: $59 \%$ had a von Willebrand disease, $16 \%$ had a factor-VII-deficiency(FD7), $12 \%$ had a factor-XIII-deficiency $\left(\mathrm{F}_{13} \mathrm{D}\right)$, and the remaining $3 \%$ had other bleeding disorders (e.g. VWS type $2+3$ and other mild factor deficiencies. Result. A standardized preoperative questionnaire can be useful in clinical practice. In our study $87 \%$ children with one or more positive evidence in the anamnesis suffer from a bleeding disorder. We found specific noticeable that we found in $75 \%$ of the children which mother has a menorrhagia a bleeding disorder. In $83 \%$ of the children we found a von Willebrand disease. We are of the opinion that we could detect more coagulation disorders if a standardized preoperative questionnaire would be used and if we pay more attention to mothers with menorrhagia.

Conclusions. Children from mothers with menorrhagia suffer more frequently from a bleeding disorder. In our patients $75 \%$ of the children with a mother with menorrhagia a bleeding disorder was found. To avoid unexpected bleeding during a planned operation or a postoperative bleeding a standardized preoperative questionnaire should be performed.

\section{DGKCH-SY-TR-5}

Plötzlicher Herztod (SCD) und Empfehlungen zur Prävention in der Kinder- und Jugendmedizin unter Berücksichtigung der Commotio cordis

\section{Eyermann R.}

'Dr. Richard Eyermann, Kinder- und Jugendmedizin, Kinderkardiologie, Sportmedizin, München

Einleitung. Inzidenz bei scheinbar gesunden Adoleszenten pro Jahr sportlicher Aktivität bei @1:250.00o, häufiger bei Jungen, Afro-Amerikanern, Wettkämpfern von Football und Basketball. Ätiologisch SCD bei jüngeren Sporttreibenden präexistente nichterkannte HKL-Erkrankungen (90\% strukturelle HKL-Erkrankungen, 10\% primär elektrophysiologische Störungen): Häufig dabei $\mathrm{HCM}_{3} 6 \%$, Koronaranomalien $23 \%$, idiopathische LVH 10\%; weniger häufig rupturiertes Aortenaneurysma, Myokarditis, AS, KHK, ARVD; selten WPW-Syndrom, LQTS, MKPS, Commotio cordis, Drugs. In Screeningevaluationen (n-115) bei SCD-Betroffenen nur in 3\% kardiovaskuläre Erkrankungen aufgedeckt, in $0,9 \%$ korrekte Korrelationen zum SCD hergestellt worden!

Kardiovaskuläre Anamnese. Bedeutsamstes Screeningelement, Mindestinhalt: 1) früherer Thoraxschmerz, Synkope oder Near-Synkope, unerwartete unklare Dyspnoe oder Fatigue assoziiert mit Belastung, 2) früheres Herzgeräusch oder Hypertonie, 3) positive FA auf SCD, MACE $<50$ Jahre sowie HCM, Marfan-Syndrom, LQTS, signifikante Arrhythmien. Medizinische Untersuchung, Mindestinhalt: 1) Auskultation liegend und stehend, v. a. zur Detektion von Geräuschen dynamischer LVOTO, 2) FP zum Ausschluss CoA, 3) Evaluation auf Stigmata Marfan-Syndrom, 4) RR-Messung sitzend.

Weitere Diagnostik. EKG und Echo, in USA im Routine-Screening wegen niedriger Inzidenz, hoher Rate falsch-positiver Befunde und Kosten nicht empfohlen, wohl aber in Europa (EbM: -IC). Zukünftig Gentests bei jungen High-risk-Sporttreibenden geplant.

Schlussfolgerung. Junge Sporttreibende screenen und bei kardiovaskulären Abnormitäten kardiologisch evaluieren und Belastbarkeit nach Guidelines von ACC/ACSM einstufen. Protektoren gegen Commotio cordis unsicher und sportartspezifisch behindernd. Ausweichtraining empfohlen. Basic und „advance life support" schulen.

\section{DGKCH-SY-TR-6}

Seltene Differenzialdiagnose eines Hämatothorax: multiple Exostosen der Rippen

Kujath C. ${ }^{1}$, Sinnig M. ${ }^{1}$, Bottländer M. ${ }^{1}$, Jokuti L. ${ }^{2}$, Thamer A. ${ }^{3}$, Kordonouri O. ${ }^{3}$, Ludwikowski B.'

'Medizinische Hochschule Hannover und Kinderkrankenhaus auf der Bult, Kinderchirurgie/Kinderurologie, Hannover, ${ }^{2}$ Medizinische Hochschule Hannover und Kinderkrankenhaus auf der Bult, Kinderradiologie, Hannover, ${ }^{3}$ Medizinische Hochschule Hannover und Kinderkrankenhaus auf der Bult, Allgemeinpädiatrie, Hannover

Einleitung. Exostosen der Rippen sind meist asymptomatisch. Hämatothorax oder Pneumothorax sind bekannte aber seltene Komplikationen dieser Fehlbildungen. Wir berichten über den Krankheitsverlauf bei einem 10-jährigen Patienten mit negativer Familienanamnese.

Fallbericht. Ein 10 Jahre alter Junge mit Exostosen in der Vorgeschichte wurde mit plötzlich aufgetretenen rechtsseitigen Thoraxschmerzen vorgestellt. Klinisch und laborchemisch bestanden bei dem sonst gesunden Kind keine Infektzeichen. Röntgenologisch zeigte sich ein Pleuraerguss rechts, und bei Malignomverdacht erfolgte die diagnostische Punktion mit Nachweis eines ausgeprägten Hämatothorax. Die anschließende CT-Diagnostik zeigte innenseitige Rippenexostosen der 7. Rippe links sowie der 3. Rippe rechts. Die rechtsseitige Exostose hatte zu Verwachsungen mit Pleura und Lunge und konsekutiv zu einem Hämatothorax geführt. Nach Entlastung des Hämotothorax rechts entwickelte sich ein Spannungspneumothorax, so dass eine Thoraxdrainage eingelegt wurde. Linksseitig bestand der Verdacht auf Verwachsungen der Exostose mit dem Perikard. Wir führten daher die beidseitige thorakoskopisch assistierte Exostosenabtragung durch.

Schlussfolgerung. Exostosen der Rippen können auf konventionellen Röntgenbildern nur unzureichend beurteilt werden. Wir empfehlen daher bei Auftreten von thorakalen Beschwerden bei Patienten mit bekannten Exostosen die Durchführung einer Computertomographie, um die Ausrichtung der Exostosen darzustellen und ihre Lage in Bezug zu Pleura, Lunge und Perikard beurteilen zu können. 


\section{DGKCH-SY-TR-7}

CIRS-Charité - Erfassung und Analyse von kritischen Ereignissen Lernen, bevor es zu spät ist - aktueller Stand im eigenen Zentrum

\section{Rothe K.', Degenhardt P., Christ-Steckhahn C. ${ }^{2}$}

'Charité - Universitätsmedizin Berlin, Klinik für Kinderchirurgie, Berlin, ${ }^{2}$ Charité - Universitätsmedizin Berlin, Pflegedienstleitung am Zentrum für Frauen-, Kinder und Jugendmedizin, Berlin

Einleitung. In der modernen Medizin haben sich verschiedene Systeme im Rahmen einer verbesserten Fehlerkultur etabliert, dazu gehören das Risikomanagement Weblog, das „critical incident reporting system“ (CIRS) und die verschiedenen Möglichkeiten von Morbiditäts- und Mortalitätskonferenzen. CIRS ist eine Datenbank zur Meldung von kritischen Ereignissen die zu einem Schaden hätten führen können. „CIRS-Charité" ist ein wichtiges Element auf dem Weg zu einem systematischen Risikomanagement. Vorrangiges Ziel ist es, eine funktionierende Sicherheits- und Lernkultur zu schaffen. Es soll den Effekt haben, Fehler zu identifizieren, Ursachen abzuklären und darauf basierende Maßnahmen zur künftigen Verhinderung dieser Fehler zu ergreifen. Dementsprechend steht für uns die Schaffung einer Sicherheits- und Lernkultur im Mittelpunkt von „CIRS-Charité“. Die Verbesserung der Patientensicherheit steht für uns an oberster Stelle.

Methoden. 2006 wurde an der Charité ein anonymes Fehlermeldesystem eingeführt: Das CIRS ist von jedem Rechner aus erreichbar. Jeder Mitarbeiter kann anonym Fehler, kritische Ereignisse oder Beinahe-Unfälle berichten. Erklärtes Ziel ist es, aus Beinahe-Zwischenfällen („,critical incidents“) zu lernen, um tatsächliche Zwischenfälle, bei denen ein Patient zu Schaden kommen könnte, zu vermeiden. Potenzielle Risiken sollen identifiziert werden, die Ursachen geklärt, Maßnahmen zur künftigen Vermeidung dieser Risiken formuliert und umgesetzt werden.

Schlussfolgerung. An eigenen Beispielen wollen wir die Tragweite des Systems auch für den kindermedizinischen Bereich vorstellen und ebenfalls eine Analyse unserer bisherigen Erfahrungen im Umgang mit „Beinahefehler" diskutieren. 2011 hatten wir zum ersten Mal berichtet. Was weiter geschah, berichten wir jetzt.

\section{DGKCH-SY-TR-8}

Persistierender Ductus arteriosus. Offene Ductusligatur - weiterhin gerechtfertigt?

\section{Kosk T.', Dinger J.' ', Bartsch D. ', Fitze G.'}

'Universitätsklinikum Carl Gustav Carus Dresden, Klinik und Poliklinik für Kinderchirurgie, Dresden, ${ }^{2}$ Universitätsklinikum Carl Gustav Carus Dresden, Klinik für Kinder- und Jugendmedizin, Intensivstation, Dresden

Einleitung. Der persistierende Ductus arteriosus ist eine bei Frühgeborenen häufig vorkommende Pathologie, die unbehandelt zu Herzinsuffizienz, Lungenödem und verminderter Organperfusion führt. Ist die medikamentöse Therapie nicht erfolgreich, wird der PDA durch einen Eingriff verschlossen; entweder interventionell, thorakoskopisch oder durch eine offene Operation.

Zielstellung und Methode. Die in unserer Klinik durchgeführten offenen Ductus-Ligaturen der Jahre 2005-2010 wurden retrospektiv analysiert und mit bereits veröffentlichten Ergebnissen des thorakoskopischen Ductusverschlusses und dem interventionellen Vorgehen verglichen.

Ergebnisse. In den 6 Jahren war bei 28 Frühgeborenen (durchschnittlich $815 \mathrm{~g}$ ) eine offene Ductusligatur notwendig. Sechs der Patienten (21\%) sind innerhalb des ersten Lebensjahres verstorben. In diesem Patientengut gibt es mit der interventionellen Methode nur Einzelfallberichte, die minimal 2200 g Kinder behandelten. Ein thorakoskopischer Ductusverschluss wird bei Frühgeborenen ebenfalls nur in Einzelfällen durchgeführt.

Diskussion und Schlussfolgerung. Bei einem hämodynamisch wirksamen persistierenden Ductus arteriosus ist der medikamentöse Ductusverschluss die Therapie der Wahl. Bei Nichtansprechen kann bei normalgewichtigen Frühgeborenen ein interventioneller oder thorakoskopischer Ductusverschluss mit guten Ergebnissen durchgeführt wer- den. Bei extremen Frühgeborenen ist die offene Ductusligatur weiterhin der Standard-Eingriff.

\section{DGKCH-SY-TR-9 \\ Meconium periorchitis: an unusual finding}

Fischer J.', Uhlarik S.', Siegmann H.J. ${ }^{2}$, Dübbers M. ${ }^{1}$

'Florence-Nightingale-Krankenhaus, Kinderchirurgie, Düsseldorf, ${ }^{2}$ Praenatal, Düsseldorf

We report a 7 day old boy who presented with a scrotal mass at birth. Prenatal ultrasound showed a tumor-like entity of the scrotum. On postnatal ultrasound of the scrotum, the diagnosis remained unclear, except for showing open processus vaginales on both sides. Intraoperatively, removal of paratesticular green amorphous material with calcifications was performed. Normal-appearing testicles on both sides were left in situ. The diagnosis of meconium periorchitis was confirmed on pathology. Although most cases of meconium periorchitis are diagnosed surgically, in cases with typical sonographic findings and abdominal calcifications surgery may be avoided.

\section{Intestinale Motilitätsstörungen}

\section{DGKCH-SY-IM-3 \\ Hirschsprung disease from the neuropathological perspective}

Mittelbronn M. ${ }^{1}$, Beschorner R. ${ }^{2}$, Harter P.N. ${ }^{1}$, Gfrörer S. ${ }^{1}$, Rolle U.' ${ }^{1}$ Goethe Universität, Frankfurt, ${ }^{2}$ Department Neuropathologie, Tübingen

Hirschsprung disease is one of the major causes of chronic constipation in children which can be successfully treated by resection of the pathologic intestinal segment. However, a postoperative symptom-free status can only be achieved by an adequate intraoperative (neuro-)pathologic diagnostic setting allowing for the detection of the ideal resection point avoiding the resection of both too short or too long segments. The large majority of laboratories involved in the intraoperative diagnostics of Hirschsprung disease only perform classical HE stainings to investigate the presence of ganglionic cells in the myenteric plexus. Others include additional enzyme histochemical staining methods to detect even immature ganglionic cells (NADH) to assess the number of mature ganglionic cells (NADH, LDH and/or SDH) as well as the extent of pathological cholinergic innervation by AchE to rule out pathologic transitional segments. Despite potentially prolonging the surgical procedure by additional intraoperative investigations, the application of enzyme histochemical methods to assess cholinergic innervation as well as distribution and maturity of ganglionic cells are useful tools in intraoperative Hirschsprung diagnostics since it has been shown that anastomosis to a not entirely normal transition zone have negative effects on the post-operative peristaltic competence. On the other hand, the resorptive functions might be impaired if the resected segments are too long.

Therefore, a fast and standardized interdisciplinary communication between surgeon and pathologist during the intraoperative assessment of Hirschsprung disease is the key for a most successful clinical result. 


\section{DGKCH-SY-IM-4}

\section{Modelle intestinaler Innervationsstörungen}

Obermayr F.

'Universitätsklinikum Tübingen, Kinder- und Jugendmedizin, Abteilung für Kinderchirurgie und Kinderurologie, Tübingen

Die normale Darmtätigkeit unterliegt einer komplexen Interaktion von Neuronen, interstitiellen Cajal-Zellen (ICCs) und muskulären Mechanismen. Entsprechend führen erworbene und angeborene Defekte dieser Mechanismen zu einem Verlust koordinierter Darmbewegung und $\mathrm{zu}$ gastrointestinalen Motilitätsstörungen bei Kindern und Jugendlichen. Die Ätiologie einiger dieser Erkrankungen konnte durch die Integration von Ergebnissen aus der Humangenetik und Erkenntnissen aus verschiedenen Tiermodellen, geklärt werden. Studien, vorwiegend an Mäusen, Hühnern und Zebrafischen führten zur Identifikation zahlreicher Signalwege, die bei der Entwicklung des enterischen Nervensystems und dessen Erkrankungen eine wichtige Rolle spielen. So sind die molekularen und zellulären Mechanismen, die zu einer Störung der Wanderung von Neuralleistenzellen, wie sie beim Morbus Hirschsprung auftritt, weitgehend bekannt.

Die Pathogenese von vielen anderen Motilitätsstörungen des Darmes im Kindesalter bleibt allerdings weitgehend unklar. Zwar konnte im Tiermodell der Phänotyp anderer Motilitätsstörungen generiert werden, jedoch fehlt hier meist die genetische Übereinstimmung im humanen Korrelat. Neben der außerordentlichen Rolle, die Tiermodelle bei der Erforschung von Ätiologie und Pathogenese dieser Gruppe von Erkrankungen spielen sind sie für die Entwicklung neuer Therapien wichtig. Die Möglichkeit einer Stamm- oder Vorläuferzell-basierten Therapie ist aktuell Gegenstand der Forschung im Mausmodell. Zudem werden verschiedene In-vitro-Testsysteme hinsichtlich ihrer Relevanz für gastrointestinale Motilitätsstörungen im Kindesalter diskutiert.

\section{DGKCH-SY-IM-5}

\section{CIPO. Gibt es chirurgische Therapieoptionen?}

\section{Wessel L.M. ${ }^{1},{ }^{\prime}$ Kohl M. ${ }^{2}$}

${ }^{1}$ Heidelberg University, Pediatric Surgery, Mannheim, ${ }^{2}$ Universitätsklinikum Schleswig-Holstein Campus Kiel, Klinik für Allgemeine Pädiatrie, Kiel

Einleitung. Die chronisch intestinale Pseudoobstruktion (CIPO) ist eine seltene angeborene Motilitätsstörung des Darmes ohne erkennbares mechanisches Hindernis. Klinisch führend sind Hypomotilität und chronischer Subileus. Der Krankheitsverlauf ist bei Auftreten in der Neonatalperiode dramatischer und zeigt das klinische Bild eines akuten Abdomens, das meist zur Laparotomie führt. Bei späterem Manifestationsbeginn überwiegen Hypomotilität und Subileus. Bisher handelt es sich um eine Ausschlussdiagnose, die in Zusammenarbeit mit pädiatrischen Gastroenterologen abzuklären ist. Nicht zuletzt, um unnötige Laparotomien zu vermeiden.

Fallberichte. Hier wird über 9 Kinder mit CIPO berichtet. In 5 Fällen konnte mithilfe einer funktionellen Untersuchung im Organbad sowie morphologischer histologischer und histochemischer Untersuchung das Bild erklärt werden. Es fand sich ein gemischtes Bild einer myogenen Form (3 Kinder) und einer neurogenen Form, geprägt von Hypoganglionose und Störung der Cajal-Zellen (2 Kinder). Im Vordergrund stand die Bekämpfung der bakteriellen Fehlbesiedlung. Die Kinder profitierten von Entlastung im Dünndarmbereich durch (Katheter-)Stoma $(n=3)$. Progressive Stuhlumfüllung und lokale antibiotische Therapie verbesserte die enterale Ernährbarkeit unter Reduktion der TPN. In 2 Fällen ließen sich alle Stomata zurückverlegen.

Schlussfolgerung. Die genaue Ursache für die Transportstörung und die bakterielle Fehlbesiedlung ist nur selten aufzuklären. Jedoch führt die Entlastung des Dünndarmes zu einer klinischen Besserung. Die Organbaduntersuchung an Muskelstreifen aus dem Dünndarm erlaubt Einsicht in die Pathophysiologie. Welche genauen Mechanismen im enterischen Nervensystem beteiligt sind bedarf der weiteren Forschung.

\section{DGKCH-SY-IM-6}

Funktionelle Motilitätsstörungen nach anorektaler Malformation: Landesweite Querschnittstudie zum interdisziplinären, psychound physiotherapeutischen Stuhltraining

Schmiedeke E. ', Zwink N. ${ }^{2}$, Schwarzer N. ${ }^{3}$, Häberle B. ${ }^{4}$, Palta M. ${ }^{5}$, GrasshoffDerr S. ${ }^{6}$, Holland-Cunz S. ${ }^{7}$, Hosie S. ${ }^{8}$, Märzheuser S. ${ }^{9}$ Schmidt D. ${ }^{10}$, Reutter $H{ }^{11,12}$, Jenetzky $E^{2,3}$

${ }^{1}$ Klinikum Bremen-Mitte, Klinik für Kinderchirurgie und Kinderurologie, Bremen, ${ }^{2}$ Deutsches Krebsforschungszentrum Heidelberg, Abteilung für Klinische Epidemiologie und Alternsforschung, Heidelberg, ${ }^{3}$ Patientenorganisation SoMA, München, ${ }^{4}$ Universitätsklinikum München, Dr. von Haunersches Kinderspital, Klinik für Kinderchirurgie, München, ${ }^{5}$ Evang. Krankenhaus Klinik für Kinder- und Jugendmedizin, Abteilung für Kinderchirurgie, Hamm, ${ }^{6}$ Universitätsklinikum Würzburg, Klinik für Kinderchirurgie, Würzburg, ${ }^{7}$ Universitätsklinikum Heidelberg, Zentrum für Kinder- und Jugendmedizin, Klinik für Kinderchirurgie, Heidelberg, ${ }^{8}$ Technische Universität München, Klinikum Schwabing, Klinik für Kinderchirurgie, München, ${ }^{9}$ Charité - Universitätsmedizin Berlin, Klinik für Kinderchirurgie, Berlin, ${ }^{10}$ Charité - Universitätsmedizin Berlin, Klinik für Psychiatrie, Psychosomatik und Psychotherapie des Kindes- und Jugendalters, Berlin, "Universitätsklinikum Bonn, Kinderklinik, Neonatologische Abteilung, Bonn, ${ }^{12}$ Universität Bonn, Institut für Humangenetik, Bonn

Fragestellung. Patienten nach anorektaler Malformation (ARM) leiden häufig unter Obstipation und/oder Stuhlinkontinenz. Als Ursache sind neben somatischen Defiziten psychosomatische Fehlsteuerungen der Stuhlentleerung bekannt. Wir untersuchten die Situation unter konservativer Therapie durch Interdisziplinäres Stuhltraining (IST) im Vergleich zum Bowel-Management (BM, regelmäßige invasive rektale Maßnahmen wie Einläufe oder Abführzäpfchen).

Material und Methoden. Im Rahmen einer Querschnittstudie erfassten wir deutschlandweit Patientendaten nach den Krickenbeck-Kriterien. Zusätzlich wurde ein Stuhlprotokoll von den Patienten ausgefüllt. Die medizinischen Befunde entnahmen wir den klinischen Dokumenten. Ergebnisse. 323 Patienten mit ARM wurden erfasst, 190 lieferten komplette Kontinenzdaten, 56 wurden ausgeschlossen (Retardierung, Geburt vor Einführung der PSARP). 23 der 134 ausgewerteten Patienten (17\%) waren kontinent ohne BM oder IST. 25\% der Patienten führten ein IST durch, $36 \%$ davon zusätzlich ein BM. Von den übrigen 21, die sich nach IST allein auf aktive Defäkation verließen, erreichten $14 \%$ damit Kontinenz. Von den 78 inkontinenten Patienten ohne IST praktizierten $51 \%$ ein BM, $17 \%$ davon erreichten soziale Kontinenz. In allen Gruppen fand sich mit $41 \%$ Koprostase ein hoher Anteil nicht ausreichend behandelter Obstipation.

Schlussfolgerung. Patienten nach anorektaler Malformation zeigen in einer deutschlandweiten Querschnittstudie eine hohe Rate von nicht ausreichend behandelter Obstipation und Stuhlinkontinenz. Die Erfolgsraten sowohl des BM als auch des IST scheinen bei Behandler-unabhängiger Erfassung unbefriedigend. Um dies sicher zu beurteilen sind jedoch Multicenter-Längsschnittstudien nötig. Weitere Evaluation der Nachsorge ist geboten. 


\section{Forum Junge Kinderchirurgie: Arbeitszeitmodelle und Ausbildung in der Kinderchirurgie: Was ist möglich - welche Lösungen gibt es?}

\section{DGKCH-SY-JK-2}

Gesetzliche Rahmenbedingungen

\section{Rogge $P^{1,2}$}

'Birmingham Children's Hospital, Paediatric Intensive Care Unit, Birmingham, UK, ${ }^{2}$ Deutsche Gesellschaft für Kinderchirurgie (DGKCH), Arbeitskreis kinderchirurgischer Assistenten (AkA), Berlin

Einleitung. In Deutschland besteht ein über Jahre gewachsenes Recht zum Schutze der Beschäftigten und zum Erhalt Ihrer Arbeitskraft. Die ersten Grundzüge sind bereits über 100 Jahre alt. Diese gesetzlichen Rahmenbedingungen der Beschäftigung von Angestellten und Arbeitern haben sich im Laufe der Zeit und zuletzt maßgeblich beeinflusst von Entscheidungen auf Ebene der Europäischen Union (EU) weiterentwickelt.

Methoden. Die einzelnen Regelungen verteilen sich dabei in verschiedene Gesetzeswerke, wie z. B. das Bürgerliche Gesetzbuch, das Arbeitsschutzgesetz, Arbeitszeitgesetz, Mutterschutzgesetz und etwa das Gesetz über befristete Arbeitsverträge für Ärzte in der Weiterbildung. Darüber hinaus werden Detailfragen in Tarifverträgen zwischen den jeweiligen Arbeitgebern und dem Marburger Bund als Gewerkschaft der Ärzte auf Basis dieser gesetzlichen Regelung geregelt. Vielen jungen Kollegen sind weder die komplexen gesetzlichen Grundlagen noch die Tarifverträge bekannt. Darüber hinaus werden indirekte Konsequenzen aus arbeitsrechtlichen Begrenzungen, wie der potentielle Verlust des eigenen Versicherungsschutzes bei regelmäßiger Überschreitung der Arbeitszeitgrenzen, oft nicht einmal erahnt.

Schlussfolgerung. Dieser Vortrag soll einen Überblick über die arbeitszeitlichen Rahmenbedingungen und Begriffsdefinitionen sowie spezielle Aspekte der Weiterbildung geben um eine fachliche Diskussion dieser Aspekte in den folgenden Vorträgen und der Praxis zu ermöglichen.

\section{DGKCH-SY-JK-5a \\ Kinderchirurgisches Ausbildungskonzept in der Schweiz - das Nonplusultra?}

Lau $E^{1,2}$

${ }^{1}$ Kinderspital Zürich, Kinderchirurgie, Zürich, Schweiz, ${ }^{2}$ Medizinische Hochschule Hannover und Kinderkrankenhaus auf der Bult, Kinderchirurgie, Hannover

Fragestellung. Wie gut ist das Ausbildungskonzept in der deutschsprachigen Schweiz für Kinderchirurgie? Was könnten wir entlehnen? Material und Methoden. Ausbildungskonzepte und Instrumente der Kliniken der deutschsprachigen Schweiz in der Kinderchirurgie und Umfrage des Instituts für Medizinische Lehre der Universität Bern (IML) 2011/2012 zur Zufriedenheit der Assistenten in der Kinderchirurgie in diesen Kliniken.

Ergebnisse. Nach zwei Jahren Allgemeinchirurgie und mindestens einem Jahr Kinderchirurgie wird ein Weiterzubildender aus dem Assistentenpool gewählt. Er wird von einem Mentor betreut. Mit Hilfe von Arbeitsplatz-basiertem Assessment (Mini-CEX und DOPS) und 3-4 Evaluationsgespräche pro Jahr, für die alle Kaderärzte einen Beurteilungsbogen ausfüllen, ein Diagramm als Spinnennetz erstellt wird und der Weiterzubildende so seine Stärken und Schwächen gezeigt bekommt, wird eine strukturierte Beobachtung mit Feedback möglich und die Effizienz der Weiterbildung erhöht. Zusätzlich gibt es Zielvereinbarungen. All dies ist definiert und etabliert. Die Kliniken werden in verschiedene Kategorien eingeteilt und der Weiterzubildende muss für die Facharztprüfung (FMH) mindestens ein Jahr in einem Spital der Kategorie A gearbeitet haben. Obwohl nur wenige Assistenten in der Kinderchirurgie auch zum Kinderchirurgen ausgebildet werden, ist die Zufriedenheit sehr hoch.
Diskussion und Schlussfolgerung. Standardisierte Evaluationen mit Beurteilungen sowohl der Weiterbilder als auch der Weiterzubildenden sind ein gutes Mittel für die Überwachung der Ausbildung. Durch die etablierten Fremdjahre gibt es einen Austausch zwischen den einzelnen Spitälern. Die große Zufriedenheit spricht eindeutig für das Ausbildungssystem und es bleibt zu diskutieren, was wir übernehmen wollen und können.

\section{DGKCH-SY-JK-5b}

\section{Blick über den Tellerrand: die fachärztliche Weiterbildung in} England

Rogge P.

'Birmingham Children's Hospital, Paediatric Intensive Care Unit, Birmingham, UK

Aufbauend auf dem 5-jährigen Medizinstudium erwartet den jungen Arzt in England ähnlich wie in Deutschland zunächst eine zweijährige chirurgische Basisweiterbildung (Core Training, CT) gefolgt von einer 5-jährigen fachspezifischen chirurgischen Weiterbildung (Special Training, ST), so dass nach insgesamt 12 Jahren mit dem Abschluss der Weiterbildung (Certificate of Completion of Training, CCT) der Facharzt erreicht werden kann.

Die Regelungen für die Weiterbildung sind in einem Curriculum (The Intercollegiate Surgical Curriculum, Educating the surgeons of the future - Paediatric Surgery) detailliert auf 18o Seiten ausgeführt. Hierbei werden zum einen inhaltliche Vorgaben gemacht (was, wann, wie gut erlernt worden sein soll) und zum anderen die Rahmenbedingungen gesetzt (z. B. Mentoren, Weiterbildungsverantwortliche, Lehrmethoden, Beurteilungsmethoden). Darüber hinaus sind die jährliche Überwachung der Weiterbildungsdurchführung und des Weiterbildungsfortschritts hier definiert und entsprechend etabliert, so dass das Nicht-Erreichen des Weiterbildungszieles für den Weiterzubildenden sofort ersichtlich ist und das Nicht-Erbringen der Weiterbildungsleistung zeitnahe Konsequenzen für den Weiterbilder bedeuten.

In der Praxis folgt dem eine deutlich stärker auf die Vermittlung von Wissen und praktischen Fähigkeiten ausgelegte Arbeitsatmosphäre. Die Weiterzubildenden können in der Regel gut ihr Fortschreiten einschätzen und ihren weiteren Weiterbildungsweg, einschließlich Rotationen in andere Kliniken planen.

\section{Freie Vorträge}

\section{DGKCH-FV-2}

Risiken und Chancen der verbesserten Bildqualität in der sonographischen Beurteilung der akuten Appendizitis im Kindes- und Jugendalter

König T.T. , Staatz G. ${ }^{2}$, Kelsch V. ${ }^{3}$, de Lafollie J. ${ }^{4}$, Turial S. ${ }^{\text {? }}$

'Universitätsmedizin Mainz, Klinik und Poliklinik für Kinderchirurgie, Mainz, ${ }^{2}$ Universitätsmedizin Mainz, Klinik und Poliklinik für Diagnostische und Interventionelle Radiologie/ Sektion Kinderradiologie, Mainz, ${ }^{3}$ Universitätsmedizin, Mainz, ${ }^{4}$ Universitätsklinikum Giessen und Marburg, Giessen

Einleitung. Der technische Fortschritt in der Sonographie führt zu einer verbesserten Darstellung feiner anatomischer Strukturen, z. B. der Appendix vermiformis. So kommt es häufiger zu der Diagnose einer akuten Appendizitis durch den Radiologen, die jedoch nicht immer mit dem klinischen Befund korreliert. Es stellt sich die Frage, welchen Stellenwert die Sonographie in der Indikationsstellung zur Appendektomie hat.

Methode. Von 2010 bis März 2013 wurde bei 673 Kindern (Alter: 1,616,9 Jahre, Mittel: 11,6 Jahre) mit Schmerzen im rechten Unterbauch eine Abdomensonographie durch einen Kinderradiologen durchgeführt. Ausgewertet wurden die Fälle, bei denen hier sonographisch eine Appendizitis diagnostiziert wurde. Diese Befunde wurden mit dem kli- 
nischen, oder bei erfolgter Appendektomie, mit dem mikro- und makroskopischen pathologischen Befund korreliert.

Ergebnis. Bei $490(72,8 \%)$ Kindern zeigte sich ein unauffälliger sonographischer Befund des Abdomens. In insgesamt 177 Fällen wurden Auffälligkeiten an der Appendix festgestellt, in 24 Fällen (13,6\%) lag nach radiologischen Kriterien sicher eine Appendizitis vor. Bei 124 (70\%) Patienten wurde eine Appendektomie durchgeführt. 53 (30\%) der Patienten, bei denen sonographisch eine Appendizitis vorlag, wurden konservativ behandelt (mittlere Verweildauer 3 Tage, 2-9 Tage). Bei keinem der konservativ behandelten Patienten musste eine Intervall-Appendektomie durchgeführt werden.

Schlussfolgerung. $13,6 \%$ der Kinder, bei denen nach radiologischen Kriterien sicher eine Appendizitis vorlag, konnten konservativ behandelt werden. Aufgrund der verbesserten Bildqualität in der Sonographie müssen genauere Kriterien für die radiologische Diagnose einer akuten Appendizitis entwickelt werden.

\section{DGKCH-FV-3}

Postoperative Schmerztherapie der Trichterbrustkorrektur nach Nuss: patientenkontrollierte Analgesie vs. Periduralkatheter

Holler A.-S.', Scholsching J.', Bopp M. ', Noppens R. ${ }^{2}$, Turial S.'

'Universitätsmedizin der Johannes Gutenberg-Universität Mainz, Klinik und Poliklinik für Kinderchirurgie, Mainz, ${ }^{2}$ Universitätsmedizin der Johannes Gutenberg-Universität Mainz, Klinik für Anästhesiologie, Mainz

Fragestellung. Für die postoperative Schmerztherapie der Trichterbrustkorrektur nach Nuss werden sowohl die intravenöse patientenkontrollierte Analgesie (PCA) als auch ein thorakaler Periduralkatheter (PDK) eingesetzt. In einer retrospektiven Analyse sollte die Frage nach dem optimalen Schmerzregime im Hinblick auf Patientenkomfort, Mobilisation und vegetative Nebenwirkungen beantwortet werden.

Methode. Es wurde eine retrospektive Datenanalyse von Patienten nach Trichterbrustkorrektur nach Nuss im Zeitraum von 2004-2013 durchgeführt. Als Parameter für die Effektivität der Schmerztherapie und den Patientenkomfort wurden Dauer des stationären Aufenthaltes und der Schmerztherapie mittels PDK/PCA, durchschnittliche Schmerzscores, vegetative Nebenwirkungen sowie die Zeit bis zur vollständigen Mobilisation ausgewertet.

Ergebnisse. Im Auswertungszeitraum erhielten 51 Patienten eine PCA, bei 23 Patienten wurde ein PDK eingesetzt (Durchschnittsalter: 16,1 Jahre). Die mittlere Verweildauer lag bei Patienten mit PDK bei 6,6, Tagen, bei Patienten mit PCA bei 7 Tagen. Der PDK wurde im Durchschnitt am 4. postoperativen Tag entfernt, die Therapie mittels PCA am postoperativen Tag 3,3 beendet. Erbrechen trat bei $70 \%$ der Patienten mit PCA sowie bei $45 \%$ der Patienten mit PDK auf. Patienten in der PCAGruppe konnten nach 2,9 Tagen, Patienten mit PDK nach 1,8 Tagen in den Stand mobilisiert werden. Es zeigte sich kein Unterschied der in beiden Gruppen erfassten Schmerzscores.

Schlussfolgerung. Eine effektive Schmerztherapie nach Trichterbrustkorrektur nach Nuss ist sowohl mittels PCA als auch mit PDK möglich. In der PCA Gruppe waren jedoch mehr vegetative Nebenwirkungen zu verzeichnen als in der PDK-Gruppe, zudem war in der PDK-Gruppe eine frühere Mobilisation der Patienten möglich.

\section{DGKCH-FV-4}

Doppel-J-Katheter vs. transrenale transanastomotische Schienung bei laparoskopischer Pyeloplastik im Kindesalter: eine vergleichende Studie und unsere neue Technik

\section{Zöller C.', Lacher M.', Ure B.M.', Petersen C.', Kübler J.' \\ 'Medizinische Hochschule Hannover und Kinderkrankenhaus auf der Bult, Zentrum Kinderchirurgie Hannover, Hannover}

Fragestellung. Die transanastomotische Schienung bei der laparoskopischen Pyeloplastik im Kindesalter kann mit Komplikationen einherge- hen. In dieser Studie vergleichen wir unsere Erfahrungen mit intra- und extrakorporalen Stents und stellen eine neue Technik der transrenalen Schienung vor.

Material und Methoden. Die Daten aller Patienten, die in unserer Klinik von 12/2003 bis 11/2012 eine laparoskopische Pyeloplastik erhielten wurden retrospektiv analysiert. Konsekutiv wurden zunächst Doppel$J$-Katheter antegrad eingebracht $(n=48)$, danach transrenale/transkutane Katheter verwendet $(n=38)$. Von letzteren wurden 33 mittels Kanüle über die Flanke und 5 von innen transrenal nach extrakorporal mit einem modifizierten Reddonspieß eingebracht. Die Endpunkte unserer Analyse waren stentbezogene Komplikationen und Reoperationen.

Ergebnisse. 86 Patienten (62 Jungen, 24 Mädchen), mit einem mittleren Alter von 5,6 Jahren ( 78 Tage bis 17,3 Jahre) erhielten eine laparoskopische, transabdominale Pyeloplastik. Bei 9 von 48 Patienten der Gruppe der Doppel-J-Katheter war es nicht möglich, den Katheter zu platzieren. Dies war die häufigste Komplikation. Zusammen mit weiteren Komplikationen wie Dislokation, Harnwegsinfekten oder Katheterokklusion betrug die gesamte Komplikationsrate $35 \%$ in der Gruppe der Doppel-J-Katheter verglichen mit $13 \%$ in der Gruppe der transrenalen Stents ( $\mathrm{p}<0,05)$. Insgesamt war bei 4 Patienten eine Re-Pyeloplastik erforderlich. Alle diese Fälle traten in der Gruppe der Doppel-J-Katheter auf. Unsere neue Insideout-Technik hatte eine ausgezeichnete Machbarkeit.

Diskussion. Wir empfehlen bei der laparoskopischen Pyeloplastik ein transrenalesStenting des ureteropelvinen Übergangs. Unsere jetzige Technik ermöglicht hierbei ein unkompliziertes Platzieren des Stents.

\section{DGKCH-FV-5}

Thorakoskopische Eingriffe bei Kindern im Licht der evidenzbasierten Medizin

\section{Dingemann J.', Dingemann C.', Ure B.M.'}

'Medizinische Hochschule Hannover und Kinderkrankenhaus auf der Bult, Zentrum Kinderchirurgie Hannover, Hannover

Fragestellung. Thorakoskopische Eingriffe sind in der Kinderchirurgie etabliert. Postulierte Vorteile der minimal-invasiven Technik sind das geringere operative Trauma, geringere Schmerzen und weniger Komplikationen. Die Vorteile sollten jedoch standardisierten Kriterien standhalten. Das „Oxford Centre for Evidence-based Medicine (CEBM)“ ordnet Studien den Evidenzgraden 1-5 zu. Ziel der Untersuchung war es zu ermitteln, für welche Eingriffe Vorteile der Thorakoskopie mit welchem Evidenzgrad belegt sind.

Material und Methode. Systematische Literaturrecherche. Eingeschlossen wurden Studien, die thorakoskopische Verfahren direkt mit dem offenen Eingriff vergleichen. Endpunkte waren Vorteile/Nachteile der Thorakoskopie. Die Publikationen wurden nach den CEBM Kriterien bewertet. Ergebnisse. Drei Metaanalysen (MA) und 18 retrospektive komparative Studien (RKS) für 5 Eingriffe wurden eingeschlossen. Alle wurden dem Evidenzgrad 3 zugeordnet. Diagnose, Art der Studie/Anzahl/CEBMGrad/Endpunkt/Ergebnis (vs. offen), Zwerchfellhernie: MA/1/3a Rezidivrate + Überleben höher; Patchrate gleich; OP-Zeit länger, RKS/6/3b Schmerzen weniger; $\mathrm{KH}$-Aufenthalt + Beatmung kürzer; $\mathrm{pCO}_{2}$ geringer, Ösophagusatresie: MA/1/3a Leckage + Striktur gleich, RKS/4/3b $\mathrm{OP}-Z$ eit länger; $\mathrm{pCO}_{2}$, höher; Schmerzen weniger; $\mathrm{KH}$-Aufenthalt kürzer, Lungenresektion: MA/1/3a KH-Aufenthalt kürzer; Drainage kürzer; Komplikationen gleich, RKS/5/3b keine weiteren, Pneumothorax: $\mathrm{RKS} / 1 / 3 \mathrm{~b}$ Schmerzen weniger; KH-Aufenthalt kürzer; Rezidiv gleich, Neuroblastom: RKS/2/3b Blutverlust weniger.

Schlussfolgerung. Es sind nur retrospektive komparative Studien für die Thorakoskopie bei Kindern verfügbar. Der höchste CEBM-Evidenzgrad ist Grad 3. Randomisierte Studien sind notwendig um einen höheren Evidenzgrad für diese Technik zu erreichen. 


\section{DGKCH-FV-6}

\section{Purpura Schönlein-Henoch einhergehend mit einer obstruktiven} Blasenläsion

Comploj E.', Cassar W. ${ }^{2}$, Trenti E.', Palermo S. ', Reinstadler P. ', Ladurner C.', Dechet . $^{3}$, Pycha A. ${ }^{\text {' }}$

'Zentralkrankenhaus Bozen, Urologie, Bozen, Italien, ${ }^{2}$ Zentralkrankenhaus Bozen, Pädiatrie, Bozen, Italien, ${ }^{3}$ University of Utah, Division ofUrology, Salt Lake City, USA

Einleitung. Die Purpura Schönlein-Henoch (PSH) ist die häufigste Form einer immunologisch bedingten, systemischen Vaskulitis im Kindesalter, dessen Ätiologie unklar ist. Neben den charakteristischen Hautblutungen der unteren Extremität, finden sich auch klinische Varianten mit Beteiligung der Gelenke, des Gastrointestinaltraktes und der Niere. Seltene urologische Verläufe sind Obstruktionen der Harnleiter, Hodennekrosen und eine hämorrhagische Zystitis. Im Gegenteil $\mathrm{zu}$ anderen systemischen Vaskulitiden, ist die PSH selbstlimitierend und hat eine gute Prognose.

Fallbeschreibung. Ein zuvor gesundes 8-jähriges Mädchen zeigte sich in unserer Abteilung mit Petechien an der unteren Extremität und Fieberkrämpfen. Initiale Laborparameter zeigten eine neutrophile Leukozytose von $20,6 \times 103 / \mu \mathrm{l}(4,8-10,8)$, eine CRP-Erhöhung von $0,71 \mathrm{mg} / \mathrm{dl}$ $(0-0,75)$, und ein Kreatinin von o,6 mg/dl (0,5-0,9). IgA, IgA-Rheumafaktor, IgA-Immunkomplex, und Komplement $\mathrm{C}_{3}$ und $\mathrm{C}_{4}$ waren nicht erhöht. Es zeigte sich eine Proteinurie, Hämaturie und Albuminurie. Harn- und Stuhlkultur waren negativ. Die Abdomensonographie zeigte freie Flüssigkeit und verdickte Darmschlingen sowie eine intravesikale, am Blasenhals liegende $1 \mathrm{~cm}$ große Läsion, welche einen Harnverhalt verursachte. Die vermutete Diagnose war eine PSH, doch aufgrund der unklaren intravesikalen Masse, erfolgte eine Biopsie. Die histopathologische Untersuchung bestätigte die Diagnose der PSH. Das Mädchen wurden mit Kortikosteroiden therapiert und sonographisch nachkontrolliert; innerhalb von 6 Monaten verschwanden sei es die intestinalen als auch die intravesikalen Veränderungen.

Schlussfolgerung. Wir berichten über den aktuell einzigen Fall in der Literatur, in dem eine PSH, eine obstruktive Blasenmasse mit Harnverhalt verursacht.

\section{DGKCH-FV-7}

\section{Ist eine konservative Therapie eines Nierenabszesses im Kindes-} alter möglich?

Comploj E.', Cassar W. ${ }^{2}$, Gasparella P. ${ }^{3}$, Dechet C., ${ }^{1,4}$, Trenti E.', Ladurner C. , Palermo S.', Pycha A.'

'Zentralkrankenhaus Bozen, Urologie, Bozen, Italien, ${ }^{2}$ Zentralkrankenhaus Bozen, Pädiatrie, Bozen, Italien, ${ }^{3}$ Zentralkrankenhaus Bozen, Department für Kinderchirurgie, Bozen, Italien, ${ }^{4}$ University of Utah, Division of Urology, Salt Lake City, USA

Einleitung. Der Nierenabszess ist eine seltene Erkrankung im Kindesalter. Die Klinik beginnt akut, mit hohem Fieber, Flankenschmerzen und schlechtem Allgemeinzustand. Der Abszess entsteht über hämatogenen, aszendierenden oder „per continuitatem“.

Material und Methoden. Es werden 3 Fälle beschrieben zwischen 18 und 48 Monaten, welche sich mit einem rechtsseitigen über $3,5 \mathrm{~cm}$ großen Nierenabszess vorstellten. Die Diagnose und das Follow-up erfolgten mittels Sonographie. Die Therapie erfolgte bei den Kindern konservativ.

Ergebnisse. Die Kinder zeigten sich primär mit Fieber, Leukozytose, CRP- und Procalcitonin Erhöhung und Blutgerinnungsstörung sowie klinischen Symptomen. Alle Kinder hatten entweder eine Harn- und/ oder Blutkultur positiv für eine Infektion. Nach Einleitung der hoch dosierten Antibiotikatherapie wurden die Patienten innerhalb 1 Woche fieber- und symptomfrei und der Nierenabszess wurde alle 2 Tage sonographisch kontrolliert. Eine CT- Untersuchung war nicht notwendig. In diesen Fällen erzielte die alleinige Antibiotikatherapie den gewünsch- ten Erfolg, eine chirurgische Sanierung, wie häufig in der Literatur empfohlen, konnte vermieden werden.

Schlussfolgerung. In der Literatur wird die perkutane CT- oder Sonographie gesteuerte Drainage des Nierenabszesses als Gold Standard empfohlen, mit der Gefahr der akuten Blutung aber auch des Organverlustes. Aufgrund dieser 3 Fälle, vertreten wir die Meinung, dass nur Kreislauf instabile und auf die Antibiotikatherapie nicht ansprechende Patienten eine perkutane Drainage bedürfen. Da die Sonographie die Wirksamkeit des Antibiotikums dokumentiert, ist ein Arzt mit hoher Sonographie-Erfahrung unumgänglich. Zusätzlich macht sie die Computertomographie sei es bei der Diagnose als auch während des Followup überflüssig.

\section{DGKCH-FV-8 \\ Erfolgreicher Verschluss einer Riesenomphalozele mit vakuum- assistierter Wundverschlusstherapie}

Breuling K. ', Grundhuber H.J. ${ }^{,}$, Hosie S. ${ }^{,}$, Krohn C. ${ }^{1}$

${ }^{1}$ Klinikum München Schwabing, Klinik für Kinderchirurgie, München

Hintergrund. Wir berichten von einem Fall, bei dem, nach unserer Kenntnis erstmalig in Europa, der Verschluss einer Riesenomphalozele mit vakuumassistierter Wundverschlusstherapie gelungen ist, einem bisher V. a. bei der Behandlung von chronischen Wunden etabliertes Verfahren.

Kasuistik. Wir berichten von einem Neugeborenen, bei dem pränatal eine große Omphalozele diagnostiziert worden war. Bei Geburt waren Darm, Leber und Milz in die Zele prolabiert. Eine Verlagerung der Organe in die hypoplastische Bauchhöhle war nicht möglich. Es wurde ein steriler Beutel in die Bauchwand eingenäht. Nachdem es trotz regelmäBiger Redression nicht gelungen war, die Eingeweide in den Bauchraum zu verlagern, wurde eine V. A.C.-Therapie begonnen. Zwei Wochen darauf war der Verschluss des Abdomens mit komplettem Faszienverschluss ohne Fremdmaterial möglich. Hierbei machten wir uns den Raumgewinn zu Nutze, den beidseitige, große Leistenhernien anboten, welche das Intestinum vorübergehend - und aufgrund der Größe der Hernien auch ohne Inkarzerationsgefahr - aufnahmen. Der problemlose Hernienverschluss erfolgte dann im Alter von 6 bzw. 8 Monaten.

Fazit. Große Omphalozelen gefährden die Patienten einerseits bei frühem spannungsreichem Verschluss des Abdomens durch das Risiko eines abdominellen Kompartmentsyndroms, andererseits bei lange offen belassenem bzw. mit Kunstmaterial verschlossenem Abdomen durch das Risiko lebensbedrohlicher Infektionen (Peritonitis, Sepsis). Vorteile des V. A.C.-Systems könnten die verminderte Infektionsanfälligkeit durch Absaugen der Wundsekrete sowie die aktive Annäherung der Wundränder sein. Bisher sind nur 4 Kasuistiken publiziert, bei denen dieses Verfahren angewandt wurde. Dies ist nach unserer Kenntnis der erste außerhalb der U.S.A. publizierte Fall dieser Art.

\section{DGKCH-FV-9}

\section{Ösophagusatresie und extreme Frühgeburtlichkeit -} Fallbericht und Literaturübersicht

\section{Lawrenz K. ${ }^{1}$, Perez Becker R. ${ }^{2}$, Seiffert P. ${ }^{3}$}

${ }^{1}$ Helios Klinikum Krefeld, Klinik für Kinderchirurgie, Krefeld, ${ }^{2}$ Helios Klinikum Krefeld, Zentrum für Kinder- und Jugendmedizin, Krefeld, ${ }^{3} \mathrm{Helios} \mathrm{St}$. Johannes Hospital, Kinder- und Jugendklinik, Duisburg

Fallbericht. Ein nach $25+5$ SSW per Notsectio bei Placenta-Insuffizienz mit einem GG von $485 \mathrm{~g}$ entbundenes weibliches Frühgeborenes wird nach Bronchoskopie und Kontrastmitteldarstellung mit der Diagnose einer Ösphagusatreise Typ 3b nach Vogt am 2. Lebenstag verlegt. Bei hochgradiger abdomineller Distension und Magenüberblähung wird zunächst ein Gastrostoma angelegt. Am Folgetag wird das Kind extubiert und kommt mit IMV über Maske und CPAP gut zurecht, ohne dass die Fistel sich bemerkbar macht. Der Verlauf wird kompliziert 
durch eine gastrointestinale Transportstörung mit iatrogener Sigmaperforation bei rektaler Spülung 3 Tage später, die eine Notfall-Laparotomie mit Sigmaübernähung erforderlich macht, Im mittleren Ileum finden sich zwei ballonartig dilatierte Segmente, aboral davon ist der Dünndarm sehr eng gestellt, so dass ein Ileostoma angelegt. wird. Auch danach kommt die Passage nicht in Gang. Über das Gastrostoma ist regelmäßig viel Luft zu aspirieren. Darüber hinaus kommt es nun zu einer anhaltenden respiratorischen Verschlechterung. Unter HFOBeatmung steigt der $\mathrm{O}_{2}$-Bedarf auf $70 \%$, radiologisch ergibt sich Verdacht auf eine Aspiration. Nach Gabe von Surfactant und Cortison wird bei 40\% O2-Bedarf eine Thorakotomie mit Fistelverschluss und bei praktisch auf gleicher Höhe endenden Stümpfen eine spannungsfreie End-zu-End-Anastomose mit Schienung durch eine 6-Fr-Magensonde durchgeführt. Postoperativ steigt der $\mathrm{O}_{2}$-Bedarf innert 24 Stunden auf $100 \%$. Mit NO-Beatmung ab dem 2. postoperativen Tag lässt sich eine Senkung des $\mathrm{O}_{2}$-Bedarfs auf $40 \%$ erzielen, nach weiteren 48 Stunden jedoch Wiederanstieg auf 100\% und Exitus letalis am 14. Lebenstag durch respiratorische Insuffizienz.

Schlussfolgerung. Das Vorgehen wird unter Berücksichtigung der Literatur kritisch beleuchtet und zur Diskussion gestellt.

\section{DGKCH-FV-10 \\ Erfahrungsbericht: Einsatz in den Slums von Kalkutta für „Ärzte für die Dritte Welt"}

Winterhalter J.', Großer K.'

${ }^{1}$ Helios Klinikum, Kinderchirurgie, Erfurt

Fragestellung. Wie gestaltet sich die alltägliche Arbeit in den Projekten der Hilfsorganisation „Ärzte für die Dritte Welt“ anhand eines Erfahrungsberichtes aus einem 6-wöchigen Aufenthalt in Kalkutta vom 5.4.-18.5.2013. Welche Krankheitsbilder werden gesehen und wie erfolgt deren Therapie unter dem Aspekt der medizinischen Basis- und Breitenmedizin? Welche pädiatrischen Fragestellungen ergeben sich?

Material und Methoden. Retrospektive Auswertung der Patientenzahlen und erhobenen Diagnosen unter Einbezug der zur Verfügung stehenden diagnostischen und therapeutischen Optionen.

Ergebnisse. Die extreme Überbevölkerung, die armutsbedingte einseitige Ernährung und die Hygienesituation der innerstädtischen Ghettos bestimmen das Krankheitsspektrum, das die Ärztinnen und Ärzte zu sehen bekommen. Dieses Krankheitsspektrum wird dominiert von Infektionskrankheiten, die von banalen Infekten bis hin zu todbringenden Seuchenerkrankungen, z. B. Tuberkulose, reichen. Ein wichtiges Anliegen ist die Senkung der Mütter- und Kindersterblichkeit durch entsprechende Präventivmaßnahmen wie Ernährungs- und Impfprogramme sowie eine strukturierte Schwangerenvorsorge.

Schlussfolgerung. Kalkutta ist eine Stadt der Gegensätze und diese Widersprüchlichkeiten reichen bis in die Arbeit der „Ärzte für die Dritte Welt" hinein. In Kalkutta ist alles an medizinischer Infrastruktur vorhanden. Aber nur für die zahlungsfähigen Patienten (1o Prozent der Bevölkerung). Es gilt, im ärztlichen Alltag neben der bewährten und zu allererst notwendigen Basismedizin immer wieder individuell abzuwägen, welche medizinische Maßnahme sinnvoll und unterstützenswert ist, um möglichst viel Lebenszeit und -qualität für möglichst viele Menschen mit den zur Verfügung stehenden, finanziell begrenzten Mitteln, herauszuholen.

\section{Poster}

\section{DGKCH-PO-1 \\ The PBAC score is an easy tool to quantify menstrual blood loss in adolescents}

Halimeh S.

${ }^{1}$ Gerinnungszentrum Rhein/Ruhr, Duisburg

Introduction. Von Willebrand disease (VWD) is the most common inherited bleeding disorder. Menorrhagia or severe menstrual bleeding (HMB) is most common symptom of women with bleeding disorders. The menstrual blood loss can be quantified by the use of a pictorial bleeding assessment calendar (PBAC).

Samples and methods. In 195 women with menorrhagia and in 45 controls menstrual blood loss was quantified using pictorial blood assessment charts (PBAC; and results were compared.

Results. In 169 of 195 women (86\%) a bleeding disorder could be detected. In those with a bleeding disorder, the distribution was as follows: $169 / 195$ women have a coagulation disorder. $62 \%$ have a vWD, $14.4 \%$ have a factor VII deficiency, $5 \%$ have a factor XIII deficiency and $18.6 \%$ have a mild factor deficiency. PBAC in patients was $268(10-4212)$ in contrast in controls PBAC 46.5 (3-137).

Discussion. Attempts to measure the quantity of menstrual blood loss can be useful in clinical practice. A prospective method of quantifying menstrual blood loss includes the use of a pictorial bleeding assessment calendar (PBAC). We are of the opinion that we would have detected more bleeding disorders also in patients where we did not find any diagnosis until now if we would have controlled them more than one time during the cycleperiod. Conclusions. Women with hypermenorrhagia frequently suffer from a bleeding disorder. In $86 \%$ of our patients an abnormal coagulation was found. The PBAC-Score is an easy tool to quantify menstrual blood loss in women. In our study a PBAC score above 100 was suspicious of having a bleeding disorder. PBAC is a good tool to quantify menstrual blood loss in adolescents.

\section{DGKCH-PO-2}

\section{Skalpierungsverletzung durch Hundebiss bei einem 2-jährigen} Mädchen

\section{Hebestreit A. ', Lehnert T.' , Bühligen U. ', Metzger R. ${ }^{1}$}

'Universitätsklinikum Leipzig, Klinik und Poliklinik für Kinderchirurgie, Leipzig

Einleitung. Bissverletzungen im Kindesalter sind oft Grund einer ärztlichen Behandlung. Den Großteil bilden Hundebissverletzungen. Aus der Einteilung in Low-, Intermediate- und High-risk-Verletzungen (je nach Bissverursacher, Lokalisation, Ausmaß und Patientenalter) leiten sich unterschiedliche Therapiemaßnahmen ab.

Fallbericht. Es folgt die Fallvorstellung einer 2-jährigen Patientin, die durch den Kampfhund des Vaters in den Hinterkopf gebissen wurde. Hierbei verursachte das Tier einen $11 \times 7 \mathrm{~cm}$ großen Kopfschwartendefekt im Haarbereich. Es zeigte sich keine knöcherne Beteiligung. Bei der Erstversorgung erfolgte die Anlage eines VAC-Verbandes, im zweiten Schritt eine modifizierte Verschiebeplastik, die den Defekt auf $2 \times 5,5 \mathrm{~cm}$ verkleinern konnte. Zudem i.v.-antibiotische Therapie. Wir nutzten eine GUMMIZÜGELPLASTIK, welche Zug auf die Wundränder ausübte und diese weiter approximierte. Der Defekt konnte schrittweise auf eine Wundgröße von $6 x 1 \mathrm{~cm}$ reduziert werden, sodass nach 28 Tagen der sekundäre Wundverschluss erfolgte. Im Follow-up zeigte sich ein gutes kosmetisches Ergebnis. Schlussfolgerung. Insgesamt erfordern Bissverletzungen grundsätzlich eine risokogruppengerechte und individualisierte Therapie. Bei einer Bissverletzung mit großem Wunddefekt stehen mehrere Therapieoptionen zur Verfügung wie beispielsweise die VAC-Therapie, Verschiebeplastik oder Expandertechnik. Die im vorliegenden Fall durchgeführte schrittweise Behandlungsabfolge mit Gummizügelplastik erbrachte ein ansprechendes kosmetisches Ergebnis und einen zügigen Therapieverlauf. 


\section{DGKCH-PO-3}

Posttraumatisches Pankreashämatom - sekundäres operatives Vorgehen bei klinischer Verschlechterung mit Pleuraerguss

\section{Antenbrink F. ${ }^{1}$, Hoppen T. ${ }^{1}$, Pütz W. ${ }^{2}$, Meffert H. ${ }^{2}$, Tschirner F. ${ }^{3}$, Nüßlein T. ${ }^{1}$} ${ }^{1} G$ emeinschaftsklinikum Kemperhof Koblenz, Klinik für Kinder- und Jugendmedizin, Koblenz, ${ }^{2}$ Gemeinschaftsklinikum Kemperhof Koblenz, Klinik für Abdominal- und Viszeralchirurgie, Koblenz, ${ }^{3}$ Gemeinschaftsklinikum Kemperhof Koblenz, Klinik für Diagnostische und Interventionelle Radiologie, Koblenz

Hintergrund. Traumatische Verletzungen des Pankreas sind bei Kindern und Jugendlichen selten. Therapeutisch wird ein konservativer Therapieansatz propagiert.

Kasuistik. Zuweisung eines 14 9/12 Jahre alter Junge mit Pankreastrauma. Klinisch weiches Abdomen ohne Resistenz, Druckschmerz oder äußere Verletzungszeichen. Sonographisch: $3 \times 4 \times 5 \mathrm{~cm}$ große Raumforderung im Bereich des Pankreaskopfes. Computertomogramm (CT) des Abdomens: Hämatom im Pankreaskopf mit freier Flüssigkeit ohne aktive Blutung. Start einer konservativen Therapie mit vollparenteraler Ernährung, Analgesie, antibiotischer Therapie, Somatostatingabe und Bettruhe. Therapiekontrolle täglich sonographisch und laborchemisch. An Tag 5 Anstieg des CRP und sonographisch zunehmend Aszites. 2. CT an Tag 6: Größenzunahme des Pankreaskopfhämatoms und der freien Flüssigkeit, neu aufgetreten ein linksseitiger Pleuraerguss. Kernspintomographie an Tag 7: frische Blutung und Pankreasfistel. Klinische Verschlechterung mit zunehmenden Schmerzen und Ileus. Daraufhin Entscheidung zur Operation. Intraoperativ subtotale Abtrennung des Pankreaskopfes sowie Entfernung der Pankreaspseudozyste. Nach Anfrischen der Rissstelle Pankreatojejunostomie nach Roux-Y mit Drainage-Einlage im Bereich der Fistel. Postoperativ vorsichtiger Kostaufbau. Entlassung nach 25 Tagen. Ziehen der Drainage nach Förderstopp poststationär an Tag 57.

Fazit. Bei der traumatischen Pankreasverletzung im Kindes- und Jugendalter ist eine konservative Therapie oder die Anlage einer perkutanen Drainage die Regel. In diesem Fall war bei sekundärer klinischer und laborchemischer Verschlechterung und einem neu auftretenden Pleuraerguss eine operative Therapie nötig.

\section{DGKCH-PO-4 \\ Temporäre Y-Enterostomie nach Santulli bei Darmatresien mit großen Kalibersprüngen}

\section{Nissen M. ', Thränhardt R. ${ }^{1}$, Tröbs R.-B. ${ }^{1}$ \\ ${ }^{1}$ Ruhr-Universität Bochum, Marienhospital Herne, Kinderchirurgische Klinik, Herne}

Einleitung. Standardvorgehen bei Vorliegen einer Darmatresie ist die End-zu-End-Anastomose oder die Anlage eines Stomas.

Material und Methoden. Anhand zweier Fallbeispiele zeigen wir eine alternative chirurgische Strategie bei kritisch kranken Neugeborenen mit Darmatresie auf.

Ergebnisse. 1.) Ein Frühgeborenes (männlich, 34.+6. SSW, GG 1980 g; Darmkalibersprung 4:1) mit Laparoschisis und terminaler Ileumatresie (Apple-Peel-Typ) erhielt eine primäre Darmreposition mit Anlage einer Santullifistel und anschließender Bauchdeckenrekonstruktion. Kurze Nachbeatmungszeit. Stuhlentleerung zunächst via Stomaöffnung. Im Verlauf rektale Entleerung als Zeichen einer Befahrung des aboralen Schenkels. 2.) Ein Frühgeborenes (männlich, 40. SSW, GG 3975 g; Darmkalibersprung 3,6:1) mit fortgeschrittenem Ileusbild bei tiefer Kolonatresie erhielt initial ein doppelläufiges Descendostoma. Bei partieller Retraktion des aboralen Stomaschenkels erfolgte 11 Tage später die Santullifistel-Anlage. Keine Nachbeatmung vonnöten. Nach 9o Tagen und röntgenologisch verifizierter Passage komplikationslose Rückverlagerung des Anus praeter (Kalibersprung intraoperativ ca. 2:1).

Schlussfolgerung. Die Anlage der Santullifistel stellt in besonderen Situationen eine Alternative zur frühzeitigen Darmentlastung unter Herstellung einer Darmpassage im Seitenschluss dar. Die Vorteile liegen in der Konditionierung des nachgeschalteten Darmes sowie der relativ einfachen
Verschließbarkeit des Stomas und einer Minimierung der Resektionslänge unter weitestgehender Belassung dilatierter Darmanteile. Vermieden werden auch lange Zeitspannen des intraabdominellen Druckanstiegs wie sie bei der End-zu-End-Anastomose auftreten können.

\section{DGKCH-PO-5}

Rezidivierende Invaginationen bei Klein- und Schulkindern - an ein Lymphom denken!

Wortmann K. ${ }^{1}$, Neid M. ${ }^{2}$, Tröbs R.-B. ${ }^{1}$

${ }^{1}$ Ruhr-Universität Bochum, Kinderchirurgische Klinik, Herne, ${ }^{2}$ Ruhr-Universität Bochum, Institut für Pathologie, Bochum

Einleitung. Untersuchung auf zugrunde liegende Ursachen bei 1o Patienten, die im vergangenen Jahr wegen komplexer Invagination operiert und auf unserer kinderchirurgischen Intensivstation überwacht wurden. <1 LJ: 2-mal Meckeldivertikel, 1-mal Infarzierung, 3-mal einfache ileokolische Invagination; >1LJ: 1-mal Lymphadenitis mesenterialis, 1-mal nekrotisches Meckeldivertikel, 2-mal Burkitt-Lymphom. Case-Report über zwei Patienten (m 1oLJ, w 4LJ) mit rezidivierenden Invaginationen.

Fallbericht. Vorausgegangen waren wochenlange Episoden mit intermittierenden Bauchschmerzen, später Erbrechen und bei einem Patienten Diarrhoe. In beiden Fällen wurde bei Verdacht auf Rest-Invaginat nach hydrostatischer Evagination eine operative Therapie notwendig. Trotz erfolgreicher laparoskopischer Desinvagination kam es einige Tage später zur erneuten Invagination, so dass in beiden Fällen Laparotomie mit Coecotomie notwendig wurden. Endoluminal zeigte sich hyperplastisches Lymphgewebe der Valvula Bauhin als Ursache. Histopathologisch konnte in beiden Fällen ein Burkitt-Lymphom nachgewiesen werden.

Fazit. Grade bei Kindern außerhalb des typischen Altersbereiches sollte bei rezidivierenden Invaginationen an anatomische Ursachen gedacht und die Operationsindikation großzügig gestellt werden. Bei fehlendem äußeren Hypomochlion (z. B. Meckel-Divertikel, Appendixinvagination) in der Laparoskopie, sollte auch eine endoluminale Ursache wie das Burkitt-Lymphom erwogen werden.

\section{DGKCH-PO-6}

Ein 2,5 kg schweres Dysgerminom des rechten Ovars bei einem 12-jährigen Mädchen

Scholsching J. ', Holler A.-S. ', Beck O. ${ }^{2}$, Russo A. ${ }^{2}$, Faber J. ${ }^{2}$, Staatz G. ${ }^{3}$, Turial S. ${ }^{1}$

'Universitätsmedizin der Johannes Gutenberg-Universität Mainz, Klinik für Kinderchirurgie, Mainz, ${ }^{2}$ Universitätsmedizin der Johannes Gutenberg-Universität Mainz, Zentrum für Kinder- und Jugendmedizin, Mainz, ${ }^{3}$ Universitätsmedizin der Johannes Gutenberg-Universität Mainz, Klinik und Poliklinik für Diagnostische und Interventionelle Radiologie, Mainz

Einleitung. Maligne Keimzelltumoren im Kindesalter stellen mit 3,1\% aller malignen Tumoren eine seltene Tumorentität dar. Dysgerminome des Ovars treten mit 45\% am häufigsten auf. Wir beschreiben das chirurgische und kinderonkologische Vorgehen bei einem riesigen Dysgerminom ausgehend vom rechten Ovar.

Fallbericht. Das 12-jährige Mädchen wurde aufgrund eines ausladenden Abdomens zugewiesen. Die Umfangszunahme habe seit einem Jahr ohne Schmerzen oder andere Symptomatik bestanden. Im MRT zeigte sich eine Raumforderung ausgehend vom rechten Ovar, welche sich vom Leberhilus bis zum kleinen Becken erstreckte und die V. cava inf. und beide Ureteren komprimierte. Bei präoperativ erhöhten Tumormarkern $\beta$-HCG, CA-125, NSE bestand der V. a. einen gemischtzelligen Keimzelltumor. Es erfolgte die Tumor-Resektion durch Längslaparotomie und Salpingoophorektomie rechts. Bei vom Omentummajus ausgehender Gefäßinjektion zum Tumor erfolgte die Teilexcision des Omentums. Das Absetzen der Tube und Ligamenta erfolgte mit dem Ligasure. Der Tumor hatte ein Gewicht von 2,5 kg und maß maximal 27,5 cm. Das linke Ovar stellte sich makroskopisch unauffällig dar. Ein $3,5 \mathrm{~cm}$ großer Lymphknoten paraaortal zeigte einen Metastasennachweis. Nach Staging wurde die Diagnose eines reinen Dysgerminoms im Stadium pT1c, N1/FIGO IIIC 
gestellt. Gemäß den Leitlinien erfolgt in der pädiatrischen Onkologie die adjuvante Chemotherapie nach dem MAKEI-96-Protokoll.

Schlussfolgerung. Die Prognose der malignen Keimzelltumoren ist abhängig vom histologischen Subtyp, dem Tumorstadium, der operativen Resektabilität, und der adjuvanten Chemotherapie. Trotz großer Tumormasse war eine primäre Ro-Resektion möglich. Bei unauffälligem kontralateralen Ovar konnte so der Fertilitätserhalt gewährleistet werden. Die Prognose liegt nach Chemotherapie von 4 PEI-Zyklen bei $>80 \%$.

\section{DGKCH-PO-7}

\section{Zystisches Halshygrom - wie und wann? Zwei Fallberichte}

Troebs R.-B. ${ }^{1}$, Roll C. ${ }^{2}$, Teig N. ${ }^{3}$

${ }^{1}$ Marienhospital Herne, Klinik für Kinderchirurgie, Herne, ${ }^{2}$ Vestische Kinderund Jugendklinik Datteln, Universität Witten/Herdecke, Perinatalzentrum, Datteln, ${ }^{3}$ St. Josef Hospital Bochum, Perinatalzentrum, Bochum

Einleitung. Timing und Therapieplanung von zystischen Halshygromen $(\mathrm{HH})$ sind kontrovers. Die beiden Fälle illustrieren Möglichkeiten und Grenzen des chirurgischen Vorgehens.

Fallbericht. Fall 1: Sectio in der 35. SSW (2470 g) nach pränataler Diag. des HH. Intubation on placentalsupport. MRT: Großes Hygrom mit prävertebraler Ausdehnung bis zur Gegenseite. Operation am 10. LT. Unkomplizierter postoperativer Verlauf. Eine zweite transorale OP nach 6 Wo. diente der Entfernung einer pharyngealen Restzyste. 5,5 Jahre Nachbeobachtung: gute psychointellektuelle Entwicklung, kosmetisch günstige Hautnarbe sowie eine leichte Asymmetrie der Hals- und Schultermuskulatur. Fall 2: Sectio des Jungen nach pränat. Diag. in der 40. SSW (400o g). Resektion des Hygroms mit 14 Tagen ohne relev. Blutverlust. Postoperativ blutige Stühle, Bauchsymptomatik sowie ausgeprägte Pneumatosis. Bei Laparotomie ausgedehnte hämorrhagische Infarzierung des Kolon. Nach Teilresektion und Stomaanlage gute Entwicklung des Säuglings.

Fazit. Zur Behandlung großer HH stehen unterschiedliche Therapiemodalitäten zur Verfügung. Resektabilität und/oder eine potenziell vitale Bedrohung sind Argumente für die Operation. Perioperative Einflüsse sind im Einzelfall von ausschlaggebender Bedeutung. 


\section{Abstracts der 35. Jahrestagung des Berufsverbandes Kinderkrankenpflege (BeKD)}

\section{Vorträge}

Samstag, 14.09.2013

\section{Vorsorgen, umsorgen, nachsorgen - Prävention und Kinderschutz}

\section{BEKD-SY-PR-1 \\ Kinderschutz - was kann der KJGD leisten}

\section{Freynik P.}

'vormals Gesundheitsamt Stadt Essen, KJGD, Essen

Die Kinder- und Jugendgesundheitsdienste der Gesundheitsämter sind durch ihren Kontakt zu allen Sozialschichten prädestiniert, im Bereich des Kinderschutzes eine Schlüsselrolle zu übernehmen. Das Bundeskinderschutzgesetz nimmt Ärzte und andere Mitarbeiter in medizinischen Berufen, ebenso wie sonstige Berufsgeheimnisträger, in die Pflicht, frühzeitig Risikolagen zu erkennen, zeitnah zu intervenieren und falls erforderlich das Jugendamt einzuschalten. An dieser schwierigen Schnittstelle kann der öffentliche Gesundheitsdienst wichtige Vermittlungsfunktionen zwischen niedergelassenen Kinderärzten, Kindertageseinrichtungen und der Jugendhilfe übernehmen. Zusätzliche Handlungsoptionen bieten sich für den KJGD bei der Dokumentation von Vernachlässigung und/oder Misshandlung, sowie der fachlichen Beratung von nicht-medizinischem Personal zu typischen Verletzungsmustern. Eine besondere Herausforderung stellt das Angebot dar, ganz gezielt Multiproblemfamilien langfristig zu begleiten und mit regelmäßigen Untersuchungs- und Unterstützungsangeboten zu stärken; so können auch diese Eltern nach einiger Zeit ihre Erziehungs- und Versorgungsaufgaben für die eigenen Kinder erfüllen. Am Beispiel der Großstadt Essen wird dargestellt wie gut unterschiedliche Systeme miteinander kooperieren können, wenn die Rollen und Aufgaben der beteiligten Akteure aus Gesundheitswesen und Jugendhilfe klar definiert sind. Der Beitrag soll andere Kommunen darin bestärken, sich ämter- und institutionsübergreifend auf den Weg zu begeben, Kindern und Familien mit besonderen Unterstützungsbedarfen entsprechende Hilfsangebote zu unterbreiten.
BEKD-SY-PR-2

Zwischen Reihenuntersuchung und Hausbesuch - die Kinderkrankenschwester auf dem Weg zur Public Health Nurse. Eine realistische Vision für den Öffentlichen Gesundheitsdienst!?

Frischmuth S.', Klages G.'

'Gesundheitsamt Düsseldorf, Kinder- und Jugendgesundheitsdienst, Düsseldorf

Hintergrund. Public Health Nursing (PHN) ist ein in Deutschland noch wenig bekanntes Fachgebiet der Pflege. PHN bearbeitet den pflegespezifischen Beitrag zur Lösung von Gesundheitsproblemen von Bevölkerungsgruppen und Individuen.

Fragestellung. Wie kann das Arbeitsgebiet der Gesundheits- und Kinderkrankenpflege im Kinder- und Jugendgesundheitsdienst eines Gesundheitsamtes professionell begründet, gestaltet und entwickelt werden? Welche Aufgaben übernehmen Pflegefachkräfte in diesem Zusammenhang bereits? Welche Rollen können und sollten in Zukunft weiter entwickeln werden?

Ergebnisse. PHN erfordert spezifische Kompetenzerweiterungen, da die Arbeit selten von akuten Gesundheitsproblemen einzelner Personen bestimmt wird. Der Ausgangspunkt der Interventionen liegt überwiegend in den Gesundheitsbedürfnissen von Gruppen. PHN-Kompetenzen werden vorgestellt und deren Auswirkungen auf die Gestaltung ausgewählter Praxisfelder benannt.

Diskussion. Bei dem Versuch, theoretische Erklärungen für die Praxis zu finden und gleichzeitig die Praxis durch diese Erklärungen zu verbessern und zu erweitern, haben wir festgestellt, dass wir bereits nach PHN Prinzipien arbeiten. Schwerpunkte für zukünftige Entwicklung sehen wir in weiterer Umsetzung des Pflegeprozesses auch aus salutogenetischer Perspektive und zunehmender Ressourcenorientierung. Die Schnittstellen von PHN mit Medizin und Sozialarbeit bieten weitere Entwicklungsmöglichkeiten.

Schlussfolgerung. Profitieren werden sowohl Patienten wegen passgenauerer Interventionen als auch Pflegekräfte durch höhere Berufszufriedenheit und dadurch letztlich auch die Arbeitgeber. PHN ist somit auch eine interessante Perspektive für die Gesundheits- und Kinderkrankenpflege in Deutschland.

Zweitautorin ist auch präsentierende Autorin. 


\section{Abstracts der 30. Jahrestagung der Arbeitsgemeinschaft Pädiatrische Immunologie (API)}

\section{Vorträge}

\author{
Freitag, 13.09.2013
}

API Session (1)

\begin{abstract}
API-SY1-2
Hematopoietic stem cell gene therapy for Wiskott Aldrich syndrome

Witzel M. ${ }^{1}$, Braun C.J.', Boztug K. ${ }^{2,3}$, Schmidt M. ${ }^{4}$, Albert M. ${ }^{5}$, Schwarzer A. ${ }^{6}$, Modlich U. ${ }^{6}$, Beier R. ${ }^{7}$, Göhring G. ${ }^{8}$, Naundorf S. ${ }^{9}$, Kühlcke K. ${ }^{9}$, Rose M..$^{10}$, Fraser C. ${ }^{11}$, Mathias L. ${ }^{12}$, Ferrari R. ${ }^{13}$, Abboud M. ${ }^{14}$, Al-Herz W. ${ }^{15}$, Kondratenko $I^{16}{ }^{16}$, Maródi L. ${ }^{77}$, Schlegelberger B. ${ }^{8}$, Baum C. ${ }^{6}$, von Kalle C. ${ }^{4}$, Klein C. ${ }^{1}$

'Ludwig-Maximilians-Universität Munich, University Children's Hospital, Munich, ${ }^{2}$ Research Center for Molecular Medicine of the Austrain Academy of Sciences (CeMM), Vienna, Österreich, ${ }^{3}$ Department of Pediatrics and Adolescent Medicine, Medical University of Vienna, Vienna, Österreich, ${ }^{4}$ Department of Translational Oncology, National Center of Tumor Disease, Heidelberg, ${ }^{5}$ Ludwig-Maximilians-Universität Munich, Childrens Hospital, Munich, ${ }^{6}$ Department of Experimental Hematology, Hannover Medical School, Hannover, ${ }^{7}$ Department of Pediatric Hematology/Oncology, Hannover Medical School, Hannover, ${ }^{8}$ Department of Cellular and Molecular Patholgy, Hannover Medical School, Hannover, ${ }^{9}$ EUFETS AG, Idar-Oberstein, ${ }^{10}$ Department of Pediatrics, Minden Hospital, Minden, "Royal Children's Hospital, Queensland Children's Cancer Center, Queensland, Australien, ${ }^{12}$ Department of Pediatric Hematology and Oncology, Loma Linda University Medical Center, Loma Linda, USA, ${ }^{13}$ Children's Hospital Kemperhof, Koblenz, ${ }^{14}$ Children's Cancer Center of Lebanon, American University of Beirut, Beirut, Libanon, ${ }^{15}$ Pediatrics Department, Allergy and Clinical Immunology Unit, Al-Sabah Hospital, Kuwait City, Kuwait, ${ }^{16}$ Department of Clinical Immunology, Russian Clinical Children's Hospital, Moscow, Russische Föderation, ${ }^{17}$ Department of Infectious and Pediatric Immunology, Medical and Health Science Center, University of Debrecen, Debrecen, Ungarn
\end{abstract}

Introduction. The Wiskott Aldrich syndrome (WAS) is an X-linked disease caused by mutations in the WAS gene. The phenotype comprises thrombocytopenia, immunodeficiency, autoimmunity and predisposition for malignancy. Severe WAS is a lethal disease within the first two decades of life.

Methods. Between 2006 and 2009 a total number of 10 patients (mean age 5.1 years; range 2-14 years) were treated with retroviral gene therapy (GT). After GT we observed polyclonal hematopoiesis with phenotypical reconstitution of relevant cell lines in 9/10 patients. Comprehensive analysis of retroviral insertion sites revealed more than 70,000 recurring loci. However, 5/10 of patients developed T-ALL, each associated with a retroviral insertion in close proximity to the $\mathrm{LMO}_{2}$ locus. $\mathrm{Pa}-$ tients with T-ALLs are treated according to AEIOP BMF 2009 protocol. Results. In $3 / 5$ of patients poor prednisone response was noted and 3/5 patients with T-ALL qualified for allogeneic HSCT due to poor initial response, minimal residual disease relapse, or cytological relapse. Due to early relapse after HSCT $1 / 5$ of patients with T-ALL died. Futher one patient developed MDS like bone marrow changes and consecutively AML. Retrospectively, MDS1 clonal contribution to insertion sites showed a slow increase over the period of several months.

Conclusion. GT is still associated with considerable risk for insertional mutagenesis and inferior event free survival (EFS). However, non-myeloablative conditioning and an autologous strategy have many advantages - most importantly the lack of allogeneic immune reactions - which can pay out with the advent of a safer GT in the future.

\author{
API-SY1-3 \\ Langzeitüberleben nach Stammzelltransplantation bei Patienten \\ mit PNP-Mangel
}

Knirsch S. ', Schütz C. ', Schulz A. ', Friedrich W. ', Hönig M. ${ }^{1}$

'Klinik für Kinder- und Jugendmedizin, Universitätsklinikum Ulm, UIm

Einleitung. Der Purin-Nukleosid-Phosphorylase (PNP) Mangel ist eine metabolische Systemerkrankung und bedingt eine autosomal rezessive Variante eines schweren kombinierten Immundefektes. Neben dem Immundefekt treten auch Autoimmunphänomene und neurologische Auffälligkeiten auf. Durch eine Stammzelltransplantation kann der Immundefekt korrigiert werden, bezüglich der weiteren Entwicklung der neurologischen Auffälligkeiten besteht noch Unklarheit.

Methoden. Zwischen 1996 und 2013 wurden 6 Patienten mit PNP-Mangel an der Kinderklinik der Universität Ulm behandelt. Wir untersuchten retrospektiv 4 überlebende Patienten. Die Patienten (mittleres Alter 1,6 Jahre) stellten sich mit einer typischen Anamnese mit rezidivierenden Infektionen vor. Die Diagnose wurde bei allen Patienten mit einer nicht messbaren Enzymaktivität von PNP in Erythrozyten gesichert. Ergebnisse. Alle Kinder zeigten ein deutliches Entwicklungsdefizit. Bei 3 von 6 Patienten waren die neurologischen Symptome führend und führten zur Diagnosestellung. Zwei von 6 Patienten hatten nebenbefundlich andere neurologische Erkrankungen. Es erfolgten 2 haploidentische Transplantationen, 2 von HLA-identischen Fremdspendern (MUD) und 2 von passenden Familienspendern. Alle Patienten erhielten eine myeloablative Konditionierung. Die mediane Follow-up-Zeit der überlebenden Patienten beträgt aktuell 9,8 Jahre (zwei Patienten verstarben im Rahmen von Infektionen). Es wurde jeweils eine vollständige Immunrekonstitution bei $100 \%$ Spenderchimärismus beobachtet. Die 4 Überlebenden zeigen weiterhin neurologische Symptome und Lernstörungen unterschiedlichen Ausmaßes.

Schlussfolgerung. Wir präsentieren 4 Langzeitüberlebende mit PNPMangel nach SZT. Neurologische Auffälligkeiten bestanden schon vor SZT und beeinträchtigen die Patienten im weiteren Verlauf entscheidend.

\section{API Session (2)}

\section{API-SY2-2}

Impaired TCR signalling and T cell function in human ITK deficiency

Hauck F. ${ }^{1,2,3}$, Keller B. ${ }^{4}$, Bacon C. ${ }^{5}$, Stepensky P. ${ }^{6}$, Arkwright P. ${ }^{7}$, Cant A. ${ }^{8}$, Picard C. ${ }^{2,3,9}$, Warnatz K. ${ }^{4}$, Hambleton S. ${ }^{8}$, Albert M. ${ }^{1}$, Klein C. ${ }^{1}$, Latour S. ${ }^{2,3}$ 'Universitätskinderklinik LMU München, Hämatologie/Onkologie/Stammzelltransplantation, München, ${ }^{2} \mathrm{Hôpital}$ Universitaire Necker-Enfants Malades, INSERM ${ }^{768}$, Laboratoire du Développement Normal et Pathologique du Système Immunitaire, Paris, Frankreich, Institut Imagine, Université Sorbonne Paris Cité, Université Paris Descartes, Paris, Frankreich, ${ }^{4}$ University Medical Centre, Center of Chronic Immunodeficiency, Freiburg, ${ }^{5}$ Newcastle upon Tyne Hospitals NHS Foundation Trust, Royal Victoria Infirmary, Department of Cellular Pathology, Newcastle upon Tyne, UK, ${ }^{6}$ Hadassah Medical Center, Hadassah Hebrew University, Department of Paediatric Haematology/Oncology, Jerusalem, Israel, ${ }^{7}$ Royal Manchester Children's Hospital, Department of Paediatric Immunology, Manchester, UK, ${ }^{8}$ Institute of Cellular Medicine, Newcastle University, Newcastle upon Tyne, UK, ${ }^{\circ}$ Hôpital Universitaire Necker-Enfants Malades, Centre d'Etude des Déficits Immunitaires, Paris, Frankreich

Introduction. The IL-2 inducible T cell kinase (ITK) is a member of the TEC family PTKs and structural and functional data predominantly stem from in vitro testing and the Itk-/-mouse model. ITK is predominantly expressed in $\mathrm{T}$ cells and contains a $\mathrm{N}$-terminal $\mathrm{PH}$ domain, follo- 
wed by a $\mathrm{BH}$ motif, a proline rich region, a $\mathrm{SH}_{3}$ domain, a $\mathrm{SH}_{2}$ domain, a $\mathrm{SH}$-kinase linker region and a $\mathrm{C}$-terminal kinase domain. Following TCR:CD3:ל-induced assembly of the LAT:SLP-76-signalosome and $\mathrm{PI}_{3} \mathrm{~K}$ mediated generation of membrane-bound $\mathrm{PIP}_{3}$, ITK is recruited to the LAT:SLP-76-signalosome and anchors to $\mathrm{PIP}_{3}$ via its $\mathrm{PH}$ domain. SLP76-bound and PIP3-anchored ITK is activated by LCK-mediated tyrosine phosphorylation and ITK consecutively performs tyrosine autophosphorylation further stabilizing the ITK:LAT:SLP-76-signalosome. The main target of ITK is PLC $\gamma-1$ that is bound to and directly activated by ITK-mediated tyrosine phosphorylation. Thus, ITK is important for the generation of the second messengers $\mathrm{IP}_{3}$ and $\mathrm{DAG}$ and a crucial upstream mediator of Ca2+- and MAPK-signalling.

Results. Recently, human ITK-deficiency has been described as a novel CID with progressive $T$ cell lymphopenia, loss of $\mathrm{CD} 4+\mathrm{T}$ cell naïvitiy and hypogammaglobulinaemia. Importantly, human ITK-deficiency displays impaired immunity towards EBV leading to lymphoproliferative disaese and Hodgkin-like lymphoma. However, detailed immunological phenotype and signalling properties of human ITK-deficient T cells is lacking.

Conclusion. We now provide detailed immunophenotypic, TCR-signalling and T cell functional data in a cohort of ITK+/- and ITK-/- patients contributing to our understandig of the biological role of ITK in human $\mathrm{T}$ cell development and function as well as in medical diagnosing of human ITK-deficiency.

\section{API-SY2-3}

X-linked-inhibitor-of-apoptosis(XIAP)-Defizienz: unerwartet breites Spektrum der Erstmanifestation von 25 Patienten

Speckmann C. ${ }^{1}$, Lehmberg K. ${ }^{2}$, Albert M. ${ }^{3}$, Rensing-Ehl A. ${ }^{1}$, Vraetz $T_{.}{ }^{4}$, Ufheil H. ${ }^{1}$, Grimbacher B. ${ }^{1,5}$, Fuchs I.', Belohradsky B. ${ }^{3}$, Hassan A. ${ }^{6}$, Strahm B. ${ }^{4}$, Schibli S. ${ }^{7}$, Lauten M. ${ }^{8}$, Kohl M. ${ }^{8}$, Rodeck B. ${ }^{9}$, Meerpohl J. ${ }^{4}$, Kolb R. ${ }^{10}$, Salzer U. ${ }^{1}$, von Bernuth H. ${ }^{11}$, Schwarz K. ${ }^{12}$, Lorenz M. ${ }^{12}$, zur Stadt U. ${ }^{2}$, EhI S.

'Universität Freiburg, Centrum für chronische Immundefizienz, Freiburg, ${ }^{2}$ Universität, Hamburg, ${ }^{3}$ Ludwig-Maximilians-Universität, München, ${ }^{4}$ Universität, Freiburg, ${ }^{5}$ University College, London, UK, ${ }^{6}$ Great Ormond Street Hospital, London, UK, Inselspital, Bern, Schweiz, ${ }^{8}$ Universitätsklinikum Schleswig-Holstein, Lübeck, ${ }^{9}$ Marienhospital, Osnabrück, ${ }^{10} \mathrm{Klinikum,}$ Oldenburg, ${ }^{11}$ Charité - Universitätsmedizin, Berlin, ${ }^{12}$ Universität, Ulm

Einleitung. Mutationen in XIAP/BIRC4 (X-linked inhibitor of apoptosis) wurden ursprünglich in einer Kohorte von Patienten mit XLP (Xlinked lymphoproliferative syndrome) beschrieben, die keine Veränderungen im $\mathrm{SH}_{2} \mathrm{D}_{1} \mathrm{~A}$ Gen besaßen. Entsprechend zeigten in den ersten Berichten viele Patienten einen Phänotyp mit EBV assoziierter hämophagozytischer Lymphohistiozytose (HLH).

Methode und Ergebnisse. Wir berichten über 25 symptomatische XIAP Patienten, die wir zwischen 2010-2013 mittels durchflusszytometrischen Screening diagnostiziert haben. Hierunter befinden sich $17 \mathrm{~Pa}-$ tienten, deren initialen klinischen Symptome keine HLH assoziierten Beschwerden waren. Unsere Patienten manifestierten sich mit Crohnähnlicher Darmentzündung $(n=6)$, schwerer Mononukleose $(n=4)$, isolierte Splenomegalie $(n=3)$, Uveitis $(n=1)$, periodisches Fieber $(n=1)$, fistelnde Hautabszesse $(n=1)$ und schwere Giardiasis. $(n=1)$. Nachfolgend beobachtete klinische Manifestationen waren Zöliakie-ähnliche Autoimmunenteropathie, Antikörpermangel mit Infektanfälligkeit, Splenomegalie und partielle HLH. Innerhalb eines klinischen Beobachtungszeitraums von 15 Jahren haben nur 2 von 17 Patienten eine behandlungsbedürftige HLH entwickelt. Wir berichten außerdem über 8 Patienten, deren initiales klinisches Bild ein XLP Phänotyp war.

Diskussion. Ein diagnostisches Screening mittels Durchflusszytometrie identifizierte die meisten, aber nicht alle, Patienten unserer Kohorte. Weder Genotyp, noch Proteinexpression oder Apoptoseuntersuchungen können den klinischen Phänotyp verhersagen. Unsere Beobachtungen zeigen, dass XLP zwar eine wichtige phänotypische Variante der XIAP-Defizienz ist, die Krankheit sich aber v. a. initial mit einem breiteren klinischen Spektrum manifestieren kann als bisher angenommen.

\section{API-SY2-4}

\section{Immunophänotypische Charakterisierung von Patienten mit HLH}

Ammann S.', Ufheil H. ', Bode S. ', Lehmberg K. ${ }^{2}$, zur Stadt U. ${ }^{2}$, Rensing-Ehl A. ${ }^{1}$, Eh/ S. ${ }^{1}$

${ }^{1}$ Universitätsklinikum Freiburg, CCl, Freiburg, ${ }^{2}$ Universitätsklinikum Hamburg-Eppendorf, Hamburg

Einleitung. Familiäre Hämophagozytische Lymphohistiozytose (FHL) ist eine seltene primäre Immundefizienz, die sich gewöhnlich im ersten Lebensjahr manifestiert und ohne Behandlung tödlich verläuft. Charakteristisch sind eine gestörte Immunhomöostase sowie eine andauernde Aktivierung von Lymphozyten und Histiozyten. FHL ist eine genetische Erkrankung mit Mutationen im Perforin (FHL2) oder in Genen der zellulären Zytotoxizität von NK und CD8+T-Zellen (FHL 3, 4, 5). Das hämophogozytäre Syndrom (HLH) kann auch sekundär ohne genetische Disposition aufgrund Infektionen, maligner Tumoren oder rheumatischen Erkrankungen auftreten.

Methoden. Mausexperimente (LCMV infizierte Perforin-/- Mäuse) zeigen eine verstärkte Aktivierung von CD8+T-Zellen. Ob diese Beobachtung auch auf die humane Erkrankung zutrifft, ist bislang ungeklärt. Nicht alle Episoden von FHL im Menschen sind durch eine Infektion verursacht, häufig kann keine infektiöse Ursache identifiziert werden. Um dieser Frage nachzugehen, untersuchen wir das CD8+T-Zellkompartiment in verschiedenen primären und sekundären Formen der HLH während der akuten HLH Phase. Hierfür werden verschiedene phänotypische Marker benutzt (HLA-DR, CD45RA, CCR7, CD27, KLGR1, CD57, PD1).

Ergebnisse. Erste Ergebnisse zeigen eine starke CD8+T-Zell-Aktivierung in einigen, aber nicht allen Patienten mit FHL. Diese Aktivierung ist alters- und infektionsunabhängig. Ungeachtet einer genetischen Veränderung mit einer vollständigen HLH-Symptomatik zeigen Patienten im Alter von o-6 Monaten eine geringe T-Zellaktivierung. Schlussfolgerung. Diese T-Zellaktivierung und Differenzierung gibt keinen Hinweis auf die Diagnose einer genetischen oder sekundären HLH. Daher ist anzunehmen, dass die humane FHL Pathogenese komplexer ist, als es das LCMV Mausmodell vermuten lässt.

\section{API Session (3)}

\section{API-SY3-2 \\ Congenital neutropenia caused by homozygous loss-of-function mutation in the CSF3R gene}

Triot A. ', Järvinen P. ', Unal E. ', Puchalka J.', Kohistani N. ', Racek T.', Klein C.' 'Ludwig-Maximilian-Universität München, Dr. von Haunersches Kinderspital, Muenchen, ${ }^{2}$ Erciyes University Medical Faculty, Division of Pediatric Immunology Allergy, Kayseri, Türkei

Congenital neutropenia $(\mathrm{CN})$ is a genetically heterogeneous disease characterized by low absolute neutrophil count (ANC) from birth and increased susceptibility to severe and recurrent infections. Here, we report on a consanguineous Turkish family with three children affected with $\mathrm{CN}$. Clinically, patients had low neutrophil counts and multiple hospitalizations due to infection. Using exome sequencing, we identified a novel homozygous missense mutation (p.Arg308Cys) in the extracellular domain of the G-CSFR. Ectopically expressed mutant G-CSFR differed in its size and glycosylation pattern from the wild-type as detected by western blot analysis. Confocal microscopy studies showed a distinct pattern of subcellular distribution: in contrast to wild-type G-CSFR, G-CSFRArg308Cys was colocalized with the endoplasmic reticulum and was not expressed at the plasma membrane. Moreover, preliminary results also implicated mutant G-CSFR to be at least partially dysfunctional, as it had a greatly decreased response to G-CSF stimulation measured by phosphorylation of downstream $\mathrm{STAT}_{3} / 5$ molecules. Analysis of protein structure by using an already crystallized G-CSFR protein model revealed that the mutated residue is located in close proximity to a WSXWS motif, which is known to affect proper folding and transport of class I cytokine receptor proteins to the cell surface. In conclusion, we report the first cases of congenital neutropenia caused by an inherited mutation in the G-CSF-R gene. The mutated ar- 
ginine in the G-CSFR receptor appears to affect the proper folding of the receptor, leading to decreased surface expression and signal transduction.

\section{API-SY3-3 \\ Heterozygote aktivierende Mutation in CEBPE resultiert in drasti- schen Änderungen der Proteinzusammensetzung in Neutrophilen}

Prengemann N.K. ${ }^{1}$, Dieckmann R. ${ }^{2}$, Mejstrikova E. ${ }^{3}$, Garncarz W. ${ }^{1}$, Zapletal O. ${ }^{4}$, Janda A. ${ }^{5}$, Bennett K. ${ }^{1}$, Litzman J. ${ }^{6}$, Kerjaschki D. ${ }^{2}$, Boztug K. ${ }^{1,7}$

${ }^{1} \mathrm{CeMM}$ Research Center for Molecular Medicine of the Austrian Academy of Sciences, Vienna, Österreich, ${ }^{2}$ Clinical Institute of Pathology, Medical University of Vienna, Vienna, Österreich, ${ }^{32}$ nd Faculty of Medicine, University Hospital Motol, Department of Pediatric Hematology and Oncology, Prague, Tschechische Republik, ${ }^{4}$ University Hospital Brno, Department of Clinical Hematology, Brno, Tschechische Republik, ${ }^{5} \mathrm{CCl}-$ Centrum für Chronische Immundefizienz, Freiburg, ${ }^{6}$ St. Anne's University Hospital, Faculty of Medicine, Masaryk University, Department of Clinical Immunology and Allergology, Brno, Tschechische Republik, 'Medical University of Vienna, Department of Pediatrics and Adolescent Medicine, Vienna, Österreich

Einleitung. Spezifische Granuladefizienz („specific granule deficiency“, SGD) bezeichnet eine sehr seltene Erkrankung, welche durch Neutrophilendysfunktion und wiederkehrende bakterielle Infektionen gekennzeichnet ist. Die Neutrophilen der Patienten zeigen eine reduzierte Granularität, Fehlen von Markern wie Laktotransferrin und erhöhte Expression von Monozytenmarkern. Die molekulare Ursache dieses seltenen funktionellen Neutrophilendefektes besteht in Mutationen im CCAAT/enhancerbinding protein epsilon(CEBPE)-Gen, das für einen Transkriptionsfaktor kodiert, welcher entscheidend für die terminale Differenzierung von Granulozyten ist. Interessanterweise können Mutationen in CEBPE sowohl autosomal dominant als auch rezessiv vererbt werden.

Methoden. Hier beschreiben wir zwei neue Patienten mit einer bereits bekannten (Khanna-Gupta, Blood 2007) heterozygoten Mutation in CEBPE (c.T756C/T, p.V218A). Um die Rolle von CEBPE in Neutrophilen zu analysieren, untersuchten wir die Proteinzusammensetzung von Neutrophilen der Patienten mit Hilfe von Massenspektrometrie und Immunfluoreszenz. Ergebnisse. Interessanterweise konnten wir zeigen, dass mehr als 150 Proteine eine veränderte Expression im Vergleich zu Kontrollen zeigten, unter ihnen Proteine wie LTF, LCN2 und CAMP, welche normalerweise in spezifischen Granula lokalisiert sind, jedoch im Patienten nicht nachzuweisen sind. Des Weiteren konnten wir auch einige Proteine identifizieren, welche potentiell eine Rolle in der Bildung von spezifischen Granula spielen können.

Schlussfolgerung. Mit Hilfe der Aufarbeitung dieses Datensatz erhoffen wir uns Einblicke in den Krankheitsmechanismus von SGD, sowie ein erweitertes Verständnis der Biologie spezifischer Granula in neutrophilen Granulozyten.

\section{API-SY3-4}

The CD $62 \mathrm{~L}$ shedding is reliable for the diagnosis of IRAK-4-deficiency even in pneumococcal sepsis

Strehl K. ${ }^{1}$, Andres O. ${ }^{2}$, Koelsch U. ${ }^{3,4}$, Kunzmann S. ${ }^{2}$, Lebrun A.-H. ${ }^{1}$, Stroh T. ${ }^{5}$, Schwarz K. ${ }^{6}$, Morbach H. ${ }^{2}$, Liese J. ${ }^{2}$, von Bernuth $\mathrm{H}^{1,3}$

${ }^{1}$ Department of Pediatric Pneumology and Immunology, Charité Children's Hospital, Berlin, ${ }^{2}$ Division of Pediatric Infectious Diseases and Immunology and Division of Neonatology and Pediatric Intensive Care, Department of Pediatrics, University of Würzburg, Würzburg, ${ }^{3}$ Division of Immunology, Labor Berlin, Berlin, ${ }^{4}$ Institute of Medical Immunology, Charité - Universitätsmedizin Berlin, Berlin, ${ }^{5}$ Medical Department I, Charité - Universitätsmedizin Berlin, Campus Benjamin Franklin, Berlin, ${ }^{6}$ Institute for Clinical Transfusion Medicine and Immunogenetics, Ulm, German Red Cross Blood Service, Baden-Württemberg-Hessen, and Institute for Transfusion Medicine, University Hospital, Ulm

A previously healthy 9 month old boy presented with a fulminant pneumococcal sepsis with attenuated acute phase response. Despite immedia- tely started symptomatic and specific therapy the patient deceased after three days due to multi-organ failure. The combination of fulminant fatal pneumococcal sepsis and attenuated acute phase response was suspective for a defect in Toll-like receptor (TLR) signaling. The patient's granulocytes did not show CD62L shedding upon activation with the TLR-4 agonist lipopolysaccharide (LPS) and the TLR-2 agonist PAM2CSK4, whereas stimulated control granulocytes shed CD62L. Impaired production of IL-6 in whole blood upon stimulation with TLR agonists further confirmed the suspicion of a defect in TLR-signaling. Sanger sequencing identified two compound-heterozygous autosomal-recessive mutations in IRAK-4, one of them novel. RT-PCR and Western Blotting of IRAK-4 and the assessment of IRAK-1 degradation characterized the mutations as amorphic. The flow-cytometry based assessment of CD62L shedding on granulocytes upon activation with TLR-agonists had previously been reported as a reliable and fast alternative to the measurement of cytokines in the supernatant of whole blood. Here we demonstrate that even under septic conditions the CD62 L shedding assay is a fast and reliable diagnostic tool for the detection of an IRAK-4 deficiency.

\section{API-SY3-5}

Aspergillus fumigatus induces neutrophilic myeloid-derived suppressor cells through a dectin-1 and reactive oxygen speciesmediated mechanism

Rieber N. ${ }^{1}$, Bouzani M. ${ }^{2}$, Amich J. ${ }^{2}$, Ost M. ${ }^{1}$, Singh A. ${ }^{1}$, Schäfer I.', Mezger M.', Pfeiffer M. ', Handgretinger R. ', Liese J. ${ }^{3}$, Beilhack A. ${ }^{2}$, Hartl D. ${ }^{1}$

'Universitätsklinik Tübingen, Kinderheilkunde I, Tübingen, ${ }^{2}$ Medizinische Klinik III, Würzburg, ${ }^{3}$ Kinderklinik Universität, Würzburg

The coordinated action of innate and adaptive immunity is essential to protect the host against fungi. Innate immune cells recognize and destroy fungi, but overshooting inflammation causes tissue damage and defective fungal clearance. The mechanisms by which fungi impair inflammatory responses are incompletely understood. Myeloid-derived suppressor cells (MDSCs) are innate immune cells that endogenously limit inflammation. Here we show that the prototypic pathogenic fungus Aspergillus fumigatus (A. fumigatus) induces immunosuppressive neutrophilic MDSCs (PMN-MDSCs). In contrast to canonical hostinduced MDSCs, A. fumigatus-induced PMN-MDSCs expressed the G protein-coupled chemokine receptor and HIV co-receptor CXCR4. Mechanistically, A. fumigatus-induced PMN-MDSCs modulated T cell proliferation, NK cell functionality and chemokine responses. Blocking of the pattern recognition receptor dectin-1 or using cells from a patient with deficient dectin-1 downstream signaling abolished A. fumigatusdependent PMN-MDSC induction, while dectin-1 activation mimicked the induction of the PMN-MDSC phenotype. Downstream analyses demonstrated that reactive oxygen species (ROS) were essential for dectin1-mediated PMN-MDSC induction. Collectively, these studies demonstrate that fungi induce a specific subset of PMN-MDSCs through a novel dectin-1 and ROS-mediated mechanism. The fungus utilizes this mechanism to dampen pro-inflammatory responses and to establish a bistable host-pathogen interaction.

\section{API-SY3-6}

Necrotising pneumococcal pneumonia due to a soluble IL-6 inhibitory factor?

Kölsch U.', Unterwalder N. ', Durmus N. ${ }^{2}$, Bauer M. ${ }^{3}$, Renner T. ${ }^{2}$, Seeliger S. ${ }^{2}$, Meisel C. ${ }^{1,4}$, von Bernuth H. ${ }^{1,3}$

'Labor Berlin GmbH - Kompetenz von Charité Vivantes, Department of Immunology, Berlin, ${ }^{2}$ Children's Hospital, Neuburg, ${ }^{3}$ Med. Fakultät HumboldtUniversität zu Berlin/ Charité, Children's Hospital, Berlin, ${ }^{4}$ Med. Fakultät Humboldt-Universität zu Berlin/Charité, Department of Immunology, Berlin

A previously healthy 6 year old boy presented with necrotising pneumococcal pneumonia, recurring pleural effusions, lobar pleural atelectasis, 
abscess formation and attenuated acute phase response. Despite immediately started symptomatic and specific therapy the patient had to undergo a lobar resection of the lung. The combination of severe pneumococcal pneumonia and attenuated acute phase response lead to the suspicion of a defect in Toll-like receptor (TLR) and IL-1 receptor (TIR) signalling. However the patient's granulocytes showed normal CD62L-shedding upon activation with agonists for TLR2/6 (PAM2 $\mathrm{CSK}_{4}$ ) and TLR4 (LPS). In addition IL-8, IL-10 and TNFa-production were normal upon stimulation with TLR-agonists and IL-1 $\beta$ in whole blood. In contrast upon activation with TLR-agonists IL-6-production could neither be detected in the supernatant of whole blood nor in the supernatant of mononuclear cells of a healthy control incubated with patient's serum. The IL- 6 inhibiting effect of patient's serum was confirmed as in patient's whole blood STAT3 phosphorylation was severly impaired upon stimulation with IL-6. Finally recombinant IL-6 was reduced after preincubation with patient's serum. Our experiments excluded a defect in TIR signalling but strongly suggest that an IL-6-inhibitory factor in the patient's serum lead to the attenuated acute phase responses and the severe pneumococcal pneumonia.

\section{API Session (4)}

\section{API-SY4-2 \\ Chemosensitive combined immunodeficiency with EBV lympho- proliferation, severe varicella infection and vasculitis}

Ghosh S.', Hönscheid A. ', Dückers G. ${ }^{2}$, Laws H.-J.', Meisel R.', Niehues T.', Schneider D. ${ }^{3}$, Schindler D. ${ }^{4}$, Schuster F., Schwarz K. ${ }^{5}$, Speckmann C. ${ }^{6}$, Borkhardt A.

'Medical Faculty, Center of Child and Adolescent Health, Heinrich-HeineUniversity, Department of Pediatric Oncology, Hematology and Clinical Immunology, Düsseldorf, ${ }^{2}$ Department of Pediatrics, Helios Hospital Krefeld, Krefeld, ${ }^{3}$ Clinic of Pediatrics, Municipal Hospital, Dortmund, ${ }^{4}$ Institute for Human Genetics, Würzburg, ${ }^{5}$ Institute for Clinical Transfusion Medicine and Immunogenetics, Ulm, German Red Cross Blood Service, Baden-Wuerttemberg-Hessen, and Institute for Transfusion Medicine, University Hospital, Ulm, ${ }^{6}$ Centre for Chronic Immunodeficiency (CCl) and Centre of Pediatrics, Freiburg

Introduction. Reports on atypical SCIDs are continuously emerging as more and more adolescents and adults with susceptibility to severe infections are seen by clinical immunologists. While hypomorphic mutations are found in classical SCID genes, such as ARTEMIS, RAG1/2 and $\mathrm{ADA}$, there is a growing number of patients with combined immunodeficiency without a clear genetic cause.

Case report. We report on a 18-year-old boy of German origin. Since birth he had been suffering from splenomegaly and recurrent respiratory tract infections with bronchiectasis in later childhood. Furthermore the patient was hospitalized due to bacterial and varicella meningitis. However, the patient was admitted for the first time at our hospital at the age of 17 years with severe dermal necrotizing varicella infection, EBV lymphoproliferation, leukopenia and vasculitis. Interestingly, cells of the patient showed increased mitomycin $\mathrm{C}$ sensitivity, while having a normal radiosensitivity Due to the progredient clinical course, the patient underwent for haploidentical hemopoetic stem cell transplantation and is currently $>$ day +100 . Conclusion. In our presentation, we will discuss whole exome sequencing results and further efforts for functional validation to identify a possible new PID.

\section{API-SY4-3}

Klinische Charakterisierung von Patienten mit CD27-Defekt. Präsentation von 4 neuen Fällen und Literaturrecherche

Perez-Becker R. ${ }^{1}$, Driessen G. ${ }^{2}$, Daneva A. ${ }^{2}$, Wiesel T. ${ }^{3}$, Becker . $^{4}$, Seidel M. ${ }^{5}$, Dückers G. ${ }^{1}$, Siepermann K. ${ }^{1}$, van Zelm M. ${ }^{2}$, van der Burg M. ${ }^{2}$, Niehues $T .{ }^{1}$ ${ }^{1} \mathrm{HELIOS}$ Klinikum Krefeld, Zentrum für Kinder und Jugendmedizin, Krefeld, ${ }^{2}$ Erasmus MC, Department of Immunology, Rotterdam, Niederlande, ${ }^{3}$ Vestische Kinder- und Jugendklinik Datteln, Universität Witten/Herdecke, Datteln, ${ }^{4} \mathrm{HELIOS}$ Klinikum Krefeld, Institut für Hygiene und Laboratoriumsmedizin, Krefeld, ${ }^{5}$ Medizinische Universität Graz, Klinische Abteilung für pädiatrische Hämato-Onkologie, Graz, Österreich

Fragestellung. In Patienten mit einem Immundefekt kann EBV u. a. zu einer lymphoproliferativen Erkrankungen, HLH oder aplastischen Anämie führen. Bisher sind 4 monogenetische Krankheiten die mit einer spezifischen Suszeptibilität für EBV-Infektionen bekannt. Defekte in SAP, XIAP, ITK und der vor kurzem entdeckte $\mathrm{CD}_{27}$ Defekt beeinträchtigen die Kontrolle von T-Zellen über infizierte B-Zellen, was bei einer EBV-Infektion zu den oben genannten Verläufen führen kann. CD27 ist ein transmembranales Protein der Familie der TNF-Rezeptoren, das die Funktion und Differenzierung von T-Zellen, B-Zellen, NK-Zellen und Plasma-Zellen reguliert. Eine genetische Grundlage für CD27-Defizienz wurde 2012 erstmalig von Montfrans et al. beschrieben. Wir präsentieren die klinischen und laborchemischen Eigenschaften von 4 neuen Patienten und 10 bereits beschriebene Patienten mit einem CD27-Defekt.

Material und Methoden. Es wurde eine synoptische Darstellung der bisher beschriebenen plus 4 neuen Patienten hinsichtlich der Erstmanifestation, Laborauffälligkeiten, Infektionen und Behandlung durchgeführt.

Ergebnisse. In den 14 CD27-negativen Patienten verliefen die EBV Infektionen atypisch mit der Entwicklung von Hypogammaglobulinämie (5/14), HLH (4/14), Neurologische Manifestationen (1/14), aplastische Anämie (1/14), Uveitis (2/14) und Stomatitis (2/14). Eine EBV induzierte Lymphoproliferation wurde in der Hälfte $(7 / 14)$ der Patienten beobachtet. Diskussion und Schlussfolgerung. $\mathrm{CD}_{27}$-Defekte teilen viele klinische und laborchemische Eigenschaften mit SAP-, XIAP- und ITK-Defekten. Patienten die schwere, atypische oder persistierende EBV Infektionen haben oder eine EBV induzierte Lymphoproliferation entwickeln, sollten auf einen $\mathrm{CD}_{27}$-Defekt untersucht werden.

\section{API-SY4-4}

Identification by exome sequencing of novel genetic alterations as possible causes of (S)CID

Fuehrer M. ', Pannicke U. ${ }^{1}$, Hoenig M. ${ }^{2}$, Enders A. ${ }^{3}$, Holzmann K. ${ }^{4}$, Schulz A. ${ }^{2}$, Friedrich W. ${ }^{2}$, Schwarz K., ${ }^{5}$

'Institute for Transfusion Medicine, University of Ulm, ${ }^{2}$ University Children's Hospital, Ulm, ${ }^{3}$ Department of Immunology, The Australian National University, Canberra, Australia, ${ }^{4}$ Chip Facility, Internal Medicine III, University of Ulm, Institute for Clinical Transfusion Medicine and Immunogenetics, German Red Cross Blood Service, Ulm

The female patient was born to consanguinous parents and presented with eczema, hepato-splenomegalie, severe pneumonia, chronic diarrhoea, leukopenia and failure to thrive. According to the lymphocyte subsets (T cells: $385 / \mu \mathrm{l}$; B cells $60 / \mu \mathrm{l}$; NK cells: $16 / \mu \mathrm{l}$ ) the patient was classified as a Tlow/Blow/NKlow (S)CID. At the age of one year the patient received an unmanipulated bone marrow transsplant from the HLA identical mother without conditioning. After a series of otitis media, obstructive bronchitis and a drop down of the $\mathrm{T}$ cells the patient was conditioned and received a second transplant $\left(\mathrm{CD}_{34}+: 4.5 \mathrm{X} 106 \mathrm{cells} / \mathrm{kg}\right.$; $\mathrm{CD}_{3}+: 5.9 \times 106 \mathrm{cell} / \mathrm{s} / \mathrm{kg}$ ) from her mother at the age of $32 / 12$ years. Although a complete chimerism was achieved the patient suffered from recurrent infections, severe chronic lung disease and mental retardation. Assuming an autosomal recessive mode of inheritance, we performed a homozygosity mapping.The analysis did not adequately narrow down possible genetic causes for the disease, since 76 homozygous regions with 
more than 3000 genes were detected with this technique. As a next step an exome sequencing approach was performed. After filtering and comparison of the exome sequencing data with the results of the homozygosity mapping we were able to narrow down the 21375 single nucleotide variants (SNV) and 485 indels (small insert and deletions) to 12 alterations. After validating these 12 variants by Sanger sequencing of patient and parental material, cDNA-analysis and comparison with data from the 1000 Genomes Project and available knock out animal models we identified 2 plausible mutations in 2 different genes, which were not detected in a normal control collective $(\mathrm{n}=95)$. The first mutation is a homozygous stop mutation. The mutation in the second gene is a missense mutation of a phylogenetically not conserved amino acid.

We were able to detect via an exome sequencing approach two possibly causal genes which were not associated with (S)CID up to now. Protein analysis and functional testing is in progress and will reveal the role of these genetic alterations for the disease of the investigated patient.

\section{API-SY4-5 \\ Severe combined immunodeficiency, intestinal inflammation and atresia, and loss-of-function mutations in TTC7A}

Bahrami E. , Racek T.', Kotlarz D. ${ }^{1}$, Puchalka J.', Walz C. ${ }^{1}$, Kirchner T.', Avitzur Y. ${ }^{2,3,4}$, Guo C. ${ }^{3}$, Mastropaolo L.A. ${ }^{3}$, Cutz E. ${ }^{5}$, Uhlig H. ${ }^{6}$, Chen H. ${ }^{6}$, Nathrath M. ${ }^{1}$, Muise A.M. ${ }^{3,4,7}$, Snapper S.B. ${ }^{8}$, Koletzko S. ${ }^{1}$, Klein C.

'Department of Pediatrics, Dr. von Hauner Children's Hospital, LudwigMaximilians-University, Munich, ${ }^{2}$ Group for Improvement of Intestinal Function and Treatment (GIFT), Hospital for Sick Children, Toronto, Kanada, ${ }^{3}$ SickKids Inflammatory Bowel Disease Center and Cell Biology Program, Research Institute, Hospital for Sick Children, Toronto, Kanada, ${ }^{4}$ Division of Gastroenterology, Hepatology and Nutrition, Department of Pediatrics, University of Toronto, Hospital for Sick Children, Toronto, Kanada, ${ }^{5}$ Division of Pathology, The Hospital for Sick Children, Toronto, Kanada, ${ }^{6}$ Institute for Genomics and Multiscale Biology, Department of Genetics and Genomics Sciences, New York, USA, 'Institute of Medical Science, University of Toronto, Toronto, Kanada, ${ }^{8}$ Division of Pediatric Gastroenterology, Hepatology, and Nutrition, Department of Medicine, Children's Hospital Boston; Division of Gastroenterology and Hepatology, Brigham \& Women's Hospital, Department of Medicine, Harvard Medical School, Boston, USA

Introduction. Severe combined immunodeficiency can be associated with autosomal recessive multiple intestinal atresia (PMID: 2240032). Very few cases have been described in the literature. Recently, exomesequencing revealed mutations in $\mathrm{TTC}_{7} \mathrm{~A}$ in Canadian patients with this rare disease (PMID: 23423984).

Case report. We report a German family with two affected siblings who died within the first years of life after non-successful surgical resections of intestinal atresias. Targeted sequencing of the gene encoding tetratricopeptide repeat domain $7 \mathrm{~A}(\mathrm{TTC} 7 \mathrm{~A})$ showed a novel compound heterozygous mutation (IVS7-1G>T, IVS10-2A $>$ G). Each parent carries one affected allele. Pathological investigations display marked mucosal atrophy and ulceration accompanied by perimucosal fibrosis. Further examinations reveal numerous apoptotic bodies within the crypts as well as regeneration associated with increased epithelial proliferation of crypts. Immunohistochemical analysis confirms the marked lymphocytopenia with subtotal depletion of $\mathrm{CD}_{3}$-expressing $\mathrm{T}$ - and $\mathrm{CD} 2 \mathrm{O}$-expressing B-lymphocytes within the lamina propria. Immunostaining for $\mathrm{TTC}_{7} \mathrm{~A}$ showed complete absence of the protein in epithelial cells.

Conclusion. Our studies suggest that TTC 7 A represents a novel monogenic cause for infantile enterocolitis associated with intestinal atresia. Further studies are ongoing to assess the physiological function of TTC7A

\section{Samstag, 14.09.2013}

\section{API Session (5)}

\section{API-SY5-2}

Hypomorphic, homozygous mutations in Phosphoglucomutase 3 impair immunity and increase serum IgE levels

Sassi A. ${ }^{1,16}$, Lazaroski S. ${ }^{2,16}$, Wu G. ${ }^{3,16}$, Haslam S.M. ${ }^{3}$, Mellouli F. ${ }^{4}$, Unal E. ${ }^{5}$, Jouhadi Z. ${ }^{6}$, Pfeifer D. ${ }^{7}$, Jakob T. ${ }^{8}$, Khemiri M. ${ }^{9}$, Ben-Mustapha I. ${ }^{1}$, Asplund A.C. ${ }^{10}$, Gustafsson M.O. ${ }^{10}$, Lundin K.E. ${ }^{10}$, Sörqvist E.F. ${ }^{11}$, Moens L.N. ${ }^{11}$, Patiroglu T. ${ }^{5,12}$, Ozdemir M.A. ${ }^{5}$, Gungor H.E. ${ }^{12}$, Engelhardt K.R. ${ }^{13}$, Dziadzio M. ${ }^{13}$, Stauss $H_{.}{ }^{13}$, Fleckenstein $B .{ }^{14}$, Fliegauf M. ${ }^{2}$, Meier R. ${ }^{2}$, Khemis L.B. ${ }^{1}$ Kraus $H .{ }^{2}$, Eibel H. ${ }^{2}$, Nilsson M. ${ }^{11}$, Bejaoui M. ${ }^{4}$, Schäffer A.A. ${ }^{15,17}$, Smith C.I.E. ${ }^{9,17}$, Dell A. ${ }^{3,17}$, Barbouche M.-R.,17, Grimbacher B. ${ }^{2,13,17}$

'Laboratory of Immunopathology, Vaccinology and Molecular Genetics, Pasteur Institute of Tunis, Tunis, Tunesien, ${ }^{2}$ Centre of Chronic Immunodeficiency (CCI), University Medical Center Freiburg, Freiburg, ${ }^{3}$ Division of Molecular Biosciences, Department of Life Sciences, Imperial College London, London, UK, ${ }^{4}$ Pediatrics Department, Bone Marrow Transplantation Center, Tunis, Tunesien, ${ }^{5}$ Department of Pediatrics, Division of Pediatric Hematology and Oncology, Faculty of Medicine, Erciyes University, Kayseri, Tükei, ${ }^{6}$ Hassan II University, Casablanca, Marocco, ${ }^{7}$ Department of Hematology and Oncology, University Medical Center Freiburg, Freiburg, ${ }^{8}$ Allergy Research Group, Department of Dermatology, University Medical Center Freiburg, Freiburg, ${ }^{9}$ Pediatrics Department A, Children's Hospital of Tunis, Tunis, Tunisia, ${ }^{10} \mathrm{Clinical}$ Research Center, Department of Laboratory Medicine, Karolinska Institutet, Karolinska University Hospital Huddinge, Huddinge, Schweden, "1'Department of Immunology, Genetics and Pathology, Uppsala University, Rudbeck Laboratory, Uppsala, Schweden, ${ }^{12}$ Faculty of Medicine, Department of Pediatrics, Division of Pediatric Immunology,Faculty of Medicine, Erciyes University, Kayseri, Türkei, ${ }^{13}$ Royal Free Hospital, Dpt. of Immunology, University College London, UK, ${ }^{14}$ Institute of Virology, Friedrich-Alexander-University Erlangen-Nürnberg, Erlangen, ${ }^{15} \mathrm{National}$ Center for Biotechnology Information, National Institutes of Health, Department of Health and Human Services, Bethesda, Maryland, USA, ${ }^{16},{ }^{17}$ These authors contributed equally to this work and are considered aequo loco

Recurrent bacterial and fungal infections, eczema and elevated serum IgE levels characterize patients with the hyper-IgE syndrome (HIES). Known genetic causes for HIES are mutations in proteins involved in signal transduction pathways, namely $\mathrm{STAT}_{3}$ and DOCK8. However, glycosylation defects have not been described in these patients. One crucial enzyme in a glycosylation pathway is Phosphoglucomutase 3 $\left(\mathrm{PGM}_{3}\right)$, which catalyzes a key step in the synthesis of UDP-GlcNAc which is required for the biosynthesis of $\mathrm{N}$-glycan and other essential glycopolymers. Aim of our study was to elucidate the genetic cause in patients who do not have mutations in STAT3 or DOCK8. Genetic linkage analysis revealed an $11.9 \mathrm{Mb}$ linkage region on chromosome 6. Mutation detection in the positional candidate genes identified one homozygous mutation per family (L83 S and E34odel) in $\mathrm{PGM}_{3}$ (Phosphoglucomutase 3 ) that segregated perfectly with affection status and recessive inheritance. Sanger sequencing of $\mathrm{PGM}_{3}$ identified two additional HIES patients from Morocco with the homozygous $\mathrm{L} 83 \mathrm{~S}$ mutation and a Turkish patient with a third homozygous mutation ( $\mathrm{D}_{5} \mathrm{O} 2 \mathrm{Y}$ ). Functional studies showed that these mutations are hypomorphic and leave intact the enzyme's phosphoglucomutase activity, but impact on the biosynthetic reactions involving UDP-GlcNAc. Glycomics analysis revealed an aberrant glycosylation pattern in leukocytes exemplified by a reduced branching of complex-type $\mathrm{N}$-glycans. We concluded that the impairment of $\mathrm{PGM}_{3}$ function leads to a novel primary (inborn) error of immunity, as biallelic hypomorphic mutations are associated with impaired glycosylation and a hyper-IgE-like syndrome. 


\section{API-SY5-3}

B- und T-Zellen auf Tuchfühlung? Der Klassenwechsel von IgM zu IgG hängt nicht primär von der Antigen-Affinität ab

\section{Zemlin M. ${ }^{1}$, Lemke H. ${ }^{2}$ \\ ${ }^{1}$ Klinik für Kinder- und Jugendmedizin UKGM, Marburg, ${ }^{2}$ Biochemisches Institut Christian Albrechts Universität, Kiel}

Fragestellung. Werden beim Klassenwechsel von IgM- zu IgG-Antikörpern während der T-Zell-abhängigen Immunantwort die B-Zellen mit der höchsten Antigenaffinität bevorzugt?

Material und Methoden. Bei der Modell-Immunantwort gegen das Hapten Phenyloxazolon (phOx) tritt ein als Oxı bezeichneter dominanter Klon auf. Als Grund für diese Dominanz wird seine hohe Affinität für das Antigen angesehen. Wir haben neue Antikörper durch Zellfusion hergestellt und ihre Affinität mit den Ox1-Prototypen H11.5 (IgM) und NQ2/16.2 (IgG) verglichen. Die schweren und leichten Immunglobulinketten der IgM- und IgG-Antikörper wurden sequenziert.

Ergebnisse. Es wurden 92 phOx-spezifische monoklonale Antikörpersezernierende Klone nach unterschiedlichen Impfschemata hergestellt. Viele IgM-Antikörper wiesen im Vergleich zu den normalerweise dominierenden Ox1-Antikörpern eine gleich hohe oder höhere Antigenaffinität auf, kamen aber nicht zum Klassenwechsel. Dennoch war als Anzeichen der Antigenselektion bei IgG-Antikörpern gegenüber IgM die Vielfalt deutlich reduziert, die Nutzung von Variablen-Gensegmenten war eingeschränkt und die 3. Antigen-bindende Schleife (CDR- $\left.\mathrm{H}_{3}\right)$ war kürzer.

Diskussion. Wir zeigen, dass die Antigenaffinität nicht das dominierende Kriterium für den durch T-Zellen vermittelten Klassenwechsel von IgM zu IgG ist. Bei der Regulation des Klassenwechsels interagieren die T-Zellen offensichtlich mit der $\mathrm{CDR}_{-} \mathrm{H}_{3}$ Region des B-Zell-Antigenrezeptors. Da Peptide des B-Zell-Antigenrezeptors und damit auch CDR$\mathrm{H}_{3}$-Peptide nach Aktivierung durch das Antigen auf der B-Zelloberfläche durch MHC Klasse-II-Moleküle präsentiert werden, stellen wir die Hypothese auf, dass anti-idiotypische T-Zellen den Klassenwechsel von IgM zu IgG- induzieren oder hemmen können.

\section{API-SY5-4 \\ Etablierung eines Mausmodels für ICE-Fieber}

Winkler S. ${ }^{1}$, Hermsdorf A. ${ }^{1}$, Pessler F. ${ }^{2}$, Luksch H. ${ }^{\prime}$, Roesler J.', Naumann R. ${ }^{3}$, Roers $A .{ }^{4}$, Rösen-Wolff A.

${ }^{1}$ Klinik und Poliklinik für Kinder- und Jugendmedizin, Universitätsklinikum Carl Gustav Carus an der TU Dresden, Dresden, ${ }^{2}$ TWINCORE Center for Clinical and Experimental Infection Research, Hannover, ${ }^{3}$ Max Planck Institute of Molecular Cell Biology and Genetics, Dresden, ${ }^{4}$ Institut für Immunologie, TU Dresden, Dresden

Fragestellung. Kürzlich wurden von uns bei Patienten, die an rekurrierenden Fieberepisoden mit generalisierter Entzündung (ICE-Fieber) leiden, genetische Varianten im CASP1-Gen detektiert. Überraschenderweise wiesen diese Varianten der Caspase-1 eine reduzierte enzymatische Aktivität auf. Um die Effekte der CASP- Mutationen in einem vollständigen Organismus untersuchen zu können, versuchten wir ein BAC-basiertes Transgenmodel und ein Knock-in-Mausmodell zu etablieren.

Material und Methoden. Casp1C284AFlag transgene Mäuse wurden mit Casp1-Knock-out(KO)-Mäusen gekreuzt und der immunologische Phänotyp der Nachkommen wurde analysiert. Die Expressionslevels des Casp1C284AFlag-Transgens wurden mit qRT-PCR und Western blots quantifiziert. Freigesetzte Zytokine wurden mit Hilfe von Cytometric bead arrays (CBA) bestimmt.

Ergebnisse. Aus zwei unabhängigen Pronukleusinjektionen erhielten wir 180 Nachkommen. Nur ein Tier wies das komplette Transgen Casp1C284AFlag (TG) auf. Die Kreuzung mit Casp1 KO-Mäusen ergab folgende Genotypen: CaspiWT/WT/TG, CaspiWT/KO/TG und Casp1KO/KO/TG. qRT-PCR Analysen ergaben, dass die Transkription des Transgens Casp1C284AFlag nur o,1\% der Wildtyp-Casp1-Transkription betrug. Durch LPS-Stimulation konnte die Casp1C284AFlagExpression in CaspiWT/KO/TG-Zellen heraufgeregelt werden. Dies führte zu eine gesteigerten IL-6 und TNF-alpha-Ausschüttung nach LPS/ATP-Stimulation.

Diskussion. Diese Daten deuten darauf hin, dass selbst eine geringe Expression der enzymatisch inaktiven Caspase-1 die Freisetzung von Zytokinen induzieren und somit zum proinflammatorischen Phänotyp der Patienten beitragen kann. Zurzeit wird ein konditionales Knock-inMausmodel etabliert.

\section{API-SY5-5}

Therapie der systemischen juvenilen idiopathischen Arthritis (SJIA) im AID-Register

Husmann E. ${ }^{1}$, Haas J.P. ${ }^{2}$, Fischer N. ${ }^{2}$, Horneff G. ${ }^{3}$, Wittkowski H. ${ }^{4}$, Kallinich T. ${ }^{5}$, Rietschel C. ${ }^{6}$, Weißbarth-Riedel E. ${ }^{7}$, Lutz T. ${ }^{8}$, Ganser G. ${ }^{9}$, Lilienthal E. ${ }^{10}$ Berger T. ${ }^{11}$, Tenbrock K.12, Berrang J.13, Müller J. ${ }^{14}$, Neudorf U. ', Niehues T. ${ }^{15}$, Lainka E.'

'Unikinderklinik, Essen, ${ }^{2}$ Deutsches Zentrum für Kinder- und Jugendrheumatologie, Garmisch Partenkirchen, ${ }^{3}$ Asklepios Kinderklinik, St. Augustin, ${ }^{4}$ Unikinderklinik, Münster, ${ }^{5} \mathrm{Charité} \mathrm{-} \mathrm{Universitätsmedizin,} \mathrm{Berlin,}{ }^{6} \mathrm{Clemen}$ tine Hospital, Frankfurt, ${ }^{7}$ UKE, Hamburg, ${ }^{8}$ Unikinderklinik, Heidelberg, ${ }^{9} \mathrm{St}$. Josef-Stift, Sendenhorst, ${ }^{10}$ St. Josef Hospital, Bochum, "Vestische Kinderund Jugendklinik Datteln, Universität Witten/Herdecke, Datteln, ${ }^{12}$ RWTH Unikinderklinik, Aachen, ${ }^{13} \mathrm{Klinikum}$ Stuttgart, Olgahospital, Dortmund, ${ }^{14} \mathrm{St}$. Elisabeth Krankenhaus, Lörrach, ${ }^{15}$ Helios Klinikum, Krefeld

Einführung. Die SJIA gehört zu den autoinflammatorischen Erkrankungen und ist nach den ILAR-Kriterien definiert durch Arthritis und Fieber sowie mindestens ein folgendes Kriterium: Exanthem, Lymphadenopathie, Hepato(spleno)megalie oder Serositis. Sie kann als Polyarthritis weiter verlaufen und zeigt dann Eigenschaften einer Autoimmunerkrankung.

Methoden. Patienten mit SJIA nach ILAR-Kriterien wurden zum Zeitpunkt der Diagnose und im Verlauf im AID-Register (www.aid-register.uk-essen.de) dokumentiert und deskriptiv mit Median statistisch ausgewertet. Die klinischen Verläufe der Subgruppen [monozyklisch (MZ), polyzyklisch mit (PA) oder ohne Arthritis bzw. mit Autoinflammation (PZ)] wurden anhand der Wallace-Kriterien [„active disease“ (AD), ,inactive disease“ (ID), „clinical remission under medication“ (CRM), „clinical remission off medication“ (CROM)] beurteilt.

Ergebnisse. 107 Kinder ( 52 m, 55 w) waren bei Diagnosestellung 4 (o,416) Jahre alt. Die $M Z n=21, P Z n=42$ und $P A n=44$ Gruppe erhielten zu 90/79/100\% NSAR, 95/95/89\% Steroide, 95/100/100\% DMARD und 38/83/86\% Biologicals. Im Durchschnitt bekamen die PZ Gruppe 1,5 verschiedene Biologicals mit 19 Biologicalwechsel und die PA Gruppe 2 Biologicals mit 42 Biologicalwechsel innerhalb von 3 Jahren. IL1-, IL6- und TNFa-Blockaden wurden symptom- und zentrumspezifisch eingesetzt. Die MZ-, PZ- und PA-Gruppe zeigten folgendes Therapieansprechen: 42/33/25\% ID, 10/24/11\% CRM, 19/12/2\% CROM und 29/31/61\% AD.

Schlussfolgerung. Krankheitsverlauf, Therapie und Ansprechen der SJIA sind unterschiedlich in den Subgruppen. Die Krankheitsaktivität in der PA-Gruppe scheint am höchsten. Die Therapie mit Biologicals hat in den letzten Jahren stark zugenommen. Eine neue Klassifikation der SJIA und prospektive Studien sind über AID-Net in Planung. 


\section{API Session (6)}

\section{API-SY6-1 \\ PRKCD Defizienz verursacht B-Zell-Mangel in Kombination mit schwerer Autoimmunität}

Salzer E.', Santos-Valente E. ', Klaver S. ${ }^{2}$, Ban S.A. ', Emminger W. ${ }^{3}$, Prengemann N.K. ${ }^{1}$, Garncarz W. ${ }^{1}$, Müllauer L. ${ }^{4}$, Kain R. ${ }^{5}$, Boztug H. ${ }^{6}$, Heitger A. ${ }^{6}$, Arbeiter K. ${ }^{3}$, Eitelberger F. ${ }^{4}$, Seidel M.G. ${ }^{6}$, Holter W. ${ }^{6}$, Pickl W.F. ${ }^{7}$, Pollak $A .{ }^{3}$, Förster-WaldI E. ${ }^{3}$, Boztug K. ${ }^{1,3}$

${ }^{1} \mathrm{CeMM}$ Research Center for Molecular Medicine of the Austrian Academy of Sciences, Wien, Österreich, IInstituto de Ciências Biomédicas, Universidade de São Paulo, Sao Paulo, Brasilien, ${ }^{3}$ Department of Pediatrics and Adolescent Medicine, Medical University of Vienna, Wien, Österreich, ${ }^{4}$ Klinikum Wels-Grieskirchen GmbH, Linz, Österreich, ${ }^{5}$ Department of Pathology, Medical University of Vienna, Wien, Österreich, ${ }^{6}$ Department of Paediatrics, St. Anna Kinderspital and Children's Cancer Research Institute, Wien, Österreich, ${ }^{7}$ Christian Doppler Laboratory for Immunomodulation and Institute of Immunology, Center for Pathophysiology, Infectiology and Immunology, Medical University of Vienna, Wien, Österreich

Einleitung. Primäre B-Zell-Erkrankungen sind eine heterogene Gruppe von erblichen Immundefekten, häufig assoziiert mit Autoimmunität sowie signifikanter Morbidität. Die zugrunde liegende genetische Ätiologie bleibt jedoch in der Mehrzahl der Patienten ungeklärt.

Methoden. In dieser Studie untersuchten wir einen Patienten aus einer konsanguinen, türkischen Familie, der an rezidivierenden Infektionen sowie an einer schweren Lupus-ähnlichen Autoimmunität leidet. Die Immunphänotypisierung zeigte eine progrediente Reduktion der $\mathrm{CD} 19+\mathrm{B}-$ Zellen, eine Verminderung klassengewechselter IgM- und IgG-Memory-B-Zellen sowie eine erhöhte Anzahl von CD21low B-Zellen. Mittels Homozygosity Mapping in Kombination mit Exomsequenzierung gelang es eine homozygote Splice-site-Mutation im Proteinkinase C $\partial$ (PRKCD)Gen zu identifizieren, die eine komplette Abwesenheit des Proteins verursacht. Folglich wurde die Phosphorylierung von myristoyliertem Alanin-reichem C-Kinase-Substrat (MARCKS), einem wichtigen PRKCD Interaktionspartner verringert. PRKCD spielt auch eine bedeutende Rolle in der Kontrolle der IL6 Produktion, da es NF-IL6, den Transkriptionsfaktor für IL6 inhibiert. Es konnten erhöhte mRNA-Level von NF-IL6 sowie IL6 gezeigt werden. Unsere Studie beschreibt einen neuen primären Immundefekt mit B-Zelldefizienz und schwerer Autoimmunität, bedingt durch eine biallelische Mutation im PRKCD Gen.

\section{API-SY6-2 \\ Identifikation von neuen Immundefizienz-Genen durch Mutagenese-Screen im haploiden Zell-Modellsystem KBM7}

WillmannK. ${ }^{1}$, RebsamenM. ${ }^{1}$, Speckmann C. ${ }^{2}$, Rensing-EhIA. ${ }^{2}$, EhIS. ${ }^{2}$, BoztugK ${ }^{1,3}$ ${ }^{1} \mathrm{CeMM}$ Research Center for Molecular Medicine of the Austrian Academy of Sciences, Vienna, Österreich, ${ }^{2}$ Centre of Chronic Immunodeficiency, Freiburg, ${ }^{3}$ Department of Pediatrics and Adolescent Medicine, Medical University of Vienna, Vienna, Österreich

Einleitung. Das Feld der pädiatrischen Immundefizienzen hat in den letzten Jahren eine rasante Entwicklung gemacht. Neue Gendefekte wurden unter Anderem dank klassischer Linkage-Analysen und nachfolgender Kandidatengensequenzierungen sowie in jüngerer Zeit durch „Next-Generation-Sequencing“-Ansätze beschrieben. Als Ergänzung zu diesen Methoden erkunden wir neue Ansätze zur Identifikation von Kandidaten-Genen, die wir am Beispiel der Gruppe der „ALPS“-Erkrankungen (autoimmunes lymphoproliferatives Syndrom) untersuchen. ALPS Patienten mit Defekten am FAS-Liganden oder Rezeptor zeigen typische ALPS-Symptome wie Autoimmunität, Lymphoproliferation und Splenomegalie. Viele primäre ALPS bzw. ALPS-like-Patien- ten haben jedoch bisher nicht identifizierte genetische Defekte, weshalb neue Informationen über Kandidaten-Gene benötigt wird.

Methoden. In haploiden Zellinien wie KBM7 sind klassische Mutagenese-Screens möglich. Bei dem von uns verwendeten Protokoll wird hierbei eine retrovirale Insertions-Mutagenese durchgeführt, und die mutierten Zellen der Apoptose durch FAS- oder TRAIL-induzierte Rezeptoraktivierung ausgesetzt. Bei einer für den Wildtyp letalen Konzentration werden seltene resistente Kolonien herangezogen, deren Genom durch „Next-Generation-Sequencing“ analysiert wird. Gehäufte Insertionsstellen in mutanten Klonen weisen auf essentielle Gene für den funktionierenden Apoptose-Signalweg hin. Da durch ähnliche Screens schon bekannte Apoptosegene gefunden werden konnten, möchten wir diesen Ansatz zur Identifikation von neuen Genen für ALPS(-ähnliche)-Defekte anwenden und Möglichkeiten und Limitationen von Strategien zum spezifischen Screening für ImmundefizienzGene in Modellsystemen diskutieren.

\section{API-SY6-3 \\ Role of FAS signalling in negative selection of B cells in human germinal centres}

Janda A. ${ }^{1,2}$, Schwarz K. ${ }^{1,3,4}$, van der Burg M. ${ }^{5}$, Rensing-Ehl A. ${ }^{1}$, Fisch P. ${ }^{6}$, Pieper K. ${ }^{1}$, Lorenz M.R. ${ }^{3}$, Elgizouli M. ${ }^{1}$, Baerlecken N.T.', Witte T.', Ijspeert H. ${ }^{5}$, Sic H.', Seidl M. ', Hagel J.', Roesler J. ${ }^{8}$, Speckmann C. ${ }^{1,2}$, Ehl S. ${ }^{1,2}$, Eibel H. ', Rizzi M. ${ }^{1}$

'University Medical Centre Freiburg, Center for Chronic Immunodeficiency (CCl), Freiburg im Breisgau, ${ }^{2}$ University Medical Centre Freiburg, Center of Pediatrics, Freiburg im Breisgau, ${ }^{3}$ University of Ulm, Institute for Transfusion Medicine, Ulm, ${ }^{4}$ German Red Cross Blood Service, Institute for Clinical Transfusion Medicine and Immunogenetics, Ulm, ${ }^{5}$ Erasmus MC, University Medical Center Rotterdam, Department of Immunology, Rotterdam, Niederlande, ${ }^{6}$ University Medical Centre Freiburg, Department of Pathology, Freiburg im Breisgau, ${ }^{7}$ Medical University Hannover, Department of Immunology and Rheumatology, Hannover, ${ }^{8}$ University Clinic Carl Gustav Carus, Department of Pediatrics, Dresden

Introduction. Autoimmune lymphoproliferative syndrome (ALPS) is characterized by lymphoproliferative disease, autoimmune cytopenias and increased susceptibility to lymphoid malignancies. Central to the pathophysiology of the disease are defects in the FAS signaling leading to impaired lymphocyte homeostasis. Most of the patients harbor heterozygous germline or somatic mutations in FAS. Although the hallmark of the disease is the impaired FAS-mediated apoptosis of activated T cells and presence of atypical "double-negative" T cells $\left(\mathrm{CD}_{3}+\mathrm{TCR} \alpha /\right.$ $\beta+C D 4-C D 8-)$, the role of defective FAS signaling in $B$ cells in eliciting autoimmunity has still to be understood. While in murine models the importance of FAS for deletion of autoreactive B-cell clones in germinal center reaction has been demonstrated, direct evidence from humans is missing.

Methods. To address this issue, we investigated 2 patients with somatic FAS mutations in B cells. This approach enabled us to compare B cells with impaired vs. normal FAS signaling within one organism.

Results. By analyzing the phenotype ex vivo, and upon activation of primary B cells with CD4OL and IL-21, we detected high prevalence of FAS mutated B cells within the memory compartment. Furthermore FAS mutated EBV immortalized B cells showed selective advantage in culture over the FAS wild type cells, providing evidence for the advantage of mutated cells in vivo. Ongoing work by deep sequencing of variable immunoglobulin regions of FAS wild type and FAS mutated cells and autoantibody screen aims to define if autoreactive B cells are found within the FAS-mutated pool.

Conclusion. Data collected will provide insight into the role of FAS in negative B-cell selection in germinal centers of humans. 


\section{Poster}

\section{API-P0-1 \\ Mental retardation and combined Immunodeficiency with granu- lomatous hepatitis and nephritis - extending the phenotype of im- munodeficiency-centromeric instability-facial anomalies syndrome 2 (ICF2) caused by homozygous ZBTB24 gene mutations}

von Bernuth H. ${ }^{1,2}$, Du H. ${ }^{3}$, Ravindran E. ${ }^{4,5}$, Fröhler S. ${ }^{3}$, Strehl K. ${ }^{1}$, Krämer N. ${ }^{4,5}$, Issa L. ${ }^{4,5}$, Amulic B. ${ }^{6}$, Kölsch U. ${ }^{2}$, Eirich K. ${ }^{7}$, John R. ${ }^{8}$, Wahn V. ${ }^{1}$, Meisel C. ${ }^{2}$, Hauptmann K. ${ }^{9}$, Schindler D. ${ }^{7}$, Zychlynsky A. ${ }^{6}$, Chen W. ${ }^{3}$, Kaindl A. ${ }^{4,5,8}$

${ }^{1}$ Charité University Medicine Berlin, Pediatric Pneumology and Immunology, Berlin, 'Labor Berlin Charité Vivantes, Department of Immunology, Berlin, ${ }^{3}$ Max-Delbrueck-Center for Molecular Medicine, Berlin Institute for Medical Systems Biology, Berlin, ${ }^{4}$ Charité University Medicine Berlin, Institute of Cell Biology and Neurobiology, Berlin, ${ }^{5}$ Charité University Medicine Berlin, Pediatric Neurology, Berlin, ${ }^{6}$ Max Planck Institute for Infection Biology, Berlin, ${ }^{7}$ Biozentrum, Universität Würzburg, Institute for Human Genetics, Würzburg, ${ }^{8}$ Charité University Medicine Berlin, SPZ Pediatric Neurology, Berlin, ${ }^{9}$ Charité University Medicine Berlin, Pediatric Pathology, Berlin

The immunodeficiency-centromeric instability-facial anomalies (ICF) syndrome is an autosomal recessive disease characterized by immunodeficiency secondary to hypogammaglobulinemia, developmenta delay, and facial anomalies. Centromeric instability is the cytogenetic hallmark of the disorder, which results from targeted chromosomal rearrangements related to a genomic methylation defect. ICF1 is caused by mutations in the DNA methyltransferase ${ }_{3} \mathrm{~B}$ gene $\mathrm{DNMT}_{3} \mathrm{~B}$ (Xu.et al,1999) and mutations in the zinc-finger-and BTB-domain containing 24 gene ZBTB24 were first described as the genetic cause of ICF2 in 2011 (Greef et al,2011). So far, 11 families or individual patients carrying mutations in the ZBTB24 gene have been identified. A lack or dysfunction of $\mathrm{DNMT}_{3} \mathrm{~B}$ or $\mathrm{ZBTB}_{24}$ is believed to contribute to a block in late $\mathrm{B}$ cell differentiation and/or T-B-cell interaction, disturbing the formation of germinal centers. However, this does not explain the non-immunological phenotype of ICF patients. Here we describe the immunological and neurological phenotype of a further patient with this rare disease. In addition to previously described hypogammaglobulinemia and a lack of terminally differentiated B cells our patient demonstrates anomalies of $\mathrm{T}$ cell development (linked potentially to immune dysregulation), a proliferation defect as well as an increase of apoptosis that affects nonimmune cell tissues.

\section{API-PO-2 \\ Etablierung eines zielgerichteten Next-Generation-Sequencing- Ansatzes zur schnellen und kosteneffizienten Diagnose von Immundefekten}

Salzer E. ', Jandrasits C.', Santos-Valente E.', Prengemann N.K.', Ott R.', Schönegger A. ', Garncarz W. ', Dogu F. ${ }^{2}$, Bock C. ', Förster-Waldl E. ${ }^{3}$, Ikinciogullari A. ${ }^{2}$, Boztug K. ${ }^{\prime}$

${ }^{1}$ CeMM Research Center for Molecular Medicine of the Austrian Academy of Sciences, Wien, Österreich, ${ }^{2}$ Ankara University School of Medicine, Department of Pediatric Immunology, Ankara, Türkei, ${ }^{3}$ Department of Pediatrics and Adolescent Medicine, Medical University of Vienna, Wien, Österreich

Einleitung. Next-Generation-Sequencing-basierte Technologien haben die Entdeckung neuer Gendefekte revolutioniert. Ihr Einsatz zur Diagnostik von definierten Krankheitsgruppen ist jedoch noch die Ausnahme. Am Beispiel (schwerer) kombinierter Immundefekte (SCID) gelang es uns ein zielgerichtetes Next-Generation-Sequencing-basiertes Screening mit diagnostischem Potenzial zu entwickeln.

Methoden. 14 molekular undiagnostizierte SCID Patienten sowie 2 bereits diagnostizierte Patienten stellten das Testkollektiv dar. Capture beads für 30 bekannte SCID Gene, einschließlich ihrer Splice-Varianten sowie untranslatierten Regionen wurden designed. DNA der 30 SCID Gene wurde in den Patientenproben gezielt angereichert, mit einem Index versehen und mittels HiSeq2oo sequenziert. Detektierte Mutationen wurden bioinformatisch analysiert, gefiltert und anschließend mittels Sanger-Sequenzierung validiert. Simultan konnte ein bioinformatisches Modell der genauen Sequenzierungstiefe jeder einzelnen Base eines Gens, sowie der Abdeckung der angereicherten Regionen aller Gene entwickelt werden, welches nicht detektierte Mutationen mit einer Sensitivität von 95\% sicher ausschließen kann.

Schlussfolgerung. NGS-basierte Ansätze können als diagnostisches Werkzeug für die kostengünstige, schnelle und genaue Diagnose der zugrundeliegenden Mutationen von Patienten mit monogenetischen Erkrankungen dienen. Von Probenvorbereitung bis zu Datenanalyse dauerte der gesamte Prozess weniger als 4 Wochen. Unsere Ergebnisse sind als Proof-of-concept übertragbar für die rasche und kosteneffiziente Diagnostik verschiedenster Gruppen monogenetischer Erkrankungen im Bereich der Pädiatrie.

\section{API-PO-3}

Humoral immune abnormalities, infections with encapsulated bacteria and strong acute phase responses are frequent in MECP2 duplication syndrome

Bauer M. ${ }^{1}$, Kölsch U. ${ }^{2}$, Krüger R. ${ }^{1}$, Hameister K. ${ }^{3}$, Rossi R. ${ }^{4}$, Pilar Botella M. ${ }^{5}$, Budisteanu M. ${ }^{6}$, Rosello M. ${ }^{7}$, Orellana C. ${ }^{7}$, Tejada Minguez M.I. ${ }^{8}$, Papuc S.M. ${ }^{9}$, Wenner K. ${ }^{10}$, Xu X. ${ }^{11}$, Wieczorek D. ${ }^{12}$, Jezela-Stanek A. ${ }^{13}$, Martinez F.', Echenne B. ${ }^{14}$, Van Esch H. ${ }^{15}$, Wahn V., von Bernuth H. ${ }^{16}$

'Pediatric Pneumology and Immunology, Charité University Medicine, Berlin, ${ }^{2}$ Labor Berlin Charité Vivantes, Department of Immunology, Berlin, ${ }^{3}$ Pediatric Neurology and social medicine Königsborn, Unna, ${ }^{4} \mathrm{Childrens'}$ Hospital Neukölln, Berlin, ${ }^{5}$ Pediatric Neurology, Txagorritxu Hospital, Vitoria-Gasteiz, Spanien, ${ }^{6 "}$ Prof. Dr. Alexandru Obregia" Clinical Hospital of Psychiatry, Bucharest, Rumänien, 'Department of Genetics and prenatal diagnostics, Hospital Universitario La Fe, La Fe, Spanien, ${ }^{8}$ Molecular Genetics Laboratory, Genetics Service, BioCruces Health Research Institute, Cruces University Hospital, Barakaldo-Bizkaia, Spanien, ${ }^{9}$ Victor Babes' National Institute of Pathology, Bucharest, Rumänien, ${ }^{10} \mathrm{Childrens'} \mathrm{Uni-}$ versity Hospital and outpatient clinic, Hamburg-Eppendorf, Hamburg, "Department of Child Healthcare, Children's Hospital of Fudan University, Shanghai, China, ${ }^{12}$ Institute of Human Genetics, University Hospital Essen, University of Duisburg-Essen, Essen, ${ }^{13}$ Department of Medical Genetics, The Children's Memorial Health Institute, Warsaw, Polen, ${ }^{14}$ Pediatric Neurology, CHU Montpellier, Montpellier, Frankreich, ${ }^{15}$ Center for Human Genetics, University Hospital Leuven, KU Leuven, Leuven, Belgien, ${ }^{16}$ Pediatric Pneumology and Immunology, Charité University Medicine, Labor Berlin Charité Vivantes, Department of Immunology, Berlin

$\mathrm{MECP} 2$ (methyl CpG binding protein 2) duplication on chromosome Xq28 causes syndromic intellectual disability ( $\sim 1 \%$ of X-linked cases). Patients often also suffer from life-threatening infections, mainly of the respiratory tract, suggesting an additional immunodeficiency. Based on a cohort of 21 patients, including two females with $\mathrm{MECP}_{2}$ duplication syndrome we here provide for the first time a detailed description of the infectious and immunological phenotype of $\mathrm{MECP}_{2}$ duplication syndrome: 11/21 patients suffered from recurrent pneumonia and 4/21 from at least one episode of sepsis. Most frequently isolated pathogens were S. pneumoniae, $\mathrm{H}$. influenzae and S. aureus, all being encapsulated bacteria. In $4 / 12$ patients $\operatorname{IgA} / \operatorname{IgG} 2 / \operatorname{IgG} 4$-deficiency was detected. $8 / 12$ patients showed low titers against pneumococci. Three of the four patients with $\mathrm{IgA} / \mathrm{IgG} 2 / \mathrm{IgG}_{4}$-deficiency developed multiple severe infections and the most severe infectious phenotype in our cohort. Upon infections pronounced acute-phase responses were common: 6/8 patients showed CRP values above $200 \mathrm{mg} / \mathrm{l}$. Our data show for the first time systematically that increased susceptibility to infections in $\mathrm{MECP}_{2}$ duplication syndrome is associated with IgA/IgG2/IgG4-deficiency and elevated acute-phase responses. So patients with $\mathrm{MECP}_{2}$ duplication 
syndrome and low IgA/IgG2/IgG4 may benefit from prophylactic substitution of $\operatorname{sg} A$ and $\operatorname{IgG}$.

\section{API-PO-5 \\ Neuer Phäno- und Genotyp: kombinierter primärer Immundefekt mit neuem Glykolysierungsdefekt (CDG)}

\author{
Dueckers G. ', Siepermann K. ', Lübbert R. ${ }^{2}$, Lefeber D. ${ }^{2}$, Speckmann C. ${ }^{3}$, \\ Niehues T.' \\ ${ }^{1}$ Helios Kliniken Krefeld, Krefeld, ${ }^{2}$ Radbouduniversität MC, Nijmegen, Nie- \\ derlande, ${ }^{3}$ Centrum für chronische Immundefizienz, Freiburg
}

Fragestellung. Ist es bei primären Immundefekten sinnvoll, CDG zu analysieren?

Material und Methode. Zwei Brüder, deutscher nicht konsanguiner Eltern haben seit den ersten Lebensjahren eine pathologische Infektanfälligkeit auf Grund eines kombinierten primären Immundefekts (u. a. Hypogammglobulinämie, T-Zell-Lymphozytopenie, normale verminderte „switched memory“ B-Zellen und fehlende spezifische Antikörper) Normbefunde u. a. für: Adhäsion und Chemotaxis der Neutrophilen, T-Zell-Proliferation. Im Verlauf kommt es zu progredienten neurologischen Auffälligkeiten (cerebrale Konvulsionen und motorische Defizite). Zusätzlich Hepatosplenomegalie, Hypokaliämie und Thrombozytopenie. Ergebnisse. Die Multiorganbeteiligung lässt an eine übergeordnete, systemische Erkrankung denken. Die elektrophoretische Analyse der Proteinglykolysierung ergibt einen kombinierten Defekt in der N- und O-Glykolysierung. Eine neue genetische Mutation, die dem CDG Defekt zu Grunde liegt, ist zusätzlich identifiziert worden (Lefeber DJ: persönliche Kommunikation).

Diskussion oder Schlussfolgerung. CDG sollte differenzialdiagnostisch bei Patienten mit Zeichen eines kombinierten primären Immundefekts und Multiorganmanifestation in Erwägung gezogen und eine Transferrin-Elketrophorese veranlasst werden. Die Aufklärung des Pathomechanismus kann Grundlage für die Entwicklung neuer therapeutischer Ansätze sein.

\section{API-PO-6}

\section{Plastische Hyperinflammation bei CAPS}

\section{Schütz C.', Mohr V.', Lohse P. ', Debatin K.-M.', Schulz A.'}

'Universitätsklinikum Ulm, Pädiatrie, Immunologie und Rheumatologie, Ulm, ${ }^{2}$ Labor Blessing und Partner, Molekulargenetik, Singen

Einleitung. Cryopyrin-assoziierte periodische Syndrome (CAPS) sind autosomal dominant vererbte Autoinflammationssyndrome mit variablem Phänotyp. Die Pathogenese wird auf eine vermehrte Ausschüttung des proinflammatorischen Zytokins IL-1beta zurückgeführt. Bei ca. zwei Drittel aller CAPS-Patienten können Mutationen im NLRP3Gen identifiziert werden.

Fallbericht. Ein 12-jähriges Mädchen neapolitanischer Eltern wurde mit urtikariellem Exanthem, subfebrilen Temperaturen, Arthralgien und zervikaler Lymphadenopathie aufgenommen. Der Hautausschlag belästigte sie seit über zwei Jahren. Die Patientin fieberte im Verlauf bis $40^{\circ} \mathrm{C}$ und entwickelte Zeichen einer systemischen Inflammation, welche weder auf antibiotische noch auf antipyretische Therapie ansprach. Die chronische Urtikaria im Kontext eines Fieberschubes mit deutlich erhöhtem Serum-Amyloid A veranlasste uns, eine Kryopyrinopathie molekulargenetisch auszuschließen. Vor Erhalt des Ergebnisses entwickelte die Patientin eine Bizytopenie, Hyperferritinämie und Hypofibrogenämie sowie Pleura- und Perikardergüsse. Im Knochenmarksausstrich waren Hämophagozytosen nachweisbar. Die Makrophagen-Aktivierung konnte durch Einsatz von Dexamethason und Anakinra unterdrückt werden. Molekulargenetisch fand sich eine Heterozygotie für die von Exon 3 des $\mathrm{NLRP}_{3}$-Gens kodierte V198M-Substitution. Die Patientin hustete mehrere bronchiale Ausgusspräparate hoch. Diese sind wahrscheinlich auf die Hyperinflammation im Kontext von CAPS und MAS zurückzuführen.
Schlussfolgerung. Autoimmunerkrankungen wie der systemische LE und Vaskulitiden können ein Makrophagenaktivierungssyndrom triggern. Bisher ist ein MAS bei der systemischen JIA, jedoch nicht bei CAPS beschrieben. Das Ausmaß der Hyperinflammation zeigte sich plastisch als bronchiale Ausgusspräparate, welche die Patientin hochhustete.

\section{API-PO-7 \\ Myeloid-derived suppressor cells versus neutrophils: phenotypes, functionalities and therapeutic strategies}

\section{Hartl $D^{\prime}$, Rieber $N^{1}$}

'Department of Pediatrics I, University of Tübingen, Tübingen

Myeloid-derived suppressor cells (MDSCs) comprise both monocytic and neutrophilic subpopulations (MO-MDSCs and PMN-MDSCs), characterized by their functional capacity to suppress $\mathrm{T}$ and NK cell responses. However, the precise immunological identification and isolation of MDSCs subsets is hampered by their phenotypic heterogeneity and their overlapping markers with conventional non-suppressive immune cells, such as neutrophils. PMN-MDSCs predominate in humans and accumulate in chronic inflammatory diseases, such as sepsis, cystic fibrosis lung disease or infection. Here we discuss key features of PMN-MDSCs and their phenotypic and functional distinction from conventional neutrophils in humans and mice. Here we illustrate the combination of density gradient centrifugation with a specific surface marker expression profile, followed by functional CFSE T cell suppression and NK cell killing assays, for the bona fide analysis of PMN-MDSCs in patients from peripheral blood. Several aspects, such as survival, apoptosis, granule content and migration patterns, differ between PMN-MDSCs and conventional neutrophils, but experimental evidence is scarce so far. As PMN-MDSCs can be isolated based on surface markers, this cell population may represent a promising cell therapeutic in auto-inflammatory conditions.

\section{API-PO-8}

Genetic defects associated with EBV lymphoproliferative disorders

\section{Mahmoudi E.', Rezaei N.'}

'Tehran University of Medical Sciences, Children's Medical Center, Research Center for Immunodeficiencies, Tehran, Iran, Islamische Republik

Introduction. EBV is a herpes family virus that infiltrates human B lymphocytes and facilitates lymphoproliferative disorders. $\mathrm{SH}_{2} \mathrm{D}_{1} \mathrm{~A}$ gene encodes a tyrosine kinas protein known as SAP which is key regulator of Tcell maturation and proliferation signaling pathways; therefore $\mathrm{SH}_{2} \mathrm{D}_{1} \mathrm{~A}$ deficiency leads to a X-linked lymphoproliferative (XLP) disorder that is associated with higher susceptibility to EBV infection and development of lymphoproliferative complications. Recently, some new genes with autosomal recessive inheritance, such as ITK, have been discovered in this context. While ITK gene mutations have similar effects on the cell immunity, it could also lead to higher lymphoma formation in EBV infected patients.

Methods. We started a project on Iranian patients who suffered from either lymphoma or EBV infections to investigated underlying gene defects. 20 patients, including 17 cases with lymphoma, 3 of them were EBV positive, and 3 cases with EBV infection without lymphoma were enrolled in this study. $\mathrm{SH}_{2} \mathrm{D}_{1} \mathrm{~A}$ gene was sequenced in all male subjects, while ITK gene has been sequenced in 3 cases so far.

Results. Among 14 male patients, one of them had a mutation in $\mathrm{SH}_{2} \mathrm{D}_{1} \mathrm{~A}$ gene. The mutated case was EBV positive and not developed lymphoma. From the remaining 6 females, 3 of them were EBV positive: 2 with lymphoma and 1 without lymphoma. ITK gene was sequenced for these 3 patients; one of them had homozygous mutations in the ITK gene. The detected female was EBV positive and did not developed lymphoma. More investigations on these patients are to be done.

Conclusion. The results of this pilot study could show an association of underlying gene defects in those with EBV infections, which is not 
directly associated with lymphoproliferation. Further studies on this group of patients should be performed.

\section{API-PO-9 \\ Okuläre Autoantikörper im Serum von Kindern mit juveniler idiopathischer Arthritis und Uveitis}

Walscheid K. ${ }^{1,2}$, Hennig M. ${ }^{3}$, Heinz C. ${ }^{1}$, Bauer D. ${ }^{3}$, Dietzel M. ${ }^{1}$, Heiligenhaus $A .{ }^{1}$

'Augenabteilung am St. Franziskus-Hospital Münster, Münster, ${ }^{2}$ Klinik für Pädiatrische Rheumatologie und Immunologie, Universitätsklinikum Münster, Münster, ${ }^{3}$ Ophtha-Lab der Augenabteilung am St. FranziskusHospital, Münster

Fragestellung. Die Pathogenese der Uveitis bei juveniler idiopathischer Arthritis (JIA) ist bislang weitestgehend unverstanden. In der vorliegenden Studie wurden antiokuläre Autoantikörper (Ak) im Serum und deren Korrelation mit dem Krankheitsverlauf untersucht.

Material und Methoden. Serumproben von Kindern mit JIA-assoziierter Uveitis $(n=47)$, JIA ohne Uveitis $(n=67)$, idiopathischer anteriorer Uveitis (IAU, $n=12)$ und gesunden Kontrollprobanden $(n=52)$ wurden gesammelt. Das Bindungsmuster von Serumantikörpern auf Kryoschnitten von Schweinebulbi wurde mittels indirekter Immunhistochemie untersucht. Das Bindungsmuster wurde mit epidemiologischen, klinischen und laborchemischen Daten korreliert.

Ergebnisse. Die Patientengruppen unterschieden sich hinsichtlich der Ak-Bindung am Auge: JIA-assoziierte Uveitis (94\% mit Antikörpernachweis), JIA (81\%), IAU (75\%), und Gesunde (29\%). Die Ak wurden bei JIA-assoziierter Uveitis insbesondere an Iris (74\%) und Ziliarkörper (79\%) gebunden. Die positive Iris- und Ziliarkörperfärbung in der JIA-assoziierten Uveitisgruppe korrelierte mit dem Auftreten okulärer Komplikationen $(\mathrm{p}<0.001)$, nicht aber mit dem Nachweis von antinukleären Antikörpern (ANA), Rheumafaktor (RF) oder HLA-B27, und war unabhängig von der Uveitisaktivität oder der antientzündlichen Therapie.

Schlussfolgerung. Bei Patienten mit JIA-assoziierter anteriorer Uveitis finden sich im Vergleich zu den Kontrollgruppen häufiger antiokuläre Serumantikörper. Die Bindungsmuster am Auge korrelieren mit dem Uveitisverlauf, werden aber nicht durch die Uveitisaktivität oder antientzündliche Therapie beeinflusst. Sie sind jedoch nicht spezifisch für diese Uveitisentität und treten nicht in einer konstanten Kombination mit ANA, Rheumafaktor oder HLA-B27 auf

\section{API-PO-10 \\ Chronische Immunthrombozytopenie im Kindes- und Jugend- alter: multizentrische retrospektive Analyse der immunologischen Grundlagen und Therapiemodalitäten}

Sipurzynski J.', Kerbl R. ${ }^{2}$, Jauk B. ${ }^{3}$, Hammerer D. ${ }^{4}$, Kropshofer G. ${ }^{5}$, Ebetsberger-Dachs G. ${ }^{6}$, Schwinger W. ', Urban C. ${ }^{1}$, Benesch M. ', Seidel M.G. ${ }^{1}$

${ }^{1}$ Medizinische Universität Graz, Päd. Hämatologie Onkologie, Graz, Österreich, ${ }^{2}$ LKH Leoben, Kinder- u. Jugendheilkunde, Leoben, Österreich, ${ }^{3}$ LKH Klagenfurt, Päd. Hämatologie-Onkologie, Klagenfurt, Österreich, ${ }^{4}$ LKH Dornbirn, Pädiatrie, Dornbirn, Österreich, ${ }^{5}$ Universitätsklinik f. Kinder- und Jugendheilkunde, Päd. Hämatologie Onkologie, Innsbruck, Österreich, ${ }^{6}$ LFKK, Päd. Hämatologie Onkologie, Linz, Österreich

Während die akute Immunthrombozytopenie (ITP) innerhalb der Pädiatrischen Hämatologie eine selbstlimitierte para- oder postinfektiös auftretende, meist wenig belastende Bluterkrankung des Kindesalters darstellt, liegt bei der chronischen Verlaufsform der ITP oftmals ein jugendliches Patientengut mit verschiedenen zusätzlichen autoimmunologischen Risikofaktoren und eine chronische Belastung durch die Krankheit vor. Die chronische ITP kann Teilsymptom einer Multiorgan-Autoimmunkrankheit oder einer systemisch gestörten Immunregulation und somit eines Immundefekts sein und basiert mit großer
Wahrscheinlichkeit auf heterogenen pathophysiologischen Grundlagen. Internationale Therapieempfehlungen richten sich einerseits nach der Blutungsneigung der Patientinnen und Patienten, andererseits nach der Ätiologie, wobei national und international Uneinigkeit über den Einsatz diverser moderner, teilweise in der Pädiatrie bzw. für diese Indikation nicht zugelassener Medikamente besteht (z. B. Anti-D-Ig, Mycophenolat-Mofetil, Romiplostim/Eltrombopag, Rituximab).

Die nun initiierte Studie soll a), retrospektiv in verschiedenen pädiatrisch-hämatologisch-onkologischen Zentren Österreichs in den letzten drei Jahren behandelte Patienten mit chronischer ITP systematisch hinsichtlich immunologischer Grundlagen und Therapiemodalitäten, -indikationsstellung und -effizienz analysieren, wofür ein intuitives, simples klinisches Dokumentationsblatt entworfen und eine Datenbank aufgebaut wird; b) somit eine Basis für eine prospektive Studie mit konkreten Ein- und Ausschlusskriterien, standardisierten Routinediagnostik- und Therapieempfehlungen liefern und c) eine Analyse potenzieller krankheitsmodifizierender oder -verursachender Faktoren zur Hypothese der „cITP als Immundefekt" ermöglichen.

\section{API-PO-11 \\ Eine neue Mutation im STAT-1 Gen bei chronischer mukokutaner Candidiasis (CMC)}

MöllerJ.', OkadaS. ${ }^{2}$,PuelA. ${ }^{3}$, CasanovaJ.-L. ', LaaßM.', VogelbergC.', RoeslerJ.' 'Universitätsklinikum Dresden, Klinik für Kinder- und Jugendmedizin, Dresden, ${ }^{2}$ St. Giles Laboratory of Human Genetics of Infectious Diseases, The Rockefeller University, New York, USA, ${ }^{3}$ Necker Medical School and University Paris Descartes, Laboratory of Human Genetics of Infectious Diseases, Paris, Frankreich

Fallbericht. Der 7-jährige Junge litt seit vielen Jahren unter rezidivierender Impetigo, anderen Staphylokokkeninfektionen, Tinea, Mundsoor und rezidivierender Soorösophagitis mit Stenosierung der Cardia. Lokale Therapie mit Nystatin brachte Besserung. Nach systemischer Fluconazolgabe war Candida nicht mehr nachweisbar. Nach Absetzen traten jedoch immer wieder Rezidive auf. Die Ösophagusstenose wurde wiederholt bougiert. Bei Verdacht auf Immundefekt waren mehrfach Untersuchungen durchgeführt worden. Der Patient hat normale Immunglobuline und Impfantikörper sowie normale Lymphozytensubpopulationen. Aufgrund von Bronchiektasen wurde der Patient erneut mit der Frage nach Immundefekt vorgestellt. Auffallend waren ferner eine Dystrophie, eine mäßige mentale Retardierung und Pankreasinsuffizienz. Das mangelnde Gedeihen wird zumindest teilweise durch eine Alkoholembryopathie erklärt. Da das Kind in der Pflegefamilie lebt, ist wenig über die Familie bekannt. Der leibliche Vater ist bereits verstorben.

Ergebnisse. Bei klinischem Bild einer CMC und mangelnder Antikörperbildung auf Candida wurde STAT-1 sequenziert. Hier fand sich eine bisher nicht beschriebene Mutation in der coiled-coil Domäne, P293L. Vor kurzem wurden hypermorphe Mutationen in STAT-1, oft in der coiled-coil Domäne, als Ursache für eine Unterform der CMC beschrieben. Bei unserem Patienten liegt diese Unterform einer CMC vor. Dazu passen neben dem Pilzbefall die Staphylokokken-Infektionen und die Bronchiektasen. Ob sich aber alle Symptome durch CMC und Alkoholembryopathie erklären lassen, ist zurzeit noch unklar.

Schlussfolgerung. Unter Dauerprophylaxe mit Itraconazol und Cotrimoxazol hat sich der Allgemeinzustand des Kindes deutlich gebessert und die Infektionen sind fast vollständig zurückgegangen. 


\section{API-PO-12}

\section{Genotyp-Phänotyp- sowie Genotyp-Herkunft-Korrelationen bei} in Deutschland lebenden Kindern mit familiärem Mittelmeerfieber (FMF)

\section{Jeske M. ${ }^{1}$, Lohse P. ${ }^{2}$, Kallinich T. ${ }^{3}$, Berger $T_{.}{ }^{4}$, Rietschel C. ${ }^{5}$, Holzinger D. ${ }^{6}$,} Kamlah C. ${ }^{7}$, Lankisch P. ${ }^{8}$, Berendes R. $^{9}$, Dückers $G .{ }^{10}$, Horneff G. ${ }^{11}$, Lilienthal E. ${ }^{12}$, Haas J.P. ${ }^{13}$, Giese A. ${ }^{14}$, Dressler F. ${ }^{15}$, Berrang J. ${ }^{16}$, Pütter C. ${ }^{17}$, Braunewell L. ${ }^{1}$, Neudorf U. ${ }^{1}$, Niehues T. ${ }^{10}$, Lainka E. ${ }^{1}$

'Unikinderklinik, Essen, ${ }^{2}$ Labor Blessing und Partner, Singen, ${ }^{3}$ Charité Universitätsmedizin, Berlin, ${ }^{4}$ Vestische Kinder- und Jugendklinik Datteln, Universität Witten/Herdecke, Datteln, ${ }^{5} \mathrm{Clementine} \mathrm{Hospital,} \mathrm{Frankfurt,}{ }^{6}$ Unikinderklinik, Münster, ${ }^{7} \mathrm{UKE}$, Hamburg, ${ }^{8} \mathrm{HHU}$ Kinderklinik, Düsseldorf, ${ }^{9}$ Kinderkrankenhaus St. Marien, Landshut, ${ }^{10}$ Helios Klinikum, Krefeld, ${ }^{11}$ Asklepios Kinderklinik, St. Augustin, ${ }^{12}$ St. Josef Hospital, Bochum, ${ }^{13}$ Deutsches Zentrum für Kinder- und Jugendrheumatologie, Garmisch Partenkirchen, ${ }^{14}$ Marienhospital, Herne, ${ }^{15} \mathrm{MHH}$ Kinderklinik, Hannover, ${ }^{16} \mathrm{Klinikum}$, Dortmund, ${ }^{17}$ Institut für Medizinische Informatik, Biometrie und Epidemiologie, Essen

Fragestellung. Untersuchung der Korrelationen zwischen der ethnischen Herkunft, dem Phänotyp und dem Genotyp bei FMF Patienten. Methodik. Zur Bestimmung des Erkrankungsschweregrades bei 243 FMF Patienten des AID-Registers benutzten wir die für Kinder modifizierte Scores nach Mor und Pras. Für die fünf häufigsten Mutationen testeten wir auf eine Korrelation zwischen Genotyp und Phänotyp, Creaktivem Protein (CRP) sowie ethnischer Herkunft.

Ergebnisse. Bei 243 Patienten erfassten wir 433 Pyrinmutationen mit 22 verschiedenen Sequenzvariationen im MEFV-Gen, einschließlich einer neuen Mutation (p.Gly488Asp). Die fünf häufigsten Mutationen waren p.Met694Val $(55 \%, \mathrm{n}=238)$, p.Met68olle $(12 \%, \mathrm{n}=52)$, p.Val726Ala $(10 \%, n=44)$, p.Glu148Gln $(8 \%, n=34)$ and p.Met694IIe $(2.3 \%, n=10)$. Die homozygote p.Met694Val Mutation $(30 \%, n=73)$ trat häufiger mit einem schwereren Erkrankungsgrad nach Mor sowie einem höheren CRPWert $(74 \mathrm{mg} / \mathrm{l}, \mathrm{n}=60$ ) im Vergleich zu der Gruppe ohne diese Mutation (31 mg/l, n=59; p=o,o1 bzw. $\mathrm{p}<0,01$ ) auf. Beim Score nach Pras konnte keine Genotyp-Phänotyp-Korrelation festgestellt werden. Die beiden Scores waren nicht konsistent $(\kappa<0,07)$ miteinander. Die ethnische Herkunft konnte in 224 Fällen [v. a. türkisch $(83 \%, n=185)$, libanesisch $(8 \%$, $\mathrm{n}=18$ )] festgestellt werden. Obwohl eine typische Mutationsverteilung in den ethnischen Gruppen auffällig war, konnte dieser Trend nicht durch eine Korrelation statistisch erhärtet werden.

Schlussfolgerung. Die homozygote Mutation p.Met694Val im MEFVGen ist assoziiert mit einer höheren Erkrankungsaktivität. Es gibt keine Genotyp-Herkunft-Korrelation in dieser FMF-Population. Die bekannten Schweregradscores für Kinder (Mor, Pras) sind inkonsistent. Das AID-Net arbeitet an einem neuen Score-System.

\section{API-P0-13 \\ Substitutionstherapie mit Immunglobulinen bei Kindern mit primären Immundefekten: SIGNS-Register}

Borte M. ${ }^{,}$, Hensel M. ${ }^{2}$, Gold R. ${ }^{3}$, Fasshauer M. ${ }^{1}$, Pittrow D. ${ }^{4}$, Huscher D. ${ }^{5}$, Stangel M. ${ }^{6}$, Kirch W. ${ }^{4}$, Reiser M. ${ }^{7}$, Baumann U. ${ }^{8}$, SIGNS Studiengruppe ${ }^{1}$ Immundefektzentrum Leipzig (IDCL), Jeffrey Modell Diagnostic and Research Center for Primary Immunodeficiencies, Leipzig, ${ }^{2}$ Mannheimer Onkologie Praxis, Mannheim, ${ }^{3}$ St. Josef-Hospital, Klinikum der Ruhr-Universität, Klinik für Neurologie, Bochum, ${ }^{4}$ Medizinische Fakultät, Technische Universität, Institut für Klinische Pharmakologie, Dresden, ${ }^{5}$ Epidemiologie, Deutsches Rheumaforschungszentrum, Berlin, ${ }^{6}$ Medizinische Hochschule, Klinik für Neurologie, Hannover, ${ }^{7}$ Praxis für Hämatologie und Internistische Onkologie (PIOH), Köln, ${ }^{8}$ Medizinische Hochschule, Klinik für Pädiatrische Pneumologie, Allergologie und Neonatologie, Hannover

Einleitung. In Deutschland fehlen aktuelle Daten zu Kindern, die wegen eines primären Immundefekts (PID) mit Immunglobulinen (IG) behandelt werden.
Methoden. „Assessment of Immunoglobulins in a long-term non-interventional study" (SIGNS, NCT NCTo1287689) ist eine prospektive Beobachtungsstudie mit derzeit $>600$ Patienten aller Altersgruppen. Sie dokumentiert die Behandlung von Patienten mit PID und sekundären Immundefekten, die IG als Substitutionstherapie erhalten, und Patienten mit neurologischen Autoimmunerkrankungen, die IG zur Immunmodulation erhalten.

Ergebnisse. Die Zwischenauswertung zum 5. Mai 2013 umfasste 58 Kinder mit PID (67\% männlich, mittleres Alter 10,2 $\pm 4,4$ Jahre). Als Diagnosen wurden bei 27 Kindern CVID, bei 10 XLA, und bei 9 ein isolierter IG Subklassenmangel genannt. Die mittlere Krankheitsdauer betrug

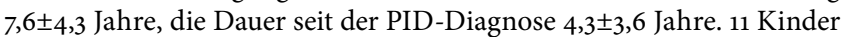
$(19 \%)$ hatten eine positive Familienanamnese für einen PID. Die mittlere Dosis bei intravenöser Gabe (27,6\% der Kinder) betrug 409 mg/kg KG alle 4,3 Wochen und bei subkutaner Gabe (74,1\% der Kinder) $148 \mathrm{mg} /$ kg KG alle 1,1 Wochen. 52 Patienten (89,7\%) erhielten $>200$ mg/kg KG bezogen auf 4 Wochen. Von den 56 Kindern, die mindestens 3 Monate vor Einschluss mit IG substituiert worden waren, hatten in den 12 Monaten vor Einschluss 42 (75,0\%) unkomplizierte Allgemeininfektionen, $3(5,3 \%)$ eine Pneumonie und 1 Kind eine andere schwerwiegende Infektion. Von den 36 Kindern aus dieser Gruppe mit 1-Jahresdaten im Behandlungsverlauf hatten nach 12 Monaten nur noch 23 (63,9\%) eine Allgemeininfektion und nur 1 Kind eine Pneumonie $(2,8 \%)$.

Schlussfolgerung. Der Mehrzahl der Kinder mit PID ist von Allgemeininfektionen betroffen, während schwerwiegende bakterielle Infektionen unter IG-Substitution deutlich seltener auftreten.

\section{API-PO-15 \\ Charakterisierung von Monozyten-Subpopulationen Erwachsener und Neugeborener nach Stimulation mit IFN $-\gamma$}

\section{Dreschers S., Kerth J.-L.', Seubert F.', Orlikowsky T.}

'Klinik für Kinder- und Jugendmedizin, RWTH Aachen, Neonatologie, Aachen

Einleitung. Im Blutkreislauf zirkulierende Monozyten lassen sich in zwei Subpopulationen aufgliedern: CD14-positive/CD16-negative und CD14+CD16-positive Monozyten. Diese Subpopulationen können durch den Einsatz von Cytokinen weiter funktionell differenziert werden und stellen die Vorläufer von Makrophagen und dendritischen Zellen dar. Methoden. In unserer Studie wollten wir untersuchen, ob die genannten Monozyten-Subpopulationen im Blut Erwachsener im Vergleich zum Blut Neugeborener Unterschiede hinsichtlich der Phagozytose, des Phagozytose-induzierten Zelltodes (PICD), der Expression von Oberflächen-Markern (CD14, CD16, CD32, CD 163) und Lymphozytenstimulierende Rezeptoren der B7-Familie sowie HLA-DR aufweisen. Zusätzlich wurden mononukleäre Zellen 3 Tage in vitro mit/ohne Interferon- $\gamma(50 \mathrm{U} / \mathrm{ml})$ kultiviert, mit E. coli infiziert und die o. g. Parameter mittels FACS-Analyse bestimmt.

Ergebnisse. Der Anteil der CD14-positiven Zellen wurde bei adulten Monozyten nicht signifikant durch IFN- $\gamma$ beeinflusst. IFN- $\gamma$ Behandlung führte zu einer Stabilisierung der Population CD14-positiver Zellen. Neugeborenen Monozyten zeigten diesen Unterschied nicht. Der Anteil der CD14+CD16-positiven Monozyten wurde durch IFN- $\gamma$ bei Erwachsenen stark gesenkt. Eine Infektion reduzierte diese Subpopulation jedoch nicht weiter. CD14+CD16-positive Monozyten wurden bei Neugeborenen generell weniger gefunden. Eine IFN- $\gamma$-Behandlung hatte keinen Einfluss. Die Fähigkeit zur Phagozytose ist bei Monozyten Neugeborener stark reduziert, IFN- $\gamma$ verändert dies nicht.

Schlussfolgerung. Die Monozyten-Subpopulationen unterscheiden sich zwischen Erwachsenen und Neugeborenen. Besonders die wichtige Subpopulation der CD14+CD16-positiven Monozyten, aus denen sich unter IFN- $\gamma$-Gabe Helfer-Makrophagen entwickeln können, ist bei Neugeborenen unterrepräsentiert. 
API-PO-16

A novel syndrome with immunodeficiency, psychomotor retardation, facial dysmorphia, and urogenital malformation associated with partial trisomy 19p13

Seidel M.G. ${ }^{1}$, Duerr C. ${ }^{2}$, Schwerin-Nagel A. ${ }^{3}$, Valente E. ${ }^{4}$, Sadeghi K. ${ }^{2}$, Uhrig

S. ${ }^{5}$, Woutsas S. ${ }^{4}$, Schwinger W. ${ }^{1}$, Urban C. ${ }^{1}$, Boztug K. ${ }^{2},{ }^{4}$, Förster-WaldI E. ${ }^{2}$

${ }^{1}$ Div. Pediatric Hematology-Oncology, Dept. Pediatrics and Adolescent Med., Medical University Graz, Graz, Österreich, '2Div. of Neonatology,

Pead. Intensive Care \& Neuropaediatrics, Dept. Pediatrics and Adolescent Med., Medical University Vienna, Wien, Österreich, ${ }^{3}$ Div. of General Pediatrics, Dept. Pediatrics and Adolescent Med., Medical University Graz, Graz, Österreich, ${ }^{4}$ CeMM Research Centre for Molecular Medicine, Austrian Academy of Sciences, Wien, Österreich, Institute of Human Genetics,

Medical University Graz, Graz, Österreich

We recently reported on a 7 year-old boy with partial trisomy 19p13 [46,XY.ish dup(19(pteràp13.2)t(15p;19p)de novo] showing a syndromic disorder associated with immunodeficiency. This boy had been born prematurely in the 32 nd week of gestation whereupon the growth restricted infant presented with profound motor and mental retardation, epilepsy, facial dysmorphy as well as urogenital malformations (perineal hypospadias). Meanwhile, another similar 2 year-old patient was identified. The boy was born prematurely, as well, at $31+1$ weeks of gestational age $(660 \mathrm{o} ; 34 \mathrm{~cm} ; 23,5 \mathrm{~cm})$ with urogenital malformations (horseshoe kidney, hypospadias). Moreover, microcephalus, flat nasal bridge, telecanthus, short upslanting palpebral fissures, long eyelashes, strabismus, hypermetropia, long philtrum, narrow/thin lips, micrognathia and pharyngeal instability were diagnosed. This patient has a comparable chromosomal duplication [arr cgh 19p13.3dup] and an additional aberration on Chromosome 16 [46,XY.ish der $(16) t(16 ; 19)$ (p13.3;p13.3)]. An array CGH analysis revealed a microdeletion involving the alpha-hemoglobin locus (16p), which results in alpha thalassemia minor/intermedia. Both patients share most syndromal features and present with comparable immunologic abnormalities. With respect to the immunodeficiency, both show recurrent invasive bacterial infections, including pneumonia, recurring bronchitis and otitis. Immunological tests found no alterations in global T-, B-, nor NK-cell counts, nor lymphocytic proliferation, but almost absent class-switched B memory cells in the second patient and reduced NK cytotoxicity in both. Immunoglobulin analysis revealed selective antibody deficiency against polysaccharide antigens in one and reduced $\operatorname{IgG}_{1},-3$ subclass levels as well as an IgM deficiency in the other boy. In both patients granulocytic oxidative burst assays demonstrated a moderate and borderline reduction, respectively, whereas monocytic respiratory burst was decreased in both. Additionally, patient 1 has a reduction and patient 2 a complete lack of mannan-binding lectin. Since immunoglobulin substitution has been initiated, both individuals thrive and the number and severity of infections was decreased significantly.

Although in patient 2 syndromal features in part resemble alphathalassemia/mental retardation syndrome (ATR-16, OMIM \#141750; 16pter-p13.3) and might occur independently of trisomy 19p13, the similar set of findings in two independent patients with a very similar chromosomal abnormality, especially with regard to the immunological phenotype, suggests that subtelomeric partial trisomy 19p leads to a complex syndromic disorder with immunodeficiency. Further analyses will need to determine the molecular origin of B lymphocyte and granulocyte abnormalities. 


\section{Abstracts der Arbeitstagung Pädiatrische Forschung (12./13.09.2013, DGKJ-Jahrestagung, Düsseldorf 2013)}

\section{Eine methylreiche Diät während der Schwangerschaft führt im Mausmodell zu einer Übermethylierung der CpG-Islands und einer Überexpression des Xist- sowie des Folatrezeptor-Gens im Hypo- thalamus des Nachwuchses}

\begin{abstract}
Brune B. ${ }^{1}$, Jakubiczka S. ${ }^{2}$, Linke R. ${ }^{3}$, Geffers $R .{ }^{4}$, Weinzierl M. ${ }^{1}$, Brune T. ${ }^{1}$ ${ }^{1}$ Universitätskinderklinik, ${ }^{2}$ Institut für Humangenetik, ${ }^{3}$ Anatomisches Institut, Universität Magdeburg, ${ }^{4} \mathrm{Helmholtz-Zentrum,} \mathrm{Braunschweig}$
\end{abstract}

Fragestellung. Verändert eine methylreiche Ernährung während der Schwangerschaft dauerhaft das Epigenoms des Nachwuchses?

Material und Methode. Fünf weibliche Mäuse $\left(\mathrm{C}_{57} \mathrm{BL} / 6\right)$ wurden während der Schwangerschaft mit einer methylreichen Diät gefüttert. Als Kontrolle dienten 5 schwangere weibliche Mäuse, die normales Futter erhielten. Beim Nachwuchs wurde im Alter von 3 Monaten jeweils die DNA von Herz, Leber, Milz, Gehirn und Hypothalamus isoliert und der Gesamtmethylierungsgrad der CpG-Islands bestimmt. Im Hypothalamusgewebe wurden zusätzlich die Genexpressionsmuster zwischen Verum und Kontrolle mittels Tissue Differential Microarray Analysis verglichen.

Ergebnisse. Der DNA-Gesamtmethylierungsgrad der einzelnen Organe ist im Folgenden aufgelistet (Kontrolle-Diät): Herz: 57-70\%, Leber: 41-50\%, Milz: 52-68\%, Gehirn: 47-91\%, Hypothalamus: 6-26\%. Der Expressionsvergleich im Hypothalamus ergab in der Verumgruppe beim Xist-Gen eine 300-fache sowie beim Folatrezeptor-Gen eine 4-fache Überexpression gegenüber der Kontrollgruppe.

Schlussfolgerung. Eine methylreiche Diät während der Schwangerschaft führt im Vergleich zu normaler Ernährung bei den Nachkommen zu einer höheren DNA-Gesamtmethylierung der ausgewählten Organe. Dieser Effekt ist besonders ausgeprägt im Gehirn und führt im Hypothalamus zu einer Überexpression des Xist- sowie des Folatrezeptor-Gens.

\section{CREMa kontrolliert die Chromatinstruktur von Zytokingenen in T-Zellen von SLE-Patienten}

Hedrich C.M. ${ }^{1,2}$, Tsokos G.C. ${ }^{2}$

'Universitätsklinikum Carl Gustav Carus, Klinik und Poliklinik für Kinderund Jugendmedizin, Dresden, ${ }^{2}$ Harvard Medical School, BIDMC, Boston, USA

Fragestellung. Die ausgewogene Expression von Zytokingenen spielt eine zentrale Rolle bei der Differenzierung von T-Zellen. Gewebespezifische Transkriptionsfaktoren kontrollieren dabei die Chromatinstruktur von Signaturgenen. T-Zellen von SLE-Patienten zeichnen sich durch gesteigerte Expression des Transkriptionsfaktors CREMa und ein Ungleichgewicht zwischen IL-2 und IL-17A aus. Wir untersuchten den Einfluss von CREMa auf IL2 und IL17A.

Material und Methoden. In naiven, zentralen und Effektor-Memory CD4+T-Zellen wurde der Einfluss von DNA-Methylierung auf die Expression von IL-2 und IL-17A untersucht. Anhand von Immunopräzipitationen, Überexpressions- und Knock-down-Experimenten wurden CREMa-vermittelte Effekte auf IL2 und IL17A dokumentiert.

Ergebnisse. CREM $\alpha$ vermittelt durch die Rekrutierung der DNA-Methyltransferase 3a in Effektor-Memory CD4+T-Zellen DNA Methylierung des IL2-Promotors, und reduziert gleichzeitig den Methylierungsgrad des IL17A-Promotors. T-Zellen von SLE-Patienten, welche vermehrt CREM $\alpha$ exprimieren, entwickeln einen Phänotyp, der dem von Effektor-Memory $\mathrm{CD}_{4}+\mathrm{T}-\mathrm{Z}$-Zllen entspricht mit epigenetisch bedingt niedriger IL-2- und gesteigerter IL-17A-Expression.
Diskussion. Unsere Daten belegen die Rolle von CREMa als Vermittler von regions- und gewebespezifischer DNA-Methylierung unter physiologischen Bedingungen sowie in SLE-T-Zellen. Die Aufklärung molekularer Mechanismen der Zytokinregulationen kann zur Entwicklung zielgerichteter Therapiemöglichkeiten beitragen und neue Biomarker hervorbringen.

Regulation von PACAP und PACAP-Rezeptoren bei der nektrotisierenden Enterocolitis des Frühgeborenen

Seeliger S. ', Kiesnat A. ${ }^{2}$, Hippe A. ${ }^{2}$, Poppe A. , Buddenkotte J. ${ }^{3}$, Steinhoff M. ${ }^{4}$, Paul T.

'Universität Göttingen, ${ }^{2}$ Düsseldorf, ${ }^{3}$ Münster, ${ }^{4}$ San Francisco

Einleitung. Die nekrotisierende Enterocolitis (NEC) ist die häufigste erworbene, lebensbedrohliche Erkrankung des Gastrointestinaltrakts des Früh- und Neugeborenen. Pathogene Bakterien sind ursächlich beteiligt. In der Literatur liegt die Insidenz der NEC bei 14\% der Frühgeborenen mit einem Geburtsgewicht $<1000 \mathrm{~g}$. Pituitary adenylate cyclase activating peptide (PACAP) und das vaso-intestinale Peptid (VIP) sind wichtige Neuropeptide, die im Magen-Darm-Trakt und ZNS vorkommen. PACAP und PACAP-Rezeptoren (VPAC1, VPAC2, PAC1) sind für das Überleben essenziell und spielen in unterschiedlichen immunmodulatorischen und entzündlichen Prozessen eine wichtige Rolle. Im Rahmen der NEC kommt es zu einer signifikanten Hochregulation von PACAP und VPAC1 auf Nervenfasern und auf mononukleären Zellen. Methoden. In Ex-vivo-Experimenten konnten wir zeigen, dass es nach Stimulation von mononukleären Zellen (PBMC) mit LPS zu einer Hochregulation von VPAC1 (FACS-Analyse) und zur Sekretion von IL8 (ELISA) kommt. Nach Inkubation mit PACAP kann ebenfalls ein verstärktes Signal von VPAC1 auf diesen Zellen im FACS abgeleitet werden. Somit konnten wir zum ersten Mal aufzeigen, dass es bei der NEC über die Aktivierung von Bakterientoxinen neben einer Hochregulation von PACAP und VPAC 1 auch zu einem proinflammatorisches Signal (IL8) kommt.

Schlussfolgerung. Dieser Pathomechanismus zeigt, dass in der initialen Phase der NEC die Inflammationskaskade über ein neurogenes Signal initiiert wird. In der Behandlung der NEC könnte dieses wohlmöglich einen therapeutischen Ansatz bieten.

Humane monoklonale Antikörper gegen das pandemische 1957 H2N2-Influenzavirus decken ein wiederkehrendes Motiv für die Antikörpererkennung der Rezeptorbindungstasche des InfluenzaHämagglutinins auf

Krause J.C. ${ }^{1,2}$, Xu R. ${ }^{4}$, Tsibane T. ${ }^{5}$, Huffman C.J. ${ }^{2}$, Blum D.L. ${ }^{2}$, Edwards K.M. ${ }^{2}$, Basler C.F. ${ }^{5}$, Wilson I.A. ${ }^{4}$, Crowe J.E., Jr. ${ }^{2}{ }^{3}$

'Universitätsklinikum Freiburg, Zentrum für Kinder- und Jugendmedizin, Freiburg, ${ }^{2}$ Departments of Pediatrics and of ${ }^{3}$ Microbiology and Immunology, Vanderbilt University Med. Center, Nashville, TN, ${ }^{4}$ Department of Integrative Structural and Computational Biology, Scripps Research Institute, La Jolla, CA, ${ }^{5}$ Dept. of Microbiology, Mount Sinai School of Med., New York, NY

Fragestellung. Influenza-H2-Hämagglutinin(HA)-reaktive monoklonale Antikörper (mAbs) zu klonieren und ihre Struktur-Funktions-Beziehungen zu bestimmen.

Material und Methoden. Wir klonten mAbs mit Hybridoma Technologie aus dem peripheren Blut gesunder Spender, die zwischen 1950 und 1968 geboren wurden, und kristallisierten die Fab Fragmente dieser mAbs im Komplex mit $\mathrm{H}_{2} \mathrm{HA}$. 
Ergebnisse. MAbs 8F8, 8M2 und $2 \mathrm{G} 1$ reagierten mit dem pandemischen $\mathrm{H}_{2} \mathrm{~N}_{2}$-Virus in Hämagglutinations-Inhibitions-Assays. MAbs $8 \mathrm{M}_{2}$ und $2 \mathrm{G} 1$ teilten das VH1-69-Keimbahn-Gen. Kristallstrukturen zeigten, dass diese drei Antikörper eine aromatische Seitenkette verwenden, um eine konservierte Vertiefung in der HA-Rezeptorbindungstasche zu besetzen.

Diskussion. Selbst vier Dekaden nach der Zirkulation von $\mathrm{H}_{2} \mathrm{~N}_{2}$-Viren konnten potente mAbs nachgewiesen werden, die eine konservierte Region des globulären Kopfes von $\mathrm{H}_{2} \mathrm{HA}$ angreifen. Diese Interaktion kann als Startpunkt für das Design von Inhibitoren gegen die konservierte hydrophobe Rezeptorbindungstasche in Influenzaviren genutzt werden.

\section{Die Expression von CREMa in T-Zellen reguliert das LPS-induzierte akute Lungenversagen}

Verjans E. ${ }^{1,2}$, Ohl K.', Yu Y. ${ }^{1}$, Schippers A. ', Wagner N. ', Uhlig S. ${ }^{2}$, Martin C. ${ }^{2}$, Tenbrock K. ${ }^{\text {? }}$

${ }^{1}$ Klinik für Kinder- und Jugendmedizin, RWTH Aachen, Aachen, ${ }^{2}$ Institut für Pharmakologie und Toxikologie, RWTH Aachen, Aachen

Einleitung. Der Transkriptionsfaktor cAMP responsive element modulator (CREM) $\alpha$ beeinflusst zahlreiche zelluläre und molekulare Eigenschaften von T-Zellen, wobei er u. a. die IL-17 und IL-2 Expression erhöht. Bei der Entwicklung des akuten Lungenversagens (ALV) ist die Einwanderung und Interaktion von Immunzellen von besonderer Bedeutung, jedoch ist die Rolle von T-Zellen weiterhin wenig geklärt. In dieser Studie sollte untersucht werden, inwieweit CREMa in T-Zellen das akute Lungenversagen regulieren kann.

Methoden. Mittels LPS-Instillation i.t. wurde in WT- und CREMa-CD2-Mäusen, die CREMa selektiv in T-Zellen überexprimieren, ein ALV hervorgerufen. Die Tiere wurden $24 \mathrm{~h}$ bzw. $72 \mathrm{~h}$ nach LPS-Applikation mittels Flexivent-Setup beatmet und unterschiedliche Lungenfunktionsparameter gemessen. Zur Charakterisierung der Inflammation wurden FACS-Analysen, ELISA-Zytokinbestimmungen, qrt-PCR-Analysen und histologische Aufarbeitungen des Lungengewebes verwendet. Zusätzlich wurde ein ALV in lymphopenen RAG1-/--Mäusen durchgeführt, die vorher einen Transfer von WT oder CREM-/- CD4+T-Zellen erhielten.

Ergebnisse. Die Überexpression von CREMa in T-Zellen bewirkt ein verstärktes Krankheitsbild $24 \mathrm{~h}$ und $72 \mathrm{~h}$ nach der LPS-Gabe. Dies zeigt sich sowohl in einer deutlichen Verschlechterung der Lungenfunktion als auch in einer erhöhten Expression und Sekretion von TNFa, IL-6 und IL-17. Zudem zeigte sich eine verminderte Einwanderung von regulatorischen T-Zellen, gekoppelt mit einer erniedrigten IL-2-Genexpression und Sekretion. Ein Transfer von CREM-/- CD4+T-Zellen in RAG1-/- Mäuse resultierte hingegen in einem deutlich milderen Krankheitsverlauf.

Schlussfolgerung. Somit beeinflusst die Expression von CREMa in TZellen den Verlauf eines akuten Lungenversagens.

\section{Immunmodulatorischer Einfluss von Pentoxifyllin auf neonatale Monozyten In-vitro-Evaluierung von Funktion und Phänotyp im Sepsis-Modell}

Schüller S.S. ${ }^{\prime}$, Spittler A. ${ }^{2}$, Helmer H. ${ }^{3}$, Husslein P. ${ }^{3}$, Pollak A. ${ }^{\prime}$, Berger A. ${ }^{1}$ 'Universitätsklinik für Kinder- und Jugendheilkunde, Medizinische Universität Wien, Österreich, ${ }^{2}$ Universitätsklinik für Chirurgie \& Core Facility Flow Cytometry, Medizinische Universität Wien, Österreich, ${ }^{3}$ Universitätsklinik für Frauenheilkunde, Medizinische Universität Wien, Österreich

Fragestellung. Frühgeborene leiden aufgrund ihrer funktionellen Unreife im Bereich des Immunsystems häufiger an schwerer Sepsis mit hohen Morbiditäts- und Mortalitätsraten. Pentoxifyllin (PTX) wird aufgrund seiner immunmodulatorischen Eigenschaften in der adjuvanten Therapie der schweren neonatalen Sepsis eingesetzt. Diese
Studie untersucht erstmals den Einfluss von PTX auf die Expression monozytärer Oberflächemarker sowie auf die Produktion von pro- und antiinflammatorischen Zytokinen beim Reif- und Frühgeborenen im Vergleich zu gesunden Erwachsenen.

Material und Methode. Nabelschnurblut von Reif- $(n=5)$ und Frühgeborenen $(n=5)$, sowie peripheres Blut von gesunden Erwachsenen $(n=5)$ wurde über $4 \mathrm{~h}, 8 \mathrm{~h}$ und $24 \mathrm{~h}$ mit LPS sowie LPS plus PTX in unterschiedlicher Dosierung stimuliert. Monozytäre Reifungs- und Differenzierungsantigene wurden durchflusszytometrisch bestimmt. Im Zellüberstand wurden die Zytokine IL-1 $\beta$, IL-6, IL-8, IL1o, TNF und IL-12 mit einem Bead Array gemessen.

Ergebnisse. Unter PTX kam es zu einer dosisabhängigen Downregulation von CD14, CD8o, CD64 und CD11b auf Monozyten in allen drei Altersgruppen, wobei sich für CD14 und CD11b besonders niedrige Werte beim Frühgeborenen fanden. Die LPS induzierte Produktion von TNF, IL-1, IL-6 und IL-8 wurde unter PTX in allen drei Altersgruppen signifikant reduziert, wobei sich beim Neu- und Frühgeborenen TNF fast völlig supprimiert zeigte.

Diskussion. Unterschiede in der Expression von CD14 und CD11b sowie in der TNF-Produktion sprechen für einen komplexen Einfluss von PTX auf LPS stimulierte neonatale Monozyten, der nur eingeschränkt mit den Daten adulter Monozyten vergleichbar ist. Um einen gezielten Einsatz von PTX in der neonatalen Sepsis zu gewährleisten, sind weitere In-vitro-Untersuchungen dringend notwendig.

\section{Ventrikuläre Interaktion - ein neues Target für die Behandlung der Herzinsuffizienz?}

Apitz C. ${ }^{1,2}$, Schranz D. ${ }^{1}$, Redington A.N. ${ }^{2}$

${ }^{1}$ Justus-Liebig-Universität, Kinderherzzentrum, Gießen, ${ }^{2}$ University of Toronto, Hospital for Sick Children, Toronto

Fragestellung. Frühere Untersuchungen konnten zeigen, dass die Bändelung der Lungenschlagader (PA) zu einer Steigerung der Kontraktilität der rechten Herzkammer (RV), aber auch der linken Kammer (LV) führt, erklärt durch ventrikuläre Interaktion über das interventrikuläre Septum. Ziel unserer Studie war es, zu untersuchen, ob dieses Prinzip auch zur Behandlung einer insuffizienten Herzkammer genutzt werden kann, um deren Funktion zu verbessern.

Material und Methode. Mithilfe eines adjustierbaren Banding-Implantats wurde in einem Kaninchenmodell der Effekt einer aortalen Konstriktion auf die Funktion eines chronisch drucküberlasteten RV mithilfe von Druck-Volumen-Messkathetern untersucht. Anschließend wurden die histologischen und molekulargenetischen Veränderungen des RV- und LV-Myokards aufgearbeitet.

Ergebnisse. Neben einer verbesserten Kontraktilität fanden sich sowohl in der Gruppe mit ausschließlicher Bändelung der PA als auch in der Gruppe mit Bändelung der PA und Aorta signifikante Veränderungen sowohl auf histologischer als auch auf molekularer Ebene, jedoch zeigte die Gruppe mit PA- und aortalem Banding deutlich kleinere Kardiomyozyten-Durchmesser, einen verminderten Kollagengehalt im RV, sowie eine verminderte myokardiale Expression von Endothelin-Rezeptor B, Matrix Metalloproteinase 9 und Transforming-Growth-Faktor- $\beta$ 1.

Schlussfolgerung. Unsere Ergebnisse zeigen, dass eine Konstriktion der Aorta in einem chronischen Modell für RV-Versagen aufgrund von RV-Drucküberlastung nicht nur zur Verbesserung der systolischen RVFunktion, sondern auch zu einem verbesserten myokardialen Remodeling führt. Die chronisch gesteigerte Nachlast des LV scheint daher in einer „physiologischeren“ Hypertrophieantwort des drucküberlasteten $\mathrm{RV}$ zu resultieren. 
LIN28B induziert Neuroblastome und dereguliert die MYCN-Expression durch Inhibition von Let7 mikroRNAs

Schulte J.H.', Molenaar J.' , Lindner S.', Thor T.', Sprüssel A. ', Versteeg R. ${ }^{2}$, Eggert A. ${ }^{?}$

'Universitätsklinikum Essen, Kinderklinik, Essen, ${ }^{2}$ AMC, Dept. of Oncogenomics, Amsterdam

Fragestellung. Eine Bedeutung des RNA-bindenden Proteins LIN28B in der Pathogenese von Krebserkrankungen wird vermutet, konnte bisher aber nicht in vivo nachgewiesen werden. Im Rahmen dieser Studie untersuchten wir die Bedeutung von LIN28B für die Pathogenese von Neuroblastomen.

Material und Methoden. Analyse der Expression von LIN28B in primären Neuroblastomen. Untersuchung der funktionellen Bedeutung von LIN28B in Neuroblastomzelllinien. Neuralleisten-spezifische Überexpression von Lin28b in Mäusen.

Ergebnisse. In den untersuchten Neuroblastomen war LIN28B deutlich höher als in anderen Tumorentitäten oder normalen Geweben exprimiert, und eine hohe Expression korrelierte mit einer schlechten Prognose. In Neuroblastomzellen inhibierte LIN28B Let7 mikroRNAs und erhöhte so die Expression des Onkogens MYCN. Die Aktivierung des LIN28B-Signalwegs blockierte die Differenzierung von Neuroblasten und von Neuroblastomzellen. Genetisch veränderte Mäuse, in deren Neuralleistenzellen Lin $28 \mathrm{~b}$ überexprimiert wurde, entwickelten aggressive Neuroblastome. Eine Behandlung dieser Mäuse mit JQ1, was zu einer Herunterregulation von MYCN führte, verminderte die Proliferation und induzierte Apoptose in den beobachteten Neuroblastomen. Schlussfolgerung. Wir konnten erstmals zeigen, dass LIN28B ein Onkogen in vivo ist, und LIN28B eine Bedeutung in der Pathogenese des Neuroblastoms zukommt. Eine Inhibition des LIN28B/Let7/MYCN Signalwegs stellt einen neuen Ansatzpunkt für eine zielgerichtete Neuroblastomtherapie dar.

\section{Atemwegsdehydration erhöht in vivo das Risiko für die allergische Atemwegsentzündung}

Fritzsching B. ${ }^{1,2}$, Dai L. ${ }^{2}$, van Bodegom C. ${ }^{2}$, Schatterny J. ${ }^{2}$, Hirtz S. ${ }^{2}$, Zhou Z. ${ }^{2}$, Mall M.A. ${ }^{1,2}$

'Sektion Pädiatrische Pneumologie, Allergologie und Mukoviszidose Zentrum, Klinik III, Zentrum für Kinder- und Jugendmedizin, Universitätsklinikum Heidelberg, ${ }^{2}$ Abteilung Translationale Pneumologie, Zentrum für Translationale Lungenforschung, Universität Heidelberg, Mitglied im Deutschen Zentrum für Lungenforschung (DZL)

Fragestellung. Unsere Vorarbeiten an Mäusen mit atemwegsspezifischer Überexpression des epithelialen $\mathrm{Na}+$-Kanals ( $\beta \mathrm{ENaC}-\mathrm{Tg})$ und Mäusen mit Deletion des Cl--Kanals SCL26A9 deuten darauf hin, dass die Atemwegsdehydration durch gestörten Ionentransport möglicherweise eine bedeutsame Rolle in der Pathogenese der allergischen Atemwegsentzündung spielt (Anagnostopoulou et al., J Clin Invest 2012). Diese Hypothese wurde in der vorliegenden Arbeit überprüft.

Material und Methode. Durch intratracheale Sensibilisierung mit Aspergillus-fumigatus-Extrakt induzierten wir in $\beta \mathrm{ENaC}$-Tg-Mäusen eine allergische Atemwegsentzündung und führten Lungenfunktionsuntersuchungen mit Metacholinprovokation, zytologische Analysen der BAL und morphologische Untersuchungen durch. Per 11-Farben FACS-Analyse charakterisierten wir die pulmonale Immunantwort.

Ergebnisse. $\beta \mathrm{ENaC}-\mathrm{Tg}$ Mäuse mit Atemwegsdehydration wiesen eine signifikante Atemwegshyperreagibilität (AHR) auf. Nach Allergenexposition zeigte sich eine verstärkte eosinophile Entzündung mit gesteigerter pulmonaler IL-13-Expression und gesteigerter AHR. In der FACS-Analyse produzierten Th2-Zellen, kürzlich entdeckten ILC-2Zellen und Atemwegsepithelzellen signifikante Mengen an IL-13. Um die Relevanz dieser Beobachtung weiter zu überprüfen, inhibierten wir den IL-13-Signalweg durch Deletion des STAT6-Gens in vivo. Tatsächlich wiesen STAT6-/- $\beta \mathrm{ENaC}$-Tg-Mäuse keine eosinophile Atemwegsentzündung nach Allergenexposition auf.
Schlussfolgerung. Atemwegsdehydration und gestörte mukoziliäre Clearance sind im Mausmodell Risikofaktoren für die Entstehung einer allergischen Atemwegsentzündung.

Gefördert durch: DFG MA 2081/3-2 und DZL82DZL00401

\section{"Multiple breath washout" ist im klinischen Alltag durchführbar und ermöglicht die Erkennung früher Veränderungen der Lungen- funktion bei Säuglingen und Kleinkindern mit zystischer Fibrose}

Stahl M.', Joachim C. ', Blessing K.', Hämmerling S.', Sommerburg 0. ', Latzin P. ${ }^{2}$, Mall M.A.

'Sektion Pädiatrische Pneumologie \& Allergologie und CF-Zentrum, Zentrum für Kinder- und Jugendmedizin und Abteilung Translationale Pneumologie, Zentrum für Translationale Lungenforschung (TLRC), Universitätsklinikum Heidelberg, Heidelberg, Deutschland, ${ }^{2}$ Abteilung Päd. Pneumologie, Universitätsklinik für Kinderheilkunde, Universitätsspital Bern, Bern, Schweiz

Hintergrund. Die Lungenerkrankung bei zystischer Fibrose (CF) beginnt in den ersten Lebensmonaten oft vor dem Beginn klinischer Symptome. Mit dem Gasauswaschverfahren („multiple breath washoutW, MBW) ist es unter Studienbedingungen in spezialisierten Lungenfunktionslaboratorien möglich, frühe Veränderungen der Lungenfunktion bei Säuglingen und Kleinkindern mit CF festzustellen. Ziel dieses Projekts war die Bestimmung der Durchführbarkeit des MBW bei o- bis 4-jährigen Kindern mit CF und nicht-CF Kontrollen im klinischen Alltag eines CFZentrums, das nicht spezialisiert war auf die Durchführung von MBW.

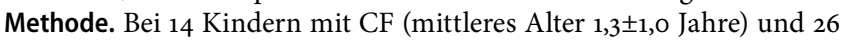
altersgematchten nicht-CF Kontrollen wurde in Chloralhydratsedierung das MBW mit Schwefelhexafluorid durchgeführt.

Ergebnisse. Die MBW-Messungen konnten bei 67,5\% aller Kinder erfolgreich durchgeführt werden. Der mittlere Lung Clearance Index (LCI) war bei Kindern mit CF im Vergleich zu den nicht-CF Kontrollen signifikant erhöht $(\mathrm{p}=0,006)$.

Schlussfolgerung. MBW ist im klinischen Alltag eines CF-Zentrums bei Säuglingen und Kleinkindern durchführbar und ermöglicht die Erkennung früher Veränderungen der Lungenfunktion bei CF.

Gefördert durch: Bundesministerium für Bildung und Forschung (82DZL00401) und Dietmar Hopp Stiftung

\section{"Myeloid-derived-suppressor cells" (MDSCs) verhindern die GVHD ("graft-vs.-host disease“) und erhalten gleichzeitig den GVT("graft- vs.-tumor ")-Effekt nach allogener Knochenmarktransplantation}

\section{Meßmann J.J.', Lutz M.B. ${ }^{2}$, Leithäuser F. ${ }^{3}$, Debatin K.-M. ', Strauß G. ${ }^{\text {' }}$}

'Universitätsklinikum Ulm, Klinik für Kinder- und Jugendmedizin, Ulm, 2Universität Würzburg, Institut für Virologie und Immunbiologie, Würzburg, ${ }^{3}$ Institut für Pathologie, Universität Ulm, Ulm

Hintergrund. Die allogene Knochenmarktransplantation (KMT) ist eine Behandlungsstrategie bei malignen hämatopoetischen Erkrankungen, da T-Zellen im Transplantat residuale Tumorzellen eliminieren können (GVT-Effekt). Gleichzeitig sind allogene T-Zellen für die Entstehung der GVHD verantwortlich. Ziel jeder KMT ist die Hemmung der GVHD bei gleichzeitiger Erhaltung des GVT Effekts. „Myeloid-derived-suppressor cells" (MDSCs) sind eine heterogene Population myeloischer Vorläuferzellen, die T-Zellaktivierung und -proliferation hemmen. Im murinen KMT-Modell wurde untersucht, ob die Transplantation von MDSCs die GVHD hemmt, ohne den GVT-Effekt zu beeinflussen. Methode. MDSCs wurden in vitro durch Inkubation von Knochenmarkzellen mit GM-CSF generiert und zusammen mit allogenem Knochenmark und T-Zellen in letal bestrahlte Empfängertiere transplantiert. Spender und Empfänger unterschieden sich in der Expression eines MHC-Klasse-I-Antigens.

Ergebnisse. Die Kotransplantation von MDSCs zusammen mit allogenem Knochenmark und T-Zellen verhinderte die Entstehung einer 
klinischen GVHD und alle Tiere überlebten, während 60\% der Tiere, denen keine MDSCs transplantiert wurden, 30 bis 50 Tage nach Transplantation starben. Die histologische GVHD im Darm, der Leber und der Haut war ebenfalls vermindert. Die transplantierten MDSCs infiltrierten sowohl die lymphatischen Organe wie GVHD Zielorgane. Bemerkenswert war, dass der GVT-Effekt erhalten blieb und residuale Tumorzellen zu $100 \%$ eliminiert wurden.

Schlussfolgerung. Zusammenfassend konnte gezeigt werden, dass in vitro generierte MDSC effizient die GVHD Entstehung hemmen und gleichzeitig den GVT-Effekt nicht beeinflussen und deshalb eine mögliche therapeutische Option nach allogener KMT darstellen.

\section{Neuroplastizität bei frühen Hirnläsionen - Neuromodulation durch funktionelle Therapie}

JuengerH. ${ }^{1}$, Mall V. ${ }^{1}$, BerweckS. ${ }^{2}$, StaudtM. ${ }^{2,3}$, Kraegeloh-Mann I. ${ }^{3}$, Burdach S. ${ }^{1}$ ${ }^{1}$ Kinderklinik München Schwabing, Klinik und Poliklinik für Kinder- und Jugendmedizin, Klinikum Schwabing und Klinikum Rechts der Isar der Technischen Universität München, München, ${ }^{2}$ Schön Klinik Vogtareuth, Klinik für Neuropädiatrie und Neurologische Rehabilitation, Epilepsiezentrum, Vogtareuth, ${ }^{3}$ Universitätskinderklinik Tübingen, Abteilung für Neuropädiatrie, Entwicklungsneurologie, Sozialpädiatrie, Tübingen

Fragestellung. Bei Patienten mit früh erworbenen (einseitigen) Hirnläsionen wurden (1.) Mechanismen kortikospinaler Reorganisation und (2.) neuroplastische Effekte von funktioneller Physiotherapie auf kortikaler und subkortikaler Ebene untersucht.

Material und Methode. Patienten mit unterschiedlichen Läsionsmustern [(A) perinatal erworbene Infarkte der A. cerebri media (kortikale Läsionen), (B) pränatal erworbene periventrikuläre Läsionen (subkortikale Läsionen)] wurden mittels komplementärer Methodik untersucht: strukturelle/funktionelle Magnetresonanztomographie [(f)MRT] inkl. Lesion-Symptom-Mapping, transkranielle Magnetstimulation (TMS), Magnetoenzephalographie (MEG), diffusionsbasierte Traktographie (DTI). Ergebnisse. Nach frühen Hirnläsionen zeigen sich wesentliche Unterschiede für die kortikospinale Reorganisation des motorischen und somatosensorischen Netzwerks. Im Gegensatz zu einer möglichen interhemisphäriellen Reorganisation des motorischen Netzwerks ( $\mathrm{M}_{1}$ und Basalganglien) mit Übernahme von Funktionen durch die nicht geschädigte Hemisphäre gilt für den primär somatosensorischen Kortex $\left(\mathrm{S}_{1}\right)$ das Prinzip einer frühen Determination ohne bedeutende interbzw. intrahemisphärielle Reorganisation. Weiterhin zeigen die Patientengruppen (A) und (B) ein unterschiedliches klinisches Ansprechen auf funktionelle Physiotherapie sowie divergierende therapieinduzierte neuroplastische Effekte in Abhängigkeit vom kortikospinalen Reorganisationsmuster.

Schlussfolgerung. Das Verständnis grundsätzlicher Mechanismen sensomotorischer Reorganisation sowie motorischen Lernens bei Patienten mit frühen Hirnschädigungen wird die Entwicklung neuer, spezifischer Therapien bei kongenitaler Hemiparese ermöglichen.

\section{Dysregulation von Epigenom und Transkriptom durch HBV in Hepa- tozyten und der Einfluss von Chemo- und Gentherapie}

Hensel K.O. ', Jenke A.C. ', Wiluhn L. ', Klein A. ', Winkler T.', Orth V. , Wirth S. Postberg J.'

'Helios Klinikum Wuppertal, Zentrum für Kinder- und Jugendmedizin, Universität Witten/Herdecke

Fragestellung. Das HBV-X-Protein ( $\mathrm{HBx})$ transreguliert hepatozelluläre Promotoren. Das führt u. a. zur Deregulation von DNS-Methyltransferasen und Histon-Acetyltransferasen, die an der Etablierung epigenetischer Signaturen beteiligt sind. Wir untersuchen, welche $\mathrm{Me}-$ chanismen für die Reprogrammierung von Leberzellen wichtig sind, die zur Chronifizierung der Hepatitis B, vor allem bei Kindern, und zur malignen Transformation führen können. Wir untersuchen auch, ob Chemotherapien oder Gentherapieversuche zur Restaurierung normaler Chromatinsignaturen führen.

Material und Methode. Die Expression von 84 Genen wurde in HBVpositiven/negativen murinen Hepatozyten durch qPCR Arrays bestimmt. Ähnliche Versuche wurden mit HBV-Hepatozyten durchgeführt, die durch RNAi Gentherapie oder Lamivudin behandelt wurden. Von einigen Genen wurden DNS Methylierungsprofile und Chromatinsignaturen durch MeDIP/ChIP-qPCR bestimmt. Um die Rolle von HBx als Transregulator zu untersuchen, wurde GST-HBx in nicht-HBV Hepatozyten exprimiert und Untersuchungen der Genexpression durchgeführt.

Ergebnisse. Wir haben Gene mit differenziellen Expressionsmustern identifiziert. In keinem Beispiel konnte eine differenzielle DNS-Methylierung beobachtet werden. Alle untersuchten Gene zeigten Hypoacetylierung, die partiell durch Therapieversuche restauriert wurde. Ektopisch exprimiertes GST-HBx führte zu deregulierten Expressionsmustern, wie sie in HBV-positiven Hepatozyten beobachtet wurden.

Diskussion und Schlussfolgerung. HBV-Infektionen führen zu Veränderungen im Epigenom von Hepatozyten und zu deregulierter Genexpression. Therapien haben einen noch näher zu untersuchenden Einfluss auf die epigenetische Signatur der Wirtszellen. HBx als wichtiger Transregulator beeinflusst die Genexpression in Hepatozyten.

\section{Wirkung von Cilengitide auf In-vitro- und In-vivo-Gliobastom- modelle}

\section{Schubert J.', Mullins C.S.', Van Gool S. ${ }^{2}$, Vandenberk L. ${ }^{2}$, Schneider B. ${ }^{3}$,} Linnebacher M. ${ }^{4}$, Classen C.F.'

'Klinik für Kinder- und Jugendheilkunde, Universität Rostock, Deutschland, ${ }^{2}$ Klinik für pädiatrische Neuroonkologie, Universität Leuven, Belgien, ${ }^{3}$ Institut für Pathologie, Universität Rostock, Deutschland, ${ }^{4}$ Klinik für Allgemeine Chirurgie, Universität Rostock, Deutschland

Fragestellung. Cilengitide (CGT), ein Antagonist von Integrinen, die an Tumor- und Endothelzellen exprimiert werden, wird in klinischen Phase-III-Studien beim Glioblastoma multiforme (GBM) eingesetzt. Es soll antiangiogenetisch und zytotoxisch wirken. Wir untersuchten seine Wirkung als Mono- und Kombinationstherapie an GBM-Modellen. Material und Methoden. An zehn patientenindividuellen GBM-Zelllinien geringer Passage wurde die Wirkung von CGT als Einzelsubstanz und in Kombination mit Temozolomid (TMZ) analysiert. Der MGMTPromoterstatus und die Expression relevanter Integrine wurden bestimmt und deren Einfluss auf die Wirkung in vitro untersucht. Mit Hilfe des syngenen orthotopen GL-261-Mausmodells wurden anschließend die In-vivo-Effekte untersucht.

Ergebnisse. Wir fanden eine positive Korrelation zwischen MGMT-Promoter-Status und TMZ-Wirkung in vitro. Die Kombinationsbehandlung von Zelllinien mit methyliertem Promoter zeigte additive Effekte, in unmethylierten Zelllinien hingegen trat ein deutlicher Trend zur Überlegenheit der CGT-Monotherapie zutage. Er korrelierte jedoch nicht mit der Integrinexpression. In-vivo wurde durch die Kombinationstherapie ein verlängertes Gesamtüberleben gegenüber der TMZMonotherapie erzielt, die CGT-Monotherapie erbrachte keinen Vorteil verglichen mit der unbehandelten Kontrollgruppe.

Diskussion und Schlussfolgerung. Patienten mit einem MGMT-Promotermethyliertem GBM könnten somit von CGT zusätzlich zur Standardtherapie mit TMZ profitieren, Patienten mit unmethyliertem GBM eher von einer CGT-Monotherapie. Das Ansprechen auf neue zielgerichtete Substanzen wie CGT hängt somit maßgeblich von dem individuellen molekularen Profil des Tumors ab. Daher sind individuelle Kombinationstherapien erforderlich, um ein optimales Ansprechen zu erzielen. 


\section{Fgf10 induziert De-novo-Alveogenese im Mausmodell der BPD}

Chao C.M. ${ }^{1,3}$, Al Alam D. ${ }^{2}$, Tiozzo C. ${ }^{2}$, Zimmer K.P. ${ }^{1}$, Bellusci S. ${ }^{3}$

'Justus-Liebig-Universität, Gießen, ${ }^{2}$ Saban Research Institute of Children's Hospital Los Angeles, ${ }^{3}$ Excellence Cluster Cardio-Pulmonary System, Gießen

Fragestellung. Die bronchopulmonale Dysplasie (BPD) ist eine chronische Lungenerkrankung der Frühgeborenen mit Wachstumsarrest, verminderte Alveolarisierung und Gefäßdysmorphien. In unserer Studie wird der Effekt der Fgfıo Überexpression auf die Lungenmorphologie (Alveolarisierung) bei Mäusen nach Hyperoxie-induzierter Lungenschädigung untersucht.

Methoden. 1) Mausmodell der BPD: Transgene Mäuse (Rosa26rtTA/ +;tet(O)solFgfr2b/+; Rosa26rtTA/+;tet(O)Fgfio) wurden von Tag o-8 einer Hyperoxiebehandlung $\left(85 \% \mathrm{O}_{2}\right)$ unterzogen. Von Tag 9-45 befanden sie sich in Normoxie und erhielten zur Aktivierung des Transgens Doxycyclin-haltiges Futter. Die lungenmorphometrische Analyse (Mean Linear Intercept [MLI], Luftfläche, Sekundärseptumdicke) erfolgte an Tag 15 und 45. 2) Toleranzuntersuchungen: Adulte Mäuse erhielten für 2 Wochen Doxycyclin-haltiges Futter und wurden anschließend evaluiert (Überlebenskurve, Histologie, Ki67 und TUNELFärbung).

Ergebnisse. 1) Die Überexpression des dominant negativen Rezeptors (solFgfrab) für Fgfio hatte keinen Einfluss auf die Lungenstruktur. 2) Die Überexpression von Fgfio führte jedoch zur signifikanten Reduktion der Alveolenrarefizierung (MLI 30,5 $\mu \mathrm{m}$ vs. 21,4 $\mu \mathrm{m}$ ). 3) FgfioÜberexpression führte zur Hyperzellularität, aber nicht zur Erhöhung der Apoptose oder Mortalität; Nebenwirkungen sind reversibel.

Schlussfolgerung. Fgfio-Überexpression triggert die De-novo-Alveogenese nach Hyperoxie-induzierter Lungenschädigung. Sie wird gut toleriert und stellt eine potentielle Therapie für die BPD dar.

\section{Haben Patienten mit Hermansky-Pudlak-Syndrom Typ 2 ein erhöh- tes Risiko für hämophagozytische Lymphohistiozytose?}

\section{Bode S.F.N.', Jessen B. ', EhI S.' \\ ${ }^{1}$ Centrum für chronische Immundefizienz, Zentrum für Kinder- und Ju- gendmedizin, Universitätsklinikum Freiburg}

Fragestellung. Patienten mit Zytotoxizitätsdefekten (ZD) haben ein erhöhtes Risiko, an hämophagozytischer Lymphohistiozytose (HLH) zu erkranken. Beim Hermansky-Pudlak-Syndrom Typ 2 (HPS2) liegt ein ZD vor. Das Risiko für eine HLH ist aufgrund der Seltenheit jedoch unklar. Bei einem HPS2-Patienten wurde eine HLH beschrieben, bei ihm lag jedoch eine zusätzliche heterozygote Rab27a-Mutation vor.

Material und Methode. Wir untersuchten die Anfälligkeit für HLH im pearl Mausmodell für HPS2. Darüber hinaus identifizierten wir eine Kohorte von Patienten mit HPS2 und analysierten klinische und immunologische Daten zum Krankheitsverlauf.

Ergebnisse. Nach Infektion mit dem lymphozytären Choriomeningitis Virus entwickelten pearl-Mäuse das klinische Bild einer HLH. Im Gegensatz zu perforindefizienten Mäusen war diese Erkrankung aber mild und ohne Behandlung transient, passend zu einer residuellen Zytotoxizität bei pearl-Mäusen. Eine zusätzliche heterozygote Rab27aMutation führte nicht zu einem ausgeprägteren Phänotyp. In der bisher größten HPS2-Kohorte konnten 22 Patienten mit 234 Patientenjahren analysiert werden. Wir konnten zu dem vorbekannten Patienten mit HLH nur einen weiteren Patienten identifizieren, welcher eine HLH entwickelte, zwei andere hatten inkomplette HLH-Episoden. Alle $16 \mathrm{~Pa}$ tienten, bei denen Zytotoxizität oder Degranulation getestet wurde, zeigten pathologische Ergebnisse.

Schlussfolgerung. Das Risiko für HPS2-Patienten eine HLH zu entwickeln ist vorhanden, aber geringer als bei anderen Albinismussyndromen wie Griscelli- und Chédiak-Higashi-Syndrom. Grund hierfür ist ein weniger stark ausgeprägter ZD. Eine präemptive SZT ist nicht gerechtfertigt, auch weil die nicht beeinflussbare pulmonale Beteiligung ein prognosebestimmender Faktor ist.

\section{BET-Bromodomain Inhibition als therapeutische Option bei Medulloblastomen}

Henssen A.', Thor T.', Eggert A.', Schulte J.H.'

${ }^{1}$ Arbeitsgruppe Pädiatrisch-Onkologische Forschung, Labor für Pädiatrische Hämatologie und Onkologie, Kinderklinik III, Zentrum für Kinder- und Jugendmedizin Universitätsklinikum Essen, Essen

Fragestellung. Medulloblastome sind die häufigsten bösartigen Hirntumoren im Kindesalter. Patienten, deren Tumoren eine Überexpression von MYC aufweisen, haben eine sehr schlechte Prognose. Jüngste Studien mit dem BET-Protein Inhibitor JQ1 zeigten, dass MYC von BETProteinen reguliert wird. Aufgrund der pathogenetisch wichtigen Rolle von MYC im Medulloblastom, vermuten wir, dass JQ1 einen therapeutischen Nutzen haben könnte.

Material und Methode. Zunächst untersuchten wir die Expression der BET-Proteine immunhistochemisch in 86 Medulloblastomen. Wir ermittelten dann die funktionelle Bedeutung von JQ1. Medulloblastomzellen wurden mit JQ1 behandelt und GI5o-Werte mittels MTT-Assay bestimmt sowie bezüglich Zellproliferation, Apoptose und Seneszenz untersucht. Die Effekte der JQ1 Behandlung auf die Expression verschiedener Gene wurde mittels Western Blot und qPCR untersucht. Wir erstellten zudem mRNA Arrays behandelter und unbehandelter Medulloblastom Zellen. Abschließend behandelten wir murine Xenografts mit JQ1.

Ergebnisse. Medulloblastome exprimieren BET-Proteine. Die Behandlung mit JQ1 reduzierte das Zellwachstum und die proliferative Kapazität sowohl in vitro als auch in vivo. JQ1 führte zu einer transkriptionellen Deregulation von MYC sowie von Genen, die im Zellzyklus und im p53-Signalweg eine Rolle spielen. Interessanter Weise reagierten p53mutierte Zellen weniger sensibel auf JQ1.

Diskussion und Schlussfolgerung. Die Hemmung von BET- Proteinen zeigte sowohl in vitro als auch in vivo einen antitumoralen Effekt im Medulloblastom. Diese Wirkung lies sich sowohl auf eine Deregulation von MYC als auch der p53 und Zellzyklus-Signalwege zurückführen. Zusammenfassend vermuten wir, dass BET-Proteine ein vielversprechendes therapeutisches Ziel bei Medulloblastomen sind.

\section{RUVBL1 ist Teil krankheitsssoziierter ziliärer Proteinkomplexe und essenziell für die renale Tubulusstruktur in vivo}

Liebau M.C. ${ }^{1,2}$, Dafinger C. ${ }^{2}$, Habbig S. ${ }^{1,2}$, Rinner $0 .{ }^{3}$, Hammerschmidt M. ${ }^{4}$, Aebersold R. ${ }^{3}$, Brüning J.C. ${ }^{5}$, Wunderlich T. ${ }^{5}$, Benzing T. ${ }^{2}$, Schermer B. ${ }^{2}$

${ }^{1}$ Kinderklinik, Uniklinik Köln, ${ }^{2}$ Nephrologisches Forschungslabor, Innere Medizin ${ }^{2}$, Uniklinik Köln, ${ }^{3}$ IMSB, ETH Zürich, ${ }^{4}$ Institut für Entwicklungsbiologie, Uni Köln, ${ }^{5}$ Institut für Genetik, Uni Köln

Fragestellung. Zystische Nierenerkrankungen gehören zu den häufigsten genetischen Ursachen eines kindlichen Nierenversagens. Die betroffenen Genprodukte konnten mit der Funktion zellulärer Monozilien assoziiert werden, aber die pathophysiologischen Prozesse bleiben unzureichend verstanden. Neue Arbeiten verbinden Zilien und Proteine der DNA-Schadensantwort.

Material und Methoden. Um die Funktion des bei der Nephronophthise am häufigsten betroffenen Proteins zu verstehen, führten wir einen Immunopräzipitations-basierten Proteomics-Screen zur Identifizierung Nephrozystin-1-interagierender Proteine durch. Vielversprechende Kandidaten wurden in Zellkultur bzw. in vivo weiterverfolgt.

Ergebnisse. Neben bekannten NPH-Proteinen fanden sich neue Kandidaten, wie die AAA ATPase RUVBL1. RUVBL1 ist an der Regulation zilienassoziierter Signaltransduktionswege und der zellulären DNASchadensantwort beteiligt. Der Knockdown des RUVBL1-Orthologs im Zebrafisch führt zu Nierenzysten. In unabhängigen Experimenten konnte RUVBL1 als Teil krankheitsassoziierter Proteinkomplexe an der Zilienbasis bestätigt werden. Der tubulusspezifische Knockout in einem neu generierten Mausmodell führt dosisabhängig zu einem schweren zystisch-renalen Phänotyp.

Diskussion. Unsere Daten geben Einblicke in die molekularen Grundlagen der Ziliopathien in vitro und in vivo. 
Starke CD57-Expression ist mit aggressiven Neuroblastomzellen in vitro und in vivo sowie mit undifferenzierten Neuroblastomzellen in situ assoziiert

Dorneburg C. ', Schlitter A.M. ', Barth T.F.E. ${ }^{2}$, Wahl J.', Schulte J.H. ${ }^{3}$, Brüderlein S. ${ }^{2}$, Debatin K.M.', Beltinger C.

${ }^{1}$ Klinik für Kinder- und Jugendmedizin, Universitätsklinikum Ulm, ${ }^{2}$ Institut für Pathologie, Universitätsklinikum Ulm, ${ }^{3}$ Universitätskinderklinik III, Uniklinikum Essen

Fragestellung. Derivate der Neuralleiste sind Ursprungszellen des Neuroblastoms (NB). CD57 markiert migrierende Neuralleistenzellen während der Entwicklung und ist in NB exprimiert. Wir untersuchten, ob starke Expression von CD57 aggressive NB-Zellen kennzeichnet. Material und Methode. NB-Zellen wurden mittels FACS in CD57high und $\mathrm{CD}_{5}$ low exprimierende Zellen getrennt. Die Fraktionen wurden auf Tumorsphärenbildung, Klonogenität, Differenzierungskapazität und Tumorigenität untersucht.

Ergebnisse. Verglichen mit CD57low-NB-Zellen, entwickelten CD57high-Zellen Tumoren mit geringerer Latenz nach orthotoper Transplantation in die Nebenniere immundefizienter Mäuse. Zudem zeigten CD57high NB-Zellen eine höhere Klonogenität, induzierten mehr Sphären, waren multipotent und zeigten eine höhere Invasivität. CD57high-Zellen siedelten sich nach intravenöser Injektion vermehrt in Leber und Lunge an und bildeten mehr Metastasen. In stromaarmen NB von Patienten waren CD57high-Zellen mit undifferenzierten Tumorzellen in allen Stadien assoziiert und nahmen nach Chemotherapie tendenziell zu.

Diskussion. Starke Expression von CD57 ist mit aggressiven Attributen von NB-Zellen assoziiert und findet sich bevorzugt auf undifferenzierten NB-Zellen von Patienten, Dies erweitert unser Wissen um die intratumorale Heterogenität des Neuroblastoms.

\section{Erfassung nosokomialer Virusinfektionen auf einer neonatologi- schen Intensivstation}

Kidszun A. ${ }^{\prime}$, Klein L. ${ }^{1}$, Hansmann A. ', Winter J.', Gröndahl B. ${ }^{2}$, Knuf M. ${ }^{2,3}$, Weise K. ${ }^{4}$, Mildenberger .' $^{\prime}$

'Sektion Neonatologie, Zentrum für Kinder- und Jugendmedizin, Universitätsmedizin Mainz, Mainz, ${ }^{2}$ AG Infektiologie, Zentrum für Kinder- und Jugendmedizin, Universitätsmedizin Mainz, Mainz, ${ }^{3}$ Kinderklinik, Dr. Horst Schmidt Klinik, Wiesbaden, ${ }^{4}$ Institut für Virologie, Universitätsmedizin Mainz, Mainz

Fragestellung. Bezüglich Häufigkeit und klinischer Bedeutung nosokomialer Virusinfektionen in der Neonatologie ist wenig bekannt. Einige Fallberichte und retrospektive Analysen legen jedoch einen beträchtlichen Einfluss auf die Morbidität neonatologischer Patienten nahe. Ziel der vorliegenden prospektiven Studie war die systematische Erfassung von Virusinfektionen bei Früh- und Neugeborenen mit vermuteter nosokomialer bakterieller Sepsis.

Material und Methode. Eingeschlossen wurden alle Patienten, die $>72 \mathrm{~h}$ auf der neonatologischen Intensivstation aufgenommen waren und bei vermuteter bakterieller Sepsis eine intravenöse antibiotische Therapie erhielten. Mittels Multiplex-PCR wurde Rachenspülwasser hinsichtlich Respiratory Syncytial Virus (RSV), Adenovirus, Influenzavirus A/B, $\mathrm{H}_{1} \mathrm{~N}_{1}$ Virus, Parainfluenzavirus 1-4, Metapneumovirus, Coronavirus und Picornavirus untersucht. Stuhl wurde mittels Antigentest und Bestätigungs-PCR auf Rota-, Noro- und Adenovirus und mittels PCR auf Enterovirus untersucht.

Ergebnisse. In 2 Jahren wurden 67 Fälle mit vermuteter nosokomialer bakterieller Sepsis ausgewertet. Eine positive Blutkultur fand sich in 7 Fällen. RSV wurde in 2 und Picornavirus in 3 Fällen nachgewiesen. Im Stuhl zeigte sich in 2 Fällen ein positiver Antigentest (Adeno- und Norovirus), der jedoch in der PCR nicht bestätigt werden konnte. Somit konnte in 7,5\% der Fälle mit vermuteter nosokomialer bakterieller Sepsis eine Virusinfektion nachgewiesen werden.
Schlussfolgerung. Diese Studie zeigt die enorme klinische Bedeutung nosokomialer Virusinfektionen in der Neonatologie. Die Häufigkeit von positiven Blutkulturen und die Häufigkeit von Virusinfektionen liegen in der gleichen Größenordnung. Eine Fortsetzungsstudie unter Einschluss größerer Patientenzahlen wurde implementiert.

\section{Gehirnphänotyp in einem Mausmodell für die humane Erkrankung "SLC35C1-congenital disorder of glycosylation"}

\section{Popovici D. ', Thiel C. ', Vogt M. ${ }^{2}$, Hoffmann G.F.', Gass P. ${ }^{2}$, Körner C. ${ }^{\prime}$}

'Zentrum für Kinder- und Jugendmedizin, Klinik für Kinderheilkunde I, Heidelberg, ${ }^{2}$ Zentralinstitut für Seelische Gesundheit, Psychiatrische Tiermodelle, Mannheim

Hintergrund. „SLC $35 \mathrm{C} 1$-congenital disorder of glycosylation $\left(\mathrm{SLC}_{35} \mathrm{C}_{1}-\right.$ CDG, ehemals CDG-IIc) wird durch Mutationen im Golgi-GDP-Fucose-Transporter $\left(\mathrm{SLC}_{35} \mathrm{C} 1\right.$ ) verursacht. Der verminderte Import von GDP-Fucose in den Golgi führt zu einer generellen Hypofucosylierung von Glykoproteinen. SLC 35 C1-CDG Patienten leiden unter persistierender Leukozytose, schweren Infektionen und Retardierung der geistigen und körperlichen Entwicklung. Durch Inaktivierung des murinen Golgi-GDP-Fucose-Transporter-Gens ( $\mathrm{Sl}_{\mathrm{c} 35 \mathrm{c} 1}$ ) gelang es uns ein Mausmodell generieren, das dem pathologischen Phänotyp der Patienten ähnelt. Die Hypofucosylierung der Glykoproteine im defizienten Mausmodell führt zu vermindertem Wachstum, Leukozytose, erweiterten Lungenalveolen und hypozellulären Lymphknoten.

Fragestellung. Aufgrund der bei SLC 35 C1-CDG Patienten beschriebenen Störungen der neuronalen Entwicklung mit unklarer Genese, wurde mit der Charakterisierung des Gehirnphänotyps der Slc35c1-defizienten Mäuse begonnen.

Ergebnisse und Schlussfolgerung. Verhaltensbiologische Untersuchungen in den Slc35c1-defizienten Mäusen ergaben eine verminderte Exploration und Hippocampus-abhängige Furchtkonditionierung. In weiterführenden histologischen Studien im Gehirn konnte eine veränderte Morphologie, bedingt durch die Hypofucosylierung, nachgewiesen werden.

\section{Protektive Effekte des mTOR-Inhibitors Everolimus auf das podozytäre Zytoskelett}

Jeruschke S. ${ }^{1}$, Büscher A.K.' , Rekasi H. ${ }^{1}$, Hoyer P.F. ${ }^{1}$, Saleem M.A. ${ }^{2}$, Oh J. ${ }^{3}$, Nalbant P. ${ }^{4}$, Weber $S$.

'Pädiatrische Nephrologie, Kinder- und Jugendmedizin II, Universitätsklinikum Essen, Essen, ${ }^{2}$ Department of Paediatric Nephrology, Bristol Royal Hospital for Children, Bristol, ${ }^{3}$ Pädiatrische Nephrologie, Klinik und Poliklinik für Kinder- und Jugendmedizin, Universitätsklinikum Hamburg-Eppendorf, Hamburg, ${ }^{4}$ Molekulare Zellbiologie, Universität Duisburg-Essen, Essen

Fragestellung. Die dynamische Regulation des podozytären Zytoskeletts ist essenziell für die Aufrechterhaltung der glomerulären Filterfunktion. Glomeruläre Erkrankungen sind häufig mit einem Rearrangement des Aktin-Zytoskeletts assoziiert. Die Therapie basiert auf der Gabe von Immunsuppressiva, die u. a. einen stabilisierenden Effekt auf das podozytäre Zytoskelett besitzen können. Ziel des Projektes ist die Untersuchung der direkten Effekte des mTOR-Inhibitors Everolimus (EV) auf das podozytäre Zytoskelett.

Material und Methode. Humane Podozyten wurden mit Puromycin (PAN, Modell der experimentellen Glomerulonephritis) und EV behandelt. Biochemische Analysen dienten zur Bestätigung der Inhibierung der mTOR-Komplexe mTORC1/-2, gefolgt von RhoA-GTPaseAktivitätsbestimmungen und Western-Blot-Untersuchungen gegen die leichte Kette von Myosin (MLC). Zur Identifizierung weiterer Marker die durch EV beeinflusst werden, führten wir Affymetrix-Chip-basierte Analysen der differenziellen Genexpression durch.

Ergebnisse. EV führte zu einer drastischen Inhibierung von mTORC1 und -2. Downstream von mTORC2 konnte der RhoA-MLC-Signalweg 
durch EV im PAN-Schädigungsmodell stabilisiert werden. Expressionsanalysen zeigten Unterschiede zwischen PAN- und PAN+EVbehandelten Podozyten bezüglich wichtiger Gene, involviert in Zytoskelett-Architektur, Adhäsion, Migration und extrazellulärer Matrix-Zusammensetzung.

Schlussfolgerung. EV besitzt einen protektiven Effekt auf humane Podozyten in vitro und könnte auch in vivo einer Podozytopenie entgegenwirken. Der zytoprotektive Effekt erfolgt nach mTORC2-Inhibierung über eine Aktivierung von RhoA und MLC. Expressionsanalysen deuten auf eine besondere Rolle weiterer Aktin-Zytoskelett-assoziierter Proteine hin, die durch EV differenziell reguliert werden.

\section{Belastungsinduzierte hyperinsulinämische Hypoglykämie bei MCT1 exprimierendem Insulinom}

Marquard J., ${ }^{1,2}$, Welters A. ${ }^{1,2}$, Buschmann $T^{2}$, Barthlen W. ${ }^{3}$, Vogelgesang $S^{4}{ }^{4}$, Klee D. ${ }^{5}$, Krausch M. ${ }^{6}$, Raffel A. ${ }^{6}$, Otter S. ${ }^{2}$, Piemonti L. ${ }^{7}$, Mayatepek E. ${ }^{1}$, Otonkoski T. ${ }^{8}$, Lammert E. ${ }^{2,9}$, Meissner T.

${ }^{1}$ Klinik für Allgemeine Pädiatrie, Neonatologie und Kinderkardiologie, Universitätskinderklinik Düsseldorf, ${ }^{2}$ Institut für Stoffwechselphysiologie, Heinrich-Heine Universität Düsseldorf, ${ }^{3}$ Klinik für Kinderchirurgie, Universitätsklinikum Greifswald, ${ }^{4}$ Institut für Neuropathologie, Universität Greifswald, ${ }^{5}$ Klinik für Diagnostische und Interventionelle Radiologie, Universitätsklinikum Düsseldorf, ${ }^{6} \mathrm{Klinik}$ für Allgemein-, Viszeral- und Kinderchirurgie, Universitätsklinikum Düsseldorf, 'Institut für Experimentelle Chirurgie, San Raffaele Institut, Mailand, Italien, ${ }^{8}$ Kinderkrankenhaus und Biomedizinisches Stammzellzentrum, Universität Helsinki, Finnland, ${ }^{9}$ Deutsches Diabetes Zentrum, Paul-Langerhans-Gruppe für Betazellforschung, Düsseldorf

Fragestellung. Belastungsinduzierte hyperinsulinämische Hypoglykämien („exercise-induced hyperinsulinism“, EIHI) sind durch eine inadäquate Insulinsekretion unter anaerober Belastung charakterisiert. Es konnte gezeigt werden, dass aktivierende Promotormutationen im MCT1-Gen, das den Monocarboxylattransporter 1 kodiert, mit EIHI assoziiert ist. MCT1-Überexpression in pankreatischen Inseln der Maus kann EIHI induzieren. Bis heute konnte MCT1 jedoch nicht bei Patienten mit EIHI in insulinproduzierenden Zellen nachgewiesen werden.

Material und Methode. Bei einem Patienten mit typischen EIHI-Symptomen und Insulinom wurde prä- und post Enukleation des Insulinoms die Insulinsekretion im standardisierten Belastungstests gemessen. Die MCT1-Expression im Insulinomgewebe wurde mittels Laserrastermikroskopie, Westernblot und quantitativer Echtzeit-PCR (qPCR) analysiert. Ferner wurde die MCT1 Expression in vier weiteren Insulinomen untersucht.

Ergebnisse. Präoperativ traten typische EIHI-Symptome im Belastungstest auf, postoperativ war der Patient symptomfrei. MCT1 konnte nicht in gesunden Inseln des Patienten nachgewiesen werden, dafür jedoch im Insulinomgewebe. Die Western Blot und qPCR Analysen zeigten eine 4- bis 5-fache MCT1-Expression im Insulinomgewebe in Vergleich $\mathrm{zu}$ gesunden Inseln. Ferner konnte MCT1 in 3 von 4 weiteren Insulinomen gefunden werden.

Schlussfolgerung. Wir beschreiben zum ersten Mal einen Patienten mit MCT1 exprimierendem Insulinom, welches mit EIHI assoziiert ist. Zudem war MCT1 auch in weiteren Insulinomen exprimiert. Unsere Ergebnisse legen nahe, dass MCT1 in menschlichen insulinproduzierendem Gewebe zum Krankheitsbild des EIHI führen kann.

\section{Mausmodell einer humanen neonatal-infantilen Epilepsie durch Mutation des Natriumkanals Nav1.2}

Fazeli W. ${ }^{1,2}$, Engeland B. ${ }^{2}$, Liu Y. ${ }^{3}$, Morellini F. ${ }^{2}$, Xompero F. ${ }^{2}$, Maljevic S. ${ }^{3}$, Hedrich $\mathrm{U}^{3}$, Beck H. ${ }^{4}$, Lerche $H^{3}{ }^{3}$, Isbrandt $D .{ }^{2}$

${ }^{1}$ Universitätskinderklinik Hamburg-Eppendorf, ${ }^{2}$ AG Experimentelle Neuropädiatrie, Universitätsklinik Hamburg-Eppendorf, ${ }^{3}$ Abteilung Neurologie mit Schwerpunkt Epileptologie, Hertie-Institut für klinische Hirnforschung, Universität Tübingen, ${ }^{4}$ Abteilung Epileptologie, Life \& Brain Center, Universität Bonn

Einleitung. Spannungsabhängige Natriumkanäle sind essenziell für die Generierung von Aktionspotenzialen. Mutationen im für den $\mathrm{Na}-$ triumkanal NaV1.2 kodierenden SCN2A-Gen sind mit neonatal-infantiler Epilepsie assoziiert. Die genetische Analyse eines Patienten mit neonatal-infantilen, pharmako-resistenten Anfällen und Episoden mit Ataxie, Myoklonien, Kopf- und Rückenschmerzen identifizierte eine Missense-Mutation im SCN2A-Gen, die zu dem Aminosäureaustausch Ala263Val führte. Diese „gain-of-function“-Veränderung des NaV1.2 führt in vitro zu einem erhöhten persistierenden Natriumstrom.

Zielsetzung. Überführung der humanen SCN2A-Mutation in ein Mausmodell zum besseren Verständnis der Pathophysiologie neonatal-infantiler Epilepsien und zur Testung neuer Therapieoptionen.

Methode. Durch Einfügen der beim Patienten gefundenen Punktmutation in das orthologe Gen der Maus generierten wir eine SCN2A A263V Knock-in-Mauslinie, um deren elektrophysiologischen und Verhaltensphänotyp zu charakterisieren.

Ergebnisse. Knock-in-Mäuse haben ein geringeres Körpergewicht, sind hyperaktiv und kognitiv beeinträchtigt im Vergleich zu Wildtyptieren. $\mathrm{Ab}$ der dritten Lebenswoche zeigen $\mathrm{SCN}_{2} \mathrm{~A} \mathrm{~A}_{2} 63 \mathrm{~V}$ Mäuse cerebrale Anfälle mit Epilepsie-typischer Aktivität im Elektrokortikogramm (ECoG). Elektrographische Anfälle können in vivo bereits in der 1. Lebenswoche nachgewiesen werden. In vitro zeigt sich eine altersabhängige zelluläre Übererregbarkeit der CA1-Pyramidenzellen.

Schlussfolgerung. Wir haben erfolgreich ein Mausmodell neonatal-infantiler epileptischer Anfälle generiert, das durch gesteigerte zelluläre und Netzwerk-Erregbarkeit und kognitive Auffälligkeiten charakterisiert ist. Am Mausmodell untersuchen wir nun die Pathophysiologie neonatal-infantiler Epilepsien und testen neuartige antikonvulsiveTherapiestrategien.

\section{Erstellung von Druck-Volumen-Kurven mittels 3D-Ultraschall und Druckdrahtmessung - eine Machbarkeitsstudie}

Gatzweiler E.', Herberg U.', Breuer T.', Breuer J.'

'Universitätsklinik Bonn, Abteilung für Kinderkardiologie, Bonn, ${ }^{2} \mathrm{Hoch}-$ schule Bonn-Rhein-Sieg, Fachbereich Informatik, Sankt Augustin

Fragestellung. Druck-Volumen-Kurven enthalten wichtige Informationen über die systolische und diastolische Herzfunktion und die Pathophysiologie von Herzerkrankungen. Die Erstellung dieser Kurven mit Hilfe der Conductance-Methode ist jedoch sehr aufwendig und teuer. Deshalb finden Druck-Volumen-Kurven im klinischen Alltag kaum Anwendung. Ziel der Studie war es, die Machbarkeit von Druck-Volumen-Kurven mittels ${ }_{3} \mathrm{D}$-Echokardiographie (3DE) und Mini-Druckdrahtmessung zu testen.

Material und Methode. Bei 31 Patienten mit angeborenen Herzfehlern (Alter: 3 Tage bis 22,7 Jahre, Gewicht: 2,75-80 kg) wurde während Routineherzkatheteruntersuchungen mit einem Mini-Druckdraht der Ventrikeldruck aufgezeichnet. Simultan wurden 3DE-Datensätze des linken und/oder rechten Ventrikels erhoben. Anschließend wurden Druck- und Volumendaten über das EKG synchronisiert. Aus den resultierenden Kurven konnten dann Parameter wie die endsystolische Elastanz, die diastolische Druck-Volumen-Beziehung, die ventrikuläre Schlagarbeit, die ventrikuloarterielle Koppelung und die Relaxationskonstante Tau bestimmt werden. 
Ergebnisse. Bei allen Probanden konnten Druck-Volumen-Kurven erstellt werden. Im Durchschnitt wurden 6 (3-11) Kurven pro Patient erstellt, mit einer zusätzlichen Untersuchungsdauer von $6,5 \pm 3,5 \mathrm{~min}$. Intra- und interindividuelle Variabilität waren für alle gemessenen Parameter gut (Variationskoeffizienten $<10 \%$ ).

Schlussfolgerung. Die Erstellung von Druck-Volumen-Kurven mittels ${ }_{3} \mathrm{DE}$ und Mini-Druckdrahtmessung ist einfach durchführbar und reproduzierbar. Auf Grund des kleinen Druckdrahtes kann die Methode selbst bei Neugeborenen angewandt werden. Die erhobenen Daten ermöglichen die detaillierte und über die Routinediagnostik hinausgehende Beurteilung der Herzfunktion.

\section{Von der X-chromosomal rezessiven Megalocornea zum regene- rativen Therapiekonzept für Erkrankungen des vorderen Augen- abschnitts}

\author{
Villavicencio-Lorini P.', Zabel B. ', Spiekerkötter U.', Lausch E. ${ }^{1}$ \\ 'Zentrum für Kinder- und Jugendmedizin, Universitätsklinikum Freiburg
}

Fragestellung. Cornea- und Linsenschädigungen sind häufige Erblindungsursachen. Aus der Aufklärung seltener Erkrankungen, wie der X-chromosomal rezessiven Megalocornea (XRMC), können neue regenerative Therapiekonzepte für Erkrankungen des vorderen Augenabschnitts resultieren.

Material und Methode. Biometrische Analysen, Next-Generation-Sequencing, mRNA-Analyse

Ergebnisse. Mittels X-chromosomaler Exom-Sequenzierung konnten wir CHRDL1 als Krankheitsgen für XRMC identifizieren. Wir konnten eine frameshift-Mutation nachweisen und zeigen, dass sie einen Zelltyp-abhängigen variablen mRNA-Abbau bewirkt. Die Charakterisierung der Familie ergab die für XRMC bekannte phänotypische Variabilität bei konstanten Merkmalen wie vergrößertem Corneadurchmesser, reduzierter Corneadicke und übernormaler Vorderkammertiefe. Fakultativ lagen eine Katarakt sowie eine Pigmentdispersion vor.

Diskussion. Die von uns identifizierte frameshift-Mutation im CHRDL1Gen als Krankheitsursache der XRMC könnte in Zusammenhang mit dem gefundenen Zelltyp-abhängigen variablen Mutationseffekt lokale Defekte der Organogenese des Auges aber auch die intrafamiliäre phänotypische Variabilität erklären. Das CHRDL1-Gen kodiert für das sekretorische Protein Ventroptin, welches als bekannter BMP4-Antagonist ein wesentlicher Schalter für zelluläre Differenzierungsvorgänge des Auges ist. In zukünftigen Forschungsprojekten soll überprüft werden, ob sich der Einsatz eines rekombinanten Ventroptins für lokale Therapieansätze bei Wundheilungsstörungen der Cornea eignet.

\section{Induktion Tetanus Toxoid (TT) spezifischer zellulärer Immun- antworten durch funktionlisierte TT-haltige Nanokapseln}

Dedters M. ', Fichter M.', Baier G. ${ }^{2}$, Pietrzak-Nguyen A. ', Pretsch L.', Meyer C.', Doganci A.', Birkholz J.', Landfester K. ${ }^{2}$, Gehring S.'

'Johannes Gutenberg-Universität, Pädiatrische Immunologie, Mainz, ${ }^{2}$ MaxPlanck Institut für Polymerforschung, Mainz

Fragestellung. Zielgerichtete Beladung von dentritischen Zellen (DCs) mit Antigenen stellt einen vielversprechenden Ansatz zur Induktion von zellulären Immunantworten dar. Ziel dieser Arbeit war die Charakterisierung von Nanokapseln (NKs) mit enkapsuliertem Tetanus-Toxoid (TT) Peptid und funktionalisiert mit anti-CD40, MPLA und IFN- $\gamma$ im Bezug auf die Aufnahme, das Sekretions-Profil von Zytokinen, den Einfluss auf die phänotypische Maturation von DCs, sowie die Untersuchung von DC-T-Zell Interaktionen nach Aufnahme von TT-NKs.

Material und Methode. NKs aus Hydroxyethylstärke (HES) dienten als Träger für das TT-Peptid, anti-CD40, MPLA und IFN- $\gamma$. Nabelschnurblut wurde nach Kaiserschnitten von gesunden Neugeborenen gewonnen. Aus PBMCs von adulten Spendern wurden DCs mittels Isolation von CD14+Zellen und Zugabe von IL-4 sowie GM-CSF für 4 Tage generiert.
Autologe T-Zellen wurden mit DCs nach Beladung mit verschiedenen NK-Formulationen kokultiviert. Aufnahme durch DCs wurde mittels Durchflusszytometrie und konfokaler Mikroskopie, Zytokin-Antworten mittels ELISA und T-Zell-Antworten mittels Proliferationsassay ermittelt. Ergebnisse. Aufnahme durch DCs war signifikant erhöht, nach Funktionalisierung mit anti-CD40, anti-DEC205 und MPLA, wobei eine kombinierte Ankopplung von MPLA und anti-CD40 oder anti-DEC205 den stärksten Effekt hatte. Ebenso zeigten die Zytokin-Profile eine TH1 gerichtete Antwort. Gleichzeitig bewirkte die Beladung von TT-NKs eine gesteigerte TT-spezifische Immunantwort.

Schlussfolgerung. HES-NKs sind ein vielversprechendes Träger-System, um Antigene zielgerichtet und effizient in humane DCs einzubringen. Gleichzeitig, bietet die simultane Stimulation von DCs durch TH1-spezifische Signale die Möglichkeit Toleranz zu überwinden und antigenspezifische zelluläre Immunität zu induzieren.

\section{Nosokomiale Infektionen bei sehr kleinen Frühgeborenen: Epidemiologie, Risikofaktoren und Präventionsmöglichkeiten}

Demmert M.', Härtel C.', Herting E.', Göpel W.' für das Deutsche Frühgeborenennetzwerk (German Neonatal Network, GNN)

'Klinik für Kinder- und Jugendmedizin der Universität Lübeck, Lübeck

Fragestellung. Das German Neonatal Network (GNN), ein Forschungsverbund mit 47 beteiligten Zentren, erhebt prospektiv Daten zu Erkrankungen und Outcome von Very-low-birth-weight(VLBW)-Frühgeborenen.

Material und Methoden. Wir führen eine prospektive, populationsbezogene Langzeitstudie durch, die bei rund 2000 VLBW-Frühgeborenen jährlich ante- und postnatale Daten erhebt. Genetische Risikofaktoren werden aus Mundschleimhaut- und Nabelschnurproben untersucht.

Ergebnisse. $10 \%$ der VLBW-Frühgeborenen im GNN erleiden eine nosokomiale Sepsis. Während das junge Gestationsalter der entscheidende Risikofaktor ist, spielen genetische Marker wie z. B. der Fucosyltransferase (FUT)-2 oder der TNF-alpha-308 G/A Polymorphismus in 2 großen Kohorten (I: n=1944, II: n=926) eine untergeordnete Rolle. Struktur- und Prozessparameter haben einen wichtigen Einfluss auf das Sepsisrisiko. Epidemische Mikrocluster (mindestens 2 Sepsisfälle mit identischem Erreger innerhalb von 3 Monaten) treten nicht selten auf. In der GNNKohorte des Geburtsjahres $2010(\mathrm{n}=2110)$ wurden 11 gramnegative SepsisMikrocluster in 7 Zentren dokumentiert. 16/26 der betroffenen Kinder hatten eine Klebsiella-Sepsis mit einem medianen Abstand zwischen 2 Erkrankungen von 14,1 Tagen. Neben Umweltfaktoren bedingen Notwendigkeit und Dauer invasiver Maßnahmen ein erhöhtes Sepsisrisiko. Unsere Umfrage in den Zentren zeigt einen hohen Grad an Standardisierung von Prozeduren und der Durchführung von wöchentlichen Screeninguntersuchungen als wichtige Präventionsstrategie.

Schlussfolgerungen. VLBW-Frühgeborene sind aufgrund ihrer Unreife und der Notwendigkeit von invasiven Maßnahmen besonders gefährdet, Infektionen zu erleiden. GNN bietet eine Plattform für weiterführende Untersuchungen zu Diagnostik, Therapie und Prävention der Sepsis. 


\section{Pharmakogenetik der hoch dosierten Methotrexattherapie bei akuter lymphoblastischer Leukämie im Kindesalter im Rahmen der therapieoptimierenden Studie ALL-BFM 2000}

Radtke S. ', Renner B. ${ }^{2}$, Paulides M. ', Zimmermann M. ${ }^{3}$, Möricke A. ${ }^{4}$, Stanulla M. ${ }^{4}$, Schrappe M. ${ }^{4}$, Langer T.', Zolk $0 .^{2}$

${ }^{1}$ Abteilung für pädiatrische Onkologie und Hämatologie - LESS Studienzentrale, Kinder- und Jugendklinik des Universitätsklinikums Erlangen, Erlangen, ${ }^{2}$ Institut für Experimentelle und Klinische Pharmakologie und Toxikologie, Universität Erlangen-Nürnberg, Erlangen, ${ }^{3} \mathrm{Abteilung}$ für Pädiatrische Hämatologie und Onkologie, Hannover Medical School, Hannover, ${ }^{4}$ Abteilung für Pädiatrie, Universitätsklinikum Schleswig-Holstein, Campus Kiel, Kiel.

Fragestellung. Hochdosiertes Methotrexat (MTX) wird erfolgreich zur Therapie der akuten lymphoblastischen Leukämie (ALL) im Kindesund Jugendalter eingesetzt. In dieser Studie wurde die Pharmakogenetik der hoch dosierten MTX Therapie mittels eines Kandidatengenansatzes untersucht.

Methoden. Acht Einzelnukleotidpolymorphismen (SNPs) in fünf Kandidatengenen des MTX-Stoffwechsels wurden in DNA Proben von 499 Patienten mit ALL bestimmt. Alle Patienten wurden einheitlich im Rahmen der ALL-BFM 2000 Studie therapiert und bekamen insgesamt 1996 Zyklen hochdosiertes MTX ( 5 mg/m² Körperoberfläche). Mittels multipler Regressionsanalysen und Cox-Regression wurden die Genotypen mit Daten zu Pharmakokinetik, Toxizität und Überleben in Verbindung gesetzt.

Ergebnisse. Die Variante rs4149056 im SLCO1B1-Gen war hochsignifikant mit einem erhöhten Integral der Plasmakonzentrations-Zeit-Kurve in den ersten 48 Stunden nach Beginn der MTX-Infusion (AUCo-48 h) assoziiert. Patienten, die mindestens ein mutiertes C-Allel in rs4149056 vorwiesen, hatten im Mittel $26 \%$ höhere AUCo-48h Werte als homozygote Träger des Wildtypallels $(\mathrm{p}=6,8 \times 10-8)$. Die AUCo-48 h war wiederum signifikant assoziiert mit dem Auftreten von Nebenwirkungen in Folge der hochdosierten MTX Therapie $\left(R_{2}=0,043 ; p=2,9 \times 10-5\right)$. Speziell für die häufige Nebenwirkung Stomatitis konnte eine Assoziation mit der rs 34743033 Variante im TYMS-Gen aufgezeigt werden $\left(\mathrm{R}_{2}=0,018 ; \mathrm{p}=0,009\right)$. Für Patienten, die homozygote Wildtypallelträger der rs1801131 Mutation im MTHFR-Gen sind, zeigte sich ein signifikant besseres Überleben im Vergleich zu Trägern mindestens eines mutierten C-Allels (Hazard Ratio 3,1; $\mathrm{p}=0,015$ ).

Schlussfolgerung. Varianten in MTX Kandidatengenen sind signifikante Prädiktoren der Kinetik, Wirkung und Verträglichkeit der hochdosierten MTX-Therapie.

\section{microRNA24-3p-vermitteltes Überleben humaner Plasmazellen}

Abram M. ', Gabler J.', Wittmann J. ${ }^{2}$, Porstner M. ${ }^{2}$, Renz H. ${ }^{3}$, Jäck H.-M. ${ }^{2}$, Zemlin M.', Maier R.F.'

'Philipps-Universität Marburg, Klinik für Kinder- und Jugendmedizin, Marburg, ${ }^{2}$ Friedrich-Alexander-Universität Erlangen-Nürnberg, Abteilung für Molekulare Immunologie, Nikolaus-Fiebiger Zentrum, Erlangen, ${ }^{3}$ PhilippsUniversität Marburg, Institut für Laboratoriumsmedizin und Pathobiochemie, Biomedizinischer Forschungszentrum (BMFZ), Marburg

Fragestellung. In den letzten Jahren wurden einige extrazelluläre Faktoren entdeckt, die in der sogenannten Knochenmarks-Überlebensnische das Überleben von Plasmazellen sicherstellen. Dagegen sind die intrazellulären Mechanismen, die die Zellhomöostase der Plasmazellen aufrechterhalten, bisher nahezu unbekannt. Wir untersuchten den Einfluss der microRNA 24-3p (miR-24-3p) auf das Überleben humaner Plasmazellen unter Einfluss der extrazellulären Überlebensfaktoren IL- 6 und SDF-1a.

Material und Methoden. Primäre B-Zellen, Plasmablasten und Plasmazellen sowie Plasmazytomzellen wurden mit deep sequencing und miR24-3p-spezifischer qPCR analysiert. miR24-3p wurde mit siRNA inhibiert. ER-Stress-Bedingungen wurden durch Stimulation mit
Tunicamycin +/- IL-6 erzeugt. Vitale Zellen wurden mit Trypanblau quantifiziert. Die MAP-Kinase Erk1/2 wurde mit Anti-ErkII-Petid und Uo126-Inhibitor supprimiert.

Ergebnisse. Deep-sequencing-Analysen zeigten eine starke Expression der miR-24-3p in primären B-Zellen, Plasmablasten und Plasmazellen sowie in Plasmazytomzellen. In-vitro-Analysen in primären und Plasmazytomzellen zeigten (i) eine antiapoptotische Funktion der miR-24$3 p$ in Plasmazellen, (ii) eine Erhöhung der miR-24-3p-Expression nach IL- 6 und SDF-1 $\alpha$-Stimulation, (iii) ein IL-6-vermitteltes Überleben von Plasmazellen unter ER-Stress-Bedingungen in Abhängigkeit der miR24-3p Expression, (iiii) eine Abhängigkeit der miR-24-3p Expression von der Aktivität der MAPk Erk1/2.

Diskussion und Schlussfolgerung. miR-24-3p hat eine antiapoptotische Funktion in Plasmazellen und wird durch Einfluss der PlasmazellÜberlebensfaktoren IL6 und SDF-1 a überexprimiert. Dies legt eine direkte Verbindung zwischen einem externen Überlebenssignal und einem intrazellulären Überlebensmechanismus der Plasmazelle nahe.

\section{Aberrante ZNF423-Expression beeinträchtigt die B-Zellmaturation und ist mit einer ungünstigen Prognose von B-Progenitor ALL im Kindesalter verknüpft}

Harder L.', Horstmann M.A. ${ }^{1,2}$

${ }^{1}$ Forschungsinstitut Kinderkrebs-Zentrum Hamburg, Hamburg, ${ }^{2}$ Klinik für pädiatrische Hämatologie und Onkologie, UKE, Hamburg

Fragestellung. Mittels intraindividueller komparativer Transkriptomanalyse wurde eine aberrante $\mathrm{ZNF}_{423}$-Expression in pädiatrischer ALL identifiziert. Das Ziel war es, die mechanistischen Grundlagen der $\mathrm{ZNF}_{423}$-Deregulation und seine Relevanz für die Leukämogenese zu definieren.

Material und Methoden. Primäre ALL aus den Studienkollektiven COALL 97 und 03 sowie einzelzellsortierte hämatopoetische Stamm- und Progenitorzellen wurden für experimentelle Studien genutzt. RT-PCR, SNP Array, ELISA, Co-IP, Luziferase Assay, Bisulfitsequenzierung und ein Tiermodell wurden angewendet.

Ergebnisse. In der Mehrzahl der analysierten ALL wurde eine aberrante ZNF423-Expression festgestellt, die mechanistisch auf eine DNA-Hypomethylierung von regulatorischen CGI am ZNF423-Locus und eine $\mathrm{BMP}_{2}$ abhängige Transaktivierung zurückzuführen ist. ZNF423 sequestriert EBF-1, hemmt dessen Zielgen-Transaktivierung und führt in vivo zum B-Zellarrest. Das ereignisfreie Überleben bei ETV6-RUNX1 negativer ALL ist mit der ZNF423-Expressionshöhe verknüpft.

Diskussion. In dieser Studie wurde ein neuer epigenetischer Mechanismus identifiziert, der neben bekannten genomischen Aberrationen von B-Zell-Differenzierungsfaktoren einen Arrest der B-Zellmaturation bewirkt. Es wird demonstriert, dass ALL nicht allein eine genetische Erkrankung ist, sondern dass Epigenetik neuartige Krankheitsmechanismen aufzudecken vermag. Der prognostische Stellenwert der ZNF423-Expression für die ALL wird in prospektiven Studien zu definieren sein.

\section{Homozygote Deletion des TSH-beta-Gens als Ursache für eine an- geborene sekundäre Hypothyreose in einer konsanguinen türkisch stämmigen Familie}

\section{Hermanns P. ${ }^{1}$, Klotz C. ${ }^{2}$, Couch R. ${ }^{3}$, Leonard N. ${ }^{2}$, Pohlenz J. ${ }^{1}$}

'Universitätsmedizin Mainz, Zentrum für Kinder- und Jugendmedizin, Molekulare Pädiatrische Endokrinologie, Mainz, ${ }^{2}$ University of Alberta Hospital, Edmonton, Canada, ${ }^{3}$ Pediatric Endocrinology, Walter Mackenzie Health Sciences Centre, Edmonton, Canada

Hintergrund. Ein 6 Wochen alter Junge präsentierte mit einem Icterus prolongatus. Schwangerschaft, Geburt und Neugeborenenscreening waren unauffällig. Bei der ersten Untersuchung waren die Werte für Thyreotropin, $\mathrm{T}_{4}$ und $\mathrm{T}_{3}$ niedrig. Das Prolaktin war geringgradig er- 
höht. Eine zentrale Hypothyreose wurde diagnostiziert und eine Mutation im TSH-beta-Gen vermutet.

Methoden. Die zwei kodierenden Exone des TSH-beta-Gens, die auf Chromosom 1 liegen, wurden mittels PCR von genomischer DNA amplifiziert und die PCR-Produkte sequenziert. Da die PCR des zweiten Exons kein Amplikon erzeugte wurde eine Deletion des zweiten Exons vermutet. Daher wurde eine aCGH-Analyse mit Proben, die für das Chromosom 1 spezifisch waren, durchgeführt.

Ergebnisse. Eine $6 \mathrm{~kb}$ lange homozygote Deletion, die die Exone 1 und 2 sowie weiter 5 ' gelegene Sequenzen umschloss, wurde detektiert. Beide Eltern waren heterozygote Träger dieser Deletion.

Schlussfolgerung. Dies ist die erste Beschreibung einer größeren Deletion im TSH-beta-Gen. Unsere Studie zeigt, dass die Bestimmung von TSH und $\mathrm{T}_{4}$ im Neugeborenenscreening sinnvoll ist, da nur hierdurch Kinder mit einer zentralen Hypothyreose schnell diagnostiziert und behandelt werden können.

\section{Transforming growth factor $\beta 1$ (TGF $\beta 1$ ) Genotypen in Korrelation zu TGF $\beta 1$ im induzierten Sputum und Serum bei cystischer Fibrose (CF)}

Schmitt-Grohé S.', Eickmeier O. ', Schreiner F.', v.d. Boom L.', Gampolo D.N.', Schubert R. ${ }^{2}$, Zielen S. ${ }^{2}$, Lentze M.J.'

${ }^{1}$ Abt. Allgemeine Pädiatrie, Zentrum für Kinderheilkunde des Universitätsklinikums Bonn, ${ }^{2}$ Pädiatrische Pulmologie, Zentrum für Kinderheilkunde der Goethe-Universität, Frankfurt

Fragestellung. Voruntersuchungen konnten zeigen, dass die high-producer TGF $\beta 1-G e n o t y p e n$ mit schwereren pulmonalen Verläufen bei CF einhergehen. Daten zu TGF $\beta_{1}$-Spiegeln (im Serum und Sputum) und deren Einfluss auf den pulmonalen Verlauf bei CF sind rar. Ziel der vorliegenden Untersuchung war es, das Verhältnis zwischen TGF $\beta_{1}$-Genotypen, TGF $\beta 1$ und der Lungenerkrankung zu erfassen.

Material und Methode. 24 Patienten delta F 508 homozygot (Altersmedian: $20,5 \mathrm{~J} ., \mathrm{m} / \mathrm{w}$ 14/10, BMI: $20,35 \mathrm{~kg} / \mathrm{m} 2$, Shwachman Score: 75 , $\mathrm{FEV} 1(\%)$ 83) und 8 Kontrollen (Altersmedian: $27,5 \mathrm{~J}, \mathrm{~m} / \mathrm{w} 5 / 3$, BMI $21,6 \mathrm{~kg} / \mathrm{m} 2$ ) wurden untersucht. Mittels ELISA erfolgte die Bestimmung von TGF $\beta_{1}$ im Serum (S) und induziertem Sputum (IS). Die Genotypisierung wurde für TGF $\beta_{1} \mathrm{C}-509 \mathrm{~T}$ und den $\mathrm{T}+869 \mathrm{C}$ Genotyp mittels RFLP durchgeführt.

Ergebnisse. Höhere TGF $\beta$-Spiegel im IS (CF/Kontrollen Median $76,5 / 59,1 \mathrm{pg} / \mathrm{ml}, \mathrm{p}<0,074)$ fanden sich bei CF. TGF $\beta_{1}$ im IS war signifikant höher als im Serum (Median IS/Serum 76,5/35,5×103 pg/ml, p=0,0oo1) bei CF. Es fand sich eine negative Korrelation zwischen TGF $\beta 1$ im Serum und Lungenfunktion (LF) [(FEV1) $(\mathrm{r}=-0,488 ; \mathrm{p}=0,025), \mathrm{MEF} 25$ $(r=-0.431 ; p=0,051), V C(r=-0,572 ; p=0,007)]$.Die Genotypen hatten keinen Einfluss auf TGF $\beta_{1}$ im IS, Serum, LF oder BMI. Es fanden sich Hinweise auf ein „linkage disequilibrium" zwischen den beiden Mutanten. Schlussfolgerung. Der Genotyp hat keinen Einfluss auf TGF $\beta_{1}$ im IS und Serum sowie auf die Lungenfunktion oder den BMI in einer kleinen Kohorte. TGF $\beta_{1}$ im Serum aber nicht im IS korreliert mit der Lungenfunktion bei CF. Unsere Daten könnten für einen wichtigen Einfluss von blutständigem TGF $\beta 1$ auf die Lungenfunktion sprechen.

\section{Inhibition des Stat3-Signalweges in der Zellkultur - eine neue Möglichkeit, um die Inflammationsreaktion nach Operationen am kardiopulmonalen Bypass abzuschwächen?}

Krauß A.', Mochner J.', Wollersheim S.', Tong G.', Berger F.',2, Schmitt K.R.L.' 'Klinik für angeborene Herzfehler und Kinderkardiologie, Deutsches Herzzentrum, Berlin, Deutschland, ${ }^{2}$ Klinik für Pädiatrie mit Schwerpunkt Kardiologie, Charité - Universitätsmedizin Berlin, Deutschland

Fragestellung. Durch Operationen am kardiopulmonalen Bypass kann ein systemisches inflammatorisches Syndrom mit der Ausschüttung von proinflammatorische Zytokinen ausgelöst werden. Obwohl tiefe Hypothermie eine Standardprozedur während komplex kardiochirur- gischer Eingriffe ist, ist sie mit teils schwerwiegenden Nebenwirkungen verbunden. Daher haben wir die Anwendung von Stattic, einem Inhibitor der STAT3-Aktivierung, auf die IL-6 und TNFa-Sekretion in einem Zell-Kultur-Modell, als möglichen Ersatz für die Hypothermiebehandlung, untersucht.

Methoden. Sowohl BV-2 Mikrogliazellen als auch HT-22 Neurone plus BV-2-Mikrogliazellen wurden entweder für 2 Stunden auf $17^{\circ} \mathrm{C}$ gekühlt, innerhalb von 2 Stunden wiedererwärmt und für weitere 24 Stunden nachbeobachtet oder anstelle der Kühlungs- und Wiedererwärmungsphase für 4 Stunden mit Stattic behandelt. Die Monokultur wurde mit Lipopolysaccharid (LPS) und die Ko-Kultur mit LPS und Gluatamat stimuliert Die Zytokin und P-Stat3-Expression wurde mittels qRTPCR, ELISA oder Western-Blot-Technik analysiert,

Ergebnisse. P-Stat 3 war unter hypothermen Bedingungen in der Monokultur signifikant herunter reguliert, was in einer Reduktion der IL-6 und TNFa Ausschüttung resultierte. In der Ko-Kultur konnte keine Regulation der P-Stat3-Expression gesehen werde. Dennoch waren IL-6 und TNFa unter Hypothermie herab reguliert. Ähnlich den Kühlungseffekten führte die Applikation von Stattic in der Mono- und Ko-Kultur zu einer signifikant verminderten IL-6-Ausschüttung und in der Monokultur zusätzlich zu einer signifikant abgeschwächten TNFa-Sekretion.

Schlussfolgerung. Hypothermie ist in der Lage eine Inflammationsreaktion abzuschwächen. In Zukunft könnte die Blockade von Stat3 zur Entwicklung neuer neuroprotektiver Substanzen beitragen.

\section{Choreatiforme Bewegungsstörung bei Tyrosinhydroxylase-Mangel mit bislang unbekannter Mutation}

Weigt-Usinger K. ${ }^{1}$, Thiels C. ${ }^{1}$, Köhler C. ${ }^{1}$, Heyer C.M. ${ }^{2}$, Hinderhofer K. ${ }^{4}$, Assmann B. ${ }^{3}$, Opladen T. ${ }^{3}$, Lücke T. ${ }^{\text {? }}$

${ }^{1}$ Abteilung für Neuropädiatrie mit Sozialpädiatrie, Klinik für Kinder- und Jugendmedizin der Ruhr-Universität Bochum, ${ }^{2}$ Institut für Diagnostische Radiologie, Interventionelle Radiologie und Nuklearmedizin, Berufsgenossenschaftliches Universitätsklinikum Bergmannsheil, ${ }^{3}$ Zentrum für Kinder- und Jugendmedizin, Stoffwechselzentrum, Universitätsklinikum Heidelberg, ${ }^{4}$ Institut für Humangenetik, Universität Heidelberg

Einleitung. Die Tyrosinhydroxylase katalysiert die Bildung von L-Dopa durch Hydroxylierung von Tyrosin und hat daher eine wichtige Bedeutung in der Synthese des Dopamins. Der Tyrosinhydroxylase-Mangel (THD) folgt einem autosomal-rezessiven Erbgang. Das TH-Gen ist lokalisiert auf Chromosom 11p15.5. Klinisch werden 2 Phänotypen unterschieden: 1. Beginn in der Neonatalperiode mit schwerem enzephalopathischem Verlauf, 2. progredientes hypokinetisch-rigides Syndrom mit Dystonie.

Fallbeispiel. Drei Monate alter Junge mit progredienten choreatiformen Bewegungsstürmen kurz nach dem Aufwachen beginnend, sistierend im Schlaf. Entwicklungs- und Gewichtsstagnation. Durch Mitbeteiligung der Zungen-Schlund-Muskulatur war im Verlauf eine selbstständige Nahrungsaufnahme nicht mehr möglich.

Diagnostik. Ausschluss infektiöser, endokrinologischer Ursachen. cMRT unauffällig. Neurotransmitter (Liquor): deutlich erniedrigte Konzentration von HVA [ $68 \mathrm{nmol} / \mathrm{l}$ (Norm 427-989 nmol/l)]. Normale Konzentration von 5-HIAA, 5 MTHF und Pterine unauffällig. DHPR-Enzymaktivität normwertig; Phenylalanin (Plasma) unauffällig.

Molekulargenetik. Mutation p.R233H (c.698G>A) in Exon 6, Sequenzvariante p.Y274* (c.822C $>\mathrm{A})$ in Exon 8 (vermutlich funktionelle Mutation) des TH-Gens.

Therapie. L-Dopa/Carbidopa [4:1] p.o. bis $10 \mathrm{mg} / \mathrm{kgKG}$, deutliche klinische Verbesserung (videodokumentiert), Sistieren der Bewegungsstürme, Fortschritte in der allgemeinen Entwicklung.

Schlussfolgerung. Ungewöhnliche Präsentation eines THD mit bislang unbekannter Mutation als Ursache einer choreatiformen anstelle der klassischen hypoton-hypokinetischen Bewegungsstörung. Gutes klinisches Ansprechen auf eine orale L-Dopa-Therapie.

Keywords. TYH, Tyrosinhydroxylase-Mangel, L-Dopa 


\section{LPS mediated activation of NFKB pathways raises NO secretion by BV2 microglia cells post hypoxia}

\section{Jung S. ', Frey D. ', Brackmann F.', Trollmann R. \\ 'University Hospital for Children and Adolescents, \\ Department of Paediatrics, Erlangen}

Background. Microglia cells are resident cells of the innate immune system and respond to a variety of stimuli. Upon activation microglia releases mediators involved in the early control of invading pathogens, but also in neurodegeneration. Studies suggest that LPS sensitize the immature brain to hypoxia mediated brain damage. Here, we investigate the impact of different stimuli on $\mathrm{NF \kappa B}$ activation and nitric oxide (NO) production.

Methods. BV2 cells were treated with LPS or transfected with different NFkB expression constructs prior exposition to $1 \% \mathrm{O}_{2}$. Expression of HIF$1 a$, NFkB, iNOS, TNFa, ILib, and IL6 were analyzed by real-time PCR, Western Blot, and ELISA. NO secretion was quantified by the Griess assay. Results. LPS exposition of $\mathrm{BV} 2$ cells mediates an over expression of iNOS mRNA and increases the production of NO. Thereby, NO secretion was raised by $52 \%$ due to LPS/hypoxia stimulation in relation to LPS alone. Moreover, LPS and hypoxia acts synergistically on the expression of HIF-1a, NFאB, TNFa, IL1b, and IL6. Comparable to LPS exposition, supernatants derived from activated $\mathrm{BV} 2$ cells are able to sensitize untreated $\mathrm{BV} 2$ cells suggesting that chemokine feedback loops may trigger $\mathrm{NO}$ secretion. Due to the involvement of NFkB activation in chemokine expression we hypothesized that the NFkB transcription factors p5o and p52 are key players in LPS mediated sensitizing of BV2 cells to hypoxia. Indeed, comparable to LPS pretreatment, expression of $\mathrm{p} 50$ and $\mathrm{p} 52$ induces an increase in NO secretion post hypoxia.

Conclusion. Our data indicate that LPS exposition induces a long lasting sensitization of $\mathrm{BV} 2$ cells to hypoxia via $\mathrm{NF \kappa B}$ activation. Eminently, enhanced secretion of $\mathrm{NO}$ by activated microglia may contribute to the observed delayed neural damage following a hypoxic insult.

\section{Medizinische und psychosoziale Folgen der extremen Adipositas bei Jugendlichen - Akzeptanz und Wirkung einer strukturierten Versor- gung. Ein Konsortium des BMBF-Kompetenznetzes Adipositas}

Lennerz B.S. ${ }^{1}$, Moss A. ${ }^{1}$, Bickenbach A. ${ }^{2}$, Geisler A. ${ }^{3}$, Holl R. ${ }^{4}$, Holle R. ${ }^{5}$, Kiess W. ${ }^{6}$, Mühlig Y. ${ }^{7}$, Neef $M .{ }^{6}{ }^{6}$ Ose $C^{8}{ }^{8}$, Reinehr ${ }^{3}{ }^{3}$, Scherag $A .{ }^{8,9}$, Teuner $C^{5}{ }^{5}$, Wiegand S. ${ }^{2}$, Wolters B. ${ }^{3}$, Hebebrand J. ${ }^{7}$, Wabitsch M. ${ }^{1}$

${ }^{1}$ Universitätsklinik für Kinder- und Jugendmedizin Universität Ulm, Sektion Pädiatrische Endokrinologie und Diabetologie, Ulm, ${ }^{2}$ Charité Universitätsmedizin Berlin, Ambulantes Adipositas Zentrum, SPZ der Kinderklinik, Berlin, ${ }^{3}$ Universität Witten/Herdecke, Vestische Kinder- und Jugendklinik, Datteln, ${ }^{4}$ Universität Ulm, Institut für Epidemiologie und medizinische Biometrie, Ulm, ${ }^{5}$ Helmholtz Zentrum, Institut für Gesundheitsökonomie und Management im Gesundheitswesen, München, ${ }^{6}$ Universitätsklinikum Leipzig, Klinik und Poliklinik für Kinder- und Jugendmedizin, Leipzig, ${ }^{7}$ LVR-Klinikum Universität Duisburg-Essen, Klinik für Psychiatrie, Psychosomatik und, Psychotherapie des Kindes- und Jugendalters, Essen, ${ }^{8}$ Universitätsklinikum Essen, Zentrum für Klinische Studien, Essen, ${ }^{2}$ Universitätsklinikum Essen, Institut für Medizinische Informatik, Biometrie und Epidemiologie, Essen

Fragestellung. Jugendliche mit extremer Adipositas haben ein erhöhtes Risiko für somatische und psychiatrische Komorbiditäten, soziale Isolation und Arbeitslosigkeit. Dennoch suchen nur wenige eine Behandlung. Ziel ist es, Akzeptanz und Effektivität einer strukturierten Versorgung zu untersuchen.

Methode.DasProjektfindetan5 deutschenUniversitätszentren(Ulm,Leipzig, Berlin, Essen, Datteln) statt und ist in 4 Teilprojekte (TP) untergliedert: TP1: Patienten (14-25 J.) mit Adipositas oder extremer Adipositas (BMI $\geq 30 \mathrm{~kg} / \mathrm{m} 2$ ) werden aus verschiedensten Umfeldern aktiv rekrutiert und über 9 Jahre untersucht. Endpunkte sind die Akzeptanz der diagnostischen und therapeutischen Maßnahmen, die Prävalenz von somatischen und psychiatrischen Komorbiditäten, sowie psychosoziale Aspekte.
$\mathrm{TP} 2$. Eine neue Intervention zur Verbesserung des resignierenden Verhaltens wird randomisiert in Bezug auf Compliance und Lebensqualität mit der Standardversorgung verglichen.

$\mathrm{TP}_{3}$ : Die Effektivität eines bariatrischen Eingriffs mit Vor- und Nachsorgeprogramm wird untersucht.

TP4. Begleitend werden gesundheitsökonomische Analysen durchgeführt.

Ergebnisse. Der Rekrutierungszeitraum ist Juli 2012 bis Juli 2014. Es wurden 189 Patienten in TP 1 und 81 Patienten in TP 2 eingeschlossen (Stand: Mai 2013).

Diskussion. Unsere Ergebnisse werden Erkenntnisse zu den medizinischen und psychosozialen Folgen der extremen Adipositas bei Jugendlichen liefern. Im Rahmen des Kompetenznetz Adipositas bauen wir ein Versorgungsnetzwerk auf, welches die medizinische sowie psychosoziale Betreuung umfasst, und eine Plattform für weitere Forschungsprojekte schafft.

Das Verbundprojekt wird durch das Bundesministerium für Bildung und Forschung (BMBF, 01Gl1120A) gefördert und ist in das Kompetenznetz Adipositas (KNA) integriert.

\section{Einfluss der menschlichen Gene auf Verlauf und Prognose von schweren bakteriellen Infektionskrankheiten - EUCLIDS, ein euro- päisches Multicenter-Projekt}

Zenz W. ', Binder A. ', Klobassa D.S.', Sellner A. ', Carrol E. ${ }^{2}$, Pollard A.J. ${ }^{3}$, Kuijpers T. ${ }^{4}$, Emonts M. ${ }^{5}$, de Groot R. ${ }^{6}$, Martinón-Torres F. ${ }^{7}$, Hibberd M.L. ${ }^{8}$, Clough J. ${ }^{9}$, Fink $\mathrm{C}^{10}$, Anderson S. ${ }^{11}$, Serruto D. ${ }^{12}$, Levin M. ${ }^{13}$ für das EUCLIDS Konsortium (www.euclids-project.eu)

${ }^{1}$ Medizinische Universität Graz, Abteilung für Allgemeine Pädiatrie, Graz, Austria, ${ }^{2}$ University of Liverpool, Institute of Child Health, UK, ${ }^{3} \mathrm{Oxford}$ University, Department of Paediatrics, UK, ${ }^{4}$ Academisch Medisch Centrum, Amsterdam, NL, ${ }^{5}$ Erasmus Universitair Medisch Centrum, Rotterdam, NL, ${ }^{6}$ Radboud University Nijmegen Medical Centre, NL, ${ }^{7}$ University Hospital of Santiago,Department of Paediatrics, Spain, ${ }^{8} \mathrm{Genome}$ Institute Singapore, Department of Infectious Disease, Singapore, ${ }^{9}$ Oxford Gene Technology, UK, ${ }^{10}$ Micropathology Ltd, UK, ${ }^{11}$ Medical Research Council (MRC), The Gambia, ${ }^{12}$ Novartis Vaccines and Diagnostics, Italy, ${ }^{13}$ Imperial College London, Department of Medicine, UK

Fragestellung. Infektionserkrankungen stehen trotz moderner Impfungen und Antibiotika weltweit noch immer an der Spitze der Ursachen für kindliche Todesfälle. Bisher wurden hauptsächlich Erreger und deren Bekämpfung erforscht - die genetische Prädisposition, die für das Auftreten und den Schweregrad einer Infektionserkrankung mitverantwortlich ist, blieb großteils unerforscht. Ziel des EUCLIDS-Projekts ist es nun, Gene und pathophysiologische Mechanismen zu identifizieren, die die Suszeptibilität und den Verlauf von lebensbedrohlichen bakteriellen Infektionen in der Kindheit mitbestimmen.

Methode. EUCLIDS ist ein internationales Multicenter-Projekt und wird durch das 7. Rahmenprogramm der EU gefördert. Zu den teilnehmenden Ländern zählen Österreich, Deutschland, Italien, England, Spanien, Singapur, die Niederlande und Gambia. Zunächst wird anhand der Meningokokkeninfektion ein Modell zur Erforschung der genetischen Grundlagen für Suszeptibilität und Verlauf entwickelt, das als Modell für andere schwere bakterielle Infektionen in der Kindheit wie Osteomyelitis, septische Arthritis, eitrige Meningitis und Sepsis dienen soll.

Ergebnisse. Bisher konnten mittels genomweiter Assoziationsstudien (GWASs) der Komplementfaktor H und das Komplement Faktor H assoziierte Protein 3 als wesentliche Faktoren für die Suszeptibilität der Meningokokkenerkrankung identifiziert werden (Davila $S$ et al., 2010). Als weiterer Suszeptibilitätsfaktor wurde das ABCA4-Gen identifiziert, diesbezüglich erfolgt derzeit die Replikation in der Gesamtkohorte. Schlussfolgerungen. Ziel dieser Studie ist das genaue Verständnis von Faktoren, die den Erwerb und Verlauf von schweren Infektionserkrankungen mitbestimmen. Dadurch kann die Grundlage für die Entwicklung neuer Impfstoffe und Therapien geschaffen werden. 


\section{Autoinflammatorische Erkrankungen und Live cell imaging}

Rabe S.', Heymann M.C.', Russ S. ', Winkler S. ', Roesler J.', Rösen-Wolff A. ', Hofmann S.R.'

${ }^{1}$ Klinik für Kinder- und Jugendmedizin, TU Dresden, Medizinische Fakultät Carl Gustav Carus, Dresden

Fragestellung. Patienten mit rekurrierenden Fieberepisoden und CASP1-Varianten leiden trotz verminderter Sekretion von IL-1 $\beta$, verursacht durch eine reduzierte enzymatische Aktivität der Procaspase-1Varianten durch Destabilisierung der Tertiärstruktur, an systemischen Entzündungsreaktionen. Eine mögliche Erklärung für dieses Paradoxon könnte die Aktivierung alternativer proinflammatorischer Signalwege sein. Das Ziel dieses Projekts ist die Identifizierung möglicher subzellulärer Mechanismen, wie Procaspase-1-Varianten zur Aktivierung alternativer proinflammatorischer Signalwege beitragen können. Material und Methoden. Unter Verwendung von THP-1-Zellen, viral mit fluoreszierenden Fusionsproteinen (Wildtyp-Procaspase-1, CASP1-L265S Variante) transduziert und mit LPS/Nigericin stimuliert (Inflammasomaktivierung), sowie konfokaler Mikroskopie, Fluoreszenz-Kreuzkorrelationsspektroskopie (FCCS) und Live-cell-imagingMethoden analysierten wir die subzelluläre Lokalisation von Procaspase-1 sowie die Interaktion mit RIP2 in humanen monozytären Zellen und Makrophagen.

Ergebnisse. Erstmals gelang es in humanen Makrophagen mittels Ko-Immunpräzipitation sowie Ko-Lokalisation eine Interaktion von Procaspase-1 und RIP2 zu zeigen, die mittels Fluoreszenz-Korrelationsspektroskopie (FCCS) bestätigt werden konnte. Erste Ergebnisse zeigten außerdem eine durch die CASP1-L265S gestörte Abspaltung von Mikrovesikeln nach Behandlung der THP-1 mit Nigericin sowie eine verminderte Kernlokalisation und gestörte Pyroptose dieser Procaspase-1-Variante.

Schlussfolgerung. Diese Ergebnisse suggerieren einen möglichen Einfluss von Procaspase-1-Varianten auf Zellmembraneigenschaften, Pyroptose und die Freisetzung von Mikrovesikeln.
Genexpressionsbasierte Therapiestratifizierung für NeuroblastomPatienten mit niedrigem und mittlerem Risiko

Fischer M. ${ }^{1,2}$, Oberthür A. ', Juraeva D. ${ }^{3}$, Sterz C. ${ }^{1}$, Volland R. ${ }^{1}$, Schmidt . $^{4}$, Faldum A. ${ }^{4}$, Hero B. ${ }^{1}$, Brors B. ${ }^{3}$, Berthold F. ${ }^{1,2}$

${ }^{1}$ Klinik und Poliklinik für Kinderheilkunde, Pädiatrische Onkologie und Hämatologie, Universität Köln, ${ }^{2}$ Zentrum für Molekulare Medizin Köln (ZMMK), Universität Köln, ${ }^{3} \mathrm{Abteilung}$ für Theoretische Bioinformatik (B $\left.{ }^{080}\right)$, DKFZ Heidelberg, ${ }^{4}$ Institut für Biometrie und Klinische Forschung, Universität Münster

Fragestellung. Neuroblastom-Patienten werden gegenwärtig in drei Risikogruppen eingeteilt und entsprechend mit unterschiedlicher Therapieintensität behandelt. Unsere Studie prüft die Hypothese, ob die Vorhersage des individuellen Patientenrisikos mit Hilfe eines genexpressionsbasierten Biomarkers verbessert werden kann.

Material und Methode. Mittels Microarray-Analysen wurden Genexpressionsprofile von 709 primären Neuroblastomen untersucht. In einer Trainingskohorte $(\mathrm{n}=75)$ wurde mit Hilfe des Support Vector Machine Algorithmus (SVM) eine prognostische Gensignatur (SVM_th10) definiert und in den verbliebenen Proben $(n=634)$ evaluiert.

Ergebnisse. Günstige und ungünstige Krankheitsverläufe wurden durch die Gensignatur präzise vorhergesagt. Der potenziell größte klinische Nutzen wurde bei Patienten mit niedrigem und mittlerem Risiko beobachtet $(n=413$; ereignisfreies Überleben [EFS]: $0,846 \pm 0,020$

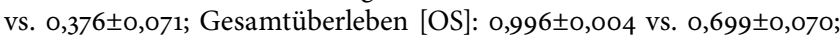
jeweils $\mathrm{p}<\mathrm{0}, \mathrm{001})$. In Regressionsanalysen war die Gensignatur in dieser Patientengruppe sowohl univariat (EFS: Hazard-Ratio [HR] 4,99; OS: HR 40,53; jeweils $\mathrm{p}<0,001$ ) als auch multivariat (EFS: HR 5,59; OS: HR 20,08; jeweils $\mathrm{p}<0,001)$ ein signifikanter prognostischer Marker und den bisherigen Prognosekriterien überlegen.

Diskussion und Schlussfolgerung. Eine genexpressionsbasierte Klassifizierung verbessert die Risikoabschätzung bei Neuroblastom-Patienten mit niedrigem und mittlerem Risiko. Wir beabsichtigen, die Gensignatur SVM_th1o als diskriminierenden Prognosemarker in die geplante GPOH-Neuroblastomstudie zu implementieren, und eine Therapiereduktion bei günstig klassifizierten Patienten sowie eine Therapieintensivierung bei ungünstig klassifizierten Patienten prospektiv zu prüfen. 


\section{Autorenindex}

A

Abboud M.

Abdul-Khaliq $\mathrm{H}$.

Abendroth $\mathrm{U}$.

Agostini $\mathrm{H}$.

Ahting U.

Aktas-Koptagel M.

Albers L.

Albert M.

Albrecht B.

Albrecht M.

Albrecht N.-J.

Alexandre P.

Al-Herz W.

Ali A.

Alston C. L.

Alt $F$.

Amich J.

Ammann S.

Amraoui Y.

Amulic B.

Anderson C. S.

Andres 0 .

Angenendt $\mathrm{S}$.

Angerer $\mathrm{D}$.

Ankermann T.

Antenbrink F.

Apitz C.

Arana A.

Arash L.

Arash-Kaps L.

Arbeiter K.

Aretz S.

Aring C.

Arkwright $\mathrm{P}$.

Armbrust $\mathrm{S}$.

Arndt V.

Asmussen M.

Asplund A.C.

Assmann B.

Astfalk W.

Aulbert W.

Avitzur Y.

\section{B}

Bächle C.

Bachour H.

Backes M.

Bacon C.

Baerlecken N. T.

Bahrami E.

Bahrke S.

Ballauff A.
API-SY1-2

DGKJ-PO-K-2

DGSPJ-SY-SG-1

DGKJ-PO-J1-7

DGKJ-PO-11-14

DGKJ-PO-N2-4

DGSPJ-PO-1

API-SY1-2, API-SY2-2,

API-SY2-3

DGKJ-PO-N1-7

DGKCH-SY-KU-1

DGSPJ-SY-TP-1

DGKJ-PO-N1-7

API-SY1-2

DGKJ-PO-I2-8

DGKJ-PO-I1-14

DGKJ-PO-I1-10

API-SY3-5

API-SY2-4

DGKJ-PO-S-4,

DGSPJ-PO-6

API-PO-1

DGKJ-PO-N2-8,

DGKJ-PO-N2-9

API-SY3-4

DGKJ-PO-P-2

DGKJ-PO-E-6

DGKJ-SY-PA1-2

DGKCH-PO-3

DGKJ-PO-K-3

DGKJ-PO-J3-1

DGKJ-PO-S-3

DGKJ-PO-S-2,

DGSPJ-PO-6

API-SY6-2

DGKJ-PO-V1-8

DGKJ-PO-I2-9,

DGKJ-PO-K-8

API-SY2-2

DGKJ-PO-V3-12

DGKJ-SY-OE-6

DGKJ-PO-I1-11

API-SY5-2

DGKJ-PO-N2-3

DGKJ-SY-PV2-4

DGKJ-PO-02-3

API-SY4-5

DGKJ-PO-E-9

DGKJ-PO-EG-6

DGSPJ-SY-SG-1

API-SY2-2

API-SY6-4

API-SY4-5

DGKJ-PO-K-11

DGKJ-PO-EG-10,

DGKJ-PO-V2-9
Ballmann M.

Ban S. A.

Banaschewski T.

Barbouche M.-R.

Bartsch D.

Bauck M.

Bauer C. P.

Bauer D.

Bauer J.J.

Bauer M.

Baum C.

Baumann M.

Baumann U.

Baumer A.

Becher T.

Beck M.

Beck 0.

Becker C.

Becker G.

Beckmann M. W.

Beetz R.

Behrens R.

Beier R.

Beilhack A.

Bejaoui M.

Belohradsky B.

Ben-Mustapha I.

Beneda R.

Benesch M.

Benjamin R.

Bennett K.

Benzrath S.

Berendes R.

Berg A.

Berg D.

Berger $F$.

Berger T.

Berghem S.

Berlemann B.

Berlien H.-P.

Berner R.

Bernhart S.

Bernius P.

Berrang J.

Berth F.

Bertram M.

Berweck S.

Beschorner R.

\begin{tabular}{l|l} 
DGKJ-PO-G-4 & Beyerlein A. \\
API-SY6-2 & \\
DGKJ-PO-N2-8 & Bialas J. \\
API-SY5-2 & Bien C. G. \\
DGKCH-SY-TR-8 & Bienemann K.
\end{tabular}

DGKCH-GÖR-4

DGSPJ-SY-FR-1

API-PO-9

DGKJ-PO-01-1

API-PO-3, API-SY3-6

API-SY1-2

DGKJ-PO-N2-1

API-PO-13, DGKJ-

PO-M-4

DGKJ-PO-N1-5

DGKJ-PO-I2-13,

DGKJ-PO-N2-10

DGKJ-PO-S-2,

DGKJ-PO-S-4,

DGSPJ-PO-6,

DGKJ-PO-S-7,DGKJ-

PO-S-10, DGKJ-PO-S-11,

DGKJ-SY-LS-3

DGKCH-PO-6

API-PO-4, API-SY4-3

DGSPJ-SY-FS-3

DGKJ-SY-G-2

DGKCH-SY-VU-3,

DGKJ-SY-P2-4

DGKJ-PO-G-1

API-SY1-2

API-SY3-5

API-SY5-2

API-SY2-3

API-SY5-2

DGKJ-PO-V1-9

API-PO-10

DGKJ-PO-J2-4

API-SY3-3

DGKJ-PO-02-5

API-PO-12

DGKJ-SY-15-2

DGKJ-SY-NP2-3

DGKJ-PO-K-7

API-PO-12, API-SY5-5,

DGKJ-PO-G-1

DGSPJ-PO-17

DGKJ-PO-E-8,

DGKJ-PO-02-5

DGKJ-PO-D-1,

DGKJ-PO-D-3

DGKJ-SY-15-2,

DGKJ-SY-RE4-1

DGKJ-PO-01-3

DGSPJ-FV-1, DGSPJ-

PO-4

API-PO-12, API-SY5-5

DGSPJ-SY-KB-3

DGKJ-PO-V1-4

DGSPJ-FV-1, DGSPJ-

PO-4

DGKCH-SY-IM-3

Bläser A.

Bläsing $\mathrm{G}$.

Blohm M.

Bloomfield R.

Bock C.

Bockmann A.-K.

Bode $\mathrm{H}$.

Bode S.

Boemers T. M.

Böhmann J.

Böhmer M.

Bohn B.

Boos J.

Bopp M.

Borkhardt A.

Born M.

Bornfeld N.

Borte M.

Borusiak P.

Bosse H. M.

Bottländer M.

Botzenhardt S.

Bouzani M.

Boztug $\mathrm{H}$.

Boztug K.

Brandi D.

Brar B.

Brauer N. D.

Braulke T.

Braun C.J.

Braunewell L.

Breitkreutz J.

DGSPJ-FV-1,

DGSPJ-PO-4

DGKJ-PO-I2-14

DGKJ-SY-NP1-4

DGKJ-PO-D-4,

DGKJ-PO-EG-2,

DGKJ-PO-02-1

Bimböse P. DGKJ-PO-N1-9

Binder V. DGKJ-PO-01-3

Blankenstein $0 . \quad$ DGKJ-PO-I2-12

DGKJ-PO-V3-9

DGKJ-PO-EG-10

DGKJ-PO-K-12

DGKJ-PO-N2-8,

DGKJ-PO-N2-9

API-PO-2

DGKJ-PO-V3-7

DGKJ-SY-CP-4,

DGKJ-SY-MI-3

API-SY2-4

DGKCH-SY-TS-5

DGKCH-SY-KU-2

DGKJ-SY-EP1-5

DGKJ-PO-J3-9

DGKJ-PO-02-10

DGKCH-FV-3

API-SY4-2, API-SY6-6,

DGKJ-PO-01-3,

DGKJ-SY-PI1-1

DGKJ-PO-EG-6,

DGKJ-PO-J1-6,

DGKJ-SY-KS-3

DGKJ-PO-V1-9

API-PO-13,

DGKJ-PO-M-4

DGSPJ-FV-3,

DGSPJ-FV-4

DGKJ-PO-J1-4,

DGKJ-PO-M-3,

DGKJ-SY-L-2

Bosserhoff A.-K. $\quad$ DGKJ-PO-V2-6 


\begin{tabular}{|c|c|}
\hline Brix 0. & $\begin{array}{l}\text { DGSPJ-FV-1, } \\
\text { DGSPJ-PO-4 }\end{array}$ \\
\hline Brockow I. & DGKJ-PO-I1-2 \\
\hline Brolund $\mathrm{A}$. & DGKJ-PO-J2-7 \\
\hline Brücker J. & DGKJ-PO-G-9 \\
\hline Brunner H. G. & DGKJ-SY-ND2-2 \\
\hline Brunner J. & DGKJ-PO-N2-1 \\
\hline Buchhorn R. & DGKJ-PO-E-5 \\
\hline Budisteanu M. & API-PO-3 \\
\hline Bufe A. & DGKJ-PO-M-8 \\
\hline Buhk J.-H. & DGKJ-PO-J2-7 \\
\hline Bühler A. & DGKJ-PO-U-4 \\
\hline Bühligen U. & DGKCH-PO-2 \\
\hline Burhenne J. & DGKJ-PO-01-10 \\
\hline Burmester $\mathrm{H}$. & DGKJ-PO-E-10 \\
\hline Bürücüoglu T. & DGKJ-PO-E-8 \\
\hline Büscher A. K. & DGKJ-SY-N2-4 \\
\hline Büsching U. & DGKJ-SY-PV2-2 \\
\hline Buschmann A. & DGKJ-PO-V3-7 \\
\hline Buschmann J. & DGKJ-SY-PV1-4 \\
\hline Busse A. & DGKJ-PO-V1-3 \\
\hline Buyken A. E. & DGKJ-SY-KE-2 \\
\hline \multicolumn{2}{|l|}{ C } \\
\hline Caballero B. & DGKJ-PO-N2-9 \\
\hline Cairns P. & DGKJ-PO-I2-5 \\
\hline Calmbach M. & DGKJ-SY-W-2 \\
\hline Calvano C. & DGKJ-PO-G-9 \\
\hline Campbell D. & DGKJ-PO-I1-4 \\
\hline Campbell K.P. & DGKJ-PO-N1-8 \\
\hline Cant A. & API-SY2-2 \\
\hline Cardo E. & DGKJ-PO-N2-9 \\
\hline Carss K. & DGKJ-PO-N1-8 \\
\hline Cartes-Zumelzu F. & DGKJ-PO-N2-1 \\
\hline Casanova J.-L. & API-PO-11 \\
\hline Cassar W. & $\begin{array}{l}\text { DGKCH-FV-6, } \\
\text { DGKCH-FV-7 }\end{array}$ \\
\hline Castillo K. & DGKJ-PO-E-9 \\
\hline Chakrapant A. B. & DGKJ-PO-I1-14 \\
\hline Chang Y. & DGKJ-PO-N1-7 \\
\hline Chen $\mathrm{H}$. & $\begin{array}{l}\text { API-SY4-5, } \\
\text { DGKJ-PO-V1-8 }\end{array}$ \\
\hline Chen W. & API-PO-1 \\
\hline Chin J. & DGKJ-PO-I2-4 \\
\hline Christ-Steckhahn C. & DGKCH-SY-TR-7 \\
\hline Chung D.-U. & DGKJ-PO-J1-4 \\
\hline \multirow[t]{2}{*}{ Cirak S. } & DGKJ-PO-N1-7, \\
\hline & DGKJ-PO-N1-8 \\
\hline \multirow[t]{2}{*}{ Civil R. } & DGKJ-PO-N2-8, \\
\hline & DGKJ-PO-N2-9 \\
\hline Claßen M. & DGKJ-PO-G-1 \\
\hline Clausen J. & DGKJ-PO-I1-1 \\
\hline Clausner A. & DGKJ-SY-PV2-4 \\
\hline Clusmann $\mathrm{H}$. & DGKJ-PO-01-9 \\
\hline \multirow[t]{2}{*}{ Coghill D. R. } & DGKJ-PO-N2-8, \\
\hline & DGKJ-PO-N2-9 \\
\hline \multirow[t]{2}{*}{ ComplojE. } & DGKCH-FV-6, \\
\hline & DGKCH-FV-7 \\
\hline Coninx F. & DGKJ-SY-HN-1 \\
\hline Cop I. & DGKJ-SY-L-5 \\
\hline Creutzfeldt R. & DGKJ-PO-I1-7 \\
\hline CutzE. & API-SY4-5 \\
\hline
\end{tabular}

D
Dai L.

Dalla Pozza R.

Damerow T.

Daneva A.

Dantonello T.

Daschkey S.

Datz N.

De Lafollie J.

Debatin K.-M.

Dechet $C$.

Decker T.

Degenhardt P.

Degner M.

Delbrück H.

Delcroix M.

Delißen J.

Dell A.

Della Marina A.

Denecke J.

Derichs U.

Desel H.D.

Deutz U.

DieckerhoffC.

Dieckmann R.

Dieks J.

Dietz H.-G.

Dietzel M.

Dimitrova T.

Dingemann C.

Dingemann J.

Dinger J.

Dinkelborg M.

Dippacher S.

Dittes C.

Dittmann R. W.

Dogu F.

Dohmen-Baterovskyy G.

Doil $\mathrm{H}$.

Döing C.

Donner B.C.

Dopp J.

Dörr H.G.

Dötsch J.

Dreschers S.

Dressler F.

Driessen G.

Drzymala S.

DuH.

Dübbers M.

Dückers G.

Duckwitz H.

Dueckers G.

Duerr C.

Duhnke J.

Düker G.

Durmus N.

Dziadzio M.
DGKJ-PO-V2-2

DGKJ-PO-P-1

DGKJ-SY-P4-4

DGKJ-PO-J1-1

API-SY4-3

DGKJ-PO-02-9

API-SY6-6

DGKJ-PO-V2-3

DGKCH-FV-2

API-PO-6

DGKCH-FV-6,

DGKCH-FV-7

DGKJ-PO-V3-12

DGKCH-SY-TR-2,

DGKCH-SY-TR-7

DGSPJ-PO-11

DGKJ-PO-N2-4

DGKJ-PO-V3-2

DGKJ-PO-P-2,

DGKJ-PO-P-3,

DGKJ-PO-P-9

API-SY5-2

DGKJ-PO-N1-13

DGKJ-PO-N1-12,

DGKJ-PO-S-13

DGKJ-PO-J2-3

DGKJ-PO-M-1

DGKJ-PO-N2-13

DGKJ-SY-NE1-1

API-SY3-3

DGKJ-PO-N1-5

DGKCH-SY-TR-1

API-PO-9

DGKJ-PO-V2-7

DGKCH-FV-5,

DGKCH-SY-TS-5

DGKCH-FV-5

DGKCH-SY-TR-8

DGKJ-PO-EG-9

DGKJ-PO-E-5

DGKJ-PO-V3-12

DGKJ-PO-N2-9

API-PO-2

DGKJ-PO-I2-9

DGKJ-PO-V1-10

DGKJ-PO-E-2

DGKJ-SY-K-2

DGKJ-PO-N1-11

DGKJ-PO-E-6

DGKJ-SY-NN-3

API-PO-15

API-PO-12,

DGKJ-SY-14-3

API-SY4-3

DGKJ-SY-12-3

API-PO-1

DGKCH-SY-TR-9

API-PO-4, API-PO-12,

API-SY4-2, API-SY4-3,

DGKJ-PO-V2-9

DGKJ-PO-N2-10

API-PO-5

API-PO-16

DGKCH-SY-TR-3

DGKJ-PO-EG-6

API-SY3-6

API-SY5-2
E

Eberding A. DGSPJ-PO-10

Ebetsberger-Dachs G. API-PO-10

Echenne B. API-PO-3

Eckardt L. $\quad$ DGKJ-PO-K-8

Eckart W. U. DGKJ-SY-H1-2

Eder S. DGKJ-SY-H1-4

Eggermann T. DGKJ-PO-U-1

Eggert A. DGKJ-PO-01-1,

DGKJ-PO-01-8

Ehl B.

Ehls.

DGSPJ-FV-5

API-SY2-3, API-SY2-4,

API-SY6-3, API-SY6-4,

DGKJ-PO-V2-8

Eibel $\mathrm{H}$.

Eirich $\mathrm{K}$.

Eis-Hübinger A. M.

Eitelberger $\mathrm{F}$.

Elgizouli M.

ElHelou S.

Ellerkamp V.

Ellsäßer G.

Elmenhorst J.

Elpers C.

API-SY5-2, API-SY6-4

API-PO-1

DGKJ-PO-J1-6

API-SY6-2

API-SY6-4

DGKJ-PO-I2-6,

DGKJ-PO-12-11

DGKJ-SY-PV2-4

DGKCH-SY-KU-3,

DGKJ-PO-LW-1,

DGKJ-PO-LW-2

DGSPJ-SY-FR-2

DGKJ-PO-N1-2,

DGKJ-PO-N2-5,

DGKJ-PO-N2-6,

DGKJ-PO-N2-12

ElSharaw A.

Emeis M.

Emminger W.

Enders A.

Eng $C$.

Engelcke G.

Engelhardt $\mathrm{H}$.

Engelhardt K.R.

Engelmann G.

Engelsberger I.

Engl G.

Epplen I.

Erdlenbruch B.

Ernst G.

Eschenburg G.

Escherich G.

DGKJ-PO-N1-7

DGKJ-PO-I1-1

API-SY6-2

API-SY4-4

DGKJ-PO-V1-8

DGKJ-PO-V2-3

DGKJ-PO-G-1

API-SY5-2

DGKJ-PO-EG-1, DGKJ-PO-LW-4 DGKJ-PO-I1-14 DGKJ-PO-V3-1

DGKJ-PO-G-4

DGKJ-PO-M-1,

DGKJ-PO-S-12

DGSPJ-PO-8

DGKJ-PO-01-6

DGKJ-PO-J3-9,

DGKJ-PO-01-11

Etti N.

Ewert P.

Eyermann $\mathrm{R}$.

DGKJ-PO-K-8

DGKJ-PO-V3-2

DGKCH-SY-TR-5,

DGKJ-PO-K-6,

DGKJ-PO-K-10,

DGKJ-PO-N1-1,

DGKJ-PO-V3-3,

DGKJ-PO-V3-4,

DGKJ-PO-V3-5,

F

Faber J.

DGKCH-PO-6

Falkenhorst $\mathrm{G}$.

Fangerau $\mathrm{H}$.

Fasshauer M.
DGKJ-SY-EP1-5

DGKJ-SY-H-3

API-PO-13,

DGKJ-PO-M-4 


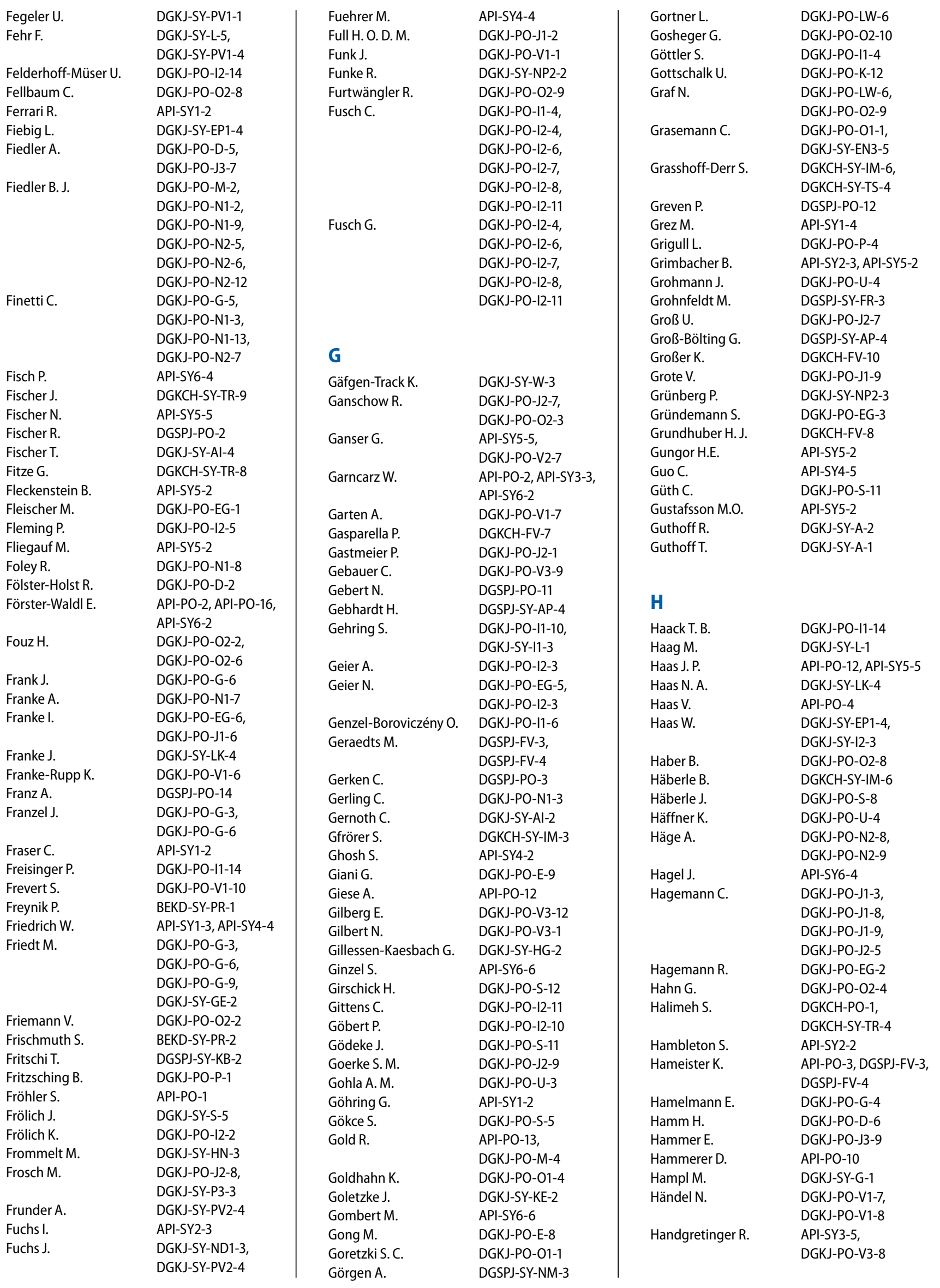




\section{Autorenindex}

Hanke S

Hansmann A.

Hardes J.

Harding D.

Harmsen S.

Harter P. N.

Hartl D.

Hartmann K.

Hartmann M. F.

Hartwig A.

Haslam S.M.

Hassan A.

Hassan M.

Hauck F.

Hauer B.

Hauffa B. P.

Hauptmann K.

Häusler M.

Haverkämper G.

Hebestreit A.

Hecking $M$.

Heckmann M.

Heep A.

Heesch K.

Hefele B.

Hehr U.

Heideking M.

Heiligenhaus A.

Heim T.

Heimann K.

Heine A.

Heinen $F$.

Heinrich B.

Heinritz W.

Heinz C.

Heisch K.

Heitger A.

Held J.

Held K. R.

Heldmann M.

Hellenbrand W.

Helmke F.

Hemmerlein B.

Hempel C.

Hempel M.

Henkes $\mathrm{H}$.

Henneke P.

Hennig M.

Hensel K.

Hensel M.

Henssen A.

Hentschke M.

Herbst M.

Herbst S. M.

Herebian D.
DGKJ-PO-J1-8,

DGKJ-PO-J2-4,

DGKJ-SY-15-3

DGKJ-SY-TP-2

DGKJ-PO-02-10

DGKJ-PO-I2-5

DGKJ-PO-N2-3

DGKCH-SY-IM-3

API-PO-7, API-SY3-5

DGKJ-PO-E-4

DGKJ-SY-EN2-3

DGKJ-SY-PV2-4

API-SY5-2

API-SY2-3

DGKJ-PO-I2-1

API-SY2-2, API-SY6-5

DGKJ-SY-12-3

DGKJ-PO-EG-2,

DGKJ-PO-01-1,

DGKJ-PO-EG-2

API-PO-1

DGKJ-PO-N2-4,

DGKJ-PO-N2-13

DGKJ-PO-K-7

DGKCH-PO-2

DGSPJ-SY-FR-3

DGKJ-PO-I1-3,

DGKJ-PO-I1-4

DGKJ-SY-NE1-3

DGKJ-PO-J1-5

DGKJ-PO-M-7

DGKJ-PO-G-7

DGKJ-PO-J1-7

API-PO-9

DGKJ-SY-PV2-4

DGKJ-PO-I1-12,

DGKJ-PO-S-9

DGKJ-PO-N1-10

DGSPJ-SY-FS-1

DGKJ-PO-S-8,

DGKJ-SY-15-2

DGKJ-PO-V3-9

API-PO-9

DGKJ-PO-V2-1

API-SY6-2

DGKJ-PO-J2-9

DGSPJ-SY-SP-3

DGKJ-PO-J3-8

DGKJ-SY-IM1-2

DGKJ-PO-N1-14

DGKJ-PO-01-7,

DGKJ-PO-V2-9

DGKJ-PO-S-12

DGKJ-PO-I1-14

DGKJ-PO-N2-5

DGKJ-PO-J1-7,

DGKJ-PO-J2-9

API-PO-9

DGKJ-PO-J3-8

API-PO-13,

DGKJ-PO-M-4

DGKJ-PO-01-8

DGKJ-PO-J2-7

DGKJ-PO-J2-8

DGKJ-PO-G-7

DGKJ-PO-S-1
Herkenrath P.

Hermanns P.

Hermanussen $M$.

Hermsdorf A.

Herrmann L.

Herrmann S.

Herzog A.

HeßB.L.

Heß K.

Hethey $S$.

Hetzer B.

Heubner G.

Heusch A.

Heusinger K.

Hezaveh K.

Higgins N.

Hilbich J.

Hilbig A.

Hildebrandt M.

Hinrichs B.

Hirsch W.

Hirtz S.

Hodgkins P.

Hoeper M. M.

Hoffmann G. F.

Hoffmann R.

Hoffmann $S$.

Hoffmann W.

Hofmann C.

Hofmeister R.

Höger P.

Hoheisel R.

Hohenfellner K.

Hohls M.

Holl R. W.

Höll J.

Holland-Cunz S.

Holler A.-S.

Hollmann H.

Hölscher G.

Holter W.

Holtrup M.

Holz M.

Holzinger D.

Holzmann K.

Hönig $M$.

Hönscheid A.

Hoppen $T$.

Horn A.

Horn B.

Hornberger $M$.

Horneff G.

Hosie S.

Hoyer P. F.

Hrivatakis G.

Huang L.
DGKJ-PO-M-2

DGKJ-PO-E-11

DGKJ-SY-PV2-3

API-SY5-4

DGKJ-PO-V3-6

DGKJ-PO-K-7

DGKJ-PO-S-3

DGSPJ-SY-AP-4

DGSPJ-SY-AP-4

DGKJ-PO-M-2

DGKJ-PO-N2-1

DGKJ-PO-J3-5,

DGKJ-PO-K-4

DGKJ-PO-J3-8

DGKJ-SY-A3-2,

DGKJ-SY-G-2

DGKJ-PO-01-3

DGKJ-PO-N2-8,

DGKJ-PO-N2-9

DGKJ-PO-I2-13

DGKJ-PO-G-8

DGKJ-PO-N1-10

DGKJ-SY-PN1-3

DGKJ-PO-V3-9

DGKJ-PO-P-1

DGKJ-PO-N2-9

DGKJ-PO-V3-2

DGKJ-PO-N2-11,

DGKJ-PO-S-8,

DGKJ-SY-L-1

DGSPJ-PO-16

DGKJ-PO-01-3

DGKJ-PO-I1-3

DGKJ-PO-S-12

DGKJ-PO-G-5

DGKJ-PO-J3-9

DGKJ-PO-LW-4

DGKJ-PO-U-3

API-PO-4

DGKJ-PO-E-9,

DGKJ-SY-DB2-2

DGKJ-PO-01-3

DGKCH-SY-IM-6

DGKCH-FV-3,

DGKCH-PO-6

DGKJ-SY-CP-3

DGKJ-PO-LW-3,

DGSPJ-PO-2

API-SY6-2

DGKJ-PO-01-7

DGKJ-PO-J2-2

API-PO-12

API-SY4-4

API-SY1-3, API-SY4-4

API-SY4-2

DGKCH-PO-3

DGKJ-PO-N2-7

DGKJ-PO-K-8

DGKJ-SY-L-1

API-PO-12, API-SY5-5,

DGKJ-SY-R-1

DGKCH-FV-8,

DGKCH-SY-IM-6

DGKJ-SY-N2-4

DGKJ-SY-PV2-4

DGKJ-PO-12-1

Hübl N.

Hübsch M.

Hüchering $B$.

Hufnagel $M$.

Hühn M.

Hummel M.

Hummler H. D.

Hundsdörfer $P$.

Hüning $B$.

Hünseler $C$.

Huppke P.

Hurles $M$.

Huscher D.

Husmann E.

Huth R. G.

Hütten $M$.

Huttner W.

Huwendiek S.

DGKJ-SY-HN-5

DGKJ-PO-02-7

DGKJ-PO-I2-13

DGKJ-PO-J1-7,

DGKJ-PO-J2-9,

DGKJ-SY-15-1,

DGKJ-SY-I5-2

DGKJ-PO-V1-8

DGKJ-PO-01-3

DGKJ-PO-I2-1

DGKJ-PO-01-6

DGKJ-PO-I2-14

DGKJ-SY-AI-1

DGKJ-SY-NP1-1

DGKJ-PO-N1-8

API-PO-13,

DGKJ-PO-M-4,

DGKJ-PO-V3-2

API-SY5-5

DGKJ-PO-I1-10

DGKJ-PO-S-9

DGKJ-PO-N1-7

DGKJ-SY-L-1,

DGKJ-SY-L-5

\section{I}

ljspeert $\mathrm{H}$ 


\section{K}

Jouhadi Z.

Josiger $\mathrm{N}$.

Jung N.

Junge $S$.

Jünger $\mathrm{H}$.

Junk L.

Jürgens $T$.

Kaatsch P.

Kabus M.

Kaemmerer $\mathrm{H}$.

Kahleyss S.

Kain R.

Kaindl A.

Kaiser R.

Kalaniti K.

Kalkum G.

Kalligerou E.

Kallinich T.

Kamlah C.

Kampmann B.

Kampmann C.

Kamrath C.

Kapenda R.

Karabul N.

Karall D.

Karch D.

Karenfort M.

Kässner F.

Kehl H. G.

Kehl T.

Keller B.

Keller K.-M.

Keller M.

Keller S.

Kellner M.

Kelsch V.

Kelter-Klöpping A.

Kemper M. J.

Kerbl R.

Kerjaschki D.

Kern W.

Kerschgens $B$.

Kersting $M$.

Kerth J.-L.

Khemiri M.

Khemis L.B.

Kidszun A.

Kiefer A.

Kiel T.

Kiesewetter M.

Kiess W.

Kim Y.-J.

Kionke J.

Kirch W.
API-SY5-2

DGKJ-PO-EG-7

DGSPJ-FV-1,

DGSPJ-PO-4

DGKJ-PO-J3-5

DGKJ-PO-11-14

DGKJ-PO-J3-9

DGKJ-PO-02-4

DGKJ-SY-EP2-3

DGKJ-PO-K-4

DGKJ-PO-V3-2

DGKJ-PO-N1-10

API-SY6-2

API-PO-1

DGKJ-PO-02-8

DGKJ-PO-I2-6

DGKJ-PO-S-3

DGKJ-PO-J1-1

API-PO-12, API-SY5-5

API-PO-12

DGKJ-SY-12-2

DGKJ-PO-S-7

DGKJ-SY-EN2-3

DGKJ-PO-J3-1

DGKJ-PO-S-2,

DGKJ-PO-S-3,

DGKJ-PO-S-5,

DGKJ-PO-S-10

DGKJ-PO-S-8

DGSPJ-PO-1

DGKJ-PO-N1-6,

DGKJ-PO-N2-3

DGKJ-PO-V1-7

DGKJ-PO-K-5,

DGKJ-PO-N2-2

DGKJ-PO-N1-12

API-SY2-2

DGKJ-PO-G-1

DGSPJ-SY-TP-3

DGKJ-PO-J1-3,

DGKJ-PO-J2-5

DGKJ-PO-P-6

DGKCH-FV-2

DGKJ-PO-02-11,

DGKJ-PO-02-12

DGKJ-SY-N2-2

API-PO-10

API-SY3-3

DGKJ-PO-J1-7

DGKJ-PO-V3-11

DGKJ-SY-KE-3,

DGKJ-SY-KE-4

API-PO-15

API-SY5-2

API-SY5-2

DGKJ-PO-I1-9

DGKJ-SY-TP-4

DGKJ-PO-EG-7

DGKJ-PO-I1-9

DGKJ-PO-V1-7

DGKJ-PO-02-9

DGKJ-PO-V1-8

API-PO-13,

DGKJ-PO-M-4
Kirchner M.

Kirchner T.

Kirwil M.

Klages $\mathrm{G}$.

Klaver S.

Klawonn F.

Klein C.

Kleinsteuber K.

Klemm T.

Klenzner T.

Klepper J.

Klingmann V.

Klinke $M$.

Klocke A.

KloßS.

Klotz D.

Kluge A.

Kluger $\mathrm{G}$.

Knirsch S.

Knoetzsch A.

Knöfler R.

Knopf H.

Knöppel C.

Knorr M.

Knuf M.

Knüpfer M.

Kobbe R.

Kock I.

Koelsch U.

Koestlin L.

Kögler G.

Kohistani N.

Kohl M.

Kohleis K.

Köhler C.

Köhler M.

Köhler T.

Kohlschütter A.

Kohns M.

Kolb R.

Koletzko B.

Koletzko S.

Kölker S.

Kölsch U.

Kondratenko I.

König B.

König T. T.

Konrad K.

Körber F.

Korczyk J.

Kordonouri $\mathrm{O}$.
DGKJ-PO-J2-3, DGKJ-PO-V2-5, DGKJ-PO-V2-6

API-SY4-5

DGKJ-PO-E-1

BEKD-SY-PR-2

API-SY6-2

DGKJ-PO-P-4

API-SY1-2, API-SY2-2,

API-SY3-2, API-SY4-5,

DGKJ-PO-V1-6

DGKJ-PO-J3-4

DGKJ-PO-J2-1

DGKJ-SY-HN-3

DGKJ-PO-S-3

DGKJ-PO-M-3

DGKJ-SY-L-1

DGKJ-SY-JM-1

DGKJ-PO-V1-10

DGKJ-PO-I2-2

DGSPJ-SY-SG-1

DGSPJ-FV-1,

DGSPJ-PO-4

API-SY1-3

DGKJ-PO-N1-10

DGKJ-PO-02-4,

DGKJ-PO-02-7

DGKJ-PO-M-6

DGKJ-PO-I2-10

DGKJ-PO-02-1

DGKJ-SY-IM1-1

DGKJ-PO-V3-9

DGKJ-PO-J2-7,

DGKJ-PO-02-3

DGKJ-PO-K-3

API-SY3-4

DGKJ-PO-V2-2

DGKJ-SY-RT-5

API-SY3-2

API-SY2-3,

DGKCH-SY-IM-5

DGKJ-SY-CP-4

DGKJ-PO-N1-14

DGKJ-PO-K-5,

DGKJ-PO-N2-2

DGSPJ-PO-4

DGKJ-SY-LS-1

DGKJ-PO-J1-4,

DGKJ-PO-J1-5,

DGKJ-PO-J2-2,

DGKJ-PO-J3-4,

DGKJ-PO-J3-6

API-SY2-3

DGKJ-SY-EN3-1

API-SY4-5

DGKJ-PO-S-8,

DGKJ-SY-RE2-1

API-PO-1, API-PO-3,

API-SY3-6

API-SY1-2

DGKJ-PO-V2-12

DGKCH-FV-2

DGKJ-SY-EN1-1

DGKJ-SY-NN-3

DGKJ-PO-EG-6

DGKCH-SY-TR-6, DGKJ-PO-V2-3

Korinthenberg $\mathrm{R}$.

DGKJ-PO-N1-8

Körner A.

Korsch E.

Kosk T.

Koster K.-L.

Kotlarz D.

Kotzaeridou U.

DGKJ-PO-V1-7

DGKJ-PO-P-6

DGKCH-SY-TR-8

DGKJ-PO-S-1

API-SY4-5

Kowalzik F. DGKJ-SY-OE-4

Krägeloh-Mann I. DGKJ-PO-V3-8

Krämer N.

Kratzsch W.

API-PO-1

Kraus $\mathrm{H}$.

Kraus de Camargo 0.

Krause G.

Krause R.

Krauspe R.

Krauth K. A.

Kreth H.-W.

Kreth J. H.

Kreuder J.

Krings A. E.

Krohn C.

Krömer U.

Kropshofer G.

Krudewig J.

Krüger $C$.

Krüger $M$.

Krüger R.

Krüger $S$.

Krupp D.

Kübler J.

Kugler T.

Kühl P. G.

Kühlcke K.

Kühn A.

Kuhnigk M.

Kühr J.

Kujath C.

Kummer S.

DGKJ-SY-PV2-1

API-SY5-2

DGSPJ-SY-SG-3 


\begin{tabular}{|c|c|c|c|c|c|}
\hline Lagler F. & DGKJ-PO-S-11 & Lilienthal E. & API-PO-12, API-SY5-5 & Maródi L. & API-SY1-2 \\
\hline Lainka E. & API-PO-12, API-SY5-5 & Lillig J.S. & DGKJ-PO-V3-8 & Marquard J. & DGKJ-PO-EG-8, \\
\hline Lamp J. & DGKJ-PO-S-6 & Lin Y.-Y. & DGKJ-PO-N1-8 & & DGKJ-SY-SW1-4 \\
\hline Lampe C. & DGKJ-PO-S-11 & Linden $\mathrm{T}$. & DGKJ-PO-N1-2, & Martens M. & DGKJ-SY-PS2-2 \\
\hline Lander F. & DGKJ-SY-I5-2 & & DGKJ-PO-N2-12 & Martin R. & DGKJ-SY-PV1-1 \\
\hline Landgraf K. & DGKJ-PO-V1-7 & Lindert J. & DGKCH-SY-TR-3 & Martinez F. & API-PO-3 \\
\hline Landgraf M. N. & DGSPJ-SY-FS-1 & Lindkamp K. & DGKJ-PO-02-11, & Marx F. M. & DGKJ-PO-J1-5, \\
\hline Lang A. & DGKJ-PO-LW-1, & & DGKJ-PO-02-12 & & DGKJ-PO-J3-4 \\
\hline & DGKJ-PO-LW-2 & Lischetzki G. & DGKJ-PO-N1-12 & Märzheuser S. & DGKCH-SY-IM-6 \\
\hline Lange A. & DGKJ-PO-I1-3 & Litzman J. & API-SY3-3 & Maschmann J. & DGKJ-PO-V3-8 \\
\hline Lange B.S. & DGKJ-PO-02-7 & Löbel U. & DGKJ-PO-01-11 & Mastropaolo L. A. & API-SY4-5 \\
\hline Lange K. & DGKJ-PO-E-9, & Lobstein S. & DGKJ-PO-K-4 & Mathes K. & DGKJ-PO-J1-2 \\
\hline & DGSPJ-PO-8 & LoffS. & DGKCH-SY-TS-5, & Mathias L. & API-SY1-2 \\
\hline Langenberger $\mathrm{D}$. & DGKJ-PO-01-3 & & DGKJ-SY-PV2-4 & Maurer M. & DGKJ-PO-I2-1 \\
\hline Langenbruch $\mathrm{B}$. & DGSPJ-SY-NL-3 & Loh N. & DGKJ-PO-V3-11 & Mayatepek E. & DGKJ-PO-E-2, \\
\hline Langer T. & DGSPJ-SY-TP-1 & Lohmann D. & DGKJ-PO-V1-9 & & DGKJ-PO-EG-8, \\
\hline Langhof $\mathrm{H}$. & DGSPJ-SY-AP-4 & Lohmöller B. & DGKJ-PO-S-6 & & DGKJ-PO-G-3, \\
\hline Längler A. & DGKJ-PO-V2-11 & Lohse P. & API-PO-6, API-PO-12, & & DGKJ-PO-G-6, \\
\hline Lankisch P. & API-PO-12 & & DGKJ-PO-V2-8 & & DGKJ-PO-J1-4, \\
\hline Lazaroski S. & API-SY5-2 & Lorenz B. & DGKJ-SY-A-4 & & DGKJ-PO-J1-5, \\
\hline Laschat M. & DGKJ-PO-EG-3 & Lorenz M. R. & API-SY6-4, API-SY2-3 & & DGKJ-PO-J2-2, \\
\hline Lassay L. & DGKJ-PO-01-9, & Lorenz N. & DGKJ-PO-J3-5, & & DGKJ-PO-J3-4, \\
\hline & DGKJ-PO-V3-11 & & DGKJ-PO-K-4 & & DGKJ-PO-J3-6, \\
\hline Latour $\mathrm{S}$. & API-SY2-2 & Losch $\mathrm{H}$. & DGKJ-PO-J2-6 & & DGKJ-PO-N1-6, \\
\hline Latus $\mathrm{H}$. & DGKJ-PO-K-3 & Löwe I. & DGKJ-PO-J3-5 & & DGKJ-PO-N2-3, \\
\hline Lau E. & DGKCH-SY-JK-5a & Lübbert R. & API-PO-5 & & DGKJ-PO-U-1 \\
\hline Laurenz M. & DGKJ-PO-V1-3 & Lucas T. & DGKJ-SY-PS2-1 & Mayer S. & DGKJ-PO-K-9 \\
\hline Lauten M. & API-SY2-3 & Lücke T. & DGKJ-PO-G-4, & Mayr J. & DGKJ-PO-I1-14 \\
\hline Lawrenz K. & DGKCH-FV-9 & & DGKJ-PO-N1-14, & Mayser P. A. & DGKJ-SY-PD2-3 \\
\hline Laws H.-J. & API-SY4-2 & & DGSPJ-PO-16 & Meerpohl J. & API-SY2-3 \\
\hline Lebrun A.-H. & API-SY3-4 & Lüders A. & DGKJ-PO-I2-12 & Meffert H. & DGKCH-PO-3 \\
\hline Lecendreux M. & DGKJ-PO-N2-8 & Ludwig M.-S. & DGSPJ-PO-2 & Meier R. & API-SY5-2 \\
\hline Lechner W. & DGKJ-PO-P-4 & Ludwikowski B. & DGKCH-SY-TR-6, & Meint S. & DGKJ-PO-E-5 \\
\hline Lee S.-Y. & DGKJ-PO-I2-6 & & DGKJ-PO-V2-3 & Meisel C. & API-PO-1, API-SY3-6 \\
\hline Leenen $\mathrm{A}$. & DGKJ-PO-J3-9 & Lukacs Z. & DGKJ-PO-S-11 & Meisel R. & API-SY4-2, DGKJ- \\
\hline Lefeber D. & API-PO-5 & Luksch H. & API-SY5-4 & & PO-02-2, DGKJ- \\
\hline Lehmann C. & DGSPJ-PO-10 & Lundin K.E. & API-SY5-2 & & PO-02-6 \\
\hline Lehmann R. & DGKJ-SY-L-1 & Lutz S. & DGKJ-PO-N1-13 & Meissner P.E. & DGKJ-SY-TP-3 \\
\hline Lehmberg K. & API-SY2-3, API-SY2-4 & Lutz T. & API-SY5-5 & Meissner T. & DGKJ-PO-E-2, \\
\hline Lehnert T. & DGKCH-PO-2 & Luxenburger E. & DGKJ-PO-S-11 & & DGKJ-PO-E-9, \\
\hline Lehrnbecher T. & DGKJ-SY-I3-3 & Luyt K. & DGKJ-PO-12-5 & & DGKJ-PO-EG-8, \\
\hline Leiz S. & DGKJ-PO-G-2 & Lyne A. & DGKJ-PO-N2-9 & & DGKJ-PO-M-3, \\
\hline Lemke H. & API-SY5-3 & & & & DGKJ-PO-S-9, \\
\hline Lenhartz $\mathrm{H}$. & DGKJ-PO-G-9 & & & & DGKJ-SY-SW1-4 \\
\hline Lenz D. & DGKJ-PO-J2-9 & M & & Meister J. & DGKJ-FS-PP-3, \\
\hline Lenze D. & DGKJ-PO-01-3 & Machens $\mathrm{P}$. & & & DGKJ-SY-PS1-3 \\
\hline Lerch C. & DGKJ-PO-EG-8, & Mahmoudi E. & API-PO-8 & Mejstrikova E. & API-SY3-3 \\
\hline & DGKJ-PO-M-3, & Mahnken A. & DGKJ-PO-N2-4 & Melchior R. & DGKJ-PO-G-1 \\
\hline & DGKJ-SY-SW1-4 & Maier 0 . & DGKJ-PO-N1-4 & Mellouli F. & API-SY5-2 \\
\hline Leube B. & DGKJ-PO-U-1 & Maier R.F & DGKJ-PO-I2-10 & Melter M. & DGKJ-PO-G-7, \\
\hline Leuschner I. & DGKJ-PO-02-9 & $\begin{array}{l}\text { Maler R.t. } \\
\text { Maier S. }\end{array}$ & & & DGKJ-SY-RE3-3 \\
\hline Libuda L. & DGKJ-SY-KE-3, & $\begin{array}{l}\text { Maler S. } \\
\text { Mailand P. }\end{array}$ & $\begin{array}{l}\text { DGKJ-SY-JMI-1 } \\
\text { DGKJ-PO-O2-11, }\end{array}$ & Mendler M. R. & DGKJ-PO-I2-1 \\
\hline & DGKJ-SY-KE-4 & & DGKJ-PO-02-12 & Mengel E. & DGKJ-PO-S-10, \\
\hline Lichtenauer N. & DGSPJ-PO-1 & & DGKJ-PO-12-11 & & DGKJ-PO-S-2, \\
\hline Liebetrau K. & DGKJ-PO-V1-3 & Makowski C. & DGKJ-PO-I1-14 & & DGKJ-PO-S-3, \\
\hline Liebl B. & DGSPJ-PO-2 & Mall M. A. & DGKJ-PO-P-1 & & DGKJ-PO-S-4, \\
\hline Lieftüchter V. & DGKJ-PO-01-4 & Mall V. & DGSPJ-FV-1. & & DGSPJ-PO-6 \\
\hline Liese J. G. & DGKJ-PO-J1-3, & & $\begin{array}{l}\text { DUSPJ-FV-I, } \\
\text { DGSPJ-PO-4 }\end{array}$ & & DGKJ-PO-S-5 \\
\hline & DGKJ-PO-J1-8, & & $\begin{array}{l}\text { DGSPJ-PO-4, } \\
\text { DGSPJ-PO-9 }\end{array}$ & Menke T. & DGKJ-PO-V2-4 \\
\hline & DGKJ-PO-J1-9, & & DGKJ-PO-EG-4 & Menrath I. & DGSPJ-PO-8, \\
\hline & DGKJ-PO-J2-4, & Malzahn J. & DGKJ-SY-OE-5 & & DGSPJ-PO-10, \\
\hline & DGKJ-PO-J2-5, & Manan A. & DGKJ-PO-I2-7 & & DGSPJ-PO-11 \\
\hline & API-SY3-4, & Mangold A. & DGKJ-PO-N1-3 & Mentzel H.J. & DGKJ-SY-KS-2, \\
\hline & API-SY3-5, & Mannhardt- & & & DGKJ-SY-NN-3 \\
\hline & DGKJ-PO-J2-8, & Laakmann W. & DGKJ-PO-J2-3, & Merkle B. & DGKJ-PO-V3-6 \\
\hline & DGKJ-PO-S-12, & & DGKJ-PO-V2-5, & Mertz D. & DGKJ-PO-I2-11 \\
\hline & DGKJ-SY-I5-3 & & DGKJ-PO-V2-6 & Mesch C. & DGKJ-SY-KE-4 \\
\hline
\end{tabular}




\begin{tabular}{|c|c|c|c|c|c|}
\hline Messing M. & DGKJ-PO-I2-9 & Naumann R. & API-SY5-4 & Opp J. & DGKJ-SY-NP2-1 \\
\hline Metzger R. & DGKCH-PO-2 & Naundorf S. & API-SY1-2 & Oppelt P. G. & DGKJ-SY-A3-2, \\
\hline Meyburg J. & DGKJ-SY-L-1 & Ndayizeye D. & DGKJ-SY-TP-4 & & DGKJ-SY-G-2 \\
\hline Meyer A. & DGKCH-SY-TS-5 & Neid M. & DGKCH-PO-5 & Orellana C. & API-PO-3 \\
\hline Meyer C. & DGKJ-PO-I2-11 & Nennstiel-Ratzel U. & DGKJ-PO-I1-2, & Orlikowsky T. & API-PO-15, \\
\hline Meyer S. & $\begin{array}{l}\text { DGKJ-PO-P-5, } \\
\text { DGKJ-PO-V2-10 }\end{array}$ & & $\begin{array}{l}\text { DGKJ-PO-I2-12, } \\
\text { DGKJ-PO-LW-3, }\end{array}$ & & $\begin{array}{l}\text { DGKJ-PO-I1-12, } \\
\text { DGKJ-PO-S-9 }\end{array}$ \\
\hline Meyer-Lenz J. & DGKJ-PO-K-1 & & DGSPJ-PO-2 & Ost M. & API-SY3-5 \\
\hline Mezger M. & API-SY3-5 & Nentwich H.-J. & DGKJ-SY-PV1-1 & Osten P. & DGKJ-SY-H1-1 \\
\hline Michaelis M. & DGKJ-PO-V3-8 & Nettesheim S. & DGKJ-PO-S-8 & Ott R. & API-PO-2 \\
\hline Michna D. & DGKJ-PO-D-4, & Neu A. & DGKJ-SY-DB2-3 & Otten J. & DGKJ-PO-V1-4 \\
\hline & DGKJ-PO-EG-2, & Neubauer G. & DGKJ-SY-JG-2 & Özcan S. & DGKJ-PO-J2-6 \\
\hline & DGKJ-PO-O2-1 & Neubersch C. & DGKJ-PO-EG-10 & Ozdemir M.A. & API-SY5-2 \\
\hline Milde T. & DGKJ-PO-01-10 & Neubert A. & DGKJ-PO-M-5, & & \\
\hline Mildenberger $\mathrm{E}$. & DGKJ-PO-I1-9 & & DGKJ-PO-M-6, & & \\
\hline Mir T. & DGKJ-PO-K-1 & & DGKJ-PO-M-7, & $\mathbf{P}$ & \\
\hline Mirza J. & DGKJ-SY-PS2-2, & & DGKJ-PO-V1-11 & Pagenstecher A. & DGKJ-PO-N1-7 \\
\hline & DGSPJ-SY-SG-1 & Neudorf U. & API-PO-12, & Palermo S. & DGKCH-FV-6, \\
\hline Mittelbronn M. & DGKCH-SY-IM-3 & & API-SY5-5 & & DGKCH-FV-7 \\
\hline Mitter D. & DGKJ-PO-V3-9 & Neuloh G. & DGKJ-PO-N2-13 & Palta M. & DGKCH-SY-IM-6 \\
\hline Modlich U. & API-SY1-2 & Neumann $\mathrm{H}$. & DGKJ-PO-N1-14 & Pannicke U. & API-SY4-4 \\
\hline Moens L.N. & API-SY5-2 & Neurath $\mathrm{H}$. & DGKJ-PO-M-1 & Papuc S. M. & API-PO-3 \\
\hline Mohnike K. & DGKJ-PO-I2-12 & Ngeow J. & DGKJ-PO-V1-8 & Parente Matschke B. & DGKJ-PO-V1-6 \\
\hline Mohr V. & API-PO-6 & Nguyen $\mathrm{H}$. & DGKJ-PO-I1-12 & Pargac K.-N. & DGKJ-PO-N1-10 \\
\hline Möller J. & API-PO-11 & Niederstadt T. & DGKJ-PO-N2-2 & Patiroglu T. & API-SY5-2 \\
\hline Mönchmeier B. & DGKJ-PO-EG-1 & Niehues T. & API-PO-4, & Paul T. & DGKJ-PO-I2-13, \\
\hline Mönkemöller K. & $\begin{array}{l}\text { DGKJ-SY-PS2-2, } \\
\text { DGSPJ-PO-10, } \\
\text { DGSPJ-SY-SG-1 }\end{array}$ & & $\begin{array}{l}\text { API-PO-5, } \\
\text { API-PO-12, } \\
\text { API-SY4-2, }\end{array}$ & & $\begin{array}{l}\text { DGKJ-PO-K-4, } \\
\text { DGKJ-PO-K-11, } \\
\text { DGKJ-PO-N1-5 }\end{array}$ \\
\hline Moog U. & DGKJ-SY-HG-1 & & API-SY4-3, & Paulsen J. & DGKJ-PO-K-9 \\
\hline Moore S. A. & DGKJ-PO-N1-8 & & API-SY5-5, DGKJ-PO- & Paulus F. W. & DGSPJ-SY-NM-1 \\
\hline Morbach $\mathrm{H}$. & API-SY3-4 & & EG-3, DGKJ-PO-01-2, & Paulussen M. & DGKJ-PO-V2-4 \\
\hline Morlock G. & DGKJ-PO-LW-3 & & DGKJ-PO-01-5, & Peitz J. & DGKJ-SY-NN-3 \\
\hline Morris-Rosendahl D. & DGKJ-PO-N1-7 & & DGKJ-PO-01-7, & Pekrun A. W. & DGKJ-PO-01-10 \\
\hline Moser J. & DGKJ-PO-J3-5 & & DGKJ-PO-V2-9, & Pereira B. & DGSPJ-PO-4 \\
\hline Moss A. & DGKJ-SY-EN3-1 & & DGKJ-SY-13-1 & Perez-Becker R. & API-SY4-3, \\
\hline Mühlenberg R. L. K. & DGKJ-SY-EN2-1 & Nilsson M. & API-SY5-2 & & DGKCH-FV-9 \\
\hline Mühlhausen C. & DGKJ-PO-S-6 & Nissen M. & DGKCH-PO-4 & Pernice W. & DGKJ-PO-V3-9 \\
\hline Muise A. M. & API-SY4-5 & Nkwouano V. & DGKJ-PO-J2-2 & Pessler F. & API-SY5-4 \\
\hline Müksch B. & DGKJ-SY-PS2-2 & Nolte A. & DGKJ-SY-HN-1 & Peterli J. & DGKJ-PO-N1-4 \\
\hline Müllauer L. & API-SY6-2 & Nolte S. H. & DGKJ-SY-PV1-3 & Petersen B. & DGKJ-PO-N1-7 \\
\hline Müller C. & DGKJ-PO-02-10, & Nolte-Buchholtz S. & DGKJ-PO-V2-1, & Petersen C. & DGKCH-FV-4 \\
\hline & DGKJ-PO-02-11, & & DGSPJ-SY-SP-4 & Petrasch M. & DGKJ-PO-12-3 \\
\hline & DGKJ-PO-O2-12 & Noppens R. & DGKCH-FV-3 & Pfeifer D. & API-SY5-2 \\
\hline Müller G. & DGKJ-PO-K-1, & Noss J. & DGKJ-PO-G-2 & Pfeifer J. & DGKJ-PO-K-2 \\
\hline & DGKJ-PO-K-12 & Notheis G. & DGKJ-PO-P-8 & Pfeiffer M. & API-SY3-5 \\
\hline Müller J. & API-SY5-5, DGKJ- & Nurnberg $\mathrm{P}$. & DGKJ-PO-N1-7 & Pfeilstetter J. & DGKJ-PO-N1-10 \\
\hline & $\mathrm{PO}-\mathrm{U}-4$ & Nüsken K.-D. & DGKJ-SY-NN-2, & Philipp C. M. & DGKJ-PO-D-1, \\
\hline Müller K. & DGKJ-SY-KE-3 & & DGKJ-SY-NN-3 & & DGKJ-PO-D-3 \\
\hline Müller U. & DGKJ-PO-D-1, & Nüßlein T. & DGKCH-PO-3 & Picard C. & API-SY2-2 \\
\hline & DGKJ-PO-D-3 & & & Pickl W.F. & API-SY6-2 \\
\hline Müller W. & DGKJ-PO-E-2 & & & Pieper K. & API-SY6-4 \\
\hline Müller-Bühl K. & DGKJ-PO-I1-1 & 0 & & Pietruschka S. A. & DGKJ-PO-V3-12 \\
\hline Müller-Godeffroy E. & DGSPJ-FV-2, & Oberhoffer R. & DGKJ-PO-V3-1, & Pigulla J. & DGKJ-PO-N2-10 \\
\hline & DGSPJ-PO-10 & & DGSPJ-SY-FR-2 & Pilar Botella M. & API-PO-3 \\
\hline Mundt D. & DGKJ-PO-M-2 & Obermayr F. & DGKCH-SY-IM-4 & Pilic D. & DGKJ-PO-G-4, \\
\hline Muntoni F. & DGKJ-PO-N1-8 & Oehme A.-K. & DGKJ-PO-M-7 & & DGKJ-SY-GE-1 \\
\hline & & Offenbecher S. & DGKCH-SY-TS-5 & Pillekamp F. & DGKJ-SY-L-2 \\
\hline & & Oh J. & DGKJ-PO-O2-3, & Piroth W. & DGKJ-PO-J3-8 \\
\hline $\mathbf{N}$ & & & DGKJ-SY-N2-3 & Pittrow D. & API-PO-13, \\
\hline Nagy P. & DGKJ-PO-N2-9 & Okada S. & API-PO-11 & & DGKJ-PO-M-4, \\
\hline Najem S. & DGKJ-PO-01-6 & Olbrich A. & DGKJ-PO-I1-4 & & DGKJ-PO-V3-2 \\
\hline Namboya F. & DGKJ-PO-J3-1 & Omran H. & DGKJ-PO-N1-2, & Placzek R. & DGKJ-PO-V1-1 \\
\hline Narayanan U. & DGSPJ-FV-1, DGSPJ- & & DGKJ-PO-N1-9, & Plecko B. & DGKJ-PO-I1-14 \\
\hline & $\mathrm{PO}-4$ & & DGKJ-PO-N2-5 & Poeschl J. & DGKJ-PO-I1-4 \\
\hline Nathrath M. & API-SY4-5 & Opgen-Rhein B. & DGKJ-PO-K-7 & Poetke M. & DGKJ-PO-D-1, \\
\hline & & Opitz D. & DGKJ-PO-S-14 & & DGKJ-PO-D-3 \\
\hline
\end{tabular}




\section{Autorenindex}

\begin{tabular}{|c|c|c|c|c|c|}
\hline Pogorzelski D. & DGKJ-PO-I2-4 & Reinshagen $\mathrm{K}$. & DGKJ-PO-01-6 & Rösen-Wolff A. & API-SY5-4 \\
\hline Pohl M. & DGKJ-PO-U-4 & Reinstadler P. & DGKCH-FV-6 & Rossi R. & API-PO-3, \\
\hline Pohlenz J. & DGKJ-PO-E-11 & Reiser M. & API-PO-13, & & DGKJ-PO-I1-1 \\
\hline Pollach G. & DGKJ-PO-J3-1, & & DGKJ-PO-M-4 & Rößlein A. & DGKJ-PO-I1-6 \\
\hline & $\begin{array}{l}\text { DGKJ-PO-J3-2, } \\
\text { DGKJ-PO-J3-3 }\end{array}$ & $\begin{array}{l}\text { Rellensmann G. } \\
\text { Remer T. }\end{array}$ & $\begin{array}{l}\text { DGKJ-PO-K-5 } \\
\text { DGKJ-SY-KE-1 }\end{array}$ & Rostasy K. & $\begin{array}{l}\text { DGKJ-PO-N2-1, } \\
\text { DGKJ-SY-NP1-3 }\end{array}$ \\
\hline Pollak A. & API-SY6-2 & Renneberg A. & DGKJ-PO-J2-6 & Rothe K. & DGKCH-SY-TR-2, \\
\hline Poplawska K. & DGKJ-PO-I1-10 & Renner G. & DGSPJ-PO-1 & & DGKCH-SY-TR-7 \\
\hline Poppert S. & DGKJ-PO-J1-7 & Renner T. & API-SY3-6 & Rother A.-K. & DGKJ-PO-P-4 \\
\hline Posovszky C. & DGKJ-PO-G-1, & Rensing-Ehl A. & API-SY2-3, & Ruckdeschel K. & DGKJ-PO-J2-7 \\
\hline & DGKJ-PO-G-9 & & API-SY2-4, & Rücker P. & DGKJ-SY-A3-4 \\
\hline Powrie F. & DGKJ-PO-V1-8 & & API-SY6-3, & Ruef $P$. & DGKJ-PO-EG-5, \\
\hline Preece M. A. & DGKJ-PO-I1-14 & & API-SY6-4 & & DGKJ-PO-I2-3; \\
\hline Prengemann N. K. & API-PO-2, & Rentzsch A. & DGKJ-PO-K-2 & & DGKJ-PO-J1-2 \\
\hline & API-SY3-3, & Reschke M. & DGKJ-PO-N1-13 & Runge B. & DGKJ-SY-15-3 \\
\hline & API-SY6-2 & Retter M. & DGKJ-PO-I1-11 & Runz H. & DGKJ-PO-S-4 \\
\hline Prifert C. & DGKJ-PO-J2-4, & Reus $\mathrm{E}$. & DGKJ-PO-LW-6 & Ruschewski W. & DGKJ-PO-K-4 \\
\hline & DGKJ-SY-I5-3 & Reuss A. & DGKJ-SY-I2-3 & Russo A. & DGKCH-PO-6 \\
\hline Primke R. & DGKJ-PO-J3-8 & Reutter $\mathrm{H}$. & DGKCH-SY-IM-6 & & \\
\hline Prokisch H. & DGKJ-PO-I1-14 & Rezaei N. & API-PO-8, API-PO-14 & & \\
\hline Proprentner M. & DGKJ-PO-EG-5 & Richter A. & DGKJ-PO-02-3 & $\mathbf{S}$ & \\
\hline Puchalka J. & API-SY3-2, & Richter M. & DGKJ-PO-V2-1 & Saadi S. & \\
\hline & API-SY4-5 & Richterich A. & DGKJ-SY-LS-4, & $\begin{array}{l}\text { Saadi S. } \\
\text { Sabir H. }\end{array}$ & $\begin{array}{l}\text { DGKJ-PU-G-2 } \\
\text { DGKJ-PO-I2-5 }\end{array}$ \\
\hline Puel A. & API-PO-11 & & DGSPJ-SY-NM-4 & Sadeghi K. & API-PO-16 \\
\hline Pulzer F. & DGKJ-PO-V3-9 & Rickert A.-T. & DGKJ-PO-EG-6 & Sadowski G. & DGSPJ-PO-3 \\
\hline Pütter C. & API-PO-12 & Rieber N. & API-PO-7, API-SY3-5 & Saft C. & DGSPJ-PO-16 \\
\hline Pütz W. & DGKCH-PO-3 & Riedel F. & DGKJ-SY-OE-2 & Salqin $B$. & DGKJ-SY-DB1-4, \\
\hline Pycha A. & DGKCH-FV-6, & Rieger M. A. & DGKJ-PO-V3-8 & & DGKJ-SY-SW1-4 \\
\hline & DGKCH-FV-7 & Rieger-Fackeldey E. & DGKJ-PO-K-5 & Salzer E. & API-PO-2. \\
\hline Pyper A. & DGKJ-PO-V2-1 & Rietschel C. & API-PO-12, & & API-SY6-2 \\
\hline & & & API-SY5-5 & Salzer U. & API-SY2-3 \\
\hline & & Ritzmann I. & DGKJ-SY-H1-3 & Salzgeber K. & DGKJ-PO-E-3 \\
\hline $\mathbf{Q}$ & & Rizzi M. & API-SY6-4 & Sandner B. & DGKJ-PO-M-8 \\
\hline Quader J. & DGKJ-PO-E-7 & Robinson B. & DGKJ-PO-V2-5 & Santer R. & DGKJ-PO-S-8 \\
\hline & & Rochow N. & DGKJ-PO-I1-4, & Santilli G. & API-SY1-4 \\
\hline & & & DGKJ-PO-I2-4, & Santos M. & DGKJ-PO-P-2 \\
\hline $\mathbf{R}$ & & & DGKJ-PO-I2-6, & Santos-Valente E. & API-PO-2, \\
\hline Racek T. & API-SY3-2, API-SY4-5 & & DGKJ-PO-I2-7, & & API-SY6-2 \\
\hline Radke D. & DGKJ-PO-I2-4 & & DGKJ-PO-I2-8 & Santra S. & DGKJ-PO-I1-14 \\
\hline Radke I. & DGKJ-PO-N2-12 & Rodeck B. & API-SY2-3, & Sarganas G. & DGKJ-PO-M-6 \\
\hline Radke M. & DGKJ-PO-EG-7 & & DGKJ-PO-G-1 & Sassen R. & DGKJ-PO-M-2 \\
\hline Radtke E. & DGKJ-PO-V3-7 & Roers A. & API-SY5-4 & Sassi A. & API-SY5-2 \\
\hline Rahner N. & DGKJ-PO-N1-6 & Roesler J. & API-PO-11, API-SY5-4, & Schaaff F. & DGKJ-SY-P2-1 \\
\hline Raile K. & DGKJ-PO-E-8 & & API-SY6-4 & Schäfer I. & API-SY3-5 \\
\hline Raja P. & DGKJ-PO-I1-4 & Rogge P. & DGKCH-SY-JK-2, & Schäffer A.A. & API-SY5-2 \\
\hline Ramseger R. & DGKJ-PO-E-4 & & DGKCH-SY-JK-5b & Schaper J. & DGKJ-PO-G-3 \\
\hline Rascher W. & DGKJ-PO-M-5, & Rohlfs A.-K. & DGKJ-SY-HN-1 & Schaper K. & DGKJ-PO-G-1 \\
\hline & DGKJ-PO-M-6, & Rohrbach M. & DGKJ-PO-I1-14 & Schara U. & DGKJ-PO-N1-13, \\
\hline & DGKJ-PO-M-7, & Rohrer T. & DGKJ-PO-J1-10, & & DGKJ-SY-RE4-3 \\
\hline & DGKJ-PO-V1-11, & & DGKJ-SY-EN1-4 & Schatterny J. & DGKJ-PO-P-1 \\
\hline & DGKJ-SY-P1-4 & Rohrschneider W. K. & DGKCH-SY-VU-2 & Schattling S. & DGKJ-PO-J1-5, \\
\hline Rashed A. N. & DGKJ-PO-M-7 & Rolinski B. & DGKJ-PO-I1-14 & & DGKJ-PO-J3-4 \\
\hline Ratajczak K. & DGKJ-PO-J2-1 & Roll C. & DGKCH-PO-7 & Schatton D. & DGKJ-SY-HN-3 \\
\hline Rath A. & DGKJ-PO-I1-7 & Rolle U. & DGKCH-SY-IM-3 & Scheewe S. & DGKJ-PO-E-10 \\
\hline Rauch A. & DGKJ-PO-N1-5 & Rose M. A. & DGKJ-PO-J1-3, & Scheffler N. & DGKJ-PO-D-2 \\
\hline Ravindran E. & API-PO-1 & & DGKJ-PO-J2-5 & Schenk J.P. & DGKJ-PO-01-10 \\
\hline Rebsamen M. & API-SY6-3 & Rose M. & API-SY1-2 & Schenk J.-P. & DGKJ-PO-02-9 \\
\hline Rehn M. & DGKJ-PO-I2-2 & Rosello M. & API-PO-3 & Schepler P. & DGSPJ-PO-12 \\
\hline Reich K. & DGKJ-PO-D-6 & Rosen A. & DGKJ-PO-EG-8 & Schibli S. & API-SY2-3 \\
\hline Reichardt J. & DGKJ-PO-V2-12 & Rosenbauer J. & DGKJ-PO-E-9, & Schiller M. & DGKJ-PO-J1-10 \\
\hline Reichenbach J. & API-SY1-4 & & DGKJ-SY-EP1-1 & Schilling S. & DGKJ-PO-V3-9 \\
\hline Reifferscheid P. & DGKCH-SY-TS-4 & Rosenbaum D. & DGKJ-PO-02-10, & Schindler D. & API-PO-1, \\
\hline Reincke M. & DGSPJ-PO-14 & & DGKJ-PO-02-11, & & API-SY4-2 \\
\hline Reinehr T. & DGKJ-SY-A1-2, & & DGKJ-PO-02-12 & Schlaud M. & DGKJ-SY-EP2-2 \\
\hline & DGKJ-SY-DB1-2 & Rosenbaum I. & DGKJ-PO-N1-3 & Schlecht M. & DGKJ-PO-I1-9 \\
\hline Reinke J. & DGSPJ-PO-6 & Rosenecker J. & $\begin{array}{l}\text { DGKJ-PO-P-8, } \\
\text { DGSPJ-SY-FR-1 }\end{array}$ & Schlegelberger B. & API-SY1-2 \\
\hline
\end{tabular}




\begin{tabular}{|c|c|c|c|c|c|}
\hline Schlune A. & $\begin{array}{l}\text { DGKJ-PO-U-1, } \\
\text { DGKJ-SY-A2-2 }\end{array}$ & Schuster F. & $\begin{array}{l}\text { API-SY4-2, } \\
\text { DGKJ-PO-O2-2, }\end{array}$ & Sinnig M. & $\begin{array}{l}\text { DGKCH-SY-TR-6, } \\
\text { DGKJ-PO-V2-3 }\end{array}$ \\
\hline Schmid G. & DGKJ-PO-V1-7 & & DGKJ-PO-02-6 & Sipurzynski J. & API-PO-10 \\
\hline Schmid M.B. & DGKJ-SY-NE1-2 & Schuster K. & DGKJ-PO-V2-8 & Sirin S. & DGKJ-PO-I2-14 \\
\hline Schmidt D. & $\begin{array}{l}\text { DGKCH-SY-IM-6, } \\
\text { DGKCH-SY-TS-4 }\end{array}$ & Schütz C. & $\begin{array}{l}\text { API-PO-6, } \\
\text { API-SY1-3 }\end{array}$ & Skrundz M. & $\begin{array}{l}\text { DGSPJ-FV-3, } \\
\text { DGSPJ-FV-4 }\end{array}$ \\
\hline Schmidt I. V. & DGKJ-PO-G-8 & Schwab K. O. & DGKJ-SY-A2-1 & Smith C.I.E. & API-SY5-2 \\
\hline Schmidt M. & API-SY1-2 & Schwanz T. & DGKJ-PO-I1-9 & Smitka M. & DGKJ-PO-S-2 \\
\hline Schmidt-Choudhury A. & $\begin{array}{l}\text { DGKJ-PO-G-4, } \\
\text { DGKJ-SY-GE-1 }\end{array}$ & Schwarz K. & $\begin{array}{l}\text { API-SY2-3, API-SY3-4, } \\
\text { API-SY4-2, API-SY4-4 }\end{array}$ & $\begin{array}{l}\text { Snapper S. B. } \\
\text { Snider D. }\end{array}$ & $\begin{array}{l}\text { API-SY4-5 } \\
\text { DGKJ-PO-I2-6 }\end{array}$ \\
\hline Schmiedeke E. & $\begin{array}{l}\text { DGKCH-SY-IM-6, } \\
\text { DGKCH-SY-TS-4 }\end{array}$ & Schwarz P. & $\begin{array}{l}\text { API-SY6-4 } \\
\text { DGKJ-PO-K-2 }\end{array}$ & Sonnenschein A. & $\begin{array}{l}\text { DGKJ-PO-J2-3, } \\
\text { DGKJ-PO-V2-5, }\end{array}$ \\
\hline Schnabel D. & $\begin{array}{l}\text { DGKJ-SY-EN3-1, } \\
\text { DGKJ-SY-EN3-3 }\end{array}$ & $\begin{array}{l}\text { Schwarzer A. } \\
\text { Schwarzer N. }\end{array}$ & $\begin{array}{l}\text { API-SY1-2 } \\
\text { DGKCH-SY-IM-6, }\end{array}$ & Sörqvist E.F. & $\begin{array}{l}\text { DGKJ-PO-V2-6 } \\
\text { API-SY5-2 }\end{array}$ \\
\hline Schneider A. & DGKCH-SY-TR-2 & & DGKCH-SY-TS-4 & Sosada U. & DGSPJ-SY-NL-3 \\
\hline Schneider D. & $\begin{array}{l}\text { API-SY4-2, } \\
\text { DGKJ-PO-E-3 }\end{array}$ & Schweiger B. & $\begin{array}{l}\text { DGKJ-PO-I2-14, } \\
\text { DGKJ-PO-N1-13 }\end{array}$ & $\begin{array}{l}\text { Soutullo C. } \\
\text { Soykök S. }\end{array}$ & $\begin{array}{l}\text { DGKJ-PO-N2-8 } \\
\text { DGSPJ-PO-9 }\end{array}$ \\
\hline Schneider G. & DGKJ-PO-O2-9 & Schwerin-Nagel A. & API-PO-16 & Speckmann C. & API-PO-5, \\
\hline Schneider $\mathrm{H}$. & DGKJ-PO-K-11 & Schwerk N. & DGKJ-PO-P-4 & & API-SY2-3, \\
\hline Schneider M. & DGKJ-SY-PD1-2 & Schwind M. & DGKJ-PO-I1-10 & & API-SY4-2, \\
\hline Schneider T. & DGSPJ-PO-2 & Schwindt W. & DGKJ-PO-N2-5, & & API-SY6-3, \\
\hline Schnekenburger $\mathrm{F}$. & DGKCH-GÖR-4 & & DGKJ-PO-N2-6 & & API-SY6-4, \\
\hline Schoberer M. & $\begin{array}{l}\text { DGKJ-PO-I1-12, } \\
\text { DGKJ-PO-S-9 }\end{array}$ & $\begin{array}{l}\text { Schwinger W. } \\
\text { Seeger K. }\end{array}$ & $\begin{array}{l}\text { API-PO-10, API-PO-16 } \\
\text { DGKJ-PO-J1-9 }\end{array}$ & Sperl W. & $\begin{array}{l}\text { DGKJ-PO-V2-8 } \\
\text { DGKJ-PO-I1-14 }\end{array}$ \\
\hline Schoen C. & $\begin{array}{l}\text { DGKJ-PO-J1-3, } \\
\text { DGKJ-PO-J2-5 }\end{array}$ & $\begin{array}{l}\text { Seegräber M. } \\
\text { Seeliger S. }\end{array}$ & $\begin{array}{l}\text { DGKJ-PO-S-2 } \\
\text { API-SY3-6, }\end{array}$ & Spiekerkötter U. & $\begin{array}{l}\text { DGKJ-PO-S-1, } \\
\text { DGKJ-PO-U-1 }\end{array}$ \\
\hline Scholsching J. & $\begin{array}{l}\text { DGKCH-FV-3, } \\
\text { DGKCH-PO-6 }\end{array}$ & & $\begin{array}{l}\text { DGKJ-PO-12-13, } \\
\text { DGKJ-PO-V3-6 }\end{array}$ & $\begin{array}{l}\text { Spindler T. } \\
\text { Spix C. }\end{array}$ & $\begin{array}{l}\text { DGKJ-SY-PA1-3 } \\
\text { DGKJ-SY-EP2-3 }\end{array}$ \\
\hline Schöndorf D. & DGKJ-PO-O2-9 & Seger R. A. & DGKJ-SY-PI1-3, & Spomer N. & DGKJ-PO-M-3 \\
\hline Schönegger A. & API-PO-2 & & API-SY1-4 & Spönemann N. & DGKJ-PO-N1-13 \\
\hline Schoner K. & DGKJ-PO-N1-7 & Segerer $\mathrm{F}$. & DGKJ-PO-J1-3, & Spranger S. & DGKJ-PO-I1-14, \\
\hline Schönlaub J. & DGKJ-PO-J2-8 & & DGKJ-PO-J2-5 & & DGKJ-SY-HG-3 \\
\hline Schoppe M. & DGKJ-PO-G-3 & Seibt A. & DGKJ-PO-J1-4, & Springer J. & DGKJ-PO-01-2, \\
\hline \multirow[t]{7}{*}{ Schramm D. } & DGKJ-PO-J1-4, & & DGKJ-PO-J2-2, & & DGKJ-PO-V2-9 \\
\hline & DGKJ-PO-J2-2, & & DGKJ-PO-J3-6 & Springer S. & DGSPJ-SY-FR-3 \\
\hline & DGKJ-PO-P-2, & Seidel M.G. & API-PO-10, API-PO-16 & Spyridonos T. & DGKJ-PO-V2-4 \\
\hline & DGKJ-PO-P-3, & & API-SY4-3, API-SY6-2 & Squires L. A. & DGKJ-PO-N2-8 \\
\hline & DGKJ-PO-P-9, & Seidl M. & API-SY6-4 & Staab D. & DGSPJ-PO-8 \\
\hline & DGKJ-SY-HN-4, & Seidl T. & DGKJ-PO-V1-1 & Staatz G. & DGKCH-FV-2, \\
\hline & DGKJ-SY-PN2-2 & Seiffert P. & DGKCH-FV-9, & & DGKCH-PO-6 \\
\hline Schranz D. & DGKJ-PO-K-3 & & DGKJ-PO-E-8, & Stachow R. & DGKJ-PO-E-10 \\
\hline Schreiber M. & DGKJ-PO-LW-5 & & DGKJ-PO-02-5 & Stadler P. & DGKJ-PO-01-3 \\
\hline Schreiver C. & DGKJ-PO-U-2 & Seigel S. & DGKJ-PO-I1-4 & Stahl-Pehe A. & DGKJ-PO-E-9 \\
\hline Schrey-Dern D. & DGSPJ-FV-5 & Seitz K.-H. & DGKJ-PO-S-14 & Stammschulte T. & DGKJ-SY-P1-3 \\
\hline Schröder L. & DGKJ-PO-J1-6 & Selvaganapathy P. R. & DGKJ-PO-I2-7 & Stangel M. & API-PO-13, \\
\hline Schröder M. & DGKJ-SY-ÄO-2 & Selzer G. & DGKJ-FS-NN-10 & & DGKJ-PO-M-4 \\
\hline Schröder S. & $\begin{array}{l}\text { DGSPJ-FV-1, } \\
\text { DGSPJ-PO-4 }\end{array}$ & $\begin{array}{l}\text { Selzer L. M. } \\
\text { Seubert F. }\end{array}$ & $\begin{array}{l}\text { DGKJ-PO-N1-14 } \\
\text { API-PO-15 }\end{array}$ & Staude $\mathrm{H}$. & $\begin{array}{l}\text { DGKJ-PO-I1-13, } \\
\text { DGKJ-PO-U-2, }\end{array}$ \\
\hline Schroeder N. & DGKJ-PO-V2-10 & Sewry C. A. & DGKJ-PO-N1-8 & Stauss $\mathrm{H}$. & API-SY5-2 \\
\hline \multirow[t]{2}{*}{ Schroers E. M. } & DGKJ-PO-E-7, & Seyfarth J. & DGKJ-PO-J1-4, & Stedtler U. & DGKJ-PO-I1-7 \\
\hline & DGKJ-PO-LW-4 & & DGKJ-PO-J2-2, & Stege D. & DGKJ-PO-K-5, \\
\hline Schubert-Bast S. & $\begin{array}{l}\text { DGKJ-PO-M-2 } \\
\text { DGKI-PO-N1-13 }\end{array}$ & & $\begin{array}{l}\text { DGKJ-PO-J3-6 } \\
\text { DGKJ-SY-TP-4 }\end{array}$ & StehrF & $\begin{array}{l}\text { DGKJ-PO-N2-2 } \\
\text { DGKI-SY-I S-5 }\end{array}$ \\
\hline Schulte J. & $\begin{array}{l}\text { DGKJ-PO-N1-13, } \\
\text { DGKJ-PO-01-8 }\end{array}$ & $\begin{array}{l}\text { Shakima F. } \\
\text { Sic H. }\end{array}$ & $\begin{array}{l}\text { DGKJ-SY-TP-4 } \\
\text { API-SY6-4 }\end{array}$ & $\begin{array}{l}\text { Stehr F. } \\
\text { Steidle G. }\end{array}$ & $\begin{array}{l}\text { DGKJ-SY-LS-5 } \\
\text { DGKJ-PO-U-3 }\end{array}$ \\
\hline Schulz A. & $\begin{array}{l}\text { API-PO-6, API-SY1-3, } \\
\text { API-SY4-4 }\end{array}$ & $\begin{array}{l}\text { Siebert R. } \\
\text { Siegmann H.J. }\end{array}$ & $\begin{array}{l}\text { DGKJ-PO-01-3 } \\
\text { DGKCH-SY-TR-9 }\end{array}$ & Steindor M. & $\begin{array}{l}\text { DGKJ-PO-J2-2, } \\
\text { DGKJ-PO-P-2, }\end{array}$ \\
\hline Schulze C. & DGKJ-SY-A3-2 & Siepermann K. & API-PO-5, API-SY4-3 & & DGKJ-PO-P-3, \\
\hline \multirow[t]{2}{*}{ Schulze I. } & DGKJ-PO-V2-8, & Siepermann M. & DGKJ-PO-O2-2 & & DGKJ-PO-P-9 \\
\hline & DGKJ-SY-PI1-2 & Sievers $\mathrm{E}$. & DGKJ-SY-MI-1 & Steiß J.-O. & DGSPJ-PO-13 \\
\hline \multirow[t]{2}{*}{ Schum C. } & DGKJ-PO-D-5, & Sigler M. & DGKJ-PO-N1-5 & Stemple D. L. & DGKJ-PO-N1-8 \\
\hline & DGKJ-PO-J3-7 & Siler U. & API-SY1-4 & Stenzel M. & DGKJ-SY-KS-2 \\
\hline Schündeln M. & DGKJ-PO-02-1 & Simaite D. & DGKJ-PO-E-8 & Stepensky P. & API-SY2-2 \\
\hline Schündeln M. M. & DGKJ-PO-01-1 & Simon A. & DGKJ-SY-L-1, & Stevens E. & DGKJ-PO-N1-8 \\
\hline \multirow[t]{3}{*}{ Schuster A. } & DGKJ-PO-P-2, & & DGKJ-SY-L-5, & Stier B. J. M. & DGKJ-SY-JG-1, \\
\hline & DGKJ-PO-P-3, & & DGKJ-PO-J1-10 & & DGKJ-SY-JM-2 \\
\hline & DGKJ-PO-P-9 & $\begin{array}{l}\text { Singh A. } \\
\text { Sinha K. }\end{array}$ & $\begin{array}{l}\text { API-SY3-5 } \\
\text { DGKJ-PO-J3-8 }\end{array}$ & Stiller B. & DGKJ-SY-K-3 \\
\hline
\end{tabular}


Stimming M.

Stock L.

Stoltenberg I.

Storck M.

Strahm B.

Strehl K.

Streng A.

Strier U.

Stroh T.

Strohschein A.

Strothmann L.

Stuhrmann S.

Stummer W.

Stumpfe K.

Sturm M.

Sukiennik J.

Sulistyo Winarto J.

Suttorp M.

Szczepanski R.
DGKJ-SY-KE-4

DGKJ-PO-E-11

DGKJ-PO-M-3

DGKJ-SY-CP-4

API-SY2-3

API-PO-1,

API-SY3-4

DGKJ-PO-J1-3,

DGKJ-PO-J1-8,

DGKJ-PO-J1-9,

DGKJ-PO-J2-4,

DGKJ-PO-J2-5,

DGKJ-PO-J2-8,

DGKJ-SY-I5-3

DGKJ-PO-E-7

API-SY3-4

DGKJ-PO-P-7

DGKJ-PO-J2-3

DGKJ-PO-I1-11

DGKJ-PO-N2-5

DGKJ-PO-S-2

DGKJ-PO-S-1

DGKJ-PO-EG-10

DGKJ-PO-P-6,

DGKJ-PO-S-7

DGKJ-PO-02-4,

DGKJ-PO-02-7

DGSPJ-PO-8,

DGSPJ-PO-10,

DGSPJ-PO-11

\section{T}

Tannert A.

Tanrikulu L.

Taylor R. W.

Teig N.

Tejada Minguez M. I.

Temming $\mathrm{P}$.

Tenbrock K.

Terhardt M.

Thabane L.

Thamer A.

Thiel C.

Thiel K.

Thiel M.

Thiele M.

Thielemann F. D. M.

Thiels C.

Thimm E.

Thomas V.

Thome U.

Thomsen E. M.

Thor T.

Thoresen M.

Thränhardt R.

Thrasher A.

Thuresson M.

Thyen U.

Thyrian R. J.
DGKJ-PO-V1-7

DGKJ-PO-N2-13

DGKJ-PO-11-14

DGKCH-PO-7

API-PO-3

DGKJ-PO-V1-9

API-SY5-5

DGKJ-SY-IM2-1

DGKJ-PO-I1-4

DGKCH-SY-TR-6,

DGKJ-PO-V2-3

DGKJ-PO-K-12

DGKJ-PO-EG-3,

DGKJ-PO-EG-10

DGKJ-PO-K-9,

DGKJ-PO-V3-10

DGSPJ-PO-13

DGKJ-SY-O-3

DGKJ-PO-N1-14,

DGSPJ-PO-16

DGKJ-FS-SW-1

DGKJ-PO-G-2

DGKJ-PO-V3-9

DGSPJ-PO-10

DGKJ-PO-01-8

DGKJ-PO-I2-5

DGKCH-PO-4

API-SY1-4

DGKJ-PO-D-2

DGSPJ-FV-2,

DGSPJ-PO-8,

DGSPJ-PO-10,

DGSPJ-PO-11

DGKJ-PO-I1-3
Tiede $\mathrm{H}$.

Till $\mathrm{H}$.

Tintelnot K.

Tischendorf J.

Titgemeyer $C$.

Tittel J.

Toni I.

Tönshoff B.

Tooley J.

Torelli S.

Toschke C.

Trah J. M.

Trechow R.

Trenkel S.

Trenti E.

Trepels-Kottek S.

Triot A.

Troebs R.-B.

Trollmann R.

Trotter A.

Tschirner F.

Turial S.

Tutdibi E.

Twal R.

Tyman S.

\section{U}

Uche-Holub E. DGKJ-PO-G-6

Ueberberg $B$.

Uebler A.

Ufheil $\mathrm{H}$.

Uhlarik S.

Uhlig $\mathrm{H}$.

Uhrig S.

Unal E.

Unterwalder $\mathrm{N}$.

Urban C.

Urban P.

Ure B. M.

Urgatz B.

Utz N.

Uyanik G.

\section{V}

Valente $\mathrm{E}$.

Van Baalen A.

Van Bodegom C.

Van der Burg M.

Van der Linden M. P. G.

DGKJ-PO-I1-12
API-PO-16

DGKJ-PO-V3-2

DGKCH-SY-TS-5

DGKJ-PO-J2-9

DGKJ-PO-01-10

DGKJ-PO-N1-10

DGKJ-PO-M-5

DGKJ-SY-L-1

DGKJ-PO-12-5

DGKJ-PO-N1-8

DGKJ-PO-EG-4

DGKJ-PO-01-11

DGKJ-PO-02-8

DGKJ-PO-EG-7

DGKCH-FV-6,

DGKCH-FV-7

DGKJ-PO-I1-12,

DGKJ-PO-S-9

API-SY3-2

DGKCH-PO-7,

DGKCH-PO-4,

DGKCH-PO-5

DGKJ-PO-M-5

DGKJ-PO-02-8

DGKCH-PO-3

DGKJ-PO-I1-10,

DGKCH-FV-2,

DGKCH-FV-3,

DGKCH-PO-6

DGKJ-PO-LW-6

DGKJ-PO-N1-11

DGKJ-PO-G-4

DGKJ-PO-J1-5

DGKJ-PO-I1-9

API-SY2-3, API-SY2-4

DGKCH-SY-TR-9

API-SY4-5, DGKJ-

PO-V1-8

API-PO-16

API-SY3-2, API-SY5-2

API-SY3-6

API-PO-10, API-PO-16

DGKJ-PO-D-1,

DGKJ-PO-D-3

DGKCH-FV-5,

DGKCH-SY-TS-5,

DGKCH-FV-4

DGKJ-PO-J3-8

DGKJ-PO-N2-7

DGKJ-PO-N1-7

\section{DGKJ-PO-M-2}

DGKJ-PO-P-1

API-SY4-3, API-SY6-4

DGKJ-PO-J1-3,

DGKJ-PO-J2-5,

DGKJ-PO-V1-2,

DGKJ-PO-V1-3,

Van Esch $\mathrm{H}$.

Van Spaendonk R.

Van Zelm M.

Vaske B.

Veigel A.

Venghaus A.

Verfürth $A$.

Vermehren J.

Vieker S.

Vieth V.

Vogelberg C.

Vögele J.

Voit T.

Vokuhl C.

Volk A.

Volk T.

Völker A.

Vollrath G.

von Beckerath $\mathrm{N}$.

von Bernuth $\mathrm{H}$.

von Bismarck S.

von Kalle $C$.

von Kries $\mathrm{R}$.

von Osten $\mathrm{H}$.

von Schweinitz D.

von Stauffenberg M.

Voss-Heine I.

Vraetz T.

DGKJ-PO-V1-4,

DGKJ-SY-EP1-5

API-PO-3

DGKJ-PO-N2-11

API-SY4-3

DGKCH-SY-TS-5

DGKJ-PO-S-14

DGKJ-PO-U-1

DGKJ-PO-K-5,

DGKJ-PO-N2-2

DGKJ-PO-G-7

DGKJ-PO-M-2

DGKJ-PO-02-10

API-PO-11,

DGKJ-SY-PA1-4

DGKJ-SY-H-1

DGKJ-PO-N1-7,

DGKJ-PO-N1-8

DGKJ-PO-02-9

DGKJ-PO-N1-7

DGKJ-PO-LW-6

DGKJ-PO-G-4

DGKJ-PO-I1-8

DGKJ-PO-K-8

API-PO-1, API-PO-3,

API-SY2-3, API-SY3-4,

API-SY3-6

DGKJ-SY-KS-4

API-SY1-2

DGKJ-PO-S-8,

DGKJ-SY-EP1-5,

DGKJ-SY-EP2-1,

DGKJ-SY-15-2,

DGSPJ-FV-1,

DGSPJ-PO-1,

DGSPJ-PO-4

DGKJ-PO-U-2

DGKJ-PO-S-11

DGKJ-SY-PS2-4 


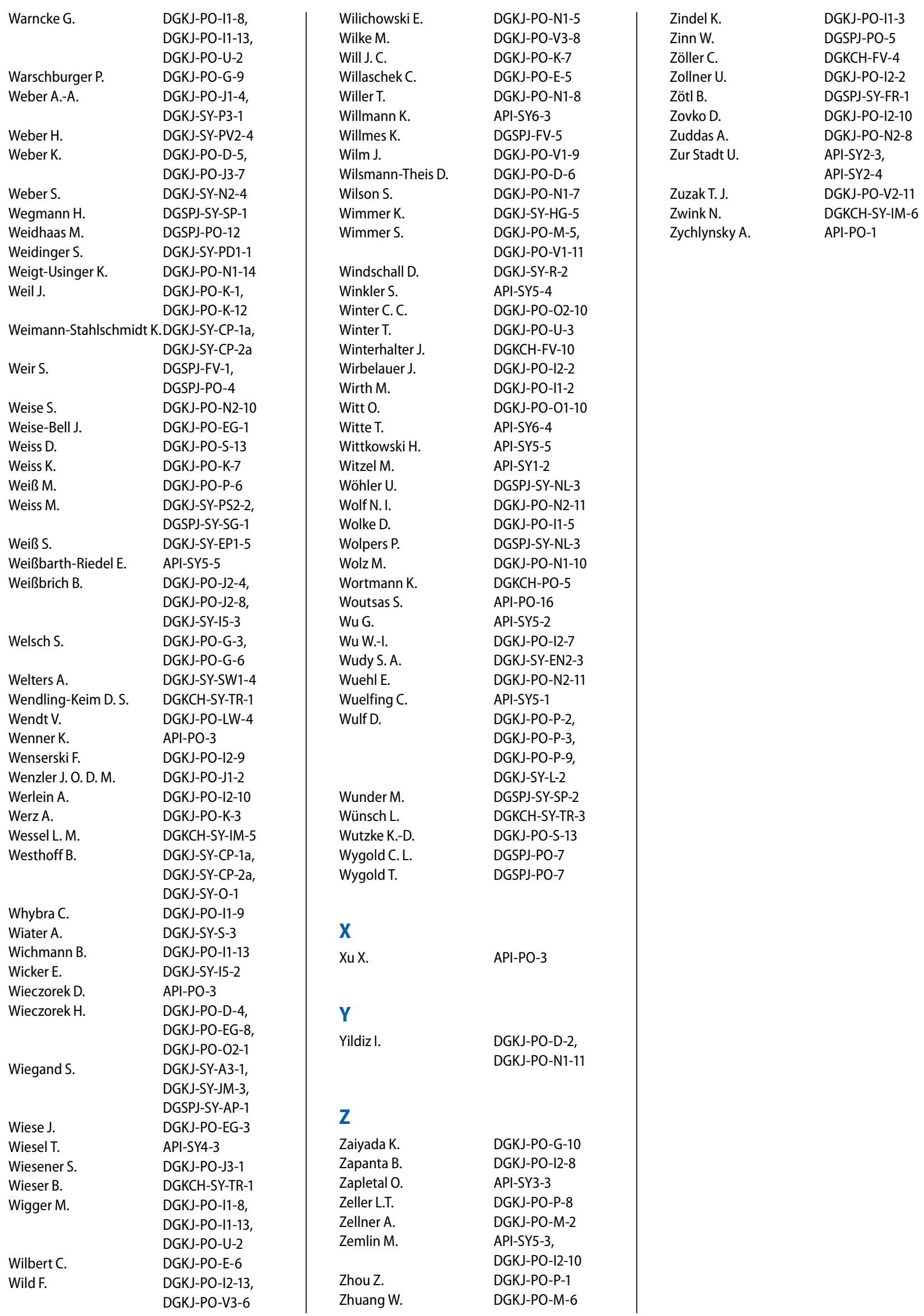

